4.

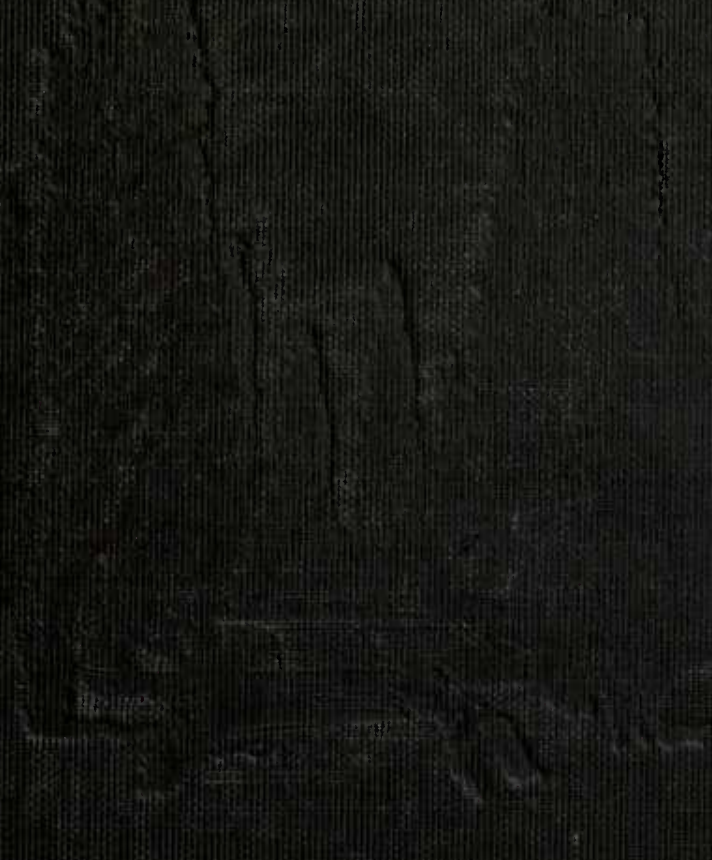




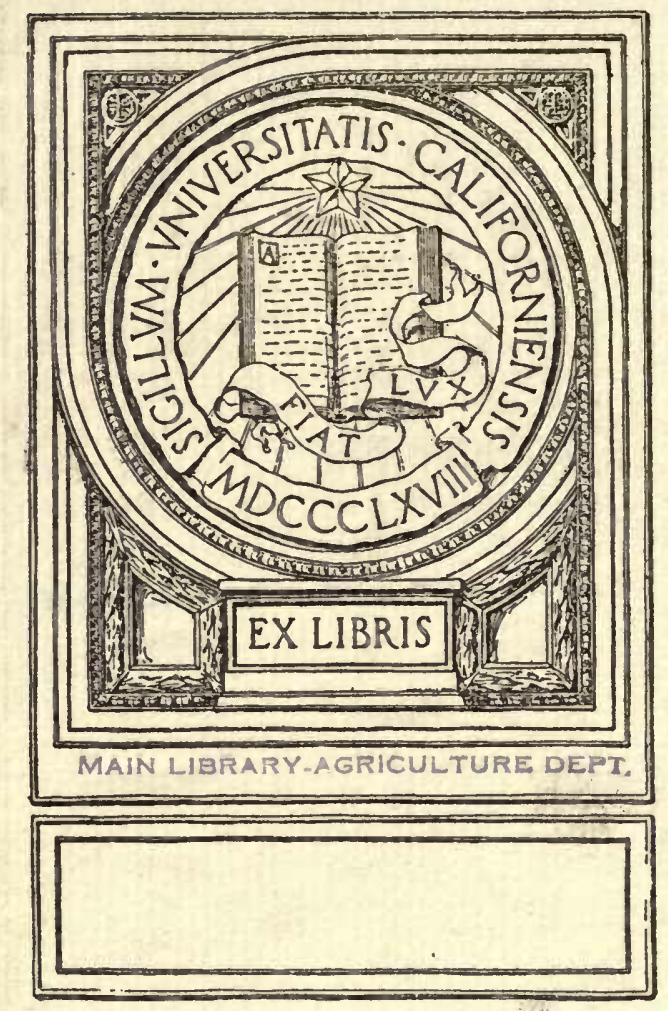




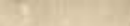

(1)25

-

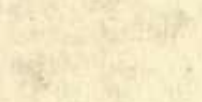

$34 x+5=5$

2 
THE COMPLETE GARDEN 
BOOKS BY ALBERT D. TAYLOR

Partial List of Plants Available for Various Uses in General Landscape Planting

Street Trees: Their Care and Preservation Complete Garden, The 



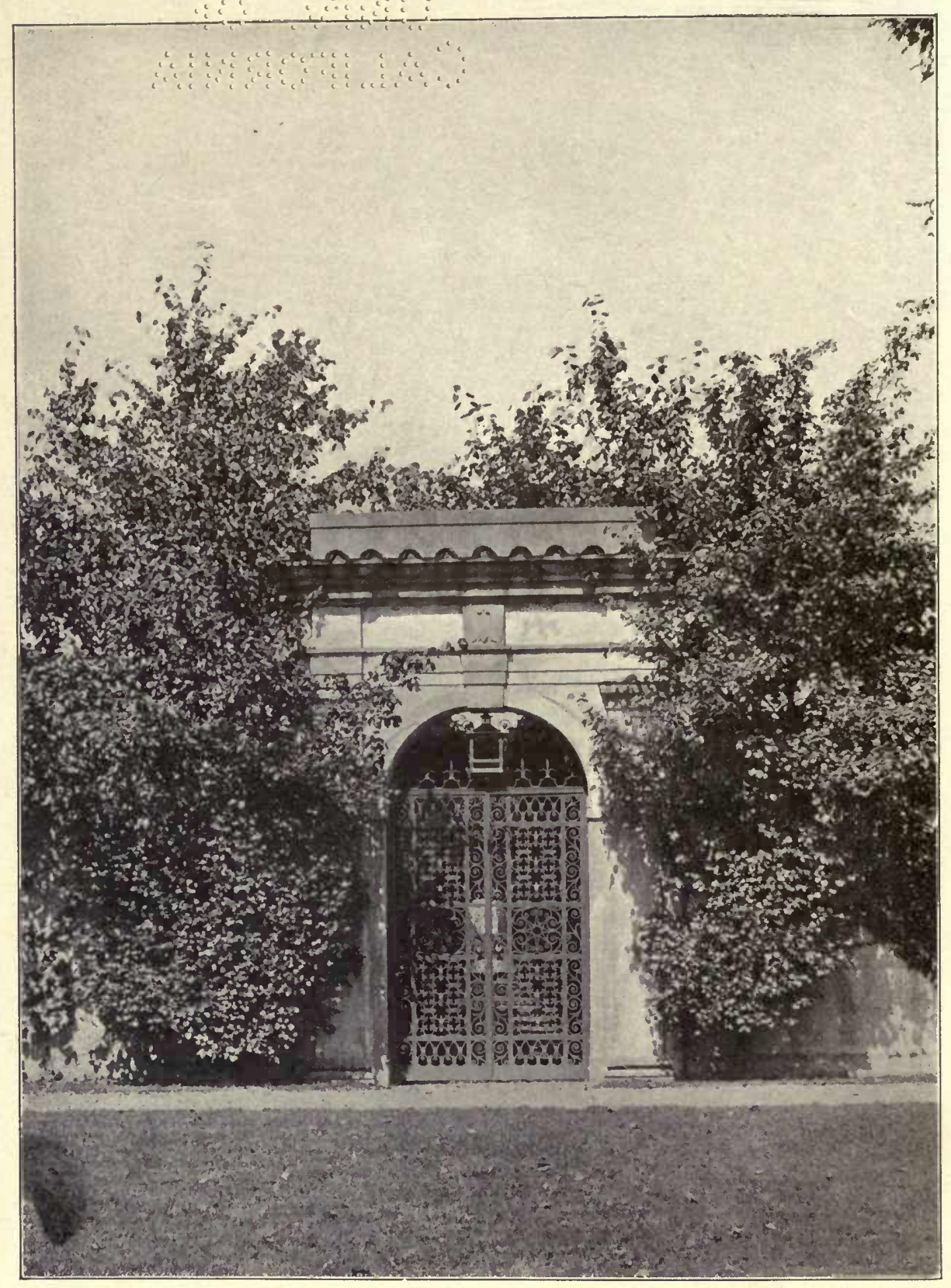

Plate I. The scarlet thorns planted on both sides of the wall on either side of the gate make an excellent frame for this architectural detail at the garden entrance. (See Plate XXIV, page I58) 


\section{THE COMPLETE GARDEN}

BY

ALBERT D. TAYLOR, M.S.A.

Fellow American Society of Landscape Architects

Non-resident Professor Landscape Architecture in Ohio State University

\section{ASSISTED BY}

GORDON D. COOPER, B.S.A.

Member American Society of Landscape Architects

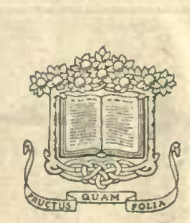

ILLUSTRATED WITH FIFTY FULL PAGE

CUTS, FOUR LINE CHARTS, AND

NINE COLOURED PLATES

GARDEN CITY, N. Y., AND TORONTO

DOUBLEDAY, PAGE \& COMPANY I92 I 


$$
\begin{aligned}
& \because \because \quad \because \because \vdots \vdots
\end{aligned}
$$

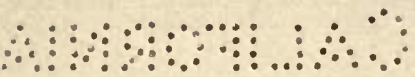

MAIK LIBRARY-AGRICULTURE DERP.

COPYRIGHT, I92I, BY

DOUBLEDAY, PAGE \& COMPANY

ALL RIGHTS RESERVED, INCLUDING THAT OF TRANSLATION INTO FOREIGN LANGUAGES, INCLUDING THE SCANDINAVIAN

PRINTED AT GARDEN CITY, N. Y., U. S. A. 


\section{PREFACE}

REAsons For This Book. The author has for some time felt that there was needed in the landscape field, especially by the amateur gardener, a book of this type. He has believed that such a book would be of value to everyone who is interested in the important work of landscape plantings, not only to the amateur but to the expert gardener and to the property owner who has made an exhaustive study of plant uses and plant adaptations.

One of the reasons for the publication of these planting lists for different purposes is that it provides a permanent record for future reference. There is no good reason why a landscape architect thoroughly familiar, as a result of years of experience, study, and observation, with the use of plants should devote his time and thought to the compilation of lists of plants for different purposes, such as wild gardens, spring gardens, rock gardens, and bog gardens in connection with some specific problem only to have each list of material cease to exist for the use of others, as soon as the work in question is completed. Plant lists compiled by capable landscape architects are too frequently used only for one problem, thus requiring the next man who starts to work upon a similar problem to begin his study, not where the other man left off, but at the same point where the other man began, duplicating work and wasting much time and energy. It is not meant to imply that all ornamental plants can be confined within definite standardized lists from which those who attempt to select plants for a specific purpose must choose. It is the author's sincere feeling that lists of plants compiled as the result of the different studies and investigations continually being made, in connection with the landscape problems of many clients, may be accepted as a starting point or a reference beyond which a planter is at full liberty to go when he wishes to use species and varieties which are unusual and rare, or whenever the conditions of his specific problem require it.

The responsibility for the original idea conceived as a basis for the development of this book may be traced to the author's experience in classroom work and in teaching. In this field of work, from a peda- 
gogical standpoint, he has felt the need of a systematic classification, based upon the association of ideas which would aid in remembering and grouping plants. Through learning to know plants by their group associations a comprehensive knowledge of them may be gathered and retained with little effort. One of the easiest ways of memorizing is through the association of ideas. This is the fundamental principle upon which the information in the various groups is based. The same condition has been found in office work. Men with the greatest range of knowledge covering the identification of plants and the botanical classification of plants have found a smaller book of this kind indispensable as a ready reminder of the possibilities of plant uses, when working out planting designs.

The first abridged edition of this book was published in 1916, primarily for the use of the author and a few of his friends in professional work. It was largely local in character. It has met with such a favourable reception, however, and so many requests have been received asking that a book of this kind be continued, and that the field be covered by comprehensive information, that this revised edition is the result.

Овјест of This Book. It is hoped that this book will serve as a ready reference to those who have no authoritative source of information, and whose limited opportunity and limited time for observation have not enabled them to become familiar with a wide range of materials, and to keep familiar with it. This information is not compiled for the purpose of taking the place of the services of a professional landscape architect, where the problem is of sufficient magnitude to justify his employment. This book will assist those who, having no available sources of reliable information at hand, are prone to accept the advice of "landscape quacks" and self-styled landscape architects with little training.

The question is often asked, "What plants can I use for a specific purpose?" This is asked by both professional landscape architects and by owners of properties. This book will place at the disposal of such persons a list of plants from which species and varieties may be selected advisedly.

The discussion does not by any means represent a complete study of this subject. It will take years of checking, verification, and criticism, before a compact compilation of this material can be put into 
final shape which will be valuable as a reference in all sections of the country, where plants other than tropical are used for landscape effects.

The correct selection of plants for various purposes in landscape work is but a part of the success of landscape plantings. One should know not only the correct use of plants as indicated in these lists, but their landscape value from the standpoint of their adaptation to design and composition, as well as how to plant and to maintain them. For those unfamiliar with plant materials the information in this book should be supplemented with additional information which may be easily procured from descriptions in nursery catalogues, encyclopedias, and garden books.

The Essential Character of the Book. The main idea behind this method of compiling information for the use of those interested in landscape plantings is that of providing a compact reference manual from which fundamental information can be easily obtained. In reality it is more in the form of a "landscape dictionary." The chapters which have been introduced into this volume are a series of summarized fundamental principles with reference to the respective chapter headings, and they are not in the form of many magazine articles, so compiled as to be interesting to many persons who really read the articles, not always because of the facts in them, but because of the camouflaged outlines.

The System of Nomenclature. In the compilation of the plant lists, and generally throughout the text of the book, an earnest effort has been made to conform to the recommendations of the American Joint Committee on Horticultural Nomenclature as adopted and published in the 1917 official code of standardized plant names. The two new rulings of this committee regarding botanical names also have been adopted. These rulings are that all botanical names except the generic name shall begin with a lower case letter and not with a capital letter; and second, that in the case of all specific names heretofore ending in a double " $i$ " one of these " $i$ 's" shall be dropped. Thus Berberis Thunbergii will become Berberis thunbergi. Since this code fails to ccver many horticultural varieties of plants it has sometimes seemed wiser to follow the nomenclature of Bailey's Standard Cyclopedia of American Horticulture, especially in the case of garden forms of plants. An effort has been made to find the most generally accepted 
common name for each plant; or, where none was available, to invent a common name which would be descriptive of the plant and helpful in fixing its valuable characteristics in mind.

Acknowledgments. For notes on the behaviour of the newer introductions and for valuable assistance in the checking of the plant lists the author is indebted to M. H. Horvath, Landscape Architect, Cleveland, Ohio, and to Henry Kohankie, Nurseryman, Painesville, Ohio, both of whom have done important work in the introduction and testing of many sorts of plants.

For many valuable observations on the behaviour, hardiness, and adaptability of ornamental plants in their respective sections of the country the author is indebted to Charles H. Ramsdell, Landscape Architect, and Phelps Wyman, Landscape Architect, of Minneapolis, Minnesota, and to A. M. Hill, Nurseryman, of Dundee, Illinois.

In addition the author is indebted: For lists of plants adapted to the South Atlantic States, to Charles F. Gillette, Landscape Architect, Richmond, Virginia, and to Earle Draper, Landscape Architect, Charlotte, North Carolina; and for lists of plants adapted to the Oregon and Washington Coastal Plain to Professor Arthur L. Peck of the Oregon State Agricultural College at Corvallis, Oregon.

For lists of plants and much information concerning planting and seeding methods in Florida the author is indebted to E. N. Reasoner, Nurseryman, Oneco, Florida; H. H. Hume, Nurseryman, Glen St. Mary's, Florida, and C. L. Whipp, Florist, Jacksonville, Florida.

For much valuable information about the preparation of lawns and golf course fairways and greens in Florida the author is indebted to O. B. Roche, Superintendent of the Palm Beach Golf Course, Palm Beach, Florida, and to J. R. Van Kleek, Sebring, Florida.

For numerous practical suggestions covering landscape uses and notes on the propagation and maintenance of all sorts of ornamental plants the writer thanks George Jacques, Superintendent of "Gwinn," Bratenahl Village, Ohio; J. R. Brydon, Superintendent of "Glen Allen," Cleveland, Ohio, and E. O. Orpet, formerly Superintendent at "Walden," Lake Forest, Illinois.

For unselfish devotion to the oftentimes uninteresting work of copy reading, checking, and indexing, without which this work would never have been completed, much credit is due to the following members of the author's office staff: Gordon D. Cooper, W. Hoxie Hillary, Lucie L. 
French, Eleanor Hills Christie, J. R. Van Kleek, E. H. Trout, Frank B. Meyer, and Anne C. Thompson.

For many of the illustrations in this book the author is indebted to the following persons:

Mattie Edwards Hewitt for plates Nos. I2, 21, 26, 44, and 48;

The D. Hill Nursery Company for plate No. 17;

Mary E. Eaton for plates Nos. 31, 34, 35, 36, 38, 39, 46, and 49; Mr. and Mrs. F. F. Prentiss for plates Nos. II, 20, 47, 52, 53, and 60 ;

Mr. W. G. Mather for plates Nos. I, 1 5, 24, 27, and 28;

J. Horace McF arland Company for plates Nos. 18, 22, 23, 30, 32, 37, $40,41,43,56,57$, and 58 ;

Woodlawn Cemetery Association for plate No. 42;

The Wm. H. Moon Company for plate No. 7;

Nathan R. Graves Company for plate No. 33;

Mr. and Mrs. W. A. Thomas for plate No. 5I;

Mr. and Mrs. Charles F. Lang for plates Nos. 45 and 54;

Mr. and Mrs. Charles Reed for plate No. 19.

Future Coöperation Invited. Corrections and criticisms will be always welcomed by the author, and this volume will be enlarged and corrected as conditions justify.

Prospect and Forty-sixth Streets,

Albert D. Taylor.

Cleveland, Ohio.

August I, 1920. 



\section{CONTENTS}

Preface

\section{PART I}

\section{General Planting Suggestions}

CHAPTER

I. Introduction . . . . . . . . . . . . . 3

II. Planting and Seeding Seasons. . . . . . . . 8

III. Pruning . . . . . . . . . . . . . . . 18

IV. Planting and Transplanting . . . . . . . . . 29

V. Lawns . . . . . . . . . . . . . 52

VI. Bulb Culture . . . . . . . . . . . . . 65

VII. Maintenance . . . . . . . . . . . . . 73

VIII. Winter Protection and Mulching. . . . . . . . 100

\section{PART II}

LISTS FOR REFERENCE

IX. Evergreens . . . . . . . . . . . . . . 109

A-Most hardy . . . . . . . . . . . III

B-Best adapted for use in mid-west . . . . . II2

C-Not adapted for use in mid-west . . . . . II3

D-Adapted to partial shade in wooded areas . . II3

E-Low-growing, formal types . . . . . . . II4

X. Street and Avenue Planting . . . . . . . . . II5

A-Trees which are entirely hardy under all conditions . . . . . II6

B-Trees which should be selected with a thorough knowledge of the conditions under which they are to be used. . . . . . . . . . . . II7

C-Trees which should never be used on streets. . 117

XI. Plants for Use in Congested City Districts . . . . . 118

A-Trees . . . . . . . . . . . . . II9

B-Shrubs . . . . . . . . . . . $\mathrm{I} 20$ 
a. Holding leaves during winter . . . . . . 123

b. Not holding leaves during winter . . . . $\quad 124$

B-Edgings for walks and for garden borders. . . I24

C-Windbreaks and solid screens . . . . . . 125

D-Privacy . . . . . . . . . . . . 125

E-Hedges for bleak exposures . . . . . . . 126

a. Late foliage . . . . . . . . . . . 126

b. Close shearing . . . . . . . . . . . 126

c. Unsheared low hedges . . . . . . . . 126

d. Fruiting hedges . . . . . . . . . . 126

e. Shady places. . . . . . . . . . . 126

XIII. Plants for Border Planting . . . . . . . . . 127

A-Masses for refined lawn areas . . . . . . 128

a. Low-growing shrubs . . . . . . . . 128

b. Medium-growing shrubs . . . . . . . 129

c. Tall-growing shrubs. . . . . . . . . . . 129

B-Masses consisting mostly of native collected shrubs . . . . . . . . . . . . 130

a. Low-growing shrubs . . . . . . . . 130

b. Medium-growing shrubs . . . . . . . 130

c. Tall-growing shrubs. . . . . . . . . $13 \mathbf{I}$

XIV. Accent and Specimen Trees and Shrubs . . . . . 132

A-Trees . . . . . . . . . . . . . 133

a. Accent and specimen trees. . . . . . . 133

b. Columnar and pyramidal trees . . . . . 134

B-Shrubs . . . . . . . . . . . . . 135

XV. Plants Valuable for Use in Rock Gardens, in Japanese

Gardens, and in Wall Crevices . . . . . . 136

A-Evergreens . . . . . . . . . . . 138

B-Deciduous trees and shrubs . . . . . . . 139

C-Perennials . . . . . . . . . . . . . 139

XVI. Plants for Heavy, Formal Effects . . . . . . . I4I

A-Border planting . . . . . . . . . . I44

B-Topiary work and close shearing . . . . . 145

a. Evergreen . . . . . . . . . . . 145

b. Deciduous . . . . . . . . . . . 145

C-Growing in tubs . . . . . . . . . 146 
D-Trees and shrubs for allees . . . . . . 146

a. Pleached . . . . . . . . 146

b. Not pleached (open allees) . . . . . . 147

I. Deciduous . . . . . . . . . . 147

2. Evergreen . . . . . . . . . . . 147

XVII. Plants for Natural, Informal Effects . . . . . . 148

XVIII. Low-Growing Plants Along the Inner Side of Curving Roadways and at Entrances . . . . . . . . 150

A-Evergreen . . . . . . . . . . . I5I

B-Deciduous . . . . . . . . . . . . I5I

XIX. Trees and Shrubs for Different Flowering Effects . . . I52

A-Producing flowers in early spring before leaves appear . . . . . . . . . . 154

B-Producing flowers in early spring after leaves appear. . . . . . . . . . . . 154

C-Producing flowers during early summer . . . 155

D-Producing flowers during late summer and early autumn . . . . . . . . . 156

E-Producing flowers in shades of red and pink . . 156

a. Early-flowering sorts . . . . . . . . 157

b. Late spring and summer-flowering sorts . . . 157

F-Producing yellow flowers . . . . . . . 157

a. Early-flowering sorts . . . . . . . . 157

b. Late spring and summer-flowering sorts . . . 158

G-Producing white flowers . . . . . . . . 158

a. Early-flowering sorts . . . . . . . . 158

b. Late spring and summer-flowering sorts . . . 158

$\mathrm{H}$-Producing blue flowers . . . . . . . . 159

I-Continuous bloom from twelve shrubs . . . . 159

XX. Plants Valuable for the Characteristics of Their Fruit. . $\quad 160$

A-Producing fruit of peculiarly interesting form or size . . . . . . . . . . I6I

B-Producing fruit valuable for its colour effects. . 162

C-Producing fruit valuable during the winter months $\quad 6_{3}$

D-Producing fruit valuable for attracting birds. . 164

a. Fruiting in summer . . . . . . . . 165

b. Holding fruit into the winter months . . . 166

c. Birds attracted by fruits . . . . . . . 166

E-Producing fruit which attracts birds away from other fruits . . . . . . . . . 167

F-Producing fruit which often makes the plant undesirable in landscape planting . . . . . . 167 
CHAPTER

XXI. Trees and Shrubs Bearing Coloured Twigs .

XXII. Plants Valuable Because of the Autumn Colouration of the Leaves

A-Early 171

B-Medium 173

C-Late

Coloured foliage.

b. Green foliage . . . . . . . . . . 174

XXIII. Fast-Growing Types Valuable for Producing Screen Effects ${ }_{176}$

A-Trees . . . . . . . . . . . . . 177

B-Shrubs . . . . . . . . . . . . . 177

XXIV. Plants Adapted to Various Types of Soil Conditions . . 178

A-Boggy and peaty soils . . . . . . . . 179

a. Boggy situations . . . . . . . . . 180

b. Peaty situations. . . . . . . . . . $\mathrm{I} 8 \mathrm{I}$

B-Light, sandy soils. . . . . . . . . . I8I

a. Trees . . . . . . . . . . . $\mathbf{I} 8 \mathbf{I}$

b. Shrubs . . . . . . . . . . $18 \mathbf{1}$

c. Vines . . . . . . . . . . . . . 182

C-Heavy types of soils . . . . . . . . . 182

a. Trees . . . . . . . . . . . 182

b. Shrubs . . . . . . . . . . 182

c. Vines . . . . . . . . . . . . . 183

D-Trees tolerant of alkali soils . . . . . 183

E-Drought-resisting plants . . . . . . . 183

XXV. Plants for Exposed Lake Front and River Conditions. . 185

A-Trees . . . . . . . . . . . . . 186

B-Shrubs . . . . . . . . . . . . 187

C-Vines . . . $\cdot$. . . . . . . . . 187

XXVI. Trees and Shrubs for Seaside Planting . . . . . . 188

A-Plants hardy under the severe exposure of the

North Atlantic Coast . . . . . . . . . 189

a. Deciduous trees . . . . . . . . . . 189

b. Conifers . . . . . . . . . . . . 190

c. Shrubs . . . . . . . . . . . . 190

B-Plants hardy in the less severe seaside exposures. I90

a. Deciduous trees . . . . . . . . . . I9I

b. Conifers . . . . . . . . . . . . 191

c. Shrubs . . . . . . . . . . . . I9I

XXVII. Plants for Partially Shaded Locations . . . . . 192 
A-Shrubs and small trees . . . . . . 196

B-Ground-cover plants . . . . . . . . 197

XXIX. Plants for Ground Cover . . . . . . . . . 199

A-Moist locations . . . . . . . . 203

B-Dry locations . . . . . . . . . . 204

C-Shady locations . . . . . . . . 205

D-Ferns . . . . . . . . . . . 205

a. Dry, shady places . .. . . . . . . . 206

b. Moist, shady places. . . . . . . . 206

E-Embankments and rocky slopes . . . . 206

a. Shrubs . . . . . . . . . . 206

b. Perennials . . . . . . . . . 207

c. Vines . . . . . . . . . . . 207

F-Small-flowering and foliage plants for crevices between stepping-stones and for paved terrace areas 208

$\mathrm{G}$-Perennials adapted to open sunny exposures . . 208

$\mathrm{H}-$ Ground cover among rhododendrons and azaleas. 209

$\mathrm{I}$-Ground cover among roses . . . . . . . 2 ro

XXX. Game Cover Plants . . . . . . . . . 211

A-Foliage, buds, and blossoms (Spring cover) . . 212

B-Nuts or seeds (Autumn cover) . . . . . . 212

XXXI. Perennials for Different Purposes . . . . . . . 214

A-Hardy perennials for general use . . . . . 22 I

B-Perennials according to colour and season. . 222

a. Perennials for spring-purple, lavender, or blue flowers . . . . . . . . . . . 222

b. Perennials for spring-white flowers . . . 222

c. Perennials for spring-pink to crimson flowers . 223

d. Perennials for spring-yellow to orange flowers. 223

e. Perennials for summer-purple, lavender, or blue flowers . . . . . . . . . . . . 224

f. Perennials for summer-white flowers . . . 224

g. Perennials for summer-pink to crimson flowers 225

h. Perennials for summer-yellow to orange flowers 225

i. Perennials for autumn-purple, lavender, or blue flowers . . . . . . . . . 226

j. Perennials for autumn-white flowers . . 226

k. Perennials for autumn-pink to crimson flowers 226

1. Perennials for autumn-yellow to orange flowers 227 
a. Tall types . . . . . . . . . . 227

b. Low types . . . . . . . . . . . 228

D-Perennials for long flowering period . . . 228

E-Perennials seldom used in small, refined, formal gardens . . . . . . . . . . . . 229

F- Perennials to supply "perpetual bloom" . . . 230

G-Perennials for use among peonies . . . . . 230

$\mathrm{H}$ - Perennials for good blooming combinations . . $23 \mathrm{I}$

I- Perennials valuable for cut flowers. . . . . 232

J-Perennials which should be treated as biennials . 233

$\mathrm{K}$ - Perennials to be transplanted frequently. . . 233

a. To be divided every two years . . . . . 233

b. To be divided every three years . . . . . 233

c. To be divided each year . . . . . . . 234

L-Perennials for water planting . . . . . 234

a. Deep water . . . . . . . . . . 234

b. Shallow water . . . . . . . . . . 234

c. Land at the water-side . . . . . . . . 234

M-Perennials for planting against the shrub border 235

$\mathrm{N}$-Perennials for attracting humming birds . . $\quad 236$

XXXII. Annuals . . . . . . . . . . . . . . . 237

A-Annuals especially valuable for cut flowers . $\quad 239$

B-Annuals to be sown for ground cover . . . . 240

C-Annuals which are difficult to transplant successfully . . . . . . . . . . . . $24 \mathrm{I}$

D-Annuals which should be planted in several sowings to insure a succession of bloom . . . . $24 \mathrm{I}$

$\mathrm{E}$-Annuals to be started indoors in order to produce good bloom before frost . . . . . . . 242

F-Annual vines . . . . . . . . . . 242

a. Delicate foliage . . . . . . . . 242

b. Heavy foliage . . . . . . . . . . 242

G-Annuals for carpet bedding . . . . . . . 243

$\mathrm{H}$-Annuals for design bedding . . . . . . 245

XXXIII. Horticultural Varieties, Select List of . . . . . 247

A-Lilacs . . . . . . . . . . . . . 249

B-Peonies . . . . . . . . . . . 250

C-Small flowering trees . . . . . . . 250 
a. Best climbing roses

a. Best climbing roses . . . . . . . . . $25 \mathrm{I}$

b. Hardiest garden roses . . . . . . . 25I

I. Hybrid perpetual, crimson and red . . . 25I

2. Hybrid perpetual, pink . . . . . . . $25 \mathrm{I}$

3. Hybrid perpetual, white. . . . . . . $25 \mathrm{I}$

4. Yellow . . . . . . . . . . . $25 \mathrm{I}$

5. Moss . . . . . . . . . . . . $25 \mathrm{I}$

c. Best hybrid tea roses . . . . . . . . $25 \mathrm{I}$

E-Broad-leaved evergreens. . . . . . . . 252

a. Rhododendrons and azaleas . . . . . . 252

b. Other broad-leaved evergreens . . . . . 252

F-Lilies . . . . . . . . . . . . . 253

a. List of lilies . . . . . . . . . . 253

b. Easy culture in garden soil . . . . . . 256

c. Moist and boggy locations. . . . . . . 256

d. Calcareous soil . . . . . . . . . . 257

e. Open sun . . . . . . . . . . . . . 257

f. Undergrowth. . . . . . . . . . 257

g. Sandy or dry soils . . . . . . . . . . 257

h. Clay soil . . . . . . . . . . . . 257

i. Shady locations . . . . . . . . 257

XXXIV. Vines. . . . . . . . . . . . 258

A-Flowering . . . . . . . . . . . . 260

B-Use on brick, stone, and masonry . . . . . 260

C-Climbing habit and heavy foliage. . . . . 260

D-Fruiting . . . . . . . . . . . . 26I

E-Fast-growing . . . . . . . . . . . . 26I

XXXV. Window Boxes and Hanging Baskets . . . . . . 262

A-Window boxes . . . . . . . . . . 264

a. South or west exposure. . . . . . . . . 264

b. East exposure . . . . . . . . . . . . $\quad .264$

c. North exposure . . . . . . . . . . 265

B-Hanging baskets . . . . . . . . . 265

a. Vine-like habit . . . . . . . . . 265

b. Upright habit and good flowers . . . . 266

c. Upright habit and good foliage . . . . . 266

XXXVI. Bulbs. . . . . . . . . . . . . . 267

A-Refined lawn and garden areas . . . . . 270

B-Naturalizing in woodland and wild gardens . . 270

C-Narcissi for different locations . . . . . . $27 \mathbf{I}$ 
D-Tulip combinations

a. Single . . . . . . . . . . . . 271

b. Double . . . . . . . . . . . 272

c. Cottage . . . . . . . . . . . 272

d. Darwin . . . . . . . . . . 272

E-Best varieties for forcing . . . . . . 273

a. Forcing in soil . . . . . . . . 273

b. Forcing in water . . . . . . . 274

XXXVII. Fragrant Plants. . . . . . . . . . . 275

A-Fragrant flowers . . . . . . . . . 275

a. Shrubs . . . . . . . . . . 275

b. Trees . . . . . . . . . . . 276

c. Perennials . . . . . . . . . . 276

B-Fragrant leaves . . . . . . . . . 277

a. Trees and shrubs . . . . . . . . . 277

b. Perennials . . . . . . . . . . . 277

XXXVIII. Poisonous Plants . . . . . . . . . . . $\quad 278$

A-Internally poisonous . . . . . . . . . 279

B-Skin irritants . . . . . . . . . . . 280

C-Causing hay fever . . . . . . . . . 280

XXXIX. Ornamental Plants Subject to Disease and Insect Pests . 282

XL. Plants Difficult to Transplant and Those Adapted for Transplanting at Specific Seasons of the Year . . . 286

A-Plants which should be transplanted in autumn . 289

B-Plants which should be transplanted in spring . 289

C-Plants which are transplanted with little success. 290

a. Plants to be rarely if ever transplanted . . . 290

b. Plants which recover slowly from the operation of transplanting . . . . . . . . . . 290

XLI. Shrubs for Forcing in Water in Early Spring . . . . 292

XLII. Pruning Lists . . . . . . . . . . . . . 294

A-Shrubs needing complete pruning . . . . . 296

a. Spring and early summer flowering . . . 296

b. Late summer and fall flowering . . . . . 297

B-Shrubs needing removal of old wood only. . . 297

a. Summer pruning . . . . . . . . 297

b. Winter pruning . . . . . . . . . . 297

C-Trees which require little or no pruning . . . 298

D-Evergreens that should be pruned in May orJune 298

E-Evergreens that may be pruned at any time. . 298 
XLIII. Plants for Florida . . . . . . . . . . 299

A-Windbreaks . . . . . . . . . 300

B-Trees for street and specimen planting . . . 30I

a. Northern list. . . . . . . . . . 30I

b. Southern list. . . . . . . . . . 30I

C-Vines . . . . . . . . . . . . 302

a. Lattices and wire fences . . . . . . 302

b. Masonry walls . . . . . . . . . . 303

D-Shrubs with attractive fruit. . . . . . 303

E-Hedges . . . . . . . . . . . . 304

a. Middle and southern Florida . . . . . 305

b. Northern Florida . . . . . . . . 305

F-Flowering shrubs for middle and southern Florida 305

a. White flowers . . . . . . . . 305

b. Pink flowers . . . . . . . . . 306

c. Yellow flowers . . . . . . . 306

d. Red flowers . . . . . . . . . 307

e. Purple and blue flowers . . . . . . . 307

G-Ground-cover plants . . . . . . . . 307

$\mathrm{H}$-Shrubs for shady conditions . . . . . 308

I-Herbaceous plants. . . . . . . . . . 308

J-Plants for seashore planting . . . . . . 3 IO

a. Trees . . . . . . . . . 310

b. Shrubs . . . . . . . . . . . 310

c. Vines . . . . . . . . . . . . . 3II

XLIV. Plants for Minnesota . . . . . . . . . . . 312

A-Hedges . . . . . . . . . . . . 313

a. Barriers . . . . . . . . . 313

b. Windbreaks . . . . . . . . . 313

B-Ground cover . . . . . . . . . . . 313

a. Shrubs . . . . . . . . . . 313

b. Vines . . . . . . . . . . 314

C-Plants valuable for autumn colouration of leaves. $3 \mathrm{I} 4$

a. Early . . . . . . . . . . . . 314

b. Medium . . . . . . . . . . . 314

D-Heavy, formal effects . . . . . . . . 314

E-Street trees . . . . . . . . . 315

a. Entirely hardy under all conditions . . . . 315

b. Which should be selected with a thorough knowledge of the conditions under which they are to be used . . . . . . . . . . . 315 
G-Not hardy in Minnesota. . . . . . . 316

XLV. Plants for South Atlantic States . . . . . . . . 318

A-Ground cover . . . . . . . . . . . 319

a. Moist places . . . . . . . . . . 319

b. Dry places . . . . . . . . . . . 319

B-Hedges. . . . . . . . . . . . 320

a. Holding leaves throughout winter. . . . 320

b. Not holding leaves throughout winter . . . 321

C-Trees for street planting. . . . . . . . $32 \mathrm{r}$

D-Evergreens most used . . . . . . . 322

E-Formal effects. . . . . . . . . . . . 322

F-Border planting . . . . . . . . . . 323

a. Low-growing deciduous shrubs . . . . 323

b. Low-growing evergreen shrubs . . . . . 324

c. Medium-growing deciduous shrubs . . . 325

d. Medium-growing evergreen shrubs . . . 326

G-Fruit valuable for its colour effects. . . . $\quad 327$

$\mathrm{H}-$ Specimen trees and shrubs . . . . . . . 327

a. Trees . . . . . . . . . . . 327

b. Shrubs . . . . . . . . . . . . 329

I-Perennials for gardens and cut flowers . . . $\quad 329$

J-Perennials for naturalizing in wild gardens . $\quad 330$

$\mathrm{K}$-Plants which are commonly and freely used in the

south but are not hardy farther north . . . . 33I

a. Trees . . . . . . . . . . . . . $33 \mathbf{I}$

b. Shrubs . . . . . . . . . . . . 332

$\mathrm{L}$-Vines for the south . . . . . . . . . . 332

XLVI. Plants for Use on the Oregon and Washington Coastal

Plain . . . . . . . . . . . . 334

A-Hedges. . . . . . . . . . . . . 335

a. Deciduous . . . . . . . . . . 335

b. Evergreen . . . . . . . . . . . 335

B-Plants for ground cover . . . . . . . 335

a. Open sun. . . . . . . . . . . . 336

b. Shade. . . . . . . . . . . . 336

C-Plants for border planting . . . . . . . 336

a. Refined lawn masses . . . . . . . $\quad$. 337

b. Native and collected plants . . . . . 337

D-Street and avenue planting . . . . . . . 337

E-Plants for heavily shaded locations . . . . 337 
F-Plants valuable for autumn colouration of leaves 338

G-Vines . . . . . . . . . . . . . 338

H-Evergreens most used . . . . . . . . 339

a. Conifers . . . . . . . . . . . 339

b. Broad-leaved . . . . . . . . . 339

Bibliography . . . . . . . . . . . . . 343

Glossary. . . . . . . . . . . . . . . 355

Index . . . . . . . . . . . . . 378 



\section{LIST OF ILLUSTRATIONS}

PLATE

I. The scarlet thorns planted on both sides of the wall on either side of the gate make an excellent frame for this architectural detail at the garden entrance . . . . . . . . . . . . . . Frontispiece

II. This map shows those portions of the United States which because of climatic environment and geographic location possess similar planting seasons. Investigation of zones of similar planting seasons has, to date, not provided complete information to the landscape architect in his planting work. For supplementary information refer to Plate No. III on Page I4. (In colour).

III. A chart to aid in determining the most favourable period for transplanting, and for seeding of lawns in various sections of the United States. Note the long winter periods of the Northern Zones and the continuous planting seasons of the Southern Zones. It is of great importance to be able to plan ahead and to order plants for delivery at the proper time for any section of the country. These are average seasons resulting from observations of normal seasons during a period of years. For supplementary information refer to Plate No. II on Page 6.

IV. The hedge which may look unkept and ragged if not pruned will in the hands of the skilled gardener assume almost any degree of refined outline. These photographs show one of our most desirable hedge plants, the Japanese privet (Ligustrum ibota)

V. The correct pruning of trees and shrubs is a great factor in the successful maintenance of landscape plantings. These diagrammatic drawings together with the explanations on the opposite page illustrate correct and incorrect methods of pruning

VI. A knowledge of the various operations involved in the work of correctly transplanting plants is essential for their subsequent normal development. These diagrammatic drawings accompanied by the explanation on the opposite page illustrate various transplanting operations.

Immediately after transplanting, the trunk of every large tree should be protected with a covering of burlap (Fig. B) which prevents excessive drying out and consequent cracking and loosening of the bark (Fig. A). This protection is especially necessary during the warmer summer months

VIII. To most of us in the northern states the method of seeding a lawn is familiar, but the method of making lawns in southern states by planting Bermuda grass is little known. In these photographs small clumps of Bermuda grass are being planted in "hills" staggered at intervals ranging from eighteen inches to thirty inches. The thicker the planting the more quickly a mat of turf can be developed 
IX. It is important to know the depth, distance apart, and time of the year at which different kinds of bulbs should be planted. Many disappointing flower effects are the result of violating these rules with reference to depth, distance apart, and time of planting

$X$. Trees are given winter protection both against injury from sun-scald and against injury from severe wind and changing temperature conditions. This photograph shows one method of protecting hemlocks against the sun's rays .

XI. The list of evergreens adapted to soil and to climatic conditions of the middle west, and valuable for low, refined mass plantings is limited. The upper photograph shows an effect produced by the use of dwarf yew, Pfitzer's and tamarisk-leaved junipers, Mugho pines and Japanese spurge edging. The lower photograph shows the effectiveness of masses of low, refined evergreens against massive architecture

XII. Under climatic and soil conditions favourable to their growth evergreens will produce a landscape picture incapable of reproduction through the use of deciduous plants. This photograph shows an effective use, under I.ong Island conditions, of arborvitae, red cedars, junipers, rhododendron, and yews as a background for a refined, formal pool.

Carefully selected and planted trees for avenue and street planting provide a uniform and a symmetrical effect together with the inviting shade, all of which are so essential to the standards of modern residential districts

XIV. The list of trees and shrubs which thrive in the congested city districts where soil conditions are poor and the air is polluted with smoke and dust is limited to a few kinds, of which the tree of heaven, locust, and catalpa are typical

$\mathrm{XV}$. An interesting use of hedges to frame one side of the refined formal garden. Japanese quince on the left side of the walk. Japanese barberry against the right side accented with sheared retinosporas, and buttresses of Japanese quince and Amoor River privet on the extreme left against the vine-covered wall, form the features of this composition

XVI. Plume-like cypress, naturally a small tree, can be maintained as a compact and a very formal low hedge if given plenty of skillful pruning and protection in winter

XVII. The Canadian hemlock, when grown from the northern seed and when well established, forms one of the best windbreaks and barriers for the protection of the garden or orchard wherever drifting snow must be overcome and seclusion also attained

XVIII. Upon a spacious lawn effective use can occasionally be made of trees and shrubs possessing symmetrical habits of growths and fine flowering and fruiting qualities. The deutzia is a shrub with these capabilities, but it is seldom seen as a specimen plant. Restraint, however, must be observed and a dotted effect avoided

XIX. The extended lawn area often requires specimen trees to lend scale and colour to the picture, and it also offers opportunity to display the natural beauty of many of our fine specimen trees. 
XX. An effective combination of stone work and of plantings in an informal lawn area. Varieties of stonecrop, moss pinks, and Scotch pinks lend charm to an otherwise uninteresting mass of stone. (See Plate No. LIII, Page 334, for lily planting shown in background of this picture.)

XXI. An uninteresting rocky slope often can be turned into an attractive landscape feature through the careful selection and planting of plants adapted to light, sandy soils. This slope is covered with a grouping of hardy pinks, evergreen candytuft, saxifrage, and tufted pansy

XXII. To develop a successful rock garden, not only must the stones be well placed, but the plants must be selected to produce an effect in keeping with the scale of the garden; otherwise the effect will be that of a collection of stones which overpower the garden picture, as shown above

XXIII. To few of us does the term "wall garden" convey a definite impression. Yet how frequently the opportunity comes, even in a small way, to change a wall of rock to a wall of flowers and foliage. In this photograph we see Scotch pinks, creeping phlox, golden tuft, tunica, and other similar plants used to excellent advantage

XXIV. An interior view of a pleached allee eight years after transplanting. Note the spacing of the larger plants of the European cork maple at intervals of three feet, with "fillers" between each two of the larger trees. Compare with Plate No. XXVII on Page 175 for the exterior view. Openings have been cut in the top of this allee to produce interesting spots of sunlight on the walk .

XXV. An excellent illustration of pleasing garden formality filled with boxwood hedges, as edgings for carpet plantings of Japanese spurge, and accented with specimens of California privet neatly trimmed in a pyramidal form to represent boxwood

XXVI. The use of bay trees in tubs is required in many of the northern gardens to produce accent points often at spots where no permanent plant can be planted in the ground. These trees are stored in cool greenhouses during the winter months.

XXVII. A pleached allee may form not only a most interesting feature as shown on Plate No. XXIV, Page 158, but this one serves as a solid screen between the lawn area and the service buildings...

XXVIII. This open allee is framed on either side by a solid row of closely sheared thorn trees. Its formal lines are softened by the row of pinkflowering dogwoods which add a charm of flowers in early spring and of fruit in the late fall. Thorns planted four to five feet apart and dogwoods eight feet apart. Width between rows of thorns twentytwo feet and between rows of dogwoods nine to ten feet. (See explanation of measurements\%on Page 144).

XXIX. An open allee twelve feet wide and eight hundred feet long, developed by the use of white birch planted three to four feet apart in each row. For a permanent allee of this type the birch is not ideal because of its short-lived characteristics and susceptibility to borer. Thorns or the European beech would be preferable.

A group of Japanese snowball, producing flowers in spring soon after the leaves appear, adds much to the attractiveness of a landscape picture 
FLATE

XXXI. It is quite important in the planting of the spring garden that the designer should know those shrubs which produce flowers before the leaves appear, similar to the Carolina azalea (B), and those early-flowering shrubs which produce flowers and leaves at the same time, similar to the bladder-nut (A). (In colour) . . . . .

XXXII. In the permanent planting no flowering tree or shrub deserves more favourable consideration than the fine type of Scheidecker's semidouble rose-flowering crab illustrated above.

XXXIII. As a specimen flowering plant for early spring effect the Japanese weeping rose-flowered cherry is extremely interesting, covered always before the leaves appear with an abundance of rose-pink flowers

XXXIV. It is a source of much satisfaction to the plant designer to know that shrubs which are carefully selected for the colour of their flowers may produce very effective colour combinations. This plate shows the St. John's wort (A) in combination with the sweetscented buddleia (B). (In colour).

XXXV. The average person who has not become interested in the colour effects produced by the fruits of our common trees and shrubs can hardly appreciate the intense colour display of the American bittersweet $(A)$, the Washington thorn $(B)$, and the white fringe $(C)$. (In colour.)

XXXVI. The garden designer must always bear in mind that many of our shrubs which produce very uninteresting flowers are the ones which produce our most attractive fruiting effects. The variation in colours of the fruits ranges from the pure white of the snowberry (A) through the purple and porcelain blue of the beauty fruit (C) to the vivid reds of which the Japanese bush cranberry $(B)$ is typical. (In colour)

XXXVII. Not only because of the interesting colour of its fruit in combination with the fruit of other shrubs, but because of the size and abundance of its fruit, the snowberry is one of our conspicuous and valuable shrubs.

XXXVIII. During the winter months when there is little else in the shrub border to attract attention, the vivid colours of the twigs of many of our shrubs present interesting spots of colour against the background of evergreens or snow. (A)-red-twigged dogwood; (B)green-stemmed dogwood; (C)-red birch; (D)-golden-twigged osier; (E)--grey dogwood; (F)-striped maple. (In colour). .

XXXIX. What is more beautiful in the landscape than the intensely brilliant colours of the autumn foliage of many of our trees and shrubs? More plants should be used for the value of their autumn foliage effect. (A)-burning bush; (B) - dark green golden bell; (C) maple-leaved viburnum; (D) -sassafras; (E)-maidenhair tree; (F)-sourwood. (In colour)

XL. In solving the difficult planting problems on exposed lake fronts and river fronts there is no plant in the limited list of adaptable types to excel the beach-plum . . . . . . . . . . 
XLI. The problem of developing desirable undergrowth plantings in wooded areas requires much study of plants as nature places them. The rhododendron, except in exposed locations, is "happy" in woodland areas where soil conditions meet the root requirements

XLII. In open sunny exposures on sandy or light loam soil there is no ground cover which surpasses the Japanese spurge in richness of colour or interesting texture of foliage, especially in combination with plantings of evergreens

XLIII. Our garden steps can be made a part of the flower garden, and not the usual cold and uninviting mass of stone or brick, by a welldesigned grouping of plants adapted for growth in the earth crevices among the rocks. Note the use of candytuft, ground phlox, moss pinks, varieties of stonecrops, and rock cress

XLIV. The large garden filled with perennials usually consists of larger groups of flowering perennials which produce masses of colour during their period of bloom. Iris, phlox, hollyhocks, gladioli, larkspur, and anemone produce the more important flower effects in this garden

XLV. A cut-flower garden; the central part filled with annuals and the outer border of perennials serving as a frame with shrubs in the extreme background. A garden of this kind can have a succession of bloom throughout the flowering season . . . . . . .

XLVI. Many of our common garden perennials possess the possibilities to produce very interesting colour effects through the colour combinations of the flowers. (A)-Italian alkanet; (B) - hardy marguerite. (In colour)

XLVII. During the early spring no woodland wild garden is complete without its quota of trilliums, grape hyacinth, and hepatica which grow luxuriantly if happily surrounded by conditions of soil and shade .

XLVIII. Among those plants which become easily established in the wild garden there is none the flower effect of which excels the Japanese windflower during the late summer

In the selection of perennials for the garden not only should the possibilities of interesting colour combinations in the flower effects be observed, but also the possibilities for interesting texture of foliage. (A)-larkspur; (B) -lemon lily (commonly called day lily). (In colour)

L. A few water-lilies may enhance a picture such as the above, but a proper restraint in their use and control is always desirable .

LI. The artificial lake or pond may receive a natural effect if the banks near the water's edge are planted with groups of water-loving plants. In this picture one sees the marsh-mallow, day-lily, iris, plantainlily, loosestrife, plume grass, and showy sedum successfully used.

LII. There are those who much prefer to develop their formal flower garden picture entirely by the use of annuals. This garden which is not for a source of cut flowers is filled with heliotrope, yellow tulip poppy, snapdragon, pentstemon, annual carnation, candytuft, and others not recognizable from this picture 
LIII. An informal planting of Scotch pines and Mugho pines may be accented by the use of a few specimens of lilies to brighten the landscape picture as well as to serve as a background for the flowering effect of

the lilies.

LIV. The knotweed is not only one of the most rapid-growing vines, but its abundance of delicate white flowers and its long-blooming period make it valuable for many locations on the lattice framework. AFirst summer after transplanting; B-Second summer after transplanting

LV. One of the best vines for use on masonry walls is the Boston ivy, but no vine should be allowed to overpower fine architectural details. This illustration also shows a perfectly developed European beech hedge (ten years old) planted in a single row with plants eighteen inches apart.

LVI. A pleasing combination of the vigorous climbing wisteria used together with window boxes filled with periwinkle to relieve the heavy and otherwise bare architectural effect

LVII. Nasturtiums, marigolds, English ivy, periwinkle, and petunias make a window box foliage and flower effect which adds greatly to the attractiveness of any home

LVIII. During the months of April and May the flower garden filled with refined types of tulips carefully arranged to produce masses of colour is the equal of the garden at any other month of the growing season. This garden is filled with the tall types of Darwin tulips.

LIX. With the first touch of spring the crocus begins to bloom upon the lawn. This plant can adapt itself either to the refined lawn area or to the woodland and field areas

LX. There is always an opportunity, on every larger estate, for the naturalizing of bulbs. Poet's narcissus is quite happy in a wild garden or field environment

LXI. Throughout the southern states the creeping fig is one of the most desirable vines for growth on masonry walls. It develops interesting foliage of a fine texture and is a vigorous grower and compares favourably with the Lowe's Boston ivy so successfully used in the northern states

I.XII. Used as a tree for screen effects, specimen planting, or hedges, the Australian pine is throughout southern Florida one of the most freely used plants

LXIII. The yellow allamanda desirable because of its heavy foliage, and because of its beautiful yellow flowers, is frequently neglected for use in Florida plantings as a shrub or a vine 


\section{PART I \\ GENERAL PLANTING SUGGESTIONS}


$\because \because \vdots \quad \because \because \vdots \vdots \vdots \vdots$

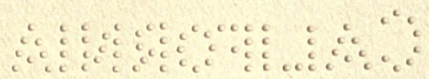




\section{THE COMPLETE GARDEN}

\section{CHAPTER I}

\section{INTRODUCTION}

The Method of Treatment. The lists of plants do not represent a complete and thoroughly exhaustive study of the subject. The general discussions and groupings will provide persons interested in the use of plant materials with essential facts, in a compact form, concerning the appropriate use of the more permanent species of trees, shrubs, vines, perennials, annuals, and bulbs.

The study of plants and their specific uses in landscape planting can to some extent be analyzed and tabulated for reference purposes in the same way that plants are grouped for purposes of identification. This study, however, is not based entirely upon scientific facts, and therefore is subject to personal points of view, and many times no hard and fast line can be drawn which will place any one plant in one list in preference to the possibility of placing it in some other list.

The Arrangement of the Material. At the beginning of each main group, and at the beginning of each sub-heading under the main groups, there is a short discussion of the fundamental principles governing that particular type of classification of plants for landscape uses. This discussion will be of some assistance by way of enabling the reader properly to consult the lists contained under these headings.

A number of chapters are included in this discussion, devoted to the following subjects: Pruning, Planting Seasons, Planting and Transplanting, Maintenance, Winter Protection and Mulching, Lawns, Selection and Planting of Bulbs. The author feels that there should be in a book of this kind a concise statement of the fundamental principles which govern work in this field of Landscape Plantings. These chapters are in no way a complete discussion of these subjects. They are more in the form of instructions and specifications which will serve 
as a guide in the right direction. For further and more complete information on these subjects reference should be made to the Bibliography (Pages 343 to $35 \mathrm{I}$ ), both of articles and of books, contained in the Appendix to this volume. The author has compiled a bibliography of articles and books which are of distinct value to the reader. But there are many other articles and books, of great interest and value to readers, some of which probably have escaped the author's attention and should be included in this list. This list will be revised from time to time.

The Use of the Index. This book is indexed very completely and in detail and has a reference both to pages and to groups. The reader will note that the book has been paged in the usual manner, and also that on each page the groups have been alphabetically arranged for the purpose of making it more easy to consult information as referred to by the Table of Contents and by the Group Index. As a matter of fact, this Index is almost equally as valuable as the complete list of plants under each of the various groups. By means of this Index the student who is familiar with some plant and wishes to find a proper use for it can readily ascertain the use or uses to which the plant is adapted.

The Purpose of the Illustrations. A number of photographs and drawings have been introduced throughout this volume. These photographs are illustrative of various group ideas covering uses of plants. Words, however carefully selected, often cannot be a literal interpretation of an idea, whereas a photograph immediately conveys the definite idea which cannot be reproduced in words. These illustrations have been selected, so far as possible, to illustrate the main features which justify the making of an individual group for reference purposes. It is hoped that they may for that reason prove to be of great value.

Method of Using the Book. Theoretically, a treatise on any subject should be so simplified that to the average reader the method of using it is self-evident. However, a few suggestions covering the methods of consulting the information in this volume may not be amiss. The Table of Contents, which is a complete compilation of all the general information in this volume, is arranged with 
many larger and more important headings to include the many minor headings. It is here that the reader can easily find reference to lists of plants which are valuable for specific uses by exactly the inverse process that he can find from the Index a reference to the different purposes for which an individual plant may be used. To the reader who is seeking to find a list of plants which can be used for a specific purpose, first, the Table of Contents and the List of Illustrations are of direct and primary value. To the reader who is seeking to find for what specific uses any plant may be adapted, secondly, the Index to pages and groups of plants is of greatest importance. To the reader who wishes to go farther into the subject of plant study, as covered by various phases of landscape work, thirdly, the Bibliography is the one reference which will be of value. The complete glossary containing a complete list of definitions covering terms frequently used by landscape architects is of real value in defining such terms.

The criticism may be raised by some who consult a volume of this kind that in reality no definite line can be drawn between the uses of some plants for one purpose or for another purpose. This is admittedly a fact. It will be quite evident from a short study of the Index that many plants frequently have a distinct and definite value as adapted to different purposes.

Range of Material Covered. While the range of material covered by the lists is sufficient to meet the requirements of the average property holder, the lists may be supplemented by additional and unusual varieties which, if selected, should be given unusual care. The information in this book has been compiled to cover the range of material which is adapted for use generally throughout the following portions of the United States: The North Atlantic States, the Great Lakes Region, the Central States as far west as the Missouri River and as far south as Arkansas. No lists have been compiled for the Great Plains and the Rocky Mountain States, but special lists have been compiled for the Atlantic Coastal Plain from Virginia to Mississippi; also for the Peninsula of Florida and for the region within a radius of one hundred and fifty miles from the Twin Cities. For the Pacific Coast, lists have been prepared for the Oregon-Washington Coastal Plain. It should be borne in mind that plants which develop one type of growth in a northern climate will develop another type of growth, because of the longer growing season, in a southern climate. 
The Range of Plant Adaptation in General. After studying a compilation of this kind the great range of plant adaptations becomes evident. There is a large group of materials which are hardy under almost all conditions. There are many other types of material, however, too numerous to mention in detail, which are adapted only to specific sections of the country.

The Adaptation of Evergreens in Particular. The question of the adaptation of evergreens is perhaps the one which may cause the most serious discussion. Evergreens are a' group of plants which. possess widely varying characteristics, especially of hardiness under different climatic conditions. The evergreens which will flourish in the humid and less severe atmosphere of Long Island will not grow through the windy regions of the Middle West, nor in the extreme exposure of the water-front conditions of the North Atlantic and the Great Lakes Region. Neither will evergreens which flourish in the sandy soils of Michigan grow upon the clay soils of the Middle Western States. Therefore, the question of evergreens has been carefully considered, and an attempt has been made to differentiate the groups and the requirements of each. This subdividing of evergreens for various locations is based entirely upon the normal protection. Many evergreens, as with other plants, will thrive under abnormal conditions if they are nursed and protected during the severe winter months. On the other hand, many evergreens which will withstand the exposures of winter conditions will not continue to thrive when placed in the clayey soils of some of our Middle Western States, where they are subjected to the severe baking and drying out of these soils during the summer months.

Method of Grouping Plants. The question of whether plants for landscape use should be grouped according to height or according to other characteristics, such as season of bloom, character of growth, soil adaptations, etc., is one that has been discussed to a considerable extent. The writer feels that in the selection of plants as a part of any landscape design, the question of height is of secondary consideration as compared with the natural characteristics and adaptations of the stock under consideration. The selection of plants for specific purposes such as background planting, undergrowth planting, windbreaks, ground cover, etc., implies that, in addition to other important characteristics of hardiness, compactness, and qualities of fruiting and 


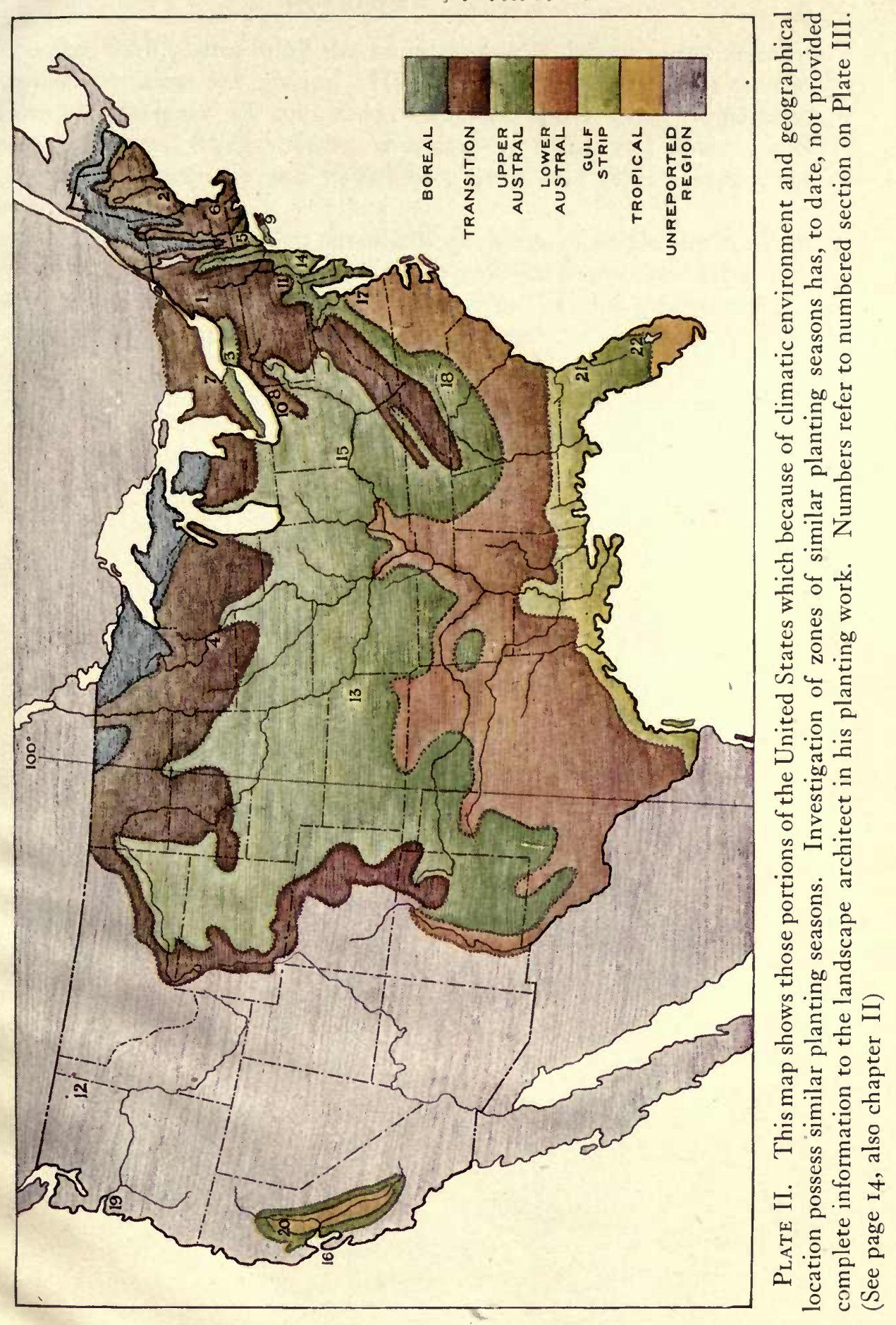



flowering, such plants fulfill the requirements of height automatically imposed by some few groups. Height of plants means little to the landscape designer as compared with the many other important requirements of foliage effects, character of fruits and flowers, soil adaptations, hardiness and habits of growth and their response to pruning operations.

In the selection of garden perennials questions of height are entirely secondary to the ability of the plants to produce flowers. and foliage of varying qualities, so essential to the success of the garden picture during different months of the growing season. 


\section{CHAPTER II}

\section{PLANTING AND SEEDING SEASONS}

General Considerations. Comparative data based on the best reliable sources of information relative to planting seasons and lawnseeding seasons are so interesting and so valuable, as a basis of establishing definite relationships among varying sections of the United States, that the writer has been prompted to attempt a diagrammatic and a tabulated analysis of this important question (See Plate III).

Considered from the standpoint of a plant the act of transplanting is a violent one and consists of stopping at once a large part of its vital activities, generally causing the loss of a considerable part of its root system. Therefore, transplanting should be accompanied by precautions to prevent too great loss of moisture by transpiration, and by measures to assist the plant in starting growth at the earliest possible date. Seeding differs from transplanting in that a seed is a ripened embryo which is a minute but complete dormant plant. As the process of germination includes the making of a vital connection between the young plant and the soil sufficient to enable the plant to produce green tissue and support itself, seedage must also be surrounded by precautions to insure proper conditions for germination. One of the most important factors in transplanting or seeding is the selection of the correct season, because upon the successful start of the operation depends the whole future of the plant. Plants grown in pots, or so root pruned that nearly all their roots may be moved with them, are, of course, in condition to be moved at all sorts of odd seasons, but this latter is the work of experts or trained gardeners and is not to be recommended to amateurs on account of the technical knowledge and skill required both during the planting operation and in the way of proper after-care and maintenance. This discussion is confined to transplanting dormant plants and to seeding of lawns, under the following headings :

(a) Deciduous Trees, Shrubs, and Vines

(b) Evergreen Plants Coniferous and Broad-leaved) 
(c) Herbaceous Perennials

(d) Lawn Grasses

Greenhouse plants and the propagation of plants by seeding, except as referring to lawn grasses, are not included because conditions vary so widely in the same locality.

Deciduous Trees, Shrubs, and Vines. The transplanting of deciduous trees, shrubs, and vines is commonly carried out during their dormant season. It is possible in the spring, however, to carry on planting of deciduous woody plants, at a time when the local plants are too far advanced to be moved, by the simple expedient of bringing plants from a storage cellar or from a more northerly nursery where they are still dormant. Again in the autumn, these same northerly grown plants may be used to start planting work before the local plants are matured and safe to move. Transplanting seasons are not so much governed by north and south latitude as they are by the condition of the plants, as explained in another paragraph under discussion of life-zones.

The beginning of the dormant period for woody deciduous plants comes in the autumn when their wood is matured and ripened and the leaves start to fall or to take on their autumn colouration. This occurs early in such plants as lilacs, lindens, flowering currants, and horsechestnuts, and it will usually be found to occur late in some of the plants which are said to be hard to move in the autumn, such as poplars and silver maples. From the beginning of the dormant period in the fall until the beginning of physiological activity in the spring, deciduous plants may be moved at any time that the ground is in proper condition and the temperature favourable. As a matter of practice, in the northern states this work is suspended entirely during a normal winter, for about four months, except where large plants are moved with a frozen ball of earth about their roots, because frozen ground and snow make the operation of transplanting smaller plants entirely impracticable. This period, longest in Maine and in the section surrounding Minneapolis, lessens as one goes farther south, until in Virginia and Georgia a continuous planting season extends without interruption through the dormant period.

It was early learned that the whole of North America could be conveniently divided into seven transcontinental belts or life-zones, based upon the length of the growing season, which has been defined 
as the period between the date in the spring when the normal mean daily temperature rises to 43 degrees Fahr., or above, and the date in the autumn when it falls to below that figure. (The reader should consult Bulletin No. ro of the U. S. Department of Agriculture, Division of Biological Survey, entitled "Life Zones and Crop Zones." Part III of that Bulletin is especially interesting). These life-zones are, as noted above, adapted to plants requiring growing seasons of similar length and temperature range. Thus, if soil conditions, exposure, and amount of annual rainfall are alike in two distant portions of a zone plants which succeed in one portion may be expected to succeed in the other portion. They may in any event be tried out with considerable confidence when all the conditions are known to be the same, as described above.

It now seems evident, from recently gathered data, that these zones correspond very closely to belts of country which have similar planting seasons for dormant woody plants, at least throughout the humid regions east of the rooth parallel of latitude. By consulting the accompanying Plate II, which has been adapted from the one in the above-mentioned Bulletin, and also the chart (Plate III), which shows the reported length of planting seasons, it will be seen that the stations reporting fall into groups which lie in respective life-zones as shown on the map.

Thus stations 2, 3, 4, and 6, all of which lie in the so-called Transition Zone, including most of New England, New York State, Pennsylvania, northeastern Ohio, the Alleghanies from Pennsylvania to Georgia, southeastern Ontario, Michigan, Wisconsin, southern Minnesota, North Dakota, and northern South Dakota, all report a short fall and spring planting season, divided by a long winter season, during which ordinary planting work is impracticable. Stations 7,8 , and ro lie in the northern limits of the upper Austral Zone where they are influenced by the Great Lakes. Stations I3, I4, I5, and 18 lie outside of the Great Lakes influence in the same zone, which includes a great territory stretching from the Coastal Plain westward to the Great Plains, and from the Transition Zone on the north to central Georgia and northern Texas on the south, except for an arm of the Lower Austral which extends northward along the Mississippi River to Cairo, Ill. The first three stations, 7, 8, and ro, show the influence of the Great Lakes in that their spring planting season is delayed, while stations $\mathrm{I}_{3}, \mathrm{I}_{4}$, and $\mathrm{I}_{5}$ show a markedly later date for stopping trans- 
planting in winter and an earlier closing date in the spring, due to the greater length of the growing season in this zone. Station 18 has such short winter interruptions that it practically offers a continuous working period from fall to spring. Stations 17 and 20 lie in the Lower Austral Zone, which includes the Atlantic Coastal Plain from the Piedmont Region to the ocean and all the southern states south of the Upper Austral Zone. The Sacramento-Fresno Valley in California also is included in this zone. These stations, together with station I9, which is probably influenced by the Japanese Current, and station $2 \mathrm{I}$, which lies in the Gulf strip of the Lower Austral, all report a continuous planting season of about the same length, which is uninterrupted by any cold weather. Station 16 reports a long fall season with a short interruption and a short spring season, while station 22, which lies just north of the Tropical Zone, reports a short, uninterrupted season which closes early.

In the extreme northernmost area, except that of Camden, Maine, the fall planting season does not open early enough, nor does the spring season extend long enough to offset the long winter period of frozen ground, which may extend to five months in the Northern Zone. Thus the total number of working planting days in the Northern Zone may be only 70 or 80 in an average year of not unusual severity of winter, while in the great central portion of the country each of the two seasons may be as much as 50 days long, giving a combined planting season of about 100 working days. In the Southern Zone, where there is no interruption during the winter, the season may be from II 5 to 150 or even 160 days long, except that the beginning of growth in the spring curtails the season at that end when the Tropical Zone is approached. It should be noted that the farther south one goes the more abruptly the spring growing season opens and the harder it becomes to prolong the planting season by any of the expedients mentioned above. The growing seasons of the southern sections of the United States open rapidly and there is greater danger in the operation of transplanting after leaf growth has started than in the cooler northerly sections of the country. It is also inadvisable to import cold storage plants into such southerly sections much after the time when local stock is in full leaf.

It is probable that as time goes on much more detailed and complete data will be published regarding safe planting seasons for the different life-zones of the country, thus enabling planters to eliminate nearly all 
of the guesswork which now exists, when one is called upon to execute work in an unfamiliar territory.

Evergreen Plants (Coniferous and Broad-leaved). The planting seasons for evergreens follow somewhat closely those for deciduous plants. It is probable that as our knowledge of broadleaved evergreens increases, their planting season can be shown to do this also. There are now about fifty known species of broad-leaved evergreens which are hardy in our northern climate if handled properly. It is important to know what are the requirements surrounding successful transplanting of evergreens. Probably the most important seasonal requirement for transplanting of evergreens is that the soil moisture shall be plentiful just prior to the time of transplanting in the location from which they are taken. In other words, in spite of all the old notions to the contrary, fall planting of evergreens should not start till the fall rains have adequately moistened the soil. Fall planting of evergreens can be successfully done as late as any other planting, provided the ground is moist when it freezes. It is better to wait for the fall rains than to plant too early and subject the plants to a hot, dry spell immediately afterward. In the spring, while it is possible to delay the planting of evergreens past the safe date for deciduous stock, due to the fact that they are practically always moved with a ball of earth, yet the best season is the earliest possible one. In both spring and fall planting, early planting has the advantage of allowing the plant to start root growth before the advent of the very hot weather of summer and the drying winds of winter, which sap the moisture content of the plant from the pores of the persistent leaves. Such sorts as biota, thuja, and taxus, which seem to establish themselves readily, can probably be successfully planted later in the season than others like picea, abies, tsuga, pinus - except nigra (austriaca), montana (Mughus), and Strobus-and chamacyparis. Evergreens of the first type will be subjected to much loss if not transplanted in a fully dormant condition immediately prior to the beginning of growth in the spring or if transplanted at a time in the fall when root growth sufficient to fix the plant in its new soil surroundings cannot be developed because of the lateness of the season.

Perennials. Planting seasons for herbaceous perennials are divided into spring and autumn in the North. One of the first factors 
when planting older plants is the blooming period of the species under consideration. As the blooming period is one of great activity above the ground, those plants which bloom late in the season, like Japanese windflowers and chrysanthemums, should be moved in the spring when they can make root growth more quickly and thus recover from the shock. On the other hand, those plants which bloom and mature early are practically dormant in late summer and early autumn. Thus, irises and peonies can be moved safely about September Ist, and will recover quickly and make new roots before cold weather sets in, whereas they are very active in the spring and often do not recover from the shock of being moved at that time unless the work is done very early. These are probably the first sorts fit to move in the autumn season, and other sorts follow along as they mature. The planting season for perennials would open earlier in the spring on a light soil than on a heavy one, both because the ground mellows earlier and because a heavy soil warms up more slowly. The texture of the soil is a factor affecting the planting season of perennials more than it does the other larger-rooted plants, and it is better to delay spring planting until the soil is in good condition to handle and is warm. Thus, the spring perennial season is likely to start later and last longer than that for woody deciduous plants, and also start earlier and stop earlier in the autumn. Pot-grown plants and seedlings can be transplanted at odd seasons whenever the weather is right, but it is generally best to wait till spring for all young herbaceous plants. Thus they are given the whole growing season in which to get established. Care should be taken not to bring tender plants out too early, before they have been hardened off, or too late, when the torrid summer days will wilt them down before they take root.

LAwns. The spring seeding season for lawn grass starts in the Lower Austral Zone in February, about the middle of the month, and continues to May Ist, but may be shut off by the advent of hot weather as early as March Ist. As one goes farther north, the season does not lengthen very much, but merely opens later, extending from about April I.5th to June Ist. Thus, this seeding season, to a great extent, overlaps the planting season and cannot be protracted past the closing date for planting without great risk of the bad effect of hot weather on the young grass. The autumn season starts in the North as early as August Ist, and closes not later than October Ist, but generally by the 
I 5 th or 20 th of September, thus not overlapping the autumn planting season to any extent. As one goes southward, the season again merely shifts along, so that, in the Upper Austral Zone, it opens about September $15^{\text {th }}$ and closes about November Ist, while in the Lower Austral it is pushed along to October I5th. Here the practice of seeding stops, except for the use of English rye as a green winter carpet, and is superseded by the practice of "sprigging" or planting pieces of Bermuda and St. Augustine grass. This grass planting is commonly done in southern Florida in June, while farther north, and especially in Alabama, it is done through the winter months so as to take advantage of the then abundant rains (See Page 59).

Grass seed sown too early in the autumn and not artificially watered will generally lie dormant until the fall rains start germination, and, likewise, seed sown too late in the autumn or too early in the spring will lie dormant until the ground warms up sufficiently to start sprouting. The grass seeding season is from the time the ground gets warm enough in the spring until it gets too cold in the autumn to start the germination process, but this season is as a matter of practice divided into two parts by the period in the summer when the ground is too dry to start germination and the weather is so hot as to require constant artificial watering, both to start germination of the seed and to keep the young plants alive. It is also generally considered wiser not to seed so late in the autumn, in the North, that the young grass plants will not be well established before freezing weather. These are the factors which influence the establishment of the lawn seeding season dates diagrammatically shown on the chart (Plate III). Making lawns in the South is a process of seeding when adaptable mixtures of northern lawn seed are used, and a process of planting roots when the native Bermuda and St. Augustine grasses are used. Northern grass is seeded in the period from September to January. Italian rye is seeded from October to January, and native grass roots are planted as shown on the chart in stations $2 \mathrm{I}$ and 22. 


\begin{tabular}{|c|c|c|c|c|c|c|c|c|c|c|c|c|c|c|c|}
\hline \multirow{2}{*}{ Nol } & \multirow{2}{*}{ LOGALITY } & \multirow{2}{*}{\begin{tabular}{|l|} 
TYPE \\
OF \\
MATERIAL
\end{tabular}} & \multicolumn{6}{|c|}{$\begin{array}{r}\text { PIANTING } \\
\end{array}$} & \multicolumn{3}{|c|}{ SEASON } & \multirow{2}{*}{ APR } & \multirow{2}{*}{\multicolumn{2}{|c|}{ MAY JONE }} & \multirow{2}{*}{ 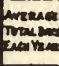 } \\
\hline & & & JULY & AUa & SEPT & $\overline{O C T}$ & Nov & DEC & JANR & FEB & 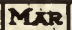 & & & & \\
\hline 1 & $\begin{array}{l}\text { NORTHERN } \\
\text { NEW YONX }\end{array}$ & 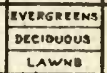 & & & & & & & & & & & & & $\frac{57}{\frac{50}{58}}$ \\
\hline 2 & $\begin{array}{l}\text { CAMDEN, AND } \\
\text { BELTAST, MAINE }\end{array}$ & \begin{tabular}{|l|} 
Evergheress \\
Deerouous \\
LAWNS \\
\end{tabular} & & & & & & & & & & & & & $\frac{53}{\frac{59}{49}}$ \\
\hline 3 & BUFFALO & \begin{tabular}{|c|} 
EVERIREZNG \\
DECIDOOUS \\
LAWNS \\
\end{tabular} & 111 & & & & & & & & & & & & $\frac{80}{61}$ \\
\hline 4 & MINNEAPOLIS & \begin{tabular}{|c|} 
EVERGREERS \\
DEciouous \\
LAWNS \\
\end{tabular} & i & & & & & & & 1 & & & & & $\frac{76}{\frac{78}{52}}$ \\
\hline 5 & $\begin{array}{l}\text { HARTFORD, AND } \\
\text { CENT.CONNECTICUT }\end{array}$ & \begin{tabular}{|c|} 
EVERGNEENG \\
DECIDUOUS \\
LAWNS \\
\end{tabular} & & & & & & & & & & & & & $\frac{83}{79}$ \\
\hline 6 & $\begin{array}{l}\text { BöTOK, AND } \\
\text { CENTAALMASS }\end{array}$ & \begin{tabular}{|c|} 
EVERGREENS \\
DECIDUDUS \\
BAWME \\
\end{tabular} & & & & & & & & & & & & & $\frac{68}{\frac{68}{62}}$ \\
\hline 7 & $\begin{array}{l}\text { TOXONTO, AND } \\
\text { UPTER ONTARIO }\end{array}$ & \begin{tabular}{|c|} 
EVzRaREzNG \\
OECIDUDUS \\
LAWNS \\
\end{tabular} & & & & & & & & & & & & & $\begin{array}{l}\frac{106}{100} \\
\frac{103}{103}\end{array}$ \\
\hline $8^{\circ}$ & $\begin{array}{r}\text { PRINEGVILLE, } \\
\text { OMIO }\end{array}$ & 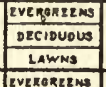 & & 11 & & & & & & & & & & & $\begin{array}{l}81 \\
\frac{87}{69} \\
9\end{array}$ \\
\hline 9 & LONG ISLAND & \begin{tabular}{|l|} 
orclouous \\
LAWNS \\
\end{tabular} & 111 & $\begin{array}{llll}1 & 1 & 1 \\
1 & 1 & 1 \\
\end{array}$ & & & & & & & & & & & $\frac{90}{70}$ \\
\hline 10 & Cleveland & \begin{tabular}{|l|} 
EVLRGREZNS \\
DECiDUOUS \\
LAWNS \\
\end{tabular} & & 11 & 1 & & & & & & & & & & $\begin{array}{l}97 \\
21 \\
22\end{array}$ \\
\hline 11 & \begin{tabular}{l|} 
SOUTHEASTERN \\
PINSSTLVANIA
\end{tabular} & \begin{tabular}{|l|} 
EVERGRELMS \\
DzCiowous' \\
LAWNS \\
\end{tabular} & & & & & & & & 1 & & & & & $\frac{131}{\frac{109}{39}}$ \\
\hline 12 & SPOKANE & \begin{tabular}{|l|} 
EVERGREINS \\
DECiduoUs \\
LAWNS \\
\end{tabular} & 1 & $\begin{array}{rl}1 & 1 \\
1 & 1 \\
1 & 1 \\
\end{array}$ & in & & & & & & & & & & $\frac{91}{97}$ \\
\hline 13 & $\begin{array}{l}\text { KANBAB CITY,AND } \\
\text { J00MLLE RUDIUS }\end{array}$ & \begin{tabular}{|c|} 
EVERGREENS \\
OECIDUOUA \\
LAWNS \\
\end{tabular} & & $\begin{array}{lll} & 1 \\
1 & 1 & 1 \\
1 & 1 & 1 \\
\end{array}$ & & & & & & & & & & & \begin{tabular}{|c|}
130 \\
70 \\
61 \\
\end{tabular} \\
\hline 14 & $\begin{array}{l}\text { NEW JERSEY } \\
\text { CONGTAL.PLAIN }\end{array}$ & \begin{tabular}{|c|} 
EVERGREZRS \\
DECIDUOUS \\
LAWNS \\
\end{tabular} & & $\begin{array}{l}1 \\
1 \\
1 \\
1\end{array}$ & & & & & & & & & & & \begin{tabular}{|c|}
105 \\
104 \\
39 \\
\end{tabular} \\
\hline 15 & CINCINUATI & \begin{tabular}{|l|} 
EVRRARIINA \\
DECIDUOUS \\
LAW'NS \\
\end{tabular} & & 111 & & & & & & & & & & & \begin{tabular}{|l|}
101 \\
100 \\
82 \\
\end{tabular} \\
\hline 16 & SAN FRANCISCO & \begin{tabular}{|c|} 
EVERGRLINS \\
DECIDUOUE \\
2AWNS \\
\end{tabular} & & $\begin{array}{ll}1 & 1 \\
1 & 1 \\
1 & 1 \\
\end{array}$ & 11 & & & & & & & & & 1: & $\frac{149}{60}$ \\
\hline 17 & $\begin{array}{l}\text { YIROINUK } \\
\text { COABTAL PIAIN }\end{array}$ & \begin{tabular}{|c|} 
EVERGREENS \\
DEGIDUOUS \\
LAWNS \\
\end{tabular} & & i 11 & & & & & & & & & 11 & $\begin{array}{llll} & 1 & 1 \\
1 & 1 & 1 \\
1 & 1 & 1 \\
\end{array}$ & \begin{tabular}{|l|}
158 \\
150 \\
103 \\
\end{tabular} \\
\hline 18 & $\begin{array}{l}\text { GR - CAROLINR } \\
\text { PIEDMONTREGION }\end{array}$ & \begin{tabular}{|c|} 
EVRRORZIKS \\
DECIOUOUS \\
LAWNS \\
\end{tabular} & & & $\begin{array}{ll}1 & 1 \\
1 & 1 \\
\end{array}$ & & & & & & & $\begin{array}{lll} & 1 \\
1 & 1 & 1 \\
1 & 1 \\
\end{array}$ & $\begin{array}{ll}1 & 1 \\
1 & 1 \\
1 & 1 \\
\end{array}$ & $\begin{array}{ll}1 & 1 \\
1 & 1 \\
\end{array}$ & \begin{tabular}{|c|}
154 \\
130 \\
02 \\
\end{tabular} \\
\hline 19 & PORTLAND, ORE & 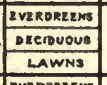 & & $\begin{array}{ll}1 \\
11 \\
1\end{array}$ & 11 & & & & & & & & 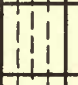 & $\begin{array}{lll}1 & 1 \\
1 & 1 & 1 \\
1 & 1 \\
\end{array}$ & \begin{tabular}{|c|}
162 \\
160 \\
90 \\
\end{tabular} \\
\hline 20) & $\begin{array}{l}\text { SACRUMENTO, } \\
\text { FRESNO VRLLIXX }\end{array}$ & \begin{tabular}{|c|} 
EVR RIRIYME \\
DECIDUOUS \\
LAWWS \\
\end{tabular} & & $\begin{array}{ll}1 & 1 \\
11 & 1 \\
1 & 1 \\
\end{array}$ & $\begin{array}{ll}1 & 1 \\
1 & 1 \\
1 & 1 \\
\end{array}$ & & & & & & & & $\begin{array}{lll}1 & 1 \\
1 & 1 \\
1 & 1 \\
1 & 1 \\
\end{array}$ & $\begin{array}{lll}1 & 1 \\
1 & 1 \\
\end{array}$ & \begin{tabular}{|l|}
150 \\
180 \\
91 \\
\end{tabular} \\
\hline 21 & $\begin{array}{l}\text { JACKSONYILLER, } \\
\text { FLORIDA }\end{array}$ & \begin{tabular}{|c|} 
EVERGREZMS \\
DIClouous \\
LAWNS \\
\end{tabular} & 11 & $\begin{array}{llll} & 1 & 1 \\
1 & 1 & 1 \\
1 & 1 & 1 \\
\end{array}$ & $\begin{array}{lll}1 & 1 & 1 \\
1 & 1 & 1\end{array}$ & $\begin{array}{l}11 \\
11 \\
\end{array}$ & & & & & & 1 & $\begin{array}{lll}1 & 1 \\
1 & 1 \\
1 & 1 & 1 \\
\end{array}$ & $\begin{array}{lll} & 1 \\
1 & 1 \\
1 & 1 \\
\end{array}$ & \begin{tabular}{|l|}
120 \\
126 \\
120 \\
\end{tabular} \\
\hline 22 & 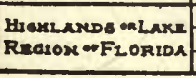 & \begin{tabular}{|c|} 
EVZROKZENS \\
OECIOUNOWS \\
LAWNS \\
\end{tabular} & 111 & $\begin{array}{llll} & 1 & 1 \\
1 & 1 & 1 \\
1 & 1 & 1\end{array}$ & $\begin{array}{lll}T & 1 \\
1 & 1 & 1 \\
1 & 1 & 1\end{array}$ & 17 & & & & $\begin{array}{lll}1 & 1 & 1 \\
1 & 1 & 1\end{array}$ & 111 & ii & $\begin{array}{lll}1 & 1 & 1 \\
1 & 1 & 1 \\
1 & 1\end{array}$ & $\begin{array}{ll}T & 1 \\
1 & 1 \\
\end{array}$ & $\begin{array}{c}78 \\
6 \\
103 \\
\end{array}$ \\
\hline
\end{tabular}

Plate III. A chart to aid in determining the most favourable period for transplanting, and for seeding of lawns in various sections of the United States. Note the long winter periods of the Northern Zones, and the continuous planting seasons of the Southern Zones. It is of great importance to be able to plan ahead and to order plants for delivery at the proper time for any section of the country. These are average seasons resulting from observations of normal seasons during a period of years. For supplementary information refer to Plate No. II on page No. 6 
3athontow 
PLANTING AND SEEDING SEASONS

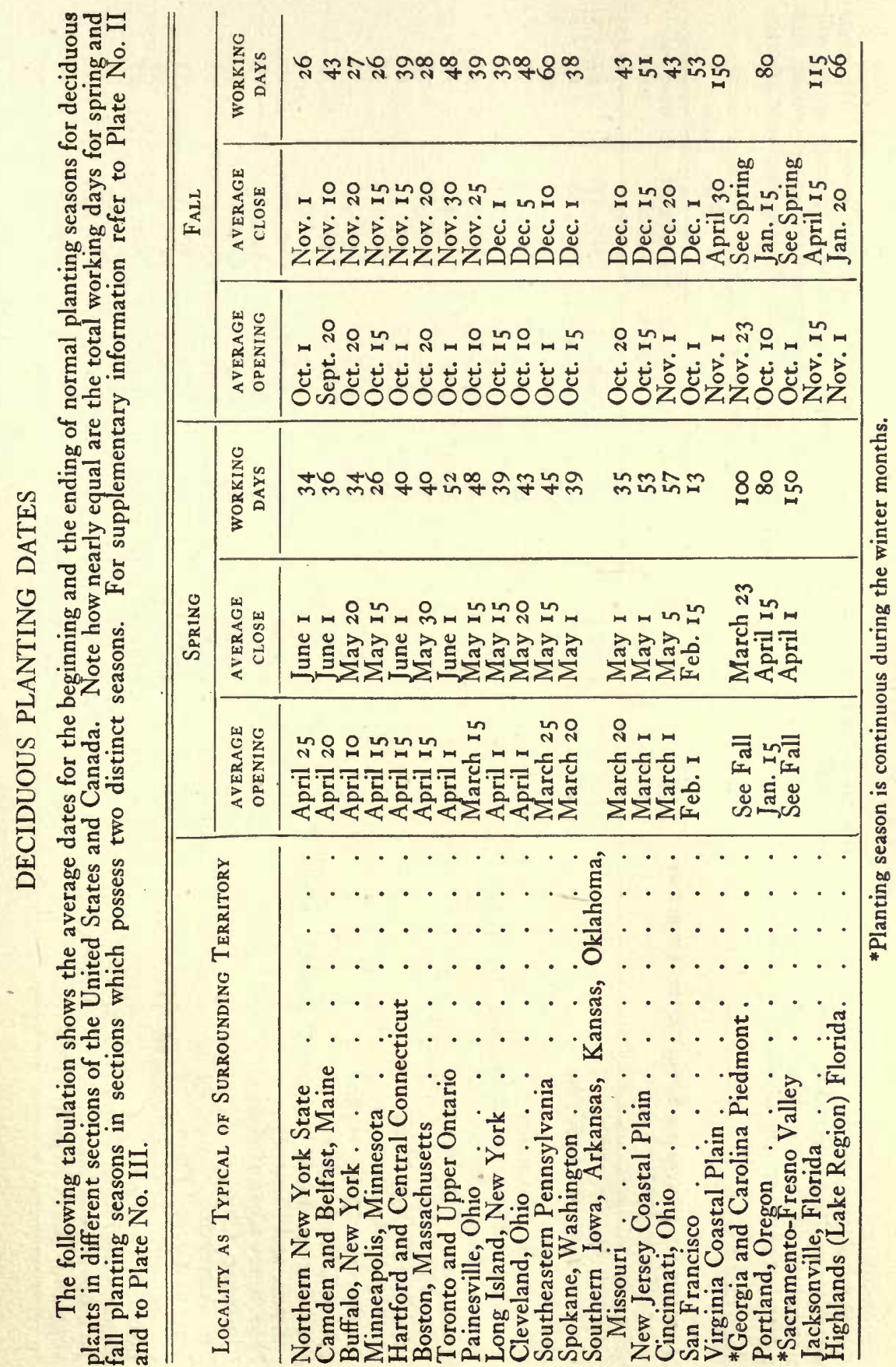




\section{THE COMPLETE GARDEN}

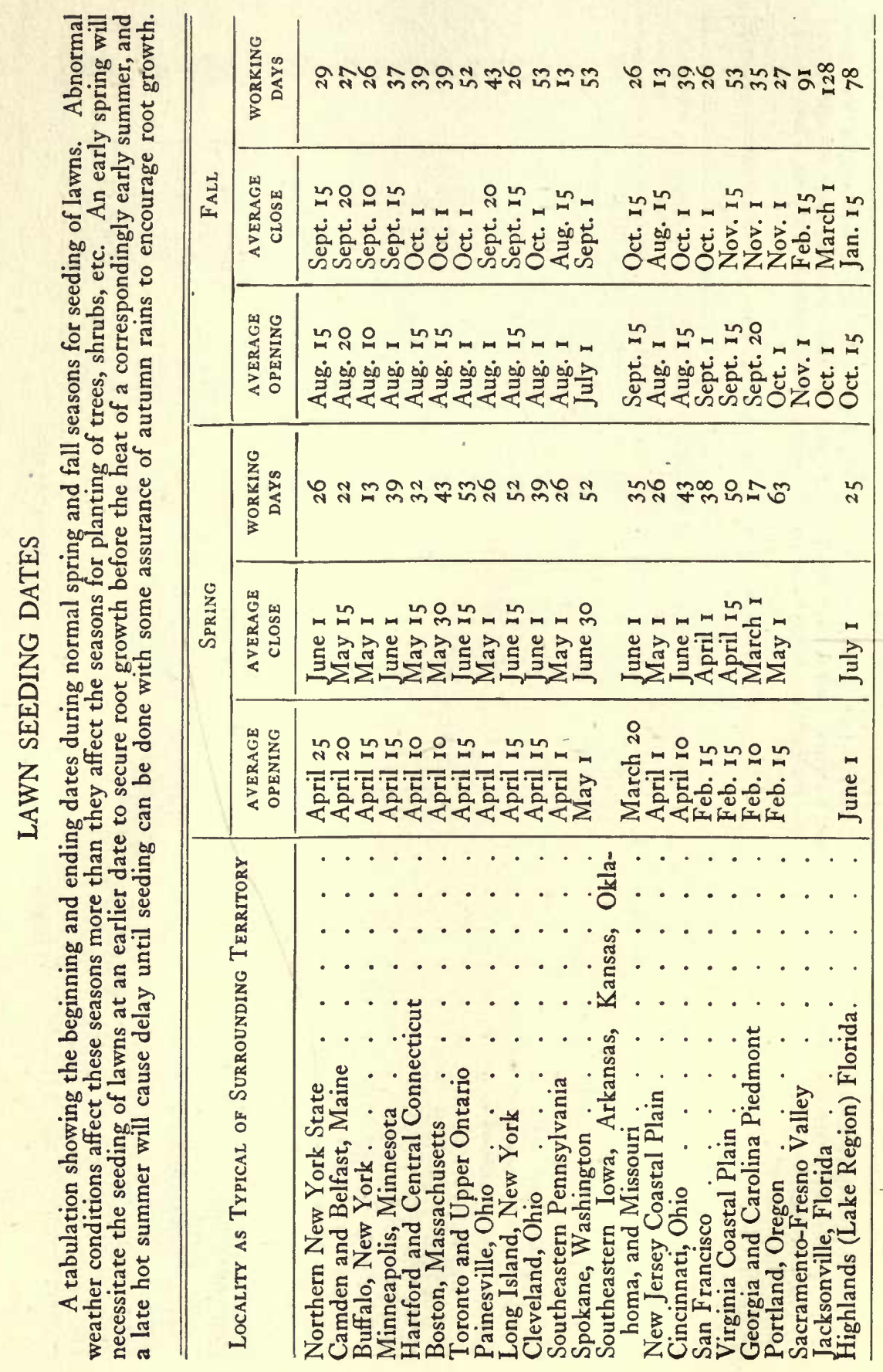




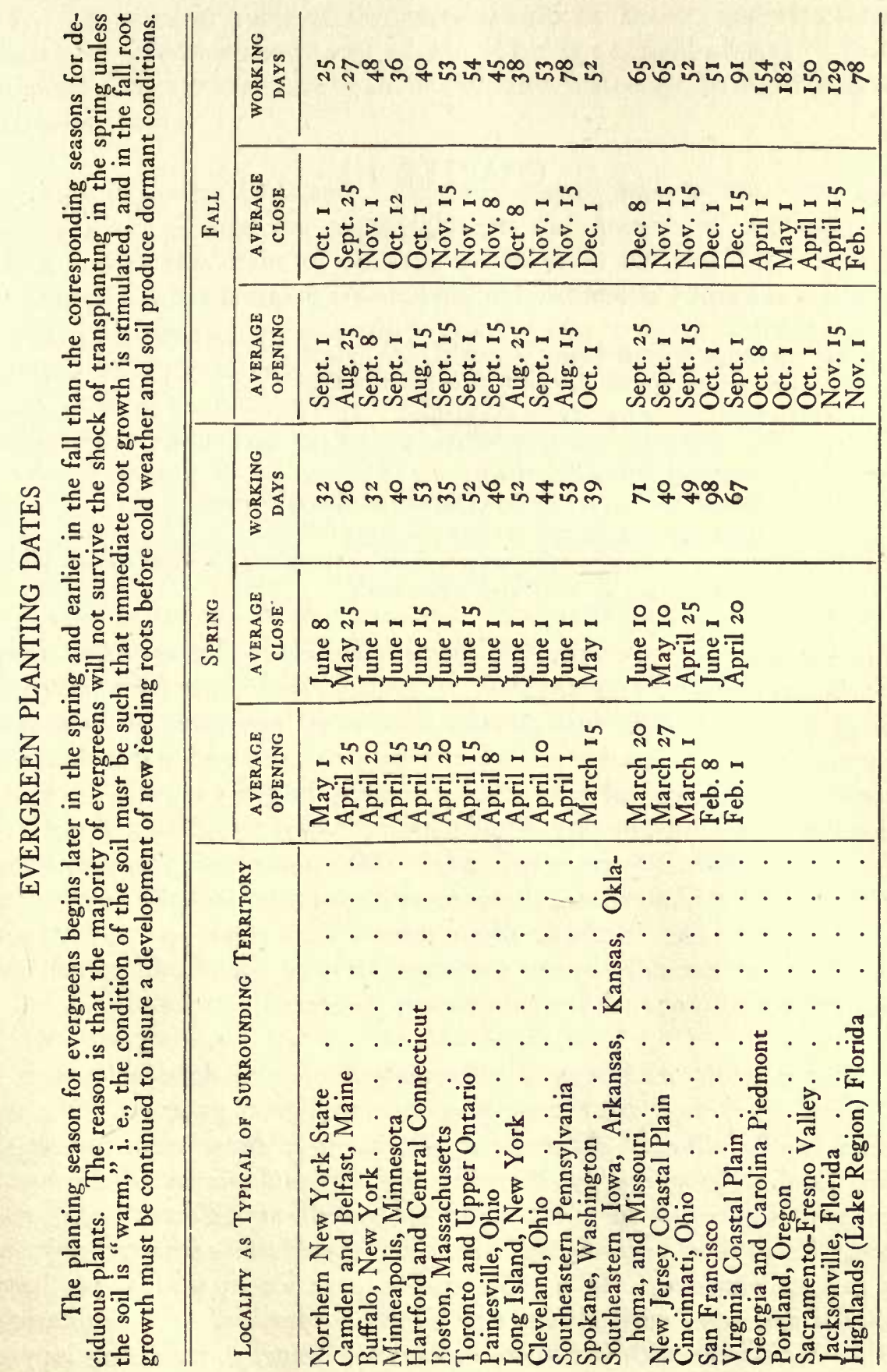




\section{CHAPTER III}

\section{PRUNING}

Reasons for Pruning. The reasons for pruning are:

(I) To secure a desired form or height of the plant;

(2) To remove injured, diseased, or dead branches;

(3) To renovate or rejuvenate old plants;

(4) To maintain a balance between root growth and top growth (as shown in the operations of transplanting);

(5) To encourage the production of an abundance of flowers;

(6) To encourage the production of a few large flowers;

(7) To improve or modify the natural form of the plant for some specific reason such as in topiary work and hedge work.

Pruning, however, is only a phase in the care of plants and must be accompanied by constant good cultivation, feeding, and management of plants. It is only through the process of intelligent pruning that shrubs especially can be maintained in a definite and natural condition of growth and also kept at a correct height to avoid in many instances the out-growing or over-powering of the design for which they were selected to become a part. Many incorrect ideas have become prevalent concerning the process of pruning, and the application of these incorrect methods often causes a slowing up or incorrect development not only in the growing habits of the shrubs but in the quality and the quantity of the flowers produced.

Precautions to Observe. Pruning should be done only with a definite ideal and after arranging an intelligent program. No set rules can be offered. Climatic conditions may cause rules correct in one locality to prove valueless in another, and plants of the same species often vary in their habit of growth at different ages, and must be pruned accordingly. Pruning should be entrusted only to a careful workman. It is too common practice in pruning to have shrubs and trees with all the tips lightly snipped off with regularity; or to have trees with the main and lateral branches ruthlessly lopped 
off. The natural habit of the plant should be known and this form preserved when removing any wood. This fact should always be kept in mind except in the case of shrubs or trees which are to be trained in artificial shapes.

Results From Pruning. Pruning always arrests but does not permanently change the natural habits and growth of a plant. It often causes the plant to assume temporarily another form than it would naturally assume. Pruned plants constantly struggle to return to their natural habit, and when pruning has been undertaken for a specific purpose it should be continued throughout the life of the plant so long as that purpose is desirable.

Root pruning tends to reduce wood production and hence to increase fruit and flower production. Top pruning favours wood production and thus more top is produced by the seemingly contrary process of cutting it off. In the case of transplanted stock tops are cut back to compensate for the roots that are lost in moving. Removal of excess top growth insures to the remaining parts of the plant more nourishment, with subsequent better development; and it also decreases the area of leaf surface and the consequent evaporation of stored-up moisture before the roots begin functioning in the new location.

Tools and Wound Dressings. Pruning shears, pruning knives, and hand saws are the best tools to use. Pole saws and hooks should be avoided as they leave ragged wounds, and pole pruners should be used only for small twigs. Never use double edge saws as they are more apt, in the hands of a careless workman, to injure the tree. A ladder will be required for the larger trees and a block and ropes for removing limbs that are near wires or that might injure property.

For dressing wounds gas tar and liquid asphaltum have proven the most satisfactory. They hinder healing the least of the common dressings and are the most durable, adhesive, and antiseptic. Coal tar and pine tar seem to be injurious and white lead apparently has no injurious or antiseptic effect. Dressings give only physical protection and cannot hasten healing, which takes place through the activity of the plant itself.

Trees-Top Pruning. Street trees should be pruned so that 
branches will not interfere with pedestrians or vehicles. The roots of street trees are more confined than those of other trees and they require top pruning to balance with the root system. Pruning should aim to preserve the natural habit of the trees; but they should also be kept symmetrical in form. If the tops become too thick and exclude too much light they should be thinned out. Main laterals, however, must not be disturbed, but rather the shoots. that spring from these main laterals should be removed.

Specimen trees on lawns require little pruning except to prevent bad crotches (which if left might cause splitting), to shorten branches which may affect the symmetry of the tree, to remove dead wood, and sometimes to remove (as in the case of maples and pin oaks) some of the finer interior branches in order to give more "character" to the tree.

It is generally best to do the heavy cutting in winter, while the trees are dormant. Pruning in early spring or summer may cause the tree to "bleed," with a consequent check to the root system from the loss of food. This is especially true of maples. One advantage, however, of spring or summer trimming is that the tree will recover more quickly and start to heal the wound, which would be impossible during the winter season. If trees are pruned in winter the "shaping up" and removal of small pieces of dead wood should be done after the leaves appear at which time symmetry can be better judged and all dead branches can be more easily discovered. To assure the least possible injury from exposure to climatic conditions winter pruning, if necessary, should be delayed until the danger from the more severe winter conditions is past.

Broken and diseased limbs must always be removed, and secondary growth and suckers cut, to open the centre of the tree to the sun and air. When limbs are pruned they should be cut back to a bud that will grow outward.

When larger branches are entirely removed, the cut should be made at the base of the branch and parallel to the tree trunk. No stump at all should be left, and care should first be taken to undercut amply on all heavy limbs so that when the cut on the upper side is completed the branch will not split the bark from the trunk. All other cuts, such as removing portions of branches, should be made perpendicular to the axis of the branch which is being shortened. The cut should always be clean, with no ragged edges left (See Plate V).

Never cut back the leader on trees that are excurrent, such as oaks, 

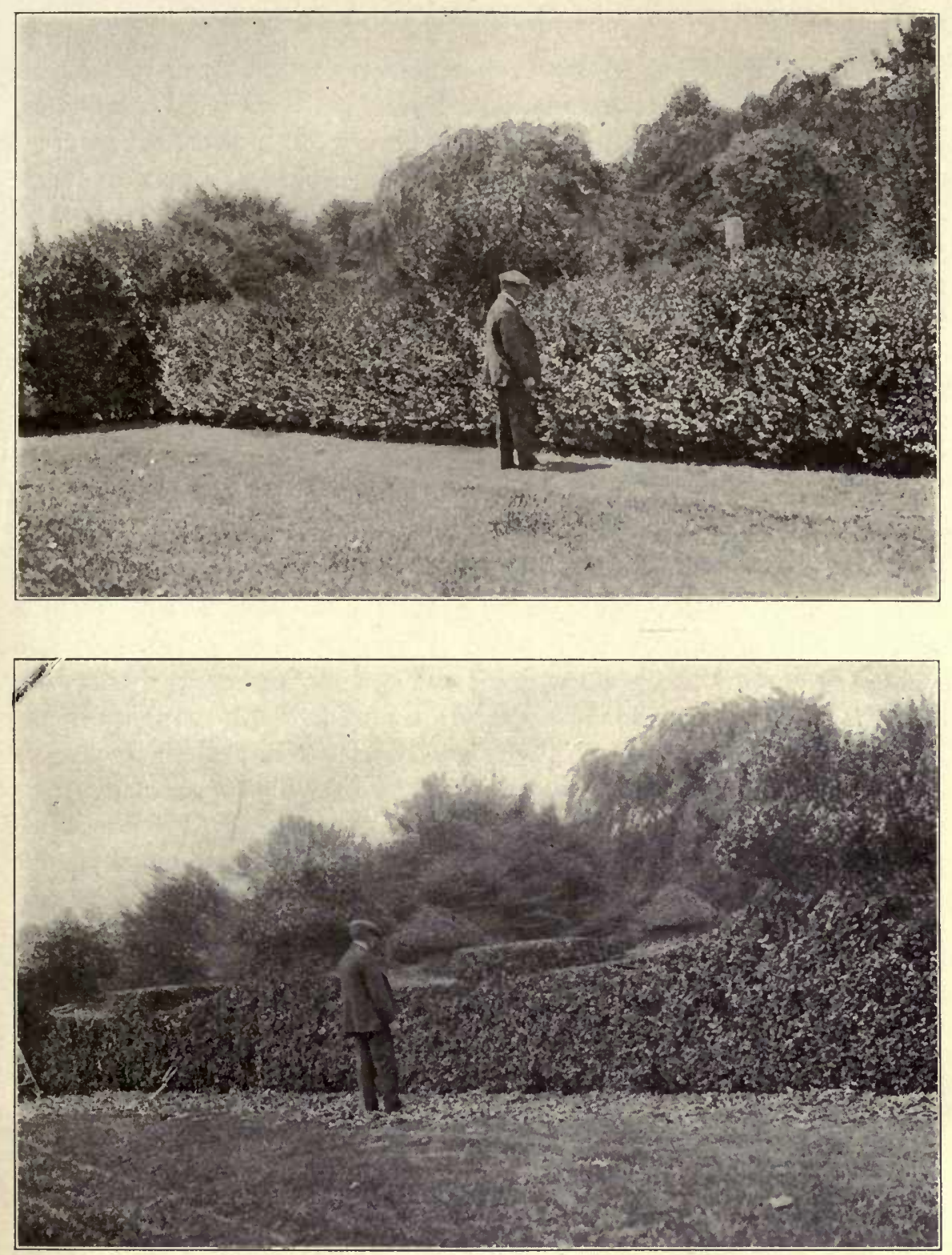

Plate IV. The hedge which may look unkept, and ragged if not pruned, will in the hands of the skilled gardener assume almost any degree of refined outline. These photographs show one of our most desirable hedge plants, the Japanese privet (Ligustrum ibota). (See Chapter III) 

birches, spruces, and sugar maples. If the leader is killed it is often possible to train the best lateral available as a substitute. This may be done by binding the lateral to a pole and tying with raffia.

If the tree is weakened or is dying, severe pruning will often aid in offsetting the trouble and may help the tree to recover its vigour. Many trees and shrubs, as poplars, soft maples, the tree of heaven, box elders, hydrangeas, and sumacs will stand very heavy pruning and recover rapidly. Oaks, elms, and flowering dogwoods should be pruned only as corrective measures and not to check growth.

During the progress of construction work in the neighbourhood of fine trees or shrubs some protection should be afforded, either by the erection of a stout fence or a stout wooden framework.

Root Pruning. Root pruning serves to check the growth of a tree and to encourage lateral or secondary growth of the roots. When a plant has a slow or a weak-growing top grafted upon a vigorous root stock, root pruning is often used advantageously to stop too great a growth of the stock. Root pruning should be done before the weather becomes too cold in the fall. If this pruning is delayed till very late no start in healing the cuts will be made before spring, and meanwhile decay will set in. The process of root pruning to assist in the successful transplanting of trees is effected by excavating a narrow trench around the tree encircling a ball of earth (Usually six to eight feet in diameter) (See Plate VI-C-I) which can be handled with a tree machine. In this way one-half to two-thirds of the large roots are severed. The trench is filled with loam, and during the remainder of the growing season a mass of new fibrous roots form, which readily come to the aid of the tree when transplanted to its new location (See Planting and Transplanting, Page 42).

All trees should be top pruned when transplanted. This is done to offset the loss of root system by removing a portion of the top. A general rule is to remove four-fifths of the current year's growth and one-eighth of the older branches. Do not cut back main laterals or leaders so as to leave large stubs, for with such pruning the stubs will rot and spoil the tree.

Trees with ample fibrous roots, such as maples and elms, are easier to move successfully than trees with few roots, or with tap roots, such as magnolias, tulips, gums, and nut trees. It is therefore necessary to prune the tops more heavily on transplanted stock with sparse root 
systems. On all transplanted stock the roots should be pruned to remove diseased, dead, or bruised portions. In older plants tap roots may be shortened if the cutting is done judiciously. Many trees, especially older trees, are moved more safely in the winter if they are root pruned not later than the last of the previous July. In transplanting fine old specimens of beech and boxwood it is sometimes necessary, and always advisable, to root prune the trees for two seasons prior to the time of transplanting, in order to insure the greatest possible success.

HeDges. Most hedge plants, such as the Japanese barberry and the privet, if allowed to grow as specimen plants unrestrained by severe pruning, will produce a considerable quantity of flowers and also of fruit. This is especially true of the Japanese barberry, which has interesting fruit. If these plants are grown in hedges, which are subject to frequent and severe trimming at least three or four times during the growing season, then all of the flowers are surely removed and if the flowers are not removed, then at the time of the next pruning the fruit is removed, therefore very few of the hedges of this character ever produce any fruit. The only way in which to have a hedge such as a Japanese barberry hedge, with a quantity of fruit upon it, is to prune the hedge during the very late winter months or early spring months and not to prune it again until after the fruiting season is over.

Hedges which are allowed to grow naturally require but little pruning, except the removal of dead and diseased wood and the checking of any portion that becomes too rampant or destroys symmetry. It often becomes desirable in the development of hedge plants to keep the growth within certain well-defined limits of height, after the plants have become a few years old. This requires judicious pruning, consisting of the removal of many of the older branches each year, but never a heavy shearing which cuts the entire top of the plant, regardless of the size or age of the branches, to a fixed height.

Hedges which are trimmed formally should be kept uniform in height and thickness. One late winter and two or three summer prunings during the growing season are better than one heavy pruning yearly. Hedges will do best if kept in a flattened ovoid shape with the widest part at the base (Plate V). In this way all the leaf surface will receive a more nearly equal portion of light, and leaves will grow 
down to the ground. It is preferable to have the top rounded rather than flat. Remember that a portion of the current year's growth must be left on the plants when pruning.

If privet hedges are winter-killed partially or wholly, or girdled by animals, they should be cut back to four or six inches above the ground. A hedge, when newly planted, should be cut back severely, often to within twelve inches of the ground. This is necessary in order to secure thick growth at the base.

Topiary EfFects. The operation of pruning to produce topiary effects is one that requires much more careful attention and more frequent pruning than almost any other type of pruning work, with the exception of possibly some hedges such as privet hedges, where it is necessary to maintain a constant, even effect. The yew and boxwood which are used for the most permanent effects in topiary work can be pruned to best advantage during the latter part of June and the early part of July, at which time all the new growth should be cut back as far as the older growth, which consists of darker green leaves. This allows opportunity for new shoots to develop within the old growth and thicken the mass. Many plants used for such topiary effects as ovals, spheres, pyramids, cones, spirals, etc., can be given a thorough trimming when the trees are young. The subsequent growth (if the loose-growing tips are kept cut back) will continue to increase the dimensions of these designs in an interesting way. The key to successful topiary effects is the accurate shape to which the tree is trimmed when the first pruning work on the specimen is undertaken.

Shrubs. Ornamental flowering shrubs may be pruned at any season of the year if no consideration is given to the question of flower production. Wounds made by pruning will heal, however, better during the growing season. Late summer pruning will sometimes encourage a new and vigorous growth which does not thoroughly ripen during the late summer and fall months, and is consequently exposed to the danger of winter-killing. Late summer pruning should accordingly not be practised especially on semi-hardy plants. During wet seasons, and when plants are over-supplied with food, summer pruning may be resorted to, in order to restrain succulent and weak growth.

Many shrubs possess a greater or less value for their flowering habits. 
The following are a series of memorandums explanatory of the drawings shown on Plate No. V, illustrating various methods of pruning trees and shrubs.

A

A large, overgrown, and "leggy" shrub with some new long shoots growing from the base of the plant. In such overgrown plants as these all of the wood which produces flowers is in the top branches at the ends of the old wood and the shrub

A-1 presents a very bare effect at its base.

The same shrub as shown under "A", but pruned for the purpose of allowing new shoots to develop from the base of the shrub and to permit a new top at a normal height, thus renovating the entire shrub during a period of two or three years.

A-2

The same shrub as in " $A$ ", showing its development after proper pruning. This produces new flowering wood and a more natural and even development of the

A-3 entire shrub, which insures a better bloom and a more satisfactory effect.

The same shrub as under "A", but incorrectly pruned or "sheared" in accordance with the method of unintelligently removing all wood, new and old, at a uniform height, irrespective of flowering habits or other habits of growth of the shrub.

A-4

The same shrub as under " $A$ ", showing the development in its growth after incorrect pruning $(A-3)$. Note that most of the new growth has developed on the old wood, producing a broom effect at the top and a "leggy" condition at the base of the shrub. Such plants cannot grow normally or produce normal flower effects.

B-1

This illustration shows the correct method of pruning hybrid tea roses in order to produce large individual blooms. The portion in light lines shows the branches to be removed.

B-2

This illustration shows the hybrid tea rose pruned to produce an abundance of flowers but not necessarily large individual blooms. The portion in light lines shows the branches to be removed.

C-1

This illustration shows the correct series of cuts to be made in removing large branches at a point close to the trunk of the trees ( $I$ is the first cut to be made, or the under cut. 2 is the second cut to be made, or the upper cut. 3 is the final cut to be made, or the close cut). Note also the healing over of a correctly made cut.

This illustration shows the incorrect method of making a cut in one operation, frequently causing the splitting down of the branch. Note also the attempt to heal an incorrect cut, which was not made sufficiently close to the trunk. The bark on such cuts dies back to the trunk and the new healing bark cannot grow over the wound.

D-1 to D. 5

Shows correct and incorrect methods of shearing or pruning hedges.

Shows the correct method known as the ovoid cross section (D-I); the truncated cross section (D-2); and the rectangular cross section (D-3). As a result of each of these methods of pruning the hedge produces a solid foliage effect at its base.

D-4 and D-5

These illustrate incorrect methods of pruning known as the inverted pyramidal cross section and the inverted cone cross section, both of which methods resulting in a wide top and a narrow base in the cross section of the hedge produce a bare effect at the base and give little foliage. 

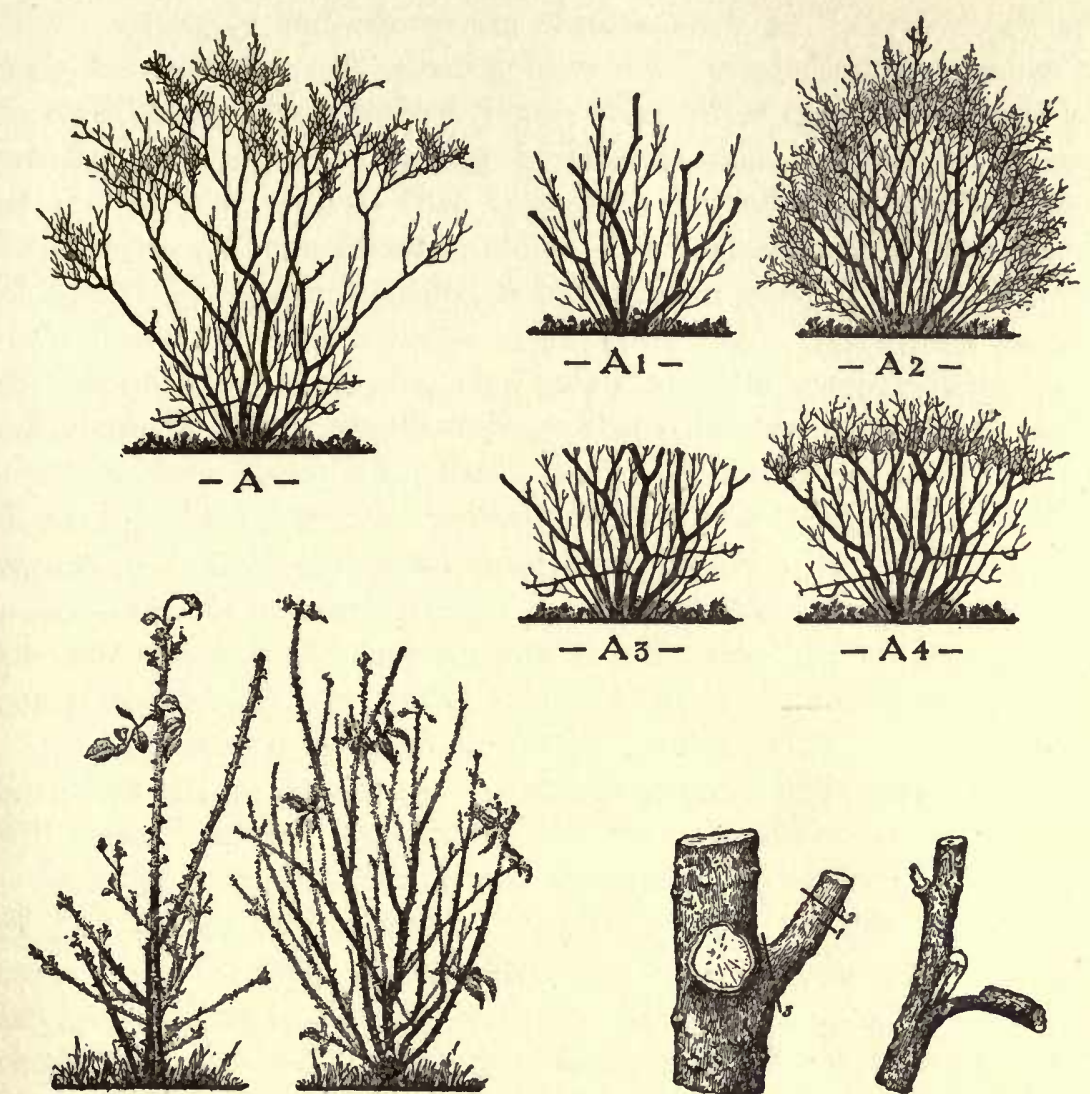

$-\mathrm{B}_{1}-$
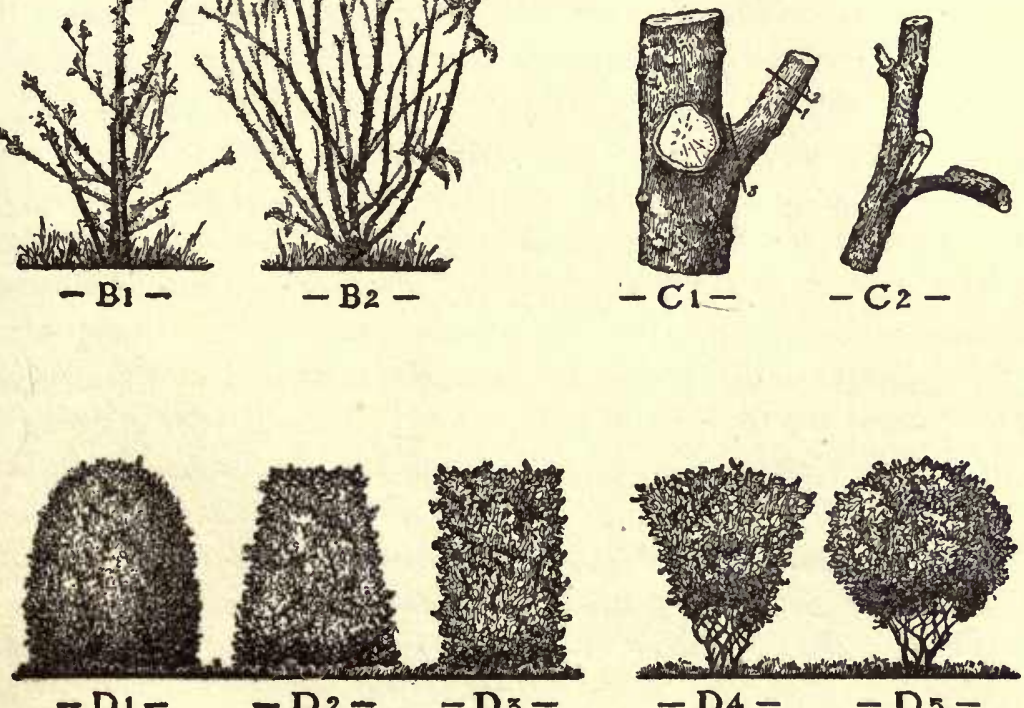

$-D_{1}-\quad-D_{2}-\quad-D_{3}-$

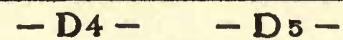

Plate V. The correct pruning of trees and shrubs is a great factor in the successful maintenance of landscape plantings. These diagrammatic drawings, together with the explanations on the opposite page, illustrate correct and incorrect methods of pruning. 

There are two types of shrubs (Chapter XLII-A, Page 296), one of which is the spring or early-flowering shrubs, such as Van Houtte's spirea, weigela, snowball, and most golden-bells, producing flowers on wood formed during the previous year. The other type consists of plants which produce flowers during the late summer and fall on the growth of the current year. This type includes the rose of Sharon, the hydrangea, and the common elder. The general rule for the pruning of flowering trees and shrubs, in order to encourage the development of more flowers, is to prune soon after flowering. Unless one has a definite knowledge of shrubs, this rule should be applied literally. The other rule is that spring-flowering shrubs should be pruned in the early summer immediately after they are through flowering, and the summerflowering shrubs can be pruned to the best advantage in the late winter and early spring before growth has commenced, to avoid the possibilities of winter-killing. Lilacs also should be pruned during the early part of the summer and shortly after the blooming period is complete and in every instance before the seed pods have formed.

Spring-blooming plants should be pruned within a week after the blossoms fall to encourage a summer growth of budded wood which will be well ripened by winter.

Summer-blooming plants may be pruned either in the late summer or just before spring growth begins, to force a new spring growth upon which summer flowers appear. Late summer pruning is never advisable. Some shrubs, such as lilacs, flowering dogwoods, and rhododendrons should not be pruned except to remove dead and diseased branches, or branches that interfere with the development of the plants. Deciduous shrubs of which the wood has become incurably affected with scale may, however, be revivified by being cut down to the ground. In the case of plants that form ornamental fruit the branches should not be cut back far, nor the pruning done after the fruit buds have formed.

Any dead or dying wood should be removed as soon as noticed. In the case of summer-blooming shrubs pruning is best done in the early spring after the leaves appear, in order to remove winter-killed tips.

Old wood should be cut out to prevent shrubs from getting "leggy, i. e., having all top with no foliage around the base. In removing old wood, cut to the base of the plant; otherwise sprouts will shoot up from stumps and fail as the latter decay. New growth should always be 
encouraged from the roots. Cutting back all branches, or giving shrubs an even shearing should be avoided, as strong shoots will develop and cause a too succulent and unbalanced top growth (See Plate V). With transplanted stock a general rule is to remove about one-fourth of the wood, to offset the loss of roots. Root pruning for shrubs is similar to that of trees (See Chapter on "Planting and Transplanting").

Old shrubs and overgrown material should be thinned out by removing some branches to the base of the plant. This will allow sun and air to reach the base of the plant and encourage growth at the bottom. The dogwoods, globe flowers, and similar shrubs lose the bright colour of their wood as they age. The old wood should be removed to encourage new growth.

Evergreens. Evergreens need but little pruning. The pruning of evergreens is done to secure formal shapes, to thicken growth, or to preserve symmetry. Tips of branches should be sheared in the spring just before they start growing. Begin pruning a year after planting and continue each succeeding year. Evergreens dry out more rapidly than deciduous growth and as they make much growth in the early spring, wounds from spring cutting heal rapidly. April is a good month for this work in the northern states. Pinching back of buds at any time in order to thicken the growth is all the pruning that most evergreens require. Shearing for formal shapes must be done carefully and a portion of the past season's growth allowed to remain on the plants. Many evergreens such as the plumeshaped cypress, Lawson's cypress, and the arborvitæ will respond to severe pruning operations. These plants grow vigorously under ideal conditions and during the growing season it is not infrequent that they require pruning two or three times. Rarely are evergreens pruned for the purpose of removing branches which are crowding, and only under very abnormal conditions is it necessary to prune evergreens in order to remove dead or diseased branches.

RHODODENDRONs. The pruning of rhododendrons, as a rule, is unsatisfactory, particularly if the wood is old. If the plant is very thrifty, and in a damp, sheltered position, fair success may be had. Not more than one-half of a plant should be pruned in any one year and the other part in the succeeding year. It should be done early 
in the spring and the bark of the stumps well moistened at least twice daily to assist the development and breaking through of the dormant leaf buds. Cuts should be made just above a whorl of leaves because adventitious buds will appear there more promptly than elsewhere. If the plants are not thrifty it might be advisable to cut half of the stalks to the ground, using care not to decrease, more than is necessary, the beauty of the plants. New shoots will be developed from the ground, and when these reach a satisfactory height, repeat the process with the remaining stalks. The root system will also be benefited by such treatment.

Pruning is seldom resorted to with rhododendrons in order to produce increased size and quantity of flowers. As an added precaution for the successful development of rhododendrons all the seed pods should be removed from the finer and less vigorous growing plants immediately after the flowering period is complete and before any of the plant energy has been expended in the development and ripening of the seed pods, thus diverting this energy into the production of new flower buds instead of into the production of useless seed pods.

ViNEs. Vines are pruned only to remove dead wood and straggling growth. Prune vines after blooming, except vines with ornamental fruit; the latter should be cut back severely in the spring, because they fruit on the new wood.

Roses. Prune hybrid perpetual and most other hardy roses in April when sap begins to flow and buds start to swell. At this time dead wood may be most easily distinguished and mulch should not be disturbed earlier. Memorial roses and rambler roses should be pruned just after the flowering season to produce wood for the next year's bloom.

Other things being equal, the pruning determines the quantity and size of flowers. Severe pruning will produce the largest and best flowers; less severe pruning is productive of a large crop of average flowers; medium pruning produces a large crop of smaller blooms (Plate V, Page 24).

For severe pruning, thin out to the base all but three to five shoots, with two to three buds on each shoot. Less severe pruning requires the same number of shoots to be cut back to from five to ten buds. For medium pruning, leave four to seven shoots and cut each back to 
one-half of its height. Always cut the stem one-fourth to one-half inch immediately above a strong bud that points out from the centre of the plant. When a plant has been pruned the shoots should be left as nearly as possible equi-distant from each other and arranged around the plant, so that it presents a well-balanced appearance on all sides with an uncrowded centre. With some hybrid perpetuals and climbers, if considerable length of stem is cut with the flowers, the plants can be induced to make some autumn bloom. Seeds should never be permitted to ripen on rose bushes, as the effect of this is extremely weakening to the plant.

When pruning hybrid perpetual roses remove branches that cross, and all weak wood also. Cut back strong canes to six buds, the top bud pointing outward. For a big outdoor display leave two-thirds of the length of four to seven canes. Sometimes it is feasible to cut away part of the tops in autumn so that the fibrous roots will not be loosened or broken by the force of winter winds swaying the plants.

Hybrid teas and teas must be cut to the surface of the soil, if necessary, in order to cut to live wood. However, as much or more wood should be left as on hybrid perpetuals, if possible. Weak growers should be cut back farther than strong growers.

Rugosas, bourbons, chinas, austrian briers, ramblers, and wichuraianas need but little pruning. Thin out and cut back only a few inches of the stems. Remove wood to the base of the plant as it becomes old.

Climbing and pillar roses need only one-third to one-fifth of the wood removed. All old wood should be removed about once in three years. In autumn any unusually long canes should be cut back slightly and tied up.

When rose blooms are cut from the plant the finest and largest blooms follow if only one bud is left to the branch. 


\section{CHAPTER IV}

\section{PLANTING AND TRANSPLANTING}

Reasons for Transplanting. Transplanting, in its general definition, is the operation of taking a plant up from the soil and planting it again in a new location, where it is expected to continue normal growth. The term "plant" is applied to trees, shrubs, vines, perennials, and annuals. Correct transplanting implies that a plant in its new position should be left in proper posture, and firmly imbedded in good soil. In addition to placing plants in new and permanent locations to have them more effective, or where they may develop to better advantage, it is often necessary to move plants from masses in order to prevent crowding and to provide more space for the remaining plants to develop. This is true especially with nursery-grown stock, and in plantations also which are made dense at the outset in order to produce an immediate effect.

Spacing of Plants. One of the important factors in successful plantings is the correct spacing of plants at the time of transplanting. Every plant requires space in which to develop normally. The result of close planting is eventually an overcrowded condition and a lack of healthy, well-developed foliage, flowers, and fruit. The more vigorous specimens crowd out the weaker ones and unless a "thinning-out" process is adopted, the mass effect becomes quite uneven and ragged.

The reason for most overcrowded plantings is the desire on the part of the designer to obtain an immediate effect. Too often our impatience and unwillingness to wait until plants mature and "fill out," develops many errors. Three years after transplanting is the normal period required for shrubs, two years for perennials, and eight to ten years for average nursery-grown trees to make the necessary growth to overcome the bare effect of the border or row of trees when planted in small sizes.

The question often arises as to whether or not it is better to use average-sized nursery stock (three to four-year-old stock) or to use 
large overgrown shrubs. Many people feel that an immediate effect is desirable and therefore the larger the shrubs that are used the more quickly the effect will be produced. The author has had considerable experience with both types of plantings. The nursery shrub will require anywhere from two to four years under normal spacing before it will develop sufficiently to produce the desired effect in the mass planting. On the other hand, the large, overgrown shrub which will produce an immediate effect generally requires severe pruning and cutting back in order to produce any growth which will fill the plant at the bottom and the top. This renovating process requires from two to three years. Therefore at the end of this period the general effect of the plantation is about the same whether large, overgrown shrubs are used or whether the smaller nursery specimens are used.

The correct method to adopt in general planting work is to allow sufficient space between plants for the normal development of each. Planting too close, although providing a more finished appearance during the first one or two seasons, is far more undesirable than liberal spacing. It is not practicable to lay down a well-defined rule for spacing plants. The planter can best be guided by the knowledge that he is seeking an immediate mass effect of foliage, requiring close spacing, or that he will wait during a proper period before expecting to see the plantation well developed. See list re "Spacing of Plants" which follows.

SPACING OF PLANTS

THE FOLLOWING IS A TABLE OF DISTANCES AS A GUIDE IN TRANSPLANTING

\begin{tabular}{|c|c|c|c|}
\hline Purpose & Typical Plants & $\begin{array}{c}\text { Close } \\
\text { Planting }\end{array}$ & $\begin{array}{l}\text { Normal } \\
\text { Distance }\end{array}$ \\
\hline $\begin{array}{l}\text { Allees-Trees } \\
\text { Open } \\
\text { Pleached }\end{array}$ & $\begin{array}{l}\text { Thorns } \\
\text { European Cork-barked Maple }\end{array}$ & $\begin{array}{l}2 \mathrm{ft} . \\
\text { I ft. }\end{array}$ & $\begin{array}{l}3 \mathrm{ft} . \\
I \frac{1}{2} \mathrm{ft}\end{array}$ \\
\hline $\begin{array}{l}\text { Annuals } \\
\text { Carpet Bedding } \\
\text { Design Bedding } \\
\text { Edgings }\end{array}$ & $\begin{array}{l}\text { Alternanthera } \\
\text { Snapdragons } \\
\text { Alyssum }\end{array}$ & $\begin{array}{l}3 \text { in. } \\
6 \text { in. } \\
4 \text { in. }\end{array}$ & $\begin{array}{l}6 \text { in. } \\
12 \text { in. } \\
6 \text { in. }\end{array}$ \\
\hline Broad-leaved Evergreens & $\begin{array}{l}\text { Great Laurel } \\
\text { Hybrid Rhododendrons } \\
\text { Mountain Laurel } \\
\text { Mountain Fetterbush } \\
\text { Japanese Azaleas }\end{array}$ & $\begin{array}{l}3 \mathrm{ft} . \\
2 \frac{1}{2} \mathrm{ft} . \\
2 \mathrm{ft} \text {. } \\
1 \frac{1}{2} \mathrm{ft} . \\
1 \frac{1}{2} \mathrm{ft} .\end{array}$ & $\begin{array}{l}5 \mathrm{ft} \\
3 \frac{1}{2} \mathrm{ft} . \\
3 \mathrm{ft} . \\
2 \frac{1}{2} \mathrm{ft} . \\
2 \mathrm{ft} .\end{array}$ \\
\hline
\end{tabular}




\section{PLANTING AND TRANSPLANTING}

SPACING OF PLANTS-Continued

\begin{tabular}{|c|c|c|c|}
\hline Purpose & Typical Plants & $\begin{array}{c}\text { Close } \\
\text { Planting }\end{array}$ & $\begin{array}{l}\text { Normal } \\
\text { Distance }\end{array}$ \\
\hline Bulbs and Tubers & $\begin{array}{l}\text { Hyacinths } \\
\text { Tulips } \\
\text { Narcissi } \\
\text { Crocus } \\
\text { Squills } \\
\text { Chionodoxas } \\
\text { Snowdrops } \\
\text { Grape Hyacinths } \\
\text { Anemones } \\
\text { Bublbous Irises } \\
\text { Lilies } \\
\text { Gladioli } \\
\text { Dahlias }\end{array}$ & $\begin{array}{l}4 \text { in. } \\
12 \text { in. } \\
2 \text { in. } \\
2 \mathrm{ft} .\end{array}$ & $\begin{array}{l}6 \text { in. } \\
6 \text { in. } \\
6 \text { in. } \\
3 \text { in. } \\
4 \text { in. } \\
2 \text { in. } \\
2 \text { in. } \\
3 \text { in. } \\
6 \text { in. } \\
4 \text { in. } \\
18 \text { in. } \\
4 \text { in. } \\
3 \text { ft. }\end{array}$ \\
\hline & $\begin{array}{l}\text { Currants } \\
\text { Gooseberries } \\
\text { Red Raspberries } \\
\text { Black Raspberries } \\
\text { Blackberries } \\
\text { Dewberries }\end{array}$ & $\begin{array}{l}4 \mathrm{ft} . \\
4 \mathrm{ft} . \\
3 \mathrm{ft} . \\
4 \mathrm{ft} . \\
4 \mathrm{ft} . \\
4 \mathrm{ft} .\end{array}$ & $\begin{array}{l}6 \mathrm{ft} . \\
6 \mathrm{ft} . \\
5 \mathrm{ft} . \\
6 \mathrm{ft} . \\
6 \mathrm{ft} . \\
6 \mathrm{ft} .\end{array}$ \\
\hline $\begin{array}{l}\text { Ground Cover } \\
\text { Deciduous Vines } \\
\text { Evergreens } \\
\text { Perennials }\end{array}$ & $\begin{array}{l}\text { Hall's Honeysuckle } \\
\text { Japanese Spurge } \\
\text { Moss Pink }\end{array}$ & $\begin{array}{l}\text { I ft. } \\
6 \text { in. } \\
9 \text { in. }\end{array}$ & $\begin{array}{l}2 \mathrm{ft} . \\
9 \text { to } 12 \text { in. } \\
12 \text { in. }\end{array}$ \\
\hline $\begin{array}{l}\text { Hedges } \\
\text { Low Sheared } \\
\text { Double Row } \\
\text { (staggered) } \\
\text { Single Row } \\
\text { High and Wide }\end{array}$ & Japanese Privet & $\begin{array}{l}\text { Io in. } \\
8 \text { in. } \\
\text { I } \frac{1}{2} \mathrm{ft} .\end{array}$ & $\begin{array}{l}12 \mathrm{in} . \\
10 \text { to } 12 \mathrm{in.} \\
2 \mathrm{ft} .\end{array}$ \\
\hline $\begin{array}{l}\text { Herbaceous Perennials } \\
\text { Edgings } \\
\text { Low } \\
\text { Medium } \\
\text { Spreading } \\
\text { Tall } \\
\text { Tall Slender }\end{array}$ & $\begin{array}{l}\text { Carpathian Harebell } \\
\text { Gold Tuft } \\
\text { Phloxes } \\
\text { Peonies } \\
\text { Larkspurs } \\
\text { Chimney Bellflower }\end{array}$ & $\begin{array}{l}4 \text { in. } \\
9 \text { in. } \\
12 \text { in. } \\
18 \text { in. } \\
12 \text { in. } \\
12 \text { in. }\end{array}$ & $\begin{array}{l}6 \text { in. } \\
12 \text { in. } \\
15 \text { in. } \\
2 \frac{1}{2} \text { to } 3 \mathrm{ft} . \\
18 \text { in. } \\
15 \text { in. }\end{array}$ \\
\hline Kitchen Garden & $\begin{array}{l}\text { Strawberries } \\
\text { Asparagus }\end{array}$ & $\begin{array}{l}\mathbf{I} \frac{1}{2} \mathrm{ft} . \\
\mathbf{I} \frac{1}{2} \mathrm{ft} .\end{array}$ & $\begin{array}{l}2 \mathrm{ft} . \\
3 \mathrm{ft} .\end{array}$ \\
\hline $\begin{array}{l}\text { Roses } \\
\text { Garden } \\
\text { Garden } \\
\text { Garden } \\
\text { Garden } \\
\text { On embankments } \\
\text { On fences }\end{array}$ & $\begin{array}{l}\text { Bush Roses } \\
\text { Hybrid Perpetual } \\
\text { Hybrid Tea } \\
\text { Polyantha } \\
\text { Dorothy Perkins } \\
\text { Tausendschoen }\end{array}$ & $\begin{array}{l}2 \mathrm{ft} . \\
2 \mathrm{ft} . \\
18 \mathrm{in} . \\
9 \text { in. } \\
2 \frac{1}{2} \mathrm{ft} . \\
8 \mathrm{ft}\end{array}$ & $\begin{array}{l}2 \frac{1}{2} \mathrm{ft} . \\
2 \frac{1}{2} \mathrm{ft} . \\
2 \mathrm{ft} . \\
12 \text { in. } \\
3 \text { to } 4 \mathrm{ft} \text {. } \\
10 \text { to } 15 \mathrm{ft} \text {. }\end{array}$ \\
\hline
\end{tabular}


SPACING OF PLANTS-Continued

\begin{tabular}{|c|c|c|c|}
\hline Purpose & Typical Plants & $\begin{array}{c}\text { Close } \\
\text { Planting }\end{array}$ & $\begin{array}{l}\text { Normal } \\
\text { Distance }\end{array}$ \\
\hline $\begin{array}{l}\text { Shrubs in Masses } \\
\text { Large } \\
\text { Low } \\
\text { Medium }\end{array}$ & $\begin{array}{l}\text { Morrow's Honeysuckle } \\
\text { Japanese Barberry } \\
\text { Van Houtte's Bridal Wreath }\end{array}$ & $\begin{array}{l}3 \mathrm{ft} . \\
2 \mathrm{ft} . \\
2 \frac{1}{2} \mathrm{ft}\end{array}$ & $\begin{array}{l}4 \text { to } 5 \mathrm{ft} \text {. } \\
2 \frac{1}{2} \mathrm{ft} \text {. } \\
3 \text { to } 4 \mathrm{ft} \text {. }\end{array}$ \\
\hline $\begin{array}{l}\text { Street Trees } \\
\text { Large } \\
\text { Medium } \\
\text { Small }\end{array}$ & $\begin{array}{l}\text { Elms } \\
\text { Sugar Maple } \\
\text { Pin Oak }\end{array}$ & $\begin{array}{l}30 \mathrm{ft} . \\
25 \mathrm{ft} . \\
25 \mathrm{ft} .\end{array}$ & $\begin{array}{l}50 \mathrm{ft} . \\
40 \mathrm{ft} . \\
35 \mathrm{ft} .\end{array}$ \\
\hline $\begin{array}{l}\text { Groves } \\
\text { Lawn specimens }\end{array}$ & $\begin{array}{l}\text { Standard Apples } \\
\text { Dwarf Apples } \\
\text { Standard Pears } \\
\text { Dwarf Pears } \\
\text { Plums } \\
\text { Peaches } \\
\text { Apricots } \\
\text { Sweet Cherries } \\
\text { Sour Cherries } \\
\text { Quinces } \\
\text { Oaks } \\
\text { Purple Beech }\end{array}$ & $\begin{array}{l}30 \mathrm{ft} . \\
8 \mathrm{ft} . \\
16 \mathrm{ft} . \\
8 \mathrm{ft} . \\
16 \mathrm{ft} . \\
16 \mathrm{ft} . \\
16 \mathrm{ft} . \\
16 \mathrm{ft} . \\
16 \mathrm{ft} . \\
10 \mathrm{ft} . \\
20 \mathrm{ft} . \\
45 \mathrm{ft} .\end{array}$ & $\begin{array}{l}40 \mathrm{ft} . \\
12 \mathrm{ft} . \\
20 \mathrm{ft} . \\
10 \mathrm{ft} . \\
20 \mathrm{ft} . \\
20 \mathrm{ft} . \\
20 \mathrm{ft} . \\
24 \mathrm{ft} . \\
20 \mathrm{ft} . \\
12 \mathrm{ft} . \\
25 \mathrm{fo} 35 \mathrm{ft} . \\
60 \mathrm{ft} .\end{array}$ \\
\hline Vine (fruit) & Grapes & $8 \mathrm{ft}$. & Io ft. \\
\hline $\begin{array}{l}\text { Vines } \\
\text { Climbers on walls } \\
\text { On embankments }\end{array}$ & $\begin{array}{l}\text { Boston Ivy } \\
\text { Hall's Honeysuckle }\end{array}$ & $\begin{array}{l}8 \mathrm{ft} . \\
2 \frac{1}{2} \mathrm{ft} .\end{array}$ & $\begin{array}{l}12 \mathrm{ft} \\
3 \frac{1}{2} \mathrm{ft}\end{array}$ \\
\hline Windbreaks (trees) & $\begin{array}{l}\text { Hornbeams } \\
\text { Spruces }\end{array}$ & $\begin{array}{l}5 \mathrm{ft} . \\
8 \mathrm{ft} .\end{array}$ & $\begin{array}{l}8 \mathrm{ft} . \\
12 \mathrm{ft} .\end{array}$ \\
\hline
\end{tabular}

Conditions for Transplanting. It is better to transplant stock on a dull, moist day, rather than on a bright, sunny day, because the planter needs to give less attention to the drying out and consequent injury to fibrous root growth. The most ideal weather for moving plants is a day when a cloudy condition exists and when there is ample moisture in the air. Avoid bright, sunny, dry days on which to do transplanting, unless plenty of water is used, or the plants are thoroughly dormant. Dry winds are equally as injurious as hot sun. The general rule is that no plant should be transplanted except with extreme care, and only when it is entirely dormant. Plants are 
generally considered dormant when the flow of sap has ceased in the top, at which time the season's growth is completed, and when the wood has had an ample opportunity to ripen and harden. Deciduous plants are dormant when the leaves have fallen or turned brown. Transplanting before the wood is thoroughly ripened is one of the sources of winter-killing. It will be noted under group No. 40-A and 40-B (on Page 289) that there are certain types of stock which should be transplanted in the spring and others which should be transplanted in the fall to secure the best results. The explanation is contained in Chapter XL. Evergreens require different rules for time of moving and must therefore be considered separately (See Page 48). It is practicable to transplant small trees, many evergreens and many shrubs, together with perennials, before they have finished their growing season or, after growth in the spring has well begun; but this should rarely if ever be attempted with large trees. In such out-of-season handling of the stock extreme caution should be used to prevent drying out, and the plant should be moved, if possible, with the earth balled about the roots.

Transplanting Nursery Stock. It is essential that the purchaser of nursery stock should request that such material be lifted and packed properly. Nursery stock in general must be dug carefully to preserve as much of the root growth as is practicable, and with roots cut as cleanly as possible. The stock should not be allowed to stand openly exposed to the injurious effects of wind and sun after lifting and before packing. For short shipments, of one or two days, stock can be packed equally well in excelsior, sphagnum-moss, or straw, but for longer shipments material should not be packed in excelsior, for it dries out too rapidly.

On receipt of nursery stock which has been shipped in boxes or crates the stock (being delivered by truck or by wagon) should be so loaded and so covered with canvas that there is a minimum of exposure to drying-out processes. Stock, when received on the grounds where it is to be planted, should be removed at once from boxes or crates, and if not planted immediately must be "heeled in" (Plate VI) or kept in some other way from drying out.

Transplanting-Collected Stock. Collected stock needs more careful attention than nursery stock. Collected material usually 


\section{The following is a descriptive memorandum to accompany Plate No. VI.}

A

If plants are not to be planted immediately (within three or four days) after the time of arrival, they should be carefully unpacked and "heeled-in," until such

\section{B-1 and B-2} time as they can be planted to advantage (See Page 36).

The average small tree as it is received from the nursery ought to be pruned before the plant is put in its permanent location. This drawing shows a nursery tree (B-I) with two leaders, and the proper pruning of this tree (B-2) by removing one of the leaders and some of the small branches.

\section{C-1 and C-2}

Large trees and trees which are difficult to transplant should be root pruned not later than July of the summer previous to the season when they are to be transplanted. Usually the fibrous part of the existing root system (C-I) is entirely removed by the transplanting operation unless root pruning is done (C-I) and the trenches filled with well-rotted compost, thus encouraging the fibrous root system (C-2) close to the trunk of the tree and within the diameter of the ball of earth usually moved with the tree.

\section{D-1, D-2, D-3, and D-4}

Hybrid roses of various types are sometimes grown on their own roots without grafting (D-I). Such roses should be transplanted slightly deeper (D-2) than in their original position (D-1). D-3 shows the same bush mounded with a depth of 6 to 8 inches of soil, for winter protection. In transplanting grafted roses the knot formation, indicated by the arrow, where the graft was made should be set about $\mathbf{I}$ inch or more below the surface of the soil (D-4). If any suckers develop from below the graft, the soil should be dug away and the suckers cut off close to the stem.

\section{E-1, E-2, and E-3}

Trees and shrubs growing at a normal depth (E-r) should be transplanted leaving the surface of the ground surrounding the stem at the same point or slightly below that point in the new location, and the basin for watering such plants should be made as shown in E-2. Plants should never be transplanted at an abnormal depth below the surface of the existing ground or permanently left with a mound of earth around the main stem as shown in E-3. 


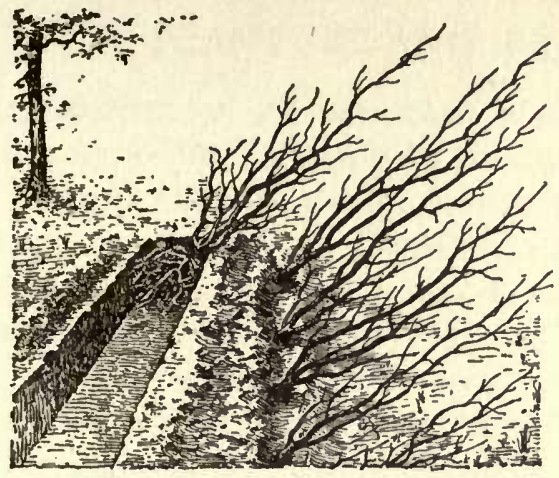

$-\mathrm{A}-$

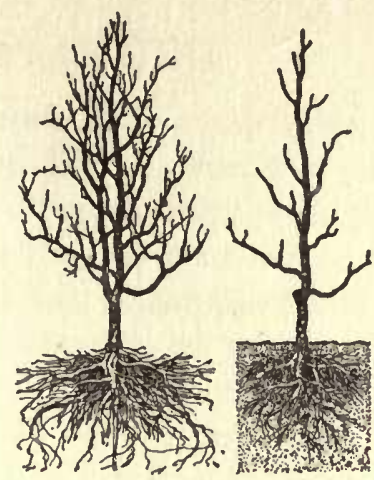

$-\mathrm{B}_{1}-\quad-\mathrm{B}_{2}-$
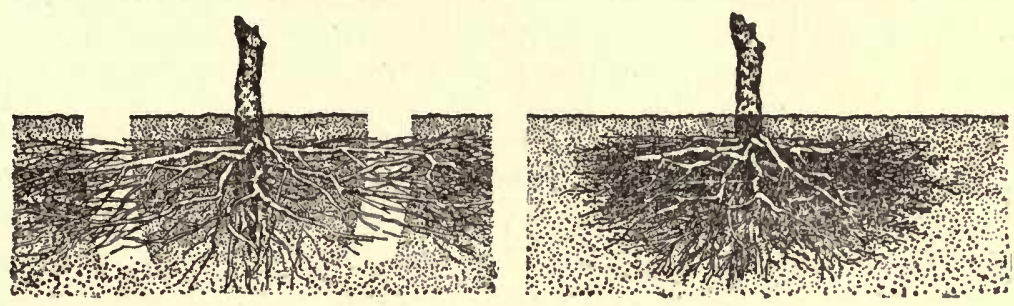

$-\mathrm{C}_{1}$ -

$-\mathrm{C}_{2}$ -
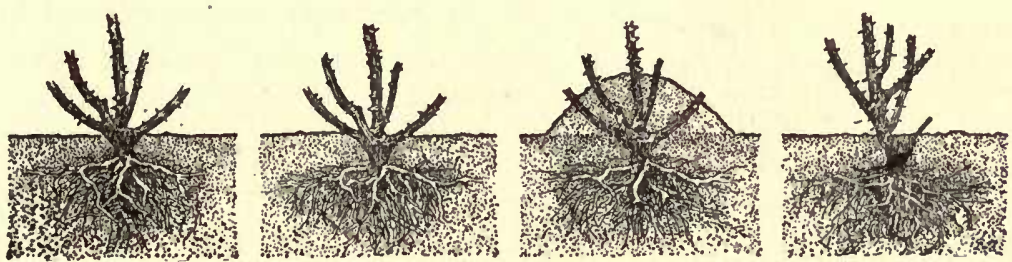

$-D_{1}-$

$-\mathrm{D} 2-$

$-D_{3}-$

$-D_{4}$ -

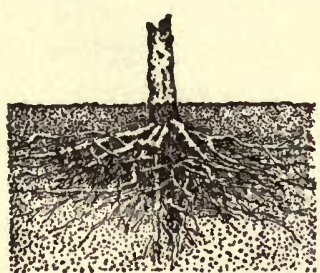

$-E_{1}$ -

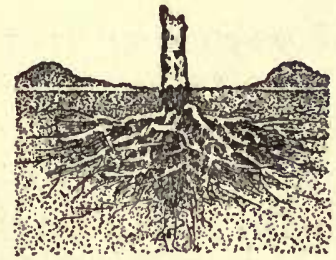

- E 2-

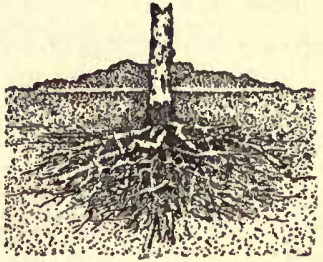

- E 3-

Plate VI. A knowledge of the various operations involved in the work of correctly transplanting plants is essential for their subsequent normal development. These diagrammatic drawings accompanied by the explanation on the opposite page illustrate various transplanting operations. 

has a larger spread of roots than plants grown in nursery rows, and as it has never been previously transplanted or root pruned it suffers more severely through loss of root system. Top pruning must therefore be more severe for collected plants than for nursery material, to offset the greater loss of roots. Collected stock usually requires a longer period in which to become well established in its new location. When the loss in transplanted stock is ten or fifteen per cent., the averrage loss in collected stock may be as high as twenty per.cent. The usual period required for establishing nursery stock in its new location is two years. The usual period for establishing collected stock may range from two to four years.

Season of Year for Transplanting. Planting seasons in different localities are influenced by many factors. Soil conditions and climatic conditions are the most important, as seen in Chapter II. Heavy soils are more friable during the fall, while during the spring they remain heavy, cold, and wet until quite late. In such soils if but little planting is to be done it is better to plant during the spring months for the reason that clay soils tend, through frost action during the winter months, to heave out material which is planted in the fall. It is undoubtedly true that fall planting, especially in heavy soils, requires more thorough winter protection than spring planting in the same soil. On the other hand, if a quantity of planting is to be done it is much safer to plant during the fall in a heavy soil, especially as a rainy season is frequently experienced during the early spring months, thus delaying planting work until growth is too far advanced. There is little actual difference between the desirability of spring planting and fall planting. There are arguments on both sides of the question and, with the exception of those plants which are adapted for transplanting only at a specific season, the writer suggests that planting should be done whenever the soil is ready to receive the plants, whether it be spring or fall. This is especially true in the loamy soils. Transplanting should not be done too late in the spring, for the reason that growth will be too far advanced for the plants to be moved with safety, and the season will become hot and dry before the plants are well established. It is for this reason that plants taken from a colder climate to a much warmer climate should preferably be transplanted in the fall. 
Planting Beds. General Preparations of. Soil for planting should be prepared carefully. Beds for shrubbery should be dug at least twelve inches deep and ample width and depth provided for trees, varying according to their size. The soil should be made loose and friable so that it will cover the roots thoroughly. Well-rotted manure should be incorporated in planting beds, but never directly in contact with the roots, especially of evergreens. Heavy soils should be lightened, if possible, by the addition of sandy loam or straw manure and light soils should be improved by the addition of vegetable matter.

Oftentimes owners of property are so anxious to do their planting in an economical way that they lose sight of the fact that thorough preparation of all planting areas, although more expensive, is good economy, and the least expensive way in the long run of obtaining good results. Poor preparation of planting beds as well as foundations for lawn areas means an increased expense in the cost of maintenance during the succeeding years after the completion of the original work. Thorough preparation of planting beds can be accomplished only through the use of good friable topsoil and an adequate supply of wellrotted manure. It is an easy matter in all planting work, especially that done in clay soils, to do so-called pocket planting and to feel that the initial expense has been very greatly reduced. In all planting areas bordering refined lawns this method of planting is not desirable. It causes a "soil-bound" and a stunted growth of the root system and does not provide the adequate food supply which plants growing freely in a loose and friable soil can obtain.

Heeling-in Stock to Be Transplanted. When shipments of stock are received it is frequently impossible to plant the material as rapidly as it is unpacked, and it is often impossible to plant the stock because the beds are not prepared. The placing of stock in temporary nursery rows immediately after it has been unpacked is called "heeling in." In this manner stock may be preserved in its normal condition until such time as it can be transplanted to its permanent location. There are a few important points in connection with the operation of "heeling-in" stock which should be clearly understood. Trees and shrubs, when "heeled-in" over winter, should be leaned to the north so that the low winter sun may not shine directly into the tops nor so readily melt the frozen ground about the stems. Thus they are protected better from freezing and thawing of the ground and from 
premature starting of the buds in the spring. Nursery stock may be placed in temporary nursery rows, either by keeping the plants tied in original bundles as taken from the packing boxes, or by taking the individual plants from each bundle and heeling them in separately. The latter method is the safer and is the one to be adopted if plants are to remain in these temporary nursery rows for a period longer than ten days or two weeks. When stock is "heeled-in" in bundles, a special effort should be made to get the fine topsoil worked into the air spaces among the roots of the plants in each bundle. Permitting the air to reach the roots in the middle of the bundle because this precaution is not taken, is one of the most frequent sources of injury. The best method to adopt to be certain that fine soil is worked in among the roots is to thoroughly water the plants when they are "heeled-in" and to make sure that the water leaves no roots suspended in air. When individual plants are placed in temporary nursery rows, where they are to remain for a period longer than three or four weeks, they should be spaced not closer than twelve inches, or even farther apart for the larger shrubs, to eliminate injury from crowding as soon as the new growth begins (See Plate VI).

Root Protection and Pudding. The important object in transplanting is to transfer the plant to its new position in such a condition that growth will immediately continue as nearly normal as possible when growing conditions become favourable. Growth is first excited and maintained by very fine, fibrous roots, almost thread-like in character, which attach themselves to the soil. It is this fine root growth which is so sensitive to injury from drying-out processes, and which must be protected against the sun's rays, and also from the effect of wind. A dry wind will work greater injury to plants which are left uncovered during any unnecessary length of time than will a bright sun on a moist day.

It is often necessary to transplant material under exceedingly unfavourable conditions, due to wind, or sun, or when plants have advanced in leaf growth. Under such circumstances it is advisable to "puddle" the roots at the time when the plants are removed from the temporary nursery rows, and before they are planted permanently. "Puddling" consists in dipping the roots of the plants in a basin hollowed out of the soil and filled with a molasses-like mixture of loam and water. This "puddling" process leaves a coating of mud over the fine roots and prevents excessive drying out until the material is planted. 
Drainage for Transplanted Stock. The soil in which plants are placed should be considered carefully. Sandy soils which have ample drainage, and clayey soils, which naturally retain water, require distinctly different treatment. It is invariably necessary in clayey soils, especially with larger trees, to provide artificial drainage. In sandy soils, on the other hand, an extra supply of water must be added, especially when stock is transplanted during the latter part of the spring season or in the warmer climates. A plant should not be placed in a "pocket," excavated in shale or clay, which will afford little or no drainage; and it is of course better not to plant on a small mound which will lose moisture rapidly during the dry season. The common practice of "hilling" earth around the stem of the plant, which sheds water away from the roots, is to be discouraged. A shallow, basin-shaped depression should be left around the stem. This will hold the water until it soaks down to the roots. But suitable allowance must be made for later settling of the loosened earth.

Balled-And-Burlapped Root Systems. Planting material is often lifted with a ball of earth left intact around the roots. The ball of earth after being lifted is then carefully wrapped with burlap. This process is used with large material, evergreens, and any plants that are difficult to move. The great danger of transplanting such material after it has been wrapped for three or four days lies in the fact that during this period the outer thin layer of earth on the ball becomes hard and dry. The general practice with many planters has been to plant the stock without further care after removing the burlap. In the course of a few months the plant dies. Loss is due to insufficient moisture reaching the outer coating of the ball to loosen it, and thus necessary water cannot reach the roots, which have become sealed inside the hard coating. The best practice with all plants which have been "balled and burlapped" is to immerse the ball in water for a short time in order to thoroughly loosen the dirt in this outer coating before transplanting. It is never advisable simply to slit the burlap with a knife without removing the covering entirely and soaking the ball with water before transplanting. Place the plant in the hole where it is to be planted, then cut the binding and remove the burlap very slowly and carefully, exercising caution to avoid disturbing the ball; then partially fill the hole with water. 
DePth for Transplanting. The question is often asked as to how deep stock should be set when it is transplanted. This is a query which must be applied to various types of material according to the special requirements of each. For example, some of the more tender perennials like the shasta daisy, the foxglove, and the cardinal flower should not be set as deep as some of the hardier types like the phlox, the larkspur, and the hardy sunflower. The suggestions here, however, are general. A plant in its new location should stand at about the same level as it stood before. There is more danger of setting a plant too deep in a clayey soil than in that which is sandy, for it is vital that the air should reach the roots. More stock is injured by deep planting than by shallow, and it often will be found well to set the plant with the crown or top of the roots an inch or more nearer the surface than it was before. This is especially true in the case of trees which, as is frequently observed, are easily killed by filling in earth around them. In the case of shrubs it is not a serious matter, except with rhododendrons and azaleas. These two plants are strongly characterized by having roots that remain near the surface. Roses of all kinds, however, are better set deep, for they readily throw out new roots above the old. Deep planting thus incidentally helps to conserve the supply of moisture so essential to success with the rose. In the case of budded rosés it is necessary to have the union at least two and a half or three inches below the surface of the ground, in order that suckers may not spring up from the stock and choke the engrafted plant. Vines, particularly grape vines, also it is well to plant deep. In fact, grape vines are often led under the ground for a rod or more to spring up at a distant point where it is desired to have them grow. But with perennials in general, extreme care must be exercised. Those like the iris, with leaves that spring from a point near the ground, are made to decay by earth heaped about them. Those with thick, fleshy roots particularly should be planted only according to a careful observance of their habit of growth. The peony does not make good bloom if the eyes, are sunk much more than two and a half inches below the surface. In the transplanting of the roots of the larkspur it should be borne in mind that the crown at the base of the plant should be covered with good topsoil to a depth of approximately two or three inches. In all transplanting calculation should be made of the possibility of the earth settling around the plant (See Plate VI). 
Fertilizing Transplanted Stock. In using fertilizers it is not advisable to apply them in any quantity so that they will come in direct contact with the roots of newly transplanted stock. It is always essential for plants to become established before they can make use of a fertilizer; otherwise injury may result. Until a tree makes a new terminal bud on the second growth its root system has not become established nor has it developed fibrous feeding rootlets sufficient to support the tree. A safe recommendation is that fertilizers should be so distributed in the soil surrounding the roots of transplanted stock that the food can become available as soon as the roots have started growth. In transplanting nursery trees and large trees a slow-acting fertilizer, such as bone meal, can be used in the soil around the roots, because the fertilizer will become available at the time when the tree has developed some of its new root growth.

TAmping and Watering. Soil should be made compact in among the roots of newly transplanted stock by watering or tamping. Tamping may be accomplished by pressing down the soil with the heel or a stick. In tamping, care should be exercised not to press too heavily immediately around the stem of the plant, as in so doing injury may be caused by the breaking of roots. Soil that can be readily packed should be used around the roots. This is necessary, as any air spaces remaining will cause drying out of roots and consequent injury to the plants.

If water is available, it is advisable to run some slowly into the holes where material is planted, either at the time of planting or immediately after planting. The best plan is to put it in when the hole is partly filled with earth around the roots. This is done further to compact the soil and to provide necessary moisture. Unless soil is particularly moist, newly transplanted stock should be watered shortly after transplanting. It is not advisable, however, to apply very much water in soils or sites extremely retentive of moisture for it is quite as easy to injure plants from over-watering as it is to preserve them by giving them just sufficient water to meet their requirements.

Transplanting Small Seedlings. For transplanting small seedlings of trees and shrubs a well-protected spot should be selected, and the ground should be prepared to a depth of twelve or fifteen inches by deep spading and careful raking. Prepare the area in the same way 


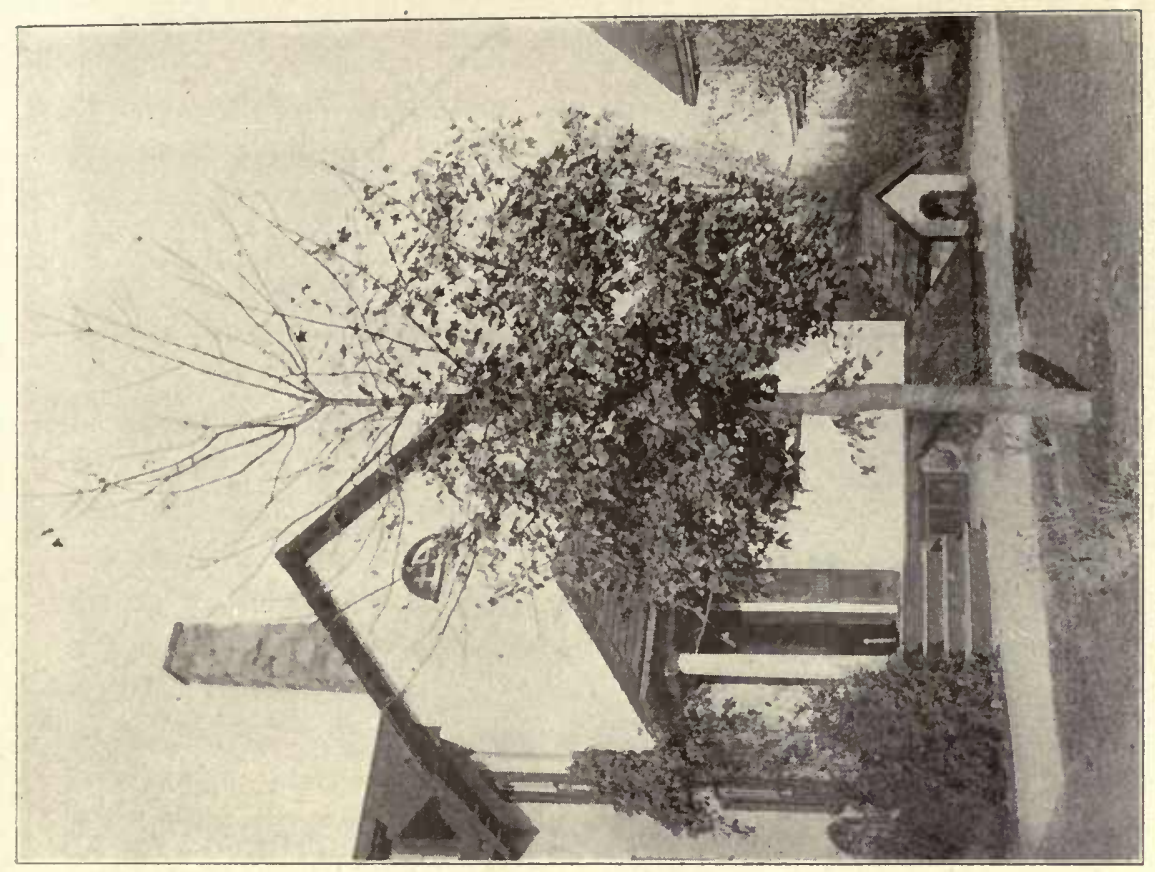

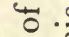

00

$\equiv$

$2 \dot{2}$

\%.

选

-

0

志

ن

空

‥

D

용

क

น

¿ 00

- $\Xi$

$0 x$

สี

논

$\overrightarrow{0}$

¿ す

40

뜽

艺司

$0 \approx$

Ð

की कर तै

.

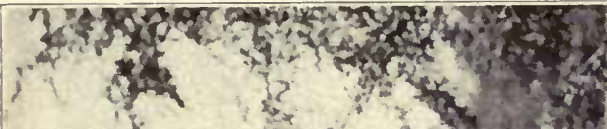

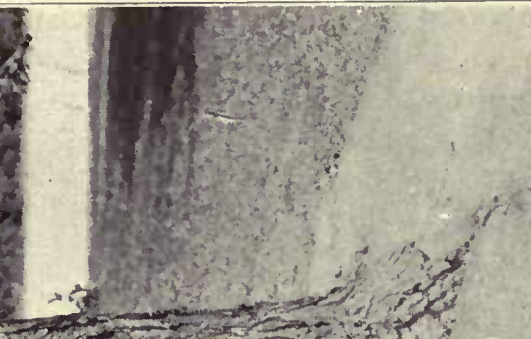

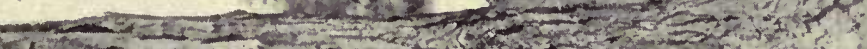

and 4 it
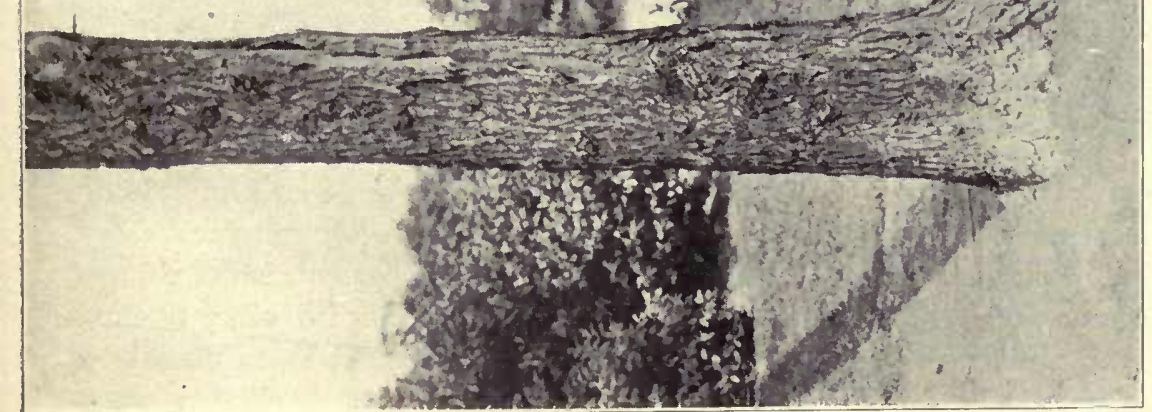

곤

के 00

疍.

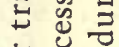

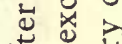

栗

焉

《.

至

ह. .

है

用 \&

F.

또

\& 2

ค出茪造 

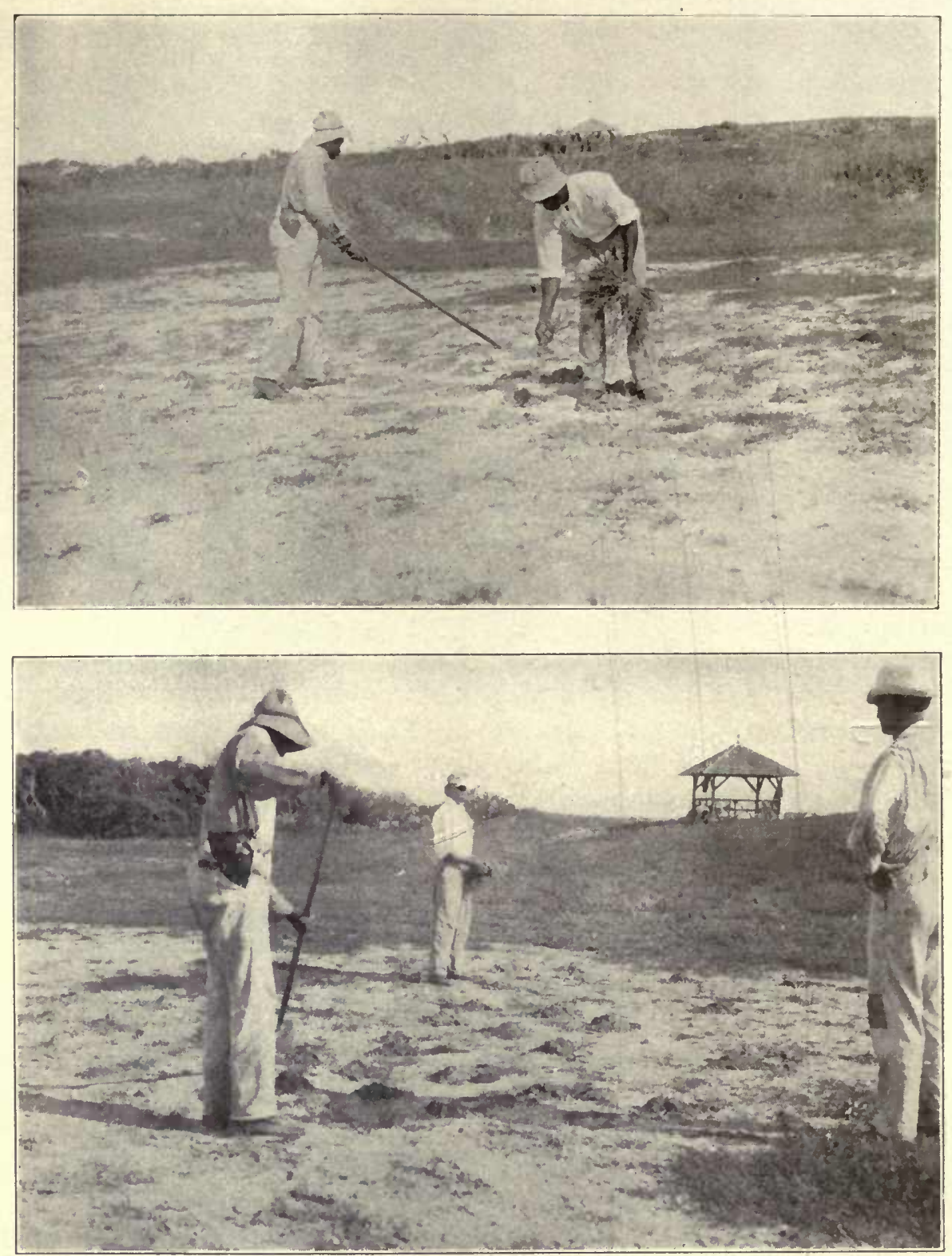

Plate VIII. To most of us in the Northern States the method of seeding a lawn is familiar, but the method of making lawns in the Southern States by planting Bermuda grass, is little known. In these photographs small clumps of Bermuda grass are being planted in "hills" staggered at intervals ranging from 18 inches to 30 inches. The thicker the planting the more quickly a mat of turf can be developed. (See page 62) 
as for a vegetable garden. The little plants, which should not have been exposed at all to the warm air or drying winds, are then best puddled before they are lined out. But in this actual planting there is danger of permitting the mud in which they werc puddled to become hardened about their roots. Further to safeguard them, particularly if they are evergreens, it is necessary to shade them until they are well established in the new home. Some evergreens, particularly the small shrubby kinds, need such shading even beyond the first year.

Pruning Transplanted Stock. Suggestions with reference to pruning are covered more fully in the chapter on "Pruning." One of the fundamental practices to be followed in connection with the correct transplanting of stock is to prune all branches and roots properly. Any branches that are crowding should be carefully pruned at the time of transplanting, especially if the transplanting is done in the spring; otherwise it is a better practice to leave the stock standing in its new position during the winter and perform the necessary pruning of the top in the early spring or later winter months. An exception to this practice is the case of maple trees, which should be pruned before sap starts to flow in the spring. With trees and shrubs having a heavy top, at least one-third of the top should be removed at the time of transplanting, or before the stock has commenced to make its new growth in the spring. This is done to offset the loss of roots incurred in moving and it is essential except with nursery stock which has been frequently root-pruned at the nursery. All bruised and broken roots should be carefully pruned, with a clean cut, at the time of transplanting. Only in this manner will roots heal and possible decay be avoided. Save as many roots as possible when moving.

Winter Protection of Newly Transplanted Stock. A necessary feature in caring for newly transplanted plants, especially those set in the fall, is to apply a suitable mulch for winter protection. This applies to all kinds of transplanted material. . A mulch, in heavier clayey soils, reduces the possible injury caused by changes of temperature and consequent heaving of the plants. A proper mulch of fresh stable litter, applied three to six inches in depth, keeps the soil at an even temperature and prevents extreme freezing conditions from 
injuring the roots. A mulch which is largely straw may provide a refuge for rabbits, rats, and mice which frequently girdle plants during the winter months.

Transplanting Trees. Some plants, particularly trees, may be transplanted successfully while young but are more difficult to move as they get older. Examples of this are the hickory and oaks, which, with the exception of the pin oak, form deep tap roots. The tulips and magnolias are hard to move because they have few fibrous roots; while maples and elms, on the contrary, have many fibrous roots and are moved more easily. Junipers transplant more readily when older, for they then have a more extensive lateral root system.

Season to Transplant, and Preparation of Holes. Large trees should be transplanted when they are dormant. It may be necessary to move other material before the growing period has stopped, but this should seldom be attempted with older trees. Large trees are moved in winter, and it is preferable to move them when the ground is frozen. The ball of earth on the roots will then remain fairly intact and there will be a minimum of root loss when moving. Holes for the trees should be dug with straight sides and with bottom rather convex or slightly rounded. This is much to be preferred to making holes bowlshaped and it permits an opportunity to spread the roots more naturally than in a hole where the middle is deeper than the sides. A common error in transplanting large trees is that of providing a hole not sufficiently large to receive the roots of the tree without cramping. A hole for a large tree greater than five to six inches in diameter should not be less than eight to ten feet in diameter, and never less than three feet in depth. The most common method of transplanting large trees is the method of cutting the roots down to a ball approximating eight to ten feet in diameter. Trees transplanted in this way are frequently subjected to a root-pruning process during the previous summer, or preferably during the previous year.

It has been stated by authorities, who are in a position to know, that the ideal method of transplanting trees is by saving all of the root system, if possible. This process is known as "combing" out the root system. Under this method all of the roots are traced down to their fine ends and then the roots are tied up in burlap in order to prevent excessive drying out of the fine fibrous roots. Transplanting 
in this way requires much more care, but it assures less loss than the other method, which is a violent process and requires strong recuperative powers in the tree which is transplanted.

Drainage of Tree Pits. Ample drainage must be provided for large trees, especially when set in clayey soil. The soil with which trees are transplanted is normally a medium loam, not too compact in character. This soil is much more porous than the heavy clay soil in which the hole for the tree may be excavated. Consequently, the natural tendency during wet seasons is for the water to drain toward the tree pit and to "water soak" the loose topsoil in which the tree has been set. This really places the tree in a reservoir. A tree will survive such treatment if it can withstand extreme moisture conditions, or if the water drains slowly away. However, the tree is generally killed during the first season, or may survive in a much weakened condition. The normal method of draining trees is to provide a four-inch tile connected with some outlet in the form of existing tile drains, or lower ground, so that the water may be taken away. In the event that there is no opportunity to provide this type of drainage it is desirable to excavate a hole to a greater depth-approximately three to five feet-and thereby provide below the tree a space of at least twelve inches which should be filled with broken stone or other porous material and in which water resulting from normal rainfall may be collected. In this way the root growth may be kept from drowning.

Method of Procedure in Transplanting Large Trees. It is economical in transplanting large trees to adopt the following method of procedure.

In selecting large trees for transplanting great care should be exercised to select only those individual trees which show a vigorous growing condition and which are more or less symmetrical.

I. Select and stake the proposed location where the tree is to be transplanted.

2. Cover this space, over a diameter of at least ten feet, with ten to twelve inches of fresh stable manure. This is more economical than to excavate the hole and fill it with topsoil for the reason that this topsoil is apt to freeze and be useless at time of transplanting.

3. Preserve a single large pile of topsoil (rather than a number of small piles, which freeze in a severe winter) and cover this with twelve or fifteen inches of 
stable litter, in order to protect it from freezing and to make it readily available when the trees are transplanted. It is quite essential that this topsoil should be friable at the time of planting.

4. When conditions are favourable for transplanting, remove the stable manure from the place where the tree is to be planted, excavate the hole, dig up the tree, place it in the hole, cover the roots with the topsoil, and then replace the stable manure over this area. This covering will then serve as a mulch and as protection against further freezing, and against evaporation in hot weather.

After trees are planted guy wires should be set to prevent wind storms from bending or tipping the trees over. It is never a safe practice to transplant any large tree without supporting it with wires. The reason for attaching guy wires to newly transplanted trees is twofold. First, to be sure that the tree does not blow over during a severe windstorm, and second, to keep the tree from swaying without blowing over and thereby loosening the root system and letting air get into the soil around the roots. This second reason for guying trees is an important one, and is sufficient in itself to require a very careful tightening of the wires which hold the trees in place. In placing guy wires on the trunk it should be protected from injury by the use of pieces of hose, bagging, or canvas.

Protection After Transplanting. Large trees when transplanted must be amply protected against evaporation during the hot summer months. This protection is given to the tree in two ways. First, a mulch consisting of straw, litter, or leaves is applied to a depth of six to eight inches, over an area eight to ten feet in diameter, immediately around the base of the tree. Second, the trunk is wrapped with burlap or bagging to prevent excessive drying out. Many newly transplanted trees are injured by the hot rays of the sun through lack of this protection which prevents a drying out of the bark and cambium tissue on the exposed trunk of the tree. This drying out often results in injury to large trees (as shown in Plate VII, Page 75) to such an extent that the bark cracks, dries up, and becomes loosened from the trunk of the tree thus exposing the inner wood immediately under the bark. It is quite as necessary to provide suitable mulch during the winter months of the next season after the transplanting, as to provide one in the summer months. In a newly transplanted tree a fine root growth is developed near to the surface of the ground, and this root growth is easily injured by any excessive freezing and thawing which may occur during a severe winter. 
Pruning Trees After Transplanting. After the transplanting, the top and the root growth of a tree must be balanced. It is necessary to remove a portion of the root growth in order to make it practicable to handle the tree, and the removal of roots and lifting of the tree from its existing location shuts off much of the supply of moisture which goes into the tree. In every plant that is moved there is stored within the plant a certain amount of food material which becomes available immediately when growth starts. A portion of the top of the tree should therefore be removed in order to lessen the possible areas of evaporation and areas of leaf growth, which draw heavily upon the store of food in the tree; otherwise this reserve supply is apt to be exhausted before root growth is started sufficiently to provide the tree with new moisture. There are instances when it is not necessary to prune because the full benefit of the top is immediately required. The latter, however, will require more care for the tree during the summer months and entails a greater liability to loss because of the unbalanced condition of the top and root growth. A tree that is properly pruned at the time of transplanting will, within three years, equal in development a similar tree that is transplanted, not pruned, and given much necessary additional care.

Fertilizing Newly Transplanted Trees. In transplanting trees there is great danger that they may be over-fertilized. A tree which has just been transplanted has suffered a severe shock to its root system. It is not in a condition to utilize a great quantity of food. It must be supplied with food slowly and only in such quantities as it can readily take up through its root system. There is great danger of over-stimulating newly transplanted trees at the time when their leaves are not sufficiently developed to digest the food which is supplied, and hence instead of forcing more growth in the tree, a condition is apt to be brought about in the soil surrounding the roots and in the tree itself which retards growth instead of encouraging it. At the time a tree is transplanted a normal amount of well-rotted manure should be worked into the soil but not in direct contact with the roots. Not until the tree shows evident signs of regaining its normal vigour by developing leaves which are full size, and new wood of a normal length, should the tree be heavily fertilized. Such trees may be "tuned up" by feeding them with a mixed fertilizer of potash, dried blood, and bone meal. Such a fertilizer may be fed to trees during the 
year previous to the time that they are transplanted, in order to make them more vigorous and better able to withstand the shock of transplanting, or such a mixed fertilizer may be fed to the tree in small quantities, five to ten pounds to an average-sized tree (six to eight inches in diameter) within the first year after the tree has been transplanted.

Under no conditions should a newly transplanted tree be left on a neatly mowed lawn area without artificial methods being resorted to for feeding it. The old saying, as quoted from Mr. Hicks, is that "Neatness is starvation." Nature provides a continual gathering of leaves and grass which rots and makes fertilizer for the tree. When the grass is kept closely clipped and the clippings taken away, and when the leaves are raked each fall, then this neatness deprives the tree of all of its possible source of food supply.

Transplanting Nursery-grown Trees. Nursery trees are trees which have been grown under nursery conditions for at least two or three years. The most desirable method of handling such trees is to ball-and-burlap them, to lessen the danger of injury from transplanting. This applies to small trees with well-developed root systems, and especially to those which have been so root pruned that the root spread is in a smaller, more compact area than that of the usual nursery tree. Holes for nursery trees should be excavated at least one foot larger than the ball preserved with the tree. In other words, the roots of the tree should never be pruned to fit the hole in which the tree is to be planted and the roots should never be crowded. It is quite essential to place small guy wires, not less than three in number, to each small nursery tree from two to five inches in diameter. This is especially necessary when trees are in exposed locations or stand alone as specimens.

When large plantations are set out and the trees will be subjected to broad sweeps of wind, it is more economical not to guy, but rather to watch the plantation, and from time to time straighten up such trees as are pushed out of their normal position by the wind. In an effort to build up plantations of native growth, such as oak, beech, hickory, basswood, and any other forest trees, it is better to plant these trees in concentric circles or a spiral arrangement so that during the first three or four years any one could cultivate among these trees without very much difficulty. If the trees in such plantations are staggered here and there without any relationship to any avenues through which 


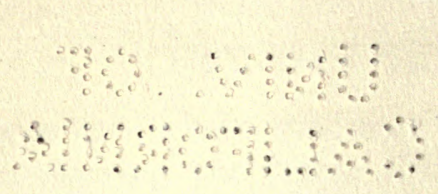


harrow or cultivator can pass, the maintenance work becomes a question of hand work instead of team work.

Transplanting Shrubs Efficientry. In transplanting shrubbery the stock should be left out of the ground as short a time as possible. A crew of two or three men under one competent planting foreman is as many as can be operated to good advantage in planting shrubbery and perennials according to some definite plan, unless the men are thoroughly familiar with methods of planting, and the required location for the plants.

Transplanting Vines. The transplanting of vines is similar to transplanting shrubs. Vines are very often planted too close to foundation walls. Care must be taken not to set plants against a wall, but rather three or four inches away. All foreign material, such as lime, bricks, etc., should be removed from the ground to a depth of at least twelve inches, and the vines placed in excellent, fine soil. Vines should not be planted against walls or buildings where the overhang of the eaves or other features of the building will deprive them of the normal amount of rain; otherwise great care must be exercised in artificial watering.

Transplanting Perennials. The season for transplanting perennials is not quite as definite as the season for transplanting trees and shrubs. Under normal conditions of cloudy days and good mulching protection to prevent later evaporation perennials can be transplanted during their growing period, except when they are nearing their maximum of growth and blooming condition. It is preferable, however, to transplant perennials as soon as their maximum growth is completed for the season, and at the time when the newly transplanted material can obtain a slight root growth in its new location before winter conditions commence. There are some types of perennials, as indicated in group No. XL-A, Page 289 , which should be transplanted in the fall, and others which should be transplanted in the spring. For most perennial stock, however, there is no difference between fall plantıng and spring planting, provided the proper time is selected at either season. The principal objection to transplanting perennials in the fall is that in heavy clay soils and in the colder climates the plants, if not carefully mulched during the winter months, are apt to be heaved from their new locations by freezing and thawing. Per- 
ennials should never be transplanted when the ground is frozen, even slightly. Do not move perennials when it is impossible to provide the plants with rich topsoil in which to continue growth. Perennials may be "heeled-in" in the same way as other plants, with one difference. Perennials must be removed from the bundles in which they are shipped and each plant "heeled-in" separately. Unless this is done the plants are apt to mildew or rot. Perennials "heeled-in" during warm weather should be covered with a light litter of straw for further protection against drying out. When transplanting perennials, especially those which have been growing for two or more years, it is quite necessary to "divide" them. This operation of dividing plants is explained in the chapter on "Maintenance-Perennials" (Page 88). Dividing should be done whenever the plants become too thick. The reason why many perennials purchased from nurseries do not do well during the first year is because the plants which are sold by the nursery are often the result of too frequent subdividing of the parent plants and the young plants are not given sufficient time to establish themselves before being sold to the prospective purchasers. The result is that those who purchase these plants must wait at least during one growing season before the perennials will develop normal flower growth. No one who is developing for the first time a perennial flower garden should expect a normal development of good flowers from perennials supplied by the average nursery. Such persons should be prepared to wait until the second growing season before expecting a normal flower effect.

Transplanting Evergreens. Evergreens should not be transplanted to a "cold" soil, but rather into a soil that is sufficiently warm to permit root growth to begin immediately and to continue either during the spring and summer or during a period of two or three weeks in the fall before the plants become dormant. The best season for transplanting evergreens, especially in colder climates, is during the spring months, just as new growth is beginning. This is done for the purpose of giving the plants an opportunity to go through one growing season and thereby better to establish themselves to withstand cold weather in their new location. Stable manure which is not thoroughly rotted should never be placed in contact with or close to the roots of any evergreen plants. Fresh stable manure mixed in any soil where evergreens are to be planted is fatal to the plants. 
When evergreens are shipped from a colder and more backward section to a more advanced growing season in a warmer section of the country it is usually advisable to transplant in the fall. Evergreens in the opposite-leaved group, comprising the arborvitæs, retinosporas, and junipers, should seldom be transplanted in the fall after the plants begin to shed their leaves. This condition may be recognized when a considerable portion of the leaves throughout the plant turn brown.

If it is necessary to transplant evergreens during the fall when the growing season is completed and the ground is subject to light freezing and thawing, the best treatment is to immediately place around each newly transplanted plant a light mulch of stable litter three or four inches in depth. This is done in order to maintain the ground at an even temperature and to keep the soil sufficiently warm so that some root growth will start before freezing conditions develop.

lt is the general practice, in shipping evergreens, to "ball-and-burlap" them. In this condition evergreens can be shipped for a considerable distance, and if properly wet before being shipped they will remain normal for a period of two or three weeks. As a rule, evergreens for transplanting are grown in a soil which is composed of some clay rather than in a soil which will not hold together around the roots.

Rhododendrons. In the northern sections of the United States it is generally assumed that spring planting of rhododendrons is more desirable than fall planting. This is recommended mostly because plants transplanted in the spring have a better opportunity to establish themselves and are less liable to injury during their first winter. If rhododendrons are to be transplanted in the fall, it should be ascertained whether the locality from which the plants are coming has received a normal amount of rainfall prior to the time that the plants are dug. The greatest difficulty in transplanting rhododendrons is that with insufficient rainfall and a dry season, before the plants are dug, there is insufficient moisture stored in the plants to offset the transpiration caused during the winter months. When material is transplanted in the late fall roots do not seem to make sufficient growth to take up the necessary moisture from the soil, and therefore the plant must carry itself through the winter on the strength of the moisture stored up in the cells. This appears to be the main cause for criticism against the fall planting of rhododendrons. It 
should be borne in mind that the roots of rhododendrons and of the kindred plants such as the azaleas, feed near the surface of the ground. For this reason, and also because of the evergreen foliage characteristics some root action should be encouraged, if possible, during the milder winter months, and thus mulching of such plants is vital. Extreme care should be exercised in transplanting these types of plants. Plants should be put in a heavy, well-rotted leaf mold soil at no greater depth than the plant stood before moving from its previous location. It is a common practice in the preparation of lawn areas and planting areas, especially in sections where clay soil predominates, to apply a large amount of lime. Because lime in the soil is an element very injurious to the growth of broad-leaved evergreens, none should ever be put in or close to any beds which are to be planted with rhododendrons. This is also true of building plaster and mortar, which is frequently thrown into the soil adjacent to the foundation of buildings where these plants may later be put.

Rhododendrons should never be planted in a location where the soil around the roots will dry out. They should be sheltered from the morning sun and also from extreme exposures of wind. During most of the growing season the falling of the dew as a result of the condensation of the moisture in the atmosphere causes little globules of water to remain on the surface of the leaves during the night. These particles of moisture are slowly evaporated during the early part of the morning. The rays of the early morning sun coming in direct contact with the leaves of rhododendrons on which these particles of moisture are still present are concentrated and focused by these many little "lenses" and cause a burning of the surface of the leaves which in the case of rhododendrons is extremely injurious to the plant. This is one of the most important reasons why rhododendrons with their sensitive leaf surface should not be exposed to the direct rays of the early morning sun, at least until after the heat of the day has caused an evaporation of the particles of moisture remaining on the leaves from the previous night. The baking out of the soil around the roots is extremely injurious to them. If this soil can be maintained at an even, cool temperature, their normal growth is better assured during the summer. They are not so much injured because of the cold, but because of the intense sun which causes evaporation of moisture from the leaves at a time when the ground is frozen and at a time when the plants are unable to replace this loss of moisture by additional water 
taken through the roots from the soil. This condition is especially true in the clay loam soils of the middle west.

They should never be watered with any water which contains lime. This is equally as important as the necessity of not planting rhododendrons in a limestone soil. It matters not how much the soil may be changed in the beds or how much leaf mold may be put in the beds in which to plant rhododendrons if the water with which they are frequently soaked comes from a limestone region.

Rhododendrons will grow in any good garden soil, but they much prefer a soil with a good deal of humus in it, and they should be thoroughly mulched with leaf mold soil which should never be cultivated, but left in its native woodland condition.

Transplanting Annuals. It is preferable to transplant annuals in a fine, loose loam, and never to transplant them in a heavier clay soil, which will pack and dry out. Upon the size of the plants will depend the care that it is necessary to give them immediately after transplanting. The smaller the plants the more care will be required in careful watering and shading during the hot portions of the day. While with proper care annuals may be transplanted at any season during the spring or early summer, yet the late spring (May through June 15 th) is preferred. Annuals will develop best outdoors if they are transplanted at least two weeks in advance of the hot summer months. Frequent shifting, in pots or flats, is very beneficial through promoting the growth of fibrous roots which make transplanting more successful. 


\section{CHAPTER V}

\section{LAWNS}

THE first part of this chapter treats of conditions in the North and the second part of the chapter treats of conditions in the South.

\section{LAWNS FOR THE NORTH}

Preparation of Lawn Areas. The keynote of success in securing a good lawn is thorough preparation of the area before seeding. Failures are almost invariably due to poor preparation rather than to poor seed. Grading should be finished with a view to seeding either in the early fall or spring. Prepare the soil thoroughly, for the permanence of the sod rests entirely on this initial outlay. The soil should be deep and porous to produce deep rooting of the turf, which means success in combating winter-killing and drought. For the ideal lawn the ground must be prepared to a depth of one foot; but eighteen inches is preferable. If the area is large enough it should be plowed; otherwise spading must be resorted to. When the soil is naturally good and there is ample topsoil (six inches to eight inches) deep plowing without subsoiling is sufficient. In heavy soils the clay subsoil should be broken up but not brought to the surface. After plowing, if the area is large enough to permit the use of a team, the soil should be worked fine by harrowing. Follow this operation by levelling with shovels and hoes, and finally with rakes. The top layer of soil should be made very fine to induce quick germination of seed and permanency of sod.

The average lawn to which the author refers is the lawn developed in the immediate vicinity of the residence. If building operations have extended over the greater portion of this lawn area, as is general on the smaller residence lots, then all of the topsoil should have been stripped and placed in one or more large piles prior to the commencement of any building operations. In the preparation of a lawn area under such conditions it is very advisable to delay actual work upon this area until after that portion of the building operations apt to cause further litter to be thrown over the lawn area is completed. While the ideal lawn 
area should have a proper depth of topsoil in which the feeding roots of grass can develop, there are many instances where for purposes of economy or otherwise a sufficient depth of topsoil is not provided.

The first step is to determine the depth of topsoil which is to be finally spread over the finished subgrade of the lawn. The less the depth of topsoil the greater will be the cost of future maintenance over a period of years succeeding the first year. The surface of the finished subgrade should be established to conform with the finished grade of the lawn area and at a definite, even depth below this finished grade of this lawn area. No topsoil should be spread over this subgrade until every precaution has been taken to be certain that an excessive depth of topsoil will not be necessary where spots of extreme depression can be located in the surface of the subgrade and previously filled. In sections of the country where the subsoil consists of a clay loam and other types of heavy soil the item of providing topsoil for the preparation of the lawn area is one of the most expensive items in the landscape development of the property. Experience has shown that topsoil is one of the items which is often subjected to the greatest amount of waste, and it should be carefully conserved and not used, in any instance, except to the correct depth as required.

When the subgrade is completed and previous to the application of any topsoil it is often well, especially on types of clay soil, to apply a coating of lime at the rate of not more than twenty-five pounds to every I,, 00 square feet. On the top of this, a layer of well-rotted manure at the rate of one cubic yard for every five hundred square feet should be applied. The lime and manure should then be spaded or harrowed into this finished surface of the subgrade and the final surface smoothed with shovels or rakes before the final layer of topsoil is applied. This thorough preparation of the subgrade is much more essential if a shallow depth (two inches to three inches of topsoil) is to be used. It is not so essential if a more generous depth (four inches to six inches of topsoil) is to be used.

Fertilizer for Lawn Preparation. In the preparation of a lawn area the problem of correctly fertilizing this area is an important one. On the less fertile and poor types of soil a liberal application of well-rotted manure together with lime should be spread. Manure should be used at the rate of one cubic yard for each five hundred square feet and lime should be used at the rate of between twelve and twenty- 
five pounds to each I, 000 square feet. On the heavy types of soil this manure should be of a light texture containing sufficient straw, while on the sandy soil this manure should be of a heavy texture containing a quantity of humus. If the preparation of a lawn area is undertaken at least one year previous to the time that the actual seeding of the lawn is to be done then the heavy types of soil can be made more fertile and more porous by the development, during each spring and fall, of a cover crop of clover, cow peas, vetch, or rye. The deep roots of these plants and the frequent cultivation caused by plowing them under will do much to produce a mellow and friable condition of the soil. On the very heavy types of soil the frequent mistake is made of spreading a heavy coating of well-rotted manure over the surface of the proposed lawn area and plowing this under to a depth of ten inches to twelve inches. On the average lawn this is a great mistake, and a considerable waste of time and money. Such lawns should be plowed thoroughly, the soil made loose, and the surface pulverized as much as is practical with a disc harrow. A heavy coating of manure at the rate of one cubic yard to one and one-half cubic yards to each five hundred square feet should then be applied and harrowed into the soil. By this method the available food in the fertilizer is within reach of normal root growth of grass while under the other method such portions of the manure as are plowed to a considerable depth (ten inches to twelve inches at least) are beyond the reach of normal root growth of lawn grasses and soon become imbedded in a heavy soil impervious to root growth.

On the average lawn a top-dressing of manure at the rate of onehalf to three-fourths cubic yards to five hundred square feet, of sheep manure at the rate of five pounds for each one hundred square feet or of bone meal at the rate of five pounds for each two hundred and fifty square feet, should be applied and raked into the surface of the lawn. Manure, whenever used, especially in the preparation of lawns in the spring, should be well rotted in order to avoid so far as possible the presence of persistent weed seeds (such weeds as grow after the lawn is seeded). Bone meal and the types of dried manures commonly purchased on the market in bags do not bring into the lawn this objectionable feature. On the other hand, such concentrated fertilizers do not provide the humus which may be almost as essential as the food contained in the fertilizers.

Drainage of Lawn Area. A part of the preparation of all lawns 
which are constructed upon the heavy types of soil should consist of correct drainage in order to secure surface conditions conducive to the growth of good lawn grasses and to provide a firm texture to the lawn. Subsoil plowing is sometimes done with the object of correcting soil water conditions. This is not permanent, however, because the soil will pack down again within a few years. Before the topsoil is applied over the subgrade all necessary tile drainage should be installed at a depth averaging from twenty-four inches to thirty inches below the finished grade of the lawn and at intervals approximating from fifteen feet to twenty-five feet between lines of tile. This interval often depends upon the expense which the owner feels justified in making to procure an ideal lawn surface.

Seeding of Lawns. A general rule is to sow in April and May; or September and October (See Plate III). It is but seldom that sowing in June or July is successful. If sown before the fall rains, grass should become sufficiently developed to withstand the winter weather. It is generally preferable to sow seed in the fall. If the soil is properly prepared in the fall, seed may be sown on a light fall of snow in the spring. The seed will sink in as the snow melts and will germinate very quickly. As a general rule a lawn seeded in the fall will develop to better advantage with less maintenance cost than a lawn seeded in the spring, because any weed seed present in the grass seed will germinate and most of the weeds will be destroyed during the winter months; while if the same seed is sown in the spring it is necessary to remove these weeds by pulling them before they go to seed. Seed should be sown at the rate of eighty pounds to one hundred pounds to the acre, or one quart to three hundred square feet. Always sow thick. Choose a day when the soil is moist, when there is little or no wind, and when the weather is comparatively cool. Seed is scattered broadcast by hand, and the hand must be kept low. Go over the area in narrow rectangular sections marked out, sowing one-half the seed; then repeat the process, walking at right angles to the previous course followed. After sowing, the ground should be raked lightly and rolled thoroughly. Very young grass must be safeguarded against drought by frequent and deep watering.

Wherever lawns are to be developed under large shade trees, such as maples, oaks, beeches, etc., great care should be used and the work of seeding should be completed at the earliest possible date in the fall. 
It is not practicable to seed lawns late in the fall where large trees drop leaves which if not removed within one or two days are apt to smother the young grass. This is an important point to keep in mind.

The best grass generally for the foundation of a lawn, except on acid soil, is Kentucky blue grass. This does not fully mature until the third year. It is better, therefore, to use Kentucky blue grass in a mixture. Other grasses such as redtop and the creeping bents will produce a quicker effect and will keep out the weeds until the blue grass is fully established. Kentucky blue grass during the first year grows thinly, and continues to become thicker with successive mowings. When it is fully established it will crowd out some of the less permanent grasses in the mixture. The ideal lawn is one composed mostly of blue grass and it is also the most difficult to establish. Many people who wish to develop a good lawn in a short space of time resort to the use of a considerable portion of white clover. Clover is of no real value in the making of a fine lawn other than that it helps to produce a quick effect, thereby crowding out many early weeds, and that it produces a soft carpet effect with little difficulty, where the process of establishing a permanent lawn of blue grass might be slow.

The immediate development of a carpet of green over the surface of a lawn area is no indication that a permanent lawn has been established. The construction of a permanent lawn which requires only a normal expense in future maintenance involves not only the question of selection of grass seed of permanent types but also questions of adequate drainage, especially on heavy types of soil, and thorough preparation of the subsoil and the topsoil as a foundation of the lawn. Unfortunately many persons ignorant of the real requirements of a permanent lawn give much credit to those persons who are able, by the use of quick growing and temporary types of grass seed together with clover seed, and quick-acting fertilizers such as sheep manure (which soon releases all of its food value and leaves the lawn in an unfertile condition), to succeed in producing an immediate effect of greensward in a remarkably short time. The permanent and desirable types of grasses will not develop within such a short period, and lawns of this temporary character, while exceedingly satisfactory during the first year, will usually prove unsatisfactory and expensive in their maintenance cost during the succeeding years. Not only do certain types of grasses die out due to the nature of the grass and the lack of proper food supply but the lawn is seriously injured during the hot summer 
because of the shallow depth of topsoil that causes feeding roots to remain near the surface of the ground.

The various grass mixtures on the market vary in quality rather than in kind. It is inadvisable to buy poor seed. Many mixtures contain a large percentage of "chaff," and some mixtures contain more or less weed seed. It is highly desirable that any one responsible for the development of a good lawn should be able to identify the important types of good seed in lawn mixtures. Of the various grass seeds used the fescue and the clovers produce a quick effect during the first year.

The most common and satisfactory lawn seed mixture for the northern states is sixteen parts by weight of Kentucky blue grass, four parts of recleaned redtop, and one part of white clover. It should be used at the rate of one pound to each three hundred square feet of lawn or one hundred and twenty pounds per acre. The Kentucky blue grass is adapted to the northeastern states and the northwestern coast. It thrives on limy soil and will occasionally grow on land devoid of lime if the drainage is extra good. It makes a dense, vivid green turf except during midsummer when it is adversely affected by hot weather. It should not be confused with Canada blue grass which produces a tough but not dense or attractive turf and sometimes succeeds where the soil is too thin for Kentucky blue grass. Redtop succeeds under a very large range of soil conditions, from drought to wet land. It is one of the best grasses for poor soils throughout the whole of the eastern United States and thus succeeds where blue grass fails. It does not make a dense turf unless planted thickly and mowed closely. White clover as a turf plant succeeds on poor soils, forms a dense, close mat, and stands mowing well. If Kentucky blue grass is sown alone one hundred and fifty pounds per acre are required and liming is beneficial. If redtop is seeded alone forty pounds of fancy "recleaned" seed per acre are sufficient and no lime is needed. Clover is never sown in a clean stand but may be sown with or after grass seed at the rate of ten pounds of seed per acre.

For a fine turf similar to putting greens, use Chewing's or New Zealand red fescue, which is a grass having a dark green colour and which makes a solid, compact turf. It is particularly adapted to sowing on sandy loam soil but succeeds well on clay loam or even on clays. When seeded alone one hundred pounds per acre should be used. It is the best lawn grass for growing in the shade under American conditions. Another fine-leaved grass making a dense, velvety turf is creeping bent. It does 
best where the summers are cool and moist; that is, in the northeastern states and on the northwest coast. When the soil is limy, other grasses, such as blue grass and white clover, tend to crowd out creeping bent. It should be sown alone except that combined with red fescue it will be satisfactory for a few years, after which the two grasses tend to separate and make circular mats.

There are standard mixtures on the market offered by the more reliable firms for special uses such as on golf greens, fairways, and shady locations.

In the section south of Washington, D. C., except in the higher altitudes, it is not advisable to use Kentucky blue grass. White clover, in this section of the country, becomes the prevailing grass in lawns. In the northern part of this area, white clover, redtop, and Rhode Island bent make an excellent lawn, but not a lawn as permanent in character as the northern turf.

SodDiNG. Sodding instead of seeding has the following advantages: (I) grass of a known texture can be obtained; (2) an immediate stand of grass is secured; (3) sod can be laid at any season except when the ground is frozen. The disadvantages, however, are quite numerous: (I) a seeded lawn is as good and generally is better within a year; (2) the expense of sodding a lawn is great; (3) it is usually difficult to procure good sod; (4) sod will heave on heavy soils if laid too late in the fall; (5) it is difficult to get perfect unions between sods. Sod is generally used along the edges of walks, borders, banks, and close to buildings, when seeding an area; and also on areas such as terraces and laundry yards which are to be used immediately. The preparation of a lawn for sodding is the same as for seeding. Sod should be laid on a firm foundation; that is, the soil should be thoroughly tamped before any sod is placed upon it. The best sod is secured from pastures which are on a heavy type of soil. Pasture turf is cropped and therefore forms a dense growth which can be removed in thin layers. Cut the sod about one and one-half inches thick, twelve inches wide, and three feet long. A foot-wide board should be laid on the turf and the strips cut along either side with an edger. The sod is lifted with a spade or preferably with a turfing iron. The strips are rolled up, grass side in, and should be relaid as soon as possible. When laying sod, fill the junctions with fine soil and then beat it down with the back of a spade or with a sod pounder, 
remembering that it cannot be pounded too hard. After being laid, sod must be cared for carefully throughout the summer.

\section{LAWNS FOR THE SOUTH}

Soil and Climatic Conditions. The extreme heat and the long dry spells during the summer months throughout the southern states make it inadvisable to try to establish a turf similar to the turf of the northern lawns, composed mostly of Kentucky blue grass, redtop, clovers, and bents. These grasses, when used in the south for a lawn turf, will completely burn out during the summer months unless an abnormal amount of labour is employed to protect them by excessive waterings. While in the northern section of the country lawns in general are developed on good loam or topsoil, the soil conditions of the south are somewhat different. The soil throughout the south, especially in Florida, is generally known as yellow or clay sand on which lawns can be developed with the least difficulty, and the white sand which contains little or no plant food and on which no satisfactory lawn can be developed without the addition of a considerable quantity of muck. The "topsoil" sand, so-called, often possesses a considerable quantity of food matter; but the ease with which water drains from it combined with the heat of summer will cause the northern types of grasses to burn out and also will kill many of the southern types of grasses.

To one who has been accustomed to the sharp line of differentiation between the topsoils and subsoils of the north the problem of drawing a definite line between the topsoil and subsoil under the conditions of the far south is somewhat puzzling. As a matter of fact, on all soils, with the exception of a good type of muck soil coming from the swampy areas and the hammock land, no good lawn can be developed without the addition of considerable fertilizer.

In the north the value of a lawn continues only during the growing season, from April until October. In the south, especially throughout the section visited by many of the northern tourists, temperature conditions are favourable for the growing of a lawn throughout the entire winter. It is therefore desirable to have types of grasses for the development of lawn areas both during the winter months and the summer months. The excessive cost of maintaining a good turf on lawn areas during the hot and dry summer months has discouraged the development of extensive lawn areas as seen in the northern states, 
except on golf courses, where the fairways and greens are maintained regardless of normal cost.

Little experimenting has been done in the far south to determine individual types or combinations of types of northern grasses which will thrive best under these climatic conditions both during the winter months and the summer months.

TYPES OF GRASSES FOR LAWNS. There are three groups of grasses which are used for the development of lawns in the far south (throughout Georgia, Alabama, and Florida). The first group consists of the more or less native grasses, Bermuda grass, St. Augustine grass, and blanket or carpet grass. These grasses will not make a perfect turf as a "perfect turf" is known in the northern states. They grow vigorously and spread rapidly when the temperature does not fall below 50 or 55 degrees. The second group, of which Ross's Southern Mixture is typical, is composed of types of northern grasses, such as orchard grass, Rhode Island bent, redtop, and a small portion of Italian rye, which as a result of experiments have produced good turf on southern lawns. The third group is made up of Italian rye, which germinates quickly and produces a green turf and lives for but a short period during the cooler winter months. It burns out quickly during the hot summer months.

TyPes of SoILs. In the preparation and development of lawn areas, especially on virgin soil, the land must be cleared and the stumps removed. It is preferable that stumps should either be pulled out by tractor or team, chopped out, or in the instance of pine lands, they should be burned out. The operation of blasting stumps, in order to remove them, leaves a considerable hole, which, when filled with loose soil, however thoroughly tamped, may cause a depression in the lawn on account of later settling. After the land is cleared and the stumps are removed, the lawn is brought to an even grade, and unless the soil is a rich yellow "topsoil" sand, it is advisable to spread a layer of muck, averaging from two to four inches in depth, over the entire lawn area. A deeper covering of muck would be better. The cost of excessive "mucking" is often the determining factor. This muck, which usually comes from the swamps, should be selected with great care. Not all so-called "muck" soil in swamps is adapted for use on lawns. It is often the case that swamp muck put on a high, dry, and sandy 
soil will, under the sun's rays, quickly dry out and become powdery. It is best to obtain, if possible, a sandy muck or black soil of a vegetable nature and not of a woody nature. This can be obtained from the edges of the hammock lands. This type of muck does not dry out. Good muck, taken from the upper layers of swamp areas, ought to be mixed thoroughly with a generous amount of lime and the entire mixture ought to remain for two or three months before it is applied to the lawn area. The mucks to be avoided are the woody and very sour types.

Planting and Seeding Lawns. The season for making a lawn varies with the kind of a lawn which is desired, and also with the season of the year when the lawn is to be used. Especially in the far southern states, some lawns may be intended for use and enjoyment throughout the entire year, while another group of lawns may be intended to be at their best during the winter months.

With the lawn developed from Bermuda grass or St. Augustine grass the period required for the development of a good turf averages from three months to four months. Therefore, if a lawn of this type is to be developed as a lawn to be maintained throughout the entire year the Bermuda grass or St. Augustine grass can be planted at any time. The ideal time just prior to the rainy season in June or July should be selected so that the roots of this grass can have the benefit of the heavy rains. If a lawn of this character is to be developed as an asset to a distinctly winter home, and artificial watering conditions are immediately available, the Bermuda grass or St. Augustine grass can be planted at any time during the growing season. It is not advisable to plant either of these grasses during the winter months from December to February when temperature conditions are apt to be so low that growth is not encouraged. On the other hand, Italian rye, which is distinctly a grass for winter lawns, cannot be seeded to advantage in the summer months from April to October.

Lawns composed of Italian rye may be seeded at any time of the year from the first of November to the first of March. . The time required for Italian rye to establish itself, and to produce a green lawn area, averages from three to five weeks. An excellent way in which to obtain a green lawn during the winter months is to seed a Bermuda grass lawn, which is at least three months old, with Italian rye at the rate of one pound for every one hundred square feet. In the middle and 
southern portions of Florida this is perhaps the most satisfactory method of making a good turf which will be more ar less firm and which will be green through the winter months. Italian rye will burn out as soon as the weather begins to get warmer during the middle or latter part of March, and can be reseeded on the foundation of Bermuda grass, in the same manner, during the succeeding fall.

Lawns composed of the northern mixtures of grass seed, of which the Ross's Southern Mixture is typical, can be seeded at any time during the cooler months between November and March. These lawns may be maintained in the same manner that any northern lawn is maintained if an excessive amount of care in watering is devoted to them during the hot summer months. It is preferable to reseed each season. This type of lawn is prepared and seeded in a manner similar to the lawns of the north and will establish itself under normal conditions in a period ranging from four to six weeks. This seed is sown at the rate of one pound for each two hundred square feet of lawn area. The operation of seeding lawns with mixtures of northern seed adapted for southern use, and also with Italian rye, is the same as sowing seed for the development of lawns in the north.

It is not advisable to try to develop Bermuda grass and St. Augustine grass lawns through seeding. A better lawn can be obtained with less difficulty by planting small clumps of Bermuda grass and St. Augustine grass (Plate VIII) in little drills ten inches or twelve inches apart or by staggering at intervals of twelve inches to eighteen inches. The greater the desire to have a close mat of Bermuda grass or St. Augustine grass the closer should the individual roots be planted. For small lawn areas, tees and greens on golf courses where the time is short in which to develop a good turf, these roots or clumps may be planted as close as six inches from each other. The usual method is to find a patch already growing. The best method of gathering Bermuda grass is to dig underneath the roots with a grub axe or mattock and to gather up the roots with some type of a fork, such as a potato fork. As much soil as possible should be taken up with the roots, where the grass is naturally in rich, fertile soil; otherwise the soil can be shaken from the roots. The best method of handling these roots is to place the entire mass in potato sacks, especially if the source of gathering the grass is at a considerable distance from the place where the lawn is being made. Just previous to planting, the grass should be either torn apart leaving roots and tops on the same stem, or it should be 


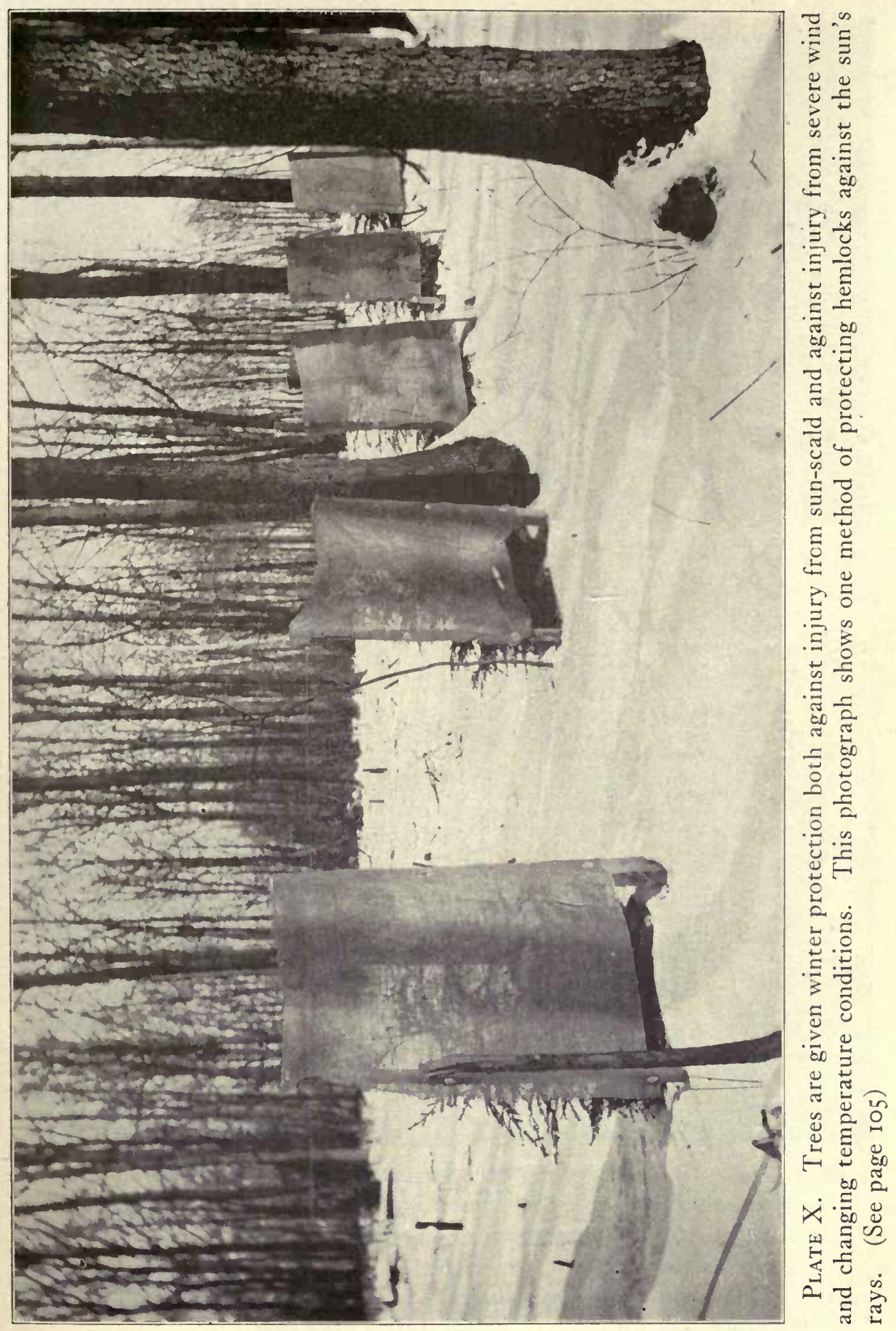



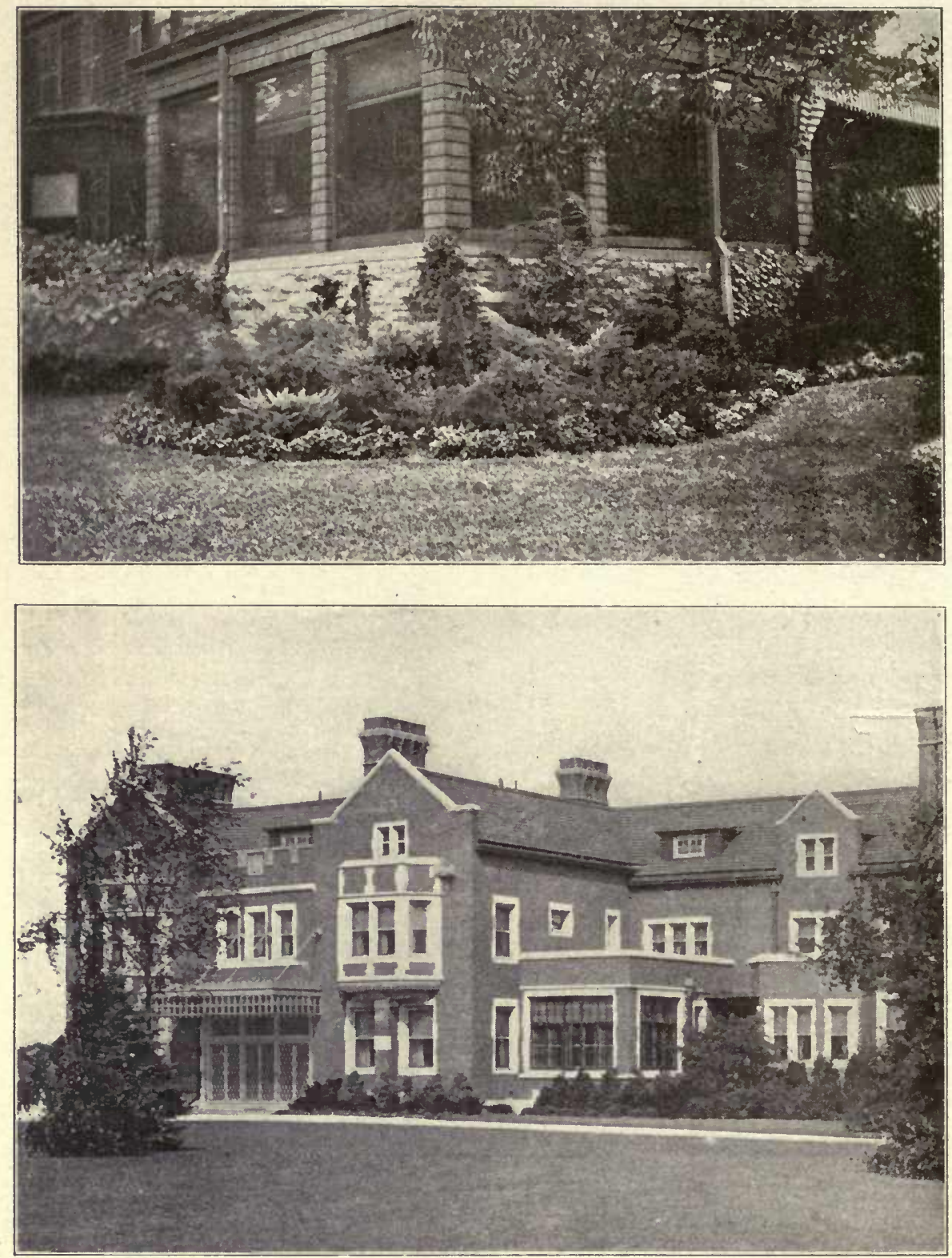

Plate XI. The list of evergreens adapted to soil and to climatic conditions of the middle-west, and valuable for low, refined, mass plantings is limited. The upper photograph shows an effect produced by the use of dwarf yew, Pfitzers and tamarisk-leaved junipers, Mugho pines and Japanese spurge edging. The lower photograph shows the effectiveness of masses of low, refined evergreens against massive architecture. (See page I I4) 
chopped into small sections. The first method is preferable. These sections of roots or small clumps are planted from three to six inches deep; more shallow if the soil is moist. Shallow planting should be adopted only where ideal conditions exist for keeping the soil moist. It requires approximately three cubic yards of these roots to plant one acre of lawn. If the roots are contained in two and one half bushel sacks it will require from one hundred and forty to one hundred and fifty of these sacks filled with Bermuda grass roots to plant one acre of lawn, or approximately one sack for each two hundred and twenty-five square feet. These roots of Bermuda grass or St. Augustine grass should not be permitted to dry out, either while piled waiting for shipment or while in transit to the place where the lawn is being made. Injury from the drying out of the roots of these plants between the time they are dug and the time they are planted is not nearly so serious as the injury caused by heating or sweating while the plants are still in the sacks. If these plants are allowed to heat or sweat they immediately turn yellow, begin to rot and die. Any plants that have been subjected to this heating or sweating process should not be planted. If the lawn which is to be developed is large, then a simple method of planting these grasses is to spread them broadcast over the ground and to disc the roots in with a harrow, or to plow a shallow furrow and plant the roots in the furrows. The discing process has sometimes proved a failure. It requires approximately twice as much grass and roots as the planting in furrows, in order to get the same stand of grass. It is a process, however, which can well be adopted where an immediate even stand of grass is not essential. This is true because in the process of planting in furrows the grass can be more evenly distributed at a shallow depth while in the discing process most of the grass finds itself at a considerable depth, thus requiring more time for the grass to reach the surface.

The Italian rye lasts only during one season. The Bermuda grass and St. Augustine grass will make a lawn nearly as permanent as any northern lawn, provided the proper maintenance and attention in rolling and watering is given. Lawns of these types should be watered at least once in ten days or two weeks, at which intervals they should be thoroughly soaked. In order to maintain a Bermuda grass lawn in its best condition the lawn should go through the process of renovation every second or third year. This process consists of a discing, done for the purpose of cutting the roots and producing new 
stoloniferous growth. The harrow should be permitted to cut this ground to a considerable depth, so as to encourage new root growth as well as a deeper root growth. Probably the average depth which the harrow cuts approximates from two to four inches. The ideal harrow for this purpose is known as the alfalfa renovator which is used for the purpose of cutting a deep furrow into the soil rather than disturbing the soil.

If the lawn area is composed of a combination of Bermuda grass and Italian rye, or of a southern mixture of northern grass seed, it should be thoroughly soaked with water as often as once every two days. Superficial watering under conditions of hot sun and dry climate is more injurious to the southern lawn than a similar watering would be to a northern lawn. Where an excellent lawn turf is desired from November to April, it is much preferable to top dress the Bermuda grass foundation with a thin coating of muck, or rich soil, and to seed each fall with Italian rye as a filler. If a lawn of northern grasses is to be maintained from November to April, experience to date has taught us that the most practical method is that of reseeding the entire lawn area during the middle or latter part of October, or early November, rather than to expend the labour necessary to maintain a turf during the hot summer months when it is not used. 


\section{CHAPTER VI \\ BULB CULTURE}

Characteristics of Bulbs. A bulb is a large dormant bud, and is a condensed plant when dormant. Bulbs can develop only flowers which were formed within them before they were ripened. The dormant period of a bulb occurs in order to carry it over the dry or cold season.

A good bulb must be fully developed, in good soil, and under good conditions. It must be kept from heating, sweating, or rotting in transit, and must not be kept out of the ground so long as to dry out to an injurious extent. When buying bulbs always take into consideration that cheap bulbs are invariably poor bulbs and that size alone does not count, but adds to the probability that the bulb is mature. Plump, solid bulbs give the best blooms, and if to this is added size, the bulb is ideal.

There are two groups of bulbs: those which should be planted in the fall to produce flowers in the spring, such as tulips, narcissi, and crocuses, and those which should be planted in the spring to produce flowers in the summer and early fall, such as gladioli. (In botanical science in the case of the gladiolus the term is "corm" rather than "bulb.")

Time for Planting Bulbs. Nothing is gained by planting springflowering bulbs, such as tulips, narcissi, crocuses, hyacinths, squills, and Spanish irises, before September or October. The reason for planting, then, is that they keep better in the ground, and as they start to root in the fall they begin growth earlier in the spring. It is hardly possible to plant bulbs of this group early enough in the spring to secure any flowers the same season. These bulbs should be planted not earlier than six weeks before the hard frosts. Narciśsi may be planted earlier, and it is preferable to plant crocuses early. Crocuses are usually planted in the lawn. An early bloom is desirable; therefore early September planting permits root growth in the fall and the 
flowers mature and pass before the grass requires cutting. Bulbs, in order to make some root growth in the fall, should not be planted very late. Autumn-flowering sorts, such as the colchicum and the saffron crocus, may be planted in August or early September, if well protected, but if planted in the spring should be set out after danger from frost is past. Narcissi and hyacinths are planted preferably early in October, while tulips, particularly the late-blooming, may wait till November. If the ground begins to freeze hard before the bulbs can be planted it should be kept warm by a litter of straw or leaves. Such a blanket spread over frozen ground early in the winter will enable the heat within the earth to thaw it out and permit quite late planting. If bulbs are planted late it is well to cover them with mulch at once in order that root growth may be made before the cold prevents it. If the bulbs are planted early in the fall, however, the mulch should be applied only after the ground has been frozen to a depth of several inches. Thus excessive top growth will not start prematurely. Gladiolus bulbs should be planted in the spring after the fro sts are over. The period required for such bulbs to mature is about ninety days. Therefore, a succession of bloom can be obtained by planting at intervals of ten days or two weeks. Under expert care, in well-drained soils and with sufficient protection, many gladiolus bulbs can be planted in the fall and thereby insure a very much earlier bloom in the summer. This should at first be tried only with extreme caution, and the plants will need protection from spring frosts.

Soil and Drainage Requirements. Bulbs should be planted in a well-drained, deep, rich soil in order to develop successfully. In wet soils put a handful of sand under each bulb to keep the water away from the immediate vicinity of the bulbs. In wet locations the beds should be raised. Hyacinths require a sandy soil and soon become diseased in heavy soils. Few lilies will succeed in limestone soil. Lilies require extra good drainage and rich soil. Some will do well in heavy soil, as the madonna lily and the tiger lily. It is best to surround lily bulbs with sand, and where drainage is not ideal, plant the bulbs on one side so that water may not collect in the heart of the bulb.

Fertilizers for Bulbs. No fresh manure should ever touch a bulb, but well-rotted manure may be incorporated deep in the soil before planting with the best of results. The manure should be ac- 
cessible to the feeding roots but be kept away from the bulb. Do not use manure at all unless the bed is excavated to a depth that makes it possible to spade the manure in below the level on which the bulbs are to rest. Tulips are less apt to be injured by manure than are narcissi. For planting with a trowel or dibble, bone meal only should be used. Leaf mold and sand should be added to heavy soils. Bone meal used with bulbs tends to increase the size of the blooms. Liquid manure, added liberally when the plants are budding, has often given excellent results. To increase the development of new bulblets and especially of gladioli, a fertilizer containing a large percentage of potash is desirable.

Depth for Planting Bulbs. Unless a bed of bulbs is planted at uniform depth they will not bloom uniformly. It is a good practice to exca vate a bed to a given depth, place the bulbs as desired over the bottom, and then cover all to the same depth, thus making certain that they are evenly planted. The larger and stronger bulbs are, the deeper they may be planted. They may be planted deeper in sandy soil than in heavy clay soil. A general rule for planting depth is three times the average diameter of the bulb. Bulbs are frequently planted too shallow. For depths at which to plant bulbs, also distances apart, see "Bulb Table" (Plate IX, Page 46). When planted in holes made with a dibble, put loose dirt or sand in the bottom of the hole to avoid air space. Planting with trowel or dibble, however, should not be done where uniform show beds are desired. For lawns, bulbs may be dibbled in, but it is better to cut the sod and press back after planting. This is done in the fall when lawns are soft from rains.

Mulching BulBs. Bulbs lie dormant, to all appearances, over winter, and should be thoroughly mulched to insure that they do not start to grow in any unseasonable warm spell of weather, and also in order to prevent heaving. Mulch with straw or leaves to a depth of four inches to six inches, but do not add this mulch too early; wait till a fairly thick crust has been frozen over the ground. Lilies always require heavy protection and will succeed better in partial shade. Remove the mulch or litter in spring before warm weather and after damage from freezing is past. The coarse part of the mulch should be picked off carefully, care being taken not to injure the tops of 
the bulbs. The finer pieces of mulch may be worked into the soil, if the cultivating is done cautiously.

Reproduction of Bulbs. Many bulbs, like the varieties of crocus and certain varieties of narcissi, will continue to multiply by developing small bulblets and in that way produce a flower effect for a considerable number of years. Other bulbs, like certain varieties of the tulips and other varieties of narcissi, will have their energy sapped during the first one or two years. They will not reproduce bulblets and the result is that in order to continue the flower effect new bulbs must be purchased and planted in their place at the end of two or three years. Spanish iris and also the English iris will, under ideal conditions of soil and cultivation, continue to develop new bulbs and to multiply. For this reason they can be left in the ground during a number of years. In cutting flowers from bulbs it is quite necessary that some leaf surface should remain after the flower stalk has been removed. This leaf surface provides a "stomach" for the plant, in which digestive functions continue and new food is supplied to the bulb for the purpose of enlarging it and for the purpose of forming new bulblets. The gladiolus is the best example of bulbs which are reproduced in the average garden by new bulblets. Many varieties of gladioli, however, will not reproduce bulblets if the flowers are removed. None of the varieties of the gladiolus will produce new bulblets or make strong bulbs if, when the flowers are cut, all of the leaves are removed.

Treatment of Bulbs After Flowering. Bulbs will not ripen if the tops are cut very soon after flowering. For best results, do not remove the tops before late June, or until leaves turn brown. When cutting flowers cut as few leaves as possible, and do not cut the entire stem of a lily. Never lift any bulbs, if it is possible to wait, before the tops are brown and limp. If bulbs must be removed to make way for other plants, take roots, top and all-some soil also with the roots. Heel-in, not too close together, in a shady spot until the tops commence to die. Autumn-flowering bulbs also should be allowed to ripen before removal for winter storage.

Oftentimes it becomes necessary in the renovating of the flower garden to dig up bulbs during the month of September or October. This is not desirable. Wherever it is foreseen that the soil in the 
flower beds must be spaded over and refertilized in the fall, all bulbs should be removed in the late spring and stored in the usual manner in a cool, dry, dark place in the cellar or shed until time to plant them in the fall. If it is necessary to dig up bulbs in the fall after some root growth has started, then these bulbs should be taken up with some soil attached to the roots. They should be kept moist and replanted just as soon as practical. They should never be left to dry out because after the root growth has once started this drying out of the roots is likely to cause considerable injury to the bulbs. Only such permanent sorts as the tulips, especially the Darwins, narcissi, and the lilies will as a rule repay the trouble entailed. Hyacinths seldom can be depended upon for good bloom after the first display, in any event, and are thus hardly worth the trouble of replanting. In the eastern states and in the Middle West root growth in bulbs hardly ever starts before the latter part of September because the dry months of late summer keep the bulbs dormant until the fall rains. When replanting of bulbs is done after September I 5 th, a good mulch of straw manure put on to keep the frost out of the ground as long as possible is essential.

Of lilies, in the case of the foreign and the hybridized, it is practically useless, in general, to try to prolong life and to improve bloom from year to year by taking the bulbs up annually. Careful study and experimenting are necessary to determine what kinds it is best to plant. The tiger lily, the speciosum, white and pink-dotted, and the madonna lily are managed easily and the native lilies are apt to be permanent, if given their natural conditions. The one named last should be planted early in the autumn or even late in the summer, not more than two or three inches deep and in heavy or somewhat clayey soil. The bulbs of this and of the others'named here may be taken up every few years, as they increase in number, and be replanted in fresh soil. The bulbs of nearly all lilies except notably the madonna may be kept over winter packed in moss or sand and stored in a cool place where they will not freeze. Then they can be successfully planted in the spring (Consult XXXIII-F, Page 253).

Narcissi are best left undisturbed for several years. It is best to allow crocuses and early tulips to run out, unless the tulips are wanted for formal effects. All tulips, like hyacinths, yield most satisfactory bloom if they are taken up annually and replanted at the proper season. Only the larger bulbs should be planted, where uniformity of effect is 
desired, while the smaller ones may be planted apart by themselves to increase in size. Late tulips often do very well undisturbed for three, four, or five years.

Crocuses, squills, and narcissi may be naturalized, especially if care is taken not to cut the tops tco closely or too soon after blooming. This is one of the strong arguments in favour of planting crocus bulbs in September. The tops will have then matured before spring mowing begins.

After the bulbs of any kind have been lifted, and the tops are dried, these tops should be carefully trimmed off and the bulbs stored in a dark, cool place until time for replanting.

Plant bulbs in combinations as shown under "Bulbs." Learn which are late flowering and which are early; also which varieties are tall and which are short. Choose lilies that are easy to grow and select varieties that have proved successful.

Forcing Bulbs. Bulbs are grown extensively, both privately and commercially, for cut flowers, and for indoor use during the winter season. It is not hard to achieve success in forcing bulbs if two important rules are observed, namely: I. Procure the strongest and best bulbs possible, for good care will improve the quality of the flowers but not the quantity. The latter is always fixed within the bulb before it is purchased. 2. Perfect root development must be insured before the tops are permitted to start growth.

The bulbs should be planted as soon as they are procurable, with late August and November as limits. The soil to use should be rich loam mixed with bone meal in a one to fifty proportion. If the soil is heavy add leaf mold or sand. It is better to avoid manure unless it is thoroughly rotted and pulverized. Five-inch pots may be used for larger bulbs, such as hyacinths; and a three or four-inch pot for one tulip or any bulb other than a hyacinth bulb of large size. It is better, however, to plant three or more bulbs in a larger pot, as soil moisture and temperature are more evenly maintained. When being forced for cut flowers, bulbs are planted in boxes or flats of a depth of three inches to four inches, with the bulbs set from one inch to two inches apart. This is a good way to grow bulbs for decoration also, since the flats can be covered with crepe paper, raffia mats, etc., when the flowers are in bloom. Broken pottery or charcoal should be put in the bottom of the pots for drainage. The soil is then sifted into the 
pot or flat, but not packed, and the bulb is so planted that the top is just below the surface. Do not press the bulbs down. After planting, water thoroughly to settle the soil firmly about the bulb and do not water again until the top growth starts unless the pots or flats are stored in a place where they will dry out.

After being planted, the bulbs must be stored away in order that they may root properly, because rooting is the most important phase in successful bulb forcing. There are several methods of storage:

I. Place the pots, flats, etc., in a cold frame or cold pit and cover with four inches of sand, rotted leaves, or ashes. Put on the sash when freezing weather arrives and open on pleasant days.

2. Pots may be placed in a cool, dark cellar, and will keep well if the soil is kept moist but not wet. The danger here is from drying out if they are not watched at frequent intervals.

3. A better method is to dig a trench one foot deep, put in three inches of ashes for drainage and to keep out worms; put in the pots and fill the trench with soil. During freezing weather cover with rough stable manure, leaves, or straw, to a depth of four inches.

4. Pots may be set out and covered with eight inches or ten inches of leaves, filling in between the pots with soil to maintain moisture.

Early bulbs, such as paper white narcissi and Roman hyacinths, will root sufficiently in a period of six weeks. It is much better, however, to leave. bulbs in storage for a period of eight weeks. Spanish iris bulbs require a longer period for the formation of root growth than most of the other bulbs. This group is probably the most difficult group to force successfully. They should remain buried in the cold frame or in the pit, with all top growth retarded, until a complete root system is established. When ample roots are formed and about one inch of top growth has appeared, it is time to lift all bulbs and remove them to a semi-dark cellar where they may be kept in a cool temperature with little light to encourage the immediate development of stems and foliage. Avoid, at this period, direct sunlight. After a reasonable amount of growth is secured, place the pots where desired. Bulbs should be taken out of storage in relays to provide a succession of bloom.

There are very few types of bulbs which are adapted for forcing in water. The paper white narcissus is best adapted to this type of forcing. A few of the other types of narcissus may be grown in this way, and occasionally early single tulips, Spanish irises, and crocuses 
can be successfully forced in water. The best method of forcing bulbs in water is that of setting each bulb in a shallow receptacle, partially filled with sand or coarse gravel, and keeping the water just even or slightly below the base of the bulb. These bulbs should then be kept in a dark, cool place for at least six weeks, and the receptacle should be frequently filled with water, which must always be clear and fresh. After the bulbs have commenced to root they may be treated in the same way as bulbs forced in soil.

Bulbs which have been forced in any manner are of no value for forcing during the second year. Such bulbs should be allowed to ripen their foliage by setting the pots or flats in a cool, light place, and providing them with sufficient water to keep the bulb from drying out until the top growth has ripened and begins to die. These bulbs may then be set in the open ground at the proper time in the autumn and they will produce some flowers during the succeeding year. It is seldom that they will recover their vigour sufficiently to be of value for the purpose of forcing during the second or third year. 


\section{CHAPTER VII}

\section{MAINTENANCE*}

ReQuirements. The maintenance of trees, shrubs, and vines, since they are almost invariably planted where they are expected to remain permanently, presents fewer difficulties than the care of perennial plantings, except where plants become diseased or subject to insect attack. Maintenance is confined mostly to cultivation, feeding, watering, pruning, and spraying.

Trees-Tree Surgery. Pruning has been discussed in Chapter III, but there is an analogous practice often followed by "tree doctors," namely, the scraping of bark from trees, which should be touched on here. The main object and accomplishment of tree scraping seems to be the providing of work for "tree doctors" during dull seasons. The ultimate consequences to the tree are seldom beneficial, and often fatal. Instances have occurred where handsome shade trees were scraped down to the cambium by ignorant "doctors" and promptly died. The outer bark of trees is placed by nature as a protective covering and should not be removed, except in the case of those trees, such as hickory and plane tree, which naturally shed bark in large scales, and then only when these scales are harbouring insects which cannot be otherwise destroyed. The criticism of the socalled tree doctors is, however, not intended in the least to discredit really expert tree surgeons nor to discourage the employing of them. Quite to the contrary, it should be noted that these men can render most valuable service and that often a greatly prized tree can be saved for many years and its growth greatly improved by having it wisely cared for. The supporting of branches where a crotch might cause a splitting of large limbs is too often neglected. The removing of broken branches often prevents decay from entering into the heart of the tree. The taking out of crossing limbs often makes possible a symmetry of development that otherwise would never be realized.

"See also Chapter III on "Pruning" and Chapter VIII on "Winter Protection and Mulching." 
The proper filling of a cavity, after the wound has been scientifically dressed, will enable the cambium to begin to grow over the space and in time to cover it entirely with tissue that will greatly promote future growth of the tree as a whole while at the same time it removes a disfigurement. But before the welfare of valuable trees is entrusted to a man who professes to be able to restore them there should be valid assurance of his being in every way proficient and thoroughly competent.

Fertilizing. Shade trees seem to be less intelligently maintained than shrubbery. It is a matter of common knowledge that the roots of trees spread as far or farther than the tops, and that most of the feeding roots are at the extremities of the large roots. Many experiments have proved that the effect of fertilizers is rarely felt very far in a lateral direction from the place where applied. Therefore, when feeding a shade tree do not bank a small pile of strawy manure around the trunk, as this encourages mice only. Spread the mulch well out over the whole area covered by the top of the tree, and neglect, if any, the area near the trunk. In case of shade or orchard trees which are not vigorous and which require feeding, recent experiments seem to show that applications of nitrate of soda and acid phosphate are effective. Quantities up to ten pounds for each tree may be used on old trees either spread evenly over the surface of the ground underneath the tree or introduced beneath the sod in quantities of a handful deposited in the bottom of holes made by a crowbar at staggered intervals of eighteen inches. Bone meal is probably one of the best fertilizers to be used in preserving the vitality of shade trees. A successful method of applying bone meal is that of spreading it broadcast over the lawn surrounding the base of the tree. This fertilizer, which is slow acting, should be applied during the winter or very early spring months, at the rate of at least twenty-five or fifty pounds for trees from ten to twelve inches in diameter, and at a proportionately less rate for trees of smaller diameter. This fertilizer should be applied at least once in two years. It is much better to apply a less amount and to fertilize the trees each year.

WATERING. Most of the deep-rooted shade trees, such as oaks, seldom need watering after they are once established, but it is often advisable to grve shade trees a heavy watering in time of drought. 
Surface sprinkling is not desirable as it encourages surface rooting and seldom does much good. In case it is necessary to water a shade tree the best plan is to throw up a shallow embankment of earth around the tree just outside the spread of the branches if possible, and flood the enclosed area at intervals not more often than once in five or six days. Many trees and shrubs will be much benefited in time of drought if their tops are sprinkled at sundown on very hot days.

SPRAYING. Spraying of plants as a scientific practice is, comparatively speaking, a modern procedure, but the necessity for doing something to protect plants against insects and plant diseases has been understood since antiquity. In their writings the Greeks, Romans, and Hebrews noted the existence of rusts and mildews, and the plague of locusts is of Biblical record.

Spraying is only one of several ways of protecting plants and among the others may be enumerated hand picking, fumigating, banding, burning, using fungous diseases as insecticides, crop rotation, soil sterilization and various other more or less practical methods. These other methods are important when understood and put into practice at the right moment and in the right way, but they are inexact compared to spraying and are seldom as efficient. Spraying, by which is meant the use of chemicals to poison or otherwise exterminate animal and vegetable parasites on plants, has been reduced very nearly to an exact science in this country, largely within the last century, and, while it is not the purpose here to go too deeply into this art, some broad rules may be laid down and some little understood points cleared up.

Our Government and State Experiment Stations have been largely responsible for the rapid strides taken in this art in this country. They have issued many bulletins and spray calendars containing exact directions for combating all the known insect pests and plant diseases and they always stand ready to help any one who asks for it. Yet much of their help comes too late and much money is wasted each year with consequent disappointment, because a few simple principles are not clearly understood. Some of the overlooked factors which are not taken into account are as follows: (I) a spray mixture must be the correct one as, for example, it does no good to use poison upon an insect at a period in its life history when it does not eat; (2) the spray mixture must not injure the plants, or else the cure will be 
worse than the disease; (3) a thorough job must be done or else the whole job may have to be done over at too late a season to secure the best results; (4) the correct time must be picked or a rain storm may undo the whole work within a few hours; (5) the spray must stick to the plant long enough to be of some use, especially in the case of poisons.

The various forms of sprays may be classified in four different ways: according to the season of spraying, the kind of chemicals used, the form in which the chemical is applied, and the kind of plants sprayed.

Seasons for Spraying. The seasons for outdoor spraying are two: the summer or growing season, and the winter or dormant season. Summer sprays are invariably not applied so strong as winter sprays, because the bark on the new shoots as well as the leaves would be injured by a spray of a strength which would not only be entirely safe, but advisable to use when a plant was dormant. Dormant sprays are mostly confined to those applied for protection against vegetable parasites and those intended to destroy scale insects. Some useful winter work is often done in the destroying of egg masses and cocoons by torches and the application of creosote or other strong paints by hand in small quantities; but this is not, strictly speaking, spraying. Summer spraying includes nearly all the methods used in the dormant season, with the spray made more or less dilute, dependent upon the exact season, as well as all the other forms of sprays. It should be noted that dormant spraying may be done at almost any time after the plants become dormant in the autumn and until they start growth in the spring; but it is not advisable to attempt to spray during freezing weather, nor too early in the winter, because in the latter event much of the benefits of the spray will be lost through the subsequent winter storms. If dormant spraying is delayed until nearly spring some beneficial results may be expected to extend into the summer, which would otherwise have been lost. Summer spraying, on the contrary, must usually be done at some precise time in order to secure the desired results, though this is not always strictly necessary.

Spray Chemicals Used. The spray chemicals used are those which are best adapted to destroy the various forms of plant and animal parasites which it is desired to attack. Sometimes it is possible to combine two forms of chemicals in one spray and thus make one 
operation serve two purposes. Those sprays intended for leaf-eating insects are classified as poisons and act like all poisons on being absorbed into the digestive tract of the insect. It is generally necessary only to secure an even distribution of such a spray, which usually contains some form of arsenic, over the leaves of the plant. Those sprays intended for insects, such as the scale insects, which do not eat leaves or green parts of plants, are classified as contact insecticides. They kill by suffocating the insect or by their direct physical action upon the body of the insect. Thus they may also be useful against leaf-eating insects as well. These sprays may be merely some powder in a form so minute that it can enter the breathing apparatus of the insect or, in the case of the sucking insects, some oil which can be held in suspension in water long enough to allow it to be sprayed over the plant. Other well-known contact insecticides are tobacco extract (nicotine sulphate) and various soaps, such as "whale oil" soap, made from fish oil. Sometimes poisonous gases are used for this purpose but that is, properly speaking, fumigation and not spraying. The third classification of sprays according to chemicals is that intended for fungous diseases, caused by low forms of vegetable parasites. Anthracnose, rust, mildew, canker, blight, and numerous other descriptive names are given to these diseases but they are nearly all treated alike by the application of a fungicide which is generally some spray containing sulphur, either lime-sulphur mixture or Bordeaux mixture, which is a lime and copper sulphate mixture. The lime-sulphur mixture also acts as a contact insecticide in some cases. Fungicides should be applied very evenly over the whole of the plant from top to bottom and may be used much stronger during the dormant season than would be safe during the growing season.

Forms of SPRAYs. The types of spray classified according to the form in which they are used are two. The most generally used form is the liquid, which generally means a chemical in suspension in water. Most sprays used in liquid form are chosen because of their ability to stay in suspension in water for a considerable length of time without either going into solution or gathering in lumps. This property of staying in suspension is a very valuable one, because it insures an even distribution of the spray material without an excessive amount of agitation to keep the mixture even. There is an increasing tendency to use the dust form of spray in which the chemicals are blown upon 
the plants in the form of a very fine powder which is largely dependent upon atmospheric moisture to make it stick to the plant. Dust sprays are used more often in a commercial way than by the average amateur when protecting ornamental plants, and this form of spray is not adapted to all the chemicals used, as, for instance, the oil and tobacco extract sprays. Sometimes poisons are mixed with bait and spread upon the ground near the plants to be protected, but this again is not spraying in the generally accepted sense of the word.

OUTFITS FOR SPRAYING. There are various spraying outfits adapted to the various requirements dependent on the amount of work to be done and the physical difficulties to be overcome. Probably the best small outfit for the amateur is the knapsack sprayer which can be easily transported and even carried up into the tops of trees if necessary. This consists of an airtight receptacle for the spray mixture, which may be strapped to the back in such a way as to easily allow the pressure to be kept up with one hand while the nozzle attached to a short length of hose is manipulated in the other hand. The best knapsack sprayers have a copper tank holding about four gallons of liquid, a brass pump, and an air pressure chamber which insures a steady stream. They weigh fifty pounds when full of liquid. A cheaper pump of about the same type but small capacity is the bucket pump which can be used with any bucket or pail. This is harder to transport about and not so satisfactory in other ways as a knapsack sprayer. There are various types of hand-operated barrel outfits. Sometimes the barrel is mounted on large wheels so that it can be easily moved about with a pump installed in the head of the barrel, or sometimes a larger hand-operated pump is mounted on a cart beside a barrel or tank. Such an outfit will take care of all but the tallest trees and is about the largest suitable for amateur spraying. It has enough capacity to take care of considerable spraying and enough pressure to insure a fine spray reaching all parts of even large plants. For occasionally spraying small shrubs and such plants as perennials and annual flowering herbs a small hand force pump is a very convenient one to have. These small pumps hold a quart of liquid in a glass or copper retainer.

The power sprayers are operated either by a gearing or sprocket and chain connecting the wheels of the outfit to the pump or by a gasoline engine mounted on a platform together with a pump and 


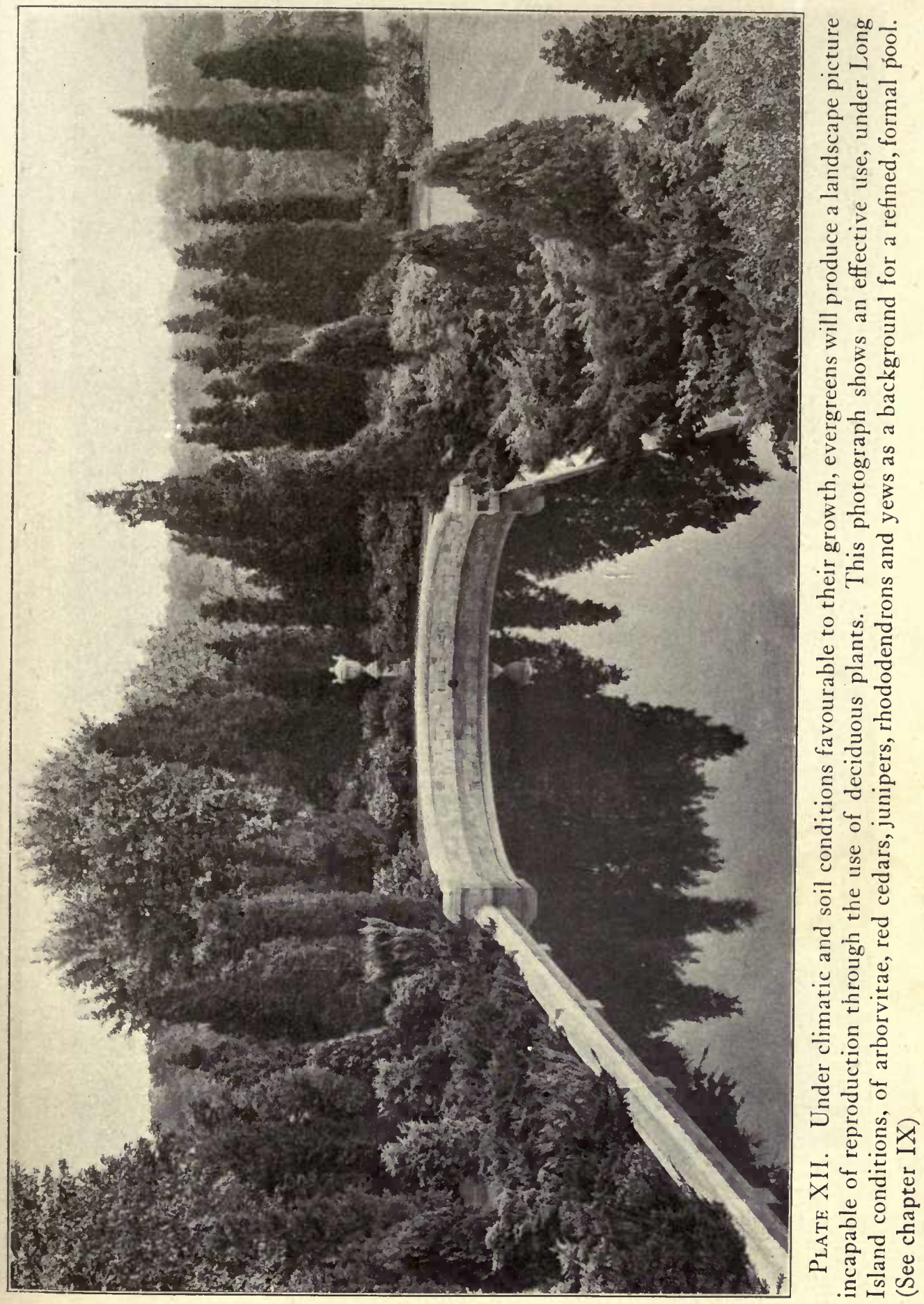




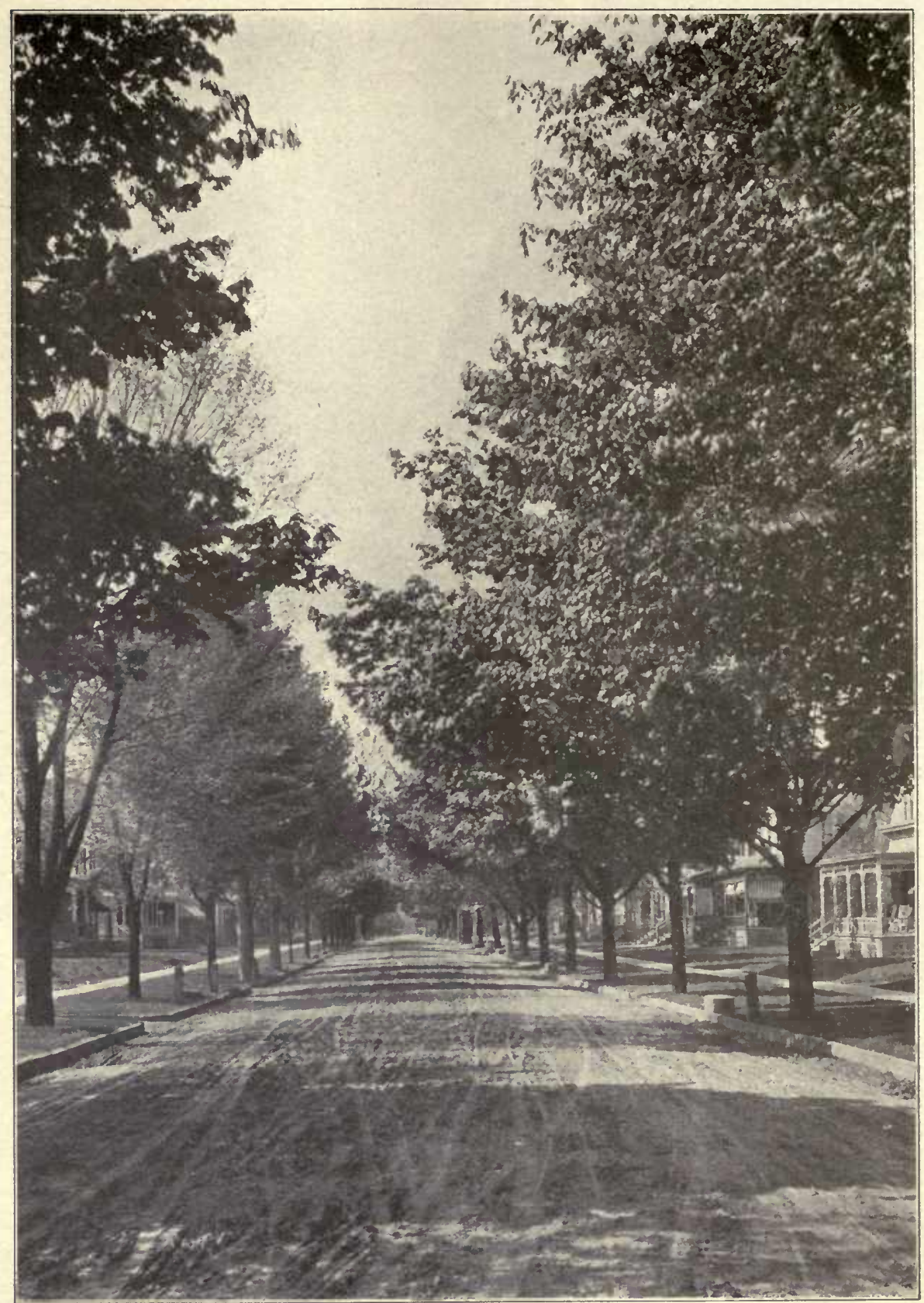

Plate XIII. Carefully selected and planted trees for avenue and street planting provide a uniform and a symmetrical effect together with the inviting shade, all of which are so essential to the standards of modern residential districts. (See page I 6 , group X-A) 
tank. When many trees are to be sprayed a power sprayer should be used in order to secure a pressure which will enable the forcing of a fine spray to all parts of the tallest trees. For spraying tall trees an apparatus which works up a pressure of two hundred pounds is required so that the spray mixture may leave the nozzle in a solid stream and break into a mist as it nears the top of the tree. This is not required for spraying smaller trees or bushes or flowers where the requirement becomes that of producing a fine spray a few feet from the nozzle.

Spray chemicals which are to be used in dust form are applied by means of so-called "powder guns" when large amounts are used on large trees. These are seldom useful on ornamental plants because of the usual proximity of houses or public streets and the consequent annoyance caused by clouds of obnoxious dust flying in the air. Many times, however, sulphur dust or hellebore can be applied by means of small hand force pumps adapted to using the dry dust, or this dust can be applied by sifting over the plants through holes punched in the container in which it is purchased.

Formulas for SPRays. The formulas for some of the simpler insecticides and fungicides will be given here; but it is generally more advisable for the amateur to purchase his chemicals already mixed and in packages of a size adapted for his immediate requirements.

\section{Poisons:}

Paris green-aceto arsenite of copper.

Arsenite of lime.

Arsenate of lead; use $2 \mathrm{lbs}$. to 50 gal. water.

Hellebore; use $\mathbf{I}$ ounce to $\mathbf{I}$ gallon of water.

Porson Barts:

For cutworms I lb. Paris green.mixed with io lb. bran.

For cutworms $\mathrm{I} \mathrm{lb}$. white arsenic and $\mathrm{I}$ lb. of sugar or molasses in $6 \mathrm{lbs}$. of bran.

For grasshoppers use the arsenic, sugar, and bran mixture, placing I tablespoonful every 6 or 8 feet.

For sow bugs or pill bugs use slices of potato dipped in a dry arsenical or a strong solution.

Contact Insecticides:

For plant lice use one $\mathrm{lb}$. soap to 5 to 8 gallons water.

For aphids and larvæ use nicotine sulphate at strength given on package or $\mathrm{r} l \mathrm{lb}$. tobacco stems boiled in 2 gal. water (Dilution of nicotine sulphate is generally $\frac{1}{4}$ pint to 50 gallons of water. The addition of 2 lbs. of soap is desirable).

For scales use 2 gal. kerosene and I gal. sour milk.

For plant lice use 2 gal. kerosene and 1 gal. soft water and $\frac{1}{2}$ lb. soap. 
For scales use in winter only a lime-sulphur spray containing about $20 \mathrm{lbs}$. of unslaked lime and 15 lbs. of flowers of sulphur to $50 \mathrm{gal}$. of water.

For red spider and plant mites use flowers of sulphur as a dry powder dusted over the trees when covered with dew or immediately after a rain.

For hibernating insects use a miscible or soluble oil at the rate of I part of oil to 12 or 15 parts of water.

\section{Fungicides:}

Bordeaux mixture; 5 lbs. copper sulphate and 5 lbs. lime in 50 gal. water.

Ammoniacal copper carbonate; 6 oz. copper carbonate and 3 pts. ammonia in 50 gal. of water.

Copper sulphate is used, with lime to colour it. For killing fungi on dormant plants. Lime sulphur mixture also acts as a fungicide.

Symptoms and Treatments. The following list shows in parallel columns (I) the symptoms which appear upon diseased plants or those with insect pests, (2) the cause and lastly (3) the indicated treatment.

\begin{tabular}{|c|c|c|}
\hline SумРтом & Cause & TREATMENT \\
\hline $\begin{array}{l}\text { Scab } \\
\text { Leaf spot }\end{array}$ & $\begin{array}{l}\text { Fungus } \\
\text { Fungus }\end{array}$ & $\begin{array}{l}\text { Bordeaux or lime-sulphur } \\
\text { Bordeaux, also gather and }\end{array}$ \\
\hline $\begin{array}{l}\text { Leaf curl } \\
\text { Canker }\end{array}$ & $\begin{array}{l}\text { Leaf curl fungus } \\
\text { Freezing or rot fungus }\end{array}$ & $\begin{array}{l}\text { Lime-sulphur or Bordeaux } \\
\text { Cut out and destroy, dis- } \\
\text { eased parts }\end{array}$ \\
\hline Rust & Rust fungus & $\begin{array}{l}\text { Bordeaux, also cut out cedar } \\
\text { apples }\end{array}$ \\
\hline Wilt & Fungus & Bordeaux \\
\hline Twig blight & Fungus & $\begin{array}{l}\text { Lime-sulphur, also cut out } \\
\text { and burn diseased parts }\end{array}$ \\
\hline Mildews & Mildew fungus & $\begin{array}{l}\text { Sulphur dust, also burn } \\
\text { leaves in autumn }\end{array}$ \\
\hline $\begin{array}{l}\text { Fruit rot } \\
\text { Smut }\end{array}$ & $\begin{array}{l}\text { Anthracnose fungus } \\
\text { Smut fungus }\end{array}$ & $\begin{array}{l}\text { Bordeaux } \\
\text { Bordeaux }\end{array}$ \\
\hline Tip burn (leaves) & $\begin{array}{l}\text { Too much water fol- } \\
\text { lowed by hot weather }\end{array}$ & Watch soil conditions \\
\hline Scald & $\begin{array}{l}\text { Freezing and thawing or } \\
\text { fungus }\end{array}$ & $\begin{array}{l}\text { Protect from winter sun and } \\
\text { use Bordeaux }\end{array}$ \\
\hline Gum excretion & Borers & $\begin{array}{l}\text { Protective wash and dig out } \\
\text { borers }\end{array}$ \\
\hline $\begin{array}{l}\text { Sawdust excretion } \\
\text { Leaf discolouration of } \\
\text { conifers }\end{array}$ & $\begin{array}{l}\text { Borers } \\
\text { Red spider }\end{array}$ & $\begin{array}{l}\text { Protective wash } \\
\text { Dry sulphur dușt }\end{array}$ \\
\hline Bark discolouration & Scales & $\begin{array}{l}\text { Lime-sulphur or kerosene } \\
\text { emulsion }\end{array}$ \\
\hline $\begin{array}{l}\text { Leaf curling } \\
\text { Wilt. }\end{array}$ & $\begin{array}{l}\text { Aphids } \\
\text { Cut worms }\end{array}$ & $\begin{array}{l}\text { Nicotine sulphate or soapsuds } \\
\text { Paris green in molasses in } \\
\text { bran }\end{array}$ \\
\hline
\end{tabular}




\begin{tabular}{l|l|l}
\hline \multicolumn{1}{c|}{ Symptom } & \multicolumn{1}{c}{ CaUse } & \multicolumn{1}{c}{ Treatment } \\
\cline { 2 - 3 } Defoliation & $\begin{array}{l}\text { Bag worms or other } \\
\text { caterpillars }\end{array}$ & $\begin{array}{l}\text { Arsenate of lead and burn } \\
\text { winter nests and egg } \\
\text { masses }\end{array}$ \\
$\begin{array}{l}\text { Defoliation } \\
\text { Defoliation } \\
\text { Defoliation } \\
\begin{array}{l}\text { Leaf discolouration of rho- } \\
\text { dodendrons }\end{array}\end{array}$ & $\begin{array}{l}\text { Rose slugs } \\
\text { Leaf beetles } \\
\text { Thrips } \\
\text { Lace-wing fly }\end{array}$ & $\begin{array}{l}\text { Arsenate of lead } \\
\text { Arsenate of lead } \\
\text { Nicotine sulphate } \\
\text { Soap solution, I bar to 20 } \\
\text { gallons. }\end{array}$ \\
\hline
\end{tabular}

\section{SPRAYING DON'TS}

Don't wait for rose pests-spray first.

Don't destroy toads or birds; they save you lots of trouble with insects. Don't mix spray materials unless you are a chemist.

Don't use liquid sprays without keeping a uniform solution by means of agitating the liquid.

Don't whitewash your tree trunks; bugs are not afraid of whitewash. Don't band tree trunks with anything but a preparation and at a time approved by an entomologist.

Don't spray exhibition plants or flowers with a discolouring spray.

Don't neglect to watch the wind when spraying; it may blow poison into someone's face and eyes or over a painted or varnished surface or scatter poison over food crops, like lettuce.

Don't dust your evergreens, coniferous or broad-leaved, with lime; the result will be more serious than any disease.

Don't be bashful about asking your State Experiment Station for help.

Shrubs-Cultivation. The cultivation of shrubs is rather overdone than underdone. The natural habitat of most woody plants includes a ground covering of leaves, forest mold, or herbaceous plants and grass; thus they are protected summer and winter against drought and cold. It is not often possible to reproduce such conditions in a made border; but the tendency should be in that direction. While a certain amount of cultivation at first in a shrub border is desirable, especially in new ground, most shrub borders would benefit by being permanently mulched, or at least by not being dug over too deeply after the roots of the shrubs have become established. The use of 
ground covers among shrubbery is excellent, and they are especially valuable toward the front of the border. When properly mulched and cared for, shrubbery will seldom need watering after the first year or two, but an occasional good soaking during the drought of summer will not come amiss. It is quite essential, at intervals of every two or three years, that the deciduous shrub borders should be carefully gone over and that the ground around the individual shrubs should be thoroughly loosened wherever it is possible to do so without disturbing the root system. At such times considerable fertilizer consisting of wellrotted manure or a heavy application of bone meal should be applied. No quick-acting fertilizer such as sheep manure, dried blood, or nitrate of soda is desirable. In the successful maintenance of the shrub border the object of supplying fertilizer to that border is not one of forcing growth but one of maintaining normal growth.

In the proper maintenance of a shrub border the crowding and dead wood should be removed each year. It often becomes necessary to transplant to other locations and to rearrange some plants where they are becoming too thick in the border plantation, in order to give the remainder of the plants an opportunity to develop normally. We often see shrub plantations which are "leggy." This can be overcome by a proper pruning each year, consisting of the removal, to a height of twelve or fifteen inches above the ground, of at least one-fourth of the old wood (See Plate No. V). This will encourage new growth from the base of the shrub and, where refined mass effects are desired, this method of pruning will eliminate much of the broken and unkept appearance of many plantations. There are instances in which the extremely old and unkept effect is more to be desired, and this process of pruning cannot be applied.

Rhododendrons. Rhododendrons, other broad-leaved evergreens, and conifers should be thoroughly watered during the late fall and never be allowed to freeze for the winter in a dry condition. This is more often the cause of winter-killing than is severe cold. The reason why these plants are more susceptible to injury on this account is because they hold their leaves during the winter months and thus transpiration continues to some degree, and if the plant is not well filled with moisture, a drying-out process occurs and the plant is devitalized. Because of the mass of fine, hairlike roots which find their way through the earth near the surface of the ground, rhododendrons can- 
not endure any considerable dry period or any cultivation of the surface of the ground, in the same manner as that adopted in caring for deciduous shrubs and the deeper-rooted evergreens.

Rhododendrons, Fertilizer For. Rhododendrons and other ericaceous plants should not be fertilized with manure until well established. In the late fall after the rhododendrons have been established one year they may be fertilized by the application of a twoinch layer of well-rotted stable manure over the top of the mulch. This should be repeated each year. Chemical fertilizers are seldom or never used on ericaceous plants. Bone meal should never be used as its bone phosphate of lime is sure to react upon the soil acidity so essential to the successful culture of rhododendrons and allied plants. The use of bone meal has been known to be fatal to these plants. Epsom salt has been recommended as a fertilizer for rhododendrons, but this is probably a mistake and in any event a doubtful procedure because of the chemical nature of this material. As epsom salt is magnesium sulphate and has been used in England to top-dress clover as a substitute for lime, it probably would react in the soil similar to lime and would be injurious to all ericaceous plants.

Evergreens. The greatest problem in the maintenance of evergreens is that of keeping them in a healthy and vigorous condition of growth. There are certain locations where it is essential to use evergreens in order to produce a desired effect. Oftentimes these locations are surrounded by a city environment with a dust-laden and smoky atmosphere which is one of the more injurious factors in the growing of evergreens. If such plants are to be maintained in a healthy condition they should never be watered on the leaves during the heat of the day when the sun is shining. They should, however, be sprayed with a strong force of water at intervals not less often than once each week in order to wash from the surface of the leaves the accumulated dust which if left causes a devitalized condition of the entire plant.

Vines. Vines require but little attention. Wood should be cut back severely in the spring on vines with ornamental fruit. Remove old canes and check any growth that becomes too rank. Shoots that are too long or spoil the general effect should be cut. All climbers 
must be furnished with some kind of support and care should be taken to fasten loose ends.

Usually vines are planted close to foundations. It must be remembered that most foundations are carefully provided with a line of drainage on the outside of the wall in order to readily care for any surface water that seeps into the soil and then later seeps through the wall if not promptly carried away. For this reason, probably, vines require more attention than most other plants in order to keep them supplied with a quantity of water necessary to their normal development. They should also be very frequently fertilized, preferably with bone meal or well-rotted manure. Well-rotted cow manure is an ideal fertilizer for most vines.

LAWNS-FERTILIZING. The maintenance of lawns consists of fertilizing, rolling, watering, and mowing in order to keep the turf in such condition that few if any woeds will have an opportunity to flourish. Fertilizing of a lawn is perhaps one of the most important items of its maintenance, for the reason that few lawns are so well prepared when first made that they do not begin to need additional food material during the second or third year after making. It is difficult to convince those who are developing lawns for the first time that money expended in the proper preparation and fertilization of a good depth of topsoil will do away with the subsequent annual expense necessary to keep a lawn, not correctly prepared when originally made, in the best condition. A good turf requires food in the form of fertilizer, and this food supply must either be provided at the time the lawn is made or it must be constantly applied from year to year afterward (See Page 53). Much thought, labour, and money are wasted in putting a mulch on lawns, only to come back later and cast it away again. It may be wise to mulch a lawn in the fall, but there is more than an even chance that if the area is covered with fresh manure, weeds will be introduced and this will more than off set any real value derived from the mulch. The use of manure as a top-dressing for lawns should be discouraged unless used in the form of a completely decomposed compost. A thick coat of manure is apt to stifle the grass. Lawns should never be mulched with manure during the spring unless with thoroughly rotted manure applied not later than early March. All mulching or top-dressing should be done preferably in the fall so that the weed seeds are killed to a great extent during the winter. It is practically 
useless to apply the manure on frozen ground, for an ensuing rain or melting of the snow may dissolve and carry away either in solution or suspension most of the fertilizing ingredients.

If a lawn is not mowed too late in the season and is not cleaned too completely of the mowed grass, it will generally provide its own mulch for the winter very satisfactorily.

Bone meal alone, especially if not very finely ground, may be used in the late fall at the rate of five hundred pounds an acre, or twelve pounds to $I, 000$ square feet every year. Bone meal seems to be the best phosphoric acid carrier for lawns. Nitrate of soda is the quickestacting fertilizer and may be used broadcast in quantities up to five hundred pounds an acre each year. This quantity must be divided among two or three separate applications. Both blue grass and clover will be encouraged by the use of air-slaked lime as a winter dressing every four or five years, at the rate of one ton an acre. Chemical fertilizers are best applied in the spring as a top-dressing and about five hundred pounds an acre should be applied. A mixture of $5 \%$ nitrogen, $6 \%$ available phosphoric acid, and $8 \%$ potash will produce good results. Equal parts of finely ground bone meal and sifted wood ashes at the rate of one ton an acre make a good spring top-dressing. Kiln-dried sheep manure may be used at the rate of one ton an acre or fifty pounds to $I, 000$ square feet, with excellent results, with the assurance that it will not bring in weed seeds. It should be applied in early spring for the best results.

WATERING LAwns. A properly prepared lawn will not require much watering unless the season is unusually dry or near-by trees are robbing the grass roots. In any event, a few thorough soakings are much more valuable than many superficial sprinklings. The effect of a good thorough soaking is not only more lasting in itself, but also encourages deep rooting of the grass, which, in turn, tends to remove the necessity for watering and also opens up new stores of plant food to the grass roots. It is better to avoid all spray nozzles and whirligig fountains, for, however handsome the effects they may produce in the sunlight, they do not insure a thorough soaking. It does not matter nearly so much at what time of the day a lawn is wet as it does how thoroughly the watering is done. Watering done in the middle of a hot, sunny day, however, is made less effective by reason of evaporation. It also involves some scorching or cooking of the blades of grass as the sun shines 
through the globules or film of moisture upon them. Do not hasten to sprinkle a lawn at the first approach of warm weather as this will discourage the tendency of the grass roots to go deeper in search of the ground water. If the lawn shows signs later in the season of being in distress, give it a thorough soaking. An effective watering should soak the ground to a depth of five or six inches.

Rolling and Weeding Lawns. Rolling of lawns is not resorted to nearly as much as formerly. Probably one good, thorough rolling in the early spring is beneficial, especially on clay land which may have heaved in spots during the winter. Except for this, rolling is of doubtful value, especially because during dry weather it causes loss of moisture through transpiration. Weeds in the lawn indicate that the grass is not properly cared for or has been carelessly seeded. Weeds may appear in a new lawn, especially if manure has been used in the preparation. It is not necessary to pull out the annuals, for if the turf is cut they will not seed themselves. Remove only the perennials, such as burdock and plantain. Tread on the holes thus left and fill them with compost and seed. It is better to weed in the fall, as in the spring crab grass is apt to get into bare spots. Perennial weeds should be cut out with a knife, securing as much of the roots as possible; or a drop or two of gasoline will generally kill the plants. Moss and sorrel in a lawn indicate a sour soil needing liberal applications of airslaked lime. Crab grass causes considerable trouble if once established and care should be taken to remove all portions of the roots.

Enemies to Lawns. Weeds are the most important enemies to lawns. The best way to eradicate weeds in a lawn that is otherwise worth saving is to dig them out, fill the holes with good topsoil, and sow fresh seed. Spraying with chemicals and patent remedies has never proved effective. Angle worms or fishworms may be destroyed by the following spray: Dissolve in two gallons of boiling water one pound of common salt and add one pound of corrosive sublimate. Dilute the above with four gallons of water to make a stock solution. One pint of the stock solution should be added to sixteen gallons of water and sprayed over the lawn. Army worms may be destroyed while young by a spray made by dissolving three pounds of arsenate of lead in fifty gallons of water. This should be sprayed over the lawn until it is white. While white grubs are among the grass roots in late July in 
preparation to emerge as adult beetles they may be crushed by rolling the lawn with a ten-ton roller, but failing this heroic treatment, there seems to be no simpler remedy.

Mowing Lawns. Mowing of lawns should be governed by the use to which the lawn is to be put. Mowing should not be very frequent in hot weather nor very long neglected at seasons when the grass is growing rapidly. Clipping should cease before the grass stops growing in the autumn, so that a long growth may be left on the lawn over winter. A portion of the clippings should be left on a lawn to act as a mulch, especially if the grass is cut often. Enough grass leaves must be left on each plant so that it can maintain its growth, but on the other hand, growth must not be carried to the point of seed production, which, more than anything else, tends to weaken the vitality of a plant. About two inches is the height most often recommended for grass. It is best to leave mower knives set high and mow more frequently rather than to allow grass to grow high and then cut it low and thus remove too large a portion of the leaf surface of the plant, and also expose the soil to the direct rays of the sun. When a lawn becomes run down it is generally better to remake it entirely, instead of wasting money on patching. It is well to consider that if the original grass could not succeed on the soil, new grass will certainly fail.

Perennials-Winter Protection. In general, the better established a perennial is, the less winter protection it requires. However, even though plants would winter over safely if uncovered, they should be protected from the heaving which follows alternate thawing and freezing. In the case of perennials planted in the autumn this is exceedingly important for the first winter. Snow is a good protective covering, but it is rarely that plants will be so covered during the entire winter. It is accordingly advisable to apply a mulch.

Mulching in the fall provides an opportunity for fertilizing as well as protection, especially if good straw manure is used. Straw or cornstalks provide excellent mulch for perennials but both encourage mice. These pests may be killed by poisoned wheat or by pouring carbon bisulphide down their burrows. Where mice are especially troublesome, a compost of leaves, sawdust, lawn rakings, etc., should be used, inasmuch as heavy litter or one containing grain is ideal for attracting animals. Perennials such as lilies, whose crowns are completely underground, require the greatest protection. Perennials such as primroses 
and foxgloves, which carry over some fleshy foliage, must be covered lightly, if at all, to prevent rotting of the crowns. It is desirable to leave dead tops, stalks, etc., on the plants until spring. The tops will protect the plants to some extent over winter and there is also less danger to the plant from premature removal of tops in the fall before the latter are entirely dead. Cultivation should cease in the fall after danger from weed seeds maturing is past. This will discourage too late growth, and any weeds will serve as a protective covering.

It is important that mulch for perennial gardens should not be applied too early. There is a great danger in applying a litter of straw manure or leaves before the warm weather is fully over, and thus encouraging top growth which either rots during the winter or is frozen. Mulch should not be applied until after the first heavy frosts, and preferably not until the ground is slightly frozen in the early winter. The tufted pansy, primrose, and Shasta daisy are very susceptible to injury from a heavy mulch.

Mulch should not be removed until danger from extreme weather is past. The time for removal is governed by local conditions. The mulch should be removed gradually-not all at once-and extreme care should be used in removal in order not to injure or destroy smaller plants or plants which appear late in the spring. Any mulch has a tendency to delay the spring development of the roots. It should be removed, however, before the ground has become so warm that root growth has become definitely encouraged and the sprouts which are starting to grow are becoming weak and spindly.

Dividing Perennials, and Renovating Beds. There are some perennials which are benefited by being allowed to remain permanently in one place, such as peonies, gas plants, and bleeding-heart, but the vast majority of plants are not likely to improve unless taken up from time to time, divided, and reset. This is especially true of plants like the iris and the sneeze-weed which spread underground and form mats, soon exhaust soil fertility, and engage in a severe struggle which hampers their ornamental development. Likewise, crowns of perennials which give the most desirable flowers bloom only two or three seasons and then die. There is also the necessity for renewing the biennials such as foxgloves, canterbury bells, hollyhocks, and sweet williams. Some perennials such as oriental poppies should not be moved but may be divided with a sharp trowel. The general practice is to 
lift and divide the roots of perennials every two or three years. Spreading and shallow-rooted perennials will thrive and flower much better if divided and transplanted each year. If this "dividing" is not undertaken each year the "clumps" become crowded and the individual flowering stocks do not have an opportunity to develop normally. The result is that many dead stocks remain in the middle of the clump and a much inferior type of flower is produced.

Illustrations of this group of perennials which should be divided each season and preferably during the early spring before growth begins are the hardy asters, the sneeze-weed, yellow marguerite, ball of snow, English daisy, and the pompom chrysanthemum. If these plants are not taken up, divided, and replanted in good rich soil, the plants during the succeeding year will not produce large flowering heads, neither will they produce the strong, vigorous growth which they are accustomed to produce. Most of these plants are vigorous growers and heavy feeders and it does not take them long to sap from the soil much of the good food matter which is so necessary to their normal growth.

The plume poppy, Shasta daisy, and yellow marguerite will be surrounded by a large number of young plants, which spread out and surround the parent plant, with the result that a number of inferior plants occupy the space which should be occupied by only a few fine, thrifty specimens, providing the parent plants are not divided and transplanted each year. With the yellow marguerite especially, it is much better to discard the old roots and to preserve in the dividing only those roots which are the result of the previous year's development as offshoots from the parent plant. Many times the seedlings that spring up around these plants are equally as preferable if transplanted and given ample space to develop normally.

In the group of plants which should be divided at least every two years are included a few of the more vigorous types of the garden phlox together with the boltonia and the bee-balm.

There is a group of perennials which should be divided on the average of once every three years. They will not be benefited through the process of being divided at more frequent intervals. This list includes the common garden phlox, painted daisy, most types of the larkspur, the lily-of-the-valley, a few asters, and the hardy sun-flowers. The common impression with reference to the lily-of-the-valley is that it should not be divided or transplanted after the time of transplanting the original plants. Those persons who have had an intimate acquain- 
tance with the flowering habits of this plant state that it should be divided at least once every three years if an abundance of large blooms is to be obtained.

Such plants as the larkspur should be divided with great care every three or four years and each division of this plant should be left with a good crown attached to which is a quantity of good fibrous root growth.

The greatest success in dividing perennials will be attained with those plants whose roots can be readily pulled apart with no severe ruptures. Those plants which have heavy roots like the larkspur and some of the irises should be subdivided with much greater care. Biennials will renew themselves by seeding if the soil is not disturbed around them to any great extent. A few perennials such as the yellow marguerite and some of the hardy asters will also renew themselves each year by seeds dropped from the parent plant. Every perennial garden is benefited by a thorough spading over at least once in three years. When a garden is filled with perennials the spading does not in general reach deep into the soil, nor does it cover the entire area. The best soil for these plants is one which is friable and not too compact. This is the reason for spading every two or three years.

Plants may be dug up and separated by hand or thinned out in the beds by cutting with a clean, sharp spade or trowel and removing the excess plants. Replanting should be done in fresh soil if possible, or some new soil and bone meal would better be worked in. Care should be taken in the replanting that the crown of the plant is not smothered. It is equally fatal to the plant to be set too low or too high. Divide and replant in the spring those fall-blooming sorts which continue in full bloom until late in the season, such as chrysanthemums and anemones, and all fleshy-rooted plants except the peony. (For the peony and the iris in particular, and for planting perennials in general see Pages 39 and 47.) The best time of the year for lifting and separating perennials in general is probably the fall. The early-flowering perennials like some of the irises and the leopard's bane should give the best result by dividing and transplanting shortly after they have completed their flowering period. One objection to fall planting, however, is that the smaller plants heave out if planted too late or are apt to get lost during mulching or in the "cleaning up" work of the spring. Plants with heavy tops or fleshy roots in general, except the iris and the peony, are more liable to rot if planted in the fall. If the planting of 
them is done at this season it should be begun in the latter part of August, if possible. The regular mulching, so necessary for all plants set in the autumn, should not be forgotten when the winter comes on.

During the summer a fine mulch of some sort may be kept on a perennial border to good advantage as it prevents loss of moisture, saves labour otherwise necessary in cultivating, stops spattering of mud over the leaves of smaller plants, and prevents baking of the soil after rains.

Fertilizing Perennials and Annuals. Perennials need a great deal of food and should have plant food to restore soil fertility. Such' heavy feeders as phloxes and peonies should receive applications of bone meal and liquid manure. Such applications when the plants are in bud will frequently improve the size and quality of the flowers. Manure for fall mulching will also enrich the plants. The finer part can be worked into the beds during the spring, but care must be taken not to injure or destroy roots or smaller plants. Peonies and irises in general, like all plants with thick, fleshy roots or rootstocks, are sickened by manure. Bone meal is perfectly safe to use and is in every way the best fertilizer for them. On the other hand, the Japanese irises, with their fibrous roots, revel in cow manure. They, like iris longipetala, are indifferent to lime which to all other moisture-loving irises, with the exception of the spuria group, is objectionable.

Beds must be kept entirely free from weeds until fall. Where mulch is not maintained around the plants cultivation should be kept up, especially after a rain, to prevent evaporation.

In the development of the annual flower garden the soil should be thoroughly spaded over each spring and well pulverized. A good coating of well-rotted manure should be thoroughly spaded into the soil to a depth of four inches to eight inches. During the flowering season of these plants it may become necessary, on account of the lack of sufficient food, to supply some quick-acting fertilizer such as sheep manure or dried blood which will force their growth and assist greatly in developing larger and more abundant flowers. A slight sprinkling of sheep manure or dried blood around each of the plants will be sufficient. It may be advisable to repeat this fertilizing operation at intervals of three or four weeks during the flowering season. Nitrate of soda is sometimes used as a plant stimulant. It is much more dangerous, however, than either sheep manure or dried blood because an overdose is very apt to burn and injure the plants. 
Watering of Perennials. Watering must be attended to, especially during dry spells. One good soaking a week is much more valuable to plants than many light sprinklings which do not wet the soil to any appreciable depth. On sandy and very light soils it will be necessary to water thoroughly every day or every second day during the dryest part of the season. Where it is not possible to water all the plants thoroughly at one time, divide the beds into sections and water the various sections in rotation. Watering in the later afternoon or evening hours has a more lasting effect than during the hotter portion of the day. Watering can be overdone as it can be carried to the point where the soil becomes water-logged and will consequently sour. Too much superficial watering of open-ground plants induces surface rooting which is not satisfactory, as such plants do not have access to large stores of food, and consequently cannot withstand drought successfully. Transplanted perennials should be watered thoroughly and left alone a few days till they become somewhat established.

The statement is sometimes made that water from wells is too cold to be suited for watering plants, and also that such water often lacks chemicals which serve as plant food. On the contrary, successful gardeners often water plants at midday on hot summer days in order to gain the cooling effect of the water when it is most needed. It is also believed by some experienced observers that water falling on the soil reaches the soil temperature very quickly after being absorbed and in all but a negligible number of instances, before it reaches the roots of plants. With regard to the question of the amount of plant food contained in water from a deep-driven well as compared to the amount found in surface water such as that flowing in a creek or river there seems to be little reason to think that water from wells is lacking in plant food to such an extent as to make it less valuable than surface water. It is nQw agreed that surface water contains more solid matter in suspension while subterranean water has its load of solid matter in solution. Therefore the plant food which occurs in water from a driven well differs from the plant food found in river water merely in being more likely to occur in solution rather than in suspension. The water which is taken from artesian wells is not always sterile and often contains nitrates in large quantities due to the reduction of the nitrates which occur in deep layers in the soil. When this water is used for irrigating the surface layer of the soil, the nitrifying bacteria 
change the nitrites back to nitrates. In regions rich in humus, ground water often contains organic as well as inorganic matter. Well water may and often does contain plant food which is very valuable in the form of nitrates or ammonia.

Removing Seed Pods and General Care. Summer care of perennials consists of removing seed stems and dead flowers. It is extremely important to remove dead flowers at once, as formation of seeds weakens a plant. And with many plants, such as the larkspur and foxglove, new flowers also will be produced if the old flowers are -removed immediately after blooming. There is a considerable difference of opinion concerning the general maintenance of the larkspur. Some persons think that the stock of this plant should be cut down to a height of four inches to six inches immediately after flowering, other persons feel that it should not be cut to a height of less than twelve inches to fifteen inches. The author's personal experience has been that if these plants are cut back immediately after flowering to a height of four inches to six inches new shoots will be developed which will not attain the height of the original plant but will develop excellent flowers during the latter part of September. Support tall-growing plants with neat stakes. In this class are asters, boltonias, and larkspurs. Do not delay the staking until the plants have begun to fall over. Bare spaces among plants in a border should be filled with annuals, if necessary, as this will not only improve the general effect but help also to keep the ground shaded and cool, and provide bright spots of colour after the first flush of bloom among the perennials is over. Bare spaces may be filled by bringing in plants from a reserve garden where they may be held in pots. New varieties of perennials and biennials should be propagated and transplanted to the bed or border to replace plants that run out or begin to fail. Seedlings will spring up from many plants, such as anemones, marguerites, hollyhocks, and campanulas, when seed pods are allowed to form. Such plants can be used to fill up open spaces.

Diseases of Perennials and Control. Perennials, taken as a class, under fairly favourable conditions are not particularly susceptible to disease. In general, when diseases attack perennial plants, the safest thing to do is to throw them away. Aphis and minor insect troubles may be easily controlled by spraying. 
The following plants, if attacked by leaf spots or mildews, may be saved by fungicides (See Page 77):

Alyssum (mildew).

Anemone (root decay and rust). Destroy affected roots.

Aquilegia (mildew and black spot).

Campanula (red and brown rust). Keep away from pinus rigida.

Chrysanthemum (leaf spot or powdery mildew). If rusted, plants should be destroyed.

Convallaria (stem rot). Burn affected plants.

Coreopsis (mildew).

Delphinium (black spot on leaves). Remove and burn.

Ferns (tip blight).

Hollyhock (leaf spot). If attacked by rust or anthracnose destroy the plants.

Iberis (club root). Use lime in soil.

Papaver (mildew).

Peony (stem rot, leaf spot, botyrides).

Phlox (leaf spot and powdery mildew, and stem canker).

Sedum (leaf spot).

Thalictrum (red spot).

Veronica (leaf disease), (leaf spot).

Violets (leaf spot and leaf blight).

Root rot of violets and nematodes on the roots require soil treatment and sterilization.

Bulb spot of irises should be treated by-soaking the bulbs for one hour in formalin solution, consisting of one ounce in two gallons of water. Root rot which is found usually only in the midst of an old matted clump is overcome by breaking the rhizomes from the clump, cutting off the decay, and planting in new soil with a watering of potassium permanganate, only enough to make the water of light pink colour.

Maintenance of Various Kinds of Gardens. No attempt should be made to develop a garden of any kind until a careful analysis has first been made concerning the probable cost for future maintenance. This applies equally as well to the extensive estate as it does to the detailed flower garden and to the average residence property. Plants are growing things and require constant attention in greater or less degree varying with types of development, whether of extreme formality or extreme informality, intended to produce certain effects. Many require an extremely abnormal quantity of labour and others require a minimum of labour for their average maintenance. 

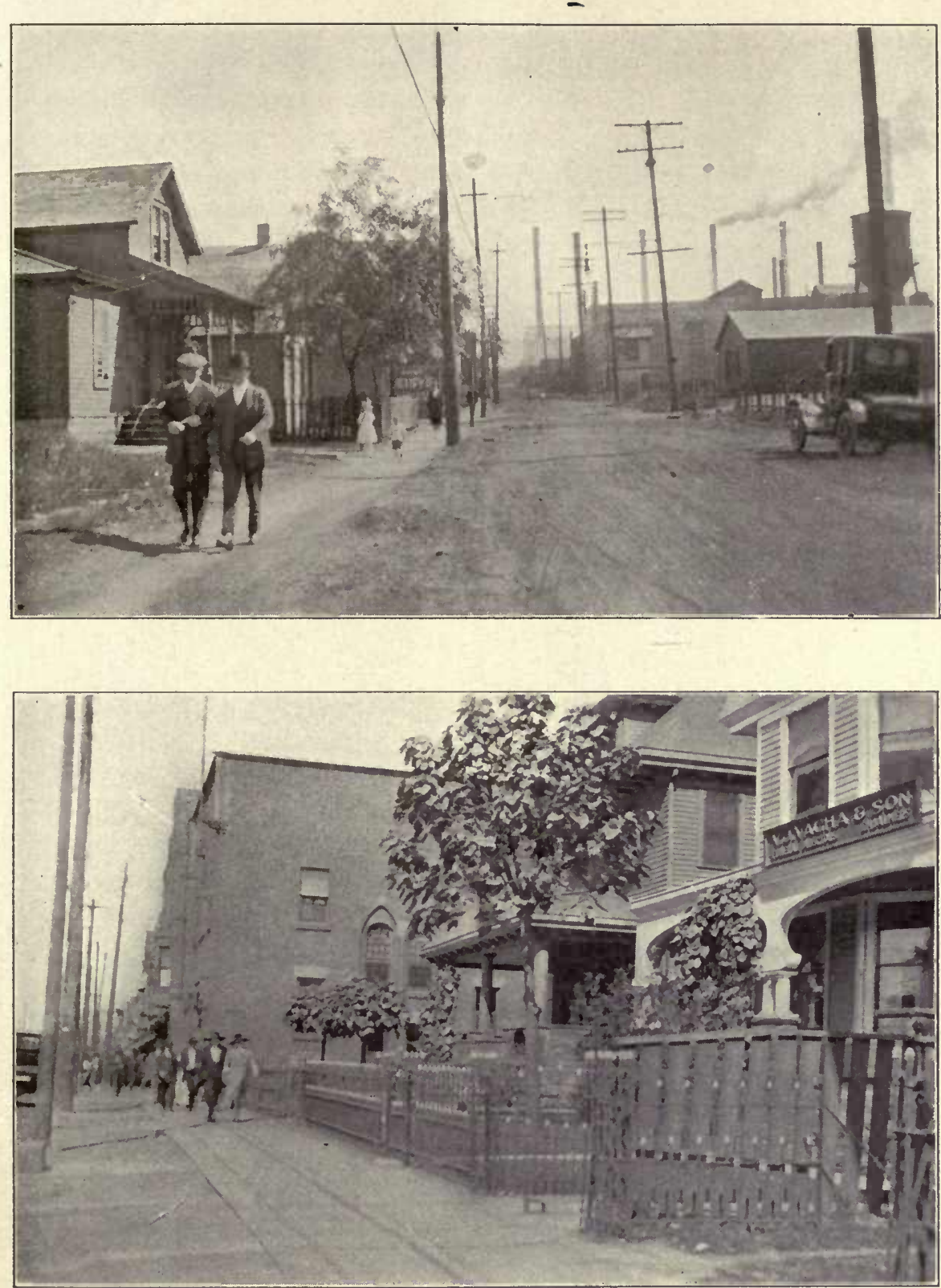

Plate XIV. The list of trees and shrubs which thrive in the congested city districts where soil conditions are poor and the air is polluted with smoke and dust, is limited to a few kinds, of which the tree-of-heaven, locust and catalpa are typical. (See page II9, group XI-A) 


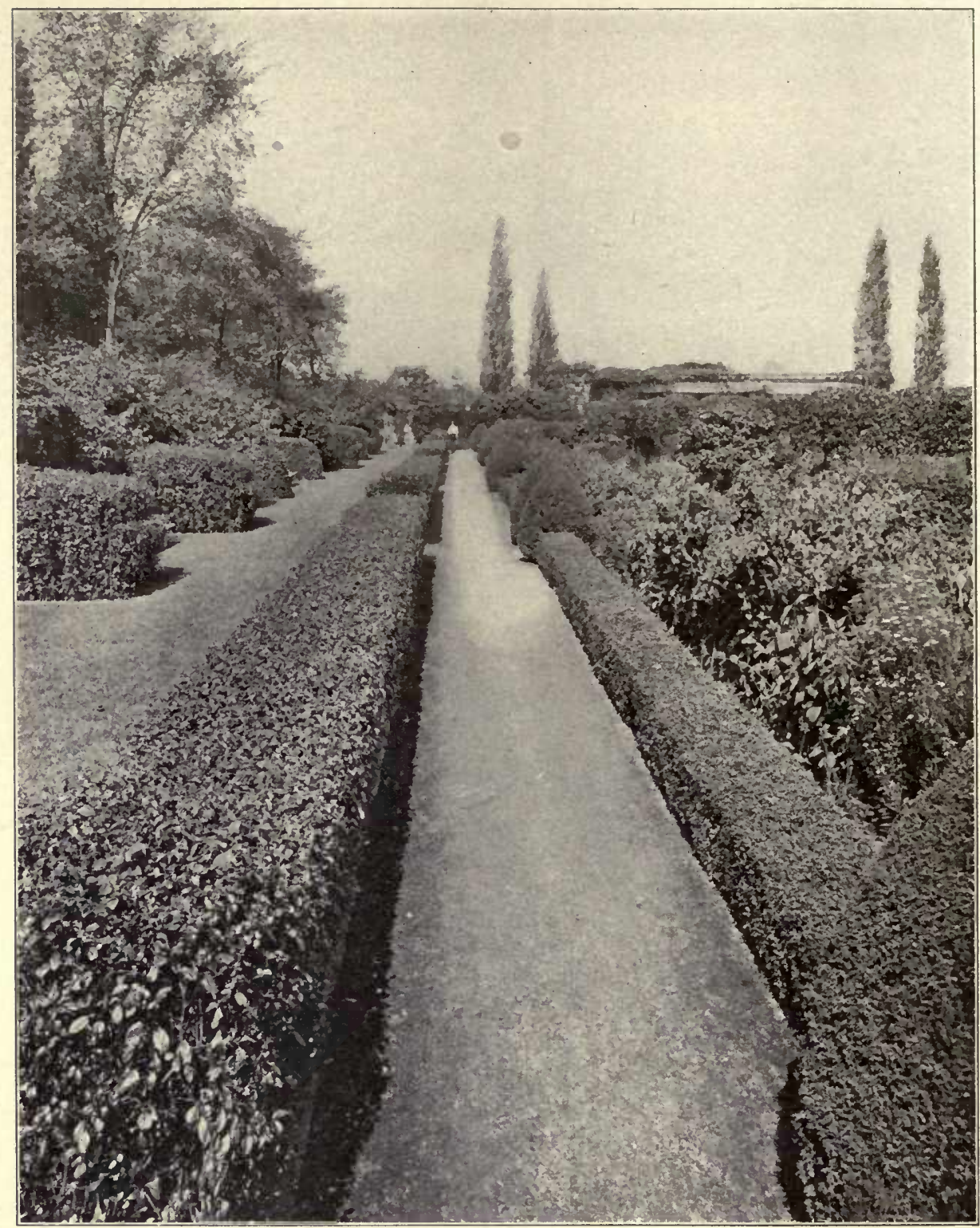

Plate XV. An interesting use of hedges to frame one side of the refined formal garden. Japanese quince on the left side of the walk, Japanese barberry against the right side accented with sheared retinosporas, and buttresses of Japanese quince and Amoor River privet on the extreme left against the vinecovered wall, form the features of this composition. (See page I24). 
Wild Garden. Many people labour under the impression that the woodland wild garden demands very little, if any, attention on the maintenance end. The maintenance of a woodland wild garden is a problem, to those who really understand its development and success, of almost as much importance as the maintenance of the more refined formal garden. It matters not what the garden may be, either the woodland wild garden or the refined garden, undesirable weeds and grass will develop if it is not given the necessary attention and cultivation. The wild garden cannot be cultivated as deep or as frequently as the refined flower garden. Not only must the owner ward against the development of weeds but he must watch carefully to be certain that those types of plants which are more vigorous growing or which seem to be best adapted to their particular location do not spread or unnecessarily crowd out certain other desirable plants less vigorous in their habit of growth and less apt to thrive in the competition to which they are subjected. There will be places in the wild garden where soil conditions are not exactly as they should be, and where soil should be renovated or manured and where additional leaf mold soil should be added.

Annual Flower Garden. Careful and frequent attention must be devoted to the maintenance of annuals during the growing season and especially during the flowering season if the best success is to be obtained with this type of garden. Those annuals like the mid-season and late asters need only normal care. Such plants have but one flowering season and it is rare that any secondary flowers are developed on these plants through intelligent cutting, as is the case especially with the snapdragons and also with calendulas, marigolds, and pansies. The snapdragon perhaps is one of the most valuable flowering annuals for a long period of bloom. It will begin its bloom in late June or early July and will continue to bloom until frost retards its growth. Such plants however, will not produce an abundance of fine flowers if encouraged to persistently produce flowers throughout the entire growing season. The snapdragon will produce the best flowers if given a rest during some part of the summer. For instance, plants which begin flowering in late June or early July should be permitted to flower for four or five weeks. They should then be severely cut back to a height of four inches to six inches and a new growth permitted to develop and produce flowers during late August and September. 
The one most important duty in the successful growing of annual flowering plants, in order to continue their period of bloom, is to keep all portions of the plant from developing seed pods. Those branches which have produced flowers should be removed as soon as the bloom has ceased. Most of the annuals like the calendulas and marigolds are encouraged to produce more bloom through this process of keeping seed pods removed and the branches severely cut back. Other annuals like the annual larkspur, the matricaria, the annual baby'sbreath, and the bachelor button will not develop a secondary growth, and must therefore be planted in successive sowings to secure a continuous supply of flowers.

Refined Formal Garden. The refined formal garden is developed through the use of various types of perennials and annuals. The same rules apply to the general maintenance of a garden of this kind that apply to the general maintenance of perennials and annuals. This type of garden however, unlike the other types of gardens, rock garden, wild garden, informal garden, etc., should, if developed, be perfectly maintained. A formal flower garden for its real success depends upon well-defined masses and definite major and minor axis lines. Extreme care should be devoted to the clipping of all hedges and the maintenance of the outlines of the definite masses of plants: All turf borders and walks should be neatly trimmed and carefully edged and little if any of the informal loose effect, so common to the informal garden and to the wild garden, should be permitted. The author attempts to discuss this question together with the question of maintenance pertaining to the other types of gardens in order to make clear that in the selection of the plants in landscape work the item of subsequent maintenance is one of the important factors in the successful development of the formal flower garden to an even greater extent than in other types of gardens.

Informal Flower Garden. The informal flower garden requires less maintenance care than the formal flower garden. It is not so essential that the masses of plants and the outline of walks should be as carefully defined. There is no garden, not even the wild garden, that does not require constant attention for the best results. The same questions of maintenance apply to the informal garden in the same way that they do to the maintenance of perennials and annuals. The 
only point which the author wishes to make clear is that from the very informal nature of the garden the question of maintenance cost is not as great as the maintenance cost of the formal garden.

Rock Garden. Many persons labour under the impression that the rock garden does not require constant attention. To successfully develop a rock garden planting requires more thorough knowledge of plants than the development of the refined flower garden or the informal garden. The reason for this is that those plants which succeed in the rock garden development are much more uncommon than the plants which succeed in other types of gardens and less opportunity is afforded for intelligent study of their habits of growth and flowering characteristics. The rock garden, like the wild garden, is often thought of as a garden in which plants enter into a competition for "the survival of the fittest." Quite to the contrary, intelligent maintenance must be applied in order to eventually develop the plan as originally intended. Most of the plants adapted to the rock garden are the dwarf, slow-growing types which continue to become larger from year to year. They must be kept within bounds by intelligent pruning which will not destroy their effect. Occasionally many plants are introduced into the rock garden planting which require much more attention on account of the water which is necessary for their normal growth. A rock garden is not a garden from which flowers are to be picked. The period of bloom is usually the period when the plant is most valuable for its effect in the garden and the flowers should not be removed at that time.

Cutting Garden. The cutting garden is perhaps the most simple garden and the easiest garden to maintain. The only problem of such a garden is to provide easy access to plants placed in definite rows with sufficient space for easy cultivation. In a garden of this kind plants are permitted their freedom of growth and the object is to feed them heavily with fertilizer in order to produce the most desirable flowers which are to be cut at a time when the plants are at their height of bloom. The problem of maintenance is one of supplying sufficient fertilizer to keep the flowers growing vigorously, of cultivating them frequently, and watering freely.

Rose Garden. The object of the average rose garden is to produce an abundance of bloom and to produce large individual flowers. The 
rose garden for the best success of the plants requires careful maintenance. The hybrid roses, which are usually grafted stock, revert quickly to the original type if suckers are allowed to develop and not kept within control. The rose garden beds should be kept clean of other plants unless provided with English tufted pansies or portulaca. If the rose garden is a part of some formal garden development and the beds are edged with any small hedge or edging plant such as the alyssum, then extreme care should be exercised to be certain that these plants are kept neatly trimmed and within definite bounds. One of the important problems in the maintenance of the rose garden is that of knowing the different types of hybrids and how these plants should be pruned in order to encourage the production of more flowers or of larger flowers. This question is too extensive to be discussed in the short space available, but there are numerous books which discuss at length the development and care of the rose garden.

Fertilizing Roses. When rose garden beds have been properly prepared by the introduction of plant food in the form of manure, bone, and lime, all that remains to be done in the way of fertilization may be easily attended to by top-dressing from time to time. Liquid manure should never be given in dry weather without first thoroughly wetting the soil with plain water, but it may be used at frequent intervals provided it is not too strong. Dried blood may be used either in water or dry at the rate of one ounce to the square yard during May, June, and July if hoed well into the surface soil. Wood ashes and bone meal in small quantities may be used in a similar manner after growth starts. These dry fertilizers should be used only just before a good rain or should be followed by a thorough soaking with the hose.

WALL GARDEN. The wall garden is perhaps one of the most interesting types of gardens. A wall garden should never be attempted unless those responsible for its maintenance feel certain that the proper kind of intelligent maintenance care can be devoted to such a garden. A list of plants which are adapted for producing wall garden effects is small. It is not so much the question of quantity of maintenance as it is the question of the degree of intelligent maintenance which makes for the failure or success of the wall garden. The greatest success is attained with wall garden development when those responsible for its maintenance make it a special point to thor- 
oughly familiarize themselves with the growing habits and the requirements of wall garden plants. If this is not done the garden is very apt to deteriorate into a normal type of garden with a few persistent weeds of various kinds and some of the more common and easily growing annuals like alyssum growing from the crevices of the rocks.

Water Garden. The water garden is the one garden which requires less attention than any other garden when it is once correctly developed. The main problem is that of keeping a supply of water which is in no degree stagnant and in knowing the requirements for the fertilizing of aquatic plants to produce the best development.

(See Page 220). 


\section{WINTER PROTECTION AND MULCHING}

Reasons for Winter Protection. Winter protection is necessary under the following conditions: First-When a plant is removed from its natural habitat to one more severe; Second-When plants are not sufficiently hardy to withstand the new climatic conditions or exposures; Third-When it is desirable to retain ground moisture during the winter for planting on exposed places, mounds and banks. Fourth -When plants (especially evergreens) are transplanted into a stiff clay soil under climatic conditions where they will be subjected to considerable freezing and thawing and it becomes necessary to protect them against heaving; Fifth-When plants, especially rhododendrons and other evergreens, must be protected against wind and sun which cause so much damage on account of excessive evaporation of moisture from the leaves at a time when no moisture is being taken into the plant through the root system. Continued, steady cold and a permanent covering of snow are generally sufficient to tide a plant through the severest part of winter, but an open winter, followed by severe cold, or the alternate freezing and thawing in spring, will work havoc. Mulching, therefore, is equally important, not only to control sudden changes in temperature in extreme weather, but also to maintain a cool, even temperature in early spring.

One of the common impressions in connection with mulching for purposes of winter protection is that plants are really being protected against extreme cold. Nothing could be farther from the truth. It is not possible to protect plants against freezing conditions, especially during the cold winters of our north when frost enters the soil to a depth of two to three feet. Under such conditions no normal depth of mulch consisting of rotted leaves or manure could keep frost out of the soil surrounding the roots of the plants.

The real reason then is a different reason from that of being a desire to ward off a freezing condition. It is the desire not of warding off the cold but of preventing abnormal evaporation of moisture from the 
leaves and especially from the lower part of such plants as the roses which are particularly sensitive to this type of evaporation. It is for this reason that plants which do not have well-ripened wood like the golden bell and certain varieties of the deutzia are subject to injury because of this evaporation. Other plants like the bush honeysuckle and lilacs which succeed in developing thoroughly ripened wood before winter approaches do not suffer so much. There are two important sources of injury (outside of the gnawing by animals) which can cause plants to be injured during the winter months and as a protection against which mulching is necessary. The first is abnormal evaporation from the roots and stems of plants that are in exposed situations, and the second a liability of being heaved from the ground where a clay loam soil is subjected to violent changes of freezing and thawing.

It is for this same reason that standard roses and climbing roses are frequently lost during the winter months because they are protected by a thin covering of straw, and evaporation is allowed to continue, when, in reality, they should be taken down and buried in soil which remains moist throughout the winter months and thus protects the stems against evaporation.

Sources of Winter InJury, and Remedies. One source of winter injury is a heaving in clayey soils which exposes roots of small and newly transplanted plants. This may be remedied by applying a ground mulch of straw litter or manure over the entire area immediately around the trees and covering the area of root growth. Another source is premature activity of the sap, due to the warmth of the sun's rays. If the ground is frozen hard and deep, and sun and severe winds strike evergreen plants they will "scorch" or dry out because sap cannot flow from the roots to take the place of that evaporated. Many evergreens which are exposed to severe winter conditions are in reality killed during the months of January and February; but the damage done does not become evident until time for spring growth to begin during the months of April and early May. If the evergreens which have been killed during the winter months in the nursery are dug and shipped to owners of estates at a time prior to spring growth and prior to a time when it is possible for a nurseryman to determine whether or not the plant is in a normal growing condition, plants killed in this manner (because of the lack of winter protection) do not show the injury until the growing season, at which time, with the beginning of warm growing weather, the 
leaves turn brown. Conditions of this kind often follow a severe winter. During a severe winter in which successive freezing and thawing conditions are a common occurrence evergreens are apt to be seriously damaged. Under such conditions it is the heat which causes the worst injury to the evergreens during these winter months and, as commonly believed, this is not injury due to excessive cold. A succession of extremely cold nights and warm thawing conditions during the day causes excessive evaporation from the leaves which, as heretofore mentioned, cannot be replaced through the dormant root system, the soil surrounding which has not been sufficiently warmed to excite growth. This evaporation may be stopped by shelter fences or by wrapping the plants with straw "overcoats." Care should be taken, however, to avoid wrapping too tightly, or injury to the plant will result from heating of foliage. Boxwood hedges also, particularly when young, should be covered to prevent winter injury in sections of the country where the temperature may fall as low as zero during the winter months. Such hedges may be boxed, or they may be banked with cornstalks or coarse litter and also with evergreen boughs. One of the best protections for boxwood hedges (as well as broad-leaved evergreens) is to be certain that they have a thorough soaking, especially during a dry fall, immediately before the freezing weather begins.

Mice often injure plants, and where this occurs mulching should be delayed until cooler weather, when the rodents will have nested elsewhere. Poisoning may be resorted to by placing poisoned wheat in drain tiles among the mulch. Mice and rabbits will gnaw certain shrubs and fruit trees, such as quinces, spireas, forsythias, etc. Such plants should be protected, especially the first year, by tar paper or burlap if mice are present. Wrapping should begin slightly below the surface of the ground at the base of the tree, and extend to a height of two feet. The author is advised on good authority that where there is excessive danger that the base of certain shrubs and fruit trees will be gnawed by mice and rabbits, an excellent method of protection is that of mulching these hedges with coal ashes to a depth of three to four inches around the immediate base of the plant. The gritty condition of this material is evidently objectionable to rabbits and mice and its use has saved a number of valuable hedge plants.

Perennials-Winter Protection of. Perennials should have a good mulch of well-rotted manure, straw, leaves, etc., applied just be- 
fore freezing weather, in a late fall, and at the beginning of freezing weather in an early fall. In reality, it is not as essential, as we often assume it to be, that perennial borders, regardless of the material they contain or the type of soil in which the perennials are planted, should be mulched during the winter months. There are hundreds of gardens which pass through the winter without any protection whatsoever being given to the plants. These gardens are not, however, those which are developed on clay loam soil. The general feeling is that plants are mulched and given this winter protection because otherwise they would not be hardy. Quite to the contrary, most of these perennials are hardy, and as a matter of fact it is rarely possible that any amount of mulching such as is ordinarily provided for the garden can make any perennial hardy which is not by nature perfectly hardy in the climatic and exposed condition where it is growing. Every person who is responsible for the mulching of a perennial garden should use only a loose texture of material for mulching purposes. When mulching perennials place stakes beside small plants and those which begin growth late in the spring. This will prevent any loss when the mulch is spaded in or removed in the spring. Perennials with persistent leaves should not be mulched with anything which will mat down. This applies to foxgloves, hollyhocks, sweet williams, and violas. Cornstalks and leaves which drop late are best for such a mulch. Boxes filled with leaves may be inverted over plants; but when this is done the top should be watertight or damage may follow. Some tender plants such as pansies and snapdragons may be carried over the winter if a heavy mulch is applied before freezing weather appears.

Bulbs and Lilies-Winter Protection of. Eremurus and the tenderest lilies should be protected by a mound of ashes which will help shed water and retain an even temperature. All bulbs should be mulched with leaves, manure, or litter. If bulbs are planted in the heavier types of soil it is quite necessary to cover the crown with a good mulch which will maintain in the ground a more even temperature and will lessen the possibility of injury to the bulbs because of sudden fluctuations of temperature (freezing and thawing conditions), which cause heaving of the soil. It should be borne in mind that bulbs start growth very early in the spring. If the mulch is left on the surface of the ground until after the bulbs have started growth, especially in a sunny exposure, then the bulbs become spindly and strong plants 
and flowers do not develop. In the planting of crocuses late in the fall it is advisable to cover the ground immediately with some fresh straw manure which will keep the temperature of the ground from becoming too cold until after the bulbs have developed slight root growth.

Vines-Winter Protection of. Vines and various climbers, such as climbing roses or trained fruit trees, when growing against a southern or western wall, should be protected by burlap from the winter and early spring sun, which may cause growth to start too soon. Very tender vines, such as jasmine and some clematises and roses, can best be taken down and buried, especially where local climatic conditions or exposures are severe. When plants are so treated they should be allowed to lie on the ground for ten days or two weeks after they have been uncovered in the spring. This allows the canes time to harden-off.

Roses-Winter Protection of. Hybrid Teas and Hybrid Perpetuals in most winters can be safely carried over by hilling up the soil about the plants to a height of six or eight inches, thus covering the lowest six buds, and then covering the plants with hardwood leaves eighteen to twenty-four inches deep. The leaves should be held in place with cornstalks or brush to prevent their being blown away. A three or four inch blanket of stable manure may be applied before the leaves are used and a windbreak of boughs of pine or fir trees, or cornstalks may be substituted for the leaves if manure is used. Cultivation should be stopped in September to discourage late growth, but the plants should be thoroughly soaked with water in October, just before hilling them up. This protection should be removed piecemeal in the spring, to gradually harden-off the plants.

Standard roses may be protected by laying them on the ground and treating them as tender vines. This is the most satisfactory method. They may also be wrapped with straw and burlap, or boxed, with a filling of leaves within the box. The safest method in severe exposures is that of burying them.

Rhododendrons-Winter Protection of. Rhododendrons, other broad-leaved evergreens and, to a certain extent, all other evergreens, are apt to be scalded in winter by the morning sun shining through the coating of ice or snow upon the leaves, unless they are 
shielded. They should be mulched also during both winter and summer. The mulching of rhododendrons for summer is done for the purpose of providing a thin layer of leaf mold which will produce as nearly as possible the natural conditions of the undisturbed soil in the woods and fields where rhododendrons grow. Mulching for winter protection is effected by banking the plants with a deep layer of leaves. These leaves prevent excessive freezing and possible heaving of the soil around the roots. Rhododendrons are further protected by building a screen of evergreen boughs or of cornstalks entirely around the plantation, but especially on the exposed side. A portion of the leaves used in the winter mulch can be left when the mulch is removed in the spring. Under no conditions should an attempt be made to spade this mulch of leaves into the ground in the spring. It may be loosened slightly with a fork, but because this plant has its roots so near the surface the ground around the roots, below the natural surface, should not be disturbed.

Trees and Shrubs-Winter Protection of. When mulching trees care should be taken to extend the mulch out as far as the roots extend, or at least as far as the ends of the branches extend. Most of the Japanese flowering peaches, cherries, etc., need a four-inch root mulch every winter in severe climates. Boxbushes, many other evergreens, and some deciduous material should be tied in winter. This is done to keep the plant from splitting under the weight of the heavy snows. Bands of rye straw or burlap are better than string for tying. Shrubs and trees when planted in groups or plantations, being thus close together, will protect each other to a considerable extent.

When plants are of doubtful hardiness, screens may be erected for protection on the most exposed sides, or completely surrounding the plants. Such screens may be made of poles to which is attached brush or burlap. Another method is to make a screen of boards. Screens are frequently used to protect evergreens, trees, and shrubs. A shed without sides also may be constructed over such plantings. This is done to avoid loss by drip from buildings, or breakage from the weight of snow. Shrubs may be wrapped with straw or burlap, the covering being bound with raffia or twine. A pole is usually placed inside the wrapping to prevent the plant from bending or breaking. It is preferable, however, to plant more hardy types of material, because screens are extremely unsightly unless the plants are in an obscure location. 
LAWns-Mulching of. After the first year it is generally not necessary to protect lawns in winter. If a mulch is desired use straw or well-rotted manure old enough so that there is no danger from weed seeds. In the spring the coarse manure should be removed and the finer portions pressed in with a heavy roller. Heavy, coarse manure is apt to suffocate the growing grass and leave bare spots on the lawn.

General Conditions. Fall-planted material, especially perennials, and in the heavier soils, should be well protected during the first winter with a mulch of strawy manure or hardwood leaves. Compact or fresh manures should be avoided. Fresh manures, free from straw, will burn the plants, and compact manures will cause decay and fermentation, due to lack of aeration. A good strawy manure should be used. In the spring the litter may be removed, and the finer portions of the mulch spaded into the beds. When leaves are used, provision must be made to prevent them from blowing away. Boards, branches, or wire netting can be used for this purpose. Mulching, applied very early, may be harmful by reason of encouraging late root action and top growth. Therefore, it is always advisable to delay root mulching until, after several light freezes, a crust has formed on the ground. Evergreen boughs, when procurable, make an excellent protective covering. After a dry fall most plants, except some perennials, are benefited by being thoroughly soaked with water before freezing weather occurs. This is especially true of conifers and broadleaved evergreens. Cultivation in shrub and perennial beds can be stopped as soon as danger from weeds maturing their seeds is over. This will furnish some protection and will also discourage late growth of plants. 
PART II

LISTS FOR REFERENCE 



\section{CHAPTER IX}

\section{EVERGREENS}

THE variation in adaptation of evergreens has come to be a muchdebated question among horticulturists and landscape architects who are called upon to use them. An interesting fact is discovered after some study of evergreens. The hardy types are not perfectly hardy under the varying conditions of climate and exposure in various sections of the country. Therefore, evergreens should be selected for landscape plantings with a considerable knowledge of their ability to withstand local conditions.

The factors which are evidently most injurious to the normal development of evergreens as a group are: (I) sudden variations in climatic conditions; (2) condition of the soil; (3) exposure; and (4) atmospheric conditions in the vicinity of congested city districts. A short discussion of these factors, as bearing upon the growth of evergreens, may be of value.

r. Climatic Conditions. It is a safe assumption that evergreens which are indigenous to sections of country where the climatic conditions are severe will withstand similar conditions in any other section of the country unless the other factors, of soil, exposure, and atmospheric conditions are extremely adverse. An interesting fact is seen in the repeated endeavour to acclimate evergreens, which otherwise are hardy, to the sudden changes of temperature experienced along the shores of the Great Lakes. Evergreens which are perfectly hardy in the severe climate of New York State and New England, and even in Michigan, will not prove hardy when used close to the shores of the Great Lakes.

While no one has given a definite reason for this, it is presumed that the sudden changes of climatic condition are responsible for the failure of many plants. In general, in the selection of evergreens, the more tender varieties should not be far. removed from climatic conditions in which they are known to be perfectly hardy, 
unless the person using such plants expects the inevitable loss which will be experienced during a very severe winter.

2. Condition of the Soil. The question of soil conditions with reference to the planting of evergreens is more important in the clayey sections of the Middle West than in most of the other sections of the country. In the northern portions of the Middle West this is not so evident, because the summer months are not as hot and dry as they are farther south. Even the more hardy evergreens will not withstand the stiff clay conditions of the Middle West during the hot summer months, at which times this clay bakes very hard. Evergreens, to be grown most successfully, should be planted in a loose, sandy-loam or clay-loam soil, and should not be planted directly in a soil the predominating portion of which is clay. Therefore the soil conditions should be examined closely before it is definitely decided to use evergreens, and the list of evergreens shown under IX-B are those which are most hardy and best adapted to the climatic conditions and soil conditions of the Middle West, as proven by years of experience and careful observation.

3. EXPOSURE. If the more tender types of evergreens which do not normally grow under the most severe climatic conditions are selected for use in a section where the climatic conditions are severe, then such plants should be so located that the exposure from the prevailing winds of winter is greatly reduced. It is possible to use most of the evergreens shown in Group IX-A in any section of the country, provided a proper exposure is selected and the proper winter protection is given. Many times this is impracticable, because evergreens are selected to be of equal value during the winter months and during the summer months. There is no windbreak or screen as yet developed for the protection of evergreens against exposure which in itself does not detract to a great extent from the beauty of these plantations during a period of the year when their foliage should be most effective.

4. Atmospheric Conditions. Many evergreens are used in the vicinity of our congested city districts, or in locations where the prevailing winds surround them with an atmosphere polluted with dust, smoke, and gases, all of which are. very injurious to most evergreens. Only the most hardy evergreens should be used under such conditions, and in order to keep them in a normal growing condition 


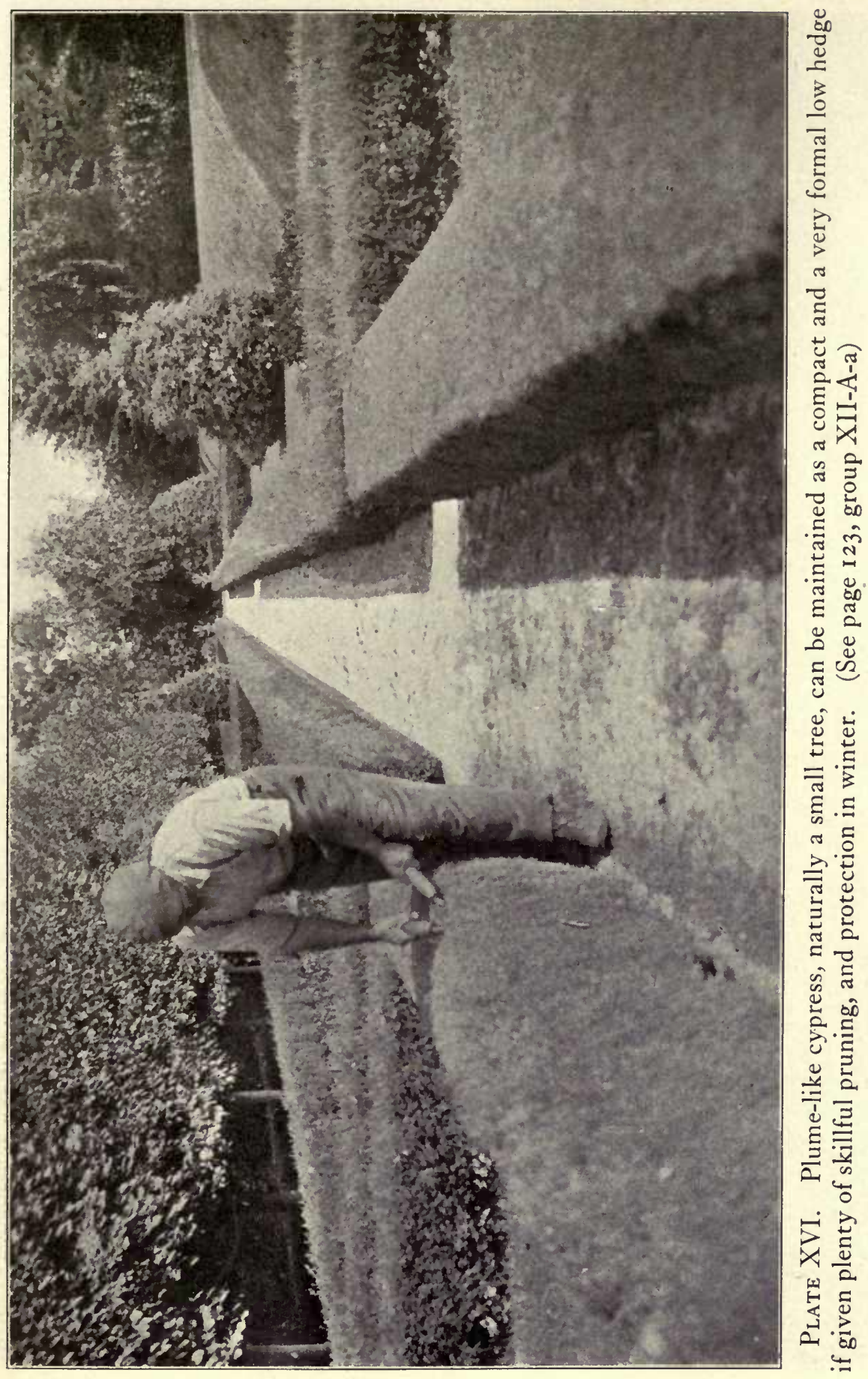




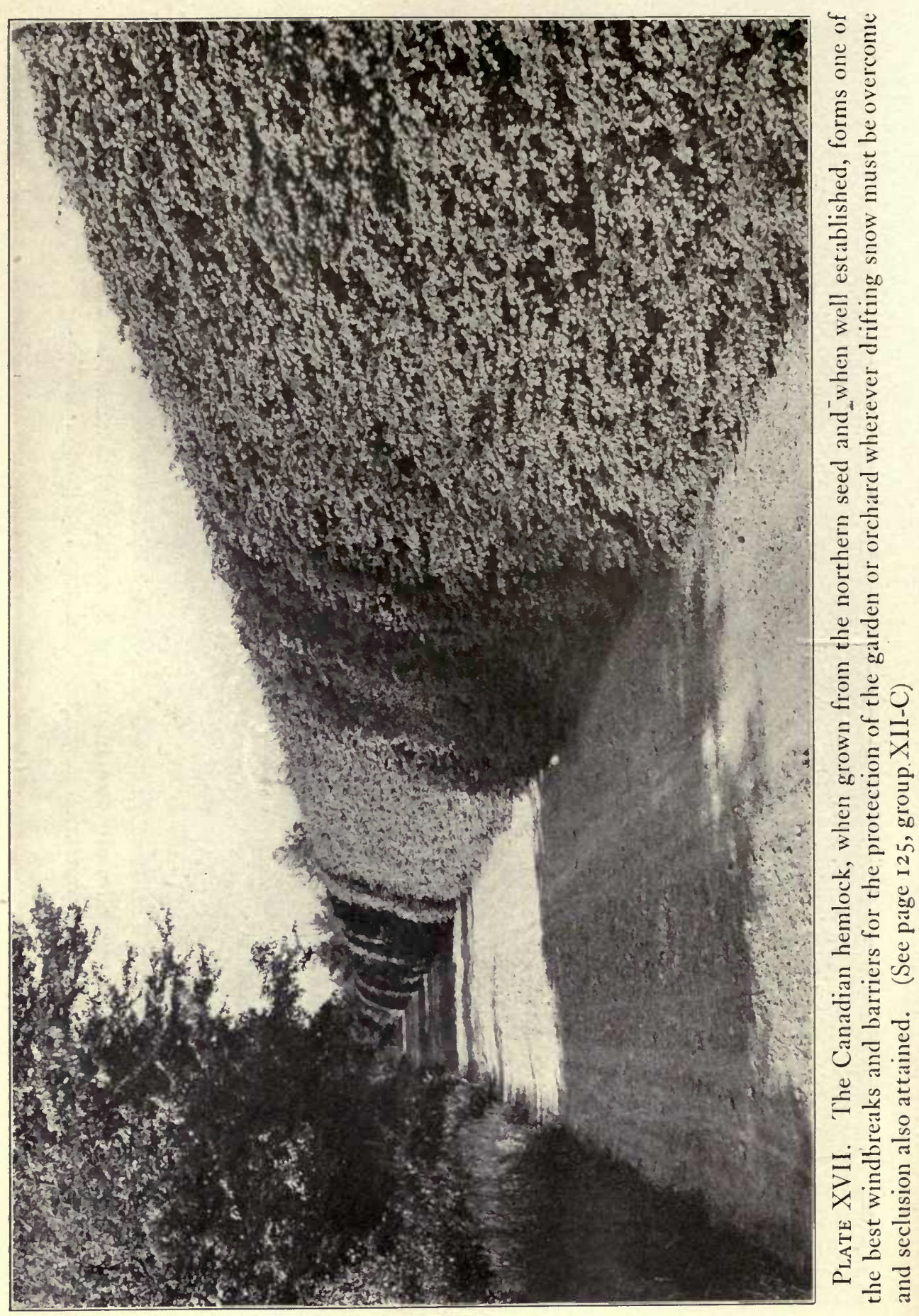




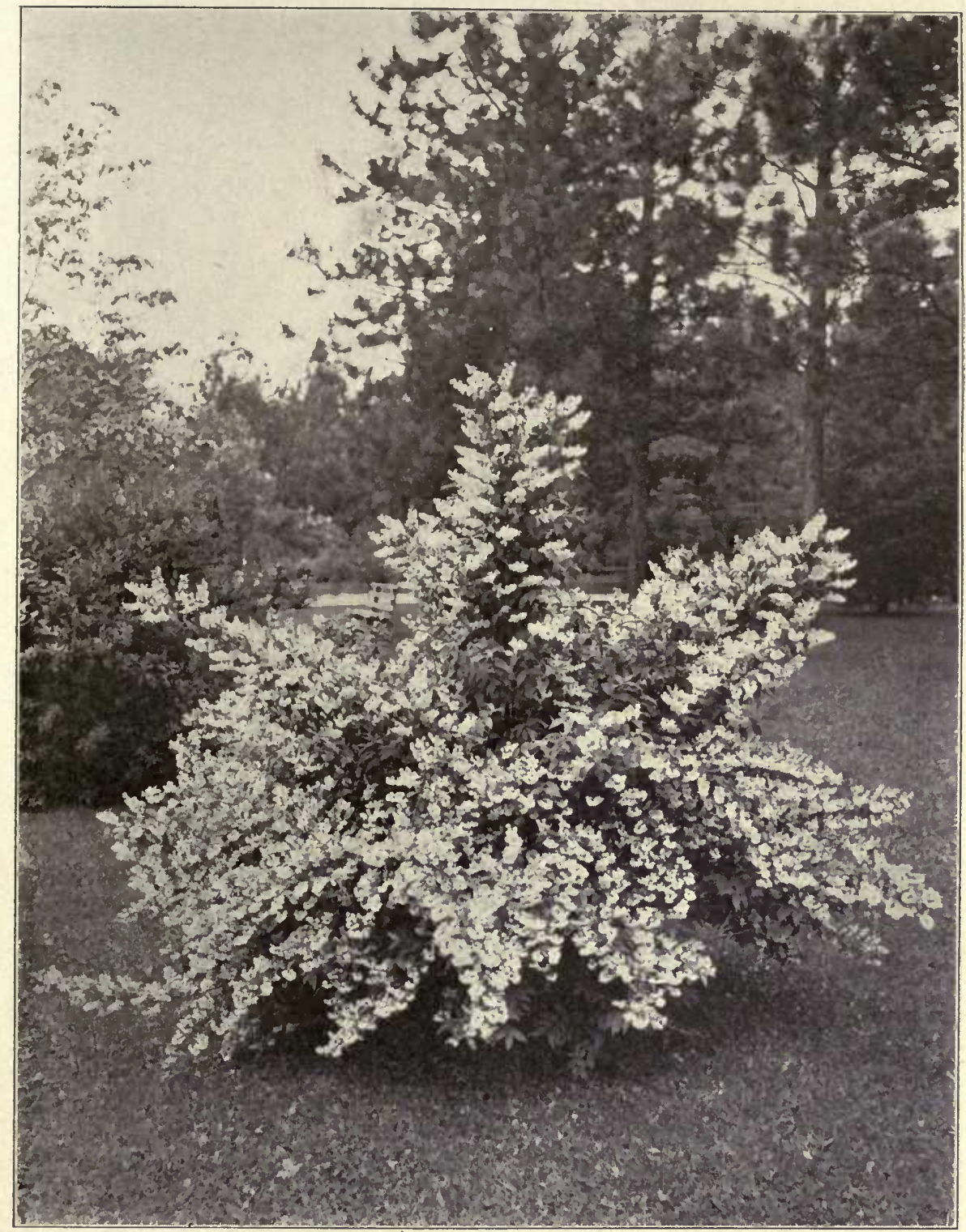

Plate XVIII. Upon a spacious lawn effective use can occasionally be made of trees and shrubs possessing symmetrical habits of growth and fine flowering and fruiting qualities. The deutzia is a shrub with these capabilities; but it is seldom seen as a specimen plant. Restraint, however, must be observed and a dotted effect avoided. (See chapter XIV) 


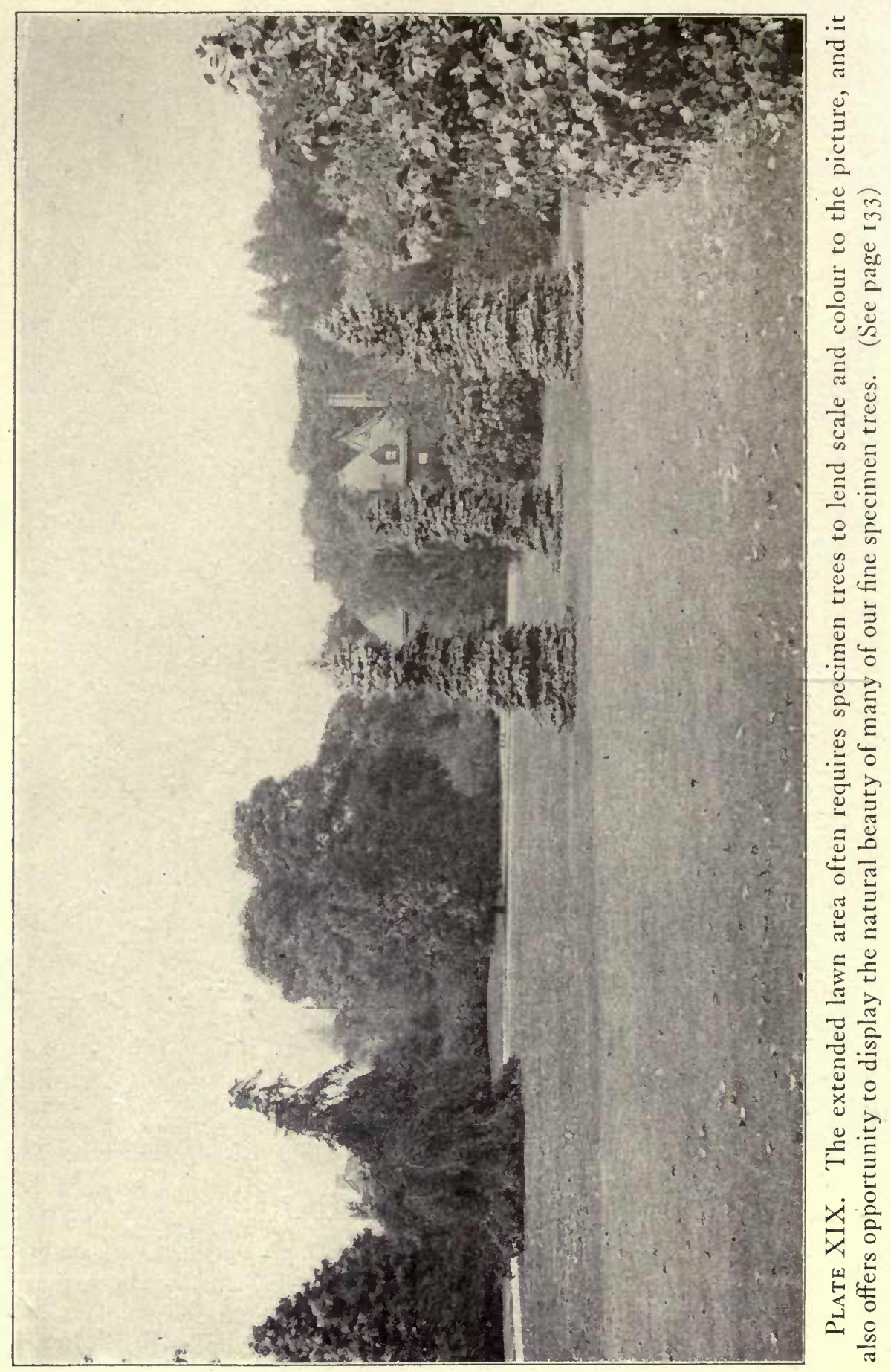


it is essential during the cooler hours of the day, and at frequent intervals, to spray these plants to wash off much of the soot which collects from the atmosphere. While the leaves of evergreens are heavily covered with a layer of cuticle, the breathing pores are very susceptible to clogging from the dust of a polluted city atmosphere.

So much for the discussion of the adaptation of evergreens to these conditions. A list of evergreens is shown in Group IX-C, found through experience to be not generally recommended for use in the Middle West.

Another condition often arises in the use of evergreens. Material is desired for undergrowth planting in shady wooded areas. There are very few kinds of evergreens which will produce anything like their normal density of foliage where they are deprived of a great portion of sunlight. This group of material is shown in Group IX-D.

It is often necessary to use groups of low-growing and refined types of evergreens to provide mass effects on private lawns and about residences, to be of value during the winter and summer months. A list of evergreens available and adapted to this use has been generally outlined. They must be of the more slow-growing types if overcrowding within the first two or three years after transplanting is to be avoided.

\section{LIST OF EVERGREENS}

A. Most Hardy. This group contains types of evergreens selected for general use under widely varied conditions throughout the northeastern section of the United States.

Abies brachyphylla
Nikko Fir
Abies concolor
White Fir
Abies oeitchi
Veitch's Silver Fir
Chamaecyparis obtusa
Japanese Cypress
Juniperus chinensis pfitzeriana
Pfitzer's Juniper
Juniperus communis
Common Juniper
Juniperus communis aurea
Golden Juniper
Juniperus excelsa stricta
Slender Greek Juniper
Juniperus horizontalis
Trailing Juniper
Juniperus horizontalis douglasi Waukegan Juniper
Juniperus sabina Savin Juniper
Juniperus scopulorum Rocky Mountain Silver Cedar
Juniperus virginiana Red Cedar
Juniperus virginiana cannarti Columnar Tufted Cedar
Juniperus virginiana schotti Schott's Red Cedar
Picea alba White Spruce
Picea alcockiana Alcock's Spruce
Picea engelmanni
Engelmann's Spruce


Picea excelsa (in variety)

Norway Spruce

Picea omorika

Servian Spruce

Picea pungens

Colorado Spruce

Pinus cembra

Swiss Stone Pine

Pinus densiflora umbraculifera

Dwarf Japanese Red Pine

- Pinus montana mughus

Dwarf Mountain Pine

Pinus nigra austriaca

Austrian Pine

Pinus resinosa

Red Pine

Pinus strobus

White Pine

Pinus sylvestris

Scotch Pine

Pseudotsuga douglasi (Colorado Form)

Douglas Fir

Sciadopitys verticillata

Umbrella Pine

Taxus baccata repandens Spreading English Yew
Taxus canadensis Ground Yew

Taxus cuspidata Japanese Yew

Taxus cuspidata brevifolia Short-leaved Japanese Yew

Thuja occidentalis aurea George Peabody's Golden Arborvitae

Thuja occidentalis douglasi Douglas' Arborvitae

Thuja occidentalis globosa Globe Arborvitae

Thuja occidentalis (Little Gem) Little Gem Arborvitae

Thuja occidentalis plicata

Tall Pointed Arborvitae

Thuja occidentalis pyramidalis Pyramidal Arborvitae

Thuja occidentalis rosenthali Rosenthal's Arborvitae

Thuja occidentalis vervaneana Vervaene's Arborvitae

Thuja occidentalis wareana Siberian Arborvitae

Tsuga canadensis Canadian Hemlock

\section{Tsuga caroliniana}

Carolina Hemlock

B. Best Adapted for Use in Mid-West. This group of evergreens will withstand climatic and soil conditions of the mid-west, especially throughout Ohio, and under average exposure these types will develop normally in the suburban and country districts.

\author{
Abies brachyphylla \\ Nikko Fir \\ Abies concolor \\ White Fir \\ Abies veitchi \\ Veitch's Silver Fir \\ Chamaecyparis obtusa \\ Japanese Cypress \\ Chamaecyparis pisifera filifera \\ Thread-branched Cypress \\ Chamaecyparis pisifera squarrosa \\ Veitch's Silver Cypress \\ Juniperus (in variety) \\ Juniper \\ Picea alba (north only) \\ White Spruce
}

\author{
Picea alcockiana \\ Alcock's Spruce \\ Picea engelmanni \\ Engelmann's Spruce \\ Picea excelsa (in variety) \\ Norway Spruce \\ Picea omorika \\ Servian Spruce \\ Picea pungens glauca \\ Koster's Blue Spruce \\ Pinus cembra \\ Swiss Stone Pine \\ $P$ inus montana mughus \\ Dwarf Mountain Pine \\ Pinus nigra austriaca \\ Austrian Pine
}


Pinus resinosa

Red Pine

Pinus strobus

White Pine

Pinus sylvestris

Scotch Pine

Pseudotsuga douglasi

Douglas Fir

Sciadopitys verticillata

Umbrella Pine

Taxus baccata repandens

Spreading English Yew
Taxus cuspidata brevifolia Short-leaved Japanese Yew

Taxus cuspidata capitata Clustered Japanese Yew

Thuja occidentalis (in variety) American Arborvitae

Thuja occidentalis wareana Siberian Arborvitae

Thuja orientalis (northern grown) Oriental Arborvitae

Tsuga canadensis Canadian Hemlock

Tsuga caroliniana

Carolina Hemlock

C. Not Adapted for Use in Mid-West. Evergreens in this group should not be used in the amateur garden of this section. Experience has shown that they have proven "treacherous" in their ability to thrive and also in their habit of growth under these peculiar climatic and soil conditions, to which they are not adapted.

Abies balsamea

Balsam Fir

Abies fraseri

Fraser's Balsam Fir

Abies nordmanniana

Nordman's Fir

Cephalotaxus (in variety)

False Yew

Chamaecyparis lawsoniana

Lawson's Cypress

Chamaecyparis pisifera

Pea-fruited Cypress

Chamaecyparis pisifera plumosa

Plume-like Cypress
Juniperus excelsa Greek Juniper

Picea mariana Black Spruce

Pinus banksiana Jack Pine

Pinus jeffeyi Jeffrey's Pine

Pinus palustris Long-leaved Pine

$P$ inus ponderosa Bull Pine

Thujopsis dolobrata Japanese Arborvitae

D. Adapted to Partial Shade in Wooded Areas. The group of evergreens which will develop normal foliage and normal growth under partial shade in wooded areas is limited. The types in this group have proven the most satisfactory.

Juniperus virginıana

Red Cedar

Pinus banksiana (for light soils)

Jack Pine

Pinus strobus

White Pine
Pseudotsuga douglasi

Douglas Fir

Taxus canadensis

Ground Yew

Thuja occidentalis

American Arborvitae 
E. Low-growing, Formal Types. This group contains types of evergreens which are valuable for accent and for specimen purposes. They should be planted on the open lawn or where there is ample space for them to develop their natural habit of growth. Evergreens from this list, and the low-growing types of a more informal character from Groups IX-A and IX-B should be selected for the refined mass plantings of evergreens as illustrated in Figure I Plate XI.

Abies concolor globosa (spherical) Globe White Fir

Chamaecyparis obtusa nana (conical) Dwarf Japanese Cypress

Chamaecyparis obtusa nana aurea (conical) Dwarf Golden Japanese Cypress

Juniperu virginiana globosa (globose) Globe Red Cedar

Picea excelsa clanbrasiliana (compact broad conical)

Cone-shaped Norway Spruce

Picea excelsa compacta (sub-globose)

Compact Norway Spruce

Picea excelsa gregoriana (sub-globose and compact)

Gregory's Dwarf Norway Spruce

Picea excelsa nana (depressed sub-globose) Dwarf Norway Spruce

Picea excelsa pygmaea (dense, small pyramid)

Dwarf Pyramidal Norway Spruce

Picea excelsa tabulaeformis (low and flat) Tablet-shaped Norway Spruce

Picea orientalis nana (low, broad pyramid) Dwarf Oriental Spruce

Picea pungens compacta (dwarf conical) Dwarf Blue Spruce

Pinus cembra compacta (dwarf conical) Dwarf Swiss Stone Pine

Pinus densiflora umbraculifera tanyosha (vase form)

Dwarf Japanese Red Pine

Pinus koraiensis (dense, broad pyramid) Corean Pine

Pinus montana mughus (globose) Dwarf Mountain Pine

Pinus strobus umbraculifera (vase form) Bush White Pine

Pinus strobus brevifolia (compact and round)

Dwarf White Pine
Pinus sylvestris pumila (globose)

Globe Scotch Pine

Pseudotsuga douglasi globosa (globose) Globe Douglas Spruce

Taxus baccata repandens (sub-globose) Spreading English Yew

Taxus cuspidata densa (hemispherical)

Dwarf Japanese Yew

Thuja occidentalis compacta (globose) Compact Arborvitae

Thuja occidentalis dumosa (dense dwarf) Dwarf Arborvitae

Thuja occidentalis ellwangeriana (low, broad pyramid)

Ellwanger's Arborvitae

Thuja occidentalis globosa (globose and very dwarf)

Globe Arborvitae

Thuja occidentalis hoveyi (dense ovate)

Hovey's Arborvitae

Thuja occidentalis (Little Gem) (flat ovate)

Little Gem Arborvitae

Thuja occidentalis nana (compact globose) Dwarf Arborvitae

Thuja occidentalis pumila (dense dwarf)

Dwarf Arborvitae

Thuja occidentalis reidi (broad dwarf) Dwarf Arborvitae

Thuja occidentalis wagneriana (globose) Dwarf Arborvitae

Thuja occidentalis woodwardi (dense globose)

Woodward's Dwarf Arborvitae

Tsuga canadensis globosa (dense globose) Globe Hemlock

Tsuga canadensis nana (depressed and spreading)

Dwarf Hemlock

Tsuga canadensis pendula (sargentr) (flat topped depressed)

Sargent's Weeping Hemlock 


\section{CHAPTER X}

\section{STREET AND AVENUE PLANTING}

THIs is a broad subject and yet it has been well covered by numerous bulletins and books. There are a few important questions, however, which should be decided very definitely in the minds of those who are selecting trees for use as street plantings. There is a group of trees most of the types of which are entirely hardy under all conditions. There is another group of trees which should seldom, if ever, be used on streets, and there is a third group of trees which possess some real value for street planting; but they should be selected only with a thorough knowledge of the conditions under which they are to be placed.

In general, trees which are selected for street planting should be symmetrical in character, they should be long lived, and they should not be readily susceptible to injury from insects and smoke.

There is a certain group of trees specimens of which can be safely selected for street planting, either in city or suburban districts. This group comprises such trees as the sugar maple, red oak, European linden, and American elm, the last of which is best adapted to planting on narrow streets because of its high-headed characteristic of growth. Though it becomes very tall its vase-form enables it to reach above dwellings that may be not far back from the street and to leave open a vista down the street axis. The low, compact-headed types of trees, such as the sugar maple, pin oak, and the linden ought to be planted only on wide streets. While the use on narrow streets of such vase-shaped trees as the elm allows for an unobstructed vista, the use of such trees as the pin oak and linden, unless the lower branches are severely pruned, has a tendency to "choke up" and to obstruct the vista.

A certain few trees should rarely, if ever, be used in street tree planting. This list comprises such trees as the horse chestnut, box elder, black locust, willows, birches, and poplars. Birches and locusts are too short lived. The horse-chestnut and the box elder are littering 
in their habit. The poplars are subject to disease as well as being short lived, and the willows are not adapted to shade tree purposes, even in their habit of growth. In spite of the fact that there are some excellent trees as shown in the first and second lists in this chapter, well adapted to street and avenue planting, and thoroughly tested through a period of years, yet many individuals responsible for the selection of these permanent assets or detriments to the public streets will still select trees such as those which are included in the third list of this chapter.

Trees such as the maidenhair tree, tree of heaven, oriental plane, and pin oak should not be used for street tree planting without a thorough knowledge of the conditions under which they are to grow and the conditions to which they are best adapted. The pin oak and the maidenhair tree are tall, pyramidal trees, which should be used only on wide streets in a heavy soil, and the maidenhair tree should never be used for street and avenue planting except in the less severe climatic conditions. The tree of heaven has a vigorous habit of growth and is an excellent tree in the smoky, congested sections of our cities where shade trees are required. Before trees in this group are used some of the important bulletins and books on our city street trees should be consulted for further information. (See Bibliography.)

Where an avenue is of such length that it passes through two or more radically different soil types care must be exercised or the trees on one soil will not grow as fast or luxuriantly, as upon another soil. This will result in an avenue of uneven height and spread in the tops of the trees and thus spoil an otherwise successful planting.

\section{LIST OF TREES FOR STREET AND AVENUE PLANTING}

A. Trees Which Are Entirely Hardy Under All Conditions. This group contains the standard types of shade trees which can be planted under almost any condition of climate or soil, with some degree of assurance that they will develop an interesting normal habit of growth. This list may be termed "the ten best trees for general use in street and avenue planting," in city, suburban, and urban districts.

Acer saccharum

Sugar Maple

Quercus alba

White Oak
Quercus coccinea

Scarlet Oak

Quercus rubra

Red Oak 
Quercus velutina

Black Oak

Tilia euchlora

Crimean Linden

Tilia tomentosa

Silver Linden
Tilia oulgaris

Common Linden

Ulmus americana

American Elm

Ulmus glabra

Scotch Elm

B. Trees Which Should Be Selected With a Thorough Knowledge of the Conditions Under Which They Are to Be USED. Before trees in this group are used, descriptive information of these types should be consulted in order to know that the soil conditions, exposure, climate, and width of streets are such that these trees will meet the requirements and develop a normal growth.
Acer platanoides
Norway Maple
Ailanthus glandulosa
Tree of Heaven
Celtis occidentalis
Nettle Tree
Fraxinus (in variety)
Ash Tree
Ginkgo biloba
Maidenhair Tree
Liquidambar styracifua Sweet Gum
Liriodendron tulipifera
Tulip Tree
Platanus orientalis
Oriental Plane
Phellodendron amurense
Chinese Cork Tree
Quercus palustris
Pin Oak

\section{Ulmus campestris \\ English Elm}

C. Trees Which Should Seldom Be Used on Streets. Many trees are selected for street planting, either because they are the easiest trees to grow or the tree which can be obtained with the least difficulty and expense. Such trees are a future liability to the community and they should never be planted except for some important reason, such as the impossibility of obtaining other types. They are adapted to specimen use rather than to street use.

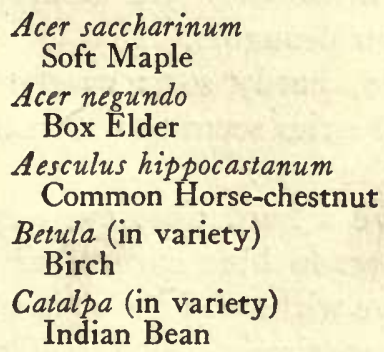

Gleditsia triacanthos Honey Locust Platanus occidentalis American Plane

Populus eugenei Carolina Poplar

Robinia pseudacacia Black Locust

Salix (in variety)

Willow

Sorbus aucuparia

European Mountain Ash 


\section{CHAPTER XI}

\section{PLANTS FOR USE IN CONGESTED CITY DISTRICTS}

THE effect of dust, smoke, and gas fumes upon vegetation is well known and yet no considerable amount of study has been given to this subject, largely because it has not been considered an economic question. Surely the people who are compelled to live in the congested districts of our large cities are as much entitled to shade and greenery as any one else, and there is no question but that the healthfulness of the congested districts is lowered by the absence of shade and grass. By the use of those plants which can survive drought, smoke, and abuse, some sort of trees or shrubbery may be had almost anywhere, except perhaps in the immediate vicinity of a steel mill or similar factories, where not even grass will survive. The first trees one comes to on the edge of the treeless districts which surround large steel mills are usually ailanthus or willow. The ailanthus is also the tree which most often appears in the closely built up sections of large cities, often providing the only greenery to be seen in whole sections of a town. Ashes, locusts, European planes, European lindens, and horsechestnuts also seem to have the ability to withstand the summer droughts and the suffocating soot that proves disastrous to so many city trees. No rough-leaved tree nor one which requires much water should be used as a street tree in a congested, sooty district, because it is doomed beforehand to a lingering death, if it survives at all. Pin oaks and willows are useful only when they are assured of a reasonable supply of water during summer droughts.

Among the shrubs such smooth-leaved, hardy sorts as the lilacs, privets, golden bells, buckthorns, and barberries seem to withstand the drawbacks of smoke, soot, and drought the best.

Most of the coniferous evergreens have a hard time even existing in any closely built up town. The Colorado blue spruce, silver fir, Scotch pine, and dwarf mountain pine have withstood the soot and gas better than any others, and some recent experiments with the Carolina hemlock seem to show that it, too, will survive in the heart of a city, 
providing it receives a certain amount of care. The common arborvitae has generally proved a failure. The exact reason why conifers are so unsuccessful has not so far appeared. Their short life seems to be due to the accumulation of soot which clogs the pores of the leaves and slowly suffocates them. They transpire so much water also during the hot summer droughts that they need an excessive amount of moisture, and they need numerous showers or washings from the hose also to keep them clean and cool. As most evergreens growing under city conditions do not get any care they rarely succeed, and when they do live, they lose their colour and are therefore not recommended.

As a rule, native collected plants seldom or never succeed when taken directly into the congested city districts, and only those plants among the deciduous shrubs and trees which are smooth-leaved are to be recommended for trial.

\section{LIST OF PLANTS FOR USE IN CONGESTED CITY DISTRICTS}

A. TREES. This group contains trees which may be used with a great deal of certainty that they will thrive under city conditions of congestion and dusty atmosphere. Wherever possible, these trees, especially evergreens, should be thoroughly sprayed at frequent intervals to wash a considerable portion of the dust from the surface of the leaves.

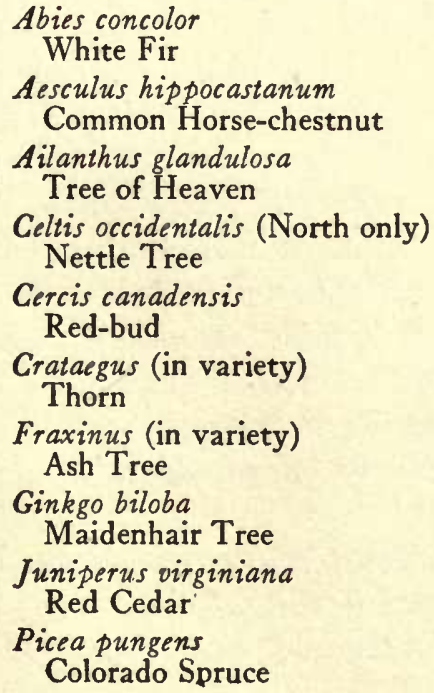

\author{
Pinus montana mughus \\ Dwarf Mountain Pine \\ Pinus sylvestris \\ Scotch Pine \\ Platanus orientalis \\ Oriental Plane \\ Quercus palustris \\ Pin Oak \\ Robinia pseudacacia \\ Black Locust \\ Salix (in variety) \\ Willow \\ Sophora japonica \\ Japanese Pagoda Tree \\ Tilia europaea \\ European Linden \\ Tilia tomentosa \\ Silver Linden \\ Ulmus campesiris \\ English Elm
}


B. Shrubs. In every city district the occupants of some homes desire shrubs in connection with their yards, which give a touch of nature to their places. The shrubs in this group have proven the most hardy under adverse city conditions and should be used as a basis for selecting types.

Aralia spinosa

Hercules' Club

Berberis thunbergi

Thunberg's Japanese Barberry

Cornus (in variety)

Dogwood

Evonymus americanus

Strawberry Bush

Forsythia (in variety)

Golden Bell

Hibiscus syriacus

Rose of Sharon
Ligustrum (in variety) Privet

Physocarpus opulifolius Ninebark

Rhamnus (in variety)

Buckthorn

Spiraea (in variety)

Spirea

Symphoricarpos (in variety)

Snowberry

Syringa vulgaris

Common Lilac

Viburnum (in variety)

Viburnum 


\section{CHAPTER XII}

\section{PLANTS FOR HEDGES}

THE selection of plants for hedges forms one of the most interesting subjects in the study of use of plants. More often than for any other purpose trees and shrubs for hedges are selected either from an economic or an aesthetic point of view. It may be desired to have a hedge for its beauty, or it may be desired for the purpose of a screen, a windbreak, or as a definite barrier.

Many times it is desirable in the development of hedge plantations, especially those which are more than the average height (three to four feet), to develop a hedge which will retain its foliage during the winter months. This may be desirable for two reasons: first, to provide a barrier and at the same time a screen against objectionable views and to secure privacy, and, second, to lend interest to a winter landscape because of the foliage effect. The only effective hedge barrier which holds its leaves during the winter is one composed of conifers. Broadleaved evergreens are not desirable for this purpose; mainly because they are not sufficiently compact in their habit of growth to meet the requirements of a hedge, and they do not lend themselves to shearing. The evergreen hedge which is planted for the purpose of providing a complete screen, and requires a normal growth of the foliage, should seldom be planted in the heavy shade of large overhanging trees. Hedge plants which are selected as barriers or screens should be close growing and compact in habit. Many among them are thorny in character, thus making passage through them very difficult.

Hedges which are planted for barriers and which do not hold their leaves during the winter are usually valuable mostly for their summer effect. They are seldom planted for the purpose of a screen, for such a screen is desirable during the months of the year when the foliage is not present.

Many flower gardens, especially large rose gardens, have been much enhanced from a landscape viewpoint by the presence of low-growing, compact hedges which accurately define the outline of the various beds 
and emphasize the main axial lines of the garden. There is a group of plants from which kinds are selected for hedge purposes, and which lend themselves to frequent clipping and shearing. These are most often used for edgings beside formal garden walks, pools, and beds of planting. The ideal hedge for this purpose is one which requires a very small amount of pruning in order to maintain its close, compact habit. It is therefore necessary to select plants for this purpose with a careful knowledge of the natural habits of growth of the mature plants and to use such plants for hedge purposes, rather than to endeavour by severe pruning to adapt larger growing types to such uses. Such hedges are usually maintained from six to twelve inches in height and should be planted at least twelve inches away from the edge of any garden walk in order to provide ample width for the hedge to spread as it matures.

Hedges for the purpose of windbreaks and solid screens are composed almost entirely of trees which are more or less compact in their habit of growth and will continue to develop while planted in a crowded space. Considerable good judgment should be used in locating a windbreak which is likely to act as a snow trap also, because the great drift of snow which accumulates behind a large windbreak may prove a nuisance in the early spring by lying deeply on the ground long after the land under it should be thawed out and ready to use. This drift may also break down small and brittle trees and shrubs and do more damage than good. For this reason, on the open prairies of the Dakotas it is often found necessary to locate windbreaks as far as one hundred feet to the windward of the buildings or road which are to be protected, because a strip approximately ten times its height is affected by a windbreak. This is shown by the snow lying drifted for this distance to the leeward after a heavy snowfall, accompanied by a driving wind.

Some thirty years ago, L. H. Bailey gave the following rules for planting windbreaks (Garden and Forest Vol. I, page 46). While primarily intended for orchardists they are well worth considering to-day by anyone who is going to do such planting on a large scale for ornamental purposes.

(1). The windbreak should not obstruct atmospheric drainage.

(2). The windbreak should never be dense enough to force the buds on fruit trees in those localities which are subject to late spring frosts.

(3). As a rule, in localities where atmospheric drainage will not be severely checked, the windbreak should have a comparatively dense bottom, formed by undergrowth or low-branched trees.

(4). Native trees and shrubs are preferable for windbreaks. 
To these rules it might be added that, while a single row of plants is often desirable, it does not take care of the contingency that arises when one or more plants die. It is consequently preferable to plant two or more staggered rows of plants which thus do not require to be planted so closely and for that reason are more likely to survive a long while and retain their lower branches. It is possible to gain a good ornamental effect also by combining evergreen trees with harmonious deciduous ones, such as hemlock or spruce with birches and maples. This type of planting is often called a "shelter belt" and when a considerable number of evergreen trees are used a pleasing effect is secured the year round, and large numbers of birds will be found to be attracted and held, not only through the nesting season but sometimes all the year.

Still another use for hedges is that of providing privacy. Most of the shrubs used in this group should be of the tall types, exceeding five feet in height, and should have a compact, heavy foliage. The natural growth of the shrubs should be close and they should hold their foliage during the late summer and early fall. Some of the shrubs which are best adapted for this purpose are the rose of Sharon, common buckthorn, and the European beech, the foliage of which does not develop until the latter part of the spring.

It is often desirable to select plants which will serve as hedges in the bleak exposures of lake fronts and ocean shores, and also in the Canadian northwest. These plants should be hardy under all severe climatic conditions of the northeast and the Canadian northwest. Most of the plants which have been suggested for this group have been found growing normally under the most severe conditions of climate and exposure.

\section{LIST OF PLANTS FOR HEDGES}

A. BARriers. This group consists of types of plants which are compact in their habit of growth and some of which are thorny. They are excellent as barriers for two reasons: either because of their thorny character or because of their extremely close habit of growth. The first list (a) contains plants which hold their leaves during the winter months, and the second list (b) contains plants which do not hold their leaves during the winter months.

a. Holding leaves during winter:

Chamaecyparis pisifera plumosa

Plume-like Cypress
Fagus sylvatica

European Beech 
Mahonia aquifolium

Oregon Grape

Picea excelsa

Norway Spruce
Pyracantha coccinea lalandi

Evergreen Thorn

Thuja (in variety)

Arborvitae

Tsuga canadensis

Canadian Hemlock

b. Not holding leaves during winter:

Acer campestre
European Cork Maple
Berberis thunbergi
Thunberg's Japanese Barberry
Carpinus betulus
European Hornbeam
Chaenomeles japonica
Japanese Quince
Citrus trifoliata
Hardy Orange
Crataegus coccinea
Scarlet-fruited Thorn
Crataegus cordata
Washington Thorn
Crataegus crus-galli
Cockspur Thorn
Crataegus oxycantha
May Thorn

Fagus americana

American Beech

Gleditsia triacanthos Honey Locust

Hippophae rhamnoides Sea Buckthorn

Lonicera fragrantissima Early Fragrant Honeysuckle

Maclura pomifera Osage Orange

Prunus spinosa Black Thorn

Rhamnus cathartica Common Buckthorn

Rhamnus frangula (variety latifolia) Alder Buckthorn

Rosa rugosa

Japanese Rose

B. Edgings for Walks and for Garden Borders. The plants in this group are either dwarf in their habit of growth or can be pruned severely in order to keep them in a low, compact form. The average height at which these hedges may be maintained is eight inches to eighteen inches.

Astilbe japonica Japanese Astilbe

Azalea amoena

Hardy Evergreen Azalea

Berberis thunbergi

Thunberg's Japanese Barberry

Buxus suffruticosa

Dwarf Box

Deutzia gracilis

Slender Deutzia

Ilex microphylla Small-leaved Holly

Ilex glabra

Inkberry

Ligustrum ibota regelianum Regel's Privet
Philadelphus coronarius nanus Dwarf Mock Orange

Philadelphus coronarius nanus aureus Golden Dwarf Mock Orange

Pieris japonica Japanese Fetterbush

Pyracantha coccinea lalandi Evergreen Thorn

Rosa blanda Meadow Rose

Rosa polyantha (in variety) Fairy Rose

Spiraea bumalda anthony waterer Crimson Spirea

Spiraea callosa alba Fortune's White Spirea 


\section{PLANTS FOR HEDGES}

Thuja occidentalis ellwangeriana

Ellwanger's Arborvitae

Thuja occidentalis globosa

Globe Arborvitae
Thuja occidentalis Tom Thumb or variety umbraculifera

Tom Thumb Arborvitae

Viburnum opulus nanum

Dwarf Bush Cranberry

C. Windbreaks and Solid Screens. Most of the trees and shrubs in this group are rapid growing and are entirely hardy under normal climatic conditions. They can be planted in close proximity to each other without injuring the individual specimens. This close planting, however, renders all the trees useless in future specimen planting.

Acer ginnala

Siberian Maple

Acer negundo

Box Elder

Acer saccharinum pyramidale

Pyramidal Silver Maple

Acer tataricum

Tartarian Maple

Carpinus caroliniana

American Hornbeam

Fagus americana

American Beech

Fagus sylvatica

European Beech

Juniperus virginiana

Red Cedar

Larix europaea

European Larch
Larix leptolep is Japanese Larch

Picea (in variety)

Spruce

Pinus resinosa

Red Pine

Pinus strobus

White Pine

Populus (in variety)

Poplar

Rhamnus caroliniana

Carolina Buckthorn

Salix (in variety)

Willow

Tsuga canadensis

Canadian Hemlock

Tsuga caroliniana

Carolina Hemlock

D. For Privacy. These types are selected because of their ability to develop a compact, heavy foliage effect and most of these types retain their foliage during the late summer and early fall months.

Acer saccharinum pyramidale

Pyramidal Silver Maple (low-branched)

Cornus mas

Cornelian Cherry

Elaeagnus angustifolia

Rüssian Olive

Fagus sylvatica

European Beech

Forsythia intermedia

Hybrid Golden Bell

Forsythia viridissima

Dark Green Golden Bell

Hibiscus syriacus

Rose of Sharon

Ligustrum (in variety)

Privet

Lonicera bella

Zabel's Honeysuckle

Lonicera maacki Late-blooming Honeysuckle

Lonicera tatarica Tartarian Honeysuckle

Rhamnus cathartica

Common Buckthorn

Spiraea vanhouttei

Van Houtte's Bridal Wreath

Syringa vulgaris

Common Lilac

Viburnum (in variety)

Viburnum 
E. Hedges for Bleak Exposures. These plants are hardy as far north as the Canadian northwest and will survive under extreme exposure. This group has been subdivided in order more clearly to differentiate between plants which should be used for their different characteristics under different exposures.

a. Late foliage:

$$
\text { Syringa vulgaris (not variety alba) }
$$

Common Lilac

b. Close shearing:

Berberis thunbergi

Thunberg's Japanese Barberry

Caragana arborescens

Siberian Pea Shrub

Caragana microphylla

Dahurian Pea Shrub

Elaeagnus angustifolia Russian Olive

Rhamnus cathartica Common Buckthorn

Shepherdia argentea Buffalo Berry

\section{Shepherdia canadensis (on lime) \\ Canadian Buffalo Berry}

c. Unsheared low hedges:

Berberis thunbergi

Thunberg's Japanese Barberry

d. Fruiting hedges:

Berberis thunbergi

Thunberg's Japanese Barberry

Crataegus (in variety)

Thorn

Hippophae rhamnoides

Sea Buckthorn

Rhamnus cathartica

Common Buckthorn

Symphoricarpos (in variety)

Spiraea vanhouttei

Van Houtte's Bridal Wreath

Rosa (in variety)

Native Rose

Rosa rugosa

Japanese Rose

Shepherdia argentea

Buffalo Berry

Shepherdia canadensis (on lime)

Canadian Buffalo Berry Snowberry

e. Shady places:

Acer saccharinum Silver Maple

Crataegus monogyna

English Hawthorn

Lonicera xylosteum

Fly Bush Honeysuckle

Philadelphus coronarius Common Mock Orange

Spiraea vanhouttei

Van Houtte's Bridal Wreath

Symphoricarpos racemosus

Snowberry 


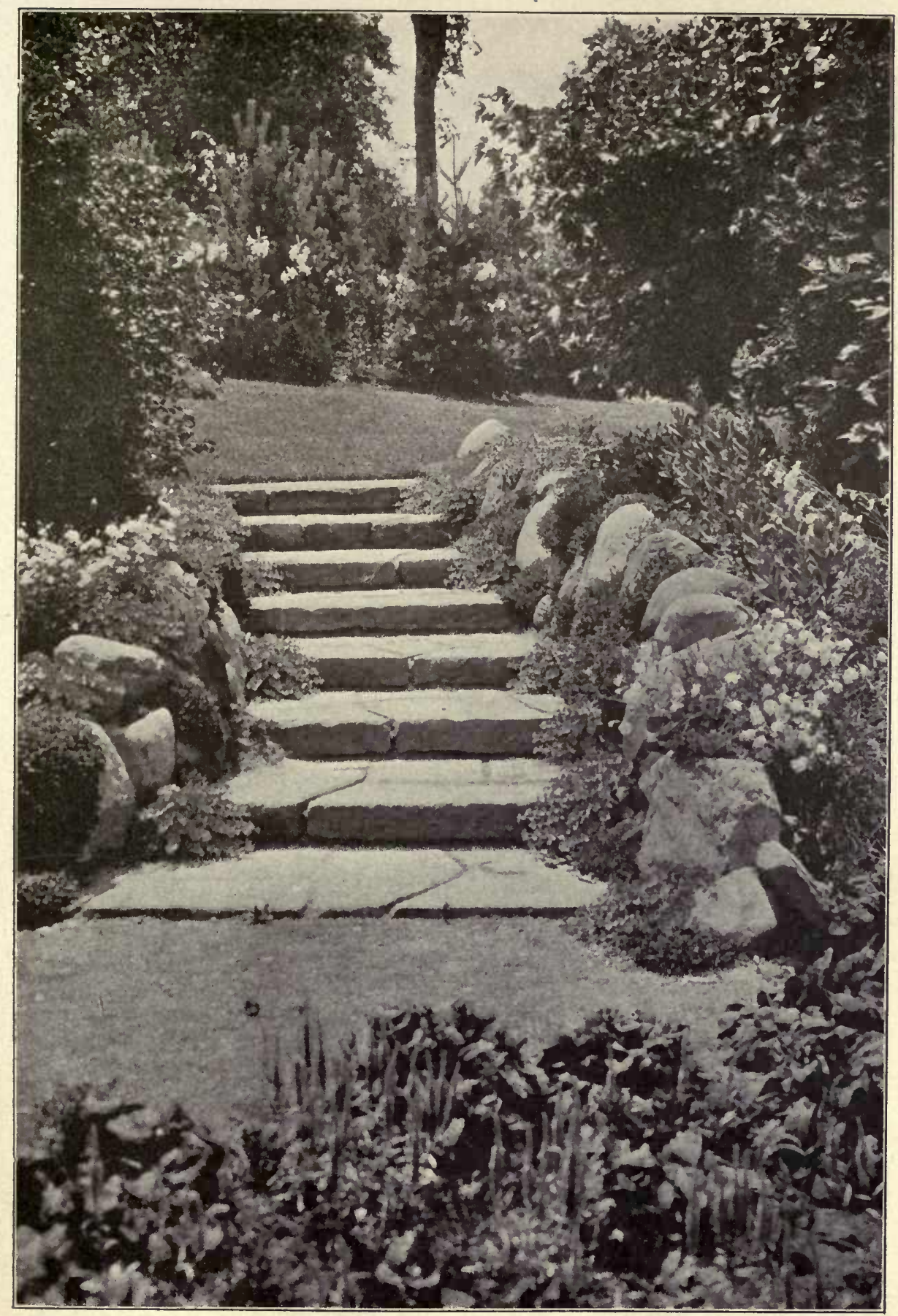

Plate XX. An effective combination of stone work and of plantings in an informal lawn. Varieties of stonecrop, moss pinks and Scotch pinks lend charm to an otherwise uninteresting mass of stone. (See plate LIII, page 334, for lily planting shown in background of this picture.) (See page 139) 


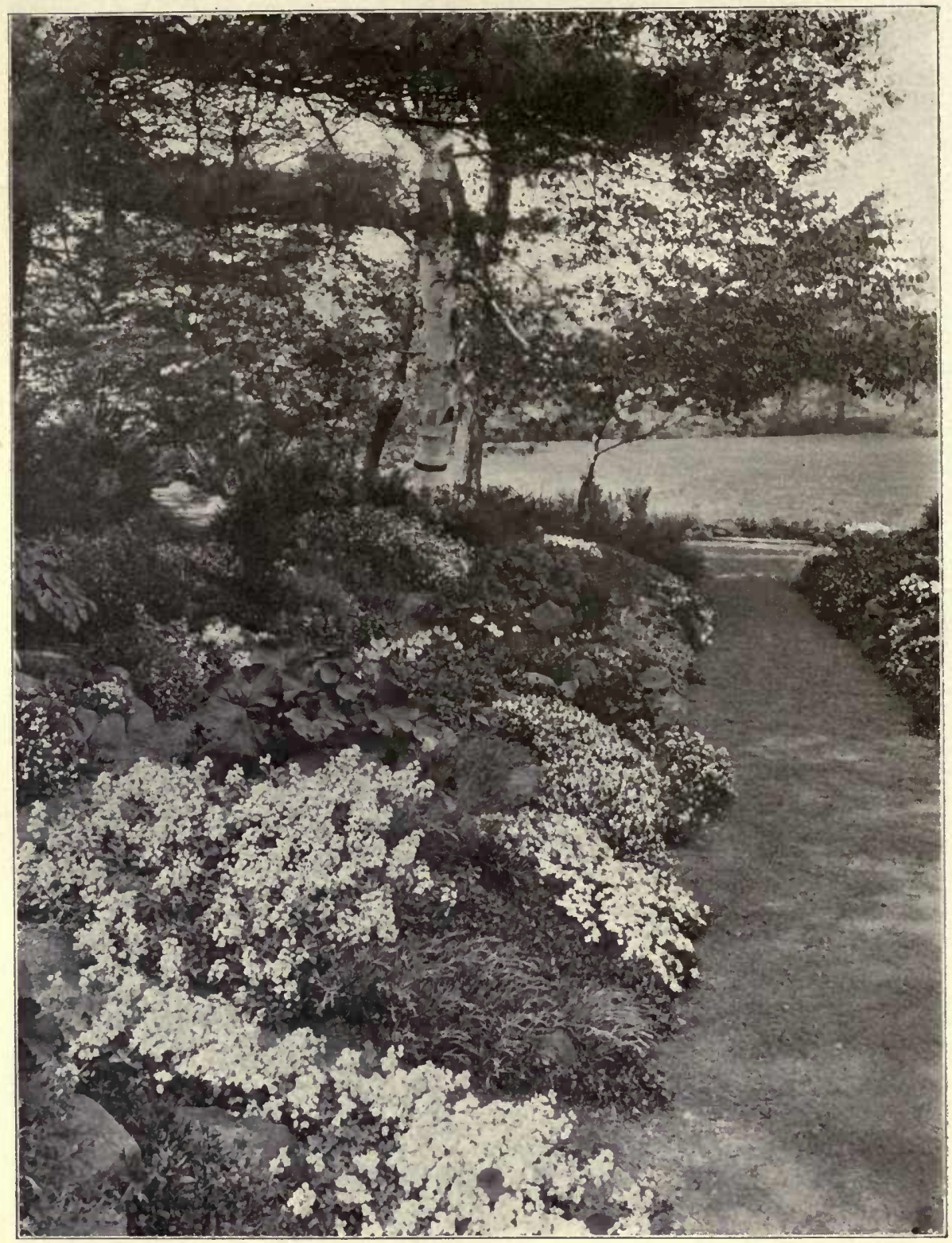

Plate XXI. An uninteresting rocky slope often can be turned into an attractive landscape feature through the careful selection and planting of plants adapted to light, sandy soils. This slope is covered with a grouping of hardy pinks, evergreen candy-tuft, saxifrage and tufted pansy. (See page 139) 


\section{CHAPTER XIII}

\section{PLANTS FOR BORDER PLANTING}

A VERY important question in the proper development of a lawn is how to give it a background and suitable enclosure of trees and shrubs. This chapter is especially concerned with the types of shrubs which are used as masses of planting in the shrub borders. These shrubs may be used in isolated groups or in a continuous border, the object of either method of arrangement being to provide a frame for the picture.

There are two types of lawns: the refined lawn area, and the more natural lawn area which fits into the existing landscape and which is not kept as well mowed and as neatly edged. The refined lawn area requires a type of shrub planting which must be neat in its outlines, possessing an interesting touch of foliage, flowers, and fruit, and naturally making a compact mass. This material is usually selected from the refined types of nursery-grown stock such as spirea, privet, snowball, golden bell, honeysuckle, and mock-orange.

In every border planting, if carefully analyzed, there will be found three distinct types of shrubs: those which are tall growing, averaging from seven to ten feet in height; those which are of medium growth, averaging from four to seven feet in height; and those which are low growing, averaging from two to four feet in height. It is essential properly to group these shrubs in order to have a compact foliage effect carrying from the higher shrubs through the lower shrubs to meet the turf.

It is very important, however, in the grouping of the different types of low, medium, and tall-growing shrubs in refined plantings not only to know the normal height which the shrubs attain but to know whether the foliage texture on one shrub is extremely fine and that on another shrub extremely coarse. For instance, the Japanese barberry is not used to the best advantage in front of the coarser, medium-growing varieties of flowering currant, sumac, or viburnum. It is much better adapted for use in front of the spirea, white kerria, and privet, shrubs with smaller types of foliage. The reason is that the sudden transition 
from the extremely coarse texture of foliage to the extremely fine texture of foliage creates a discord in the landscape picture.

There are many of the shrubs contained in the second group which are those used to compose border plantations on a large scale where the detailed study of the planting is not its most important side, but rather where the general mass effects seen at a distance produce the interesting effect. Shrubs which are selected for border planting on the refined lawn areas, which are usually much more restricted than the extensive lawns, must stand the test of detailed study at the same time that they prove their value as mass effects.

The shrubs which are valuable for the less-refined and extensive lawn areas may consist of some of the shrubs for refined lawn plantings, such as the snowballs and the honeysuckles; but in general many of these shrubs are more or less native and generally collected locally. It is a difficult task to define the material which should be used in border plantings on the larger lawn areas where the coarser mass effects will meet the requirements. In general, most of the shrubs which are adapted to plantings on the refined lawn areas are adapted to the second type of plantings; but not all of the shrubs included in the second group and adapted to the more unrefined lawn areas are adapted in any way to use on the limited refined lawn areas.

\section{LIST OF PLANTS FOR BORDER PLANTING}

A. Masses for Refined Lawn Areas. This group consists of both low-growing and tall-growing types of shrubs, mostly of a hardy foliage type, neat in the habit of their growth, compact in the texture of their foliage, and comparatively free from the ravages of insects and scale. The evergreen shrubs which can appropriately be interjected into border plantings are few in number and must be used sparingly. They are omitted from the following altogether.

a. Low-growing shrubs (approximately three feet tall):

Berberis thunbergi
Thunberg's Japanese Barberry
Callicarpa purpurea
Beauty Fruit
Caryopteris incana
Blue Spirea
Deutzia gracilis
Slender Deutzia

Berberis thunbergi

Callicarpa purpurea

Beauty Fruit

Caryopieris incana

Deutzia gracilis

Slender Deutzia
Deutzia lemoinei

Lemoine's Deutzia

Hypericum moserianum

Gold Flower

Hypericum patulum henryi

Hybrid St. John's Wort

Kerria japonica

Globe Flower 


\section{PLANTS FOR BORDER PLANTING}

Myrica cerifera

Bayberry

Rosa spinosissima

Scotch Rose

Spiraea arguta

Hybrid Snow Garland

Spirae bumalda anthony waterer

Crimson Spirea
Spiraea japonica alba

Dwarf White Spirea

Stephanandra flexuosa Stephanandra

Symphoricarpos racemosus

Snowberry

Symphoricarpos oulgaris

Indian Currant

Xanthorrhiza apiifolia

Yellowroot

b. Medium-growing shrubs (from four to seven feet tall):

Amelanchier rotundifolia

June Berry

Aralia pentaphylla

Five-leaved Angelica

Cornus (in variety)

Dogwood

Cotoneaster dielsiana

Chinese Cotoneaster

Cotoneaster lucida

Hybrid Cotoneaster

Diervilla hybrida-Eva Rathke

Hybrid Weigela

Evonymus alatus

Cork-barked Burning Bush

Evonymus yedoensis

Japanese Spindle Tree

Forsythia intermedia spectabilis

Hybrid Golden Bell

Ligustrum amurense

Amoor River Privet

Ligustrum ibota regelianum

Regel's Privet

Magnolia stellata

Starry Magnolia

Prunus japonica (in variety)

Flowering Almond
Prunus triloba

Flowering Plum

Rhodotypos kerrioides

White Kerria

Rhus canadensis (horizontal form)

Fragrant Sumac

Rhus copallina

Shining Sumac

Ribes aureum

Flowering Currant

Sophora viciifolia

Sophora

Spiraea prunifolia

Bridal Wreath

Spiraea vanhouttei

Van Houtte's Bridal Wreath

Spiraea veitchi

Veitch's Spirea

Syringa persica

Persian Lilac

Viburnum carlesi

Korean Viburnum

Viburnum cassinoides

Withe-rod

Viburnum dilatatum

Japanese Bush Cranberry

$V$ iburnum tomentosum

Single Japanese Snowball

c. Tall-growing shrubs (growing over seven feet tall):

Cercis canadensis

Red-bud

Diervilla floribunda

Pink Weigela

Diervilla florida

Rose-coloured Weigela
Evonymus bungeanus Bunge's Spindle Tree

Evonymus europaeus European Spindle Tree

Exochorda grandiflora

Pearl Bush 
Forsythia intermedia

Hybrid Golden Bell

Forsythia suspensa fortunei

Fortune's Golden Bell

Forsythia viridissima

Dark Green Golden Bell

Lonicera bella

Zabel's Honeysuckle

Lonicera maacki

Late-blooming Honeysuckle

Lonicera morrowi

Japanese Bush Honeysuckle
Lonicera tatarica

Tartarian Honeysuckle

Philadelphus coronarius

Common Mock Orange

Philadelphus falconeri

Falconer's Mock Orange

Syringa (in variety)

Lilac

Viburnum lantana

Wayfaring Tree

Viburnum lentago

Sheep Berry

Viburnum opulus

High Bush Cranberry

B. Masses Consisting Mostly of Native Collected Shrubs. This group consists mostly of shrubs which are indigenous to the section of the country where they are used. These plants are adapted to plantations on a large or small scale, where a feeling of formality or of definite refinement of detail is not required. It is difficult to differentiate fully between the two groups in this chapter. A number of shrubs may equally well, under expert selection and placing, be used in either group interchangeably.

a. Low-growing shrubs:

Aralea lutea

Flame-coloured Azalea

Aralea nudiflora

Pinkster Flower

Azalea vaseyi

Carolina Azalea

Callicarpa purpurea

Beauty Fruit

Ceanothus americanus

New Jersey Tea

Compronia asplenifolia

Sweet Fern

Diervilla trifida

Bush Honeysuckle
Filipendula purpurea

Steeple Bush

Hypericum aureum

Large-flowered St. John's Wort

Itea virginica

Virginian Willow

Myrica cerifera

Bayberry

Rhodora canadensis

Rhodora

Rosa nitida

Shining-leaved Rose

Symphoricarpos racemosus

Snowberry

Symphoricarpos oulgaris

Indian Currant

b. Medium-growing shrubs:

Amorpha fruticosa

False Indigo

Aronia arbutifolia

Red Chokeberry
Aronia melanocarpa

Black Chokeberry

Azalea arborescens

Smooth Azalea 


\section{PLANTS FOR BORDER PLANTING}

Calycanthus floridus Strawberry Shrub

Cephalanthus occidentalis Button Bush

Clethra alnifolia Sweet Pepper Bush

Dirca palustris

Leatherwood

Evonymus americanus Strawberry Bush

Hydrangea arborescens Wild Hydrangea

c. Tall-growing shrubs:

Amelanchier canadensis Shad-bush

Chionanthus virginica

White Fringe

Cornus florida

Flowering Dogwood

Corylus americana Hazelnut

Crataegus (in variety) Thorn

Evonymus atropurpureus Burning Bush
Ilex glabra Inkberry

Kalmia

Laurel

Rhododendron (in variety)

Rhododendron

Rhus canadensis

Fragrant Sumac

Roses

(In variety)

Viburnum acerifolium

Maple-leaved Viburnum

Hamamelis virginiana

Witch Hazel

Ilex verticillata

Winterberry

Pyrus (in variety)

Crab

Sambucus canadensis American Elder

Sambucus racemosa Red-berried Elder

Staphylea trifolia American Bladder-nut

Viburnum (in variety)

Viburnum 


\section{CHAPTER XIV}

\section{ACCENT AND SPECIMEN TREES AND SHRUBS}

There are two kinds of specimen plants, those which are used as single specimens, with full space allowed for their normal development, and those which are used as accent plants in masses of border planting, because, as such, on account of their flowering and foliage habits, they lend a definite touch of interest to the plantation.

The various plants included in this group are those which have a normal symmetrical habit of growth, or those which can easily be kept in a neat, symmetrical outline. In order fully to understand the difference between specimen trees and shrubs, and trees and shrubs for border plantings in groups, the reader should first know that many of our trees and shrubs are not adapted to so-called "mass plantings." Under the crowded condition of mass plantings these trees and shrubs do not produce any of their interesting characteristics of flowers and general outline. Much dead growth becomes evident on account of the exclusion of light and air necessary for their proper development. It is necessary to examine but a few plantations further to know that many trees and shrubs most interesting when used as individual specimens or as groups of two or three plants make a most uninteresting group when massed in quantity.

In general it may be said that specimen piants are used as such because of their fruiting habit, flowering habit, interesting outline, or general foliage effect, which is evidenced at its best when the material is planterl as ințividual specimens.

So-called specimen plants in this group are often used as accent plants in the larger and massed plantations, because of the quality of the flowers, the colour of the foliage, the habit of their growth, or the texture and colour of twigs. Many specimen plants can be used to good advantage scattered here and there in the border plantations to emphasize one or more of these interesting characteristics, and they sometimes are even more effectively used in this way as accent plants than as specimen plants on the lawn.

Whenever material is selected as specimen material it should be 
planted as such, and space should be provided wherein the plants can develop their individual and normal characteristic habits of growth; but when they are used as accent plants it is not so essential to provide space for normal development. Illustrations of this may be seen in the use of the burning bush, the sourwood, and the silver bell.

\section{LIST OF ACCENT AND SPECIMEN TREES AND SHRUBS}

The types of plants in these two groups are sometimes used in large masses as specimens or as accent plants. The best effect as specimens is obtained when they are used singly and as accent plants when they are used either singly or in groups varying from one to three specimens. These plants are valuable because of flowers, foliage, habit of growth, texture of growth, colour of twigs, or fruiting effect.

A. Trees.

a. Accent and specimen trees:

Abies (in variety) Fir

Acer palmatum (in variety) Japanese Maple

Acer platanoides schwedleri Schwedler's Purple Maple

Aesculus (in variety) Horse-chestnut

Betula (in variety) Birch

Catalpa bungei Round-leaved Catalpa

Cercidiphyllum japonicum Kadsura Tree

Cercis canadensis Red-bud

Chamaecyparis (in variety) Cypress

Cladrastris lutea Yellow-wood

Cornus florida Flowering Dogwood

Cornus kousa Japanese Dogwood

Crataegus (in variety) Thorn

Fagus (in variety) Beech

Fagus sylvatica heterophylla Fern-leaved European Beech
Juniperus virginiana Red Cedar

Koelreuteria paniculata Varnish Tree

Larix (in variety) Larch

Liquidambar styracifua Sweet Gum

Magnolia (in variety) Magnolia

Morus alba tatarica pendula Tea's Weeping Mulberry

Nyssa sylvatica

Tupela.

Oxydendrum arboreum Sourwood

Picea (in variety) Spruce

Pinus (in variety) " Pine

Populus alba pyramidalis Bolle's Poplar

Populus nigra italica Lombardy Poplar

Prunus fruticosa pendula Weeping Cherry

Prunus pacius commutata Hybrid European Bird Cherry

Prunus persica

Flowering Peach 
Prunus pissardi

Purple-leaved Plum

Pyrus (in variety)

Crab

Quercus (in variety)

Oak

Salix blanda

Wisconsin Weeping Willow

Salix vitellina britzensis

Hybrid Yellow Willow

Sciadopitys verticillata

Umbrella Pine
Sorbus quercifolia

Oak-leaved Mountain Ash

Taxodium distichum

Bald Cypress

Tilia tomentosa

Silver Linden

Thuja (in variety)

Arborvitae

Tsuga canadensis (in variety)

Canadian Hemlock

Ulmus foliacea wheatleyi

Wheatley's Cornish Elm

Ulmus glabra camperdowni

Camperdown Weeping Elm

\section{b. Columnar and pyramidal trees:}

Oftentimes situations arise in the solution of landscape problems where the use of trees for their pyramidal or columnar habit of growth becomes almost a necessity. This necessity may arise because of such features being an important part of the landscape composition, or it may arise because of the screen effect which the designer is desirous of producing where trees must develop within a narrow space of from two to four feet. Most of the trees in this group develop normally into a pyramidal or columnar form like the pyramidal maples, the poplars, and the red cedar, quite unlike the spreading habit of the sugar maples, horse-chestnut, and beech. None of these trees lend themselves to use in plantations where a broad, informal character is desired in the picture; but all lend themselves for use in landscape planting where it is necessary to have a background of heavy foliage and an immediate garden planting close to these trees. The planter should always bear in mind that a background of trees of this type, planted closely together, will be very injurious to a flower garden development, provided the screen planting is located on the southerly side of the flower garden, thus throwing dense shade over the garden during the greater part of the day. From another point of view, however, this type of tree planted closely together will prove a wonderful asset if planted on the southerly side of some fountain or garden terminus where it is desired to produce a heavy shade.

Abies brachyphylla

Nikko Fir

Abies concolor

White Fis
Acer Saccharinum pyramidale Pyramidal Silver Maple

Acer saccharum monumentale

Pyramidal Sugar Maple 


\section{ACCENT AND SPECIMEN TREES AND SHRUBS}

Betula alba fastigiata

Pyramidal White Birch

Carpinus betulus fastigiata Pyramidal Hornbeam

Chamaecyparis lawsoniana Lawson's Cypress

Juniperus communis suecica Swedish Juniper

Juniperus virginiana pyramidalis Pyramidal Red Cedar

Juniperus virginiana schotti Schott's Red Cedar

Liriodendron tulipifera pyramidalis Pyramidal Tulip Tree

Picea excelsa columnaris Columnar Norway Spruce

Picea excelsa pyramidalis Pyramidal Norway Spruce

Populus alba pyramidalis Bolle's Poplar

Populus nigra italica Lombardy Poplar

Quercus robur pyramidalis Pyramidal English Oak

Robinia pseudacacia pyramidalis Pyramidal Black Locust

Sorbus hybrida fastigiata Pyramidal Mountain Ash

Taxodium distichum pyramidatum Pyramidal Bald Cypress

Thuja occidentalis fastigiata Fastigiate Arborvitae

Thuja occidentalis plicata Pyramidal Arborvitae

Thuja orientalis pyramidalis Columnar Oriental Arborvitae

Tsuga heterophylla Western Hemlock

Ulmus foliacea dampieri Fastigiate Elm

Ulmus foliacea wheatleyi

Wheatley's Cornish Elm

\section{B. Shrubs.}

Aesculus parviflora

Dwarf Horse-chestnut

Azalea (in variety)

$$
\text { Azalea }
$$

Caragana arborescens Siberian Pea Shrub

Chaenomeles japonica Japanese Quince

Chionanthus retusa Chinese Fringe Tree

Chionanthus virginica White Fringe

Cornus stolonifera flavirammea Golden-twigged Osier

Corylus maxima purpurea Purple-leaved Hazel

Diervilla hybrida lutea-marginata Variegated Weigela

Deutzia scabra Single White Deutzia

Evonymus alatus Cork-barked Burning Bush

Evonymus americanus Strawberry Bush
Evonymus europaeus European Spindle Tree

Exochorda grandiflora

Pearl Bush

Halesia carolina

Silver Bell

Hibiscus syriacus

Rose of Sharon

$H y d r a n g e a$ (in variety)

Hydrangea

Prunus japonica

Flowering Almond

Prunus triloba

Flowering Plum

Rhus cotinus

Smoke Bush

Robinia hispida (grafted high)

Rose Acacia

Sambucus canadensis aurea Golden Elder

Stewartia pentagyna Alleghany Stewartia

Tamarix odessana Caspian Tamarisk 


\section{CHAPTER XV}

\section{PLANTS VALUABLE FOR USE IN ROCK GARDENS, IN JAPANESE GARDENS, AND IN WALL CREVICES}

A FULLY developed estate to-day is not complete without an interesting rock garden, not because it gives an interesting physical variety to the landscape, but because it provides an opportunity for the development of one of our most interesting groups of plants, those plants which grow their best and prove most interesting in a miniature landscape of this rocky character. These gardens have been developed to perfection on many English estates.

The group of plants valuable for the development of rock garden work is comparatively little known to the amateur, and yet there are used in rock gardens many interesting types frequently used for other purposes. It is true that many of the plants grown for rock gardens are very dwarf in their habit of growth and much more sensitive to changed conditions of soil and exposure, and that many of them therefore require expert labour for their normal development.

The most interesting group of plants, perhaps, for rock garden work, includes the planits known as "alpine" plants, which are low-growing, very dense, and compact in their habit of growth. Most of these plants have small leaves and the flowers are rather brilliant and marked in their colours. The term "alpine" plants to-day is applied in its general use to that dwarf and low-growing group of plants which have a tendency to compactness of habit, and which in their mature form of development seem to fit into the confined atmosphere of the average rock garden. The true rock garden plants may perhaps be the "alpine" types, but those plants which landscape architects use to-day for rock garden purposes include not only the "alpine" types but many small plants, even though they come from the lowlands, from the woods, or from the more arid desert sections. There are a few of the tall-growing types of plants, such as foxgloves and some of the single roses, which, though not dwarf in character, are admirably fitted to the scale of rock garden work. 
To one who is in the beginning of this work of selecting plants for rock garden use the impression should not be conveyed that every plant which is dwarf in its habit of growth is desirable for the rock garden. Many of these plants are extremely undesirable, such as the creeping Jenny (lysimachia) and dead nettle (lamium maculatum), mostly because of their tendency to grow rampant and to crowd out and smother many of the more sensitive and more beautiful types of rock garden plants. These plants are also difficult to eradicate from the garden when once they become established. They should never be used except in a rock garden on an extensive scale where the tendency to spread will not eventually become offensive. In order to maintain the true rock garden character it is very essential that plants should be selected which are in harmony with the spirit of the garden. Many so-called rock gardens are filled with the more common annuals, with sweet williams, phlox, hollyhocks, and even large irises-plants which belong to an entirely different type of garden, or which, because of their size, are not in keeping with the scale of a minutely detailed rock garden.

It is not necessary, in the development of an interesting rock garden, to use a large quantity of different types of plants. The success of a rock garden is dependent largely upon the ability of the designer to select proper types of plants for a specific purpose, whether the rock garden be very small and occupying only a corner of the lawn, or whether it be an extensive area in some wooded portion of the property. Such plants as hydrangeas, spireas, petunias, and many plants of these types which the reader has often seen in rock garden work, give evidence immediately of the lack of knowledge of plants and of their proper usage.

It is true also that the plants which are used in rock gardens require an amount of care in their maintenance equal to that given plants in the more refined and formal types of garden work.

For the person who has progressed along the path of successful rock gardening it might be well to suggest that he should endeavour to become intimately acquainted with the plants which he is using, especially their source of origin and the conditions under which they grew in their native locations. Plants which will withstand extreme drought, hot suns, and extreme cold, if they are planted in the correct locations in a rock garden, will not be hardy to any extent when planted in the open border. In other words, such plants as the cheddar pink 
and the wild pink are considered to be true crevice plants, and they should be used only for that purpose in rock garden work. These plants have a type of environment equally as much as persons or animals and under which they thrive best. The beginner who is developing this type of garden should therefore only use the more common types of plants which have withstood the abuse of "amateurs" and should make use of the specialized plants only after a thorough knowledge is gained concerning them.

One writer has said concerning the development of a rock garden that the designer should "have an idea and stick to it." We see so many rock gardens which are so-called and which in reality are only a miscellaneous pile of stones. Rock gardens in their true sense are an imitation of some condition of nature, both from their physical makeup and from their planting. We should therefore make a double effort to strive toward the development of the idea.

One of the most successful ways for obtaining good rock garden plants is to grow them from seed. It is often easier to seed plants in rock garden groups than it is to plant nursery-grown stock.

\section{LIST OF PLANTS VALUABLE FOR USE IN ROCK GARDENS, IN JAPANESE GARDENS, AND IN WALL CREVICES}

A. Evergreens. In every garden development of this kind, a touch of evergreen foliage, the texture of which is peculiar to evergreen plantings, is essential to lend the desired interest to the garden. These evergreens are extremely dwarf in character and not vigorous in their habit of growth.

Buxus suffruticosa Dwarf Box

Chamaecyparis obtusa nana Dwarf Japanese Cypress

Chamaecyparis obtusa nana aurea Dwarf Golden Japanese Cypress

Cornus canadensis Bunchberry

Daphne cneorum Garland Flower

Erica vagans Cornish Heath

Gaultheria procumbens Wintergreen

Juniperus communis Common Juniper
Juniperus sabina Savin Juniper

Juniperus sabina tamariscifolia Tamarisk-leaved Savin

Linnaea borealis Twin Flower

Mahonia repens Creeping Mahonia

Pachistima canbyi Canby's Mountain Lover

Pachysandra terminalis Japanese Spurge

Picea excelsa gregoriana Gregory's Dwarf Norway Spruce

Pieris floribunda Mountain Fetterbush 
Pinus montana mughus Dwarf Mountain Pine

Pyxidanthera barbulata Flowering Moss

Rhododendron carolinianum Dwarf Rhododendron

Rhododendron ferrugineum Rusty-leaved Rhododendron
Shortia galacifolia

Shortia

Taxus baccata repandens Spreading English Yew

Taxus canadensis Ground Yew

Taxus cuspidata nana Japanese Yew

B. Deciduous Trees and Shrubs. Trees used in gardens of this kind must be the low-growing types with a compact habit of growth, and the shrubs also must be types which will lend themselves readily to the character of this kind of garden. It is hardly possible to define in words the exact character which the shrubbery must possess in order to be valuable for this type of planting. The trees and shrubs in this group may be used with safety, and there are many other shrubs which can be selected from other lists and used by experts.

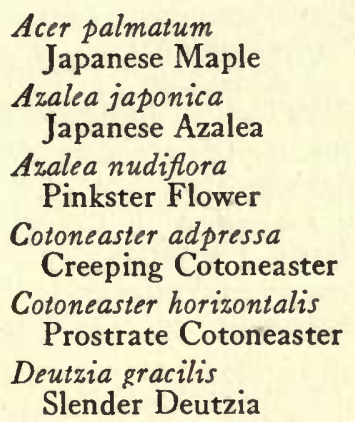

Evonymus obovatus Running Strawberry Bush Hypericum moserianum Gold-flower

Lonicera spinosa alberti Large-fruited Honeysuckle

Philadelphus coronarius nanus Dwarf Mock Orange

Rhodora canadensis Rhodora

Viburnum opulus nanum Dwarf Bush Cranberry

C. Perennials. This group of plants forms one of the most interesting phases of rock garden development. Most of these perennials are either heavy in their texture of foliage, or very dwarf in their habit of growth. They will adapt themselves to cultivation in the congested spaces so often found in garden developments of this kind.

Achillea boule de neige

Ball of Snow

*Alyssum argenteum Silvery Madwort

* Alyssum saxatile compactum Golden Tuft

Anemone pennsylvanica

Canadian Windflower

Aquilegia canadensis

American Columbine
* Arabis alpina nana compacta Dwarf Alpine Rock Cress

* Arenaria montana

Sandwort

Campanula carpatica Carpathian Harebell

Centaurea montana Mountain Bluet

*Cerastium tomentosum

Snow-in-summer

*Plants especially well adapted for use in crevices of walls and paved areas. 
Ceratostigma plumbaginoides

Leadwort

Coreopsis verticillata

Dwarf Tickseed

Coronilla varia

Crown Vetch

Dalibarda repens

Barren Strawberry

*Dianthus deltoides

Maiden Pink

*Dianthus plumarius

Scotch Pink

Dicentra eximia

Wild Bleeding Heart

Dodecatheon media

Shooting Star

Draba azoides

Aizoon-like Whitlow Grass

Epimedium macranthum

Japanese Barrenwort

Erysimum pulchellum

Rock-loving Hedge Mustard

Euphorbia corollata

Flowering Spurge

Geranium sanguineum

Crane's Bill

Hedera helix conglomerata

Small-leaved English Ivy

Helianthemum croceum

Rock Rose

Heuchera brizoides

Red Coral-bells

Heuchera sanguinea

Coral-bells

Iberis sempervirens

Evergreen Candytuft

Iris cristata

Crested Iris

Linaria cymbalaria

Kenilworth Ivy

Linaria cymbalaria maxima

Large-flowered Kenilworth Ivy

Linum perenne

Perennial Flax

Lychnis viscaria splendens

Ragged Robin

Mitchella repens

Partridge Berry
Nepeta mussini Catmint

Pachysandra terminalis Japanese Spurge

*Phlox stolonifera Creeping Phlox

Phlox subulata Moss Pink

Primula veris English Cowslip

Ranunculus acris flore pleno Double Buttercup

Saponaria ocymoides Rock Soapwort

Saxifraga cordifolia Saxifrage

*Sedum acre Mossy Stonecrop

*Sedum album White Stonecrop

* Sedum sexangulare Dark Green Stonecrop

Sedum spectabile Brilliant Stonecrop

Silene maritima Seaside Campion

Silene pennsylvanica Wild Pink

Silene schafia Autumn Campion

Stellaria holostea Starwort

Stokesia cyanea Stokes' Aster

Thalictrum aquilegifolium Meadow-rue

*Thymus serpyllum languinosus Downy Thyme

*Tunica saxifraga Saxifrage-like Tunica

$V$ ancouveria hexandra American Barrenwort

Veronica incana Hoary Speedwell

*Veronica repens Creeping Speedwell

Vinca minor Periwinkle

Viola (various species) Violet

*Plants especially well adapted for use in crevices of walls and paved areas. 


\section{CHAPTER XVI}

\section{PLANTS FOR HEAVY FORMAL EFFECTS}

WhILE many trees and shrubs in the hands of expert designers and gardeners may be used interchangeably for either formal or informal effects, the fact still remains that there is a group of plants which are best adapted for use to produce the heavier and more compact formal effects. The effect of formality is obtained by emphasizing geometric lines or surfaces. Plants which are upright, slow-growing, and more compact in their habit, are better adapted for this purpose than plants which are more vigorous in their habit of growth, more spreading, and looser in texture and therefore less apt to retain a consistent, definite form.

The expert may select plants from Chapter XVII and in many instances produce an effect equally as attractive as that produced by plants in this group. The possibilities of failure, however, are much greater, and the subsequent necessity of pruning to retain approximate forms is much greater.

We speak of heavy formality as a contrasting term to plants which are loose. Compact may be a better word. It is often necessary to develop border plantations surrounding lawns filled with a feeling of formality, because of numerous axial lines, and also to surround or border definite formal garden areas with trees and shrubs. To be successful these masses of plants must lend themselves to this formal effect. They must be such as can be kept within definite limits with the normal amount of pruning. The European hornbeam, the red cedar, pyramidal arborvitae, and tartarian honeysuckle are excellent illustrations of this type of material. A so-called formal effect in a border planting is not necessarily produced by the use of trees. It may be equally well produced by shrubs depending upon the scale of the landscape setting. It is not necessary either to resort to the use of evergreens, although there are certain types of architectural details beside which deciduous plantings appear "weak." Climatic conditions being favourable for a normal growth of the type of material 
best suited, the decision to use evergreens or deciduous material will be governed by the effect which is desired.

Topiary work as a type of planting producing formal effects is the extreme of artificial methods. Trees and shrubs which are selected for this purpose are included almost without exception in the group known as "evergreens and broad-leaved evergreens," such as the yews, holly, and boxwoods. The hawthorn and the beech are the marked exceptions to this general rule, and are plants capable of severe pruning to produce artificial and fantastic shapes. These plants must lend themselves readily to frequent and to severe prunings in order to produce these forms. While topiary work as a matter of design is extremely limited in its application, there will often arise situations in which this extreme and violent treatment to produce the artificial forms in plants is justified. Topiary work has at times been very appropriately termed verdant sculpture. It is nothing more nor less than sculpture in plant forms so far as plants will lend themselves to details of such experiments. All of these plants which are especially adapted to topiary work are extremely slow growing and long lived. While many fantastic forms can be developed from such plants as the privet and hawthorn within a comparatively short period, the rare, more perfect, and permanent forms are usually the result of using the boxwood or yew. Most of these trees which are adapted to topiary work, especially the pyramidal form of topiary work, are upright growing, single-stemmed specimens. Plants which are adapted to these effects must also be of a compact texture with foliage evenly developed to a point close to the ground.

There are many deciduous plants which, while not being adapted to topiary work, are adapted to close shearing to produce formal effects. Many experts do not realize that there are various species of the same genera which lend themselves much more effectively to close shearing in definite forms than other species of that genera. The Japanese privet is much more effective in the lower hedge of two to four feet, because of its tendency to "mat," than the.Amoor River privet, which has a tendency to make long growths. All of the deciduous plants in these groups are comparatively slow in growing habit. . They have a tendency to frequent branching and a further tendency to throw out new growths from dormant buds when the ends of the existing branches are removed.

While there is a considerable list of plants which are adapted for 


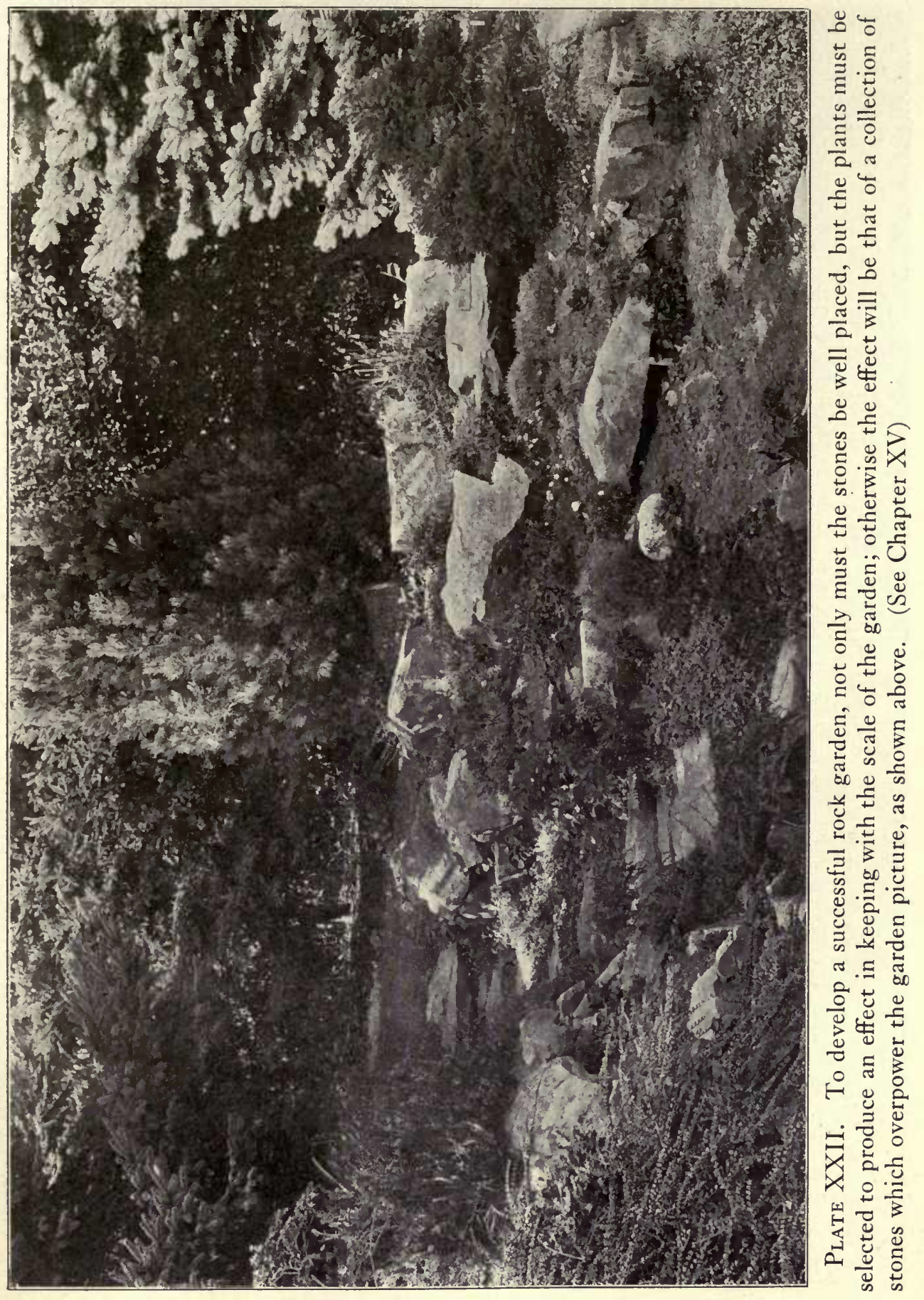




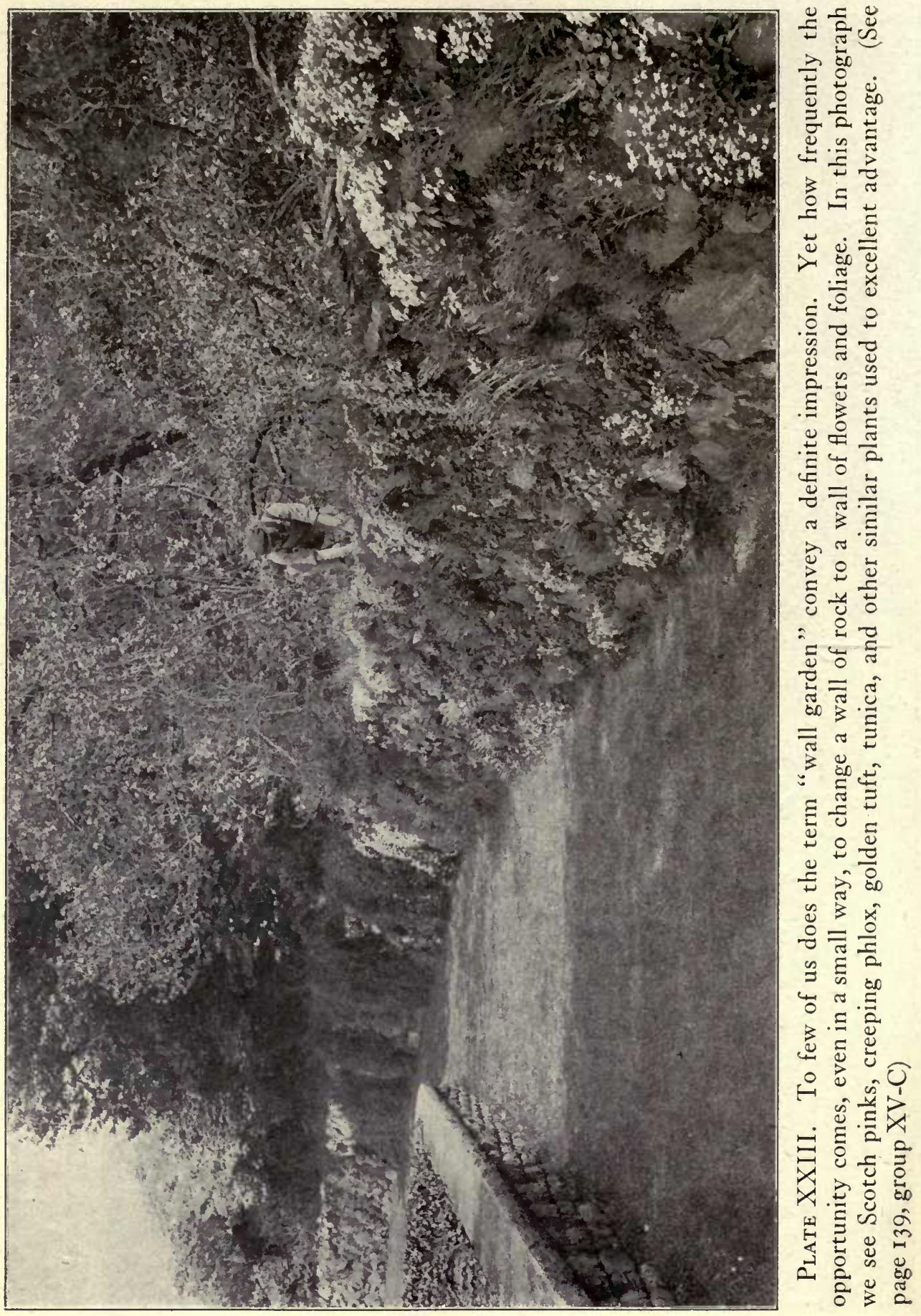


grorring in tubs, as frequently seen, for accent points in a formal garden or on a terrace, the amateur should best confine himself to the Japanese laurel, the evergreen evonymus, the greenhouse hydrangea, pyramidal arborvitae, and the boxwood. Most of these should be transferred during the winter months, preferably to a cold cellar or to a cold house, and even those which are semi-hardy, if left out of doors, should be carefully boxed and protected.

Perhaps the most interesting groups of trees and shrubs for formal effects are those which are valuable for use in pleached allees. This feature in the design of large estates has not yet reached its height and will become more popular with the development of landscape design as applied to American estates and gardens. The plants of this group must be resistant to disease and insect pests and they must be able to thrive under conditions of severe pruning. The one most important requisite is that they shall be long lived and not easily broken by winter storms. The texture of branching must be close. To use for pleached allees trees, such as the birches, which are short lived and which always begin to deteriorate at a time when the allee should be most picturesque and at its height, is landscape folly. It takes years, five to eight years, to develop a pleached allee so that the tops will come together. To endeavour to hasten the growth of plants by excessive fertilization during the first two or three years will have a tendency to split the bark and to expose the trunks to severe injury from freezing and rotting. These plants should be of a spreading habit of growth as contrasted with the columnar habit of growth desired for open allees. While these specimens are planted at intervals of eighteen to twentyfour inches in rows, it often becomes necessary to interplant with the smaller specimens which will serve as fillers for the base. The normal distance between rows on either side of a pleached allee is six feet to eight feet. It is most advisable to train these plants to the pleached form by the use of iron pipe and wire. This can be done by a skilled gardener, by constant attention and the frequent use of pruning shears.

Trees and shrubs for open allees must meet the one requirement of being close growing and columnar in their habit. An open allee may be developed with rapid-growing material as well as with slow-growing material, and the time required is less than two-thirds as long as the time required to develop a pleached allee of the same height. Six to ten years may be required to develop an open allee eight to ten feet in height. The scale of the allee, whether wide, with a tall border 
on either side, or narrow, with a lower border, governs the type of material which should be selected. Here again, with such plants as the thorns and elms, a larger specimen may be used with a high head, and the smaller specimens may be planted between and on either side to produce the mass of foliage at the bottom. An illustration of this is shown in plate No. XXVIII on Page 190. This interesting open allee of thorns and flowering dogwood is planted according to the following measurements. The distance between the middle line of each row of thorns is twenty-two feet six inches. Each row was originally planted with high-headed thorns at a distance of four feet six inches apart in the row. Equally spaced at a distance approximating one foot six inches apart, small specimens two feet to three feet high were planted in a single row at a distance of one foot six inches on either side of the main row of thorns. These small thorns were for the purpose of producing a foliage effect beginning at the ground and extending into the higher heads of the larger thorns. The width between the rows of flowering dogwood is eight feet and the distance between each flowering dogwood plant in each row is eight feet. The width of the walk in this picture is four feet. It is very essential to use types which have a branching habit to the extreme base of the main trunk if a perfect open allee is desired.

\section{LIST OF PLANTS FOR HEAVY FORMAL EFFECTS}

A. Border Planting. This group of trees and shrubs is composed of those specimens which either lend themselves to a natural, compact effect when pruned, or which possess an even, close habit of growth, fitting them particularly for formal effects. Plants used for this purpose should not be those which have a tendency to sucker and to make any indifferent growths in different directions.

\author{
Acer saccharinum pyramidale \\ Pyramidal Silver Maple \\ Acer saccharum monumentale \\ Columnar Sugar Maple \\ Betula alba fastigiata \\ Pyramidal White Birch \\ Carpinus betulus \\ European Hornbeam \\ Catalpa bungei \\ Round-leaved Catalpa \\ Cercidiphyllum japonicum \\ Kadsura Tree
}

Hibiscus syriacus Rose of Sharon

Juniperus communis hibernica Irish Juniper

Juniperus communis suecica Swedish Juniper

Juniperus virginiana Red Cedar

Juniperus virginiana cannarti Columnar Tufted Cedar

Juniperus virginiana glauca Blue Virginia Cedar 


\section{PLANTS FOR HEAVY FORMAL EFFECTS}

Juniperus virginiana schotti

Schott's Red Cedar

Lonicera tatarica

Tartarian Honeysuckle

Picea excelsa pyramidalis

Pyramidal Norway Spruce

Populus alba pyramidalis

Bolle's Poplar
Populus nigra italica

Lombardy Poplar

Quercus robur fastigiata

English Oak

Sciadopitys verticillata

Umbrella Pine

Thuja occidentalis pyramidalis

Pyramidal Arborvitae

B. Topiary Work and Close Shearing. The plants in these two groups ( $a$ and $b)$ are selected because they will adapt themselves, with careful attention, to close shearing and interesting topiary work. There are many plants which if sheared closely do not produce any effect of foliage until they have recovered from the pruning. All these specimens, however, can be sheared and still retain a mass foliage effect.

a. Evergreen:

Buxus (all sorts)

Boxwood

Chamaecyparis nootkatensis Yellow Cedar

Chamaecyparis obtusa nana Dwarf Japanese Cypress

Ilex crenata Japanese Holly

Picea excelsa

Norway Spruce

Picea orientalis

Oriental Spruce

Pinus cembra

Swiss Stone Pine

Pinus densiflora umbraculifera

Dwarf Japanese Red Pine

Pinus montana

Swiss Mountain Pine

Pinus montana mughus

Dwarf Mountain Pine

Taxus cuspidata

Japanese Yew

Taxus cuspidata nana

Tsuga canadensis

Japanese Yew

Canadian Hemlock

b. Deciduous:

Acer campestre

European Cork Maple

Acer platanoides globosum

Globe Norway Maple

Berberis thunbergi

Thunberg's Japanese Barberry

Carpinus betulus

European Hornbeam

Carpinus betulus globosa

Globe Hornbeam

Catalpa bignonioides nana

Dwarf Indian Bean

Cornus paniculata

Grey Dogwood

Crataegus crus-galli

Cockspur Thorn

Crataegus oxycantha

May Thorn

Evonymus alatus

Cork-barked Burning Bush

Ilex glabra

Inkberry

Ligustrum ibota

Japanese Privet

Ligustrum oulgare

European Privet

Viburnum opulus nanum

Dwarf Bush Cranberry

Viburnum prunifolium

Black Haw 
C. Growing in Tubs. One of the most successful sources of obtaining refinement of detail in formal work is through the use of plants grown in tubs. These are particularly adapted to terraces, areas around pools, and places where plants must be trained for a specific detailed effect, and of tentimes cannot be planted in the ground at the place where the effect is desired.

Abelia grandiflora
Hybrid Abelia
Agapanthus umbellatus
Blue Lily-of-the-Nile
Allamanda (in variety)
Allamanda Vine
Aucuba japonica
Japanese Laurel
Bougainvillea (in variety)
Paper Flower
Buxus (many sorts)
Boxwood
Caryopteris incana
Blue Spirea
Eleagnus pungens
Bronze Oleaster
Eoonymus japonicus
Evergreen Evonymus
Hibiscus rosa-sinensis
Chinese Hibiscus

\author{
Hydrangea opuloides otaksa \\ Hydrangea \\ Lagerstroemia indica \\ Crape Myrtle \\ Laurus nobilis \\ Bay Tree \\ Musa ensete \\ Abyssinian Banana \\ Nerium (in variety) \\ Oleander \\ Pyracantha coccinea lalandi \\ Evergreen Thorn \\ Thuja occidentalis pyramidalis \\ Pyramidal Arborvitae \\ Tabernaemontana (in variety) \\ Crape Jasmine \\ Trained fruit trees \\ (all sorts) \\ Vitex agnus-castus \\ Chaste Tree
}

D. Trees and Shrubs for Allees. All plants which are adapted to allee effects must be of a type which will respond to the operations of severe pruning. Those plants in Group a must have a special adaptation for a spreading habit of growth and yet a compact habit of growth. They must be such plants as will retain their foliage during a considerable period in order to produce and maintain the pleached allee effect. The deciduous and evergreen trees and shrubs shown in Group $b$ of this list are all adapted to types of open allee developments on different scales, to be in keeping with the general landscape effect.

\section{a. Pleached}

\author{
Acer campestre \\ European Cork Maple \\ Carpinus caroliniana \\ American Hornbeam \\ Carpinus betulus \\ European Hornbeam
}

\author{
Corylus maxima \\ Filbert \\ Crataegus oxycantha \\ May Thorn \\ Fagus sylvatica \\ European Beech
}




\section{PLANTS FOR HEAVY FORMAL EFFECTS}

Quercus laurifolia (South of Washington) Salix pentandra

\section{Laurel Oak}

Rhamnus cathartica

Common Buckthorn

b. Not pleached (Open Allees):

I. Deciduous:

Acer saccharinum pyramidale Pyramidal Silver Maple

Acer saccharum monumentale Columnar Sugar Maple

Betula alba fastigiata

Pyramidal White Birch

Crataegus oxycantha

May Thorn

Larix leptolepsis

Japanese Larch

Populus nigra italica

Lombardy Poplar

2. Evergreen:

Abies brachyphylla

Nikko Fir

Juniperus excelsa stricta Slender Greek Juniper

Juniperus virginiana schotti Schott's Red Cedar

Picea excelsa columnaris

Columnar Norway Spruce

Picea excelsa pyramidalis

Pyramidal Norway Spruce
Laurel-leaved Willow

Ulmus campestris

English Elm
Quercus robur fastigiata

English Oak

Sorbus quercifolia

Oak-leaved Mountain Ash

Taxodium distichum

Bald Cypress

Taxus baccata fastigiata

Irish Yew

Ulmus foliacea wheatleyi

Wheatley's Cornish Elm

Ulmus glabra fastigiata

Columnar Elm

\author{
Picea omorika \\ Servian Spruce \\ Thuja occidentalis lutea \\ Oriental Arborvitae \\ Thuja occidentalis wareana \\ Siberian Arborvitae \\ Thuja orientalis (northern grown) \\ Oriental Arborvitae \\ Thuja plicata \\ Western Arborvitae
}




\section{PLANTS FOR NATURAL, INFORMAL EFFECTS}

As contrasted with plants adapted to heavy or compact formal effects the plants of this group have a more open, looser habit of growth. They are apt to be not quite as refined in character in some instances, and they are not required to produce the neat line of foliage which are part of the more formal designs.

It is difficult to define clearly, and to specify, what plants are to be used in informal effects. At the same time, a few standard kinds of plants to be used in the border plantations of lawns, in the border plantations of wild garden areas and informal garden areas should be listed for ready reference. It is much easier to use some of the plants included in the former list, especially those with the more vigorous, open habit of growth, for this type of planting, than to use plants included in this list for the same purpose as those included in the former list. Most large and small lawns which are not developed on definite, formal axial lines, should be bordered with plants of this kind.

The reader is warranted in concluding that all plants not adapted for use in the preceding groups of plants for formal effects are automatically placed in this present group. It is safe to select any plant indigenous to the locality and also many of the introduced horticultural varieties, such as high-bush cranberry, flowering currant and dogwoods. Lilacs, tartarian honeysuckle, and hybrid rhododendrons, however, with greater refinement of foliage and of bloom, on the other hand, are obviously of more value in the more formal plantings.

Collected stock is of great value for natural, informal effects. To reproduce nature and her group effects should be the object of natural, informal planting. A natural planting impresses the observer as does nature untouched by the hand of the designer, and this is a most difficult effect to obtain artificially.

\section{LIST OF PLANTS FOR NATURAL, INFORMAL EFFECTS}

It is difficult to define the effects which it is intended to produce through the use of plants included in this list. In general, these 
plants are selected because they are somewhat irregular in outline, loose in habit and texture of growth, and are not adapted to producing the neat lines of foliage required in formal development.

Amelanchier oblongifolia

Shad-bush

Amelanchier rotundifolia June Berry

Chionanthus virginica White Fringe

Cornus (in variety)

$$
\text { Dogwood }
$$

Deutzia (in variety)

Deutzia

Diervilla (in variety)

Weigela

Forsythia suspensa

Drooping Golden Bell

Hippophae rhamnoides Sea Buckthorn

Laburnum vulgare Golden Chain

Lonicera fragrantissima

Early Fragrant Honeysuckle

Philadelphus grandiflorus

Large-flowered Mock Orange

Physocarpus opulifolius

Ninebark

Prunus avium plena

European Double-flowering Cherry
Ptelea trifoliata

Hop Tree

Rhododendron (in variety)

Native Varieties

Rhus (in variety)

Sumac

Ribes (in variety)

Flowering Currant

Robinia pseudacacia

Black Locust

Rosa rugosa

Japanese Rose

Salix babylonica

Weeping Willow

Sambucus canadensis

American Elder

Spiraea vanhouttei

Van Houtte's Bridal Wreath

Symphoricarpos racemosus

Snowberry

Symphoricarpos oulgaris Indian Currant

Tamarix gallica

French Tamarisk

Viburnum opulus

High-bush Cranberry 


\section{LOW-GROWING PLANTS ALONG THE INNER SIDE OF CURVING ROADWAYS AND AT ENTRANCES}

Plants which are selected for use in this group must have a normally low-growing habit. In general, their maximum height should approximate not more than five to six feet.

If the eventual height of these plants is to be greater than this, they should be of such types as will lend themselves readily to pruning and still retain their natural outlines.

On many private estates, at the sharp curves of entrance drives and on either side of the main entrance, safety of traffic demands that an open view be preserved in order to avoid accidents. It becomes an important question in the development of such plans to decide upon material which should be selected for this purpose. If the degree of care which this material is to receive in the years subsequent to its original planting is that ordinarily given by an expert gardener, the designer may select many taller-growing species of shrubs, which, under this expert care, can be kept within the desired limits of growth. For those who wish to be perfectly safe in their selection, material included in this list represents the general range of the important genera and species which are available.

There are many locations where high planting as a part of the general design is more desirable. In such instances a vista formed by using a group of lower shrubs can be used. If higher shrubs are desirable as a part of the design it is sometimes possible to preserve the open views by setting the tall shrubs farther back from the sides of the drive.

The fragrant honeysuckle is a good substitute where one might otherwise use types such as the tartarian honeysuckle. The pink weigela is much to be preferred to the other, coarser-growing types of weigelas.

\section{LIST OF LOW-GROWING PLANTS ALONG THE INNER SIDE OF CURVING ROADWAYS AND AT ENTRANCES}

The plants in this group are selected because of their low-growing habit. Many other specimens may be used, which under the care of 
an expert gardener can be kept within definite bounds. Where open views are essential and expert care is lacking, the plants indicated in these groups should be used.

\section{A. Evergreen:}

\section{Andromeda polifolia}

Wild Rosemary

Chamaedaphne calyculata

Leather-leaf

Evonymus radicans carrieri

Carrier's Japanese Evergreen Ivy

Evonymus radicans vegetus

Scarlet-fruited Japanese Evergreen Ivy

Juniperus communis depressa

Dwarf Juniper

Juniperus horizontalis

Trailing Juniper

Juniperus sabina tamariscifolia

Tamarisk-leaved Savin

Juniperus virginiana tripartita

Spreading Red Cedar

Kalmia angustifolia

Sheep Laurel (except clay or lime soil)
Mahonia repens

Creeping Mahonia

Picea excelsa gregoriana

Gregory's Dwarf Norway Spruce

Picea excelsa nana

Dwarf Norway Spruce

Pieris floribunda

Mountain Fetterbush

Taxus baccata repandens

Spreading English Yew

Taxus cuspidata brevifolia

Short-leaved Japanese Yew

Thuja occidentalis globosa

Globe Arborvitae

Thuja occidentalis (Little Gem)

Little Gem Arborvitae

Yucca filamentosa

Adam's Needle

\section{Yucca flaccida}

Drooping-leaved Adam's Needle

\section{B. Deciduous:}

Amorpha canescens

Lead Plant

Ceanothus americanus

New Jersey Tea

Celastrus orbiculatus

Japanese Bittersweet

Deutzia gracilis

Slender Deutzia

Deutria lemoinei

Lemoine's Deutzia

Deutzia rosea

Dwarf Pink Deutzia

Diervilla trifida

Bush Honeysuckle

Evonymus obovatus

Running Strawberry Bush

Itea virginica

Virginian Willow
Lonicera fragrantissima

Early Fragrant Honeysuckle

Lonicera japonica halliana Japanese Honeysuckle

Lonicera spinosa alberti

Large-fruited Honeysuckle

Myrica cerifera

Bayberry

Rosa carolina

Carolina Rose

Rosa setigera

Prairie Rose

Rosa spinosissima altaica

Scotch Rose

Rosa wichuraiana

Memorial Rose

Viburnum opulus nanum

Dwarf Bush Cranberry

Xanthorrhiza apiifolia

Yellowroot 


\section{CHAPTER XIX}

\section{TREES AND SHRUBS FOR DIFFERENT FLOWERING EFFECTS}

Perhaps the most important use of plants is for the effect of the flowers. At least ninety per cent. of those who develop landscape plantations have foremost in their minds the effect that is to be produced by the flowers on the trees and shrubs grown in the plantation, whether it be on a large estate or on a small home lot. There are many other valuable characteristics, however, among which are the fruiting and the foliage effects. All of these, however, are entirely secondary to this one consideration concerning the flowers.

The first thought in the use of shrubs for this purpose is to obtain flowers. It is only after some study and some thought on the subject that one realizes that shrubs may be used for many different flowering effects. We may use trees and shrubs to produce flowers at certain definite seasons, or we may use trees and shrubs to produce flowers of different colours at different seasons. The owner of the average home occupies his residence throughout the entire year. There is a group of people, however, owning both large and small homes, who occupy two or more homes each year, depending upon the season. They usually spend the spring and fall months at their residence, and hot summer months at a country home, either at the seashore or among the mountains. The first home owner must be provided with trees and shrubs which will produce as nearly as possible a flowering effect throughout the growing season, beginning with the shrubs which produce flowers before the leaves appear, such as the golden bell and the flowering plums, and ending with the shrubs such as altheas and the hydrangeas which produce flowers in the summer months. The family that occupies both a permanent residence and a country home, however, must have trees and shrubs surrounding the former which produce flowers during the spring and during the late summer and fall months; and at their summer home they must have, so far as 
possible, the summer-flowering types of trees and shrubs. For this reason, various groups have been outlined to embrace trees and shrubs producing flowers in the early spring before the leaves appear, and producing flowers in the early spring after the leaves appear, such as the spirea and the lilac; producing flowers during the summer months, such as the weigela and the mock orange; and producing flowers during the late summer and autumn months, such as the rose of Sharon and the hydrangea. It is therefore important in connection with our various plantations of trees and shrubs to consider specifically the period during the blooming season, when the maximum effect of flowers is desired.

The second important consideration, in designing plantings of trees and shrubs, is the colour of the flowers. Flowering trees and shrubs, with respect to the colour of their flowers, may be divided into four definite groups: those which produce flowers in the shades of red and pink, such as pink-flowering dogwood, flowering peach, and the flowering crab; those which produce yellow flowers, such as the Scotch broom, yellow jasmine, and the golden bell; those which produce white flowers, such as the white fringe, hawthorn, hydrangea, and elders; and those which produce blue flowers (the smallest list of all), such as the blue spirea, blue rose of Sharon, and blue lilacs. Each of these groups may be divided, as shown by the tabulations, into earlyflowering and late summer-flowering sorts. The entire discussion concerning the colour of the flowers in the average planting is more theoretical than practical; but in the other plantations, where there is sufficient space to obtain masses of flowering effects during the blooming period, considerable study should be given to the colour of the flowers.

The small home owner in general is much more interested in his ability to procure trees and shrubs which will give him a continuous succession of bloom. This also is not always practical; but there is a group of standard shrubs, the use of which will provide as continuous bloom as can be obtained through the combination of any group of shrubs. It must be remembered that some varieties of shrubs will flower at a slightly later period than other varieties, and for this reason it is quite possible to obtain what seems to be a continuous series of bloom. The most prolific blooming shrubs, however, seem to flower during the months of May and June. During the latter part of July we have but a few shrubs, such as the hydrangea, the 
rose of Sharon, and the groundsel tree, which will produce flower effects.

\section{LIST OF TREES AND SHRUBS FOR DIFFERENT FLOWERING EFFECTS}

A. Producing Flowers in Early Spring Before the Leaves Appear. The trees and shrubs included in this group produce, when in bloom, a very interesting colour note in a landscape which has been uninteresting during the winter months. Most of these plants produce their best effect when used in small masses; their effect in large masses is increased only in proportion to the extensiveness of the landscape setting in which they are planted. Many interesting colour effects can be produced by the proper selection of plants from this group.

Acer rubrum
Red Maple
Amelanchier oblongifolia
Shad-bush
Azalea lutea
Flame-coloured Azalea
Azalea nudiflora
Pinkster Flower
Azalea vaseyi
Carolina Azalea
Benzoin aestivale
Spice Bush
Cercis canadensis
Red-bud
Chaenomeles japonica
Japanese Quince
Cornus florida
Flowering Dogwood
Daphne cneorum
Garland Flower

Forsythia (in variety)

Golden Bell

Hamamelis japonica Japanese Witch Hazel

Lonicera fragrantissima

Early Fragrant Honeysuckle

Lonicera-standishi

Standish's Bush Honeysuckle

Magnolia (Asiatic varieties)

Magnolia

Mahonia aquifolium

Oregon Grape

Prunus (in variety)
Japanese Flowering Cherry

Prunus triloba

Flowering Plum

Salix caprea

Goat Willow

Spiraea arguta

Spiraea prunifolia flore pleno

Hybrid Snow Garland

Bridal Wreath

B. Producing Flowers in Early Spring After the Leaves ApPEAR. Through a careful selection of plants the season of bloom from flowering trees and shrubs can be made almost continuous. There are many trees and shrubs which flower during the early spring after the leaves appear. Only those trees and shrubs which produce an 
TREES AND SHRUBS FOR FLOWERING EFFECTS 155

abundance of flowers, effective against a background of green foliage, are given here.
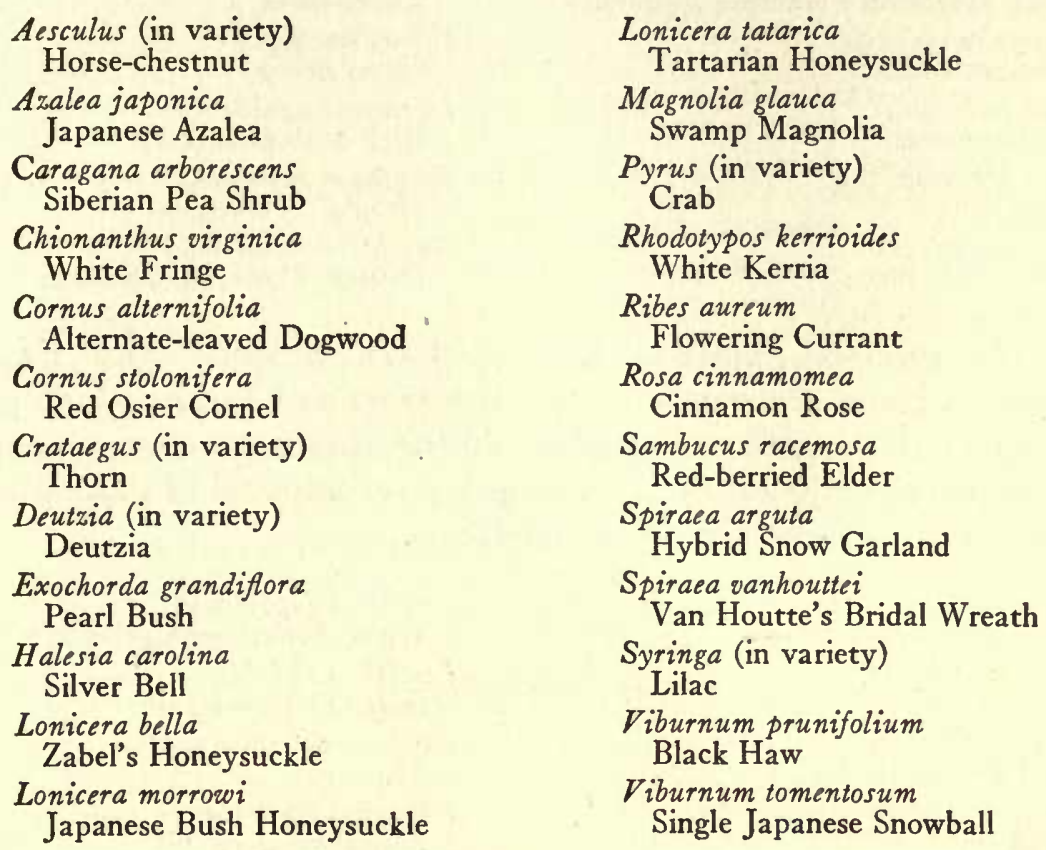

C. Producing Flowers During Early Summer. The largest group of flowering trees and shrubs is that containing the types which flower during the early summer months. Carefully selected groupings of these plants may produce a continuous flower effect through June and July.

\author{
Astilbe japonica \\ Japanese Astilbe \\ Catalpa (in variety) \\ Indian Bean \\ Cladrastis lutea \\ Yellow-wood \\ Cornus alba sibirica \\ Siberian Dogwood \\ Cornus paniculata \\ Grey Dogwood \\ Diervilla hybrida \\ Hybrid Weigela \\ Hydrangea arborescens sterilis \\ Hills of Snow
}

\author{
Kalmia latifolia \\ Mountain Laurel \\ Koelreuteria paniculata \\ Varnish Tree \\ Ligustrum ibota \\ Japanese Privet \\ Philadelphus (in variety) \\ Mock Orange \\ Rhododendron catawbiense hybridum \\ Hybrid Rhododendron \\ Rhus cotinus \\ Smoke Bush \\ Robinia pseudacacia \\ Black Locust
}


Roses (in variety)

$$
\text { Roses }
$$

Rubus deliciosus

Rocky Mountain Flowering Raspberry

Sambucus canadensis

American Elder

Spiraea salicifolia

Meadow-sweet

Syringa japonica

Tree Lilac

Viburnum carlesi

Korean Viburnum
Viburnum cassinoides

Withe-rod

Viburnum dentatum

Arrow-wood

Viburnum lentago

Sheep Berry

Viburnum opulus

High-bush Cranberry

Viburnum sieboldi

Siebold's Viburnum

Xanthoceras sorbifolia

Chinese Flowering Chestnut

D. Producing Flowers During Late Summer and Early Autumn. There are comparatively few trees and shrubs which produce an interesting flowering effect during the late summer months and during the early autumn. This group is composed of those plants whose flowers are effective in the landscape.

Baccharis halimifolia

Groundsel Bush

Buddleia veitchiana

Summer Lilac

Clethra alnifolia

Sweet Pepper Bush

Elsholtzia stauntoni

Elsholtzia

Hamamelis virginiana

Witch Hazel

Hibiscus syriacus

Rose of Sharon

Hydrangea arborescens

Wild Hydrangea

Hydrangea paniculata

Panicled Hydrangea

Hydrangea paniculata grandiflora

Large-flowered Hydrangea

Hypericum (in variety)

St. John's Wort
Lespedeza japonicum

White-flowering Desmodium

Lespedeza sieboldi

Siebold's Desmodium

Oxydendrum arboreum Sourwood

Potentilla fruticosa Shrubby Cinquefoil

Sorbaria arborea glabrata

Chinese Mountain Ash Spirea

Spiraea billardi Billiard's Spirea

Spiraea bumalda anthony waterer Crimson Spirea

Spiraea callosa alba Fortune's White Spirea

Stewartia pentagyna Alleghany Stewartia

Tamarix (in variety)

Tamarisk

\section{Vitex agnus-castus}

Chaste Tree

E. Producing Flowers in Shades of Red and Pink. In the development of interesting colour combinations for the flowers in landscape planting some definite association of colour schemes should be listed to assist one more readily in the selection of plants for varying colour effects. All plants in the following group produce flowers in shades of red and pink. The early-flowering sorts are shown in 


\section{TREES AND SHRUBS FOR FLOWERING EFFECTS 157}

Group $a$ and the late spring and summer-flowering sorts are shown in Group $b$.

a. Early-flowering sorts:

Azalea nudiflora

Pinkster Flower

Azalea vaseyi

Carolina Azalea

Cercis canadensis

Red-bud.

Cornus florida rubra

Red-flowering Dogwood

Kalmia angustifolia

Sheep Laurel

Magnolia soulangeana

Soulange's Magnolia

Prunus besseyi

Western Sand Cherry

Prunus japonica (in variety)

Flowering Almond
Prunus persica vulgaris

Common Peach

Prunus subhirtella (in variety)

Japanese Flowering Cherry

Prunus tomentosa

Japanese Plum

Pyrus angustifolia

Narrow-leaved Crab

Pyrus coronaria

Wild Crab

Pyrus floribunda

Flowering Crab

Pyrus halliana parkmani

Parkman's Crab

Rhodora canadensis

Rhodora

b. Late spring and summer-flowering sorts:

Deutzia rosea

Dwarf Pink Deutzia

Diervilla florida

Rose-coloured Weigela

Kalmia latifolia

Mountain Laurel
Pyrus ioensis bechteli

Bechtel's Crab

Roses (in variety)

Roses

Spiraea bumalda anthony waterer

Crimson Spirea

Spiraea tomentosa

Hardhack

F. Producing Yellow Flowers. Until the trees and shrubs producing yellow flowers are grouped the reader can hardly appreciate how great is the wealth of this material. The group is divided, as are the preceding groups in the chapter, into the early-flowering types and the late-flowering types.

a. Early-flowering sorts:

Benzoin aestivale

Spice Bush

Berberis (in variety)

Barberry

Cornus mas

Cornelian Cherry

Corylopsis pauciflora Japanese Flowering Hazel
Cytisus scoparius

Scotch Broom

Elaeagnus angustifolia

Russian Olive

Elaeagnus longipes

Japanese Oleaster

Forsythia (in variety)

Golden Bell 
Hamamelis japonica Japanese Witch Hazel

Jasminum nudiflorum Naked-flowered Jasmine

Lonicera fragrantissima Early Fragrant Honeysuckle
Ribes aureum Flowering Currant

Salix caprea Goat Willow

Salix discolor Pussy Willow

b. Late spring and summer-flowering sorts:

\section{Aralea lutea}

Flame-coloured Azalea

Caragana arborescens

Siberian Pea Shrub

Colutea arborescens

Bladder Senna

Genista tinctoria

Dyer's Greenweed

Hypericum (in variety)

St. John's Wort

Kerria japonica

Globe Flower
Koelreuteria paniculata

Varnish Tree

Laburnum vulgare

Golden Chain

Potentilla fruticosa

Shrubby Cinquefoil

Sophora japonica Japanese Pagoda Tree

Rosa foetida (variety harisoni)

Harrison's Yellow Rose

Rosa hugonis

Father Hugo's Rose

G. Producing White Flowers. This group of plants is subdivided in the same way as are the two preceding groups, and consists only of those plants producing white flowers in sufficient quantity and size to be an effective element in the landscape planting.

a. Early-flowering sorts:

Aralea viscosa

Swamp Azalea

Chionanthus virginica

White Fringe

Cornus (in variety)

Dogwood

Crataegus (in variety) Thorn

Halesia carolina Silver Bell

Lonicera morrowi Japanese Bush Honeysuckle
Lonicera tatarica alba

White Tartarian Honeysuckle.

Magnolia stellata

Starry Magnolia

Prunus (in variety)

Plum

Spiraea arguta

Hybrid Snow Garland

Spiraea vanhouttei

Van Houtte's Bridal Wreath

Viburnum (in variety)

Viburnum

b. Late spring and summer-flowering sorts:

Aesculus parviflora

Dwarf Horse-chestnut

Cladrastis lutea

Yellow-wood

Clethra alnifolia

Sweet Pepper Bush

Deutzia (in variety)

Deutzia
Hydrangea (in variety) Hydrangea

Ligustrum (in variety) Privet

Philadelphus (in variety) Mock Orange

Physocarpus opulifolius Ninebark 


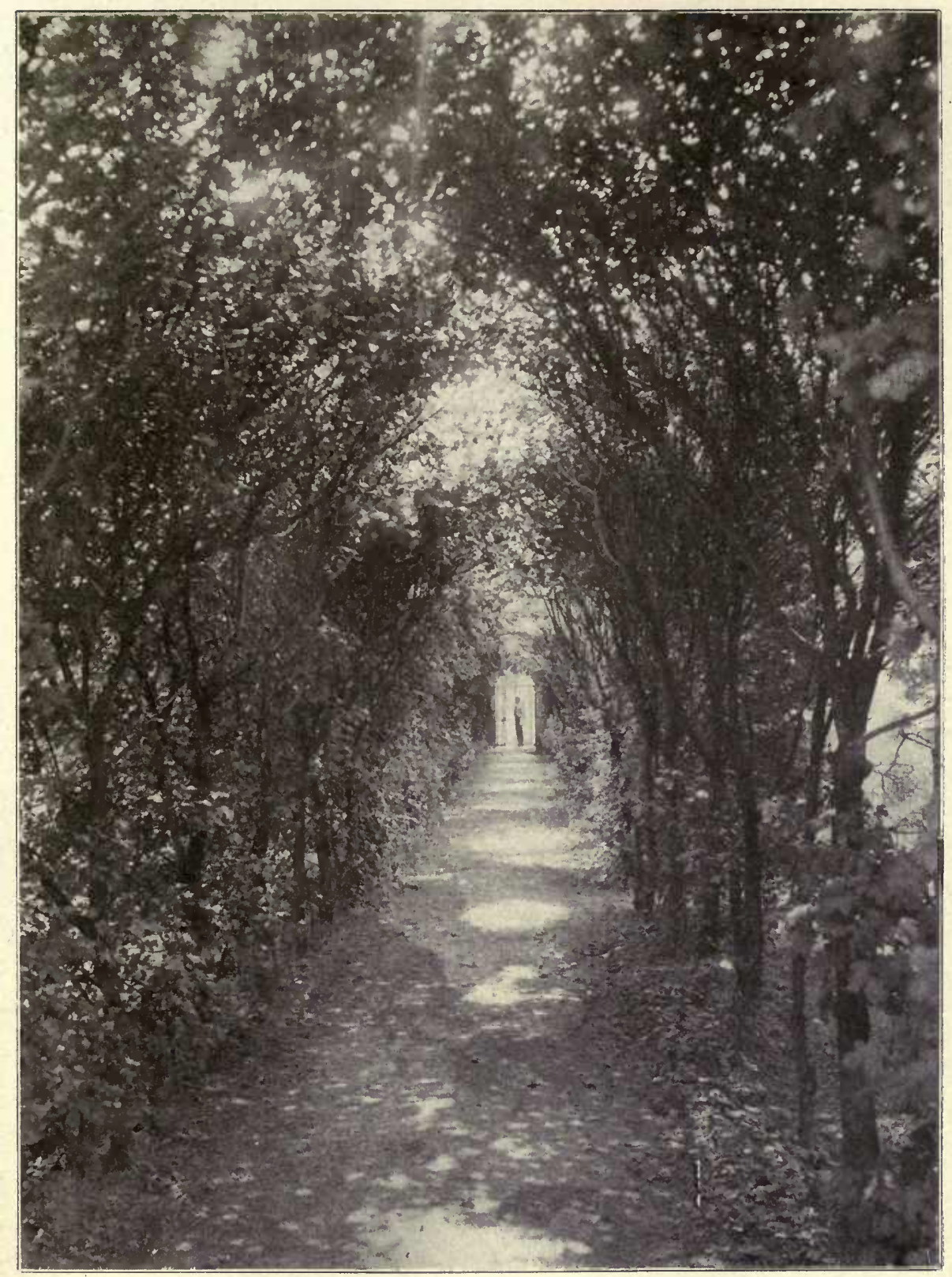

Plate XXIV. An interior view of a pleached allee eight years after transplanting. Note the spacing of the larger plants of the European cork maple at intervals of three feet, with "fillers" between each two of the larger trees. Compare with Plate No. XXVII on page 175 for the exterior view. Openings have been cut in the top of this allee to produce interesting spots of sunlight on the walk. (See page I46, group XVI-D-a, also frontispiece) 


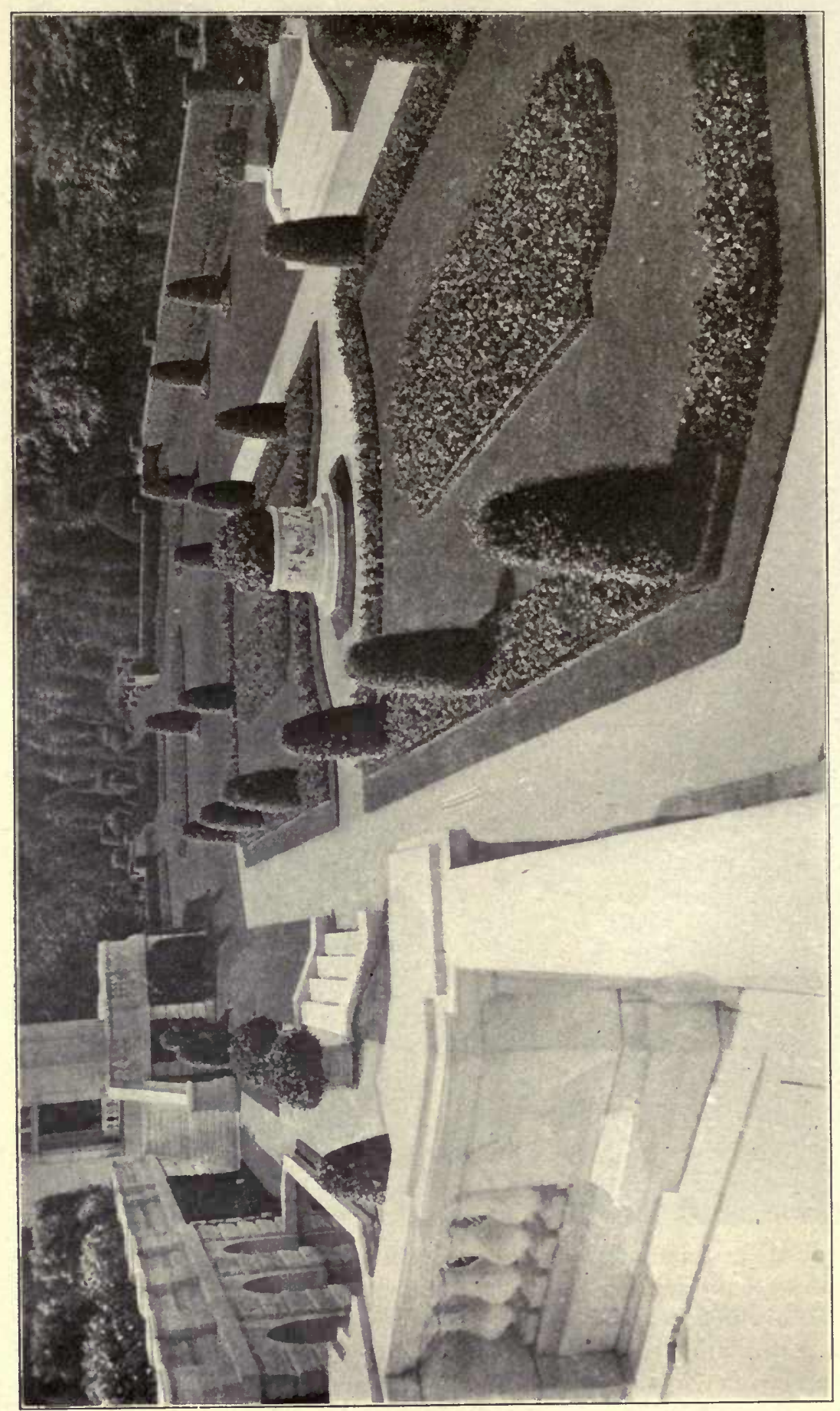

站

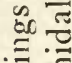

हु ह

ป

की

品

$=\Xi$

:

3

8 ส

동

$\overrightarrow{3}$

를

도.

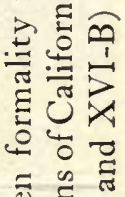

อี है

串氙

to

-

늘

苍 n

웡

ส

节

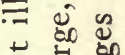

๘

ए क

ن d

运藏

.

B

.

됟 ह

兵这

๑. 
Rhododendron (white) Rhododendron

Rhodotypos kerrioides White Kerria

Robinia pseudacacia Black Locust

Rosa alba

White-flowered Rose

Rosa lucida alba

White-flowered Glossy Rose
Rosa multiflora

Japanese Climbing Rose

Rosa spinosissima

Scotch Rose

Sambucus canadensis

American Elder

Sambucus racemosa Red-berried Elder

Spiraea prunifolia

Bridal Wreath

Stewartia pentagyna

Alleghany Stewartia

H. Producing Blue Flowers. The group of plants producing blue flowers is extremely limited. A few plants which are shown in this list are extremely interesting for their flowering effect and with the exception of the rose of Sharon and the lilac, many of them are seldom used.
Amorpha fruticosa
False Indigo
Buddleia veitchiana Summer Lilac
Caryopteris incana Blue Spirea
Elsholtzia stauntoni Elsholtzia
Hibiscus syriacus ardens Blue Rose of Sharon
Paulownia tomentosa Empress Tree
Syringa oulgaris, President Greoy Double Blue Lilac
Vitex agnus-castus Chaste Tree

I. Continuous Bloom from Twelve Shrubs. The reader should be able to refer to some list such as the following, which will provide him with a ready reference for the selection of shrubs giving a succession of bloom. The plants in this group, if properly arranged, will develop an interesting succession of bloom from the early spring until the late fall.

\author{
Chaenomeles japonica \\ Japanese Quince \\ Diervilla hybrida \\ Hybrid Weigela \\ Forsythia suspensa \\ Drooping Golden Bell \\ Hibiscus syriacus \\ Rose of Sharon \\ Hydrangea paniculata grandiflora \\ Large-flowered Hydrangea \\ Lonicera tatarica \\ Tartarian Honeysuckle
}

Philadelphus coronarius

Common Mock Orange

Sorbaria arborea glabrata Chinese Mountain Ash Spirea

Spiraea bumalda anthony waterer Crimson Spirea

Spiraea vanhouttei

Van Houtte's Bridal Wreath

Syringa vilgaris hybrida Hybrid Lilac

Viburnum americanum American High-bush Cranberry 


\section{CHAPTER XX}

\section{PLANTS VALUABLE FOR THE CHARACTERISTICS OF THEIR FRUIT}

THE charm of many landscape plantings during fall and early winter months is due almost entirely to the interesting effects produced by the fruit of various trees, shrubs, and vines. Too little attention is given to the landscape value of plants because of their fruiting characteristics. It is the general impression that plants for landscape value have completed their greatest purpose when they have produced their foliage and flowers. As a matter of fact, instances may be common within the recollection of everyone where some interesting touch of colour in the landscape has been noticed and on further study has been found due entirely to the colour effect coming from a mass of hanging fruit.

To those people who occupy their permanent homes only during the fall and winter months, and whose greatest enjoyment from their landscape plantings should be produced by the fruiting effects, this is an important problem. It is admitted that many of our plants, such as the horse-chestnut, tree of heaven, honey locust, and hackberry, produce fruit which because of its littering habit is objectionable. These plants, however, are very few. The list of plants which produce fruit valuable because of certain characteristics such as interesting form and size, colour effects, and the ability to retain the fruit during the later winter months, includes many of our trees, shrubs, and vines that are valuable for their flowering effects also. This question is such an important one that each of the groups should be taken up in an individual discussion. The value of plants for their fruits which attract our many bird friends presents such an interesting study that this has been taken up as a distinct part of this chapter.

Among plants useful on the more refined lawn areas, where the detailed development of landscape plants is one of the most interesting features, there are a number of plants, such as the burning bush, cucumber tree, and the oriental plane, representative of the group pro- 
ducing fruit singularly interesting and conspicuous because of its form. There are other trees such as the Kentucky coffee tree, the western catalpa, and the tulip tree, the fruit of which is interesting on account of its size.

One of the most interesting characteristics of fruit is its colour. From the clear white fruit of the grey dogwood to the brilliant red fruit of the thorn there is a wonderful variation in colour effect produced by fruits. The beauty fruit, with its brilliant porcelainblue berries, adds an interesting touch of colour to landscape plantings nearly as effective as that of flowers, if not more so. In many of these shrubs, such as some varieties of the thorn, the honeysuckle, and the elder, the beautiful colours of the fruit against the background of green foliage are extremely effective. The great majority of our shrubs retain their fruit for a greater or less period after the leaves have fallen. With the first signs of freezing and real winter weather these fruits rapidly wither and decay and those which are not removed by the birds soon drop from the plants. The fruit of the elderberries, roses, blue berries, and honeysuckles is dropped well before the middle of December, and even as early as the first of December. In the average winter the fruit of the dogwoods, the spindle tree, the snowberry, and the burning bush retain their interesting colour until the early part of January. Of this group of plants there are many which retain their fruit well into the winter months. The Japanese barberry and the winterberry or deciduous holly hold their fruit much longer than the other plants, while the brilliantly coloured fruit of the bittersweet, the thorn, and the high-bush cranberry remains until the really severe winter weather begins. From a landscape point of view there is nothing much more effective in a pictorial composition than the brilliantly coloured fruit and brilliantly coloured twigs of many of our trees and shrubs presented against a background of snow.

\section{LIST OF PLANTS VALUABLE FOR THE CHARACTERISTICS OF THEIR FRUIT}

A. Producing Fruit of Peculiarly Interesting Form or Size. This group consists of types of plants which produce fruit that has a landscape value on account of its peculiarly interesting form and size. Practically all of our trees and shrubs produce fruit, but only those having fruit which is of real landscape value are listed in this and in succeeding groups. 


\begin{tabular}{lc} 
Asimina triloba & Liquidambar styracifua \\
Paw-Paw & Sweet Gum \\
Catalpa speciosa & Liriodendron tulipifera \\
Western Catalpa & Tulip Tree \\
Cephalanthus occidentalis & Maclura pomifera \\
Button Bush & Osage Orange \\
Colutea arborescens & Magnolia acuminata \\
Bladder Senna & Cucumber Tree \\
Diospyros virginiana & Platanus orientalis \\
Persimmon & Oriental Plane \\
Evonymus atropurpureus & Pyrus baccata (in variety) \\
Burning Bush & Siberian Flowering Crab \\
Gleditsia triacanthos & Staphylea pinnata \\
Honey Locust & European Bladder-nut \\
Gymnocladus dioica & Staphylea trifolia \\
Kentucky Coffee Tree & American Bladder-nut \\
\multicolumn{2}{c}{ Fruit Trees (in variety) }
\end{tabular}

B. Producing Fruit Valuable for Its Colour Effects. The colour effect of fruit may be equally as effective as the colour effect of flowers. Some fruit is effective as a combination of colour against the background of green foliage. Other fruit is effective because of its colour at a season of the year when the foliage is gone. Many more plants should be used for the colour effect of the fruit than are now seen in our landscape plantings.

Acer rubrum
Red Maple
Aralia spinosa
Hercules Club
Berberis (in variety)
Barberry
Callicarpa purpurea
Beauty Fruit
Celastrus scandens
American Bittersweet
Chionanthus virginica
White Fringe
Colutea arborescens
Bladder Senna
Cornus alba sibirica
Siberian Dogwood
Cornus alternifolia
Alternate-leaved Dogwood
Cornus florida
Flowering Dogwood
Cornus paniculata
Grey Dogwood

Cornus stolonifera Red Osier Cornel

Cotoneaster dielsiana Chinese Cotoneaster

Cotoneaster divaricata Cotoneaster

Cotoneaster horizontalis perpusilla Hybrid Prostrate Cotoneaster

Cotoneaster hupehensis Cotoneaster

Cotoneaster multiflora calocarpa Cotoneaster

Cotoneaster racemiflora Cotoneaster

Cotoneaster salicifolia floccosa Cotoneaster

Crataegus (in variety) Thorn

Eleagnus longipes Japanese Oleaster

Evonymus alatus Cork-barked Burning Bush 
Evonymus americanus Strawberry Bush

Evonymus atropurpureus Burning Bush

Evonymus europaeus European Spindle Tree

Hippophae rhamnoides Sea Buckthorn

Ilex crenata Japanese Holly

Ilex opaca American Holly

Ilex verticillata

Winterberry

Ligustrum (in variety) Privet

Lonicera morrowi Japanese Bush Honeysuckle

Lonicera tatarica

Tartarian Honeysuckle

Myrica cerifera

Bayberry

Physocarpus opulifolius

Ninebark

Pyracantha coccinea

Evergreen Thorn

Rhodotypos kerrioides White Kerria

Rhus glabra

Smooth Sumac
Rhus typhina

Staghorn Sumac

Rosa blanda

Meadow Rose

Rosa multiflora Japanese Climbing Rose

Rosa rubiginosa

Sweet Brier

Rosa rubrifolia

Red-leaved Rose

Rosa rugosa

Japanese Rose

Sambucus canadensis American Elder

Sambucus racemosa Red-berried Elder

Sorbus aucuparia European Mountain Ash

Staphylea trifolia American Bladder-nut

Symphoricarpos racemosus Snowberry

Symphoricarpos oulgaris Indian Currant

Symplocus paniculata Japanese Sweet Leaf

Vaccinium (in variety) Blueberry

Viburnum (in variety)

Viburnum

C. Producing Fruit Valuable During the Winter Months. The group of trees and shrubs which retain interesting fruit well into the winter months is comparatively limited. A few of these plants should be in every landscape planting to give a touch of colour and life during the dead winter months.

Berberis (in variety)
Barberry
Celastrus scandens
American Bitter-sweet
Crataegus (in variety)
Thorn
Ilex opaca
American Holly
Ilex verticillata
Winterberry
Ligustrum ibota
Japanese Privet

Berberis (in variety)

Barberry

American Bitter-sweet

Crataegus (in variety)

Thorn

lex opaca

American Holly

Winterberry

igustrum ibota
Ligustrum vulgare

European Privet

Myrica cerifera

Bayberry

Pyracantha coccinea

Evergreen Thorn

Rhodotypos kerrioides

White Kerria

Rhus glabra

Smooth Sumac

Rhus typhina

Staghorn Sumac 
Rosa blanda

Meadow Rose

Rosa multiflora

Japanese Climbing Rose

Rosa rugosa

Japanese Rose
Viburnum americanum

American High Bush Cranberry

Viburnum dilatatum

Japanese Bush Cranberry

Viburnum opulus

High-bush Cranberry

\section{PLANTS USED FOR ATTRACTING BIRDS}

It is often advisable, in the making of landscape plantings, to use trees and shrubs which possess ornamental values from a landscape viewpoint, and which also produce fruit that attracts various species of birds: It is sometimes possible to use these plants in large groups, while in other instances it is advisable to use such plants as specimens at intervals in the proposed plantings. This type of plant must be one which produces fruit or seed pods which can be eaten by the birds. In this manner a large number of birds may be kept on many home grounds throughout the different months of the year, especially if plants are selected which attract the birds in these different months. It is much easier to se'ect a group of plants which will attract birds during the winter months when no food is available than it is to choose plants which will attract birds during the summer months when food is plentiful.

There are many plants, such as sumacs, mulberries, blackberrylilies, jewel weeds, and hazels, which should be used, occasionally, because their main value is the value of their fruit for the feeding of birds, while they possess a very minor value for ornamental landscape planting. On the other hand, there is a surprisingly large list of plants which are desirable and which are grown commercially in the nursery for use in ordinary landscape planting which do not produce valuable fruit.

In this list the reader will readily note that different kinds of shrubs produce fruit which attracts different kinds of birds. The owner of an estate should therefore know the birds which generally frequent the locality in question and should use plants producing fruit attractive to these species of bird life. There are many shrubs the fruit of which is either too hard or too acid for birds to eat, such as the following: privets, sweet shrub, and bladder-nut.

To successfully attract birds a plant must possess certain requirements such as ability to produce a quantity of edible fruit, to afford shelter from the extreme heat of bright sunny days, shelter from wind, 
and to provide sufficient seclusion so that certain types of birds may be protected from the view of persons. On another page there is a list of plants which are used during the growing season to attract birds and to keep them away from the fruits in the garden, particularly the berries. In fact, many farmers, as well as the owners of ornamental plantings, have found that cultivated fruits are greatly protected from damage if wild fruit is plentiful in that special locality, and that they are subject to much damage where wild fruit is scarce. An interesting point in the discussion of plants used for attracting birds is the fact that many birds feed upon fleshy fruits in order to obtain the water which they contain. Therefore the presence of bird baths on home grounds, where cultivated fruits require protection, will often keep many of the birds away from the fruit.

The barberries, snowballs, sumacs, elderberries, bush honeysuckles, mulberries, bitter-sweets, and wild grapes attract the greater number of birds.

D. Producing Fruit Valuable for Attracting Birds. There are numerous species of trees, shrubs, and vines, which are not only useful in a decorative way, but also add much to the interest of a place, attracting the birds by their fruit. Plants found in this list are among the most important for furnishing food for birds. The names of the birds which feed upon the various fruits follow the plant list. The numbers after each plant in this list correspond with the index number of the birds in List $c$.

\section{a. Fruiting in summer:}

Amelanchier (in variety) - I, 2, 5, 7, 10, 12, I5, 18, 21, 26.

Shad-bush

Ampelopsis quinquefolia-2, 7, 11, 14, 17, 18, $19,26$.

Virginia Creeper

Aronia (in variety) $-9,10,12,13$.

Chokeberry

Benzoin aestivale-11, 17, 19, 26.

Spice Bush

Berberis (in variety) $-5,7,11,14,17,18$, 19, 26.

Barberry

Celtis occidentalis- $\mathbf{I}, 2,5,7,18,26$.

Nettle Tree
Cornus (in variety) -I, 2, 4, 5, 6, 7, 10, $12,13,15,17,18,19,20,22,24,26$. Dogwood

Gaultheria procumbens-10, 13, 9, 5.

Wintergreen

Lonicera (in variety) $-9,10,12,13$.

Honeysuckle

Morus rubra-I, 2, 3, 4, 5, 7, 8, 10, 11, 12, $14,15,16,17,18,19,21,22,24,26$. Red Mulberry

Nyssa sylvatica-4, 12, 18, 17, 22, 26.

Tupelo

Prunus (in variety) - I, 4, 5, 7, 10, 12, 14, I $5,18,22,25,26$.

Cherry and Plum 
Rubus (in variety)-1, 2, 12, 18, 19.

Brambles

Sambucus (in variety) $-1,2,4,5,7,10$, II, Elder

$12,13,14,15,16,17,18,19,22,24,26$,

Symphoricarpos (in variety) $\longrightarrow 9,10,12,13$.

Indian Currant and Snowberry
$V$ accinium (in variety) $-4,5,7,11,12$, 14, 18, 19, 26.

Blueberry

$V$ itis (in variety) $-1,5,7,11,12,14,17$, 18, 19, 22, 26.

Grape

b. Holding fruit into the winter months:

Celastrus (in variety)-2, II, 17, 18, 26. Bitter-sweet

Crataegus coccinea-7, 11, 12, 18 . Scarlet-fruited Thorn

Crataegus cordata-7, I1, 12. Washington Thorn

Crataegus crus-galli-7, II, 12, 18. Cockspur Thorn

Crataegus oxycantha-7, II, I2, 18. May Thorn

Evonymus (in variety)-2, 18, 19, 26. Burning Bush and Spindle Tree

Ilex opaca-2, 7, 17, 18, 26. American Holly

Ilex verticillata-2, 7, 17, 18, 26. Winterberry

Juniperus (in variety) $-2,5,6,9,10,14$, $16,17,18,19,23,25,26$. Red Cedar

Lonicera (in variety) $-9,10,12,13$. Honeysuckle
Myrica cerifera-1, 6, 7, 11, 14, I7, 18, I9, 20, 25, 26.

Bayberry

Rhamnus (in variety) - 4, 5, 10, 12, 13, 14, I8, 22.

Buckthorn

Rhus (in variety)-1, 2, 4, 5, 6, 7, 10, I1, I2, 14, 17, 18, 19, 20, 22, 24, 25, 26.

Sumac

Sorbus (in variety) $-2,5,9,10,11,18$, 19, 26.

Mountain Ash

Symphoricarpos (in variety) 9, 10, 12, 13.

Snowberry and Indian Currant

Tsuga canadensis

Canadian Hemlock

Viburnum (in variety) except variety americanum-2, 5, 7, 11, 17, 18, 19, $22,25,26$.

Viburnum

Hips of the following roses are eaten by many species of birds.

Rosa blanda

Meadow Rose

Rosa carolina

Carolina Rose

Rosa lucida

Glossy Rose

Rosa multiflora

Japanese Climbing Rose

Rosa nitida

Shining-leaved Rose
Rosa rubiginosa

Sweet Brier

Rosa rubrifolia

Red-leaved Rose

Rosa rugosa and single hybrids Japanese Rose

Rosa setigera

Prairie Rose

Rosa spinosissima

Scotch Rose

Rosa wichuraiana

Memorial Rose

c. Birds attracted by the fruit. The following is a tabulation of the interesting types of birds which are attracted by the various 
kinds of fruit grown on the plants in list XX-D $-a$ and $b$. The numbers appearing after the names of the plants on Pages 165 and 166 refer to the numbers opposite the names of the different birds in the following list. All of these birds feed upon one or more of the kinds of fruit shown on the preceding pages.
I. Blackbird
2. Bluebird
3. Bobolink
4. Catbird
5. Cedarbird
6. Chickadee
7. Crow
8. Cuckoo
9. Finch
Io. Grosbeak
I I. Grouse
I2. Jay
13. Junco
14. Kingbird
I5. Oriole
I6. Phoebe
17. Quail
18. Robin

I9. Sparrow

20. Swallow

2I. Tanager

22. Thrasher

23. Thrush

24. Vireo

25. Warbler

26. Woodpecker

E. Producing Fruit Which Attracts Birds Away From Other Fruit. Mulberries and shad-bushes will protect cherries and strawberries. Elders, Virginia creeper, and black cherry will protect grapes. Elders and mulberries will protect raspberries and blackberries.

F. Producing Fruit Which Often Makes the Plant Undesirable in Landscape Planting.

Aesculus hippocastanum Common Horse-chestnut

Ailanthus glandulosa

Tree of Heaven

Catalpa (in variety) Indian Bean
Celtis occidentalis

Nettle Tree

Gleditsia triacanthos

Honey Locust

Nut Trees (in variety) 


\section{CHAPTER XXI}

\section{TREES AND SHRUBS BEARING COLOURED TWIGS}

THE trees and shrubs in the following list are those whose twigs are coloured sufficiently to make them of value from a landscape standpoint. The colour effect of twigs may be interesting from two points of view: either because of the vivid colouring, such as is seen in the red-twigged dogwood, and in the glossy rose, or of the general tone of colour such as seen in the American olive and the golden-barked willow, in which the colour as a mass is much more effective at a distance than upon close examination.

Many of the interesting shrubs included in this group are oftentimes selected because of the sharp contrast between the colour of their twigs and the white background of snow or the green background of evergreens during the winter months. This is especially true of the birches and the dogwoods. In fact, there is equally as much interest during the winter months in a planting of this kind, properly developed, as in the difference of foliage effects during the summer months. It is a feature of landscape plantings to which very little attention has been given and one which demands careful study in order to be successfully worked out.

On extensive lawn areas, in our parks and large private estates, many specimens of these plants can be tucked away in large groups, where during the winter months the colour effect of the twigs will lend an interesting tone and more feeling of life to the otherwise monotonous effect of the background.

The development of many vistas is oftentimes emphasized through the careful selection of such plants as the birches, willows, and Russian olive, to give the feeling of greater depth in the landscape picture. Such specimens, planted in the immediate background, with a heavy texture of planting in the foreground, will greatly add to the suggested feeling of distance.

The plants included in this group are those which carry an interesting and vivid colour of the branches and twigs throughout the winter 
months. In the great majority of plants the new twigs show an interesting colour for perhaps part of the year, usually during the early spring months when the sap begins to flow. Later the colour becomes softened or deadened and it does not carry through to the late fall and winter. There are practically no shrubs which can be selected for the colour of their twigs during the summer months. It is not necessary to select plants for this purpose because there are so many other equally interesting effects to be obtained from flowers and foliage.

The first two years' growth, especially the first year's growth on any tree or shrub, the twigs of which have a definite colour, is much brighter than the colour of the twigs after they are more than two years old and are becoming definite branches of the plant. This is a suggestion that severe pruning, or cutting back, will often enhance the effect, as in the case of the red-twigged dogwood.

Twigs are also extremely interesting because of the markings. The tamarix and silky dogwood are types to study in detail as well as being valuable for the mass colour effect seen at a distance.

Colour effects of twigs form the most interesting feature of landscape twig effects, and yet the coverings of older branches and tree trunks on many trees are very effective in summer and winter. Every tree has its individual markings of trunk and branches, of great interest to the landscape student. The white oak, white birch, plane tree, and hackberry, with their peculiar bark, are valuable in landscape planting.

\section{LIST OF TREES AND SHRUBS BEARING COLOURED TWIGS}

This list consists of types of plants which are extremely interesting because of the colour effect of their twigs. A memorandum is indicated opposite each type showing the special colour effect which is produced if the twigs are less than two years old. As twigs grow older the colour of the bark becomes more neutral, and consequently these plants should be frequently pruned in order to produce new growth with its more vivid colour effects.

Acer pennsylvanicum-striped greenwhite branches

Striped Maple

Betula nigra-reddish brown bark

Red Birch

Betula papyrifera-white bark

Paper Birch
Betula populifolia-white bark American White Birch

Cornus alba-blood-red branches Red-twigged Dogwood

Cornus alba sibirica-coral-red branches Siberian Dogwood 
Cornus paniculata-grey bark Grey Dogwood

Cornus sanguinea viridissima - green twigs Green-stemmed Dogwood

Cornus stolonifera flavirammea-yellow bark

Golden-twigged Osier

Elaeagnus (in variety) - silvery bark American Olive

Fagus americana-grey bark American Beech

Forsythia viridissima - dark green branches

Dark-green Golden Bell

Kerria japonica-green branches Globe Flower
Platanus orientalis - white bark Oriental Plane

Populus tremuloides - silvery green branches

Trembling Aspen

Rosa blanda-reddish purple twigs Meadow Rose

Rosa lucida-reddish twigs Glossy Rose

Rosa lucida alba-greenish twigs White-flowered Glossy Rose

Salix alba-yellowish bark White Willow

Salix vitellina aurea-golden yellow Golden-barked Willow

Salix vitellina britzensis-reddish bronze

Hybrid Yellow Willow 


\section{CHAPTER XXII}

\section{PLANTS VALUABLE BECAUSE OF THE AUTUMN COLOURATION OF THE LEAVES}

ONE of the most charming features of our northern landscapes, especially through the northeastern United States where such a great variety of deciduous trees are indigenous, is the autumn colouration of the foliage. During the normal growing seasons, when ample rains have fallen and the trees are full with sap at the end of the season, the autumn colours are much more vivid than during a dry season.

It is extremely important in designing landscape plantings that thought should be given to the fruiting effects during the fall and winter months and also to the autumn colours of the foliage of our trees and shrubs. A small touch of colour in the border shrub plantings of the average lawn is usually the difference between an uninteresting and an interesting planting at that season of the year. Every planting should have introduced into it a few plants which, if not valuable for their fruiting and flowering characteristics, will produce a touch of colour as accents to relieve the monotony of the dead greens and browns during late September and October.

Autumn colouration is the result of an interesting physiological function within the plant. Contrary to the average opinion that autumn colour is the result of sharp freezes, the presence of frost serves but in a slight degree to hasten this colouring, because the degree of cold necessary to produce a freeze further retards the flow of any sap. The production of the vivid autumn colours is caused by a devitalized or increasingly dormant condition of the plant. The lessened flow of new sap to the leaves, caused by the formation of corky tissue at the extreme base of the leaf to cover and protect the leaf scar during the winter months, results in a chemical reaction of the acids within the leaf itself. The results of this chemical reaction are evident in the autumn colours. The factors determining the kind and degree of autumn colouration is the presence of different 
acids within the leaf. These acids are present constantly in their respective types of plants.

It is a peculiar fact that in some trees autumn colouration is much more vivid than in other trees, because of the presence of certain acids the chemical reaction of which produces these vivid colours. The autumn colouration of foliage ranges from the dull browns through the yellows and orange to the brilliant red and scarlet. Some of our trees and shrubs such as the red maple, Judas tree, sourwood, sumac, and sassafras, develop their autumn colours during the early part of the fall. In these trees growth stops early in the season and the wood matures more quickly. There is one group of plants such as the Virginia creeper, Thunberg's barberry, red oak, highbush cranberry, and arrow-wood, in which the autumn colouration is produced shortly after the early trees have shown their autumn colours. The American beech, golden bell, scarlet oak, and burning bush, and some others mature and ripen last of all and are included in the group with late autumn colouration. With the great opportunity for selection of trees and shrubs from these three well-defined groups a succession, if it may be so termed, of autumn colouration may be obtained, which will supplement and add interest to the fruiting effects produced by a well-selected group of plants valuable for the characteristics of their fruit.

One has only to observe our native trees and shrubs in the northeast to appreciate the wonderful colour effects which are produced during the autumn months and are evidenced on all of our hillsides. So seldom are shrubs se'ected for landscape grouping with a.specific intention of emphasizing their value because of autumn colouration, that we find there are few good illustrations, and those at scattered intervals, showing the autumn colours and their values in the settings. of our lawns.

\section{LIST OF PLANTS VALUABLE BECAUSE OF THE AUTUMN COLOURATION OF THE LEAVES}

The plants in the following three groups have been separated and grouped because of the interesting colour effects of the foliage. The most important factor in selecting plants for the autumn colouration of their foliage is to select material which will provide a succession of colour from early fall to late fall. The colours produced by the foliage of the different types are indicated after each type. 


\section{PLANTS FOR AUTUMN COLOURATION}

A. Early:

Acer ginnala (scarlet)

Siberian Maple

Acer negundo (yellow)

Box Elder

Acer rubrum (scarlet)

Red Maple

Acer saccharum (red)

Sugar Maple

Betula lutea (yellow)

Yellow Birch

Betula nigra (yellow)

Red Birch

Cercidiphyllum japonicum (yellow to crimson)

Kadsura Tree

Cercis canadensis (yellow)

Red-bud

B. Medium:

Acer palmatum (red)

Japanese Maple

Amelanchier (bright yellow)

Shad-bush

Ampelopsis quinquefolia (red)

Virginia Creeper

Berberis thunbergi (scariet)

Thunberg's Japanese Barberry

Carpinus caroliniana (orange)

American Hornbeam

Cotoneaster (in variety) (red)

Cotoneaster

Crataegus (in variety) (orange to red) Thorn

Fraxinus americana (yellow)

White Ash

Carya alba (rich brown)

Hickory

\section{Late:}

a. Coloured foliage.

Acer platanoides (green)

Norway Maple

Cladrastis lutea (yellow)

Yellow-wood
Chionanthus virginica (yellow)

White Fringe

Koelreuteria paniculata (yellow)

Varnish Tree

Liquidambar styraciflua (scarlet)

Sweet Gum

Liriodendron tulipifera (yellow)

Tulip Tree

Oxydendrum arboreum (scarlet)

Sourwood

Platanus orientalis (yellow)

Oriental Plane

Rhus typhina (scarlet)

Staghorn Sumac

Sassafras officinale (orange and scarlet)

Common Sassafras

Ulmus americana (yellow)

American Elm

Hydrangea quercifolia (yellow)

Oak-leaved Hydrangea

Nyssa sylvatica (red)

Tupelo

Quercus rubra (red)

Red Oak

Quercus velutina (orange and red)

Black Oak

Rhus canadensis (red)

Fragrant Sumac

Ribes aureum (yellow)

Flowering Currant

Vaccinium corymbosum (crimson)

High-bush Blueberry

Viburnum acerifolium (purple)

Maple-leaved Viburnum

Viburnum dentatum (red)

Arrow-wood

Cornus florida (scarlet)

Flowering Dogwood

Evonymus alatus (scarlet)

Cork-barked Burning Bush 
Evonymus atropurpureus (red)

Burning Bush

Evonymus europaeus (red) European Spindle Tree

Fagus americana (rich yellow) American Beech

Forsythia viridissima (purple) Dark Green Golden Bell

Ginkgo biloba (yellow) Maidenhair Tree

Hamamelis virginiana (yellow) Witch Hazel
Mahonia aquifolium (bronze)

Oregon Grape

Myrica cerifera (bronze) Bayberry

Ostrya virginica (yellow)

Hop Hornbeam

Pieris floribunda (bronze)

Mountain Fetterbush

Quercus alba (purple)

White Oak

Quercus coccinea (scarlet) Scarlet oak

b. Green Foliage. Some trees and shrubs are exceedingly interesting in the landscape composition because of the varying and vivid colours of their autumn foliage, ranging from brown or brownish yellow, through to vivid scarlet and bright red. There is another group of shrubs which are not so valuable because of the autumn colour of their foliage, but because of the fact that their foliage is retained until extremely late in the fall, or possibly into the early winter. Such shrubs as the privets, and many others shown in this list, are very valuable in landscape plantations where the owner cannot, because of climatic or soil conditions, resort to the use of evergreens, and is still desirous of producing a foliage effect that will serve as a background or a screen until late into October or early November. Many of these shrubs are somewhat tender and the fact that they do carry their leaves unchanged until late in the autumn often shows that they are not able to mature their wood during a normal growing season. Since they often do not mature their leaves they are also liable to go into the winter with tender wood. Many of the shrubs given in this list should therefore not be planted in exposed places.

I. Shrubs:

\author{
Abelia grandiflora \\ Hybrid Abelia \\ Aralia pentaphyla \\ Five-leaved Angelica \\ Berberis wilsonae \\ Wilson's Barberry \\ Chaenomeles japonica \\ Japanese Quince \\ Cotoneaster adpressa \\ Creeping Cotoneaster
}

Cotoneaster horizontalis

Prostrate Cotoneaster

Eleagnus multiflora rotundifolia

Round-leaved Gumi

Evonymus bungeanus semipersistens Half-evergreen Spindle Tree

Fontanesia fortunei

Fortune's Fontanesia

Forsythia viridissima

Dark green Golden Bell 


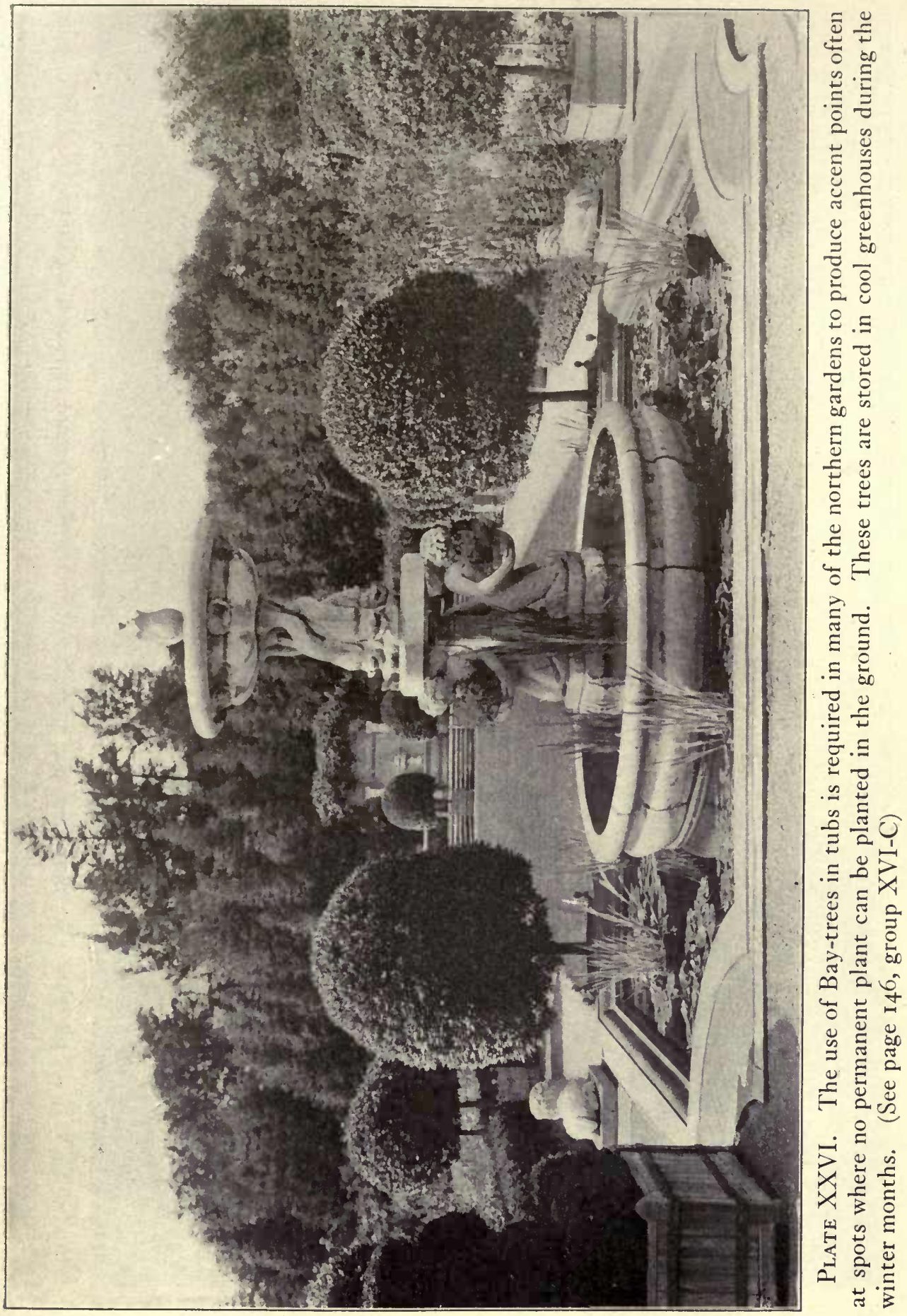




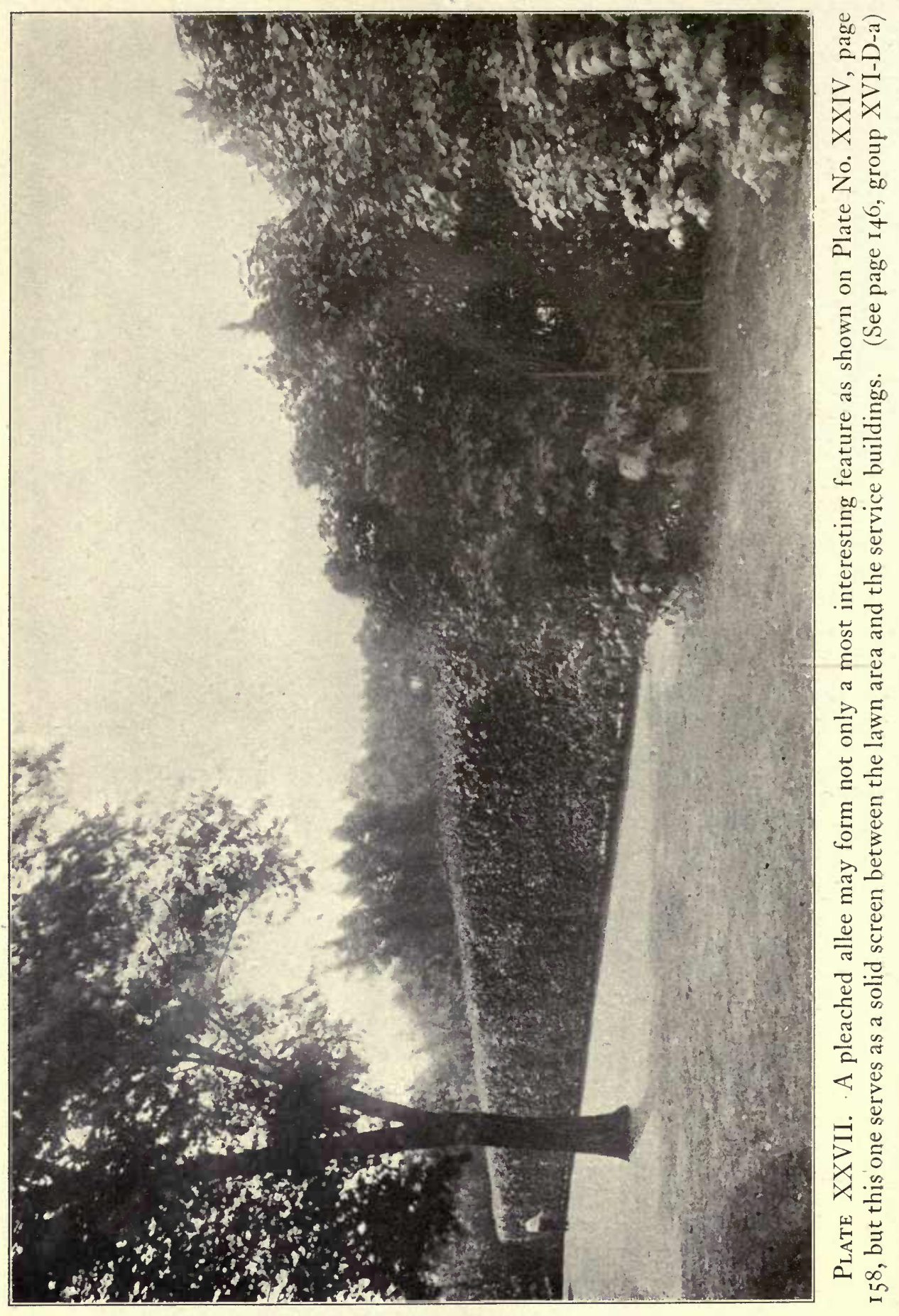




\section{PLANTS FOR AUTUMN COLOURATION}

Hypericum buckleyi

Buckley's St. John's Wort

Hypericum patulum henryi

Hybrid St. John's Wort

Ligustrum japonicum

Evergreen Privet

Ligustrum ooalifolium California Privet

Ligustrum oulgare sempervirens Half-evergreen European Privet

Ligustrum amurense Amoor River Privet
Lonicera fragrantissima

Early Fragrant Honeysuckle

Lonicera sempervirens

Coral Honeysuckle

Lonicera standishi

Standish's Bush Honeysuckle

Viburnum macrocephalum

Chinese Snowball

Viburnum opulus nanum

Dwarf Bush Cranberry

Viburnum rhytidophyllum

Evergreen Viburnum

Viburnum sieboldi

Siebold's Viburnum

2. Vines:

Akebia lobata

Divided-leaved Akebia

Akebia quinata

Five-leaved Akebia

Clematis paniculata. Japanese Clematis

Lonicera japonica halliana Japanese Honeysuckle

Smilax hispida

Prickly Greenbrier 


\section{CHAPTER XXIII}

\section{FAST-GROWING TYPES VALUABLE FOR PRODUCING SCREEN EFFECTS}

IT OFTEN becomes necessary to find some fast-growing type of tree or shrub to produce an immediate screen. This is especially true in the development of new landscapes where a foliage effect is desired and the more permanent types of shrubs in the plantation require a longer period to produce the desired effect. In such instances the more rapid-growing types of shrubs may be planted and removed after the first one or two years, at which time the more permanent types have developed far enough so that during the succeeding years they will produce the effect which the designer had in mind when they were first selected. The great danger in using quickgrowing types of temporary materials for immediate effects lies in the fact that for the success of such plantations the owner must have the "courage of his convictions" and remove the temporary types of material when the time comes that they are beginning to crowd and to injure the more permanent types.

In other instances, where it is necessary to screen service buildings or blank walls of other buildings such quick-growing types of trees and shrubs as the ailanthus, poplars, willows, and elders may be planted. The ailanthus especially is used to form a mass of foliage against service buildings and blank walls during the summe rmonths, but this tree is cut back each year to a height of three or four feet and the new growth produces the effect during the next year.

The fast-growing types of trees and shrubs often used to produce quick effects are correspondingly short lived. Those trees and shrubs which grow rapidly, mature and decay nearly as rapidly. Very few of these types should be placed in permanent plantings.

This list consists of two distinct groups of fast-growing material: that group of which the ailanthus, poplar, willow, and elder are typical, being the very rapid-growing types of material, and that group of which the remaining trees and shrubs are typical being rapid-growing types 
which are more or less permanent in their character of growth. The types contained in this last group establish themselves much more quickly than trees and shrubs of a similar kind, which require a longer period after transplanting before making a normal growth.

Such shrubs as the weigela, the ninebark, and the privet are often used to obtain quick mass effects of foliage around the base of buildings in locations where the slower-growing types of shrubs, such as lilacs, bridal wreaths, and snowballs would require a much longer time to develop a similar effect.

\section{LIST OF FAST-GROWING TYPES VALUABLE FOR PRODUC- ING SCREEN EFFECTS}

These groups contain the very fastest growing and most temporary types of trees and shrubs, and the more rapid-growing types of trees and shrubs often used in permanent plantings. Material may be selected from these groups when an immediate foliage effect is desired.

\section{A. Trees:}

Acer negundo

Box Elder

Acer saccharinum

Silver Maple

Ailanthus glandulosa.

Tree of Heaven

Catalpa speciosa

Western Catalpa

Larix europea

European Larch

Maclura pomifera

Osage Orange

Morus alba tatarica

Mulberry

B. Shrubs:

Cornus alba sibirica

Siberian Dogwood

Cornus stolonifera

Red Osier Cornel

Deutzia crenata Pride of Rochester

Large-flowered Deutzia

Dieroilla florida

Rose-coloured Weigela

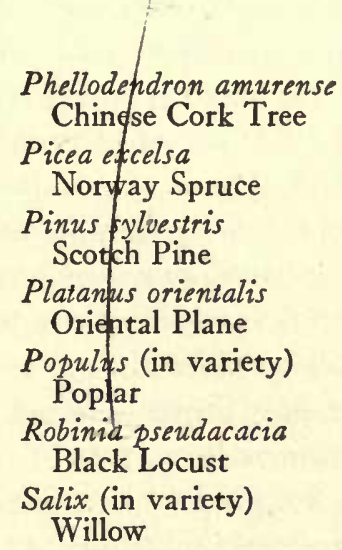

Ligustrum amurense Amoor River Privet

Lonicera (in variety) Bush Honeysuckle

Philadelphus grandiflorus Large-flowered Mock Orange

Physocarpus opulifolius Ninebark

Sambucus canadensis

American Elder 


\section{CHAPTER XXIV}

\section{PLANTS ADAPTED TO VARIOUS TYPES OF SOIL CONDITIONS}

A VERY important factor in determining the sorts of plants adapted to any specific location is the soil type. By soil type is meant the relative acidity or alkalinity of the soil elements, the relative fineness of the soil particles, and the relative state of dryness of the soil material. All of these conditions overlap and combine with one another and produce soil types which are favourable for certain groups of plants and unfavourable for other groups. The exact physiological reasons why a plant should succeed so much better on one soil type than on another is seldom exactly understood; but practical experience has helped to solve many problems and to bring out many interesting facts.

Plants adapted to boggy soils are likely to be shallow-rooted like the elm, and they are able to withstand a soil condition which is poorly aerated and almost invariably acid. In fact, a pond full of alkaline or limy water will generally be found practically devoid of plant life, while in an acid pond plants thrive so that they gradually displace the water as in sphagnum bogs, which were open ponds at one time but have lost that character through the excessive growth of plants. In a true bog there is practically no free drainage except during the spring thaw or flood time.

Plants adapted to bog gardens are called bog plants. Perhaps the most prominent of these perennials are the different varieties of the lady-slipper and the pitcher plant. One of the most essential things for the success of bog garden plants is to have a moist condition which does not vary to any marked degree. It is much better to have the ground surrounding the roots of these plants over-saturated than to have the degree of moisture become too much depleted; as the water table throughout the entire area of the bog garden should be maintained at a constant level and at the same time the water should not be allowed to become stagnant. If the area which is being developed as a bog garden does-not naturally possess a growth of certain plants which one knows to be indigenous to bog areas then investigation should be 
made to be sure that the artificial bog garden can have moist soil conditions which will be congenial to the plants in this location.

Peat soils are not only naturally acid but it is believed they contain low forms of plant life also which are of great assistance in promoting the growth of ericaceous plants that especially thrive on peaty soils. Peat bog soils lack available nitrogen and therefore carnivorous plants occur, such as pitcher plants and sundew. Humic acid is present and low temperatures are the prevailing ones. The humic acid acts upon the roots of the plants. Plants adapted to peat are likely to be those requiring considerable humus also a cool, moist, deep, loamy soil and a position not in full sun when transplanted.

Since in a light, sandy soil the particles are relatively large such a soil is generally well aerated and not retentive of moisture. Thus, plants adapted to such a soil are as a rule very hardy and possessed of a large root system due to the fact that the roots generally have to extend considerable distances in search of water which may fail just when most needed, that is, during summer droughts and winter freezeups accompanied by a drying wind. Also since this soil type is well aerated it is not likely to contain much humus or to be acid in character as the aeration or oxidation of the humus removes one cause of the soil acidity.

On the other hand, clay soils are composed of very fine particles, poorly aerated, and are retentive of moisture and tend to be acid in reaction. Therefore, plants adapted to clay soils are generally moisture loving, free from large fibrous root systems, and are not nearly so likely to be hardy, especially if removed to another soil type.

Light soils are said to be warmer than heavy ones. What is really meant by that is that the period of growth from spring to autumn is longer on a light soil than on a heavy one. For this reason, plants which start growth early in the spring, like peaches, or bloom late in the autumn, like chrysanthemums, generally succeed better on a light soil. For the present, and until the underlying reasons are better understood, experience will prove the best guide in selecting plants for the different soil types.

\section{LIST OF PLANTS ADAPTED TO VARIOUS TYPES OF SOIL CONDITIONS}

A. Boggy and Peaty Solls. Plants in this group have proved their ability to thrive under extremely wet conditions in boggy or peaty 
types of soil. The evergreens in this group should never be planted in a soil containing limestone or in a soil which is supplied with water from a source where limestone is present, or be fertilized with bone meal.

a. Boggy situations (Trees and Shrubs):

Acer rubrum

Red Maple

Alnus glutinosa

Black Alder

Alnus incana Speckled Alder

Alnus rugosa serrulata

Smooth Alder

Aronia arbutifolia

Red Chokeberry

Aronia melanocarpa

Black Chokeberry

Betula nigra

Red Birch

Cephalanthus occidentalis $S$

Button Bush

Chamaecyparis thyoides

White Cedar

Clethra alnifolia

Sweet Pepper Bush

Fraxinus americana

White Ash

Hypericum densiflorum

Bushy St. John's Wort

Ilex verticillata

Winterberry

Boggy situations (Perennials):

Ascelpias rubra

Red Milkweed

Aster nemoralis

Bog Aster

Cypripedium candidum Small White Lady's Slipper

Eupatorium verbenaefolium Rough Thoroughwort

Gaultheria procumbens

Wintergreen

Helonias bullata

Swamp-pink
Itea virginica

Virginian Willow

Larix laricina

Tamarack

Nyssa sylvatica

Tupelo

Picea alba

White Spruce

Quercus alba

White Oak

Quercus bicolor

Swamp White Oak

Quercus palustris

Pin Oak

Salix (in variety)

Willow

Taxodium distichum

Bald Cypress

Thuja occidentalis

American Arborvitae

Tilia americana

American Linden

Ulmus americana

American Elm

Vaccinium (in variety)

Blueberry

Mitchella repens

Partridge Berry

Osmunda cinnamomea

Cinnamon Fern

Osmunda regalis

Royal Fern

Rhexia virginica

Meadow Beauty

Rynchospora alba

White Beaked-rush

Sarracenia purpurea

Pitcher Plant 
b. Peaty situations:

Kalmia angustifolia

Sheep Laurel

Kalmia latifolia

Mountain Laurel

Ledum groenlandicum

Labrador Tea

Pachistima canbyi

Canby's Mountain Lover
Pieris floribunda
Mountain Fetterbush
Rhododendron (in variety)
Rhododendron
Taxus canadensis
Ground Yew
Viburnum nudum
Large Withe-rod

Xanthorrhiza apiifolia

Yellowroot

B. Light, SANDy SoILs. This group contains many hardy types of trees and shrubs which seem to flourish under poor soil conditions. In general they have a deep root system which enables them to obtain moisture and food material during periods of dry weather.

a. Trees:

Cornus florida

Flowering Dogwood

Juniperus virginiana

Red Cedar

Pinus banksiana

Jack Pine

Pinus rigida

Pitch Pine

Pinus strobus

White Pine

b. Shrubs:

Azalea nudiflora

Pinkster Flower

Caragana arborescens

Siberian Pea Shrub

Comptonia asplenifolia

Sweet Fern

Cornus mas

Cornelian Cherry

Cytisus scoparius

Scotch Broom

Hamamelis virginiana

Witch Hazel

Hippophae rhamnoides

Sea Buckthorn

Hydrangea paniculata grandiflora

Large-flowering Hydrangea
Pinus sylvestris

Scotch Pine

Prunus padus commutata

Hybrid European Bird Cherry

Pyrus baccata (in variety)

Siberian Flowering Crab

Quercus rubra

Red Oak

Robinia pseudacacia

Black Locust

Juniperus communis

Common Juniper

Mahonia aquifolium

Oregon Grape

Myrica cerifera

Bayberry

Prunus maritima

Beach Plum

Rhamnus cathartica

Common Buckthorn

Rhus canadensis

Fragrant Sumac

Rosa rugosa

Japanese Rose

Salix tristis

Dwarf Grey Willow 
Sophora viciifolia Sophora

Spiraea vanhouttci

Van Houtte's Bridal Wreath

Symphoricarpos oulgaris

Indian Currant

c. Vines:

Actinidia (in variety)

Silver Vine

Ampelopsis quinquefolia

Virginia Creeper

Celastrus (in variety)

Bitter-sweet

\author{
Tamarix (in variety) \\ Tamarisk \\ Vaccinium corymbosum \\ High-bush Blueberry \\ Viburnum (in variety) \\ Viburnum
}
Lonicera japonica halliana Japanese Honeysuckle
Lycium halimifolium Matrimony Vine
$V$ itis (in variety)
Grape

C. Heavy Types of Soils. Most of the plants in this group are not of a deep-rooted type and are better adapted for use in the heavy types of soil. These plants, under normal conditions, should be planted in heavy clay soil which is not well drained. This list is compiled for reference where the extreme of clayey soil conditions exist and a particularly safe group of plants is desired from which to select.

a. Trees:

Abies balsamea

Balsam Fir

Abies brachyphylla

Nikko Fir

Abies veitchi

Veitch's Silver Fir

Acer rubrum

Red Maple

Acer saccharum

Sugar Maple

Catalpa bignonioides

Indian Bean

Fagus (in variety)

Beech

b. Shrubs:

Aralia (in variety)

Angelica Tree

Berberis thunbergi

Thunberg's Japanese Barberry

Calycanthus floridus

Strawberry Shrub

Cornus (in variety)

Dogwood

\author{
Larix europaca \\ European Larch \\ Larix laricina \\ Tamarack \\ Larix leptolepsis \\ Japanese Larch \\ Picea excelsa \\ Norway Spruce \\ Pinus strobus \\ White Pine \\ Thuja occidentalis \\ American Arborvitae \\ Tsuga canadensis \\ Canadian Hemlock
}
Corylus avellane
Filbert
Diervilla trifida
Bush Honeysuckle
Halesia carolina
Silver Bell
Hamamelis virginiana
Witch Hazel

Viburnum (native varieties)

Viburnum 
c. Vines:

Actinidia (in variety)

Silver Vine

Akebia quinata

Five-leaved Akebia
Lonicera japonica halliana Japanese Honeysuckle

Wisteria sinensis

Chinese Wisteria

D. Trees Tolerant of Alkali Soils. Trees which are used in this type of soil should be extremely vigorous in their habit of growth. There is no special reason which can be set forth, from a physiological standpoint as a guide, for selecting types of trees for these conditions. The best and safest guide is the experience of others.

(Black Alkali Soils-Sodium Carbonate):

\section{Koelreuteria paniculata} Varnish Tree

(White Alkali Soils.)

Ailanthus altissima

Tree of Heaven

Elaeagnus angustifolia

Russian Olive

Gleditsia triacanthos

Honey Locust (only fairly tolerant)

Halimodendron halodendron

Salt Tree

Platanus orientalis

Oriental Plane
Populus fremonti

Western Cottonwood

Prunus davidiana

David's Flowering Peach

Quercus lobata

California White Oak

Robinia pseudacacia

- Black Locust

Ulmus (in variety)

Elm (only fairly tolerant)

Note: All varieties of Prunus will thrive in alkali soils if grafted on Prunus davidiana.

E. Drought-resisting Plants. The ability of some plants to resist drought lies not in their ability to extract more water than other plants from the same soil, as commonly supposed, but in their ability to send deep roots after water, or else to cut down the loss of moisture through their tops when soil moisture is scarce. All plants require about the same amount of available moisture in the soil around their roots, to keep them from wilting when growing in the same type of soil. But soil types vary in their ability to give up moisture, and the moisture content in a sandy soil can fall much lower than in a more retentive loam or clay soil before plants begin to wilt. This explains why plants adapted to drought conditions and growing in a sandy soil can survive a period of drought which will seriously injure other plants growing near by upon a clay loam soil actually containing more water. 
All of the plants in the following list possess some characteristic which fits them for growing in dry places and should be chosen for planting in those dry spots upon embankments or on sandy soil where it is so hard to secure results with ordinary herbaceous perennials. While the plants included in this list are called drought-resisting plants they are not such plants as will withstand deliberate abuse through lack of cultivation or other normal care. The attempt to adapt plants of this kind to extreme soil conditions should not be made until a decision has been reached that no changes in soil conditions are practicable or justifiable.

\author{
Achillea filipendula \\ Oriental Yarrow \\ Anchusa italica \\ Alkanet \\ Anchusa mysotidiflora \\ Caucasian Alkanet \\ Arabis alpina \\ Rock Cress \\ Arenaria montana \\ Sandwort \\ Artemisia abrotanum \\ Southernwood \\ Artemisia stelleriana \\ Beach Wormwood \\ Calandrinia umbellata \\ Rock Purslane \\ Cerastium tomentosum \\ Snow-in-Summer \\ Cheiranthus allioni \\ Hybrid Wallflower \\ Dianthus deltoides \\ Maiden Pink \\ Draba azoides \\ Aizoon-like Whitlow Grass \\ Echinops ritro \\ Globe Thistle \\ Erigeron speciosus \\ Oregon Fleabane \\ Eryngium amethystinum \\ Amethyst Sea Holly \\ Euphorbia epithymoides \\ Yellow Wolf's-milk \\ Glaucium flavum \\ Sea Poppy \\ Helianthemum (in variety) \\ Frostweed \\ Liatris pycnostachya \\ Blazing Star
}

Liatris scariosa

Large Button Snakeroot

Linaria dalmatica Dalmatian Toad-flax

Lupinus polyphyllus Perennial Lupin

Nepeta mussini

Catmint

Oenothera fruticosa Sundrops

Oenothera speciosa Missouri Evening Primrose

Papaver orientale Oriental Poppy

Platycodon grandiflorum Balloon Flower

Salvia azurea Blue Salvia

Salvia pratensis Meadow Sage

Santolina chamaecyparisus Lavender Cotton

Sedum (in variety) Stonecrop

Sempervivum (in variety) Houseleeks

Stachys lanata Wooly Woundwort

Tunica saxifraga Saxifrage-like Tunica

Verbascum olympicum Greek Mullein

Verbascum phoeniceum Purple Mullein

Verbascum phlomoides Clasping-leaved Mullein $Y$ ucca (in variety) Adam's Needle 


\section{CHAPTER XXV}

\section{PLANTS FOR EXPOSED LAKE FRONT AND RIVER CONDITIONS}

WE HAVE often noticed plantations along exposed lake fronts and river fronts where normal development seems to have been greatly retarded and a considerable loss from winter-killing has been experienced. A definite problem in the selection of plants adapted to these locations is presented, especially where the prevailing winds during the colder periods in the year are from the water.

The plant materials listed in this group are selected from those which have been found hardy under the exposed lake front and river front conditions near the Great Lakes and the smaller rivers of the northern portions of the middle west. Many plants which apparently are hardy under the more even and severe climatic conditions of the inland are not hardy under these water-front conditions. This is largely due to the sudden changes of temperature during the worst of the winter months, and also to the possible effects of the spray freezing on the stems. In general plants which do not ripen their growth until very late in the season are not recommended for use under these conditions.

No plants, not even the more hardy types of those included in these lists, will adapt themselves to normal conditions of growth as early as the same plants would adapt themselves under inland conditions of climate and atmosphere. A greater percentage of loss will be experienced and the only practical method for obtaining a complete planting is by careful addition and replacement during the first three or four years. It is necessary for much of this material to become acclimated to these more severe conditions, and it may be advisable at times to plant some of the more rapid-growing trees and shrubs as a partial protection during the first two or three years.

It is preferable that material used on the steeper slopes of river fronts and lake fronts should possess a deep root system which will aid in protecting the slopes against erosion. If the slopes are steep 
and wash badly during periods of rain such types as locust, sumacs, willows, and the matrimony vine will form a deep root system quickly.

The process of naturalizing trees and shrubs on the slopes of river banks and lake shores is a slow one. It should never be attempted as a single operation. The material should be young, a great percentage of loss must be expected, and only the "survival of the fittest" rule can apply.

\section{LIST OF PLANTS FOR EXPOSED LAKE FRONT AND RIVER CONDITIONS}

The plants in Groups A, B, and C of this list include the hardy types of trees and shrubs. All of these types have been known to thrive under the severe exposures of lake shore and river frontage throughout the northeastern United States. Most of these plants are adapted for use on the slopes so often found along rivers and lakes.

A. Trees:

Acer ginnala
Siberian Maple
Alnus glutinosa
Black Alder
Betula alba
European White Birch
Betula populifolia
American White Birch
Caragana arborescens
Siberian Pea Shrub
Crataegus coccinea
Scarlet-fruited Thorn
Crataegus oxycantha
May Thorn
Elaeagnus angustifolia
Russian Olive
Fraxinus americana
White Ash
Juniperus communis
Common Juniper
Juniperus virginiana
Red Cedar
Picea alba
White Spruce
Picea excelsa
Norway Spruce

Pinus banksiana Jack Pine

Pinus montana mughus Dwarf Mountain Pine

Pinus nigra austriaca Austrian Pine

Pinus rigida Pitch Pine

Pinus sylvestris Scotch Pine

Populus balsamifera Balsam Poplar

Populus eugenei Carolina Poplar

Ptelea trifoliata Hop Tree

Pyrus baccata Siberian Flowering Crab

Quercus macrocarpa Mossy Cup Oak

Robinia pseudacacia Black Locust

Salix vitellina Yellow Willow

Sorbus americana American Mountain Ash 
B. Shrubs:

Cornus alba sibirica Siberian Dogwood

Eleagnus argentea

Silver Berry

Myrica cerifera

Bayberry

Philadelphus coronarius

Common Mock Orange

Prunus maritima

Beach Plum

Rhamnus cathartica

Common Buckthorn

Rhus canadensis

Fragrant Sumac

Rhus glabra

Smooth Sumac

Rhus typhina

Staghorn Sumac

C. Vines:

Actinidia arguta

Dark-leaved Silver Vine

Actinidia polygama

Silver Vine

Ampelopsis aconitifolia

Cut-leaved Vitis

Ampelopsis heterophylla Asiatic Creeper

Ampelopsis quinquefolia

Virginia Creeper
Ribes americanum

American Black Currant

Rosa rugosa

Japanese Rose

Salix incana

Rosemary Willow

Shepherdia canadensis

Canadian Buffalo Berry

Sorbaria sorbifolia

Mountain Ash-leaved Spirea

Spiraea tomentosa

Hardhack

Symphoricarpos occidentalis

Wolfberry

Syringa vulgaris

Common Lilac

Viburnum opulus

High-bush Cranberry

Celastrus scandens

American Bittersweet

Lonicera japonica halliana Japanese Honeysuckle

Lycium halimifolium

Matrimony Vine

Periploca graeca

Silk Vine

Smilax rotundifolia Bull Brier

$V$ itis (in variety)

Grapes 


\section{CHAPTER XXVI}

\section{TREES AND SHRUBS FOR SEASIDE PLANTING}

A PECULIAR situation exists in the relative hardiness of trees and shrubs for seaside exposures. Plants which are entirely hardy on exposed river front and fresh water locations are apt not to thrive at the seaside, especially along the Maine Coast and the more exposed points of New England. Where the climatic conditions of the winter are not extremely severe, as on Long Island and the points farther south, most of the hardy trees and shrubs are well adapted. There are locations on the exposed frontages of the Great Lakes where conditions are equally as severe as are conditions on the east coast of the northeastern United States. The salt air condition and the salt spray during the winter months does not become a factor, however, in lake front exposures.

Perhaps the most severe conditions of seaside exposure in the country are along the shores of Penobscot Bay and the Maine Coast. In all ornamental plantings in these locations it has been a question of experimenting to determine the trees and shrubs to be used to withstand the extreme and severe conditions of the winter months. The growing season is short. Therefore trees and shrubs which require a longer ripening period in the mid-summer and early fall months are subject to considerable winter-killing because of the immature condition of the wood when freezing weather begins. This same factor also deprives the early spring-flowering shrubs of the wood which produces flowers on buds formed the year before. The deciduous trees which are hardy along the coast of Maine are those which are indigenous to that section such as beeches, red oaks, willows, and red maples. None of the more refined types of evergreens, with the exception of the red cedar and the prostrate juniper, have proved hardy. in these locations. The American arborvitae in many instances is hardy, and in others has not proved hardy. The white cypress is rarely seen. A number of shrubs which are included in this list have proved themselves extremely hardy and able to develop into mature 
types which make excellent specimens and good mass plantings. The location considered in this discussion is along the northeast shore, where the exposure is the most severe. In the inland sections, removed from the severe exposure of the salt water, and protected by buildings and woodland developments, a large part of the list of generally hardy shrubs used throughout New England can be planted with safety. All of the material in this group, however, has been under observation for a number of years and has proven itself thoroughly hardy.

In going farther south along the less-exposed New England shores we find a group of trees and shrubs which are fully hardy, but which do not develop at their best along the severe exposures of the Maine Coast. All of the material shown in the first list is fully hardy along the New England Coast and the less-exposed shore locations. There are many other shrubs which might prove hardy. Under the author's observation many types of this material have been used at one time or another. Sources of responsible information have been further consulted and many plants of questionable hardiness, which might otherwise have been included in these groups, have been for the present omitted.

\section{LIST OF TREES AND SHRUBS FOR SEASIDE PLANTING}

A. Plants Hardy Under the Severe Exposure of the North Atlantic Coast. Our only safe guide in the selection of plant types for the extreme exposures along the northeast coast is the experience of those who have endeavoured to acclimate a wide range of plant materials. These plants have proved thoroughly hardy, but it is possible that other plants which may be tested out in other locations or in the future will prove equally as hardy.

a. Deciduous trees:

Acer rubrum
Red Maple
Betula papyrifera
Paper Birch
Betula populifolia
American White Birch
Populus alba
White Poplar
Populus balsamifera
Balsam Poplar

Populus deltoides monilifera Northern Cottonwood

Populus nigra italica Lombardy Poplar

Prunus serotina Wild Black Cherry

Quercus rubra Red Oak

Salix alba

White Willow

Salix lucida

Shining Willow 
b. Conifers:

Juniperus prostrata Dwarf Savin

Juniperus virginiana (native forms) Red Cedar

Larix laricina Tamarack

Picea alba White Spruce

Picea pungens glauca Koster's Blue Spruce

c. Shrubs:

Alnus incana Speckled Alder

Alnus rugosa serrulata Smooth Alder

Ampelopsis quinquefolia Virginia Creeper

Baccharis halimifolia Groundsel Bush

Berberis thunbergi Thunberg's Japanese Barberry

Chamaedaphne calyculata Leather-leaf

Comptonia asplenifolia Sweet Fern

Hippophae thamnoides Sea Buckthorn

Hydrangea arborescens grandiflora Large-flowered Wild Hydrangea

Ilex verticillata Winterberry

Ligustrum ibota regelianum Regel's Privet

Ligustrum oulgare European Privet

Lonicera tatarica

Tartarian Honeysuckle

Lycium barbarum

African Matrimony Vine
Picea rubra Red Spruce

Pinus banksiana Jack Pine

Pinus montana Swiss Mountain Pine

Pinus resinosa Red Pine

Pinus rigida Pitch Pine

Lyonia ligustrina Andromeda

Myrica cerifera Bayberry

Nemopanthus mucronata Mountain Holly

Prunus maritima Beach Plum

Rhus glabra Smooth Sumac

Rhus typhina Staghorn Sumac

Rosa lucida Glossy Rose

Rosa rugosa Japanese Rose

Rosa setigera Prairie Rose

Sambucus canadensis American Elder

Shepherdia canadensis Canadian Buffalo Berry

Spiraea salicifolia

Meadowsweet

Viburnum cassinoides Withe-rod

Viburnum dentatum Arrow-wood

\section{B. Plants Hardy in the Less Severe Seaside Exposures.} Under the less severe conditions of seaside exposure there is a greater range of plants which may be used in addition to those shown under Group A. Most of the material in this part of the list is not adapted for use in the extreme northern section of the seacoast. 

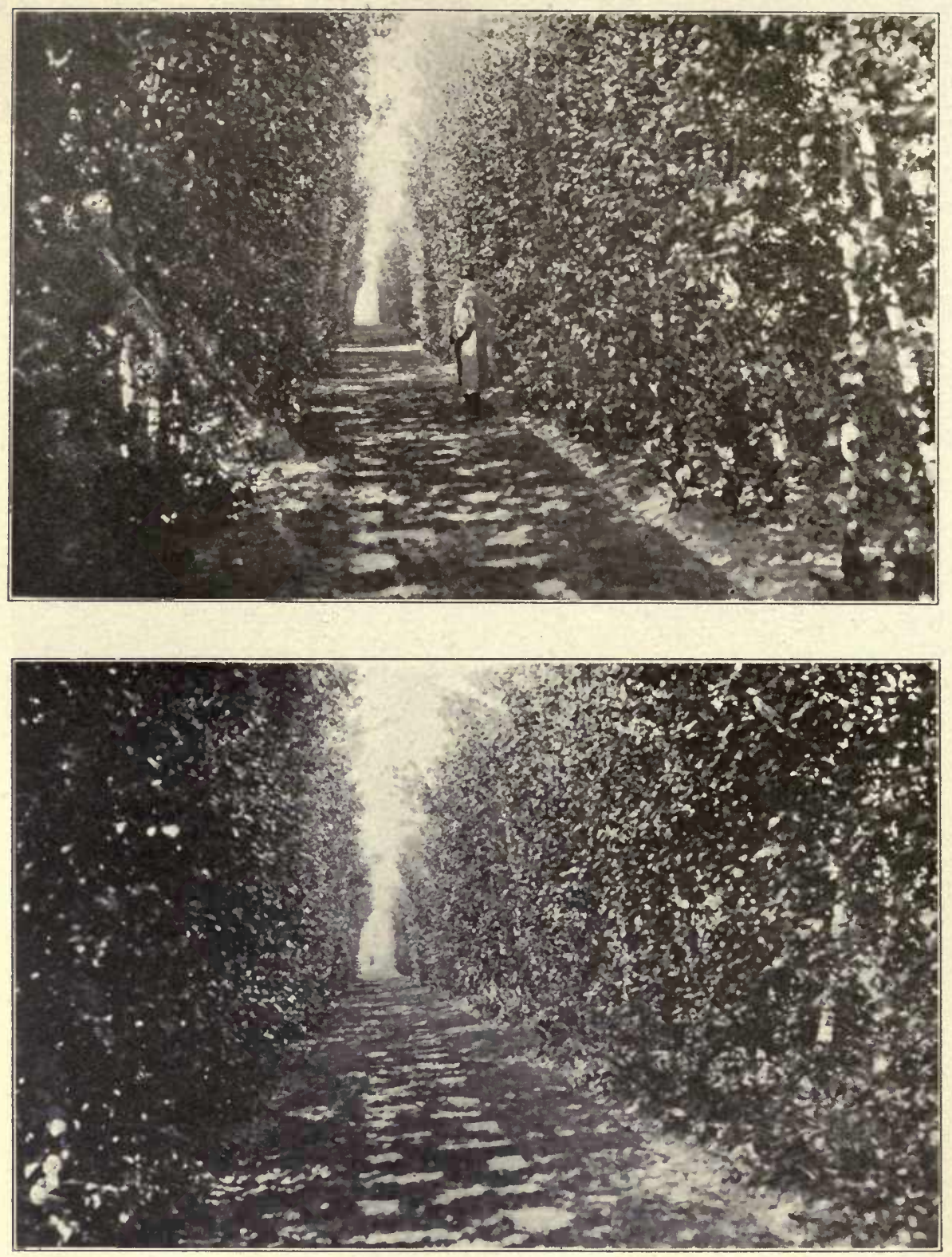

Plate XXIX. An open allee 2 feet wide and 800 feet long, developed by the use of white birch planted 3 to 4 feet apart in each row. For a permanent allee of this type the birch is not ideal because of its short-lived characteristics and susceptibility to borer. Thorns, or the European beech would be preferable. (See page 147 , group XVI-D-b-I) 
a. Deciduous trees:

Acer ginnale

Siberian Maple

Amelanchier oblongifolia

Shad-bush

Celtis occidentalis

Nettle Tree

Crataegus coccinea Scarlet-fruited Thorn

Crataegus cordata

Washington Thorn

Crataegus crus-galli

Cockspur Thorn

Crataegus oxycantha

May Thorn

\author{
Gleditsia triacanthos \\ Honey Locust \\ Platanus occidentalis \\ American Plane \\ Populus alba pyramidalis \\ Bolle's Poplar \\ Prunus pumila \\ Sand Cherry \\ Ptelea trifoliata \\ Hop Tree \\ Robinia pseudacacia \\ Black Locust \\ Salix pentandra \\ Laurel-leaved Willow
}

Salix vitellina aurea

Golden-barked Willow

\section{b. Conifers:}

Juniperus sabina (in variety)

Savin Juniper

Pinus densiflora

Japanese Red Pine

c. Shrubs:

Calluna oulgaris

Scotch Heather

Clethra alnifolia

Sweet Pepper Bush

Cornus amomum

Silky Dogwood

Cytisus scoparius

Scotch Broom

Dirca palustris

Leather-wood

Genista tinctoria

Dyer's Greenweed

Hibiscus syriacus

Rose of Sharon

Hydrangea (in variety)

Hydrangea

Hypericum kalmianum

Kalm's St. John's Wort

Itea virginica

Virginian Willow

Lycium chinense

Chinese Matrimony Vine

\section{Pinus nigra austriaca Austrian Pine \\ Pinus sylvestris Scotch Pine}

\author{
Rhodotypos kerrioides \\ White Kerria \\ Rhus copallina \\ Shining Sumac \\ Robinia hispida \\ Rose Acacia \\ Rosa blanda \\ Meadow Rose \\ Rosa carolina \\ Carolina Rose \\ Rosa multiflora
} Japanese Climbing Rose

Rosa nitida Shining-leaved Rose

Rosa spinosissima Scotch Rose

Rubus odoratus Flowering Raspberry

Symphoricarpos vulgaris Indian Currant

Viburnum lentago Sheep Berry 


\section{CHAPTER XXVII}

\section{PLANTS FOR PARTIALLY SHADED LOCATIONS}

IT ofTEN becomes necessary to make a selection of the lowergrowing trees and shrubs to be planted in partially shaded situations. This condition may be brought about by the location of buildings, by the location of individual groups of large trees, and by the location of scattered specimen trees. We are not considering, in this compilation, the group of materials shown in Chapter XXVIII, which is not only adapted to this same condition of partial shade but has further value in being adapted to heavily shaded areas under wooded conditions. The shrubs in this list are those which may be used to a great degree of safety on lawn areas where a more or less refined planting is necessary, and where native plants are not so much desired.

The difficulty with many kinds of trees and shrubs planted in shaded locations is that the lack of sunlight prevents them from attaining a normal development. The foliage becomes thin and the branches are apt to grow long and spindly. Plants indigenous to such conditions, however, and which have come to thrive with this lessened supply of light, in partially shaded conditions, develop an interesting type of foliage; but flower effects on such plants are never quite as heavy as on plants which are supplied with sufficient light. In the making of plantations of this kind the only logical hope can be that of producing a foliage effect which serves as a background for a lawn and also often serves as a partial screen to give privacy to some garden or to shut off a service yard or other undesirable area.

The bush honeysuckle, the arrow-wood, and the privet form a denser foliage than any of the other types of plants in this group.

\section{LIST OF PLANTS FOR PARTIALLY SHADED LOCATIONS}

As contrasted with the plants listed under Chapter XXVIII, most of the types in this list are adapted for use on the refined lawn areas where fruit and flowers, together with a heavy texture of foliage in the mature plant, are of great value. In fact, some of these plants such as the 


\section{PLANTS FOR PARTIALLY SHADED LOCATIONS}

ground yew and the kalmia, will thrive better under partially shaded conditions than under conditions of open exposure to the sun.

Acer pennsylvanicum Striped Maple

Amelanchier oblongifolia Shad-bush

Azalea (in variety) Native Azalea

Benzoin aestivale Spice Bush

Calycanthus floridus Strawberry Shrub

Ceanothus americanus New Jersey Tea

Clethra alnifolia Sweet Pepper Bush

Cornus alternifolia Alternate-leaved Dogwood

Cornus florida Flowering Dogwood

Cornus mas Cornelian Cherry

Diervilla hybrida lutea-marginata Variegated Weigela

Diervilla trifida Bush Honeysuckle

Hamamelis virginiana Witch Hazel

Hydrangea arborescens Wild Hydrangea

$H y d r a n g e a$ quercifolia

Oak-leaved Hydrangea

Kalmia latifolia Mountain Laurel

Ligustrum (in variety) Privet
Lonicera tatarica Tartarian Honeysuckle

Philadelphus coronarius Mock Orange

Picea alba

White Spruce

Rhamnus caroliniana Carolina Buckthorn

Rhododendron (in variety)

Rhododendron

Rhodotypos kerrioides

White Kerria

Symphoricarpos racemosus Snowberry

Symphoricarpos vulgaris Indian Currant

Taxus canadensis Ground Yew

Tsuga canadensis Canadian Hemlock

Viburnum acerifolium Maple-leaved Viburnum

Viburnum alnifolium Hobble-bush

Viburnum dentatum Arrow-wood

Viburnum lentago Sheep Berry

Viburnum opulus High-bush Cranberry

Viburnum prunifolium Black Haw

Viburnum pubescens Downy-leaved Arrow-wood

Zanthoxylum americanum

Prickly-ash 


\section{CHAPTER XXVIII}

\section{PLANTS FOR UNDERGROWTH PLANTING IN WOODED AREAS}

THE plants which most successfully fill the requirements for undergrowth planting are our native woodland species. These requirements are mainly the ability to succeed in partial or dense shade and also to survive the struggle for moisture, food, and room which always exists in a naturalistic planting where the ground below and the air above are already well occupied by large trees. Our northern forests contain a profusion of plants which will succeed as undergrowth. But too often in the past not enough care has been taken to choose only those plants which are desirable from an ornamental point of view. It is possible, however, to select from the large amount of available material all the plants which are necessary to carry out an undergrowth planting on any scale, and at the same time use only plants which are desirable on account of their flowering habits, their fruits, the autumn colouration of their leaves, their evergreen character, or some equally valuable characteristic quality.

One of the best examples of a successful shrub for undergrowth is the well-known maple-leaved viburnum, which produces white flowers in June and blue fruits in the autumn, and whose leaves in autumn have a striking pink colour. Other shrubs which lend themselves very readily to undergrowth planting are the sweet pepper bush, with its profuse white flowers; the Carolina allspice, on account of its fragrance and autumn colour; and the chokeberries and winterberry, useful for their striking autumn fruits. Among the coniferous evergreens the native hemlock and the balsam fir are very satisfactory plants. The Douglas spruce also promises well and is adaptable to almost any soil.

In choosing smaller plants of perennial herbaceous character much care should be taken to avoid weedy species or those without some especially worth-while characteristic. There are many native forms which are valuable for their green foliage alone, such as the Christmas fern, which is evergreen also, the ostrich fern, Clayton's fern, and the 
maidenhair fern. Among the valuable asters are several which bloom profusely during the late summer and autumn months when other woodland flowers are scarce. The old-fashioned dead nettle, which does not sting, and its variegated leaved variety, provide flowers from May to September, when colonized in moist shade, and the goldenrods also, such as the blue-stemmed and the variety called speciosa, enliven the woods from August to October. Among the plants which will be found valuable for forming mats of ground cover and some of which are evergreen in character are the moneywort, English ivy, running strawberry-bush, spotted wintergreen, and the dwarf cornus or bunchberry.

As a rule these plants succeed best when planted in small colonies and when used to face down clumps of shrubs which may in turn be used against an evergreen background. Thus, plantings may be grouped so as to provide interesting combinations along the sides of paths and at ends of vistas. If the natural mulch layer has disappeared an effort should be made to reproduce it as soon as possible after planting and care should be taken to see that forest fires do not burn off the autumn leaves which nature provides for a winter cover. When leaves drift in so thickly as to threaten to smother the smaller plants a portion of these leaves may be removed; but as a general rule it is not wise to do too much cleaning up unless the desirable plants are in danger of being overwhelmed by the mulch or by larger native plants. One of the most common faults in woodland landscape developments is the attempt to "clean up" existing undergrowth rather than to study its interesting possibilities in combination with many types of plants valuable for foliage, flowers, and fruit.

All these types of plants are adapted for use in woodland wild garden areas, and without exception they will in time naturalize themselves. In developing plantings of this type it is much better practice to lay the foundation during the first season by planting sparsely over the entire planting area. During the succeeding season many plants can be added to supplement the planting which is in place and to replace those which have died in the process of establishing themselves. The best results are obtained by so laying out the planting development that a period of at least three years is required in which to put all of the material into its permanent location. The development of mass plantations under heavily shaded conditions is quite a different problem from the development of mass plantations on open and refined 
lawn areas where planting should be practically completed during the first two seasons. Experience has taught those who have watched this type of plantations develop that a great percentage of loss must be anticipated, for two reasons: In the first place, plants are placed under abnormal conditions of lack of sunlight, and second, the available artificial water supply is apt to be very limited. The process of naturalizing plants and acclimating them to conditions of this kind must naturally be a slow process if the results when the work is completed are to be a success from a landscape standpoint.

It is quite essential in naturalizing perennials in a wild garden that conditions similar to those under which the plant was previously growing should be reproduced. A number of wild garden developments have at different times become failures because as trees have died, thus changing the conditions of shade, these trees have not been replaced, and the result is that this changing of shade conditions has caused the killing out of many types of perennials which are especially susceptible to changed conditions of this character.

\section{LIST OF PLANTS FOR UNDERGROWTH PLANTING IN WOODED AREAS}

Most of the plants contained in this list can be collected from the fields and woods. The larger plants are valuable as background for wild garden planting and for undergrowth planting in wooded areas. For information supplementing this refer to Chapter XXIX-C.

A. Shrubs and Small Trees:

Abies balsamea
Balsam Fir
Acer saccharum
Sugar Maple
Arctostaphylos uva-ursi
Bearberry
Aronia arbutifolia
Red Chokeberry
Aronia melanocarpa
Black Chokeberry
Benzoin aestivale
Spice Bush
Calycanthus floridus
Strawberry Shrub
Carpinus caroliniana
American Hornbeam

Ceanothus americanus New Jersey Tea

Clethra alnifolia Sweet Pepper Bush

Cornus alternifolia Alternate-leaved Dogwood

Cornus florida

Flowering Dogwood

Hamamelis virginiana Witch Hazel

Hydrangea arborescens

Wild Hydrangea

Ilex verticillata

Winterberry

Leucothoe catesbaei

Catesby's Andromeda 


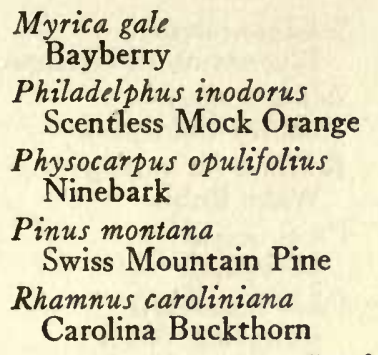

Rhododendron (Native Collected) Rhododendron

Rubus odoratus

Flowering Raspberry

Staphylea trifolia American Bladdernut

Tsuga canadensis Canadian Hemlock

Viburnum acerifolium Zanthoxylum americanum Maple-leaved Viburnum

\section{Prickly-ash}

B. Ground Cover Plants:

Actaea spicata
Cohosh
Adiantum pedatum
Maidenhair Fern
Ajuga reptans
Bugle
Anemone pennsylvanica
Canadian Windflower
Aralia racemosa
American Spikenard
Aspidium acrostichoides
Christmas Fern
Aspidium marginale
Margined Fern
Aster acuminatus
Sharp-leaved Aster
Aster cordifolius
Starwort Aster
Aster corymbosus
Wild Aster
Aster patens
Spreading Aster
Chimaphila maculata
Pipsissewa
Cimicifuga racemosa
Snakeroot
Convallaria majalis
Lily-of-the-valley
Cornus canadensis
Bunchberry
Cypripedium
Lady's Slipper
Dennstaedtia punctilobula
Hay-scented Fern
Evonymus obovatus
Running Strawberry Bush

Evonymus radicans

Climbing Evonymus

Evonymus radicans acutus

Hybrid Japanese Evergreen Ivy

Galium boreale

Northern Bedstraw

Geranium maculatum

Crane's Bill

Hedera helix

English Ivy

Helianthemum chamaecistus

Rock Rose

Hepatica triloba

Hepatica

Hydrastis canadensis

Golden Seal

Hypericum calycinum

Aaron's Beard

Hypericum kalmianum

Kalm's St. John's Wort

Lamium maculatum

Dead Nettle

Lysimachia nummularia

Moneywort

Mahonia repens

Creeping Mahonia

Mitchella repens Partridge Berry

Onoclea sensibilis

Sensitive Fern

Onoclea struthiopteris Ostrich Fern

Osmunda claytoniana Clayton's Fern

Pachistima canbyi

Canby's Mountain Lover 
Phlox divaricata Wild Sweet William

Podophyllum peltatum Mandrake

Polypodium vulgare Polypody

Sanguinaria canadensis Bloodroot

Solidago arguta Sharp-leaved Goldenrod

Viola cucullata

Common Violet
Solidago caesia Blue-stemmed Goldenrod

Solidago speciosa Showy Goldenrod

Trillium (in variety) Wake Robin

$V$ inca minor Periwinkle

Viola canadensis Canadian Violet 


\section{CHAPTER XXIX}

\section{PLANTS FOR GROUND COVER}

Ground-cover plants are distinctly valuable for a use covered by the literal interpretation of the word. The conditions which they overcome may not be unsightly or entirely barren. Their general use is to provide on the ground an interesting carpet, which may be closegrowing, as in the instance of vines and the very low perennials, or taller-growing, as in the instance of yellowroot and flowering raspberry.

We may say that ground-cover plants are used to make a more interesting mat, which is an aesthetic use, or to form a carpet for the purpose of preventing excessive evaporation. Many of these plants are useful because of their fruiting characteristics, and also their ability to retain their foliage, both during the hot, dry summer months and during the winter months. In the selection of this material there are many different and distinct uses which can be definitely grouped under various headings, as shown in this chapter.

As a matter of fact, any plants, whether high or low, serve as a ground cover in some sense of the word. The tall-growing plants, which are often seen planted in close masses and included in the groups of tall-growing shrubs, are discussed under the headings of "mass plantings" and also "undergrowth plantations." This discussion does not attempt to treat those groups.

It has seemed best, rather than to include in one general list all of the plants used for ground cover, to make an effort, at least, to separate into a number of subheadings the specific uses for which groundcover plants may be selected. The person familiar with plant adaptations knows that there are distinct groups of plants which are adapted to low, moist conditions, as there are distinct groups of plants adapted to dry and sunny conditions also. Those of us who have had considerable experience in the planting of perennials in different types of garden soil, as affected either by the type of soil or the kind of drainage, know that certain plants will thrive in a very moist soil, while other plants take a great dislike to moist conditions, and will thrive only 
when the soil is well drained or light and sandy. There are some plants, however, like the moss pink, the sea thrift, and the Japanese evergreen ivy, which seem to thrive almost equally well in moist situations or dry situations. The plants shown in Group A are those which have proved their value as being adapted to conditions which are continually moist, and should preferably be grown in the open sunlight and not subjected to any considerable degree of shade.

Plants which are adapted to dry situations, especially conditions of sandy soil or extreme drainage where grass will not thrive, include a small group which have proved themselves very hardy. The barberry, the Japanese spurge, the moss pink, and the stonecrops are fully representative of this group. The mat of foliage formed by the plants in their more mature development serves to shade the ground beneath and, to a certain extent, to retain much moisture in the soil which otherwise would be lost through evaporation. This group includes the close-growing types of plants which are selected mostly because of their ability to form a definite mat. Many of them such as the stonecrops, the tunica, and the moss pink, are extremely valuable because of their flowering habit, although effective during a short period only. The Japanese spurge, the partridge berry, and the bearberry are valuable distinctly on account of their foliage habits.

The plantsman is often called upon to select material which may be vines, perennials, or low-growing shrubs, to be used for ground-cover purposes under large trees, and in situations heavily shaded by buildings. Most of these plants should have, for their most successful growth, an excellent topsoil containing a small percentage of clay, or a rich woodland loam consisting mostly of well-rotted leaf mold and fibrous roots. These plants are valuable because of their ability to thrive under extreme shade. One often sees in large lawn areas and at the edges of woods, or on the shady side of buildings, spots which receive little or no sunlight where grass will not thrive and where most of our ordinary shrubs and perennials grow thin, leggy, and not vigorous. In such locations the only real solution lies in the selection of plants which will form a ground cover and thus preserve a mat of interesting green foliage. Many of these plants also, like the bunchberry, the ground yew, and the partridge berry, have interesting fruit. The waterleaf, the moneywort, and the Japanese evergreen spurge are types valuable only because of their foliage, and the stonecrops, the periwinkle, and the wake robin are valuable also because of their inter- 
esting flowers. This list of plants does not endeavour to cover the group shown under "perennials valuable for ground cover in wild garden areas," but if one is seeking more complete information on this subject both this group and the discussion on "wild garden areas" should be consulted. (Chapter XXXI-C.)

The question of how to make interesting those embankments and slopes that are otherwise unattractive is one which often confronts us. The plants which are used for this purpose are included under the groups of shrubs, 'perennials, and vines, and the kind of materials selected, whether shrubs, perennials, or vines, depends upon the scale of the effect which is desired. That is, for coarse, rocky embankments, marked with large boulders, and which are to have a rocky appearance, the larger shrubs and vines are most valuable, while for a more refined effect in the intimate portions of the landscape setting the perennials and smaller-growing vines are more effective. Most embankments and rocky slopes are composed of sandy, well-drained, and generally dry soil. Here plants such as roses, matrimony vine, and buffalo berry are valuable for their fruit. The honeysuckles and the yellow-root are valuable for their foliage, and the flowering raspberry and prairie rose for their flowers. Most plantings in such situations will require considerable care and watering during the first two years after transplanting. But subsequent to this time these plants, if properly selected, will continue to thrive, having been thoroughly acclimated to the new location.

Another valuable group of ground-cover plants are those which are used to fill crevices between stepping-stones or between the flagging of paved terrace areas. This list is composed of small-flowering and foliage plants, both perennials and annuals, which are usually planted in small soil spaces between the stones. Their greatest value is to relieve the monotonous, bare effect of walks and terrace areas, to which so much interest would be added by a touch of colour, either in foliage or flowers, obtained through a proper planting of wellselected material included in this group. Many of these plants, if left to themselves, will after the first two or three years spread rapidly and will require much attention to keep them within the proper limits. Many paved walk and terrace areas are overplanted and consequently a careful selection of a few of these plants is much better than an over-supply. The rock cress, sea thrift, stonecrop, and creeping phlox are types which are adapted to the small, refined spaces, while for 
terraces on a large scale, the dwarf iris, evergreen candytuft, tunica, and speedwell are plants which should be used. It is quite probable, in many instances on paved areas which to be on a firm foundation have but a small layer of loam between the stone and the cinders, that these plants will be frequently winter-killed and require replacing. If it so happens that these paved areas can be successfully laid, because of local climatic conditions, upon a good depth of sandy loam, then these plants must seldom be replaced, but rather frequently thinned out.

There are many indigenous mosses which can readily be transplanted in tufts to fill the crevices between the stones on paved walks, thus presenting the appearance of age during the first years after construction. Most of the mosses require a considerable quantity of water to make them thrive. There are a few varieties, however, found in open, sunny locations, that will thrive with little moisture. Therefore, before using moss to fill the crevices between flags on paved areas, the natural habitat of the moss to be used should be known.

In one of the former groups of plants for dry locations and for embankments, the discussion was directed toward the effects of drying out. There are instances where the open exposure and the effect of the sun develop a situation requiring plants that will withstand extreme sun exposure. These plants can be adapted to light, sandy soil, and they form a small group, with the stonecrops, the Adam's needle, and the maiden pink as typical varieties, which may be plarted under the most adverse conditions of exposure and sun.

Quite often one finds plantations of rhododendrons and azaleas which have fallen just short of being really interesting because of the lack of some ground-cover planting to give the added and desired touch of interest. This may be for the purpose of relieving the bare ground around the edges of the plantation, so often covered in a successful manner with Japanese spurge, periwinkles, ferns, and andromedas. It may be that one desires a touch of colour so often obtained by the introduction of the different types of lilies, which can be successfully grown in plantations of hybrid rhododendrons. Especially in plantings of large and native rhododendrons, many of these ground-cover plants can be introduced with a great degree of success to relieve the "leggy" appearance of these plants and to make an interesting mat over the ground which might otherwise be more or less bare. The ground among rhododendrons is subject to more or less heavy shade for two 
reasons. In the first place, the rhododendron foliage itself provides considerable shade at the base of the plant, and the nature of the rhododendron plant requires shade for its successful growth. Consequently, these ground-cover plants should be such as are adapted to the general conditions of woodland shade. It is inadvisable to cultivate the soil around the base of rhododendrons and azaleas. These plants ought to be such that when once planted they will require no further cultivation other than the addition of a small amount of leaf mold from year to year, to provide the necessary food supply.

The last and one of the interesting types of ground cover is that used in the development of rose gardens, to provide a mat of foliage or flowers between the rose bushes. Plants used for this purpose, such as the tufted pansy, the common verbena, and rose moss, ought to be shallow-rooted types, with low, spreading characteristics. The reason why a ground cover is desired in a rose garden is that during a portion of the summer months the ground is often bare. There is an argument, however, against the use of any ground cover throughout the rose garden in that the constant cultivation which is the best aid to the good development of roses cannot be done. Many of the successful English rose gardens are filled with these ground-cover plants. Where plants of this kind are used the roses should be well cultivated in the early spring and should be well cultivated again in the early or late fall, and they should be well fertilized also to insure sufficient food in the soil to provide for both the growth of the ground-cover plants and the roses. These plants, all of which are interesting for their flowering habits, provide an interesting group of colour at a season of the year when most of the roses have passed the height of their bloom.

\section{LIST OF PLANTS FOR GROUND COVER}

A. Moist Locations. This group of plants is adapted for locations where the soil conditions are apt to be continually moist. There are some perennials which will not thrive and will rot where the ground is continually moist. It is therefore desirable to have a group from which to select plants when these exceptional conditions of soil or drainage are encountered.

Achillea tomentosa
Yellow Milfoil
Ajuga reptans
Bugle

Achille a tomentosa juga reptans Bugle

\author{
Alyssum saxatile compactum \\ Golden Tuft \\ Arabis alpina \\ Alpine Rock Cress
}


Armeria maritima

Sea Thrift

Asperula odorata

Sweet Woodruff

Bellis perennis

English Daisy

Campanula carpatica

Carpathian Harebell

Daphne cneorum

Garland Flower

Epigaea repens

Trailing Arbutus

Erica

Heath

Evonymus radicans

Climbing Evonymus

Evonymus radicans acutus

Hybrid Japanese Evergreen Ivy

Evonymus radicans vegetus

Scarlet-fruited Japanese Evergreen Ivy

Festuca glauca

Blue Fescue Grass

Funkia (in variety)

Plaintain Lily

Helleborus niger

Christmas Rose

Herniaria glabra

Herniary
Iberis sempervirens

Evergreen Candytuft

Iris florentina

Orris Root

Lysimachia nummularia

Moneywort

Myosotis palustris

Forget-me-not

Nepeta glechoma

Ground Ivy

Phlox stolonifera

Creeping Phlox

Phlox subulata (in variety) Moss Pink

Potentilla fruticosa Shrubby Cinquefoil

Saponaria ocymoides Rock Soapwort

Stellaria holostea

Starwort

Thymus serpyllum lanuginosus Downy Thyme

Veronica repens

Creeping Speedwell

$V$ inca minor

Periwinkle

Viola cornuta

Tufted Pansy

Viola tricolor

Pansy

B. Dry Locations. The plants in the following group are especially adapted for growing on slopes which are continuously more or less dry. The heavy foliage of the plants often forms a ground cover which conserves the moisture and many of them are the deep-rooted types which will thrive on sandy soils where a normal amount of water is not always available.

\author{
Arctostaphylos uva-ursi \\ Bearberry \\ Arenaria caespitosa \\ Tufted Sandwort \\ Aster ericoides \\ White Heath Aster \\ Cerastium tomentosum \\ Snow-in-summer \\ Dianthus deltoides \\ Maiden Pink \\ Dianthus plumarius \\ Scotch Pink
}

\author{
Festuca glauca \\ Blue Fescue Grass \\ Gaultheria procumbens \\ Wintergreen \\ Helianthemum croceum (protect in winter) \\ Rock Rose \\ Leiophyllum \\ Sand Myrtle \\ Mitchella repens \\ Partridge Berry \\ Pachysandra terminalis \\ Japanese Spurge
}




\section{PLANTS FOR GROUND COVER}

Phlox subulata

Moss Pink

Santolina chamaecyparissus

Lavender Cotton

Sedum album

White Stonecrop

Sedum spurium

Spreading Stonecrop
Sedum stoloniferum

Purple Stonecrop

Tunica saxifraga

Saxifrage-like Tunica

Vinca minor

Periwinkle

Yucca filamentosa

Adam's Needle

C. Shady Locations. The following group of plants contains only the most common types which have proved successful for ground cover under large trees and in heavily shaded situations on lawns. It is best for most of these plants to have as a basis for their growth good soil, although some of them, such as the periwinkle and the Japanese spurge, will grow under extreme conditions of light soil with little moisture. For the greatest success with this list of plants they should be well moistened during dry spells. For supplementary information on ground-cover plants, in shaded locations, see sub-group No. XXXI-C.

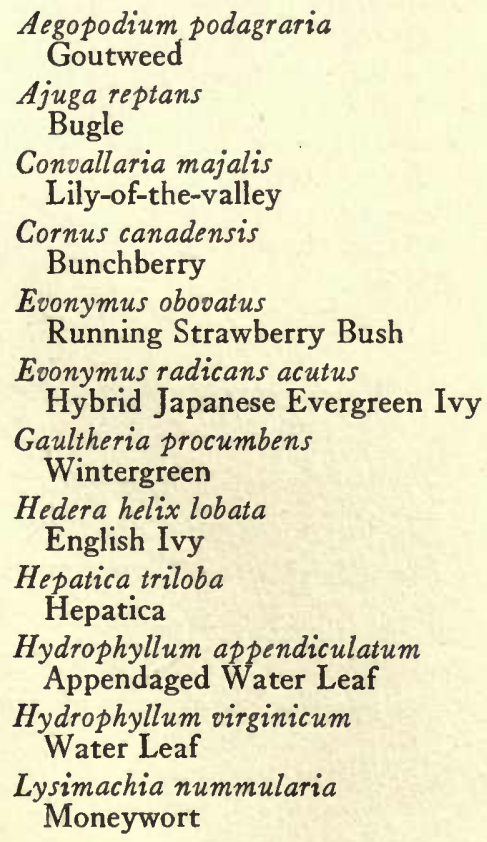

Mahonia repens
Creeping Mahonia
Mitchella repens
Partridge Berry
Pachysandra caroliniana
Carolina Spurge
Pachysandra terminalis
Japanese Spurge
Polygala paucifolia
Milkwort
Polygonatum multiflorum
Solomon's Seal
Sanguinaria canadensis
Bloodroot
Sedum spurium
Spreading Stonecrop
Taxus canadensis
Ground Yew
Trillium erectum album
White Wake Robin
Tussilago farfara
Colt's Foot
Vinca minor
Periwinkle

D. Ferns. There is a great variety of ferns adapted for use in different types of soil, both as a ground cover in the open and more 
dry shaded places and also in the locations where the ground is continually moist. In sub-group $a$ and sub-group $b$ are listed the more important types of ferns which may be selected for plantings where it is desired to use ferns.

a. Dry, shady places:

Asplenium ebeneum Ebony Spleenwort

Asplenium trichomanes

Maidenhair Spleenwort

Aspidium acrostichoides

Christmas Fern

Aspidium marginale

Margined Fern

\author{
Camptosorus rhizophyllus \\ Walking Fern \\ Dennstaedtia punctilobula \\ Hay-scented Fern \\ Osmunda claytoniana \\ Clayton's Fern \\ Polypodium oulgare \\ Woodsia obtusa \\ Polypody
}

b. Moist, shady places:

Adiantum pedatum

Maidenhair Fern

Aspidium acrostichoides

Christmas Fern

Aspidium cristatum

Dwarf Fern

Aspidium goldieanum

Goldie's Wood Fern

Aspidium marginale

Margined Fern

Asplenium filix-foemina

Lady Fern
Onoclea sensibilis

Sensitive Fern

Onoclea struthiopteris

Ostrich Fern

Osmunda cinnamomea

Cinnamon Fern

Osmunda regalis

Royal Fern

Phegopteris hexagonoptera

Broad Beech Fern

Woodwardia virginica

Virginia Chain Fern

E. Embankments and Rocky Slopes. This group consists mostly of vines and scrambling types of shrubs, together with a very few interesting hardy perennials. Banks and rocky slopes do not generally retain a considerable amount of moisture, and accordingly the material which is used should possess a vigorous constitution and low, spreading habit of growth, and the ability to withstand lack of moisture. The embankments which are composed of excellent heavy types of soil, and which are constantly cared for, may be covered with any of the low, spreading types of shrubs and perennials.

a. Shrubs:

Arctostaphylos uva-ursi Bearberry
Comptonia asplenifalia

Sweet Fern 


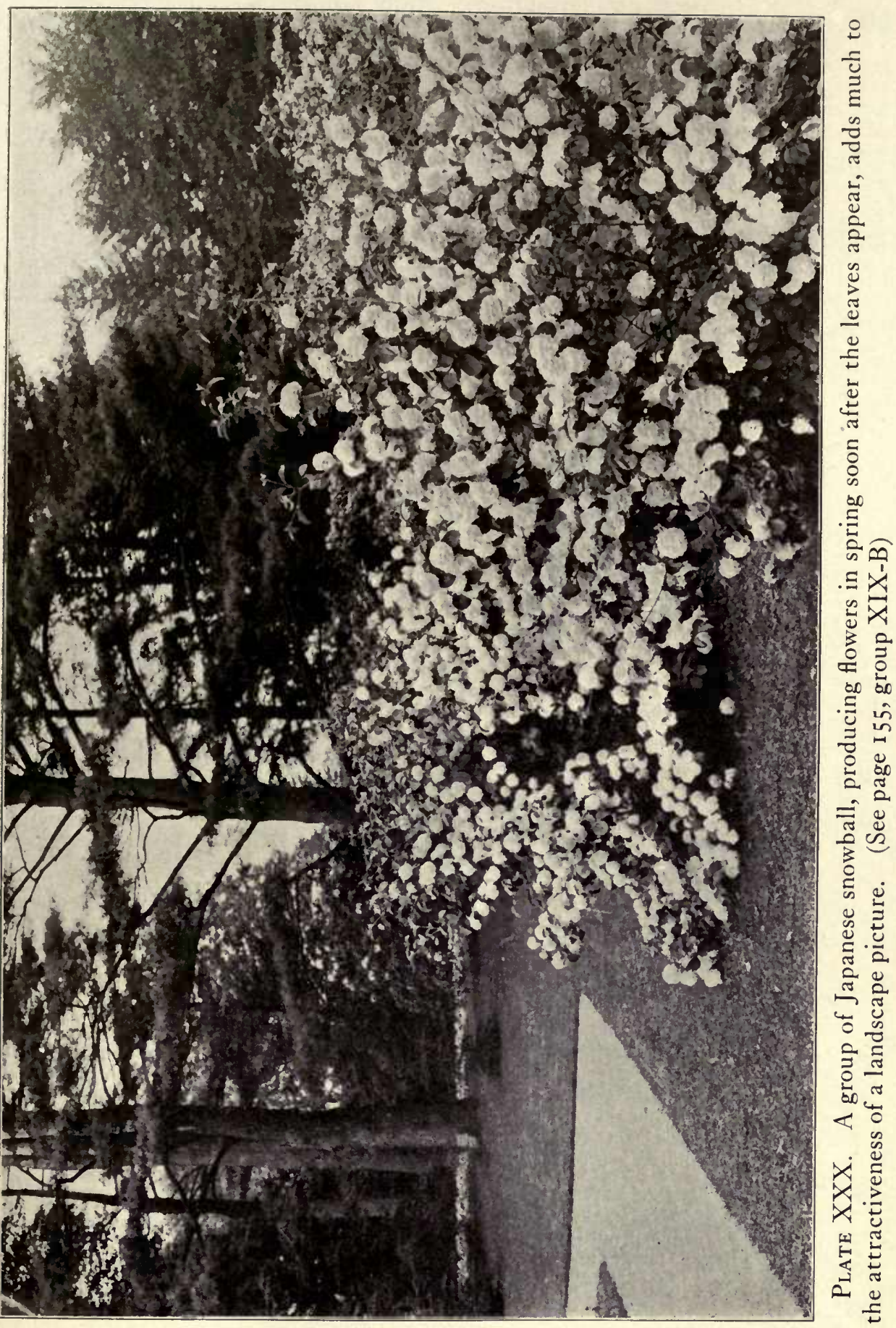





\section{PLANTS FOR GROUND COVER}

Cotoneaster horizontalis Prostrate Cotoneaster

Genista tinctoria

Dyer's Greenweed

Juniperus (prostrate forms)

Red Cedar

Kalmia angustifolia

Sheep Laurel

Lonicera prostrata

Prostrate Honeysuckle

Lonicera spinosa alberti

Large-fruited Honeysuckle

Lonicera syringantha

Heliotrope Honeysuckle

Myrica cerifera

Bayberry

Rhus canadensis

Fragrant Sumac

Rhus copallina

Shining Sumac

Rhus glabra

Rhus typhina

Staghorn Sumac
Smooth Sumac

Rosa setigera

Prairie Rose

Rosa spinosissima altaica Scotch Rose

Rubus crataegifolius

Thorn-leaved Raspberry

Rubus deliciosus

Rocky Mountain Flowering Raspberry

Rubus dumetorum

European Dewberry

Rubus odoratus Flowering Raspberry

Shepherdia canadensis Canadian Buffalo Berry

Sorbaria sorbifolia

Mountain Ash-leaved Spirea

Spiraea salicifolia

Meadow-sweet

Spiraea tomentosa

Hardhack

Symphoricarpos vulgaris

Indian-currant

Xanthorrhiza apiifolia

Yellow-root

Zanthoxylum americanum

Prickly-ash

\section{b. Perennials:}

Hypericum calycinum Aaron's Beard

Pachysandra terminalis Japanese Spurge

\section{c. Vines:}

Ampelopsis aconitifolia Cut-leaved Vitis

Ampelopsis heterophylla Asiatic Creeper

Ampelopsis quinquefolia Virginia Creeper

Bignonia radicans (in variety) Trumpet Vine

Celastrus orbiculatus Japanese Bitter-sweet

Celastrus scandens American Bitter-sweet

\author{
Phlox subulata \\ Moss Pink \\ Vinca minor \\ Periwinkle
}

Evonymus radicans acutus

Hybrid Japanese Evergreen Ivy

Lonicera japonica halliana

Japanese Honeysuckle

Lycium halimifolium

Matrimony Vine

Periploca graeca

Silk Vine

Pueraria thunbergiana

Kudzu Vine

Rosa wichuraiana (in variety)

Memorial Rose

$V$ itis coignetiae

Crimson Glory Vine 
F. Small-flowering and Foliage Plants for Crevices Between Stepping-stones and for Paved Terrace Areas. This group consists of the very dwarf perennials and annuals which may be planted in the limited soil pockets between stepping-stones, between flagging on paved terraces, and in the narrow crevices between rock garden work. Most of the indigenous mosses which are adapted to either shady or sunny exposures can be readily transplanted to a corresponding condition, thus providing an appearance of age during the first year.

Arabis albida

Rock Cress

Arabis alpina

Alpine Rock Cress

Armeria maritima

Sea Thrift

Asperula odorata (in shade)

Sweet Woodruff

Aubrietia deltoidea

Purple Rock Cress

Bellis perennis

English Daisy

Camptosorus rhizophyllus

Walking Fern

Cerastium tomentosum

Snow-in-summer

Ceratostigma plumbaginoides

Leadwort

Dianthus deltoides

Maiden Pink

Evonymus radicans minima

Small-leaved Japanese Evergreen Ivy

Goodyera pubescens

Rattle-snake Plantain

Iberis sempervirens

Evergreen Candytuft

Iris cristata

Crested Iris

Iris pumila

Dwarf Flag

Iris oerna

American Dwarf Iris

Linnaea borealis

Twin Flower

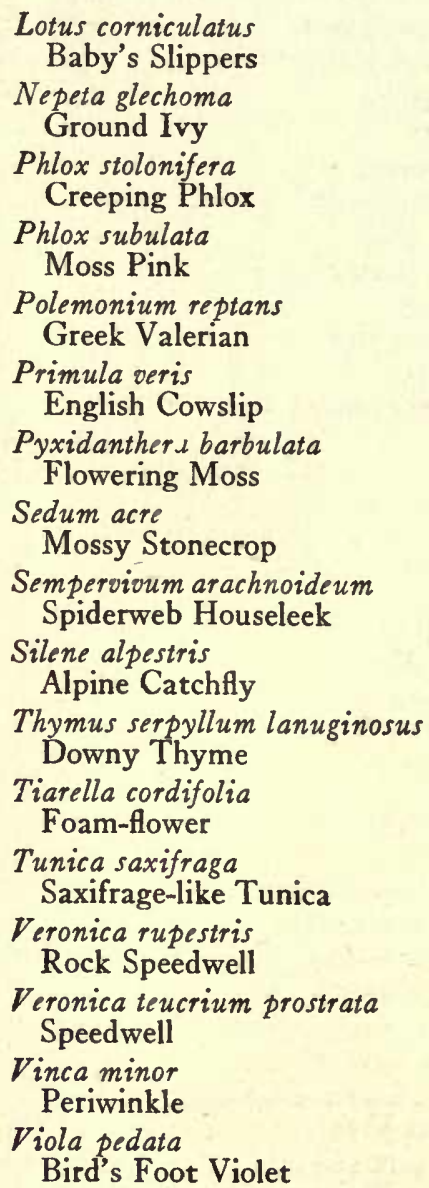

G. Perennials Adapted to Open, Sunny Exposures. This small list contains perennials which will withstand extreme exposure to the sun. Most of these plants will thrive on a light, sandy soil. 


\section{PLANTS FOR GROUND COVER}
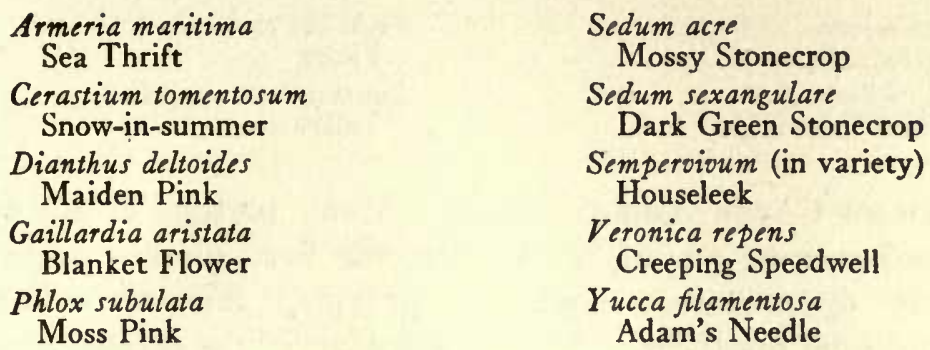

H. Ground Cover Among Rhododendrons and Azaleas. This group contains plants which are excellently adapted to the same kind of soil and the same kind of treatment as are the types of rhododendrons and azaleas with which they are used. Many of these plants such as the lilies, hypericums, and some others, provide flowers during a portion of the season when the large shrubs are not in flower.

Aronia arbutifolia

Red Chokeberry

Asarum canadense

Wild Ginger

Chamaedaphne calyculata

Leather-leaf

Cotoneaster horizontalis

Prostrate Cotoneaster

Erythronium (in variety)

Adder's-tongue

Fern (in variety)

Fern.

Galax aphylla

Galax

Goodyera pubescens

Rattle-snake Plantain

Helonias bullata

Swamp-pink

Houstonia caerulea

Bluet

Hypericum calycinum

Aaron's Beard

Hypericum moserianum

Gold-flower

Ilex glabra

Inkberry

Ledum groenlandicum

Labrador Tea

Leiophyllum (in variety)

Mountain Heath
Leucothoë catesbaei

Catesby's Andromeda

Lilium canadense

Wild Yellow Lily

Lilium pardalinum

Panther Lily

Lilium speciosum Japanese Lily

Lilium superbum Turks' Cap Lily

Lilium tenuifolium Siberian Coral Lily

Mertensia virginica

Bluebell

Mitchella repens

Partridge Berry

Pachysandra terminalis Japanese Spurge

$P$ ieris (in variety)

Fetterbush

Pyxidanthera barbulata

Flowering Moss

Rhodora canadensis

Rhodora

Shortia galacifolia

Shortia

Taxus canadensis

Ground Yew

Trillium (in variety)

Wake Robin 
Vinca minor

Periwinkle

Vinca minor alba

White Periwinkle
Viola (in variety)

Violet

Xanthorrhiza apiifolia

Yellow-root

I. Ground Cover Among Roses. Many persons object to the bare ground existing among roses. For the best success in growing roses every opportunity should be provided for cultivating the area around each rosebush. During a portion of the season, however, this bareness of the soil can be overcome by the use of an interesting carpet, providing colour at a season of the year when the roses have passed the height of their bloom. Any ground-cover planting among roses should be watched carefully in order to eliminate the possibility that the ground-cover plants absorb food which should remain for the rose plants, or that they should prevent cultivation at a time when the roses need cultivating.

Alyssum maritimum Sweet Alyssum

Dianthus heddewigi Japanese Pink

Petunia hybrida Petunia

Phlox drummondi Annual Phlox
Portulaca grandiflora

Rose Moss

Reseda odorata

Mignonette

Verbena hybrida

Verbena

Viola cornuta (in variety)

Tufted Pansy

Viola tricolor

Pansy 


\section{CHAPTER XXX}

\section{GAME COVER PLANTS}

WHEN selecting ground-cover plants and undergrowth plants for locations which are naturally attractive to birds, especially the game birds, it is possible to provide a more inviting "sanctuary" for these birds by the use of plants which produce food either in the way of buds and foliage, or of nuts and seeds. These plants are mostly native species and many of them are not offered in the catalogs of the growers of ornamental plants. They could be easily collected where they occur locally or secured from some of the collectors of native plants. Seeds also might be easily collected and sown where they are to grow. These game cover plants should be established in areas ranging from one hundred feet square to a number of acres, to provide combined shelter and food for several kinds of birds at one time. The location of these plantings should be chosen so that they will not need to be disturbed for some years, and will also be within easy flying distance of dense woods, if possible. An ideal location would be in a clearing entirely surrounded by woods which contain hemlocks or pines or other dense shelter.

Not only will such plants used as a bird-sanctuary attract our permanent bird residents such as the ruffed grouse, bob white, goldfinches, nuthatches, and chickadees, but they will attract many other seed-eating birds until the cold weather drives them south.

\section{LIST OF GAME COVER PLANTS}

The following group of plants are valuable for use as ground cover where there is also a chance to provide suitable shelters for game birds, especially grouse. These groups are: (A) Plants of which the buds, blossoms, and foliage are eaten by game birds, and (B) Plants of which the nuts or seeds are eaten by game birds. These are mostly native plants. 
A. Foliage, Buds, and Blossoms (Spring Cover):

Acer (in variety)
Maple
Alnus (in variety)
Alder
Aster (in variety)
Hardy Aster
Astilbe biternata
False Goat's Beard
Azalea (in variety)
Azalea
Benzoin aestivale
Spice Bush
Betula (in variety)
Birch
Corylus (in variety)
Hazelnut
Epigaea repens
Trailing Arbutus
Equisetum hyemale!
Horse-tail Rushes
Fagus (in variety)
Beech
Heuchera (in variety)
Coral-bells
Kalmia (in variety)
Laurel
Mitchella repens
Partridge Berry
Ostrya virginiana
Hop Hornbeam
Oxalis (in variety)
Wood Sorrel
Picea (in variety)
Spruce

Populus (in variety) Poplar

Portulaca oleracea Purslane

Prunus (in variety) Wild Cherry and Plum

Pyrus (in variety) Crab

Ranunculus (in variety) Buttercup

Rubus (in variety) Brambles

Salix (in variety) Willow

Sambucus (in variety) Elderberry

Saxifraga (in variety) Stone-breaker

Smilax (in variety) Greenbrier

Stellaria media Chickweed

Taraxacum officinale Dandelion

Thalictrum (in variety) Meadow-rue

Thuja (in variety) Arborvitae

Trifolium (in variety)

- Clover

$V$ accinium (in variety) Blueberry

Veronica (in variety) Speedwell

B. Nuts or Seeds (Autumn Cover):

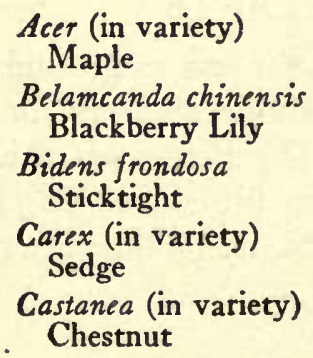

Corylus (in variety) Hazelnut

Fagus americana Beechnut

Geum (in variety) Avens

Hamamelis virginiana Witch Hazel

Helianthemum canadense Frost-weed 


\section{GAME COVER PLANTS}

Impatiens pallida

Jewel-weed

Leptamnium virginianum

Beechdrop

Meiboma (in variety)

Tick Trefoil

Ostrya virginiana

Hop Hornbeam

Pinus rigida

Pitch Pine
Polygonum persicaria Lady's Thumb

Quercus (in variety)

Oak

Rumex acetosella

Sheep Sorrel

Stellaria media

Chickweed

Tsuga canadensis

Canadian Hemlock

Vicia (in variety)

Vetch 


\section{CHAPTER XXXI}

\section{PERENNIALS FOR DIFFERENT PURPOSES}

Whether to use annuals or perennials, what perennials to use for different flowering effects, and how to take care of the perennial garden are important questions, the correct answers to which make for the success or failure of a flower garden. A flower garden in itself is the intimate companion either of those who own it and enjoy working in it, or of those who are only sufficiently interested to be thoroughly satisfied when an interesting flower effect is produced. There is no part of the field of landscape design, from the standpoint of the professional designer, from which so much criticism can arise as through the failure to produce an interesting flower garden. It is useless to discuss the question of taste, concerning the individual preferences for various colours of garden flowers; yet to everyone the successful garden implies a garden filled with flowers. The proper relationship between the unusual types and unusual effects becomes a secondary and yet an important consideration.

The success of a perennial planting does not rest entirely with the proper selection and proper planting of perennials. A perennial garden cannot stand still. It cannot be made to-day and exist tomorrow without some care. Many gardens in which the types of plants have been selected with extra care have completely failed because whoever was responsible for their subsequent maintenance has not understood the nature and requirements of the plants with which he was dealing. The general rule can be laid down for the success of any perennial garden that the one who assumes responsibility for its success must be as intimately acquainted with the plants, their habits and requirements, as with the members of one's own family.

Trees, and Their Effect on the Flower Garden. The old saying is true, either the flower effect of the garden or the quantity of flowers cut for house use must be greatly reduced if the same garden is to serve two purposes. It is also true that trees and desirable sorts of 


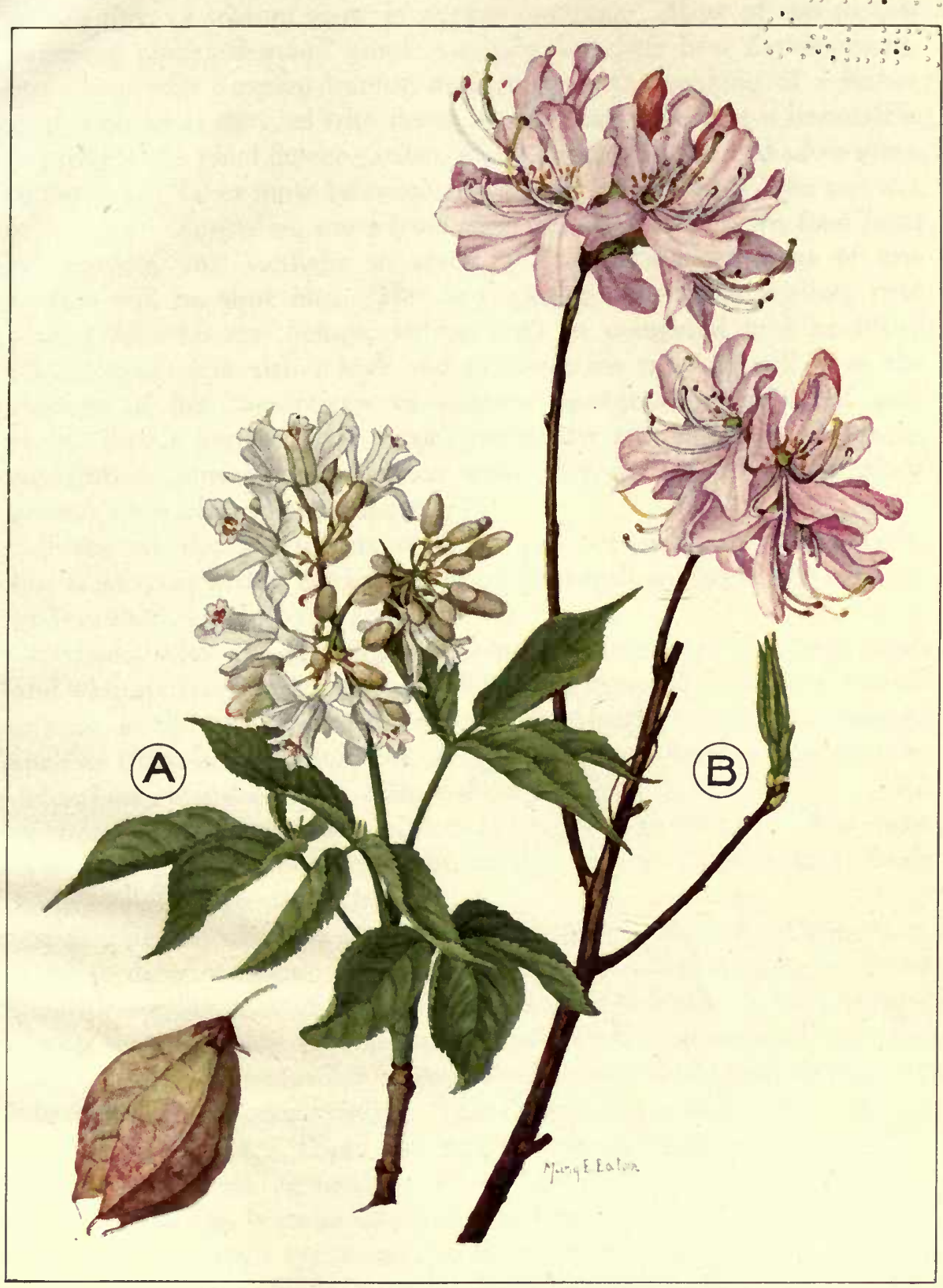

Plate XXXI. It is quite important in the planting of the spring garden that the designer should know those shrubs which produce flowers before the leaves appear, similar to the Carolina azalea (B), and those early-flowering shrubs which produce flowers and leaves at the same time, similar to the bladdernut (A). (See page I54, group XIX-A) 

garden flowers seldom grow in nature together. Most of the garden flowering plants demand ample sunlight for their best development. For those who develop homes, and attempt the making of a flower garden on areas covered with dense shade of large trees, it is impossible to provide the ideal flower garden which one may have wished so often to possess. Trees must be sacrificed, or soil conditions will be too wet or too dry. Spreading roots from such trees will steal plant food from the garden, and sunlight so essential for the development of fine flowers will be shut out. The true garden lover who realizes that plants, like human beings, thrive only in congenial and healthful surroundings will either love and preserve his trees or will have the courage of his convictions to remove unnecessary trees and give to his flower garden ideal conditions of air and sunlight. Morning sunlight is generally considered more effective in producing plant growth than afternoon sunlight.

Trees on the north side of a garden are seldom objectionable; but most trees within the garden or on the south and west side are very undesirable.

Persons who are planting a perennial garden for the first time, and who are not familiar with the flowering types of perennials, should adhere, in the selection of plants, to a few hardy types of perennials, such as the iris, the phlox, the larkspur, the chrysanthemum, and the columbine, together with others shown in this list (XXXI-A). All of these, with average care, are certain to produce flowers. The more unusual types can be selected and introduced into the garden as one's knowledge of them increases.

For a person who is a lover of garden flowers, and who attempts to procure definite colour combinations during different periods of the growing season, it is well to outline groups of perennials, from each of which material may be selected to produce the desired effect. We should associate perennials in groups for season and colour in order to use them most successfully. This knowledge comes only with a certain experience. There also may be plants found outside of these groups which can be used to advantage. The object in compiling these groups has been to establish a definite reference list from which the more important types can readily be found and associated in one's mind with the definite purpose for which they can be best used. Frequently, as a matter of taste, one person may desire a garden with yellows and blues predominating. Another may desire a garden with 
pinks and whites. It is essential that one should be able to readily and definitely select plants for these different purposes.

The woodland wild garden becomes an important problem because the selection of material adapted to partially shaded conditions existing in such garden areas does not present the same problems as the selection of a type of material adapted to a sunny, open exposure. The term "wild garden" applies to the use of plants which can be naturalized; plants which, when once planted and given normal care during the first year, will become thoroughly acclimated and continue to grow vigorously and multiply as the years go by. In the selection of material there are two types of plants which can be selected: the tall-growing types and the low-growing types. The low-growing types are adapted for use in the more intimate, small garden areas, where the taller types should be used with great care. It must be remembered that many types of wild garden perennials, such as the day lilies, the bergamot, and the Japanese loosestrife, will multiply so rapidly that they will crowd out many of the less vigorous plants such as hepatica and spring beauty which are not able to survive such competition. Consequently it is not safe to say that material selected for wild garden areas does not require a certain amount of care after the first planting of the garden. It should also be borne very definitely in mind that plants such as the cardinal flower, some irises, the blazing star, the lily-of-the-valley, the cowslip, and the violet require partial shade and a moist condition of the soil, while such types as the beebalm, sweet william, asters, and moss pink thrive in a much more exposed and lighter soil. The success of a wild garden, either large or small, depends very largely upon the proper selection of materials to produce the required effects. The development of wild garden planting requires a series of years in which to complete it and bring it to perfection. It is a process, beyond a certain point, of the survival of the fittest, and the elimination finally of those plants which prove through the first few years their inability to meet the soil and exposure requirements of the local situation. A successful wild garden area never shows the amount of work that has been expended in its development, because every detail looks finally as though nature had provided it without the assistance of man.

Perennials for wild garden planting are not in use as much as they should be even in extensive estate development, because of the lack of knowledge concerning the ability of many of the wild flowers 
to adapt themselves to these new environments. Yet this group of plants provides to those who are really interested in the development of our wild flowers an excellent source of satisfaction. In this day of large country estates with the varying types of garden conditions there is no reason why the wild garden consisting of plants which have become naturalized should not be as important as any other type of garden, especially to those who are real garden lovers. It is true that many of these plants, such as the varieties of the native ferns, require special conditions of the soil from a standpoint of soil texture, special conditions of the soil from the standpoint of moisture, and also special conditions of exposure concerning the question of open sunlight and the question of shade. It is unfair to expect that any plants which we attempt to naturalize in the wild garden development will continue to grow under conditions which are exactly opposite from the conditions of nature in which these plants have been living a "happy" existence in their surroundings of soil and sunlight. The wild garden requires, more than anything else, a soil which contains plenty of humus and is commonly termed leaf mold soil. If such soil is not available then only well-rotted manure or compost should be used. No fertilizer such as sheep manure, dried blood, or other fertilizers commonly used for the forcing of plants should be applied to wild garden material.

In the use of perennials another problem is often met: that of selecting proper types for planting at the water's edge. These plants must be of the kind that will thrive with their "feet in water." The group from which selection can be made is comparatively limited, especially with reference to genera. Many of these plants, such as the lemon lily, the loosestrife, and the iris will soon spread beyond control if not carefully thinned out and kept within bounds during the succeeding years. Most of this material is adapted to growth in the open sun and will not withstand extreme shade conditions.

In the selection of perennials to be used in the development of the large flower garden areas the entire field of perennials is open from which to choose. The development of a small, refined flower garden, the intimate details of which add to its charm, requires a more careful knowledge of perennials, especially of those which usage has proven cannot be safely introduced into such limited areas. These types of perennials should be avoided in the development of a small flower garden. They can be used by one who will give them consistent at- 
tention to keep them within bounds by staking and cutting back. Otherwise they will produce a loose, ragged effect not in keeping with the neat lines desired in a small garden, and will often crowd out interesting types of smaller perennials which mean more to the success of the garden.

Most varieties of the hardy aster or Michaelmas daisy, the sneezeweed, the loosestrife, and the plume poppy are too rampant and vigorous in their habit of growth to be successful in a small garden.

The most important requirement in the development of any flower garden is to provide perpetual bloom throughout the growing season. There are a variety of combinations of perennials which can be used to accomplish this purpose. As illustrative of a possible range of plants it is well to list some of the thoroughly tested varieties that will grow in any good garden soil and which will provide flowers from early spring until late fall. For a person who understands plants to some extent the lists of perennials, grouped according to colour and season, will make an excellent source of reference from which to select types for continuous blooming effects.

There are some perennials, among the most important of which are the peony, of which the blooming period is very short and the foliage effect during a great part of the summer may be consequently monotonous and uninteresting. In such plants it is highly desirable to have touches of colour throughout the later parts of the season. To accomplish this there can be introduced, among the peony plants, such types as the monkshood, the blazing star, lilies and gladioli, to provide flowers and add interest to the otherwise monotonous mass of green leaves.

A considerable part of the success of any perennial flower garden is the presence of groups of perennials which present good blooming combinations. Often a garden is seen where some particular colour note attracts special attention. On close examination it is found that this effect is produced by a combination of colour brought about by the successful grouping of two or more perennials. The average garden lover cannot become familiar, from his limited study of plants, with all of the interesting types of perennials which produce colour effects that harmonize with each other. A list of these groupings has been included in this chapter, and through further study many others may be found which will be equally effective.

Annuals are most often planted because of their ability to produce 
flowers for cutting. Many perennials are planted for this same purpose. There are a few perennials, such as the blanket flower, ball of snow, larkspur, and marguerite, which are benefited by constant cutting, and the flowering season of which is lengthened through this process. There are other perennials, such as the foxglove, peony, and iris, with which the process of cutting flowers does not encourage. growth of others during the same season. If such perennials are to be used for cut-flower purposes it is best to plant them in a distinct cut-flower garden. The same discussion concerning a cut-flower garden, and a flower garden as an interesting design, applies to the planting of perennials in the same manner that it applies to the planting of annuals (See Chapter XXXII, Page 238).

The majority of perennials will continue to increase from year to year and will require "dividing" and transplanting every two or three years. There are other perennials which should be treated as biennials and accordingly replaced completely by new plants at the end of every second year. These plants, such as the foxglove, white pink, English daisy, and bellflower will "run out" after a period of two or three years. They will still continue to grow, but their vigour will be so much less that their presence will be but an apology for strong, healthy specimens. All of these plants are known as perennials; but in reality they develop only as biennials. Other perennials, such as the aster, phlox, and iris, which grow into large clumps, should be divided at least every three years. If they are not so treated they will become crowded and the plants will not have space to develop properly and the result will be spindly, unhealthy plants which will not produce normal flower effects. But the peony, in good soil, with space of a diameter of approximately three feet in which to grow, is best left to grow undisturbed for a score of years or more (Page 88).

Taken on the whole, no more picturesque or graceful effects can be produced anywhere than by appropriate planting along the banks of ponds and streams. The more bold and picturesque a planting mass is, the better it looks when reflected in a still pool; while the flowing lines of a stream are supplemented by the graceful, arching branches of shrubs and vines. Among the most successful and beautiful plants for watersides are the herbaceous perennials.

Perennials for planting in deep water are largely confined to the lotus and water lilies. These plants should not be permanently planted in ponds which freeze solid during the winter, nor where there is not 
plenty of rich soil on the bottom, and an abundance of clear water and uninterrupted sunlight. The best locations are on the margins of sluggish streams and of bays and in sheltered nooks. Water which flows too swiftly or is too cold or contains mud is not good for aquatic plants, nor should they be planted in newly constructed cement tanks which have not been thoroughly washed and rinsed so as to remove all the caustic property of the new cement. The best fertilizer for aquatic plants is cow manure, which may be mixed with twice its bulk of strong loam and used for planting beds.

In the water near the margin of a pond many more sorts of aquatic and bog plants may be used, such as the native irises or flags, water plantains, bulrushes, arrowheads, and marsh marigolds. These plants are more hardy and less exacting in their requirements. Indeed, they are likely, when congenial conditions occur, to grow so luxuriantly as to prove annoying if planted in very large quantities. A rich alluvial mud provides the proper soil for most sorts, and once established where there is not too much lime in the water, or too swift a current, they will take care of themselves.

For planting on the land at the water's side, a still larger list of plants is available. These include many of our common herbaceous garden perennials, such as sneeze-weed, Japanese iris, and lemon lily, as well as native herbs, such as gentians, cow parsnips, and some of our native orchids. With these perennials should be combined, if possible, some of the moisture-loving native shrubs. For this purpose nothing is better than the swamp honeysuckle, button bush, red chokeberry, rhodora, leather leaf, and wild rosemary, not to mention the more commonly known dogwoods or cornels.

If no special place is assigned to perennials, room may always be found for some in the shrub border. Here there should be reluctance to place any sorts that require considerable culture or the full development of which might be desired, particularly if they be sorts that are prized. One would be loath to subject a valuable variety of the peony, for example, to a life-long competition with vigorous shrubs which, in addition to sending out more rapid-growing roots, would have the advantage of overtopping it. But there are certain types of perennials that can, in every way, be appropriately used to fill bare spaces among shrubs that do not yet cover all the space, or at the front edge of the border. Here at the edge, if the shrubs do not droop too low or are not too vigorous in their habit of growth, may be found a place for a 
fine thing like the evergreen candytuft. In the edge of the shrubbery bed can always be found room for some bulbs; they really seem to prefer the slight protection of the overhanging branches and the soil around the roots of the other plants. An additional consideration is that the flowering season of bulbs is not encroached upon by the foliage of the shrubs, as would occur to the detriment of perennials that flower later in the year. Formal regularity in planting should be avoided because most perennials and bulbs appear best in small masses or clumps.

In designing a border planting of perennials or annuals located at the edge of masses of shrubs an ample width of four or five feet should be allowed, especially if this is the only place for the development of a flower border. Unless this provision is made and frequent pruning of the shrubs resorted to, the branches of the shrubs even then are apt to encroach upon the smaller plants at the front. This does not, however, apply to bulbs. Where it is necessary to develop a flower border in combination with a border of shrubs which shall serve as its background, little success will follow the attempt to develop such a border, especially in relation to tall-growing shrubs, if the flower border is placed upon the north side. If the shrub border or hedge is to consist of tall and vigorous-growing shrubs or columnar trees to provide a screen against objectionable views, the designer must always remember that competition of perennials with the greedy root systems of such plants will starve the perennials.

\section{LIST OF PERENNIALS FOR DIFFERENT PURPOSES}

A. Types of Hardy Perennials for General Use. For the average person who is developing a small garden a knowledge of some of the standard types of hardy perennials, which are well adapted for general use, will often meet the requirements. This group contains standard types of perennials which are adapted for general use, and which with ordinary cultivation will produce interesting flower effects.

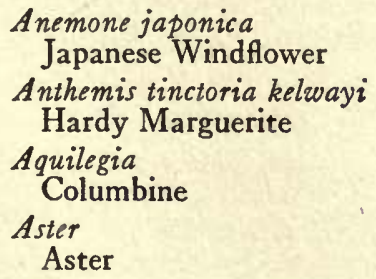

Chrysanthemum Chrysanthemum

Delphinium

Larkspur

Dianthus

Pink

Doronicum plantagineum Leopard's Bane 


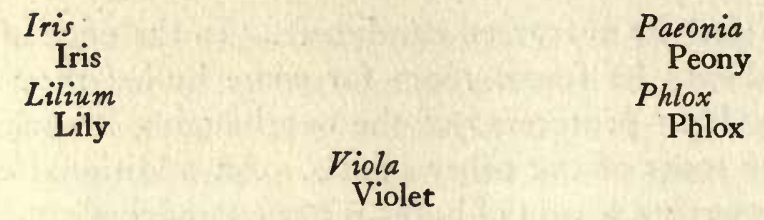

B. Perennials According to Colour and Season. This, with its sub-groups, is an interesting group. The division of seasons in these groups is merely relative and is made for the purpose of obtaining some relationship in the succession of bloom throughout the growing season. Many perennials in these groups lap over from one group into the other, but for convenience of reference they are listed only in the season during which they are at their height of bloom. The subdivisions into colours of flowers, as a matter of easy reference, will prove valuable as a check on one's memory and a saving of time in being able to readily select flowers for varying colour effects at different seasons.

a. Perennials for spring-purple, lavender, or blue flowers:

Ajuga genevensis

Erect Bugle

Anchusa italica

Italian Alkanet

Aquilegia caerulea hybrida

Rocky Mountain Columbine

Aubrietia deltoidea graeca

Grecian Purple Rock Cress

Iris cristata

Crested Iris

Iris germanica hybrids

German Iris

Iris pumila azurea

European Dwarf Iris

Iris oersicolor

Dwarf Blue Flag

Linum perenne

Perennial Flax
Mertensia virginica Bluebell

Myosotis palustris semperflorens Forget-me-not

Polemonium reptans Greek Valerian

Primula denticulata Himalayan Primrose

Saxifraga cordifolia Saxifrage

Tradescantia Spiderwort

Veronica incana Hoary Speedwell

$V$ inca minor Periwinkle

Viola cornuta Tufted Pansy

\section{Viola odorata}

Scented Violet

b. Perennials for spring-white flowers:

Anemone pennsyloanica

Canadian Windflower

Anemone sylvestris

Snowdrop Windflower
Aquilegia nivea grandiflora White Columbine

Arabis albida

Rock Cress 


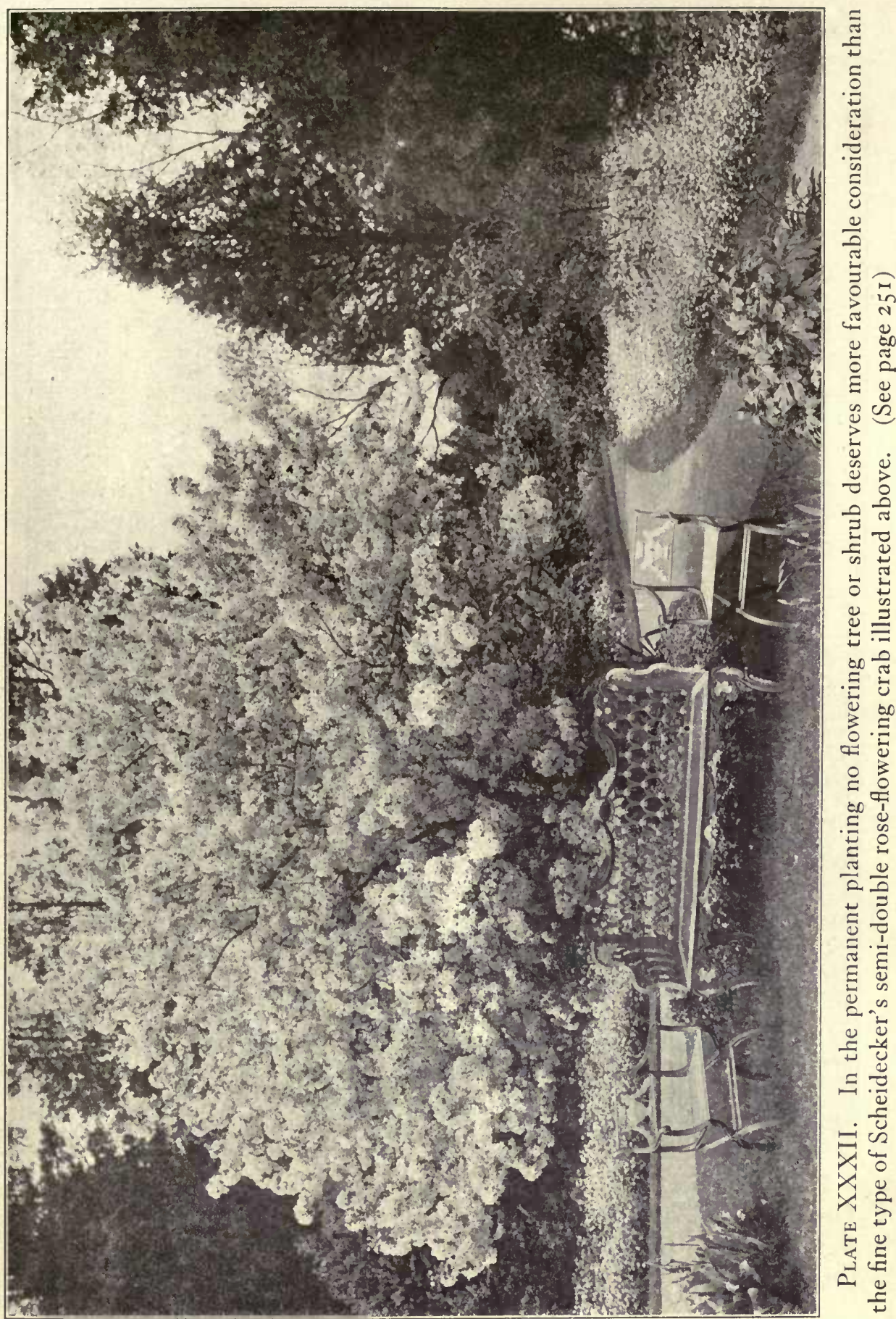




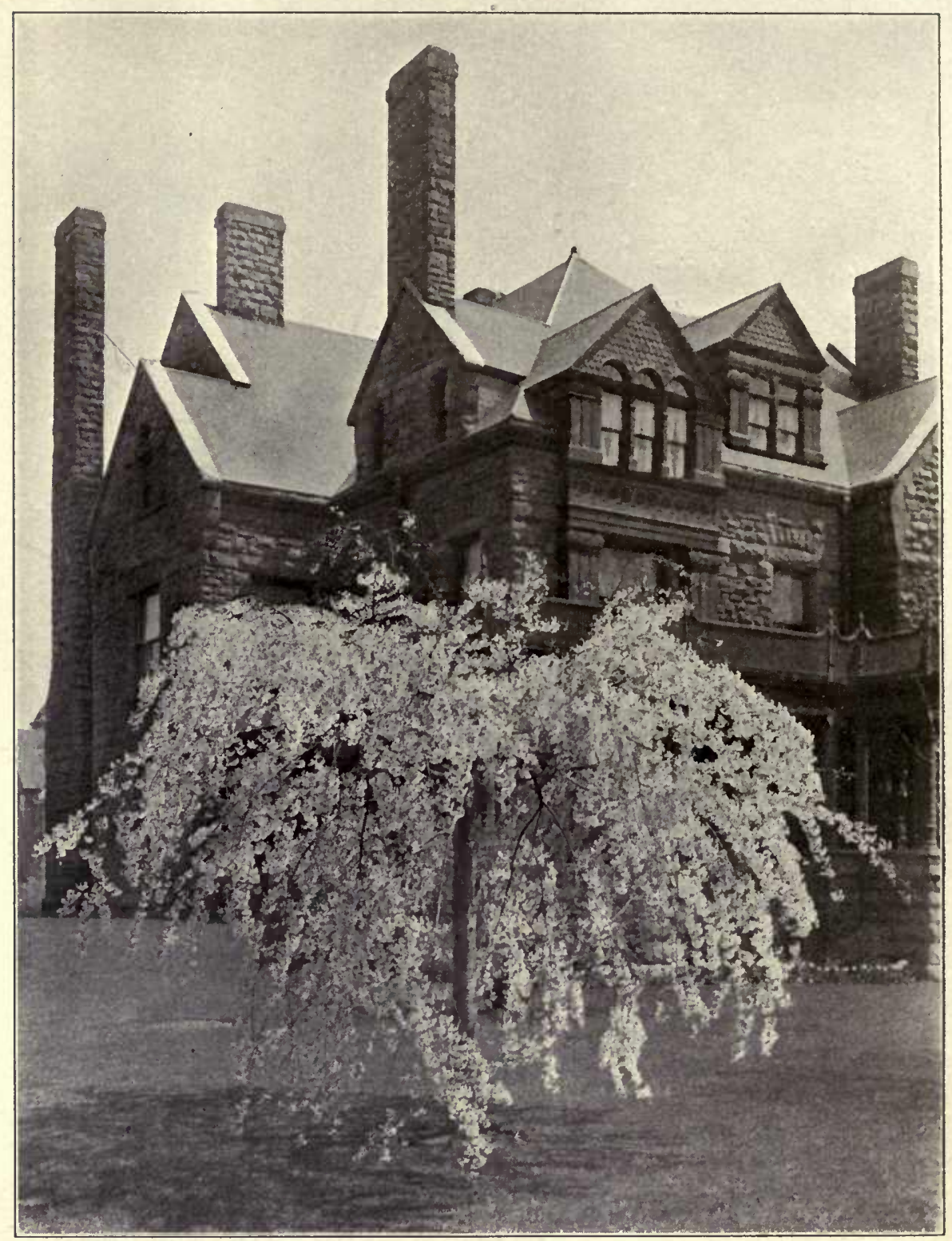

Plate XXXIII. As a specimen flowering plant for early spring effect, the Japanese weeping rose-flowered cherry is extremely interesting covered, always before the leaves appear, with an abundance of rose-pink flowers. (See

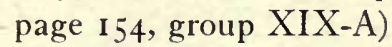




\section{PERENNIALS FOR DIFFERENT PURPOSES}

Arabis alpina

Alpine Rock Cress

Armeria maritima alba

White Sea Thrift

Cerastium tomentosum

Snow-in-summer

Convallaria majalis

Lily-of-the-valley

Dianthus plumarius

Scotch Pink

Helleborus niger

Christmas Rose

Iberis sempervirens

Evergreen Candytuft
Paeonia officinalis alba Old-fashioned Peony

Paconia suffruticosa Tree Peony

Phlox subulata alba White Ground Pink

Sanguinaria canadensis Bloodroot

Stellaria holostea. Starwort

Thalictrum aquilegifolium Meadow-rue

Trillium grandiflorum Large-flowered Wake Robin

Viola cornuta alba

Horned Violet

c. Perennials for spring-pink to crimson flowers:

Aquilegia canadensis American Columbine

Aquilegia formosa hybrida

California Hybrid Columbine

Aquilegia hybrida Rose Queen

Hybrid Pink Columbine

Armeria maritima laucheana

Lauch's Sea Thrift

Bellis perennis

English Daisy

Dianthus deltoides

Maiden Pink

Dianthus plumarius

Scotch Pink

Dicentra spectabilis

Bleeding Heart

Geranium sanguineum Crane's Bill
Geum coccineum Avens

Heuchera sanguinea Coral-bells

Iris germanica Queen of May Pink German Iris

Paeonia officinalis Old-fashioned Red Peony

Paeonia suffruticosa Tree Peony

Paeonia tenuifolia Fennel-leaved Peony

Phlox stolonifera

Creeping Phlox

Phlox subulata

Moss Pink

Primula japonica

Japanese Primrose

Saponaria ocymoides Rock Soapwort

d. Perennials for spring-yellow to orange flowers:

Adonis vernalis

Pheasant's Eye

Alyssum saxatile

Golden Tuft

Aquilegia chrysantha

Gold-spurred Columbine

Baptisia tinctoria

Yellow False Indigo
Doronicum excelsum

Leopard's Bane

Geum heldreichi

Orange Avenas

Helianthemum croceum

Rock Rose

Iris germanica flavescens

German Iris 
Iris pseudacorus

Yellow Water Flag

Iris pumila hybrida

European Dwarf Iris
Primula veris English Cowslip

Trollius europaeus Globe-flower

Viola cornuta lutea

Yellow Horned Violet

e. Perennials for summer-purple, lavender, or blue flowers:

Baptisia australis

Blue Indigo

Campanula carpatica Carpathian Harebell

Campanula medium Canterbury Bells

Campanula persicifolia

Peach-leaved Harebell

Campanula pyramidalis

Chimney Bell-flower

Centaurea montana

Mountain Bluet

Clematis davidiana

David's Clematis

Delphinium (in variety)

Larkspur

Echinops ritro

Globe Thistle

Eryngium amethystinum Amethyst Sea Holly

Funkia caerulea Blue Plantain Lily

Funkia fortunei Fortune's Plantain Lily

Funkia lancifolia Spear-leaved Plantain Lily

Funkia sieboldiana Siebold's Plantain Lily
Iris kaempferi Japanese Iris

Iris pallida dalmatica Dalmatian Iris

Iris sibirica Siberian Iris

Lobelia syphilitica Blue Cardinal Flower

Lupinus polyphyllus Perennial Lupin

Phlox paniculata variety Crepuscule variety Esperance variety Blue Hill (royal purple) variety Le Mahdi variety Antoine Mercie Garden Phlox

Platycodon grandiflorum Balloon Flower

Scabiosa caucasica Mourning Bride

Statice latifolia Broad-leaved Sea Lavender

Stokesia cyanea

Stokes' Aster

Veronica longifolia subsessilis Japanese Speedwell

Veronica spicata Spike-flowered Speedwell

f. Perennials for summer-white flowers:

Achillea boule de neige

Ball of Snow

Althaea rosea alba

Hollyhock

Artemisia lactiflora

Southernwood

Aruncus sylvester

Goat's Beard

Astilbe japonica

Japanese Astilbe
Bocconia cordata Plume Poppy

Campanula carpatica alba Carpathian Harebell

Campanula medium calycanthema alba Canterbury Bell

Campanula persicifolia alba Peach-leaved Harebell

Campanula pyramidalis alba ,Chimney Bell-flower 


\section{PERENNIALS FOR DIFFERENT PURPOSES}

Chrysanthemum shasta daisy

Shasta Daisy

Clematis recta

Herbaceous Clematis

Delphinium grandiflorum album

Chinese Larkspur

Dianthus barbatus - white

Sweet William

Dictamnus fraxinella alba

Gas Plant

Filipendula hexapetala flore pleno

Dropwort

Funkia subcordata grandiflora

Large-flowered Plantain Lily

Gypsophila paniculata

Baby's Breath
Iris kaempferi-white Japanese Iris

Iris sibirica Snow Queen Siberian Iris

Paeonia albiflora sinensis (in variety) Chinese Peony

Papaver orientale-white

Oriental Poppy

Phlox paniculata (in variety)

Garden Phlox

Phlox suffruticosa Miss Lingard Early-flowering Phlox

Sidalce a candida

Sidalcea

Yucca filamentosa Adam's Needle

g. Perennials for summer-pink to crimson flowers:

Althaea rosea

Hollyhock

Astilbe davidi

David's Spirea

Campanula medium-pink Canterbury Bells

Dianthus barbatus

Sweet William

Dicentra eximia

Wild Bleeding Heart

Dictamnus fraxinella

Gas Plant

Digitalis purpurea rosea Pink Foxglove

Lobelia cardinalis Cardinal Flower

Lychnis chalcedonica Maltese Cross
Lychnis coronaria

Mullein Pink

Lychnis oiscaria splendens Ragged Robin

Lythrum salicaria roseum superbum Pink Loose-strife

Monarda didyma

Bergamot

Paeonia albiflora sinensis

Chinese Peony

Papaver orientale (in variety)

Oriental Poppy

Pentstemon barbatus

Bearded Pentstemon

Phlox paniculata (in variety)

Garden Phlox

Physostegia virginiana

False Dragon Head

Pyrethrum roseum

Painted Daisy

h. Perennials for summer-yellow to orange flowers:

Achillea tomentosa

Yellow Milfoil

Althaea rosea-yellow

Hollyhock

Anthemis tinctoria kelwayi

Hardy Marguerite

Centaurea macrocephala

Knapweed
Cephalaria tatarica Giant Scabiosa

Coreopsis grandiflora

Tickseed

Coreopsis lanceolata

Lance-leaved Tickseed

Digitalis grandiflora

Yellow Foxglove 


\section{THE COMPLETE GARDEN}

Gaillardia aristata

Blanket Flower

Helianthus (in variety)

Hardy Sun-flower

Heliopsis (in variety)

Ox-eye Daisy

Hemerocallis (in variety)

Day Lily

Hypericum moserianum

Gold-flower

Oenothera missouriensis Missouri Primrose

Rudbeckia (in variety) Cone-flower

Thalictrum adiantifolium Maidenhair Thalictrum

Thermopsis caroliniana

False Lupine

i. Perennials for autumn-purple, lavender, or blue flowers:

Aconitum (in variety)

Monkshood

Aster-Hardy varieties

Climax-Blue

Edward VII-Blue

Ed Beckett-Blue

Feltham's Blue

novae-angliae-Violet

tartaricus-Violet (Last to bloom)
Caryopteris incana (treat as a perennial) Blue Spirea

Ceratostigma plumbaginoides Leadwort

Eupatorium coelestinum. Mist Flower

Salvia azurea grandiflora

Blue Salvia

Statice latifolia

Broad-leaved Sea Lavender

j. Perennials for autumn-white flowers:

Anemone japonica

Japanese Windflower

Artemisia lactiflora

Southernwood

Aster (in variety)

Hardy Aster

Boltonia asteroides

Aster-like Boltonia

Sedum (in variety)

Caryopteris incana candida (treat as a perennial)

- Blue Spirea

Chrysanthemum (in variety)

Hardy Chrysanthemum

Eupatorium ageratoides

White Snakeroot

Hibiscus moscheutos Swamp Mallow

Stonecrop

k. Perennials for autumn - pink to crimson flowers:

Anemone japonica-pink

Japanese Windflower

Aster (in variety)

Perry's Favorite

St. Egwin

novae-angliae rubra

Perry's Pink

Boltonia latisquama

Broad-scaled Boltonia
Chrysanthemum (in variety) Hardy Chrysanthemum

Hibiscus moscheutos Swamp Mallow

Kniphofia uvaria Red-hot Poker Plant

Sedum (in variety)

Stonecrop 


\section{PERENNIALS FOR DIFFERENT PURPOSES}

l. Perennials for autumn-yellow to orange flowers:

Chrysanthemum (in variety)

Hardy Chrysanthemum

Helenium autumnale

Yellow Sneezeweed
Helenium Riverton Beauty

Yellow Sneezeweed

Kniphofia pitzeri

Red-hot Poker Plant

Solidago (in variety)

Goldenrod

C. Perennials for Naturalizing in Wild Garden Areas. This group contains two sub-groups showing types of perennials which are valuable for naturalizing in wild garden areas. Most of these plants will thrive in the open sun, as contrasted with the preceding list of plants under Chapter XXVIII.

a. Tall types:

\author{
Actaca alba \\ White Baneberry \\ Anemone pennsylvanica \\ Canadian Windflower \\ Aquilegia canadensis \\ American Columbine \\ Aquilegia vulgaris \\ European Columbine \\ Aruncus sylvester \\ Goat's Beard \\ Asclepias tuberosa \\ Butterfly Weed \\ Aster cordifolius \\ Starwort Aster \\ Aster corymbosus \\ Wild Aster \\ Aster ericoides \\ White Heath Aster \\ Cimicifuga racemosa \\ Snakeroot \\ Digitalis purpurea \\ Foxglove \\ Echinacea purpurea \\ Purple Cone-flower \\ Eupatorium purpureum \\ Joe-pye Weed \\ Fern (in variety) \\ Fern \\ Filipendula hexapetala \\ Herbaceous Meadow-sweet
}

Filipendula rubra Japanese Meadow-sweet

Helianthus (in variety) Hardy Sun-flower

Hemerocallis (in variety) Day Lily

Hesperis matronalis Sweet Rocket

Iris pseudacorus Yellow Water Flag

Iris sibirica Siberian Iris

Iris versicolor Dwarf Blue Flag

Liatris pycnostachya Blazing Star

Lobelia cardinalis Cardinal Flower

Lychnis (in variety) Catchfly

Lysimachia clethroides Japanese Loose-strife

Monarda fistulosa Wild Bergamot

Phlox divaricata Wild Sweet William

Polemonium caeruleum American Jacob's Ladder

Senecio clivorum

Groundsel 
Sidalcea candida Sidalcea

Smilacina racemosa False Spikenard
Solidago canadensis Goldenrod

Thalictrum aquilegifolium Meadow-rue

Tradescantia (in variety) Spiderwort

b. Low types:

$\begin{array}{cc}\text { Aspidium marginale } & \text { Phlox ovata } \\ \text { Margined Fern } & \text { Mountain Phlox } \\ \text { Asperula hexaphylla } & \text { Phlox stolonifera } \\ \text { Woodruff } & \text { Creeping Phlox } \\ \text { Claytonia virginica } & \text { Phlox subulata } \\ \text { Spring Beauty } & \text { Moss Pink } \\ \text { Convallaria majalis } & \text { Polemonium reptans } \\ \text { Lily-of-the-valley } & \text { Greek Valerian } \\ \text { Hepatica triloba } & \text { Polygonatum multiflorum } \\ \text { Hepatica } & \text { Solomon's Seal } \\ \text { Heuchera sanguinea } & \text { Primula (in variety) } \\ \text { Coral-bell } & \text { Primrose } \\ \text { Iris cristata } & \text { Sanguinaria canadensis } \\ \text { Crested Iris } & \text { Bloodroot } \\ \text { Lamium maculatum } & \text { Saponaria ocymoides } \\ \text { Dead Nettle } & \text { Rock Soapwort } \\ \text { Mitchella repens } & \text { Trillium grandiflorum } \\ \text { Partridge Berry } & \text { Large-flowered Wake Robin } \\ \text { Myosotis palustris } & \text { Tunica saxifraga } \\ \text { Forget-me-not } & \text { Saxifrage-like Tunica } \\ \text { Oenothera biennis } & \text { Viola canadensis } \\ \text { Evening Primrose } & \text { Canadian Violet } \\ \text { Phlox divaricata } & \text { Viola canina } \\ \text { Wild Sweet William } & \text { Dog-tooth Violet } \\ & \end{array}$

D. Perennials for Long Flowering Period. Not only are perennials selected because of the colours of the flowers and other characteristics such as good blooming combinations, perpetual bloom, and good flowers, as shown in the following groups, but many times certain types are selected because of their long blooming period. Such plants as the yellow marguerite, the Shasta daisy, the blanket flower, and certain hardy phloxes, are very valuable in the garden because they produce flowers over a long blooming period, extending in instances for three or four weeks. Some of these plants require cutting back, like the larkspurs and nettle-leaved mulleins, thus causing them to produce a second crop of bloom. They are all useful to insure a bridging of the gaps between the flowering period of other sorts or to plant in those places where only one, or at most a few sorts, can be used. The 
tickseed, the Shasta daisy, the blanket flower, and the scabiosa all carry their bloom at intervals from June until frost, while the violet, the forget-me-not, and the toad-flax start in .May and last until well into August.

Achillea ptarmica flore pleno

Double Tansy

Anthemis tinctoria kelwayi

Hardy Marguerite

Campanula carpatica

Carpathian Harebell

Chrysanthemum maximum King Edward

Large Shasta Daisy

Coreopsis lanceolata

Tickseed

Delphinium (in variety)

Larkspur

Dianthus deltoides

Maiden Pink

Gaillardia aristata

Blanket Flower

Geum coccineum

Avens

Heuchera brizoides

Red Coral-bells

Knifophia uvaria

Red-hot Poker Plant
Lathyrus latifolius

Hardy Sweet Pea

Linaria dalmatica

Dalmatian Toad-flax

Lychnis coronaria Mullein Pink

Myosotis palustris semperflorens

Forget-me-not

Oenothera fruticosa youngi

Young's Evening Primrose

Papaver nudicaule Iceland Poppy'

Phlox glaberrima suffuticosa Early Garden Phlox

Scabiosa graminifolia Grass-leaved Scabiosa

Scabiosa syloatica

Woodland Scabiosa

Tradescantia virginica

Common Spiderwort

$V$ erbascum (in variety)

Nettle-leaved Mullein

Viola cornuta

Tufted Pansy

E. Perennials Seldom Used in Small, Refined, Formal Gardens. This group contains a few types which should be consistently avoided in the development of a small, formal flower garden, where refinement of detail is the main requirement. These plants, when not given careful attention, such as staking and constant cutting back, will produce a loose, ragged effect and will crowd out many of the small types of perennials which are admirably adapted for use in small formal flower gardens.

Achillea ptarmica flore pleno

Double Tansy

Aconitum wilsoni

Wilson's Monkshood

Althaea rosea

Hollyhock

Arundo donax

Giant Reed
Aster (in variety)

Hardy Aster

Astilbe grandis

Large-flowered Astilbe

Bocconia cordata

Plume Poppy

Boltonia asteroides

Aster-like Boltonia 
Eupatorium (in variety)

White Snakeroot

Filipendula camtschatica

Siberian Goat's Beard

Helenium autumnale superbum

Tall Sneezeweed

Helianthus (in variety)

Hardy Sun-flower

Hibiscus moscheutos

Swamp Mallow

Liatris pycnostachya

Blazing Star

Lythrum salicaria roseum

Pink Loose-strife
Miscanthus (in variety)

Plume Grass

Physostegia virginiana

False Dragon Head

Polygonum sachalinense

Knotweed

Rudbeckia laciniata

Golden Glow

Rudbeckia maxima

Cone-flower

Solidago (in variety)

Goldenrod

Stenanthium robustum

Mountain Feather Fleece

F. Perennials to Supply "Perpetual Bloom." This group of perennials will prove helpful in providing continuous bloom through-. out the season. Most of these plants are the well-known, thoroughly tested kinds which will grow in any average garden soil and will combine well in their colour effects and habits of growth. By a lover of flowers, who has acquired expert knowledge of flowers, many similar groupings can be formed.

Anemone japonica

Japanese Windflower

Aquilegia hybrida

Columbine

Aster (in variety)

Hardy Aster

Boltonia asteroides

Aster-like Boltonia

Chrysanthemum (in variety)

Hardy Chrysanthemum

Chrysanthemum shasta daisy

Shasta Daisy

Delphinium belladonna

Everblooming Larkspur

Dicentra spectabilis

Bleeding Heart
Gaillardia aristata

Blanket Flower

Helleborus niger

Christmas Rose

Hemerocallis (in variety)

Day Lily

Iris germanica

German Iris

Iris kaempferi

Japanese Iris

Paeonia albiflora sinensis

Chinese Peony

Phlox paniculata

Garden Phlox

Rudbeckia maxima

Cone-flower

Viola cornuta hybrida

Horned Violet

G. Perennials for Use Among Peonies. When peonies have completed their period of flowering there remains during the balance of the season a mass of green foliage which can often be made much more interesting by the addition of a few types of perennials which do not require any considerable space for their development, and which 


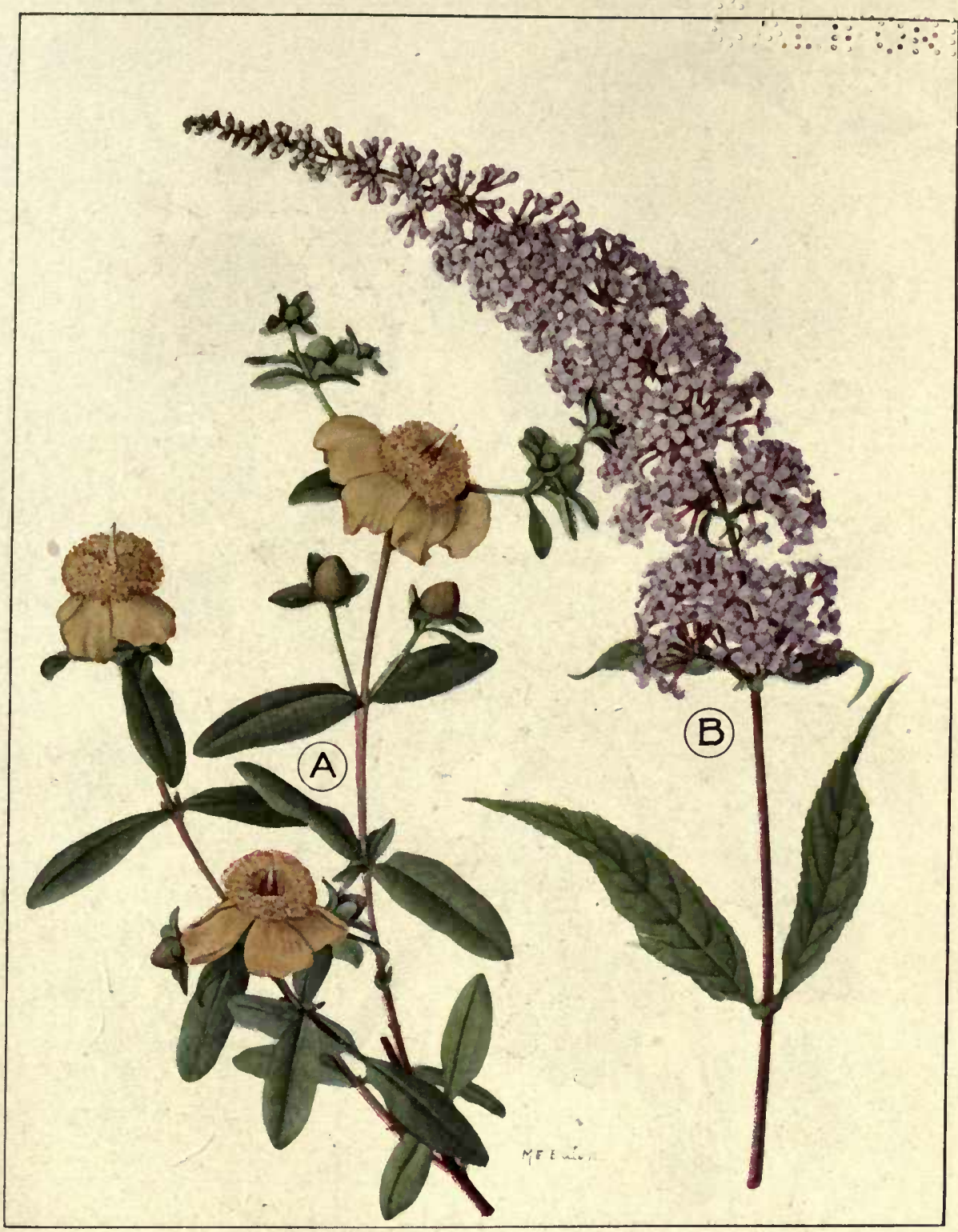

PLATE XXXIV. It is a source of much satisfaction to the plant designer to know that shrubs which are carefully selected for the colour of their flowers may produce very effective colour combinations. This plate shows the St. John's Wort (A), in combination with the sweet-scented buddleia (B). 


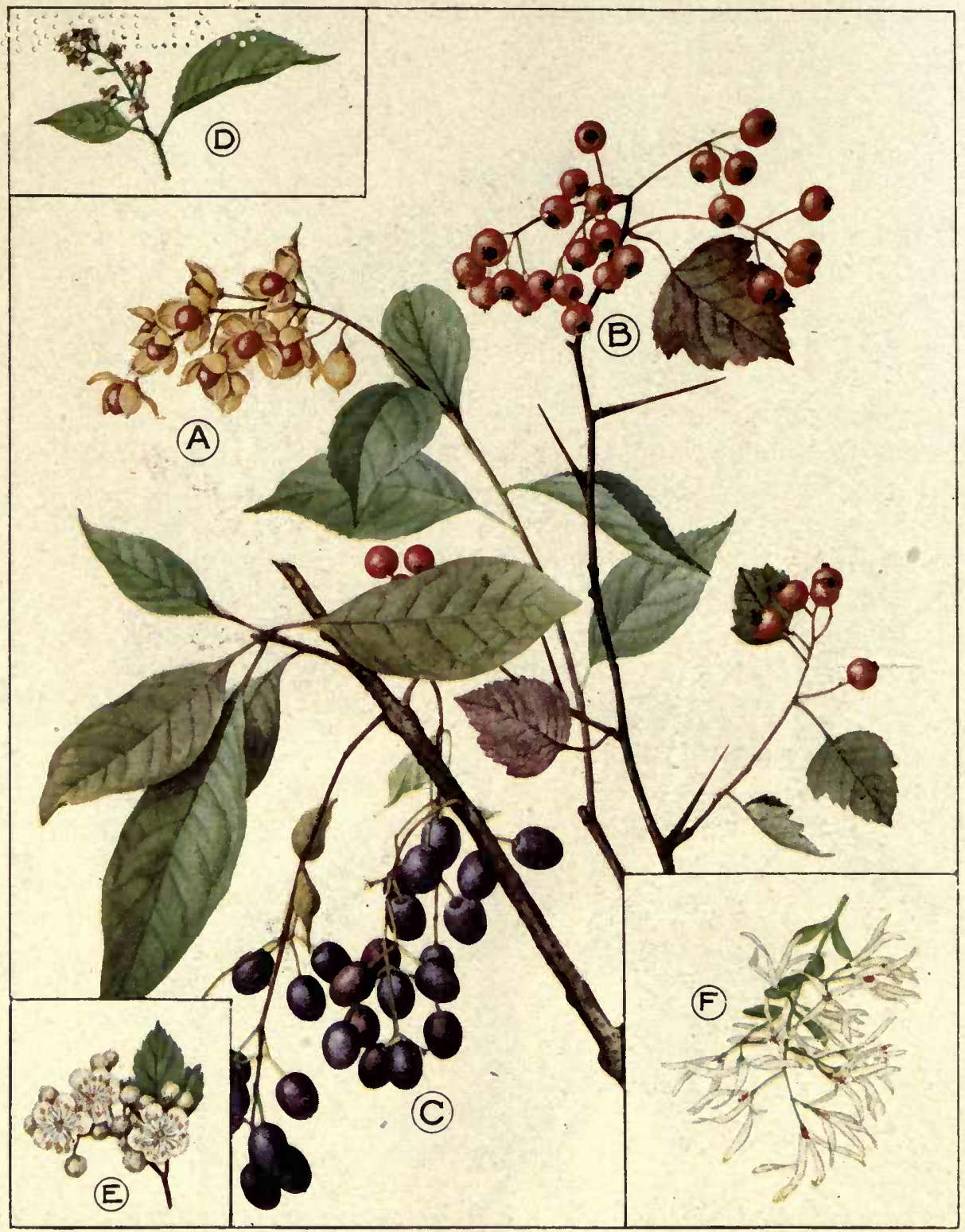

Plate XXXV. The average person who has not become interested in the colour effects produced by the fruits of our common trees and shrubs can hardly appreciate the intense colour display of the American bittersweet (A), the Washington thorn (B) and the white fringe (C). For flowers: (D) bittersweet, (E) thorn and (F) fringe. (See page 162 , group XX-B) 


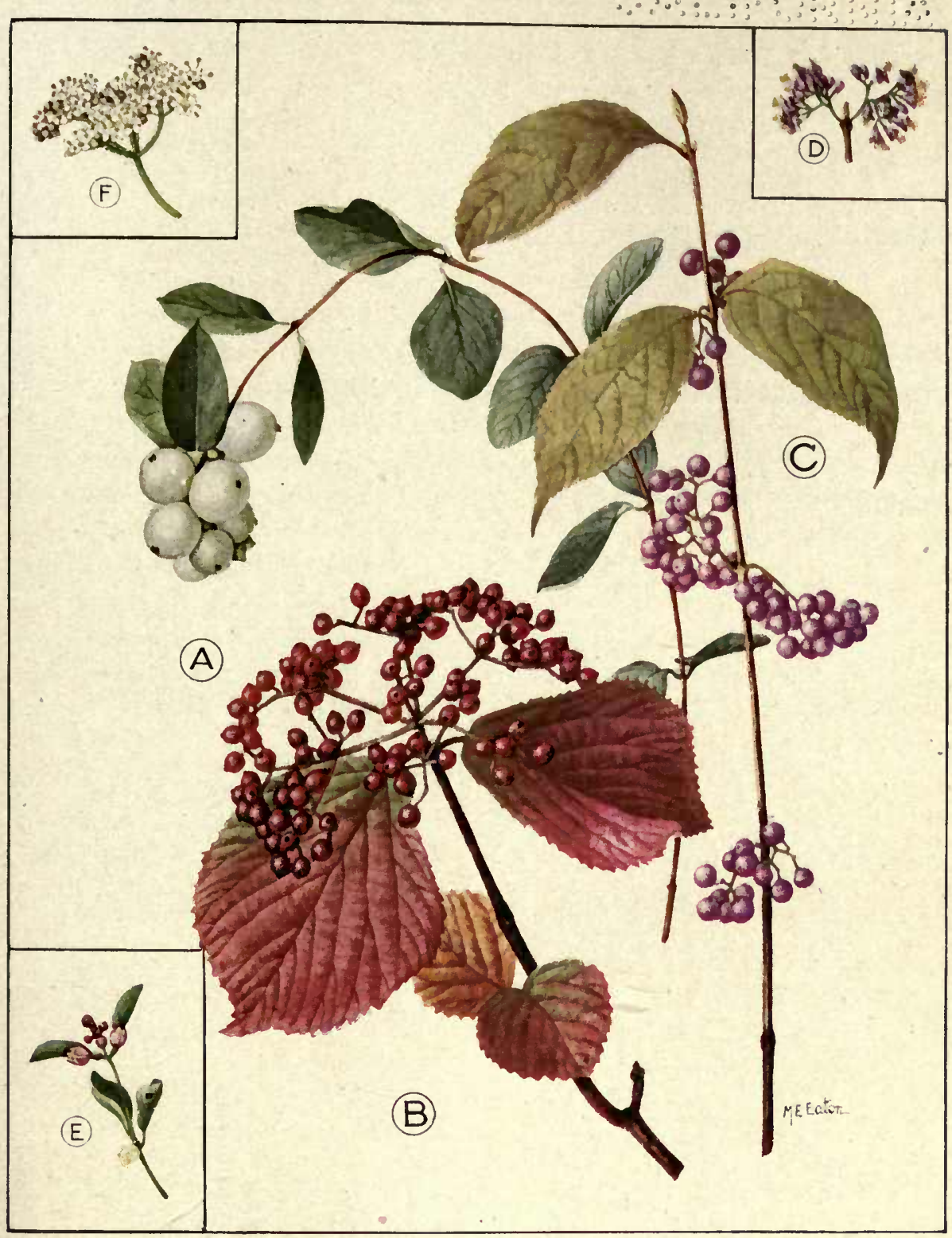

Plate XXXVI. The garden designer must always bear in mind that many of our shrubs which produce very uninteresting flowers are the ones which produce our most attractive fruiting effects. The variation in colours of the fruits ranges from the pure white of the snowberry (A), through the purple and porcelain blue of the beauty fruit $(\mathrm{C})$, to the vivid reds of which the Japanese bush cranberry (B) is typical. For flowers: (D) beauty fruit, (E) snowberry, (F) Japanese bush cranberry. (See page 162, group XX-B) 

will lend touches of colour to this mass of green during the summer months.

Aconitum fischeri
Monkshood
Aconitum napellus
Monkshood
Gladiolus (in variety)
Sword Flower
Hyacinthus candicans
Summer Hyacinth
Kniphofia pfitzeri
Red-hot Poker Plant
Liatris (in variety)
Blazing Star
Lilium (See List No. XXXIII-F)
Lily
Physostegia virginiana
False. Dragon Head

H. Perennials for Good Blooming Combinations. The following group contains interesting combinations of perennials which, if planted together, will produce in each case a pleasing colour effect. The perennial garden is valuable for two effects: either for a succession of bloom, or for interesting colour combinations of those flowers which bloom at the same time. The following is an endeavour to provide such combinations:*

I. Rosa foetida harisoni and Aquilegia caerulea, blue.

2. Heuchera sanguinea, coral; Aquilegia caerulea, blue; Iris germanica Kharput, purple.

3. Paeonia festiva maxima, white; Dianthus latifolius atrococcineus, crimson; Paeonia, pink (in variety); Clematis recta, white (as background) and Dianthus barbatus, variety "Newport", pink.

4. Iris pallida dalmatica, lavender; and Thermopsis caroliniana, yellow.

5. Cerastium tomentosum, white; Linum perenne, blue.

6. Phlox Miss Lingard, white; and Campanula persicifolia caerulea, blue.

7. Phlox Miss Lingard, white; Aquilegia chrysantha, yellow; and Heuchera sanguinea, coral.

8. Hemerocallis flava, or Anthemis tinctoria kelwayi, yellow; with Delphinium formosum or Baptisia australis, blue; or Iris Celeste, blue.

9. Hemerocallis fulva, orange with Clematis recta, white.

10. Coreopsis lanceolata, or Thermopsis caroliniana, yellow; with Delphinium in deep blue shades.

I1. Chrysanthemum shasta daisy, white; Anthemis tinctoria kelwayi, yellow; and Delphinium belladonna, blue.

12. Delphinium belladonna or hybrids, blue; and Lilium candidum, white.

13. Anchusa italica, blue; and Anthemis tinctoria kelwayi, yellow.

14. Chrysanthemum shasta daisy, white; and Iris kaempferi in purple shades, or Dianthus Napoleon III, crimson.

15. Monarda didyma Cambridge, scarlet; and Phlox paniculata, white.

16. Phlox paniculata, pink; Lilium speciosum, white; and Veronica longifolia subsessilis, violet.

17. Thalictrum dipterocarpum, blue; Veronica longifolia subsessilis, violet; and Anemone japonica, white.

*For common names refer to index and page references. 
18. Veronica spicata, blue; and Oenothera missouriensis, yellow.

19. Eupatorium ageratoides, white; and Helenium Riverton Beauty, yellow and black.

20. Eupatorium ageratoides, white; and Chrysanthemum, Glory of Seven Oaks, yellow.

21. Buddleia (in variety), lilac, lavender, violet, purple; and Anemone japonica, white or pink.

22. Anemone japonica, white and pink; and Aconitum autumnale, blue.

23. Aster Climax, blue; and Helenium Riverton Beauty, yellow and black.

I. Perennials Valuable for Cut Flowers. The perennial cutflower garden should provide an abundance of cut flowers. Most of the perennials in this group will provide flowers which can be cut for house use and which have lasting qualities. There are many perennials which do not produce masses of flowers of sufficient substance to be effective when cut for house use.

Achillea boule de neige

Ball of Snow

Anemone japonica

Japanese Windflower

Aquilegia (long-spurred hybrids)

Columbine

Aster novae-angliae Climax

Blue Hardy Aster

Astilbe japonica

Japanese Astilbe

Boltonia asteroides Aster-like Boltonia

Centaurea montana Mountain Bluet

Chrysanthemum (in variety)

Chrysanthemum

Chrysanthemum shasta daisy Shasta Daisy

Convallaria majalis Lily-of-the-valley

Coreopsis lanceolata Lance-leaved Tickseed

Delphinium (in variety)

Larkspur

Dianthus barbatus

Sweet William

Digitalis (in variety) Foxglove

Eupatorium coelestinum Mist Flower
Gaillardia aristata

Blanket Flower

Gypsophila paniculata

Baby's Breath

Helianthus (in variety)

Hardy Sun-flower

Heuchera sanguinea

Coral-bells

Iris germanica

German Iris

Iris kaempferi

Japanese Iris

Kniphofia uvaria

Red-hot Poker Plant

Paeonia (in variety)

Peony

Physostegia virginiana

False Dragonhead

Phlox paniculata

Garden Phlox

Primula (in variety)

Primrose

Pyrethrum roseum

Painted Daisy

Rudbeckia (in variety)

Cone-flower

Scabiosa caucasica

Mourning Bride

Stokesia cyanea

Stokes' Aster

Veronica (in variety)

Speedwell 
J. Perennials Which Should Be Treated as Biennials. There are certain plants generally known as perennials which will "run out" in the average garden after a period of two to three years. They may still continue to grow, but after the first two years they are much less vigorous. The plants in this group should be planted with the idea that at the end of two years the old plants will be removed and new ones put into their places.

\author{
Antirrhinum majus \\ Snapdragon \\ Bellis perennis \\ English Daisy \\ Campanula medium \\ Canterbury Bells \\ Campanula pyramidalis \\ Chimney Bell-flower \\ Dianthus barbatus \\ Sweet William \\ Digitalis purpurea \\ Foxglove \\ Glaucium luteum \\ Yellow Horned Poppy
}

\author{
Hedysarum coronarium \\ French Honeysuckle \\ Lunaria annua \\ Honesty \\ Lychnis alba \\ White Pink \\ Lychnis coronaria \\ Mullein Pink \\ Lychnis dioica \\ Red Campion \\ Viola cornuta \\ Tufted Pansy \\ Viola tricolor \\ Pansy
}

K. Perennials to be Transplanted Frequently. There are certain perennials which require special attention for their best development. The perennials in this group should be taken up, divided, and replanted every two or three years, as they grow more vigorously and multiply faster than the other groups of perennials.

a. To be divided every two years:

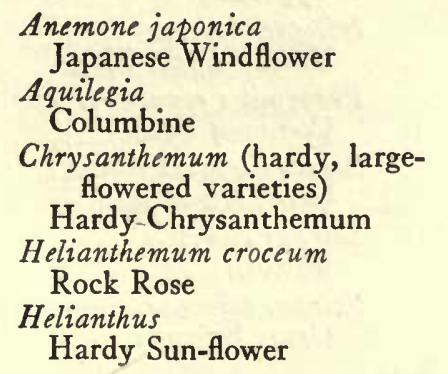

b. To be divided every three years:

\author{
Lychnis coronaria \\ Mullein Pink \\ Monarda didyma \\ Bergamot \\ Paeonia (in variety) \\ Peony (only to multiply) \\ Phlox paniculata \\ Garden Phlox \\ Rudbeckia \\ Cone-flower
}

Armeria (in variety) Sea Thrift

Iris (all varieties) Iris

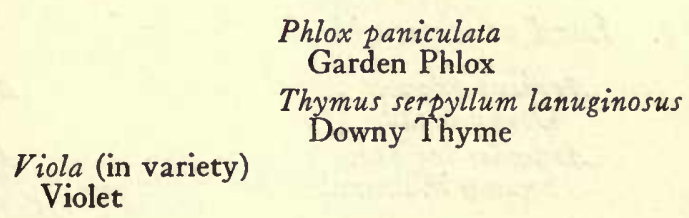

Phlox paniculata Garden Phlox

Thymus serpyllum lanuginosus Downy Thyme

Viola (in variety)

Violet 
c. To be divided each year:

Anthemis tinctoria kelwayi

Hardy Marguerite

Aster novae-angliae (in variety)

Hardy Garden Aster

Aster novi-belgi (in variety)

Hardy Garden Aster

Bellis perennis

English Daisy
Bocconia cordata

Plume Poppy

Chrysanthemum indicum Pompom Chrysanthemum

Chrysanthemum maximum Shasta Daisy

Helenium (in variety)

Sneezeweed

L. Perennials for Water Planting. In the development of informal and formal pools the following group provides a ready reference for interesting types of perennials adapted for use in water gardens. For growing in wet soil along stream sides the closed gentian is one of the best plants. The cardinal flower naturally grows along stream sides or edges of ponds and will thrive, if in a damp soil, either in open sunlight or shade, but prefers shade.

a. Deep water:

$\begin{array}{cr}\text { Nelumbo (in variety) } & \text { Nymphaea marliacea } \\ \text { Lotus } & \text { Hybrid Water-lily } \\ \text { Nymphaea alba } & \text { Nymphaea odorata } \\ \text { White Water-lily } & \text { Native Pond-lily } \\ & \text { Nymphaea odorata sulphurea } \\ & \text { Yellow Water-lily }\end{array}$

b. Shallow water:

Acorus japonicus variegatus
Variegated Sweet Sedge
Alisma plantago
Great Water-plantain
Butomus umbellatus
Flowering Rush
Calla palustris
Water Arum
Caltha palustris
Marsh Marigold
Carex
Sedge

Cyperus strigosus

Cyperus

Iris pseudacorus

Yellow Water Flag

Phragmites communis

Common Reed

Sagittaria montevidensis

Giant Arrowhead

Scirpus lacustris

Bulrush

Scirpus tabernaemontanus zebrinus Great Bulrush

Thalia dealbata

Thalia

c. Land at water-side:
Aruncus sylvester
Goat's Beard
Asclepias incarnata
Swamp Milkweed

\author{
Aster (in variety) \\ Hardy Aster \\ Astilbe davidi \\ David's Spirea
}




\section{PERENNIALS FOR DIFFERENT PURPOSES}

Caltha palustris flore pleno Marsh Marigold

Eupatorium ageratoides White Snakeroot

Eupatorium coelestinum Mist Flower

Filipendula purpurea Steeple Bush

Gentiana andrewsi Closed Gentian

Helenium autumnale superbum Tall Sneezeweed

Helonias bullata Swamp-pink

Hemerocallis flava Lemon Lily

Heracleum mantegazzianum Giant Cow-parsnip

Hibiscus moscheutos Swamp Mallow

Iris kaempferi Japanese Iris

Iris orientalis Oriental Iris
Leucanthemum lacustre Leucanthemum

Leucojum aestivum Summer Snowflake

Lobelia cardinalis

Cardinal Flower

Lysimachia oulgaris Common Yellow Loose-strife

Lythrum salicaria roseum

Pink Loose-strife

Miscanthus (in variety)

Plume Grass

Myosotis palustris

Forget-me-not

Phalaris arundinacea

Ribbon-grass

Primula japonica (in variety) Japanese Primrose

Rheum officinale Medicinal Rhubarb

Sarracenia drummondi Pitcher Plant

Senecio clivorum Groundsel

Thalictrum dipterocarpum

Meadow-rue

M. Perennials for Planting on Edge of and in Front of SHRUB BORDERs.

a. Low Growing:

Cerastium tomentosum

Snow-in-summer

Ceratostigma plumbaginoides

Leadwort

Funkia (in variety)

Plantain Lily

b. Tall Growing:

Acanthus
Bear's Breech
Aster
Starwort
Baptisia
False Indigo
Bocconia
Plume Poppy

Iberis sempervirens

Evergreen Candytuft

Saxifraga (in variety)

Saxifrage

Sedum (in variety)

Stonecrop

Doronicum

Leopard's Bane

Ferns

Native Ferns

Helianthus

Hardy Sun-flower

Hemerocallis

Day Lily

Hibiscus moscheutos hybrida

Mallow Marvels 
N. Perennials for Attracting Humming Birds. Humming birds have long bills and hollow tongues which permit them to search for insects and honey in their favourite flowers. By planting some of the following sorts of perennials, as well as the trumpet vine, these beautiful birds will be encouraged to visit the garden.

Aconitum (in variety) Monkshood

Althaea rosea

Hollyhock

Aquilegia (in variety)

Columbine

Delphinium (in variety)

Larkspur
Dianthus barbatus Sweet William

Digitalis gloxinaeflora Foxglove

Impatiens biflora Jewel-weed

Lychnis (in variety) Mullein Pink

Melissa officinalis

Lemon Balm 


\section{CHAPTER XXXII}

\section{ANNUALS}

No GARDEN is complete without its quota of annuals. The socalled perennial garden, to be really successful, must be supplemented each year with a quantity of annuals, especially if the garden is to be studied in close detail. If only the larger mass effects of flowers and foliage are required, a perennial planting properly selected is sufficient in itself.

The opinion prevails among those who have devoted but little study to this subject that a complete flower garden can be developed during the first one or two years after planting through the use of properly selected types of perennials only. Such a garden may be developed after the first one or two years, under the care of an expert gardener. It is almost impossible to develop such a garden in the early stages, because perennials, on account of the nature of the plants, continue each year to increase their mass and so require more space for their normal development. Therefore, when perennials are first planted, sufficient space should be allowed between plants to permit of a normal development for at least three or four years, at the end of which period the clumps of plants, except the peony, should be "divided." (See "Maintenance of Perennials.") If the first planting is not overcrowded there will be during the first year, and often during the second year, bare spots in the garden which should be filled with annuals. Perennials during the first year after transplanting rarely become established sufficiently to produce normal flower effects, and this is one reason for the use of annuals to develop a successful garden.

Annuals are plants which are grown from seed each year and whose roots die each winter. The roots of perennials continue to live in a dormant condition and develop new growth again at the top with the coming of the next spring.

The first principle in the successful development of any flower garden is to determine the use for which the flower garden is developed. A garden designed, either of annuals or of perennials, to show a succession 
of interesting bloom and to make an interesting garden picture, either as masses of colour or spots of colour, is a different garden from the so-called cut-flower garden, from which the flowers, as soon as they mature, are apt to be cut and used for table decoration. The best success in garden development is obtained when a clear-cut line is drawn between the so-called cut-flower garden and the flower garden as a piece of landscape design. There is nothing more discouraging to the expert designer than to see masses of flowers at the height of their bloom, and at a time when they should be most effective in the garden design, deliberately cut for table use and a resulting criticism extended that the garden is not a success because it has no flowers. This discussion applies equally well to a garden filled with perennials and to a garden filled with annuals. A garden should be, if space permits, either for one purpose or for the other, and if a space is desired where cut flowers may be obtained, then a separate garden should be provided from which flowers may be cut as soon as they have matured.

There are many interesting questions concerning the use of annuals. Perhaps the most interesting group of annuals is that containing the plants which are valuable for cut flowers, such as the larkspur, marigold, snapdragon, Mexican poppy, and nasturtium. These plants to be most successful for cut flowers should be in rows for purposes of cultivation, and given ample space to develop fully. Most of them, as with the other annuals which have early flowers, are sown in the seed beds in mid-February and early March or in the hot frames during the last of March and early April and later transplanted. Most of the annuals can be sown in the open ground during the last of April and early May, but the flowering season is apt to be much shorter because the flowers mature at a later date.

There is a group of annuals which are extremely desirable as ground cover and edgings. They are plants which, when sown thin in the open ground, need not necessarily be thinned out although an intelligent thinning is better. These annuals form beautiful edgings to the flower borders and fill many otherwise bare spaces in the front of the lower annual plantings.

There is a group of annuals which should preferably be sown in the open ground where they are to bloom, and which should be thinned out to the proper spacing between plants as the small plants develop. These annuals are difficult to transplant successfully, and include such types as baby's breath, lupine, nasturtium, cornflower, and poppy, 


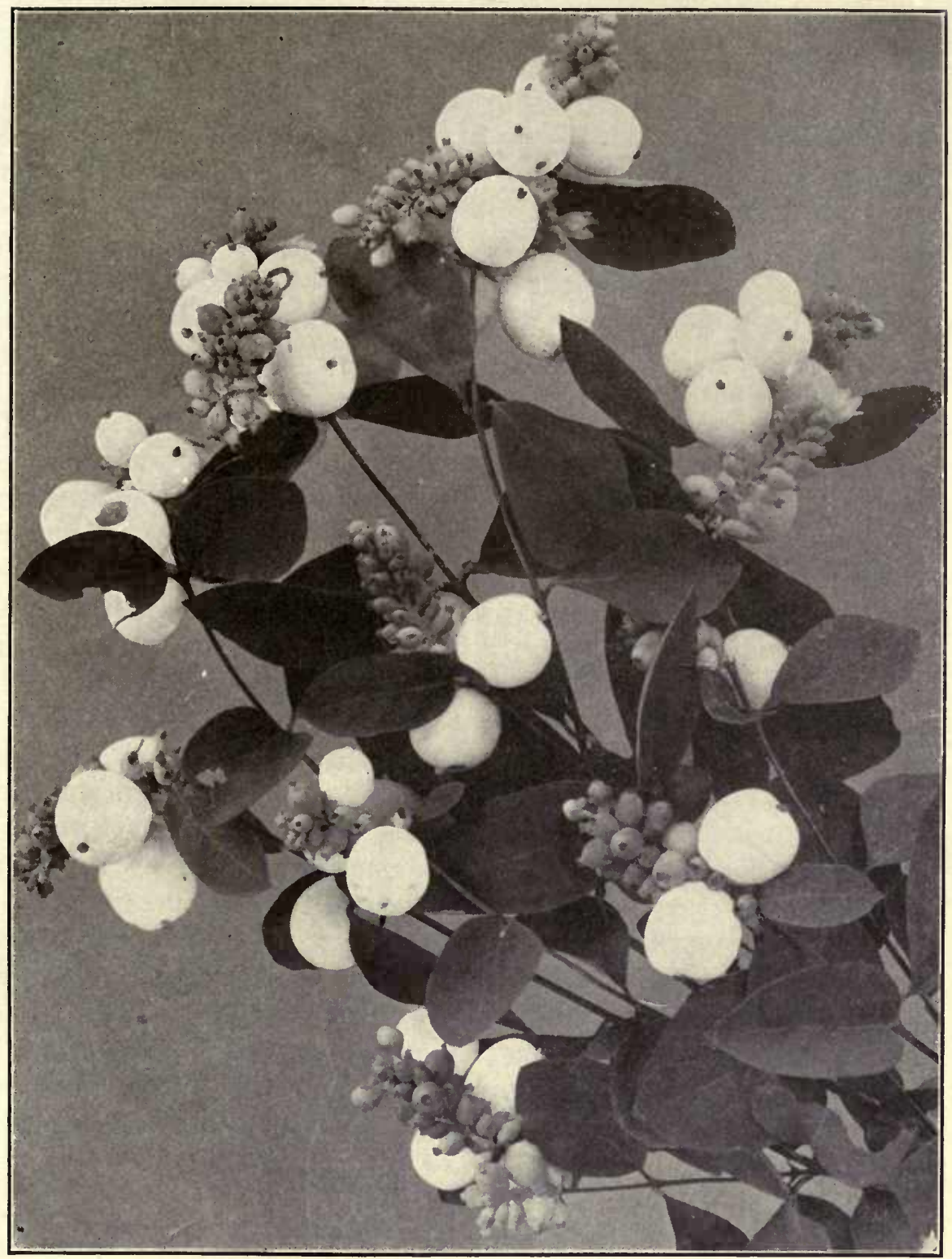

Plate XXXVII. Not only because of the interesting colour of its fruit in combination with the fruit of other shrubs, but because of the size and abundance of its fruit, the snowberry is one of our conspicuous and valuable shrubs. (See page I62, group XX-B) 

Annuals, unlike perennials, can be started in many instances at different periods during the season, in order to insure a succession of bloom. There is a normal period required between the time of seeding and the time of blooming, and if this period is definitely known, then at intervals of not less than ten days or two weeks three or four successive sowings may be made in the early and late spring so that a continuous succession of bloom from these plants may be obtained during the summer months. Typical of these plants are the phlox, forget-me-not, and baby's breath.

Most of our annuals can be sown, if necessary, in the open ground. There are a few types, however, which must be started in seed beds, either in a greenhouse or in hot frames, in order to produce good bloom before the frost injures the tops. These types include the China asters, cosmos, ten-weeks' stock, petunia, and butterfly flower, all of which require a longer season for the period of maturing after seeding. Many times when the seeds of these plants are sown late, the plants reach their mature development and are on the point of producing flowers when they are suddenly injured by an early frost.

It often becomes necessary or desirable to supplement plantings of perennial or woody vines, which are naturally slow growing, with annual quick-growing vines to cover fences and lattice work. It is seldom that perennial vines can be planted and produce an adequate covering for a lattice work or fence during the first year. The time required for the full development of such woody vines as the clematis, bitter-sweet, and rose is from two to three years. In such instances the cup and saucer vine, hop vine, cardinal vine, and the morning glory can be planted to fill the bare areas during the first year or two. Many of these annual vines have a heavy foliage, valuable for screen effects, and the writer has therefore divided this group into two sub-groups, indicating those with delicate foliage and those with heavy foliage.

\section{LIST OF ANNUALS}

A. Annuals Espectally Valuable for Cut Flowers. The group of annuals which are valuable for cut flowers is much greater than might be anticipated. This group is comprehensive and those plants which are marked with a star $\left(^{*}\right)$ are the most interesting types, and provide the greatest abundance of cut flowers. The other annuals in the group are valuable for cut flowers, but should not be selected unless ample space exists so that the more important types also can be grown. 
Ageratum houstonianum

Floss Flower

Alyssum maritimum

Sweet Alyssum

*Antirrhinum majus

Snapdragon (treated as an annual)

Arctotis grandis

African Daisy

Brachycome iberidifolia

Swan River Daisy

*Calendula officinalis

Pot Marigold

Callistephus hortensis

China Aster

* Centaurea americana

American Cornflower

Centaurea cyanus

Old-fashioned Cornflower

Centaurea imperialis

Sweet Sultan

* Chrysanthemum coronarium

Summer Chrysanthemum

*Coreopsis tinctoria

Tickseed

*Cosmos bipinnatus

Cosmos

*Delphinium ajacis

Annual Larkspur

Dianthus chinensis

Chinese Pink

Dianthus heddewigi

Japanese Pink

Emilia flammea

Flora's Paint-brush

Eschscholtzia californica

California Poppy

Eucharidium grandiflorum

Large-flowered Eucharidium

* Gaillardia pulchella picta

Blanket Flower

Gomphrena globosa

Globe Amaranth
Grasses in variety Grass

* Gypsophila elegans Baby's Breath

* Helianthus annuus Single Annual Sunflower

Helichrysum bracteatum Straw Flower

Heliotropium peruvianum Heliotrope

Hunnemannia fumariaefolia Mexican Poppy

Iberis umbellata Candytuft

Impatiens balsamina Garden Balsam

* Lathyrus odoratus Sweet Pea

Matthiola incana Common Stock

Nigella damascena Love-in-a-mist

†Papaver (in variety) Annual Poppy

Reseda odorata Mignonette

* Salpiglossis sinuata Painted Tongue

*Scabiosa atropurpurea Mourning Bride

Schizanthus pinnatus Butterfly Flower

Tagetes erecta Marigold, African varieties

*Tropaeolum majus Nasturtium

Verbena hybrida Verbena

Viola tricolor

Pansy:

*Zinnia elegans

Zinnia

tThe variety Shirley is particularly to be commended.

B. Annuals to Be Sown for Ground Cover. Often along the edges of borders in the garden, or in otherwise bare spots, a small ground cover of annuals to produce a carpet of flowers may be desired. This often happens at the edge of shrubbery which grows 
on a bank where it is difficult to train the branches so that they will come to the edge of the sod, thus covering the bare soil.

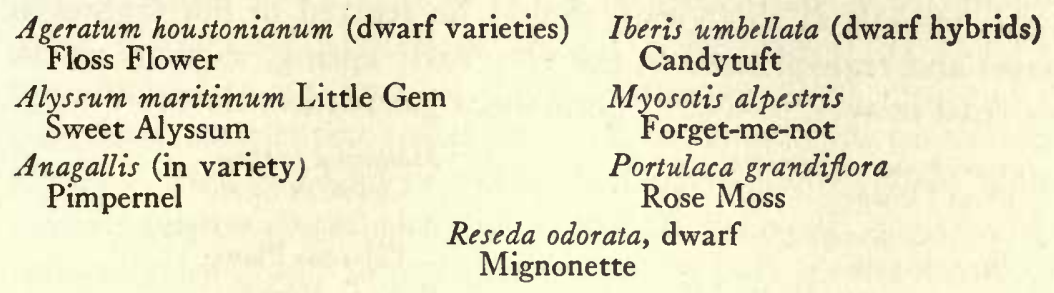

C. Annuals Which Are Difficult to Transplant Successfully. This group contains annuals which should be sown in the place where they are expected to remain. The only work which should be done to them after sowing is to thin them out in order to give the individual plants more space to develop.

Centaurea cyanus

Old-fashioned Cornflower

Delphinium ajacis

Annual Larkspur

Emilia flammea

Flora's Paint-brush

Eschscholtzia californica

California Poppy

Gypsophila elegans

Baby's Breath

Gypsophila muralis

Pink Baby's Breath
Lathyrus odoratus Sweet Pea

Lavatera trimestris splendens Mallow

Lupinus hirsutus

Lupin

Nigella damascena

Love-in-a-mist

Papaver (in variety)

Poppy

Tropaeolum majus

Nasturtium

D. Annuals Which Should Be Planted in Several Sowings to Insure a Succession of Bloom. To provide a succession of bloom with annuals those included in the following group should be sown in two or three successive plantings. Very few annual seeds should be sown after the hot summer weather begins, unless great care is given to the watering.

Centaurea Cyanus

Old-fashioned Cornflower

Coreopsis tinctoria

Tickseed

Gypsophila elegans

Baby's Breath (sow every three weeks)

Iberis umbellata

Candytuft (sow every three weeks)
Myosotis palustris

Forget-me-not

Nigella damascena

Love-in-a-mist (sow every six weeks)

Papaver (in variety)

Poppy (sow every four weeks)

Phlox drummondi

Drummond's Phlox

Reseda odorata

Mignonette (sow every three weeks) 
E. Annuals to Be Started Indoors in Order to Produce Bloom Before Frost. For the best results and for early summer flowers, the annuals in this group should be started in hot frames or greenhouses and transplanted in the very early spring, as soon as the danger of frost is over, into their permanent garden locations.

$\begin{array}{lc}\text { Ageratum houstonianum } & \text { Matthiola incana } \\ \text { Floss Flower } & \text { Common Stock } \\ \text { Antirrhinum majus } & \text { Nicotiana (in variety) } \\ \text { Snapdragon } & \text { Tobacco Plant } \\ \text { Brachycome iberidifolia } & \text { Petunia hybrida } \\ \text { Swan River Daisy } & \text { Petunia } \\ \text { Callistephus hortensis } & \text { Salpiglossis sinuata } \\ \text { China Aster } & \text { Painted Tongue } \\ \text { Cheiranthus cheiri } & \text { Salvia splendens } \\ \text { Wallfower } & \text { Scarlet Sage } \\ \text { Cosmos bipinnatus } & \text { Schizanthus pinnatus } \\ \text { Cosmos } & \text { Butterfly Flower } \\ \text { Heliotropium peruvianum } & \text { Verbena hybrida } \\ \text { Heliotrope } & \text { Verbena } \\ \text { Lobelia erinus (in variety) } & \text { Viola tricolor } \\ \text { Lobelia } & \text { Pansy }\end{array}$

F. Annual Vines. While the more permanent perennial types of woody vines are developing during the first two or three years after transplanting it is often desirable to fill the bare spaces on fences and walls with the annual vines that will produce a mass foliage effect. Any of the vines shown in this group are valuable for that purpose.

a. Delicate foliage:

Adlumia cirrhosa (biennial)

Alleghany Vine

Cardiospermum halicacabum Balloon Vine

b. Heary foliage:

Calonyction aculeatum Moon Vine

Dolichos lablab

Hyacinth Bean

Echinocystis lobata

Wild Cucumber

Humulus lupulus Hop Vine

Humulus lupulus japonica Cut-leaved Hop Vine
Cobaea scandens (sow indoors)

Cup and Saucer Vine

Tropaeolum canariense (sow indoors)

Canary Bird Vine

Ipomoea hederacea (Japanese varieties) Japanese Morning Glory

Ipomoea purpurea.

Common Morning Glory

Phaseolus multiflorus

Scarlet Runner Bean

Quamoclit pinnata

Cypress Vine

Quamoclit coccinea hederifolia

Cardinal Climber 
G. Plants for Carpet Bedding. Carpet bedding as a part of design in landscape planting has a specific place and is used for a specific purpose. This type of planting lends itself to extremely formal areas throughout parks and around architectural treatments. It is not adapted in any way for use in connection with informal types of American landscapes either in park developments or in settings of homes. This is a field of work which gives the gardener an excellent opportunity to show his skill in the trimming of plants and the arrangement of plants to produce interesting pattern effects. There is no other group of plants from which specimens can be selected which will perform the same functions in the landscape picture as plants selected from this group. The perennials are mostly propagated from cuttings, and the annual plants are grown each year from seeds. They are usually planted very closely-from three to six inches apart-so as to secure an even colour effect and a complete blanket of foliage with welldefined lines of separation between the varieties. Few of these plants are sold under their proper scientific names, but the common names here given will identify them.

The types of plants adapted for this purpose are usually selected because of well-defined characteristics such as:

(a) Long flowering period and abundance of bloom.

(b) Compact habit of growth.

(c) Ability to thrive under crowded conditions.

(d) Ability to respond to frequent and severe cutting back.

(e) Interesting colour and texture of foliage.

a. Low-growing plants from two to six inches tall:

1. Foliage plants:

Alyssum maritimum variegatum

Variegated-leaved Sweet Alyssum

Echeveria atropurpurea

Purple-leaved Echeveria

Echeveria fulgens

Smooth-stemmed Echeveria

Echeveria glauca

Glaucous Echeveria

Echeveria secunda

Red-margined Echeveria

Oxalis corniculata

Creeping Oxalis

Pelargonium hortorum Madame Salleroi Mme. Salleroi Geranium
Sempervioum arachnoideum (in variety) Spiderweb Houseleek

Sempervioum calcareum Alpine Houseleek

Sempervioum tectorum (in variety) Houseleek

Telanthera amoena Alternanthera

Telanthera bettzickiana

Narrow-leaved Alternanthera

Telanthera versicolor

Round-leaved Alternanthera

Thymus serpyllum (in variety) Mother of Thyme 
2. Flowering plants:

Ageratum "Imperial Dwarf Blue"

Dwarf Blue Floss Flower

Ageratum "Imperial Dwarf White"

Dwarf White Floss Flower

Alyssum maritimum Lilac Queen

Lilac Sweet Alyssum

Alyssum maritimum Little Gem

White Sweet Alyssum

Brachycome iberidifolia

Swan River Daisy.

Cuphea ignea

Cigar Plant

Iberis amara coronaria Rocket Candytuft
Iberis umbellata (in variety) Candytuft

Lobelia erinus"alba

White Compact Lobelia

Lobelia erinus compacta Crystal Palace Blue Compact Lobelia

Lobelia erinus flore pleno

Double Lobelia

Lobelia erinus tricolor Spotted Lobelia

Phlox drummondi

Drummond's Phlox

Portulaca grandiflora (in variety) Rose Moss

Yellow Torenia

b. Taller-growing plants from twelve to twenty inches tall:

r. Foliage plants:

Acalypha wilkesiana (in variety)

Copper-leaf

Centaurea cineraria

Dusty Miller

Centaurea gymnocarpa

Plumose-leaved Dusty Miller

Chrysanthemum parthenium aureum Golden Feather

Chrysanthemuin parthenium glaucum Dusty Feverfew

Coleus blumei verschaffelti

Branched Coleus
Iresine herbsti

Round-leaved Achyranthes

Iresine lindeni

Narrow-leaved Achyranthes

Pelargonium hortorum (in variety)

Bronze-leaved Geranium

Phalaris arundinacea

Ribbon Grass

Piqueria trinerva

Stevia

Santolina chamaecyparissus

Senecio cineraria

Lavender Cotton

Dusty Miller

2. Flowering plants:

Ageratum houstonianum

Floss Flower

Begonia rex (in variety)

Rex Begonia

Begonia semperflorens Triomphe de Lorraine

Cherry Red Bedding Begonia

Begonia semperflorens Vernon

Bedding Begonia

Chrysanthemum coronarium flore pleno

Double Summer Chrysanthemum

Cuphea llavea

Cigar Plant
Heliotropium Queen of Violets Blue Garden Heliotrope

Lantana camara (in variety) Lantana

Pelargonium (in variety)

Geranium

Petunia hybrida

Petunia

Salvia splendens (in variety)

Scarlet Sage

Tropaeoleum minus Dwarf Nasturtium 
H. Annuals for Design Bedding. Oftentimes in the development of the flower garden the owner wishes for a massing of annual flowering plants to produce certain definite outlines. The amateur in selecting types for such effects will not be successful if he uses plants with habits of growth not adapted to the refinement of detail in the design being produced. Some annuals, like the dwarf snapdragon, French marigold, annual phlox, and dwarf zinnia, will develop within small spaces to produce complicated designs. Others like late asters, tall snapdragons, tall zinnias, and African marigolds lend themselves successfully only to simple bedding effects with larger and less complicated units.

The incorrect selection of annuals results in the following errors: (I) Loss of all trace of the original design because growth of plants used is out of scale with intent of the design (loose-growing, tall plants cannot maintain neat lines of a compact design); (2) Irregular and spotted flowering effect, because definite masses of plants do not bloom at the same time (e. g., early-flowering asters and late-flowering calendulas do not bloom at the same time).

The best rule to adopt is to become thoroughly familiar with the flowering period and with the normal height to which the different types of annuals will grow. No other way is so good as to buy packets of seed and grow some of the different sorts for a season. The woody and herbaceous perennial plants are as a rule sold as named varieties which are thoroughly understood the world over; but no such uniformity exists in regard to the seedsman's names for annual plants. It is not uncommon for seedsmen to sell identical seeds under different trade names or to give the same name to entirely different strains of seed. Therefore seeds of annuals should be bought of a reliable seedsman, preferably one who grows the seed, and one should not utilize novelties or unknown strains of seed in bedding work. By sticking to the best seedsmen and their established strains of seed excellent results will follow.

a. Low-growing sorts, growing twelve to twenty-four inches:

Antirrhinum majus nanum (in variety) Half-dwarf Snapdragon

Calendula officinalis (in variery) Pot Marigold

Callistephus chinensis King type Quilled China Aster

Callistephus chinensis Queen of the Market

Early Half-dwarf China Aster

Centaurea cyanus

Old-fashioned Cornflower 
Clarkia pulchella

Clustered-flowered Clarkia

Dianthus barbatus

Sweet William

Dimorphotheca aurantiaca

Orange Daisy

Eschscholtria californica

California Poppy

Gaillardia pulchella picta

Blanket Flower

Hunnemannia fumariaefolia

Mexican Poppy

Matthiola incana

Common Stock
Matthiola incana annua Ten-week Stock

Petunia hybrida (in variety)

Petunia

Phlox drummondi (in variety) Drummond's Phlox

Salpiglossis sinuata (in variety) Painted Tongue

Tagetes erecta African Marigold

Tagetes patula French Marigold

Verbena hybrida Verbena

Zinnia elegans

Zinnia

b. Taller sorts, growing twenty-four to thirty-six inches:

Antirrhinum majus (in variety)

Snapdragon

Callistephus chinensis Cregos Giant Chrysanthemum-flowered China Aster

Callistephus chinensis Late-branching Late-flowering China Aster

Celosia argentea.

Plumed Celosia

Clarkia elegans

Broad-leaved Clarkia
Delphinium ajacis Double Stock-flowering Annual Larkspur

Heliotropium regale Garden Heliotrope

Matthiola Mammoth Beauty of Nice Brompton Stocks

Tagetes erecta Lemon Queen Tall Double African Marigold

Tagetes erecta Orange Prince Tall Double African Marigold

Zinnia elegans robusta

\section{Tall Zinnia}




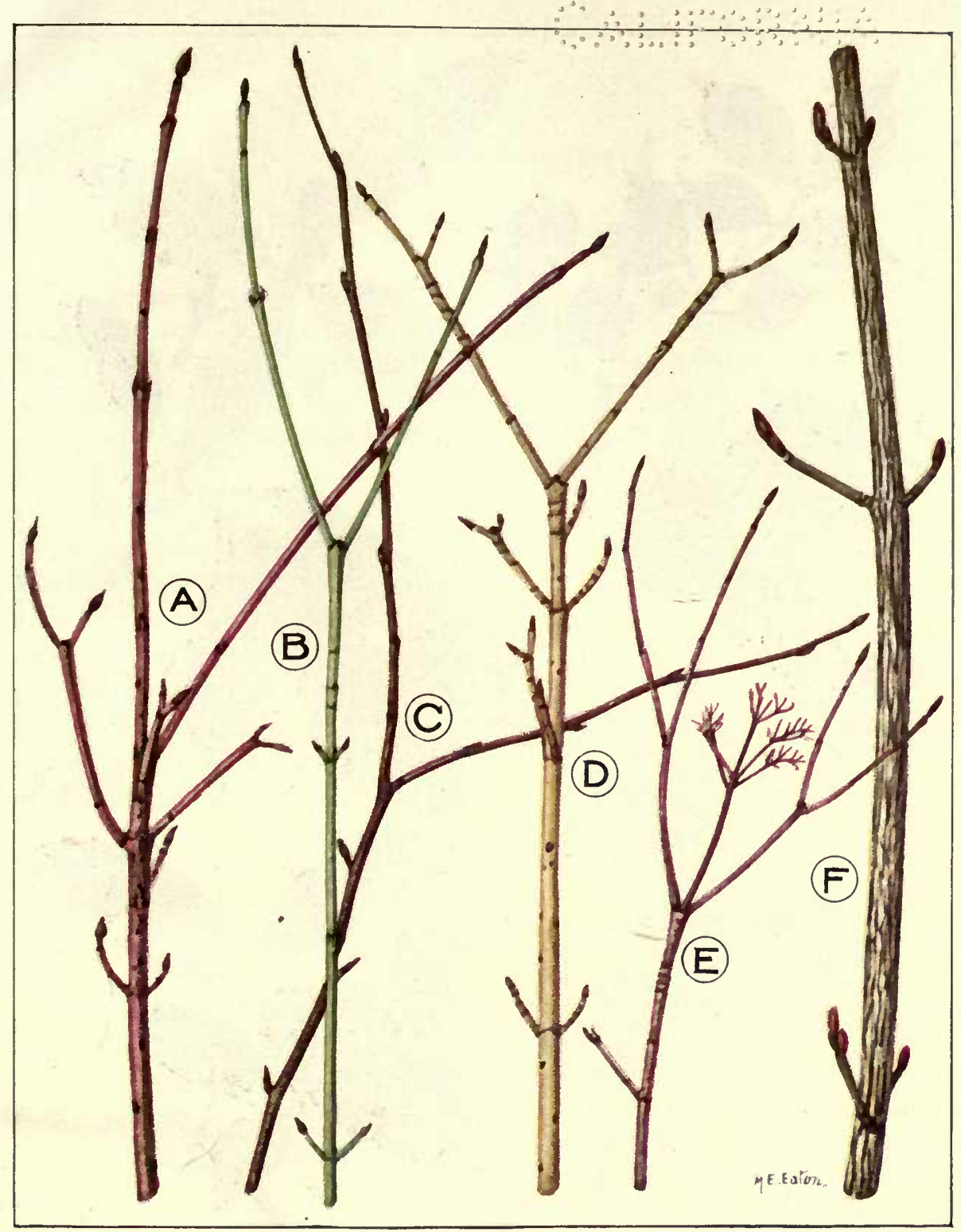

PLATE XXXVIII. During the winter months when there is little else in the shrub border to attract attention, the vivid colours of the twigs of many of our shrubs present interesting spots of colour against the background of ever zreens or snow. (A) red-twigged dogwood; (B) green-stemmed dogwood; (C) red birch; (D) golden-twigged osier; (E) gray dogwood; (F) striped maple. (Sce rage I69, group XXI) 


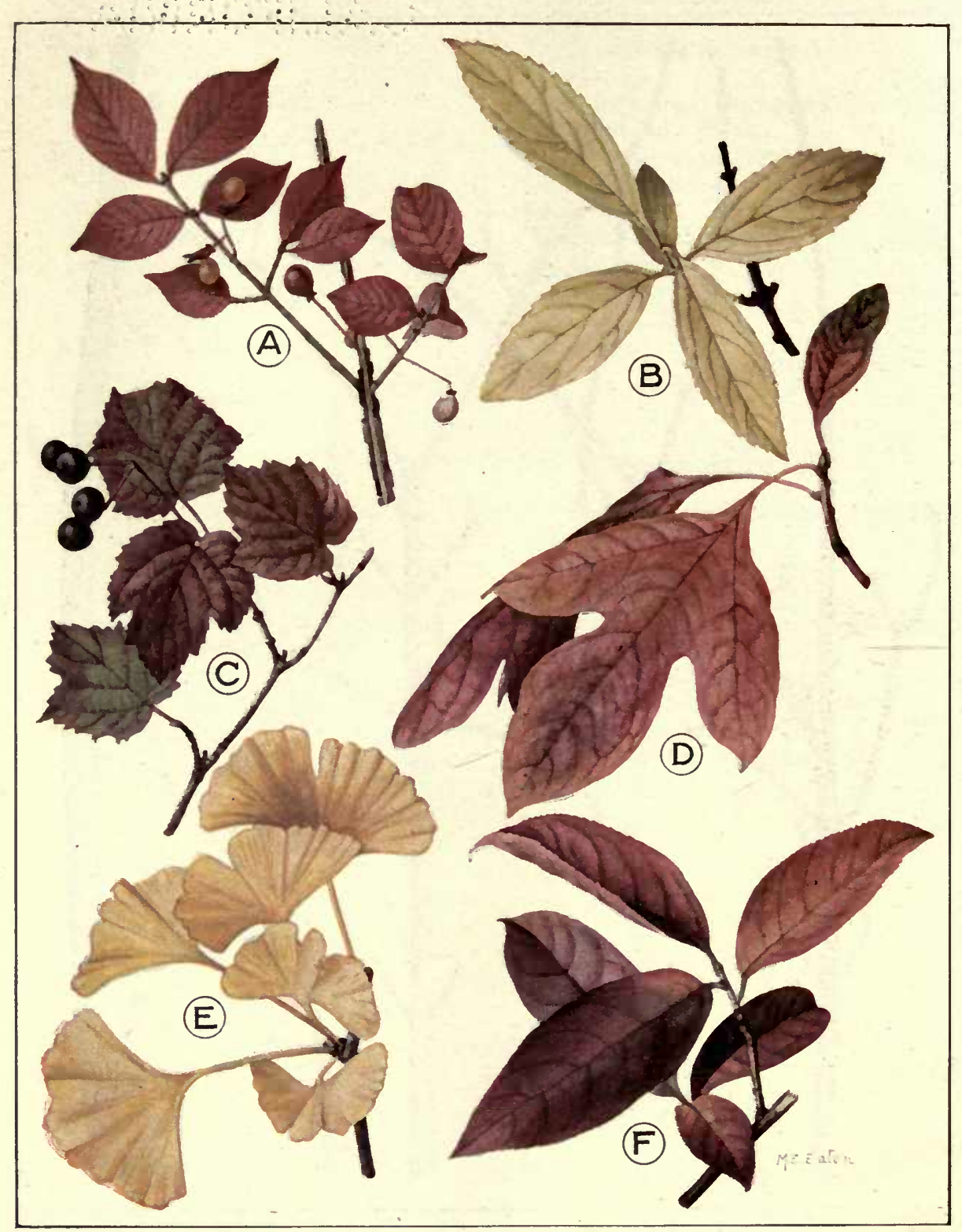

Plate XXXIX. What is more beautiful in the landscape than the intensely brilliant colours of the autumn foliage of many of our trees and shrubs? More plants should be used for the value of their autumn foliage effect. (A) burning bush; (B) dark green golden bell; (C) maple-leaved viburnum; (D) sassafras; (E) maidenhair tree; (F) sourwood. (See page 173, group XXII) 


\section{CHAPTER XXXIII}

\section{HORTICULTURAL VARIETIES}

THE great variations among plants and flowers that to most people seem very much alike should become better known both for the enjoyment this study yields and for its educational and cultural value. The formation of a fine collection of one or two genera of plants like the peony, the iris, or the gladiolus, may become a hobby that will give for the study and time and money expended upon it much reward, additional to that obtained from enjoying the blooms of one's own choice plants. Not only are ideals of excellence improved and the aesthetic sense cultivated, but there is genuine and lasting pleasure found in becoming acquainted with congenial persons through a wide range of territory, united by community of plant interest in a pursuit that leads to refinement. The interchange of ideas expressed in their publications yields a satisfaction greatly enhanced when the members of the society interested in "promoting" the flower meet in convention. It all becomes fascinating to a degree unintelligible to a person who has not yet given himself enthusiastically to specializing in a flower. For those who have the inclination or the financial means that justify them in seeking the satisfaction that comes from possessing rare varieties of a flower, there are available the publications of the societies such as have been named.

Many treasures consisting of native plants still generally unknown, and of rare horticultural varieties, have long been denied to the purchasers of nursery stock in this country, either because they have not been properly presented to the public by the nurserymen, or because the prospective purchaser has been too timid to try new varieties of old plants. Thus much of our American ornamental planting has a sameness which tends to discourage people who have wearied of seeing the old familiar plants but would respond quickly to an opportunity to secure and use new and better varieties.

Peonies, lilacs, and irises are now becoming very well known, many amateurs have collections which are equal to the best, and people 
often travel long distances to see them in bloom. Garden roses, too, have their societies and have secured a place in the regard and the knowledge of the public which is not altogether justified by their position in the horticultural world. Aside from their flowers roses have nothing to recommend them for ornamental planting. Lilies, small flowering trees, rhododendrons, azaleas, and other broad-leaved evergreens all possess better foliage and are more free from bugs, mildew, and other diseases.

Magnificent effects may be secured by using the proper sorts of lilies, properly planted. Lilies seem, on the whole, to thrive better in soil which is full of the roots of other plants, and thus they are most happily used in conjunction with other herbaceous or small woody plants. They may be selected to provide bloom continuously from May till September and to suit any type of soil or condition of shade or open sun.

During recent years numerous named sorts of thorn apples, crabapples, flowering cherries, and other small trees have been put on the market. These trees could, with splendid results, be substituted for the round-leaved or umbrella catalpa and weeping mulberry of the old-time nursery salesman. They are not only hardy, shapely, and beautiful in flower, but many of the single-flowering sorts produce handsome fruit and others have a good autumn colour.

There are now at least fifty sorts of small evergreen shrubs and vines, aside from the rhododendrons, which are reasonably hardy throughout the northern states. It is coming to be generally recognized that, aside from the antipathy to calcareous soils which is shown by the rhododendrons and other ericaceae, the chief drawback to the use of many of our charming broad-leaved evergreens has not been so much the finding of a proper soil as the securing of a proper exposure and a condition of continuous moisture without stagnation. As the smokiness of our cities continues to increase the list of coniferous evergreens that will survive this condition grows smaller. Therefore for winter effects in cities we should turn to broad-leaved evergreens, many of which are not only able to survive smoke and dust, provided they are occasionally washed down and are kept always moist at the roots, but which contain among them some of the finest flowering plants which can be secured.

Care should be taken when purchasing horticultural varieties 
of plants not to invest too heavily in "novelties" which have not withstood any test or been passed upon by horticultural societies or other authorities. Many so-called novelties are merely old varieties, which have long since been superseded, masquerading under new names while others are likely to be untried and may be undesirable sorts. The amateur in his selection of horticultural varieties should adhere to standard varieties which have been generally recognized for a considerable period. The use of horticultural varieties which are advertised as a good substitute for standard varieties, unless from some reliable nursery, should be avoided.

\section{SELECT LISTS OF HORTICULTURAL VARIETIES}

The question of publishing special lists of the more standard horticultural varieties may be open to some criticism. These lists are interesting for reference. The writer has therefore compiled the following lists which may be considered, at the time of publication of this manuscript, as some of the best varieties offered by the trade. Owing to importation and hybridization, new varieties are introduced each year and, after being thoroughly tested, should be added to these lists in order to keep them up to date.

A. Lilacs.

White:

Single:

Alba Major

Marie Legraye

Virginalis

Princess Alexandria

Frau Bertha Damann

Double:

Miss Ellen Willmott

Madame Casimir Perier

Madame Lemoine

Rabelais

Madame Abel Chatenay

Pink to Rosy:

Single:

Gloire de Moulins

Lilarosa

Othello

Machrostachya

Double:

Emile Lemoine

M. Maxime Cornu

Belle de Nancy
Blue to Bluish Lavender:

Single:

Bleuatre

Caerulea superba

Colmariensis

Double:

President Carnot

Doyon Keteleer

President Grevy

Deep Purple Red to Reddish:

Single:

Congo

Philemon

Charles X

Souvenir de Ludwig Spaeth

Double:

Charles Joly

La Tour d'Auvergne 
B. Peonies.

\author{
White: \\ Le Cygne \\ Elizabeth B. Browning \\ Kelway's Glorious \\ Festiva Maxima \\ Baroness Schroeder \\ Mme. Emil Lemoine \\ Francis Willard \\ Albatre \\ Alsace Lorraine \\ James Kelway \\ Enchantresse \\ Marie Lemoine \\ Light Pink: \\ Therese \\ Mme. Jules Dessert \\ Tourangelle \\ Lady Alexander Duff \\ La France \\ La Fee \\ Martha Bullock \\ Mary Woodbury Shaylor \\ Plea's Jubilee \\ Sarah Bernhardt \\ La Fontaine \\ Standard Bearer
}

\section{Small Flowering Trees.}

\section{Crataegus arnoldiana}

Large-flowering Thorn

Crataegus carrieri

Carrier's Red-flowering Thorn

Crataegus cordata

Washington Thorn

Crataegus mollis

Red-flowering Thorn

Crataegus monogyna alba plena

Double White-flowering Hawthorn

Crataegus monogyna punicea

Single Pink Hawthorn

Crataegus monogyna rosea

Pink-flowering Hawthorn

Crataegus monogyna rubra plena

Double Red-flowering Hawthorn

Crataegus oxycantha pauli

Paul's Double Scarlet-flowering Thorn

Crataegus puntcata

Large-fruited Thorn

Prunus cerasus James H. Veitch

Rose-pink Flowering Cherry
La Lorraine

Mignon

Elwood Pleas

Marie Crousse

Milton Hill

Rosa Bonheur

Georgiana Shaylor

Loveliness

Opal

Grandiflora

Deep Pink:

Mons. Jules Elie

Walter Faxon

Red:

Phillipe Rivoire

Karl Rosenfeld

Longfellow

Mary Brand

Mikado

Richard Carvel

L'Etincelante (single)

Mme. Gaudichau

Yellow:

Solange

Primevere
Prunus persica alba plena

Double White-flowering Peach

Prunus persica rosea plena

Double Rose-flowering Peach

Prunus serrulata (many forms)

Japanese Flowering Cherry

Prunus sieboldi

Japanese Pink-flowering Cherry

Prunus subhirtella pendula

Japanese Weeping Rose-flowering Cherry

Prunus triloba

Flowering Plum

Pyrus atrosanguinea

Carmine-flowering Crab

Pyrus baccata

Siberian Flowering Crab

Pyrus halliana parkmani

Parkman's Crab

Pyrus ioensis bechteli

Bechtel's Crab 


\section{HORTICULTURAL VARIETIES}

Pyrus malus niedzwetzkyana

Deep Pink-flowering Crab

Pyrus pulcherrima arnoldiana.

Arnold's Large Rose-flowering Crab

Pyrus pulcherrima scheideckeri

Scheidecker's Semi-double Rose-

flowering Crab
Pyrus sargenti

Sargent's White-flowering Crab

Pyrus sieboldi

Siebold's Blush-flowering Crab

Pyrus spectabilis riversi

Rivers' Semi-double Chinese Flowering Crab

Pyrus zumi
Low-growing Japanese Crab

D. Roses.

a. Best Climbing Roses: (The first three have proven hardy as far north as central Ontario.)

Dorothy Perkins (Pink clusters)

Baltimore Belle (Blush clusters)

Prairie Queen (Bright pink clusters)

Tausendschoen (Double pink)

American Pillar (Single pink)

Dr. W. Van Fleet (Semi-double light pink)

Silver Moon (Semi-double white)

Excelsa (Red Dorothy Perkins)

Hiawatha (Single red)

b. The Hardiest Garden Roses: (Tested in central Ontario and Maine.)

I. Hybrid Perpetual, Crimson and Red:

Alfred Colomb

Baron de Bonstetten

Eugene Furst

General Jacqueminot

2. Hybrid Perpetual, Pink:

Paul Neyron

Mrs. Sharman-Crawford

Mrs. John Laing

3. Hybrid Perpetual, White:

Margaret Dickson

Frau Karl Druschki

John Hopper

Marshall P. Wilder

Ulrich Brunner

Gruss an Teplitz

Prince Camille de Rohan

4. Yellow Roses:

Harison's Yellow

Anna de Diesbach

Magna Charta

Madame Gabrielle Luizet

5. Moss Roses:

Blanche Moreau

Madame Plantier

Soleil d'Or

Crested Moss

Glory of Mosses

c. The best hybrid tea roses:

Duchess of Wellington (yellow to orange)

Killarney (light pink)

Kaiserin Augusta Victoria (white to lemon)

Madame Ravary (orange yellow)

Radiance (rose carmine)

I.von (salmon pink)

Madame Jules Bouche (white to blush)

Lady Ashtown (pale rose)

Jonkheer J. L. Mock (carmine)

Gruss an Teplitz (scarlet)

Harry Kirk (sulphur yellow)

Betty (coppery rose)

Mrs. A. R. Waddell (coppery salmon)

Antoine Rivoire (flesh to cream) 


\section{E. Broad-leaved Evergreens.}

\section{a. Rhododendrons and azaleas:}

Hybrids.

Album elegans (light blush)

Album grandiflora (light blush)

Alexander Dancer (light rose)

Atrosanguineum (blood red early)

Caractacus (rich purplish crimson)

Charles Bagley (cherry red, late)

Charles Dickens (bright scarlet, early)

C. S. Sargent (rich crimson)

Lady Armstrong (pale rose-best pink)

Mrs. C. S. Sargent (bright pink-similar to Everestianum)

Mrs. Milner (rich crimson)

Roseum elegans (deep rosy purple)

Boule de Neige (best dwarf white)

Caerulescens (pale lilac blue)

Everestianum (rosy lilac-the best)

F. L. Ames (pale pink)

Guido (rich crimson)

H. W. Sargent (crimson, late)

James Bateman (rich scarlet)

Kettledrum (deep red, late)

Lady Grey-Edgerton (light mauve, very fine)

Old Port (rich crimson)

Purpureum grandiflorum (best purple, late)

Species.

Rhododendron maximum (white to pink - June to July - tall)

Rhododendron catawbiense (lilac to purple)

Rhododendron catawbiense album (white)

Rhododendron carolinianum (roseJune) Best dwarf
Rhododendron arbutifolium (rich pinkJuly)

Rhododendron ferrugineum (carmineJune to August)

Rhododendron hirsutum (Pink-June to August) (Does not dislike lime)

Rhododendron myrtifolium (Deep rosy pink-July)

Rhododendron smirnovi (Rosy redMay)

Rhododendron azaleoides (Fragrant pink - May and June)

Rhododendron campanulatum (LilacJune)

Azaleas (Hardy except in windswept locations)

Rhododendron obtusum amoenum (Purple-May) (Azalea amoena)

Rhododendron canadense (Rhodora canadensis)

Rhododendron vaseyi (Azalea vaseyi)

Rhododendron nudiflorum (Azalea lutea)

Rhododendron japonicum (Azalea mollis)

Rhododendron canescens (Azalea canéscens)

Rhododendron calendulaceum (Azalea calendula)

Rhododendron arborescens (Azalea arborescens)

Rhododendron viscosum (Azalea viscosa)

Rhododendron kaempferi (Rhododendron indicum kaempferi)

Rhododendron morteri (Azalea gandavensis)

Rhododendron ledifolium (Azalea ledifolia)

b. Other broad-leaved evergreens which should be tried:

Andromeda polifolia

Wild Rosemary

Arctostaphylos uva-ursi

Bearberry

Aspidium acrostichoides

Christmas Fern

Aubrietia deltoidea

Purple Rock Cress
Berberis sargentiana

Evergreen Barberry

Chamaedaphne calyculata

Leather-leaf

Chimaphila maculata

Pipsissewa

Chimaphila umbellata

Pipsissewa 
Chiogenes hispidula Evergreen Snowberry

Cotoneaster adpressa (semi-evergreen) Creeping Cotoneaster

Cotoneaster horizontalis (semi-evergreen) Prostrate Cotoneaster

Cotoneaster microphylla Small-leaved Cotoneaster

Daphne blagayana White Garland Flower

Daphne cneorum Garland Flower

Empetrum atropurpureum Red-fruited Crowberry

Empetrum nigrum Black-fruited Crowberry

Empetrum eamesi Pink-fruited Crowberry

Epigaea repens Trailing Arbutus

Eronymus radicans (in variety) Climbing Evonymus

Galax aphylla (north exposure only) Galax

Gaultheria procumbens Wintergreen

Helianthemum chamaecistus Rock Rose

Helleborus niger Christmas Rose

Hippophae rhamnoides Sea Buckthorn

Hypericum aureum Large-flowered St. John's Wort

Iberis sempervirens Evergreen Candytuft

Kalmia angustifolia Sheep Laurel

Kalmia carolina Carolina Laurel

Kalmia latifolia (in variety) Mountain Laurel
Kalmia polifolia Swam Laurel

Ledum groenlandicum Labrador Tea

Ledum palustre Narrow-leaved Labrador Tea

Leiophyllum buxifolium Sand Myrtle

Leucothoë catesbaei Catesby's Andromeda

Mahonia aquifolium (scorches in sun) Oregon Grape

Mahonia repens Creeping Mahonia

Mahonia pinnata wagneri Pinnate-leaved Mahonia

Pachysandra terminalis Japanese Spurge

Pieris floribunda Mountain Fetterbush

Polygala chamaebuxus Box-leaved Milkwort

Potentilla tridentata Evergreen Cinquefoil

Pyracantha coccinea Evergreen Thorn

Pyracantha coccinea pauciflora Low-growing Fiery Thorn

Pyxidanthera barbulata Flowering Moss

Shortia galacifolia Shortia

Thymus serpyllum lanuginosus

Downy Thyme

Vaccinium (in variety)

Blueberry

Viburnum rhytidophyllum Evergreen Viburnum

Vinca minor

Periwinkle

Yucca filamentosa

Adam's Needle

Zenobia pulverulenta

Zenobia

F. Lilies.

a. List of lilies:

The following table contains the best sorts for the average grower and indicates the culture, season of bloom, colour of flower, and usual 
height. There are four clearly defined types of lilies as indicated in the table by the letters A, B, C, and D. First the funnel form like the Easter lily (A); then the pendant, spreading, or bell form (B). The same flower erect is the cup-like type (C), which flowers earliest of all; and the Turk's cap group with petals completely reversed (D).

(o) All the lilies marked thus should thrive in any ordinary fertile garden soil. If the available soil is naturally compact or adhesive it can be lightened and made more porous by digging some coarse sand or leaf mold into it. If the soil is light and sandy, procure and incorporate with it some clay loam; but in a broad sense all these lilies can be depended upon to live and increase under average garden conditions.

(t) These lilies require a good soil and if the soil is heavy it should be lightened by the addition of some leaf mold or peat; these lilies do not quite so well withstand heat and drought either. Partial shade is beneficial, especially at their roots, which can be provided by interplanting them among other plants that will shade, yet not too densely cover the ground.

(=) This group embraces all native species and they are shade and moisture loving. Although they lift up their tall flower spikes to the bright sun, they like a cool root run at all times. In a cool north corner, or by lake or stream or in any moist hollow, about or near the garden, these lilies are a host in themselves wherewith to make a summer picture.

$\left(^{*}\right)$ Lilies marked in this manner are stem-rooting. Therefore they can be transplanted in the spring.

TABLE OF LILIES

\begin{tabular}{|c|c|c|c|c|c|}
\hline KEY & $\begin{array}{l}\text { TRADE OR } \\
\text { NURSERY CATA- } \\
\text { LOGUE NAME }\end{array}$ & $\begin{array}{l}\text { SEASON OF } \\
\text { BLOOM }\end{array}$ & $\begin{array}{l}\text { TYPE OF } \\
\text { FLOWER }\end{array}$ & $\begin{array}{l}\text { COLOUR OF } \\
\text { FLOWER }\end{array}$ & $\begin{array}{l}\text { AVERAGE } \\
\text { HEIGHT }\end{array}$ \\
\hline & elegans aluta- & May & C & Apricot & 9 inches \\
\hline $\begin{array}{ll}* & 0 \\
* & 0\end{array}$ & bulbiferum & June & C & Crimson & I foot \\
\hline * & $\begin{array}{l}\text { Wilson } \\
\text { elegans aurora }\end{array}$ & $\begin{array}{l}\text { June } \\
\text { June }\end{array}$ & $\stackrel{\mathrm{C}}{\mathrm{C}}$ & $\begin{array}{l}\text { Lemon yellow } \\
\text { Orange, suffused with } \\
\text { red }\end{array}$ & $I \frac{1}{2} \mathrm{ft}$. \\
\hline * 0 & $\begin{array}{l}\text { elegans incom- } \\
\text { parabile }\end{array}$ & June & C & Rich crimson red & $1 \mathrm{ft}$ \\
\hline & $\begin{array}{l}\text { elegans van- } \\
\text { houttei }\end{array}$ & June & C & Crimson & \\
\hline
\end{tabular}




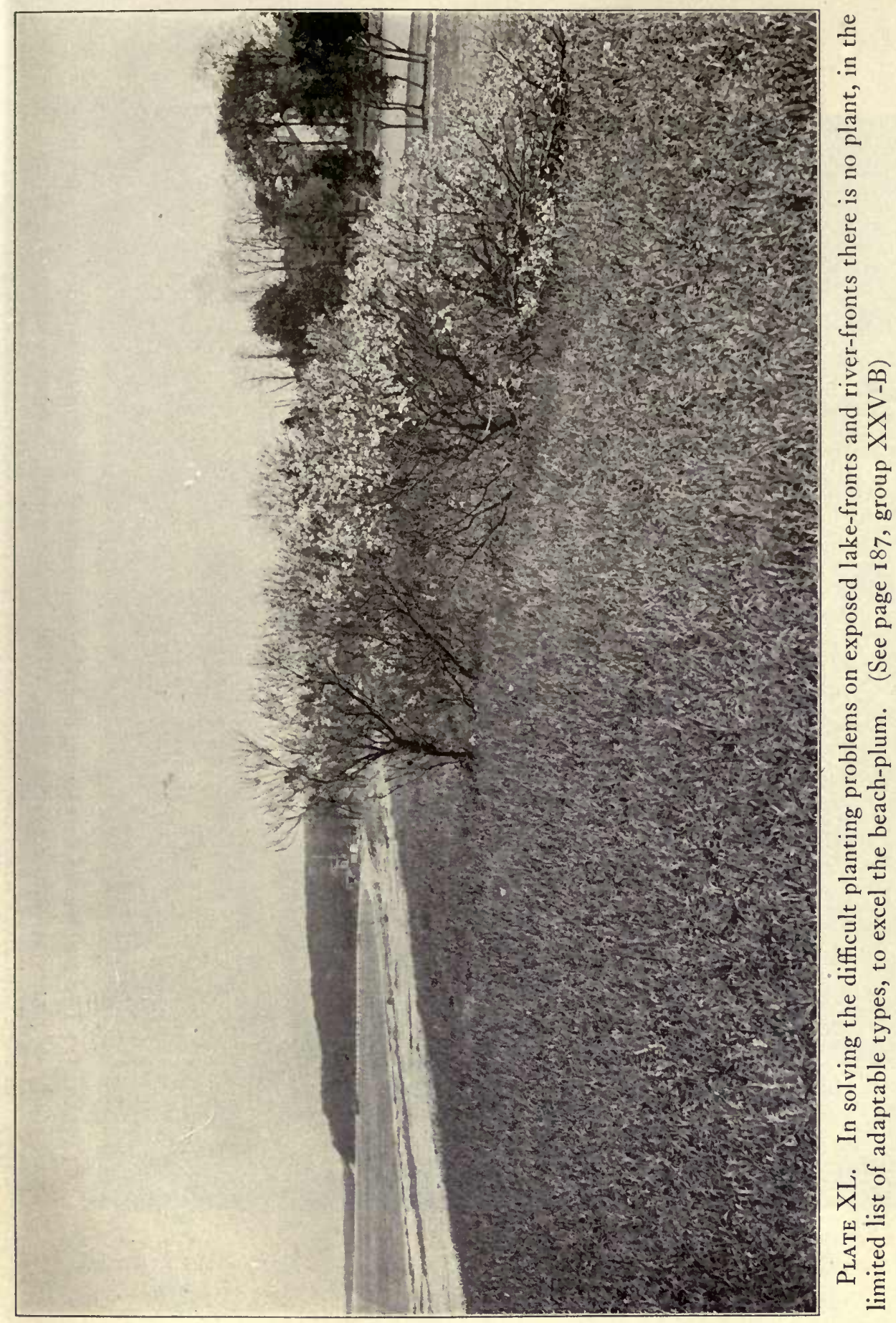




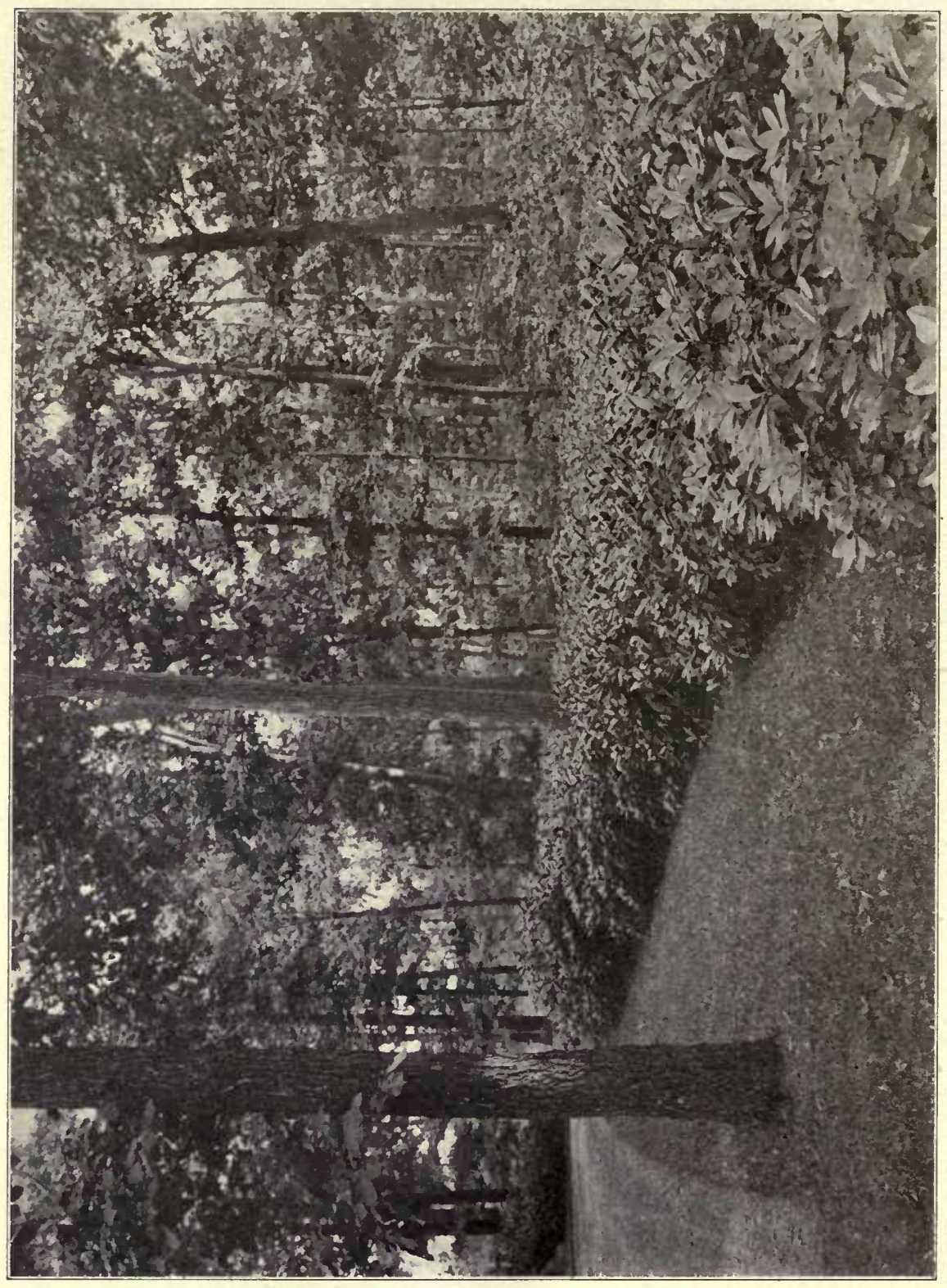

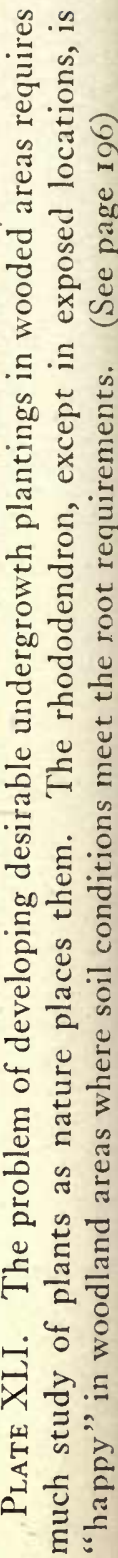


TABLE OF LILIES (Continued)

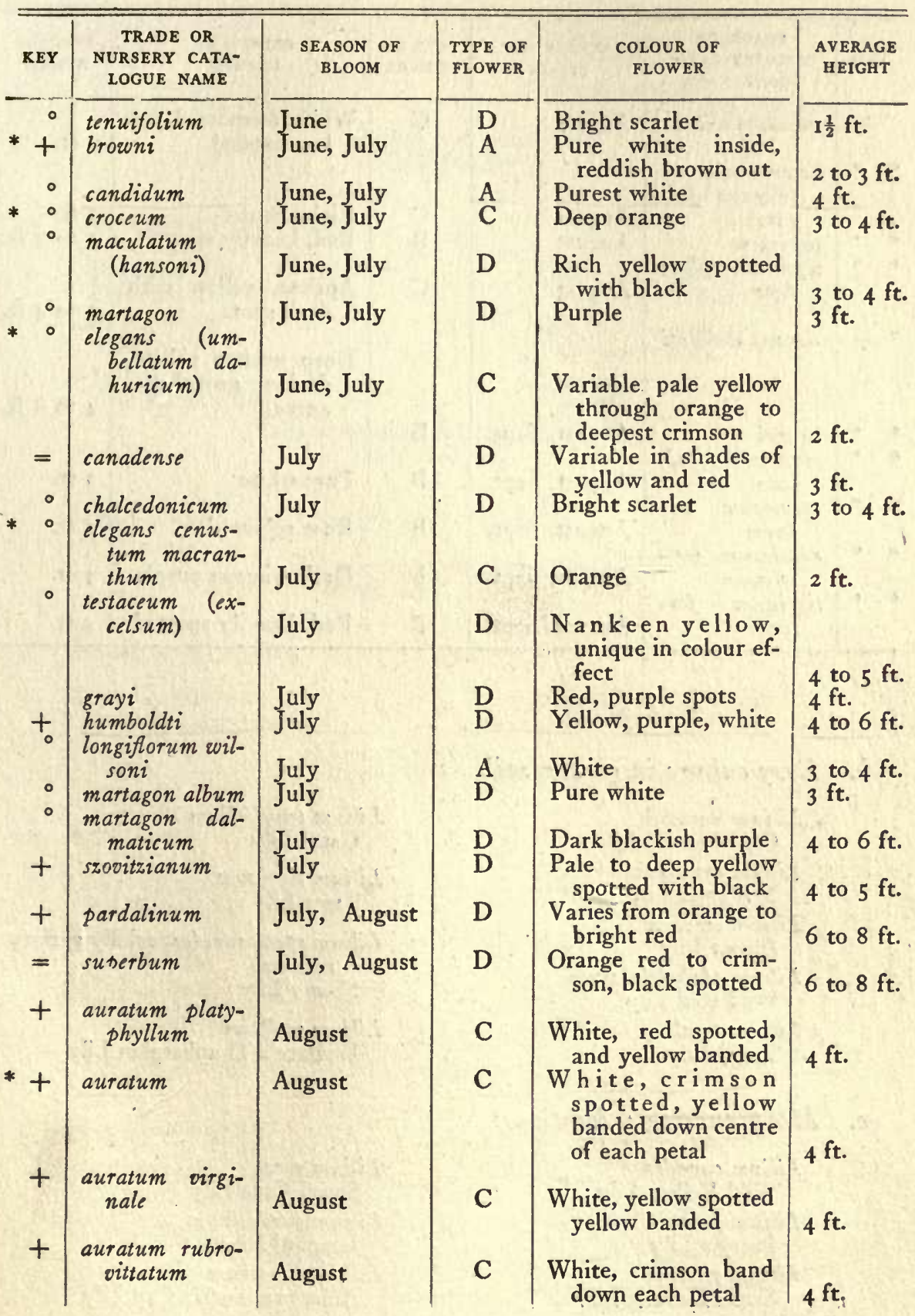


TABLE OF LILIES (Continued)

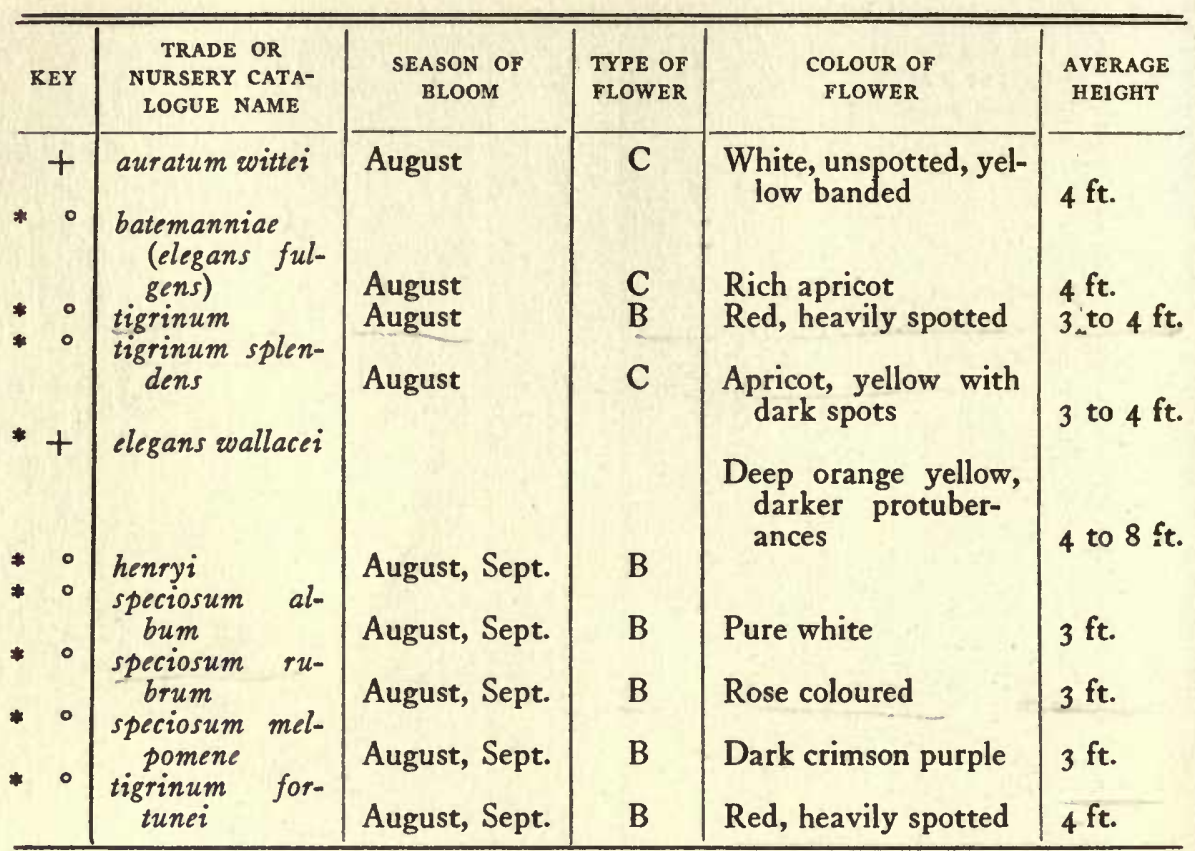

b. Easy culture in garden soil:

Lilium auratum Gold-banded Lily

Lilium candidum Madonna Lily

Lilium croceum Alpine Lily

Lilium philadelphicum Wild Red Lily

Lilium regale Regal Lily

c. Moist and boggy locations:

\author{
Lilium canadense \\ Wild Yellow Lily \\ Lilium parryi \\ Parry's Lily \\ Lilium paroum \\ Sierra Nevada Lily
}

\author{
Lilium tenuifolium \\ Coral Lily \\ Lilium tigrinum \\ Tiger Lily \\ Lilium speciosum (especially variety \\ rubrum) \\ Showy Lily \\ Lilium wallacei \\ Wallace's Thunbergian Lily
}

\author{
Lilium roezli \\ Santa Cruz Lily \\ Lilium pardalinum \\ Leopard Lily \\ Lilium superbum \\ American Turk's Cap Lily
}


d. Calcareous soil:

Lilium candidum

Madonna Lily

Lilium hansoni

Golden Turk's Cap Lily

\author{
Lilium monadelphum \\ Caucasian Lily \\ Lilium martagon \\ European Turk's Cap Lily
}

Lilium testaceum

Nankeen Lily

e. Open sunny positions:

Lilium candidum

Madonna Lily

Lilium croceum

Alpine Lily

Lilium elegans

Thunbergian Lily

Lilium philadelphicum (best of all)

Lilium martagon

European Turk's Cap Lily

Lilium monadelphum

Caucasian Lily

Lilium tigrinum

Tiger Lily

Wild Red Lily

f. Undergrowth under shrubs and small trees:

Lilium speciosum (all sorts)

Showy Lily

g. Sandy or dry soils:

Lilium bolanderi

Boland's Lily

Lilium philadelphicum

Wild Red Lily

Lilium carolinianum

Southern Swamp Lily

h. Clay soil:

Lilium candidum Madonna Lily

Lilium croceum

Alpine Lily

Lilium elegans

Thunbergian Lily

Lilium hansoni Golden Turk's Cap Lily

Lilium monodelphum

Caucasian Lily

Lilium tigrinum

Tiger Lily

Lilium philadelphicum

Wild Red Lily

i. Shady locations:

Lilium auratum

Gold-banded Lily

Lilium hansoni

Golden Turk's Cap Lily

Lilium henryi

Yellow Showy Lily

Lilium japonicum Japanese Lily

Lilium parryi

Parry's Lily

Lilium washingtonianum

Washington Lily 


\section{CHAPTER XXXIV}

\section{VINES}

VINEs constitute a small but important group of plants possessing certain characteristics which are very valuable for use in landscape design. The annual vines develop to maturity and must be started again each season from seed. Perennial vines, once firmly established, continue to increase indefinitely, at least during a period of years. Many vines, such as the wisteria and ivies, are seen on buildings hundreds of years old and, in general, the average long-lived vine will outlive its period of usefulness on any building, especially on wooden structures, which are subject to decay and to periodical repairs.

To many people a "vine is a vine" without any differentiation as to its usefulness. As a matter of fact, vines may be divided into certain definite groups which are valuable for different purposes. The knotweed, honeysuckle, and climbing roses represent a group which are very desirable for their flowering effect. It often happens that vines are desired, not so much for their screen effects as for the effect of producing flowers within a limited space, and thus adding spots of beauty to otherwise unattractive and monotonous surfaces.

It is quite necessary in selecting vines for use on brick work, stone and masonry surfaces, that the method of growth of such vines should be fully understood. Those vines which grow upon fences and lattice work are either scramblers or twiners or they grow by means of tendrils, as do the Virginia creeper and the grape. None of these vines are adapted for use on brick work and masonry surfaces. There is a group of vines which grow and cling to these surfaces by means of little growths, at intervals along their stems, the tips of which, as soon as they come in contact with any surface, produce a sticky fluid that immediately "cements" the vine to the wall. In the case of the Boston ivy the little tendril, at the tip of which is the adhesive substance, has a tendency to contract in the manner of a twisted cord and thus pull the stem closer to the wall. This is a peculiar provision of nature. This list of vines is comparatively small and is represented generally 
by the Boston ivy, English ivy, and the climbing evonymus or Japanese evergreen ivy. The ivies in general are much more rapid growers than the evonymus.

There is one group of vines which possesses a very vigorous climbing habit and develops a heavy foliage, such as the Dutchman's pipe, Virginia creeper, kudzu vine, and the knotweed. Of this list of vines the American bitter-sweet and the Dutchman's pipe possess an interesting heavy foliage.

Vines are valuable not only for their flowering effect but they are valuable for the effect of their fruit also. Some vines, such as the matrimony vine, with its brilliant orange fruit, and the American bitter-sweet, with its red and orange fruit, together with the Virginia creeper, with its interesting blue fruit, are valuable in a landscape setting far into the winter months.

Oftentimes local conditions require the selection of a permanent vine with a fast growing habit. It may not be advisable to use annuals, but rather to use a more permanent type and accordingly the designer resorts to such plants as the Dutchman's pipe, the knotweed, and the kudzu vine, which under normal conditions will make a growth ranging from ten to forty feet in a single season. The knotweed is not entirely hardy in severe exposures and the young plants should not be planted in the open ground before the latter part of May.

In general, vines fill a gap in the field of landscape planting which cannot be filled with shrubs. Where conditions develop in which only a limited space is available for foliage, flower and fruiting effects, vines must be accepted as the logical solution of the planting problem. A quite common mistake in the use of vines is to select types which are too fast growing or which are not adapted to the special purpose for which they are used. A common mistake also is that of covering interesting pieces of brick work and stone masonry with vines which completely obscure the beauty of the architectural detail. Vines should be used on buildings to emphasize the architectural detail; otherwise there is little use in spending sums of money to produce added beauty in architecture if such detail is immediately to be covered with vines. We often see an elevation of a house on which appears a chimney with the entire surface of the house and chimney covered with vines. In such instances the vines, for the purpose of architectural composition, should be planted only on the chimney or on the surfaces at either side of the chimney and not on the chimney. 
Many persons object to the use of certain types of vines such as the Virginia creeper and the ivies, which form a beautiful roosting place for sparrows immediately opposite sleeping-room windows, and for such locations a type of vine similar to the evonymus should be used, which does not provide a shelter for these pests.

\section{LIST OF VINES}

The vines included in the groups of this list are respectively valuable for their ability to produce flowers, for their use on brick and stone masonry, for foliage effect, for fruiting characteristics, and for their fast growing characteristics. Certain vines may be included in one or more groups because of the value of certain characteristics in each group. It should be remembered that the distinction between vines of different types for different purposes is equally as marked as the difference in shrubs and perennials.

A. Flowering:

Actinidia arguta

Dark-leaved Silver Vine

Aristolochia sipho

Dutchman's Pipe

Bignonia radicans

Trumpet Vine

Clematis (in variety)

Clematis

Lathryus latifolius

Hardy Sweet Pea
Lonicera (in variety)

Honeysuckle

Polygonum baldschuanicum

Knotweed

Quamoclit pinnata

Cypress Vine

Rosa (in variety)

Climbing Rose

Wisteria (in variety)

Wisteria

B. Use on Brick, Stone, and Masonry:

Ampelopsis engelmanni

Engelmann's Ampelopsis

Ampelopsis tricuspidata lowi

Lowe's Boston Ivy

Ampelopsis tricuspidata veitchi

Boston Ivy

Schizophragma hydrangeoides

Bignonia radicans

Trumpet Vine

Eronymus radicans

Climbing Evonymus

Hedera helix

English Ivy

Climbing Hydrangea

C. Climbing Habit and Heary Foliage:

Actinidia (in variety)

Silver Vine

Ampelopsis quinquefolia

Virginia Creeper
Aristolochia sipho

Dutchman's Pipe

Bignonia radicans

Trumpet Vine 
Celastrus scandens

American Bitter-sweet

Clematis paniculata

Japanese Clematis

Clematis virginiana

Wild Clematis

Eoonymus radicans

Climbing Evonymus

D. Fruiting:

Actinidia (in variety)

Silver Vine

Akebia quinata

Five-leaved Akebia

Ampelopsis aconitifolia

Cut-leaved Vitis

Ampelopsis heterophylla

Asiatic Creeper

Ampelopsis quinquefolia

Virginia Creeper

Celastrus orbiculatus

Japanese Bitter-sweet

E. Fast Growing:

Actinidia (in variety)

Silver Vine

Ampelopsis aconitifolia

Cut-leaved Vitis

Ampelopsis heterophylla

Asiatic Creeper

Aristolochia sipho

Dutchman's Pipe

Bignonia radicans

Trumpet Vine
Lonicera (in variety)

Honeysuckle

Periploca graeca

Silk Vine

Pueraria thunbergiana

Kudzu Vine

Wisteria (in variety)

Wisteria

Celastrus scandens

American Bitter-sweet

Clematis paniculata Japanese Clematis

Clematis virginiana Wild Clematis

Lycium halimifolium Matrimony Vine

Rosa (in variety) Climbing Rose

Solanum dulcamara Woody.Nightshade

Clematis paniculata Japanese Clematis

Humulus japonicus Japanese Hop

Lonicera japonica halliana Japanese Honeysuckle

Periploca graeca Silk Vine

Pueraria thunbergiana Kudzu Vine

Polygonum baldschuanicum

Knotweed 


\section{CHAPTER XXXV}

\section{WINDOW BOXES AND HANGING BASKETS}

STRICTLY speaking, window boxes do not come under the category of planting or designing the grounds, but in a vital way they serve to tie the house to the lawn and gardens and thus help to produce the immediate effect of a harmonious whole. Particularly are they valuable in imparting a cozy and "lived-in" atmosphere to a new house. Many otherwise uninteresting houses have been made very attractive through the use of window boxes. A severe type of architecture demands a window-box treatment developed with the heavier kinds of foliage plants such as English ivy, geraniums, and fuchsias, while a lighter architectural design requires vincas, snapdragons, and ageratums. The selection of plants for successful window boxes must be the result of some study of the effect to be produced and the kinds of materials necessary to produce the effect.

Not all of our plants can be used in window-box planting. Plants for this purpose must retain their foliage throughout the summer, the period of bloom must continue for a number of weeks, and the normal growth of the plant should not be impaired by crowding the root development within a small area.

Two cardinal principles apply to the design and use of window boxes. Never put window boxes on a building unless the architectural composition requires them, and do not select for them plants which are out of scale with the architectural detail. When planning the window boxes the effect of the colour scheme should be considered from the inside of the various rooms in the house as well as the effect upon the aspect of the house itself.

There are numerous possibilities outside of the conventional boxes planted with periwinkle, geraniums, and daisies. Almost any of the showy dwarf-growing annuals may be used and the opportunity for various colour schemes with them is practically endless.

If bright colour is needed the dwarf, giant-flowering snapdragon, which comes in many brilliant shades and grows about twelve inches 
high, is good. The dwarf zinnia is perhaps even more brilliant in its various colours. It is also stiffer in its habit of growth and consequently better for a windy location. California poppies can be had in all shades of yellow and orange and could be used with nicotiana for a white and yellow box. Another good combination is blue lobelia, pink verbena, and asparagus fern.

Care should be taken to select the flowers which will bloom simultaneously. Foliage plants should be used to provide an abundance of green, and enough vines and flowers of a drooping habit should be introduced to counteract the stiffness of the box.

When planting, pack the roots in firmly on account of the wind. For an unusually windy position it is best to use a deeper box. In choosing the plants, exposure is the first important consideration. (See the following lists.) For sunny positions the more vigorous growing and flowering plants are apt to do best, while in shade ferns and foliage plants, generally speaking, are more successful. In a dusty location smoother-leaved plants such as myrtle and ivy geraniums should be used.

Inside window boxes should get sunshine and plenty of fresh air but must never be placed in a draft. The temperature for the average house plant is between $55^{\circ}$ at night to $70^{\circ}$ in the daytime. The plants should be watered regularly and the foliage sprayed two or three times a week, with the exception of those plants with fuzzy foliage, such as gloxinia, where moisture upon the leaves would cause decay. Hanging baskets should be lined with moss in order to retain their moisture.

The soil used in all window boxes must be rich, as the roots are so crowded and ample plant food must be available. A good soil mixture for this purpose is two parts garden loam, one part rotted leaf mold, and one part sand, mixed with one part well-rotted manure. This mixture can be procured from any florist. As the box becomes filled with roots it is necessary to furnish food to the plants by working into the soil a small amount of bone meal or well-rotted manure every week or ten days.

The box may be constructed of various materials: concrete, terra cotta, or wood. The inside measurements for a window box should be six inches to eight inches deep and ten inches to twelve inches wide. The outside measurements should be fourteen inches wide and one inch shorter than the window or space it is to occupy. A very long box can be made in sections averaging three feet to four feet in length, 
to facilitate the handling of it. Three-quarter inch holes should be bored in the bottom of the box every twelve inches, to provide drainage.

A zinc or galvanized iron lining in a wooden box is desirable but not absolutely necessary. However, if a lining is not used it is best to have the inside of the box charred to prevent rotting of the wood. This is done by washing the inside, both bottom and sides, with kerosene and then lighting the oil and allowing it to burn until a thin charred coating is formed. The box is turned upside down to smother the flames. The most permanent types of window boxes are lined with copper. All boxes, whether or not they are lined, must be provided with holes for drainage. The absence of these holes may cause the soil to become sour from overwatering, a condition which is avoided when drainage is provided.

A. Window Boxes. The following group of plants are those adapted for window boxes in varying exposures of sunlight. These plants should not be placed in window boxes which cannot be thoroughly drained unless great care is exercised in watering; otherwise the soil will become sour and the plants will be "drowned out."

a. South or west exposure:

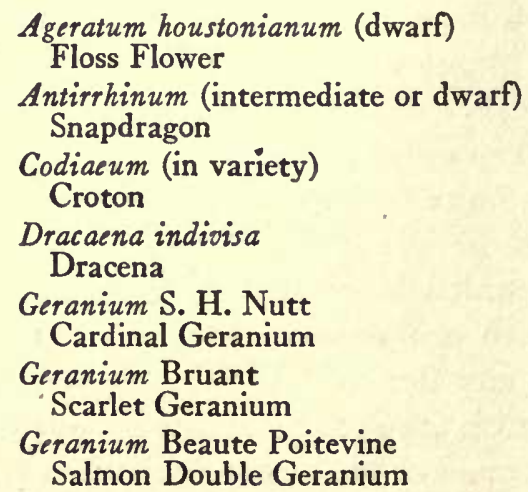

Hedera helix English Ivy

Heliotropium peruvianum Heliotrope

Lobelia

Annual Lobelia

Maurandia (in variety)

Maurandy Vine

Nepeta glechoma

Ground Ivy

Pelargonium peltatum

Ivy-leaved Geranium

Swainsona galegifolia

Phlox drummondi

Drummond's Phlox

Swainsonia

b. East exposure:
Antirrhinum (dwarf or intermediate) Snapdragon
Begonia (tuberous-tooted)
Tuberous Begonia
Dracaena indivisa Dracena
Ferns
Many varieties




\section{WINDOW BOXES AND HANGING BASKETS}

Heliotropium peruvianum Heliotrope

Linaria cymbalaria Kenilworth Ivy

Pelargonium peltatum Ivy-leaved Geranium
Petunia hybridà Petunia

Solanum jasminoides Jerusalem Cherry Vine

Chas. Turner Tropaeolum majus Nasturtium

Vinca major (variegated)

Trailing Vinca

c. North exposure:

Ageratum houstonianum (dwarf)

Floss Flower

Asparagus sprengeri

Asparagus Fern

Caladium (small leaf varieties) Fern

Elephant's Ear

Boston Fern

$$
\begin{aligned}
& \text { Fuchsia (in variety) } \\
& \text { Trailing Fuchsia } \\
& \text { Ipomoea (in variety) } \\
& \text { Morning Glory } \\
& \text { Nepeta glechoma } \\
& \text { Ground Ivy } \\
& \text { Petunia hybrida } \\
& \text { Petunia }
\end{aligned}
$$

Vinca major (variegated)

Trailing Vinca

B. Hanging Baskets. The group of plants adapted for use in hanging baskets is much larger than might at first be anticipated. The great danger in the cultivation of plants in hanging baskets is the danger of drying out.

\section{a. Vine-like habit:}

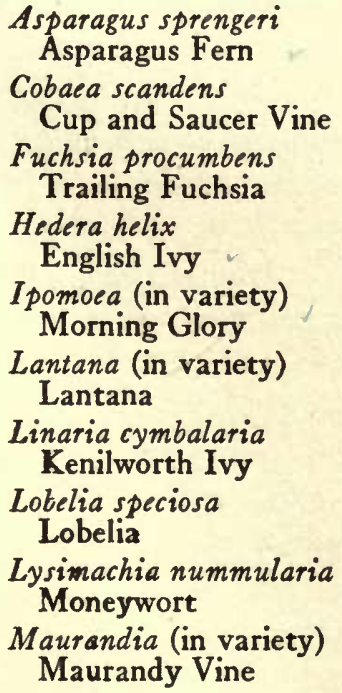

Asparagus sprengeri Asparagus Fern

Cobaea scandens

Cup and Saucer Vine

Fuchsia procumbens Trailing Fuchsia

Hedera helix

English Ivy

Ipomoea (in variety)

Morning Glory

Lantana (in variety)

Lantana

Linaria cymbalaria

Kenilworth Ivy

Lobelia speciosa

Lobelia

Lysimachia nummularia Moneywort

Maurandia (in variety) Maurandy Vine

\author{
Nepeta glechoma \\ Ground Ivy \\ Oxalis floribunda \\ Oxalis \\ Passiflora caerulea \\ Passion Flower \\ Petunia hybrida \\ Petunia \\ Saxifraga sarmentosa \\ Strawberry Geranium \\ Senecio scandens \\ Summer Ivy \\ Solanum jasminoides \\ Jerusalem Cherry Vine \\ Thunbergia alata \\ Thunbergia \\ Tropaeolum majus \\ Nasturtium \\ Verbena hybrida \\ Verbena
}

Vinca major (variegated) Trailing Vinca 
b. Upright habit and good flowers:

Begonia (tuberous varieties)

Tuberous Begonia

Cuphea llavea

Cigar Plant

Fuchsia (in variety)

Ladies' Eardrop

Geranium (in variety)

Geranium

Impatiens sultana

Touch-me-not

c. Upright habit and good foliage:
Lantana (in variety) Lantana

Nierembergia gracilis White Cup

Petunia hybrida Petunia

Salvia splendens Scarlet Sage

Stevia serrata nana

Dwarf Stevia
Aspidistra lurida
Tall Evergreen Aspidistra
Caladium
Elephant's Ear
Cineraria maritima
Dusty Miller
Coleus blumei verschaffelti
Coleus

Cyperus alternifolius Umbrella Plant

Dracaena indivisa Dracena

Fern

(in variety)

Iresine lindeni

Narrow-leaved Achyranthes

Palms (in variety) 


\section{CHAPTER XXXVI}

\section{BULBS}

THIs is a type of planting which can provide as many interesting flower effects as any annual, perennial, or shrub planting. It is the type of planting that provides flowers at a period of the year from late March until the latter part of May, when the garden and lawn are otherwise bare of flowers. The information concerning this group of plantings covering the possible types to be used, the effects to be obtained, and the care of the mature plants, has not been so freely distributed to the owners of our homes as it should have been. After the monotonous, uninteresting landscape presented by the lawn and garden areas in the vicinity of residences during the long winter months, these touches of flower effects are of double value as an introduction to the possibilities of the flowering shrubs and garden plants. So important is this subject that an entire chapter of this book, Chapter VI, has been devoted to the culture of bulbs.

It is the general impression that "bulbs are bulbs" for practically one use. It is not realized that such a wide variation exists in the purposes for which bulbs may be used and in the different types of bulbs which are used.

As a matter of fact, with the proper planting of bulbs, a continuous succession of flowers can be obtained during a normal season from the middle part of March, beginning with the crocuses and the early narcissi, extending through the early part of May, with the early tulips and the late narcissi, and ending with the Darwin tulips during the last part of May to be immediately followed by such garden flowers as the early iris, the columbine, the alyssum, and the lilac.

There are bulbs which are logically adapted to refined lawn and garden areas, bulbs which are adapted for naturalizing in woodlands and wild gardens, interesting combinations of bulbs, and types of bulbs valuable for forcing during the late winter months. The life of the average bulb under normal conditions is approximately three years after which time the bulbs must be replaced with new material; the 
only exception being that such bulbs as those of the crocus and three varieties of narcissi, Von Sion, Victoria, and the poet's, will continue to multiply under ideal conditions for a number of years, provided the tops are permitted to remain a sufficient time after flowering in order to ripen the bulb.

In the selection of bulbs for garden plantings we have practically the entire field from which to draw for material adapted to the refined lawn and garden planting. The degree of refinement depends largely upon our knowledge of the proper combinations of bulbs which will give interesting flower effects, flowers that appear at the same and at successive dates, and flowers of the same height. In making plantings of bulbs for lawn and garden effects careful attention should be given to the other groups showing narcissi for different locations, and the interesting tulip combinations.

One of the most interesting groups of bulbs is the group valuable for naturalization in woodland and wild garden areas. These bulbs must be of the kind that will continue to multiply without further care than is ordinarily given to such areas on the average estate. All of the bulbs in this list should, after being properly planted, grow in succeeding years into clumps through the increase of the small bulblets, and the mature plants should be almost as vigorous as during the first year or two after the bulbs were planted. In other words, they should not show a tendency to run out. Occasionally, unless conditions are ideal, such plants as the trillium and some of the lilies will continue to grow but will not multiply. This is a freak of plant life which those who have given considerable thought to experimenting in the naturalization of plants cannot fully explain. Many of the bulbs in this group such as the yellow lily leek, lily-of-the-valley, adder's tongue, and trillium, desire a great amount of shade. The other bulbs such as lilies, narcissi, squills, and tulips require more sunlight.

It is well to know the adaptations of different varieties of the narcissus. The writer has accordingly referred to this in passing, and we should bear closely in mind the fact that the poet's narcissus, with its varieties, is adapted to the heavy lower ground, while the large trumpet types are adapted to a rich, well-drained loam. The proper selection of combinations of bulbs for flowering effects, either simultaneous flowering or a succession of bloom, is one of the interesting studies in bulb plantings. So many extremely interesting effects can be obtained with a proper selection and planting, and so many uninteresting 
flowering effects can be avoided, that a few standard types of bulb combinations have been shown under this discussion. Bulbs are divided into the early-flowering types, most of which are single, and the late-flowering types among which are the Darwin tulips, most of which grow twice as tall as the early flowering. There are so many varieties of tulips and such a confusion of nomenclature that to lay down definite rules and to frame ironclad lists of bulbs would be futile. It is sufficient to suggest that bulbs for excellent plantings should be selected and grouped by an expert, or that sources of expert information should be consulted in order to insure the proper effects. So often, for example, yellow and white or orange and yellow tulips are planted for a combination of flower effect, when in reality one of the bulbs is of the early-flowering type and the other variety is of the lateflowering type, neither of which will be in bloom during the blooming period of the other. To avoid mistakes of this kind, and for the use of the amateur who has no ready access to the sources of information, nor the time to devote the necessary study to this question, a number of bulb combinations have been given which will serve to meet the average requirements. As a matter of fact, bulbs planted for their individual flowers fall far short of providing the most interesting effect. They should be planted for their mass effect and as an interesting combination of colour.

Bulbs may be planted either for a formal or for an informal and more natural effect. The first planting requires the stiff symmetrical lines of refined lawn and garden areas; the second effect requires the more informal; flowing lines, either of the refined lawn areas or of the informal garden areas. It is quite a matter of taste which of these effects should be desired. Many persons desire the conventional, uninteresting ribbon boundary bordering the edges of shrubbery, while others desire the more natural, scattered mass effect which gives here and there a spot of colour and a certain relief to the bare effect of the shrubbery plantings prior to the time of breaking their buds, and also to the ground underneath. It is important to know the time of flowering for various types of bulbs in order that the late-flowering types, such as the Darwin tulips, may not be scattered through a shrub planting of the bridal wreath spirea, or the early honeysuckle, where the full leaf effect will obscure the flower effect of the bulbs.

Not every variety of bulb is suitable for forcing purposes. A few varieties of bulbs are extremely suitable, while a few of the varieties 
of the crocus and of the Spanish iris can be forced successfully only under the most favourable conditions of heat and light. Some of the early tulips are preëminently good for forcing while some varieties are not adapted to this method of growing them. Many of the cottage tulips and nearly all the Darwins can be used successfully. All hyacinths, some more than others, and many narcissi are satisfactory. But before trying varieties not named in the list one should consult a reliable trade catalogue. For early forcing particular care should be used to select large, plump bulbs.

\section{LIST OF BULBS}

A. Refined Lawn and Garden Areas. This group contains only the standard types and varieties of bulbs from which to select material for the average planting. There are hundreds of varieties of bulbs which may be used with more or less success; but this list is intended to be merely a safe guide to the beginner.
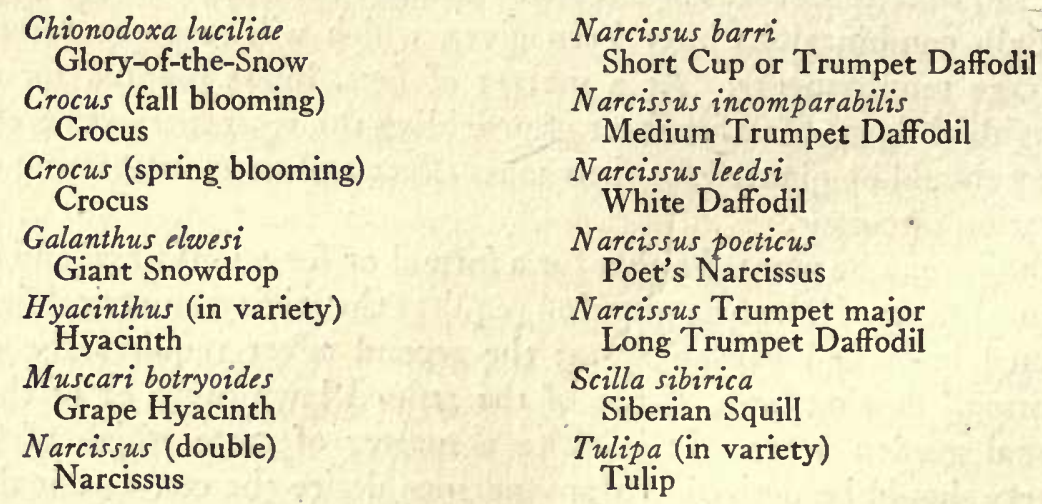

B. Naturalizing in Woodland and Wild Gardens. Bulbs valuable for naturalization in woodland and wild garden areas must be of the kind which will continue to increase without further care than is ordinarily given to such an area. All of the material in this group, except the gold-banded lily, may be expected, after being properly planted, to continue with the succeeding years to become thicker in growth and still remain nearly as vigorous as when first planted.
Allium moly
Yellow Lily Leek
Camassia esculenta
Wild Hyacinth

\section{Convallaria majalis \\ Lily-of-the-valley \\ Eranthis hyemalis}

Winter Aconite 


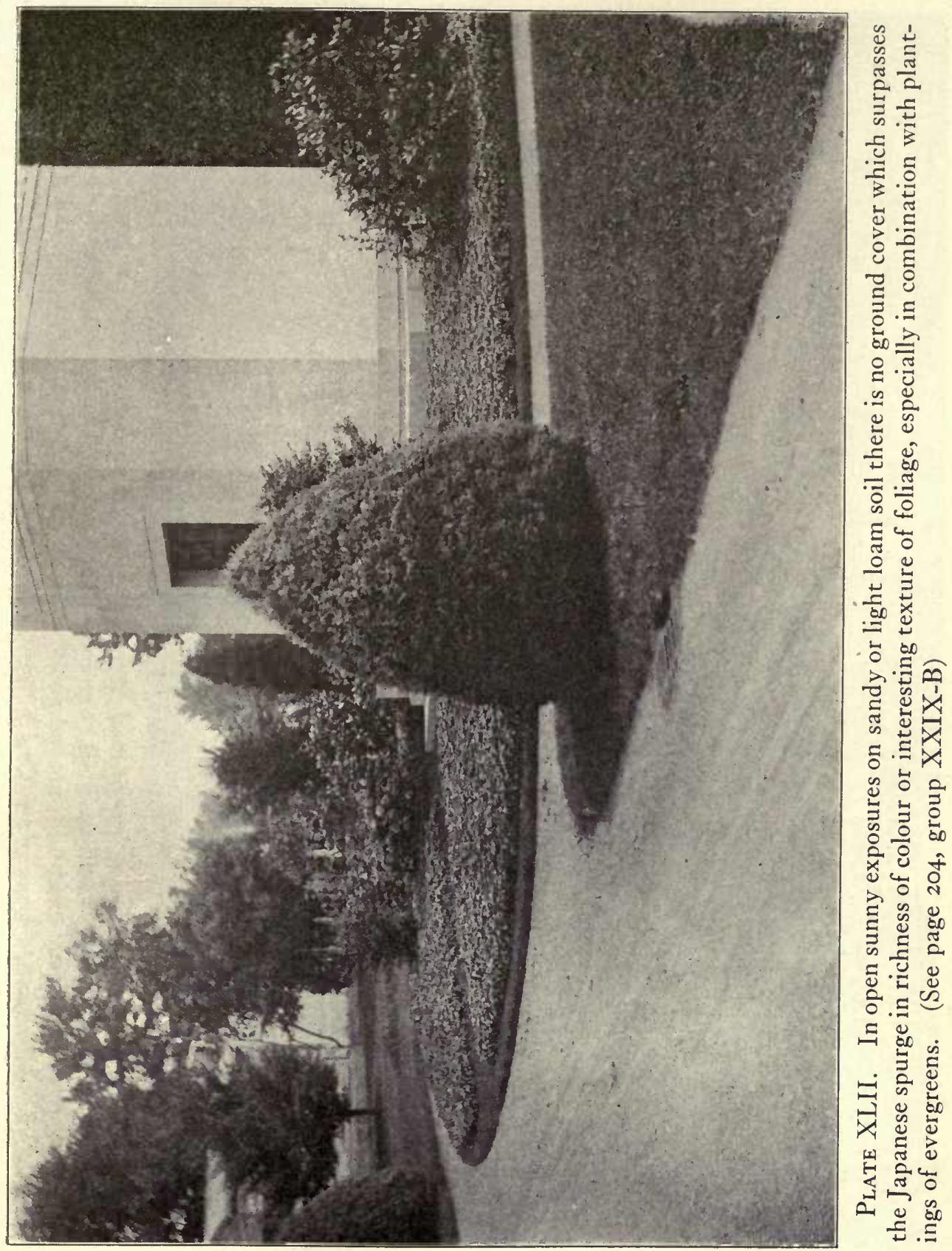




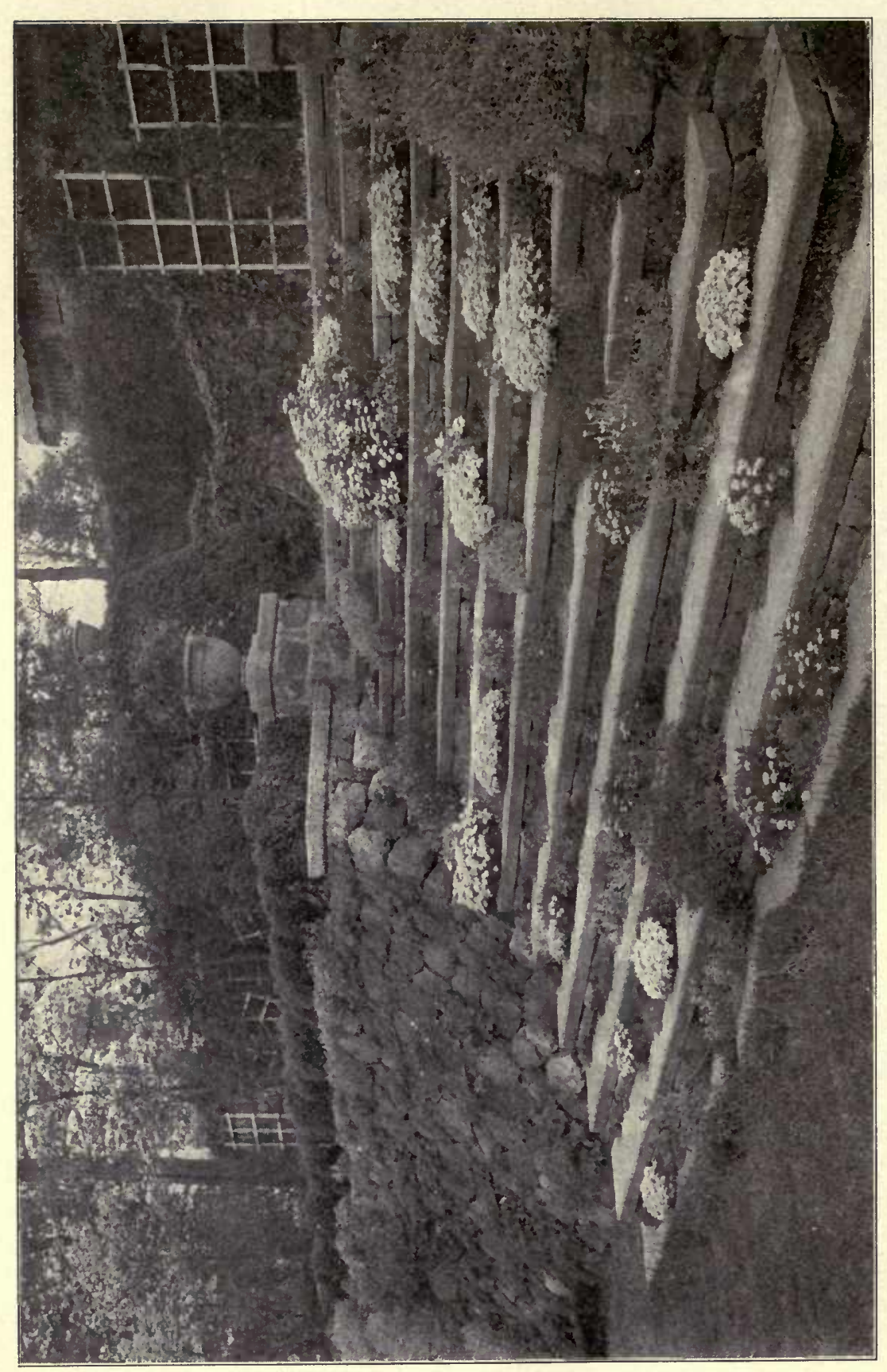

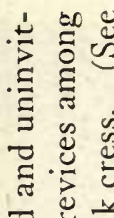

든

8 -

ปี

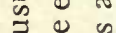

픙

Ð.

등

룬

त 500

हี 용

흥. 일

60

त $>$

ह

世

I

पे

․․ㄹ

ㄷ.

은

䓃

$\therefore \stackrel{0}{00}_{0.5}$

더요

讷

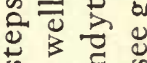

क

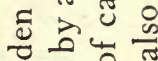

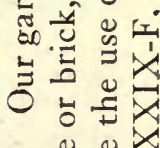

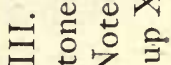

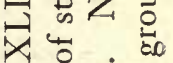

11

岕过

ᄃ 
Erythronium americanum Adder's tongue

Frittilaria meleagris

Guinea-hen Flower

Leucojum vernum carpaticum Snowflake

Lilium auratum Gold-banded Lily

Lilium canadense Wild Yellow Lily

Lilium candidum Madonna Lily

Lilium philadelphicum Wild Red Lily

Lilium speciosum Showy Lily

Lilium tigrinum

Tiger Lily
Narcissus poeticus

Poet's Narcissus

Narcissus leedsi amabilis

Short-cupped White Daffodil

Narcissus Trumpet Major

Long Trumpet Daffodil

Ornithogalum umbellatum

Star of Bethlehem

Scilla campanulata

Squill

Trillium erectum

Wake Robin

Trillium grandiflorum

Large-flowered Wake Robin

Tulipa clusiana

Lady Tulip

Tulipa greigi

Early-flowering Red Tulip

C. NARcissi for Different Locations. In moist, well-drained loam use the large trumpet types. In heavier, damper, lower ground use the poeticus and double gardenia-flowered form. In warmer climates, on damp, moist soil, use the double daffodil. In rockeries use the hoop-petticoat, cyclamen-flowered, and triandrus sections.

D. Tulip Combinations. The most interesting effect can be obtained from the planting of tulips when study and thought are given to the colour effects of the flowers. Many interesting plantings of tulips have been completely spoiled from the standpoint of the landscape effect in a garden and on a lawn because sufficient thought has not been given to the relationship between the colours of the flowers and the season of bloom. It sometimes requires a complementary colour or a contrasting colour to make the most interesting flower effect. There are many tulip combinations which may be selected, but the following are a few which may be used as a guide:

a. Single:

$\{$ Jeannette (crimson red, edged old rose) $\{$ Rose precoce (creamy white)

\{ Queen of the Netherlands (pale rose) $\{$ Van Berghem (carmine red)
Kohinoor (crimson red, purplish bloom) $\{$ Rose Aplati (blush white, edged salmon rose)

Primrose Queen (primrose edged canary $\left\{\begin{array}{l}\text { yellow) } \\ \text { Wout }\end{array}\right.$

Wouverman (dark purple) 
\{ Goldfinch (chrome yellow)

$\{$ Princess Helena (pure white)

$\{$ Chrysolora (clear golden yellow)

$\{$ Dusart (vermilion red)

Golden Lion(primrose yellow, edged red) $\{$ White Hawk (pure white)

$\left\{\begin{array}{l}\text { Primrose Queen (primrose edged canary } \\ \text { yellow) } \\ \text { Princess Wilhelmina (deep pink) }\end{array}\right.$
Lady Boreel (snowy white) $\left\{\begin{array}{c}\text { Joost Van Vondel (cherry red flaked } \\ \text { white) }\end{array}\right.$

(Rose Aplati (white edged salmon rose) Jaune Aplati (sulphur yellow flushed pale rose)

\section{A trifle (five to six days) later than the above are:}

$\{$ Golden Horn (primrose yellow)

$\{$ Rosa Mundi Huyckman (rose pink)

(LeReve (old rose flushed buff)

$\{$ White Swan (pure white)

(L'Interessante (dark violet)

b. Double: Not as graceful as single. Heavy rains quickly bend over or break the stems of the huge blooms. A trifle later than singles:

\{Lac van Haarlem (rosy violet)

$\{$ Safrano (pale sulphur yellow)

\section{LeMatador (glowing scarlet)}

$\{$ Schoonoord (white sport from Murillo)

Sweetheart (white, slightly tinged pale $\{$ Boule de Niege (pure white)

$\{$ Couronne d'Or (deep yellow)

$\left\{\begin{array}{l}\text { rose) } \\ \text { Don Carlos (glowing crimson) }\end{array}\right.$

$\left\{\begin{array}{l}\text { Rose d'Amour (pale flesh rose) } \\ \text { Salvator Rosa (deep rose, flushed white) }\end{array}\right.$

$\{$ Blue Celeste (violet purple)

$\{$ Yellow Rose (yellow)

\section{c. Cottage:}

(Carnation (white, margined rose) $\{$ Solferino (pale yellow)

(Fairy Queen (rosy lilac)

(Picotee (white, margined rose)

Inglescombe Pink (rosy pink)

(Doris (rosy lilac)

(Moonlight (canary yellow)

$\{$ Twilight (mauve)

Bouton d'Or (deep yellow)

\section{d. Darwins:}

(Chestnut (dark mahogany)

Clara Butt (rose)

Europa (light American beauty)

$\left\{\begin{array}{l}\text { Franz Hals (reddish heliotrope) } \\ \text { Princess Juliana (American beauty) } \\ \text { Dream (pale heliotrope) }\end{array}\right.$

Gretchen (pale pink)

$\{$ Clara Butt (rose)

Crepuscule (lilac)

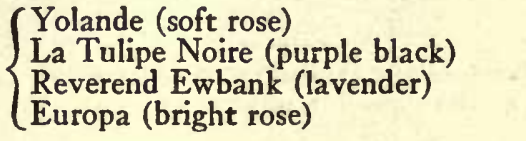


E. Best Varieties for Forcing. The following bulbs are good varieties for forcing. A few kinds (see Group $b$ ) will flower if kept in bowls of water with enough pebbles to hold them upright.

\section{a. Forcing in soil.}

Tulips-early single:

Duc Van Tholl (various colours)

Duchesse de Parma (crimson with yellow margin)

Chrysolora (yellow)

Cottage Maid (pink)

Flamingo (pink)

Vermilion Brilliant (scarlet)

Joost van Vondel (striped, red and white)

Proserpine (deep rose with metallic petals)

Medium-flowering tulips:

Thomas Moore (orange)

Yellow Prince (yellow)

White Swan (white)

Rose Grisdelin (pink)

Pottebakker (scarlet, yellow, and white)

Couleur Cardinal (dark crimson)

Double tulips for forcing:

Boule de Neige (white)

Murillo (pink)

Crown of Gold (yellow)

Imperator Rubrorum (scarlet)

Cottage Tulips:

Bouton d'Or (chrome yellow)

Carnation (white margined carmine)

Elegans alba (creamy white)

Fairy Queen (rosy lilac)

Inglescombe Pink (soft rosy pink)

La Candeur (silvery white)

Striped Beauty (silvery rose)

Vitellina (primrose to creamy white)

\section{Darwin Tulips:}

For late February or early March:

Bartigon (deep red)

Pride of Haarlem (purple rose)

William Copeland (lavender)

William Pitt (dark red)

Rev. H. Ewbank (light lavender)

For late March and early April:

All names in above

Dream (dark lilac)

Europe (vivid red)

Massachusetts (silvery pink)

White Queen (white, flushed pink)

Harry Veitch (brown red)

Princess Elizabeth (deep pink)
Psyche (pink)

Sieraad van Flora (vivid rose)

Farnecombe Sanders (fiery scarlet)

Mme. Krelage (dark pink) For late April or early May:

Clara Butt (shell pink)

Baronne de la Tonnaye (bright rose)

Gretchen (soft pink)

Loveliness (bright rose)

Nora Ware (lilac)

Hyacinths (in order of earliness):

Garibaldi (deep crimson)

Hein Roozen (white)

Lady Derby (rose pink)

Yellow Hammer (creamy yellow)

Buff Beauty (pale yellow striped with straw)

Corregio (white)

Count Andrassy (lavender blue)

Enchantress (porcelain blue)

General de Wet (soft light pink)

Pink Perfection (mauve rose)

La Grandesse (white)

Oranjeboven (pale salmon-tinged rose)

King of the Blues (dark blue)

Etna (dark rose)

\section{Large trumpet Narcissi:}

Emperor

Empress

Golden Spur

Horsfieldi

Mme. de Graaff

Olympia

Silver Spur

Victoria

W. P. Milner

William Goldring

Medium trumpet narcissi:

Sir Watkin

Barri conspicuous

Poeticus ornatus

Sea Gull

White Lady

Double narcissi:

Van Sion

Orange Phoenix 
Paper White Narcissus (all varieties)

Miscellaneous Bulbs:

Chionodoxa

Glory-of-the-snow

Convallaria majalis

Lily-of-the-valley

Freesia refracta alba

Freesia

b. Forcing in water

Crocus

Mammoth Yellow Crocus

Hyacinth Roman

(large bulbs)

Narcissus Golden Spur

Trumpet Narcissus
Galanthus Snowdrop

Gladiolus The Bride Sword Flower

Hyacinth Dutch and Roman Early single varieties

Ixia

African Corn Lily

Narcissus horsfieldi

Trumpet Narcissus

Narcissus polyanthus totus albus Paper White Narcissus

Narcissus polyanthus Soleil d'Or

Yellow Paper White Narcissus

Sprekelia formosissima

Jacobaean Lily 


\section{CHAPTER XXXVII}

\section{FRAGRANT PLANTS}

THE group of trees, shrubs, and perennials whose flowers or leaves are fragrant is an important group in the development of an interesting variation in landscape plantings, especially on the larger places. There are certain varieties of shrubs, such as the common mock orange, the flowers of which are extremely fragrant, while the flowers of some of the other varieties have no odour whatever. This is a peculiar condition which has not been fully explained, but one which makes a marked difference in the effect of plantings from the standpoint of the fragrance of their flowers. A garden possesses greater charm if fragrance is one of its attributes. In older times many plants were grown for their sweet odours, both of flowers and leaves. This feature has not been given its due importance in the landscape plantings of to-day, and a little study will convince one that a wealth of fragrance can be easily obtained in any planting of trees, shrubs, and perennials, by the proper selection of a few types of plants. The fragrant honeysuckle has a very attractive odour, while the tartarian honeysuckle has flowers with no fragrant odour whatever. The horse-chestnut has flowers with little or no odour, while the false acacia and the black locust fill the air with fragrance. Violets, trailing arbutus, and lilies-of-the-valley add a certain fragrance to the garden, which odour is entirely lacking in many other varieties of perennials.

\section{LIST OF FRAGRANT PLANTS}

A. Fragrant Flowers. The plants in this group are valuable because of the fragrance of their flowers. It is an interesting fact that many species of the same genus are not equally valuable because of the flower fragrance. This is true especially with the mock orange.

a. Shrubs:

Azalea arborescens Smooth Azalea
Azalea canescens

Fragrant Mountain Azalea 
Aralea riscosa

Swamp Azalea

Buddleia veitchiana

Summer Lilac

Calycanthus floridus Strawberry Shrub

Clethra alnifolia

Sweet Pepper Bush

Corylopsis spicata

Flowering $\mathrm{Hazel}$

Daphne cneorum Garland Flower

Itea virginica Virginian Willow

Lonicera fragrantissima Early Fragrant Honeysuckle

Lonicera spinosa alberti Large-fruited Honeysuckle

Lonicera xylosteum Fly Bush Honeysuckle

Magnolia conspicua

Chinese White Magnolia

Magnolia glauca Swamp Magnolia

Osmanthus aquifolium Fragrant Olive

Philadelphus coronarius Common Mock Orange

Philadelphus zeyheri Hybrid Mock Orange

\section{b. Trees:}

Catalpa speciosa Western Catalpa

Gleditsia triacanthos

Honey Locust

\section{c. Perennials:}

Arabis albida

Rock Cress

Artemisia lactiflora

Southernwood

Asperula odorata

Sweet Woodruff

Cheiranthus cheiri (tender)

Wallfower
Pyrus angustifolia Narrow-leaved Crab

Pyrus baccata Siberian Flowering Crab

Pyrus coronaria Wild Crab

Pyrus floribunda

Flowering Crab

Pyrus ioensis bechteli Bechtel's Crab

Pyrus spectabilis riversi Rivers' Semi-double Chinese Flowering Crab

Rhododendron azaleoides Hybrid Pinkster Flower

Ribes aureum Flowering Currant

Ribes gordonianum Flowering Currant

Rosa (in variety) Rose

Rubus deliciosus

Rocky Mountain Flowering Raspberry

Rubus odoratus Flowering Raspberry

Syringa vulgaris Common Lilac

Viburnum carlesi Korean viburnum

Paulownia tomentosa Empress Tree

Robinia pseudacacia Black Locust

Tilia (in variety)

Linden 
Dictamnus fraxinella

Gas Plant

Epigaea repens

Trailing Arbutus

Funkia (in variety)

Plantain Lily

Hemerocallis aurantiaca

Fragrant Orange Lily

Hemerocallis flava

Lemon Lily

Hemerocallis thunbergi

Lemon Lily

Hesperis matronalis

Sweet Rocket

Iris germanica

German Iris

Lavandula vera

Lavender
Malva moschata

Musk Mallow

Monarda (in variety)

Bergamot

Oenothera (in variety)

Evening Primrose

Paeonia albiflora sinensis

Chinese Peony

Phlox paniculata

Garden Phlox

Trifolium repens

White Clover

Valeriana (in variety)

Valerian

Viola odorata semperflorens

Violet

Yucca filamentosa

Adam's Needle

B. Fragrant Leaves. This is a small but very interesting group of plants. Most produce an attractive odour from the leaves either growing on the plant, or dried and crushed.

a. Trees and shrubs:

Benroin aestivale

Spice Bush

Buxus

Boxwood

Comptonia asplenifolia

¿ Sweet Fern

b. Perennials:

Anthemis

Chamomile

Artemisia abrotanum

1 Southernwood

Artemisia dracunculus

Tarragon

Asperula odorata

Sweet Woodruff

Cedronella

Balm of Gilead

Dictamnus fraxinella

Gas Plant

\author{
Rhus canadensis \\ Fragrant Sumac \\ Rosa rubiginosa \\ Sweet Brier \\ Rosa rubiginosa hybrida \\ Lord Penzance Hybrid Brier
}

Lavandula vera

Lavender

Monarda didyma

Bergamot

Rosmarinus officinalis

Rosemary

Salvia officinalis

Mammoth Sage

Sanguisorba minor

Burnet

Santolina chamaecyparissus

Lavender Cotton 


\section{CHAPTER XXXVIII}

\section{POISONOUS PLANTS}

THE increase in the number of country homes that are being built on "new land" makes important an understanding of the common poisonous plants which are likely to occur and which should not be collected for use in planting, but should rather be removed if they are so situated as to prove dangerous to people, or where they may be browsed by animals. A few of these plants are sold by growers and if planted they should be located after some forethought.

Of those in the first list there are several that are really desirable because of their flowers; but all in the second list can easily be dispensed with. Similar to the poison ivy or poison oak is the woodbine or Virginia creeper; but the latter has five leaflets on a stem while the objectionable vine has three. There are several desirable species of sumac in addition to the poisonous kind. The species to be avoided can be recognized by its growing in swamps, and it is rarely found in ground at all well drained. It and the poison ivy alike are distinguished by their white fruits. The first plant in List B, however, primula obconica, the hairy primrose, popular as a house plant, need not be discarded if any person who is susceptible to contact poisons will rinse his hands in alcohol and then wash with soap and water after handling this plant.

Where animals may browse, the planter should not place any form of the kalmia or laurel. This is the only desirable plant in List A of considerable range that grazing animals are apt to feed upon. In the west, particularly Wyoming, many sheep are killed by eating the woody aster or the death camas. The darnel poisons men, dogs, horses, and sheep, but does not harm cows, pigs, and ducks.

Of those in the first group, the mushroom is the only one that is likely to be eaten by a human being. The more dangerous species of it is the amanita phalloides or "deadly amanita," for it is widely distributed in woods and meadows and for the phallin that it con- 
tains no antidote is known. It is all the more to be guarded against in its pure white form, resembling the lepiote or edible mushrooms, but, as a rule, the upper surface of the cap is grayish, brownish or greenish. (The different edible mushrooms additional to the white variety as referred to above have caps that are slaty gray, reddish brown, or brownish yellow.)

In general, it might be remarked that there is risk in taking into the system any part of a plant the properties of which are not known. The leaves of the wild black cherry, for example, are quite poisonous, especially when dried, and the seeds of the Jamestown weed are more deadly than the rest of the plant; but the physician may make proper use of belladonna, strychnine, and aconite.

\section{LIST OF POISONOUS PLANTS}

Poisonous plants may be divided into two groups: A. Plants which if taken internally either cause irritation or poison the blood. B. Skin irritants. The majority of the plants in the first group are more harmful to farm animals than to human beings. In the second group the reverse is true.

\section{A. Internally Poisonous:}

Aconitum napellus
Monkshood
Amanita muscaria
Mushroom
Amanita phalloides
Mushroom
Arisaema triphyllum
Jack-in-the-pulpit
Atropa belladonna
Deadly Night-shade
Cicuta maculata
Cowbane
Conium maculatum
Poison Hemlock
Datura stramonium
Jamestown Weed
Delphinium geyi
Larkspur

Helleborus niger Christmas Rose

Kalmia angustifolia Sheep Laurel

Kalmia latifolia Mountain Laurel

Lolium temulentum Darnel

Oxytropus lambertini Slender Loco-weed

Passiflora incarnata Passion Flower

Prunus serotina (leaves) Wild Black Cherry

Veratrum viride Green Hellebore

Xylorrhiza parryi Woody Aster 
B. Skin Irritants:
Primula obconica Hairy Primula Rhus radicans Poison Ivy

\author{
Rhus toxicodendron \\ Poison Oak \\ Rhus vernix \\ Poison Sumac
}

Stipa spartea (skin irritant for animals only) Porcupine Grass

C. Causing Hay Fever. East of the rooth meridian in the United States ninety per cent. of the cases of hay fever are caused by the common ragweed (Ambrosia elatior) while in the Rocky Mountain and Pacific states the sage brush (Artemisia) replaces the ragweed as the most common hay fever weed. The so-called "rose fever" from which many people suffer each year is not caused by roses at all but by pollen from several different grasses. There are a number of commonly planted ornamental plants which possess hay-fever producing characteristics, as follows:

I. The flowers must be wind pollinated.

2. The flowers must be very numerous.

3. The flowers are generally unscented and not conspicuously coloured.

Some plants, like the goldenrods (Solidago), when used in large quantities in a room may prove irritant, but the pollen is not wind borne and thus it is not a true hay-fever plant. Dandelions have been known to cause irritation when children press the flowers too closely to their nostrils; but the dandelion is not a true hay-fever plant. The list of plants given below has been divided into two parts: (a) those plants which are active hay-fever producers, and (b) those which are mild. None of these plants should be used about hospitals, nor where hay-fever sufferers are likely to come in contact with them.

\section{a. Active:}

Artemisia frigida

Wormwood Sage

Aster ericoides

White Heath Aster

Aster novae-angliae

Hardy Garden Aster

Carya ovata

Hickory

Centaurea cyanus

Old-fashioned Cornflower
Chrysanthemum leucanthemum Ox-eye Daisy

Dianthus chinensis

Chinese Pink

Miscanthus compactus

Plume Grass

Eupatorium sessifolium

Upland Grass

Helianthus angustifolius

Hardy Sun-flower 
Ipomoea purpurea

Common Morning Glory

Iva ciliata

Marsh Elder

Juglans nigra

Black Walnut

Juniperus virginiana

Red Cedar

Poa annua

Annual Meadow Grass

\section{b. Mild:}

\section{Acer rubrum}

Red Maple

Acer rubrum drummondi

Drummond's Maple

Salix nigra

Black Willow
Populus deltoides Southern Cottonwood

Quercus nigra

Water Oak

Solidago canadensis

Goldenrod

Spiraea vanhouttei

Van Houtte's Bridal Wreath

Vernonia noveboracencis Ironweed

\author{
Lonicera flava \\ Yellow Honeysuckle \\ Rhus typhina \\ Staghorn Sumac
}




\section{CHAPTER XXXIX}

\section{ORNAMENTAL PLANTS SUBJECT TO DISEASE AND INSECT PESTS}

THE purpose of the list of plants given below is not to discourage any prospective planter, even though the list is a formidable one, nor to catalogue all the ornamental plants which may be affected by insects or disease. It should be remembered that ornamental plants, like animals, are much less subject to disease, and less likely to be harmed also when in good condition. Thus the average person who grows ornamental plants will, if he keeps them from being damaged by mechanical factors such as wounds, lack of food and water, poor soil aeration, and so on, not need to worry very much as to whether they will succumb easily to disease or insect attacks.

The true diseases of plants are either physiological, such as tip burn, due to over-transpiration of water during a hot wind, or parasitic. The parasitic diseases either kill by the secretion of toxins and enzymes which destroy plant tissues, or these toxins and enzymes cause excessive tissue growth or diversion of food substances of the plant to the use of the parasite. When the plant tissue is killed a rot, blight, or leaf spot appears and when the second effect takes place the result is a gall, leaf curl, rust, or smut. The first effect, which results in the immediate death of the plant tissue, is of course the most harmful. Anthracnose is a disease caused by one definite sort of fungus or parasite.

While the diseases of plants are not something new, since the historical writings of the ancients mentioned rusts, cankers, and smuts, the study of how to combat them is not only a new but an everchanging subject. Accordingly, the reader is urged to consult the latest bulletins of his State Experiment Station or of the U. S. Department of Agriculture before embarking very far upon a programme of spraying or of otherwise combating these diseases.

Not all insects which live on or about plants are harmful. Thus the honey bees, the "lady-bugs," and many others are beneficial since they either pollenate the flowers or eat other harmful insects. The 
types of injurious insects are as follows: plant lice, scales, borers, fruiteating insects, root-feeding insects, and leaf or bud-feeding insects. The leaf or bud-feeding insects are the most harmful to the appearance of ornamental plants, though borers and scales do a vast amount of damage. Plant lice also, during some seasons of the year, spoil the appearance of some ornamental plants as well as do damage.

Much valuable study and thought have been given to the subject of eradication of insect pests and the information available on this subject is very complete. The spray calendars published by the State Experiment Stations should be consulted for details of how to keep ornamental plants clean and thrifty.

\section{LIST OF ORNAMENTAL PLANTS SUBJECT TO DISEASE AND INSECT PESTS}

Not all trees are equally seriously affected by insect pests and in the list below where a long list of insects and diseases are given after a plant name it does not signify that all those insects and diseases commonly occur, but merely that they are known to occur on one or more species of the genus. The list is given merely as a guide showing along what lines to look for further information, and it also indicates the sort of treatment required as outlined in the chapter on Maintenance, under the spraying discussion (See Page 75).

Considerable study throughout New York and Ohio in regard to the immunity of trees from insect injury points to the following conclusions: The arborvitae, tree of heaven, and the ginkgo are practically immune from injurious insects. The American and Oriental planes, the red and scarlet oaks, and the tulip tree and junipers are occasionally attacked. The red, Norway, sugar, and sycamore maples, the white and bur oaks, the honey locust, catalpa, the birches, the spruces, and the white pine have each one serious insect pest. Among the trees very likely to be attacked by insects are the European and American lindens, the American and the water or red elms, the soft maple, the horse-chestnut and buckeyes, and the hackberry. The European and Scotch elms and the willows are very seriously injured by insects, while the yellow locusts and poplars and cottonwoods are so seriously injured as to make it doubtful whether they should ever be used in ornamental planting.

In the following alphabetical list of plants all the defoliating larval forms of insects are classed as caterpillars for the sake of brevity, and 
because they are all treated in the same way when spraying is resorted to; namely, by a poison or a contact insecticide.

Alder (powdery mildew, borers, leaf roller, caterpillars, maple scale).

Apple (canker, aphids, caterpillars, scales, and bark louse).

Arborvitae (bagworm).

Ash (trunk rot, canker, leaf spot, borer, caterpillars, and scales).

Aster (wilt and blister beetle).

Azalea (leaf spot and caterpillar).

Barberry (rust, plant louse, and caterpillar).

Bayberry (caterpillar).

Beech (leaf diseases, anthracnose, mildew on leaves, maple scale, and caterpillars).

Birch (anthracnose, heart rot, canker, borer, and caterpillars).

Bitter-sweet, (evonymus scale).

Box Elder (canker, scales, and caterpillars).

Boston Ivy (caterpillars).

Buckeye (scales, bark louse, and caterpillars).

Catalpa (leaf blight, powdery mildew, and caterpillars).

Cherry (black knot, scales, aphis, leaf spot, mildew, and caterpillars).

Chestnut (anthracnose, bark disease, weevil, and caterpillars).

Chrysanthemum (leaf spot).

Columbine (borers).

Daphne (magnolia scale).

Dogwood (San Jose scale, oyster shell scale, dogwood scale, and bark louse).

Elm (leaf diseases, leaf beetle, canker, scale, leaf gall, and caterpillars).

Englemann's spruce (red spider).

English Ivy (leaf blight).

Evonymus (evonymus scale, and cottony maple scale).

Fir (saw fly, timber beetle, borer, and caterpillars).

Hackberry (scale and caterpillars).

Hazel (caterpillars).

Hickory (leaf spot, borers, shuck worm, tussock moth caterpillar, bark beetle, and canker worm).

Hollyhock (anthracnose and rust).

Hornbeam (caterpillars).

Horse-chestnut (leaf blight, rust, tussock moth, bag worm, scales, and bark lice).

Hydrangea (leaf blight and rust).

Iris (bulb spot, root rot, and leaf blight).

Juniper (cedar rust, red spider, and caterpillars).

Larch (canker, saw fly, and tussock moth).

Lilac (powdery mildew, San Jose scale, bark lice, and caterpillars).

Linden (borers, leaf beetle, caterpillars, scale, and red spider).

Locust (heart rot, borers, leaf beetle, maple scale, and caterpillars).

Magnolia (magnolia scale).

Maple (anthracnose, tip burn, sun scald, borers, caterpillars, scale, and twig pruner).

Mulberry (bacterial disease, cottony maple scale). 
Narcissus (aphids and eel worms).

Oak (anthracnose, caterpillars, powdery mildew, scale, leaf beetle, and twig pruner).

Osage Orange (scale, bark louse, and caterpillar).

Peach (scales, caterpillars, and borers).

Peony (stem rot and leaf spot).

Phlox (leaf spot fungus and powdery mildew).

Pine (rust, leaf spot, leaf scale, bark louse, saw fly, and weevil).

Poplar (anthracnose, rust, leaf beetle, scales, bark louse, borers, and caterpillars.)

Privet (anthracnose, twig blight, and webworm).

Quince (anthracnose, black rot, and San Jose scale).

Red-bud (caterpillars).

Rhododendron (lace-wing fly and borers).

Rose (anthracnose, mildew, crown gall, nematodes, slugs, scales, and thrips).

Shad-bush (red spider).

Snapdragon (anthracnose, stem rot, and wilt).

Snowball Bush viburnum (aphids).

Solomon's Seal (leaf fungus).

Sour Gum (caterpillars).

Spice Bush (scale and caterpillars).

Spruce (leaf spot, red spider, bug worm, caterpillars, and weevil).

Sumac (canker, scale, and caterpillars).

Sweet Gum (bagworm and other caterpillars).

Sycamore (anthracnose, powdery mildew, leaf folders, caterpillars, and scales).

Thorn (caterpillars, scales, plant lice, aphids, and leaf beetle).

Tree of Heaven (rose scale).

Tulip Tree (scale and caterpillars).

Verbena (mildew).

Veronica (leaf diseases).

Viburnum (see Snowball Bush).

Violet (nematodes and leaf spot).

Virginia Creeper (leaf spot, caterpillars, and scales).

Walnut (anthracnose, mildew, canker worms, caterpillars, and scales).

Willow (caterpillars, leaf beetles, borers, and bark louse).

Wisteria (leaf beetle).

Witch Hazel (caterpillars).

Yucca (caterpillars and grubs.) 


\section{PLANTS DIFFICULT TO TRANSPLANT AND THOSE ADAPTED FOR TRANSPLANTING AT SPECIFIC SEASONS OF THE YEAR}

THE fact is well appreciated that of all our great range of material used in landscape plantings there are a certain number of these species and varieties which are better adapted to being transplanted at some specific season, either during the spring or during the fall. It is generally safe to assume that plants such as the poplars, willows, and the rose of Sharon, the wood of which is late in ripening, should preferably be transplanted in the spring. If these types are transplanted in the fall, they are, during a normal severe winter, subjected to a considerable winter-killing, and must be severely cut back in the early spring; whereas, if planted in the spring they almost invariably continue co grow and require little or no cutting back.

The group of perennials which should not be transplanted in the spring consists mostly of those plants which begin their growth at the first sign of spring, and before the ground is really in fit condition to "work." These plants, by the time the ground is warm and dry enough to permit transplanting in friable soil, have developed so much growth of roots or of both roots and top, that unless they can be immediately moved without any period of delay from their existing location to a new location they should by all means be transplanted during the fall. If such plants are transplanted in the spring the usual result is a check to growth and exceptionally weak development of flowers and of foliage during that season. The fall transplanting of perennials ought to be done, especially with these early spring-flowering types, during September rather than during the latter part of October and November, when the ground is cold and growth is completely stopped. Transplanting earlier in the fall enables the plants to start some root growth and thus to establish themselves to better withstand the winter conditions, especially in the soils containing more or less clay. Especially should the peony, for any degree of success, be trans- 


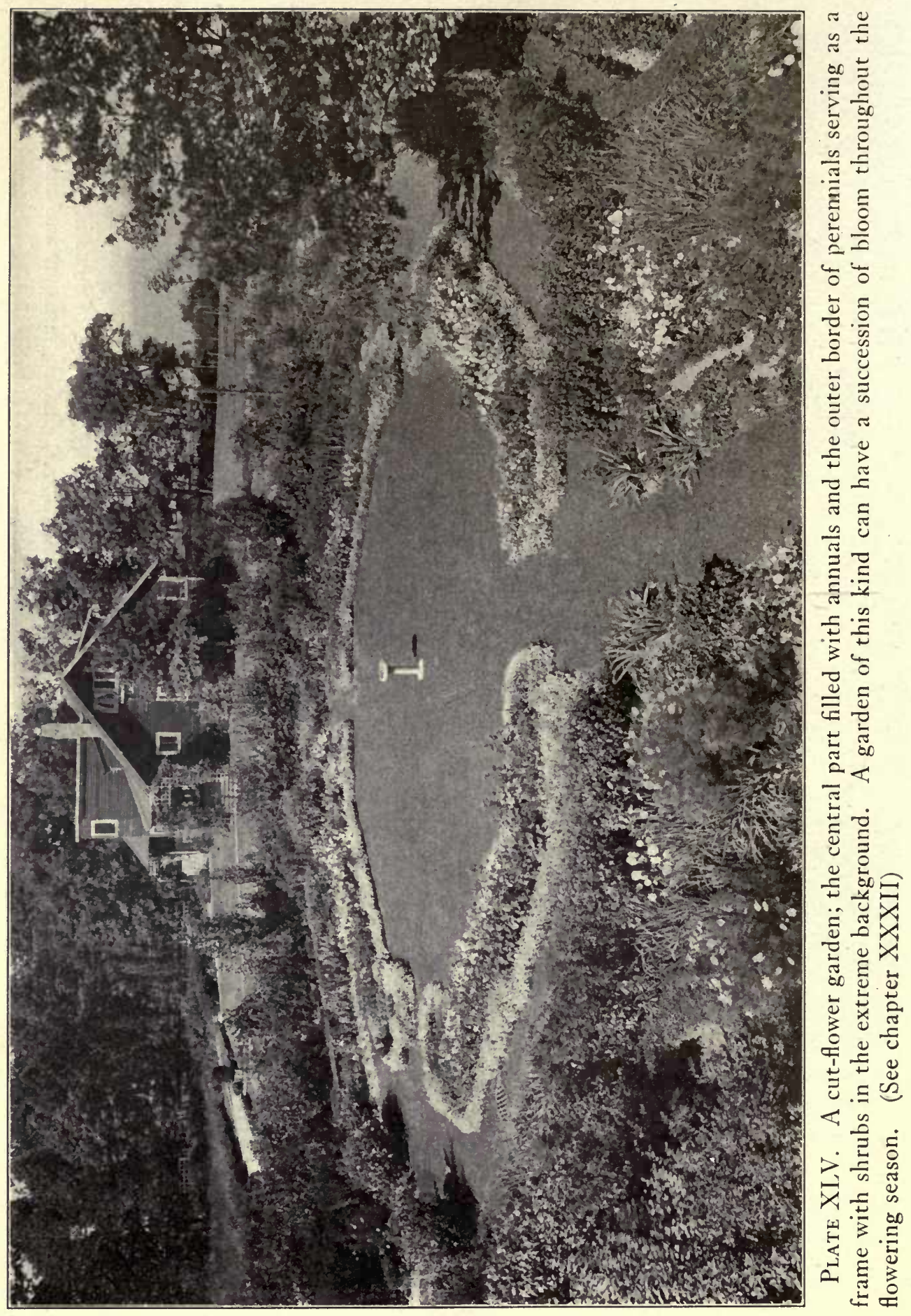


planted in the fall. The iris is peculiar and can be successfully transplanted at any time when the ground is not frozen. The best time is believed to be immediately after flowering.

Plants which are not vigorous in their habit of root growth and which are very susceptible to abnormal conditions of freezing and thawing, or to excessive moisture in the soil during the winter months, should not be transplanted in the autumn. The most important illustrations of this type of plants are the beech, the flowering dogwood, and some of the less hardy types of evergreens, such as the arborvitae and the pea-fruited cypress. Many good plantsmen are of the opinion that rhododendrons and azaleas should be planted during the spring months. As is the case with the refined types of evergreens, there is usually less loss from spring planting of this material than from fall planting. iThe question of period of transplanting in connection with rhododendrons and with evergreens has been discussed under the chapter on Planting and Transplanting (Page 49).

While it is desirable in the transplanting of evergreens and of rhododendrons in particular to move them at a time when they are just ready to begin growth, in order to prevent them from standing in a "cold soil," it is, on the other hand, necessary to transplant such trees as the beech and the birch when they are absolutely dormant. If they have shown the least signs of growth through the swelling of the buds, the operation of transplanting becomes more difficult, and yet to transplant such material in the fall and to permit it to stand through the winter, especially in a heavy soil, subjects it to the possibility of considerable loss. There is a well-defined group of perennials, typical of which are the chrysanthemum and the Japanese anemone, which can seldom be transplanted with any success during the fall season. The reason for this is that the plant produces flowers at such a late period in the growing season that further root action necessary to establish the plant in a new location and successfully carry it through the winter is not encouraged.

Group C includes plants divided into two sub-groups, $a$ those which transplant with difficulty and should rarely if ever be transplanted, but grown in their permanent location from seed, cuttings, or very small seedlings, and $b$ those which after being transplanted recover very slowly. All of the plants in the first group are the extremely slow-growing types, such as the walnut, the butternut, the ironwood, and the sweet fern. Those typical of the second groups are 
the Japanese snowball, the rose of Sharon, boxwood, nursery-grown beech trees, and sweet gum. The author does not intend to convey the impression that any of the plants in either of these groups, especially the first group, cannot be transplanted with success by those who are in a position to know the plants intimately, and to take thorough precautions against any possible injury through transplanting. For the person who is not an expert plantsman and who does not thoroughly understand all of the conditions necessary for the successful transplanting of the extremely slow-growing types of trees and shrubs the plants in the first group should be avoided, and extreme care should be given to the work of transplanting any of the trees or shrubs included in the second group.

Most of the plants included in the second group should be transplanted for best success during the spring months. Their habit of slow growth and inability to adapt themselves readily to new conditions of soil make them very liable to injury on account of drowningout because of excessive depth of planting, or injury from winter conditions. All of these types are apt to be extremely unsatisfactory during the first two years after transplanting, but when once they have recovered from the shock of transplanting they will grow wonderfully well.

\section{LIST OF PLANTS ADAPTED FOR TRANSPLANTING AT SPECIFIC SEASONS OF THE YEAR}

Under excellent care, good results may be attained by transplanting all plants during the fall planting season, or during the spring planting season. For the best results, however, it is advisable to plant some types during the fall planting season and other types during the spring planting season. The two groups $\mathrm{A}$ and $\mathrm{B}$ contain plants specifcally adapted for planting; some in the fall and some in the spring. Group C contains a list of plants which transplant with extreme difficulty, and can be transplanted with better success during the spring months with the exception of the trailing arbutus listed in Group C-a. This plant is extremely difficult to transplant with any success at any season. Those who have had considerable experience with the trailing arbutus are of the general opinion that if it is taken up during the month of July and moved with a goodly amount of soil about its roots together with some additional soil in which to plant it in the new location, some success may be assured. Special care should be taken 
immediately after this plant is transplanted to give it a mulch of some light texture such as partially decayed oak leaves in order to provide a satisfactory fertilizer and to prevent excessive evaporation from the soil which surrounds the roots.

A. Plants Which Should Be Transplanted in Autuma:

Anemone pennsylvanica

Canadian Windflower

Aquilegia (in variety)

Columbine

Dicentra spectabilis Bleeding-heart

Doronicum plantagineum excelsum Leopard's Bane

Hepatica triloba Hepatica

Iris (in variety)

Iris (See Page 90)

\author{
Lilium (not stem-rooting) \\ Lily \\ Paeonia \\ Peony \\ Phlox divaricata \\ Wild Sweet William \\ Primula (in variety) \\ Primrose \\ Sanguinaria canadensis \\ Bloodroot \\ Trillium (in variety) \\ Wake Robin
}

Trollius europaeus

Globe-flower

B. Plants Which Should Be Transplanted in Spring:

\author{
Acer rubrum \\ Red Maple \\ Acer saccharinum \\ Silver Maple \\ Anemone japonica \\ Japanese Windflower \\ Azalea (in variety) \\ Azalea \\ Benzoin aestivale \\ Spice Bush \\ Betula (in variety) \\ Birch \\ Buddleia veitchiana \\ Summer Lilac \\ Calycanthus floridus \\ Strawberry Shrub \\ Chrysanthemum (in variety) \\ Chrysanthemum \\ Colutea arborescens \\ Bladder Senna \\ Cornus florida \\ Flowering Dogwood \\ Cotoneaster horizontalis \\ Prostrate Cotoneaster \\ Crataegus (in variety) \\ Thorn
}

Ericaceous plants of all sorts

Fagus sylvatica European Beech

Hedera helix

English Ivy

Hibiscus syriacus

Rose of Sharon

Kalmia (in variety

Laurel

Kerria japonica

Globe-flower

Liquidambar styraciflua Sweet Gum

Liriodendron tulipifera Tulip Tree

Magnolia (in variety)

Magnolia

Morus rubra

Red Mulberry

Pieris (in variety)

Fetterbush

Populus (in variety)

Poplar

Rhododendron (in variety)

Rhododendron 
Rhus canadensis

Fragrant Sumac

Rosa rugosa

Japanese Rose

Stephanandra flexuosa

Stephanandra

Tamarix gallica

French Tamarisk
Taxus (in variety) Yew

Ulmus americana American Elm

Viburnum plicatum Japanese Snowball

Vitex agnus-castus Chaste Tree

C. Plants Which Are Transplanted with Little Success:

a. Plants to be rarely if ever transplanted. Some plants, especially if collected from the wild, seldom survive the shock of transplanting. Some plants, like the beeches, must be entirely dormant if they are to be moved successfully. The letter (c) after a name indicates that collected plants move with little or no success; but nursery-grown plants move with fair success.
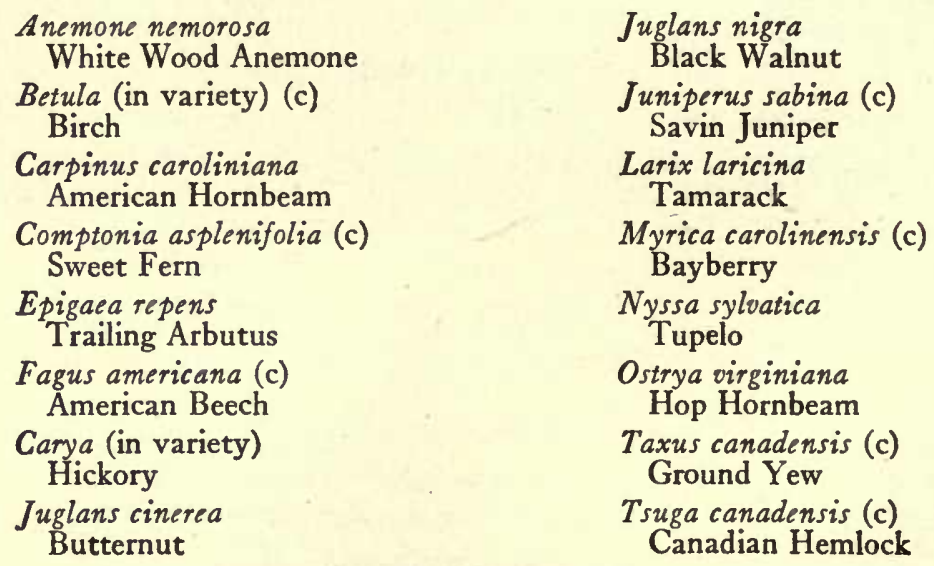

\section{Vaccinium vacillans (c) \\ Low Blueberry}

b. Plants which recover slowly from the operation of transplanting. Some fine species of ornamental plants never recover quickly from the effects of being transplanted. No matter how carefully this work may be carried out there is sure to be a considerable period following when the plant is disappointing in appearance and when it requires careful maintenance if future growth is to fulfill the expectation of the planter.

Abelia grandiflora

Hybrid Abelia

Acer palmatum

Japanese Maple
Betula (in variety) Birch

Buxus sempervirens Tree Box 
Calluna vulgaris Scotch Heather

Carpinus betulus European Hornbeam

Cercis canadensis Red-bud

Cornus florida Flowering Dogwood

Crataegus (in variety) Thorn

Fagus sylvatica European Beech

Hibiscus syriacus Rose of Sharon

Ilex glabra

Inkberry

Ilex opaca

American Holly
Kalmia latifolia

Mountain Laurel

Liquidambar styraciflua

Sweet Gum

Liriodendron tulipifera

Tulip Tree

Mahonia aquifolium

Oregon Grape

Pyrus (in variety)

Crab

Quercus rubra

Red Oak

Rhamnus cathartica

Common Buckthorn

Syringa vulgaris (in variety) Common Lilac

Viburnum tomentosum plicatum Japanese Snowball 


\section{SHRUBS FOR FORCING IN WATER IN EARLY SPRING}

BEFORE winter has gone and the warm days of early spring cause our early-flowering shrubs to mature some very interesting flowers may be developed indoors on twigs of such plants. These flowers, the harbingers of spring, may be developed almost as well indoors as out of doors at a later date on the plants. The reason for such normal development under abnormal conditions is that the flowers, complete in miniature form, lie within the existing flower buds ready to burst forth when given sufficient heat and moisture.

When forcing cut stems of hard wooded ornamental plants in water in winter or early spring, the best results are secured by following a few simple rules. When flowers are desired, select branches of plants which produce flowers from buds formed the previous year. Otherwise, only leaves will result, which of course are sometimes desirable as an addition to the flowers of other sorts. Since all the flowers and leaves which will appear must come from buds already upon the twigs and branches be careful to cut only branches containing plump, full buds, especially when flowers are desired. It is possible to cut these branches at any time from February to April. After cutting the branches care must be taken to keep them from drying out and it is often well worth while to soak the whole twigs for a few hours in warm water, both before starting to force them and occasionally afterward at intervals of a week. This will loosen the bud scales, soften the whole fibre of the twig, and remove dust, thus taking the place of spring showers. The twigs should be from twelve to thirty inches long and placed. in fairly large receptacles with plenty of water. The water should be changed every second or third day and should have small pieces of charcoal added in order to help keep it sweet. Each two or three days it is advisable to make fresh cuts at the bottom ends of the twigs and it is often worth while to wash the cut ends in mild soap and water to prevent sliminess.

The forsythias or golden bells are the easiest and most successful 292 
plants for forcing in water. All sorts of currants are likely to be successful, even including the common black currant of our gardens. The dogwoods, especially the cornelian cherry, should not be overlooked. The fruit trees, such as apples, plums, cherries, and pears, may all be forced though they respond slowly and require several weeks' time and much patience. The lilacs do not seem to respond easily to forcing in water, nor do the magnolias. There are many common sorts of shrubs, some of which are listed below, which will provide flowers or catkins.

In general, those woody plants which flower first in the spring are the ones easiest to force in water. Those which require a longer period to develop flowers from the buds are not forced successfully.

\section{LIST OF SHRUBS FOR FORCING IN WATER IN EARLY SPRING}

Generally speaking, flowers of all early-blooming shrubs, flowering upon wood of previous season, can be forced. The branches may be cut any time after January; but the best results are obtained when the branches are cut after the sap begins to run. Place the branches in water and spray tops several times daily to force bloom.

\author{
Amelanchier (white and pink) \\ Shad-bush \\ Caragana frutescens (yellow) \\ Siberian Pea Shrub \\ Cercis canadensis (pink) \\ Red-bud \\ Chaenomeles japonica (pink and red) \\ Japanese Quince \\ Colutea arborescens (light yellow) \\ Bladder Senna \\ Cornus mas (light yellow) \\ Cornelian Cherry \\ Corylus americana (brown) \\ Hazelnut \\ Deutzia gracilis (white) \\ Slender Deutzia \\ Forsythia (all sorts) (yellow) \\ Golden Bell
}

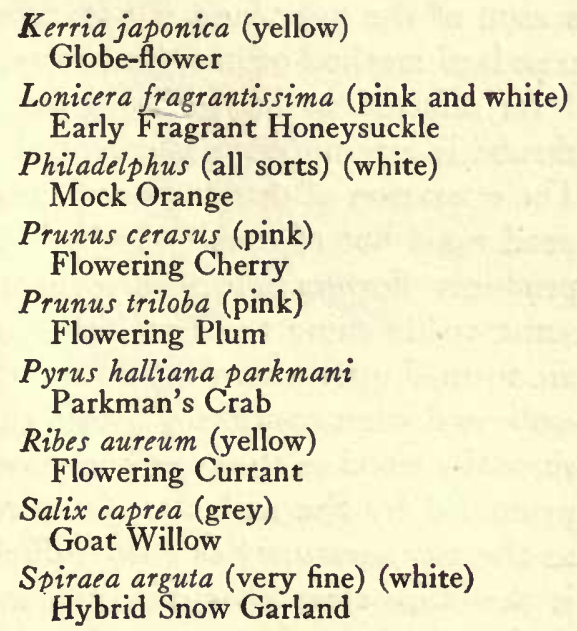




\section{CHAPTER XLII \\ PRUNING REQUIREMENTS}

THE question of the necessary pruning required by various trees and shrubs is a natural one. Many persons are under the impression that every tree and shrub requires a certain amount of pruning each year. Many are under the further impression that all of this pruning should be done in the winter and spring, while others are under the impression that it should be done during the summer or fall.

The most important fact to be known in connection with the operation of pruning is that one should be thoroughly familiar with the flowering characteristics of the plants to be pruned. Our lawn shrubs especially, which are often subject to the most indiscriminate kinds of pruning, comprise a group of plants with which this chapter is concerned. Pruning is done for various purposes, as outlined and discussed in the chapter on Pruning. The question under discussion in this chapter is whether or not all shrubs shall be pruned at a definite season of the year, and if not, what are the special reasons why this standard method of procedure should not be adopted.

As referred to in the foregoing paragraph, before any pruning of shrubs is attempted it is essential to recognize their flowering habits. The operation of pruning necessarily involves the removal not only of dead wood but of much wood which is alive and growing; wood which produces flowers and, subsequently, fruit. The spring and early summer-blooming trees and shrubs produce flowers from buds which are formed upon the wood during the previous growing season. These embryo flowers contained within the buds have existed in the bud form since the wood of the previous season had begun to ripen, and they are protected by the scales or outer covering of the bud until such time as the temperature has been sufficient to encourage their growth. It is therefore clear that any pruning which is done upon such plants during the late winter or early spring months, prior to the time when these plants have produced their flowers, is an operation whereby a greater or less quantity of flowers is deliberately removed from the plant. 


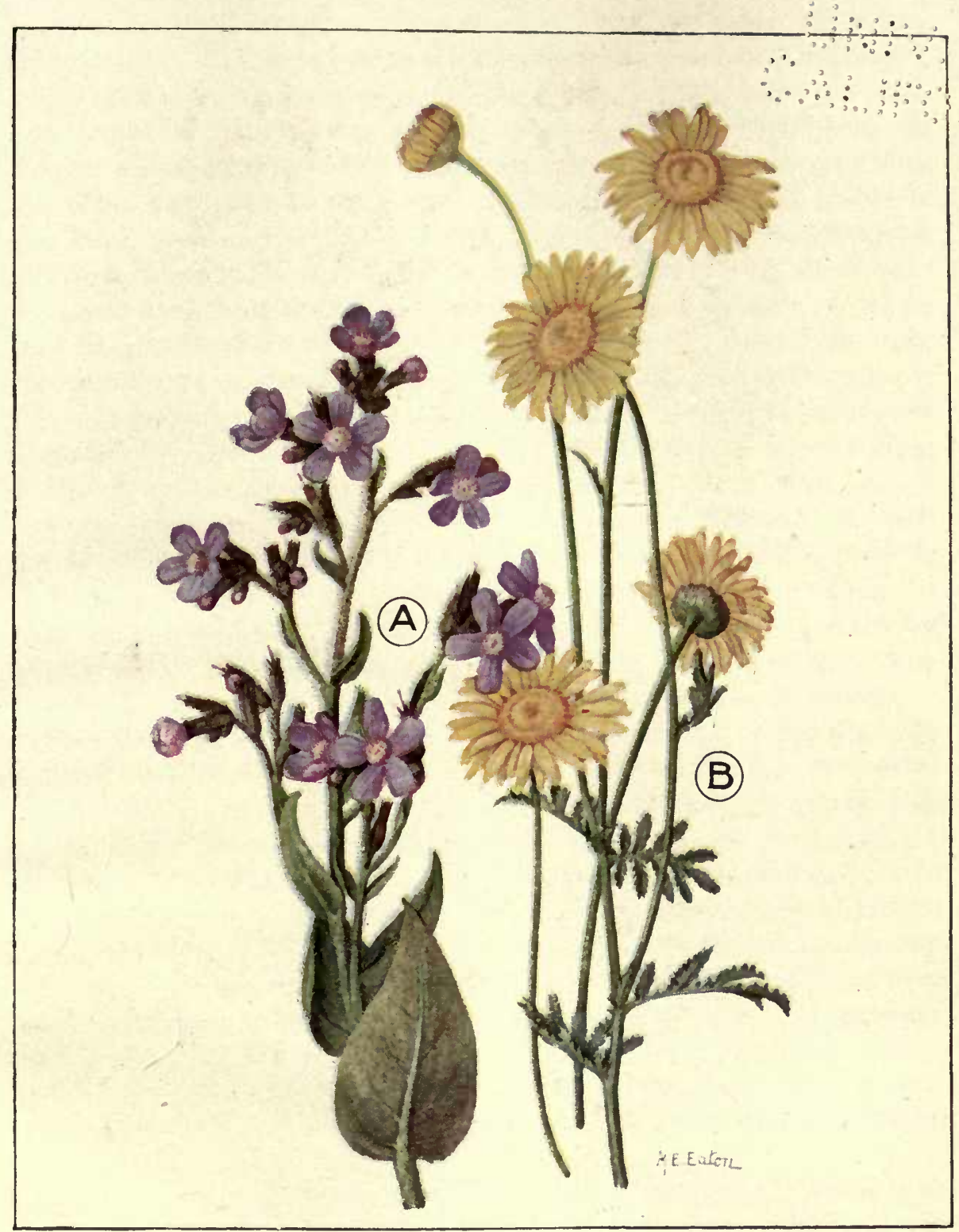

Plate XLVI. Many of our common garden perennials possess the possibilities to produce very interesting colour effects through the colour combination of the flowers. (A) Italian alkanet; (B) hardy marguerite. (See page 23I) 

An ornamental plant is rarely over-supplied with flowers. It therefore behooves us to preserve, so far as possible, all of the buds which produce flowers. Practically all of the growth of new wood on these plants, which adds to the increasing size of the plant, develops after the plant has completed its flowering period. Buds containing the flowers for the succeeding year are often developed on wood which is formed after the plant has matured its flowers. Therefore, pruning on plants of this kind, such as the mock orange, high-bush cranberry, snowball, and Van Houtte's spirea, should be done immediately after the flowers have matured, to stimulate a correct kind of new growth on which may be developed flower buds for the next season. One of the most common faults in connection with the pruning of trees and shrubs is that of applying the same principles of pruning to all kinds of shrubs regardless of whether they are early spring-flowering or late summerflowering, and in so doing to deprive the plant of much of its beauty and attractiveness exhibited through its mass of flowers. In such shrubs, of the spring and early summer-flowering types, which produce flowers from buds on the growth of the previous year, pruning, to produce the maximum of new growth for increasing the quantity of flowers during the succeeding year, should never be delayed more than two weeks beyond the time when the plant has matured its flowers.

On the other hand, there is a group of shrubs of which the best examples are the rose of Sharon, butterfly bush, hydrangea, and snowberry, which are of the late summer and fall-blooming types, and on which the flower-producing buds are formed on the same season's growth. To produce the maximum of flowers on such shrubs it is necessary that they should be pruned during the late winter and early spring months before growth for that season has commenced. In this way much of the old wood is removed, and a greater quantity of new wood, with its accompanying flower buds, is encouraged. If a general rule is to be applied to all trees and shrubs it would be much preferable to give them a so-called summer pruning, which means that the operation of pruning should be delayed until shortly after the shrubs have completed their flowering.

In connection with this discussion it should be borne in mind that there are also some trees and shrubs such as the flowering dogwood, Judas tree, and lilac, which are not so much benefited by annual pruning, and which should be pruned only by the most capable of experts. 
There is a group of plants which practically require only the removal of dead wood and superfluous growth. These trees and shrubs are apt to be more or less injured by the operation of pruning. They normally are comparatively slow growing. They have a tendency to grow informally and to maintain the normal shape of the plant as they continue to increase in size. The operation of pruning does not encourage a sufficient new growth and oftentimes so changes the physiological condition of the plant that the flowering ability is impaired to a marked degree during the succeeding one or two years.

From the foregoing discussions it is evident that the operation of pruning, as applied to the questions of just what shrubs to prune in spring and what shrubs to prune in summer, and what shrubs should never or rarely be pruned, is an important one. It is not an operation the decision for doing which should be placed in the hands of any but those who are skilled in the art and those who are thoroughly familiar with the reasons pro and con.

\section{PRUNING LISTS}

\section{A. Shrubs Needing Complete Pruning:}

a. Spring and early summer-flowering:

Benzoin aestivale
Spice Bush
Berberis thunbergi
Thunberg's Japanese Barberry
Cephalanthus occidentalis
Button Bush
Cercis canadensis
Red-bud
Chionanthus virginica
White Fringe
Cornus (in variety)
Dogwood
Cotoneaster (in variety)
Cotoneaster
Deutzia (in variety)
Deutzia
Dieroilla hybrida
Hybrid Weigela
Dirca palustris
Leather-wood
Elaeagnus angustifolia
Russian Olive
Evonymus (in variety)
Burning Bush

Forsythia (in variety) Golden Bell

Hamamelis virginiana Witch Hazel

Hippophae rhamnoides Sea Buckthorn

Hydrangea arborescens Wild Hydrangea

Kerria japonica Globe-flower

Ligustrum (in variety) Privet

Lonicera (in variety) Honeysuckle

Philadelphus (in variety) Mock Orange

Physocarpus opulifolius Ninebark

Rhamnus cathartica Common Buckthorn

Rhodotypos kerrioides White Kerria

Robinia hispida Rose Acacia 
PRUNING REQUIREMENTS

Sambucus canadensis

American Elder

Spiraea arguta

Hybrid Snow Garland

Spiraea billardi

Billard's Spirea

Spiraea prunifolia

Bridal Wreath
Spiraea tomentosa

Hardhack

Spiraea vanhouttei

Van Houtte's Bridal Wreath

Stephanandra flexuosa

Stephanandra

Syringa (in variety)

Lilac

Viburnum (in variety)

Viburnum

b. Late summer and fall-flowering:

Amorpha fruticosa

False Indigo

Buddleia davidi (Cut back in spring to prevent danger of rotting)

Sweet-scented Buddleia

Ceanothus americanus

New Jersey Tea

Clethra alnifolia

Sweet Pepper Bush

Hibiscus syriacus

Rose of Sharon
Hydrangea (in variety)

Hydrangea

Sorbaria arborea

Chinese Mountain Ash Spirea

Spiraea douglasi

Douglas' Spirea

Symphoricarpos racemosus

Snowberry

Vitex incisa

Cut-leaved Hemp-tree

\section{B. Shrubs Needing Removal of Old Wood Only: \\ a. Summer pruning:}

\section{Caragana \\ Pea Shrub \\ Daphne \\ Deciduous Daphne \\ Halesia \\ Silver Bell \\ Koelreuteria \\ Varnish Tree \\ Laburnum vulgare \\ Golden Chain \\ Lonicera tatarica \\ Tartarian Honeysuckle}

$$
\begin{aligned}
& \text { Magnolia } \\
& \text { Magnolia } \\
& \text { Mahonia } \\
& \text { Oregon Grape } \\
& \text { Prunus cerasus } \\
& \text { Flowering Cherry } \\
& \text { Pyracantha } \\
& \text { Evergreen Thorn } \\
& \text { Rhododendron } \\
& \text { Rhododendron } \\
& \text { Staphylea } \\
& \text { Bladder-nut }
\end{aligned}
$$

Chinese Flowering Chestnut

b. Winter pruning:

\section{Aralia \\ Angelica Tree \\ Artemisia \\ Wormwood \\ Cladrastis \\ Yellow-wood}

\author{
Pavia \\ Dwarf Horse-chestnut \\ Robinia Pseudacacia \\ Black Locust \\ Yucca \\ Adam's Needle
}


C. Trees Which Require Little or No Pruning:

Aesculus

Horse-chestnut

Catalpa

Indian Bean

Liriodendron

Tulip Tree
Paulownia Empress Tree

Robinia

Locust

Sophora

Pagoda Tree

\section{Sorbus}

Mountain Ash

D. Evergreens That Should Be Pruned in May or June:

Abies

Picea

Fir

Spruce

Pinus

E. Evergreens That May Be Pruned at Any Time:

Chamaecyparis

Cypress

Juniperus

Juniper

Taxus

Thuja

Arborvitae 


\section{CHAPTER XLIII \\ PLANTS FOR FLORIDA}

THE following compilation covers information concerning plants used for different landscape purposes in the Florida zones. Some of these plants are followed by the letter $(T)$ which indicates that such material is tropical and is not adapted to the middle-south and northern portion of this state.

This list is subject to considerable modification as further study of these plants brings more complete information concerning their adaptations and uses.

The subject of Florida horticulture, especially from the landscape viewpoint, concerning the use and adaptations of plant materials, is yet in its infancy. Very few men have given any serious thought to this subject; at least very little information is now in printed form and available to those interested in this work.

Florida is fast developing into one of the great winter playgrounds and home sections for many northern people who wish to escape the undesirable winter conditions. These people enter the state with the intention of developing homes and with every desire to beautify them, as is customary in connection with northern homes. A great disappointment is encountered as soon as they endeavour to consult information which will tend to assist them in the landscape development of their property. This list will be of some value to those persons and to many others who are interested in the use of landscape materials throughout this section of the south.

In selecting material for various types of Florida plantings two things must be taken definitely into consideration: Material should be selected which is of real value during the summer months in Florida, and also material must often be selected which is of distinct value during the winter months. The plants included in this list have been selected for their general value throughout the year and more particularly during the winter months. In view of this it is essential that this material should be interesting because of its 
foliage or its flowers during the months from November to the first of April.

There are many northern types of material which can easily be used in Florida plantations for its value during the winter months. There are many other types of northern material with which experiments should be conducted concerning their value for plantations in this climate.

Many of the plants so familiar to northern plantings can be equally well used in plantings of the far south. Privet, golden bell, magnolia, and spirea are among this group which have value during the winter months. Most of the more hardy-flowering shrubs can be used in plantings, but because their period of flowering and of fruiting does not come during these winter months (December to April) they have been little used. The northern tourist is seeking colour of flowers while occupying his winter home in Florida. He also seeks air and sunshine. The heavy shade provided by the silk oak and the water oak so much desired by Floridians he wishes replaced by warmth of winter sunshine and tropical growth of palms which cast but little shade. The familiar growth of shrubs carrying the atmosphere of the north must be replaced by shrubs and vines with brilliantly coloured flowers and foliage like the croton, oleander, trumpet-vine, Chinese hibiscus, and chenille plant.

The great tendency in Florida plantings has been to develop a "spotty" effect at the expense of sacrificing interesting landscape compositions. The "mass" planting of the north is seldom seen. Most types of southern plants are perhaps better adapted to specimen planting than to mass effects. For effective mass planting around buildings, the croton, Chinese hibiscus, and chenille plant are among the best.

\section{LIST OF PLANTS FOR FLORIDA}

A. Windbreaks. It is often necessary in many locations, especially along the water fronts, to plant windbreaks that will preserve the more tender types of plants and which will preserve the lighter soils against heavy windstorms coming from the direction of the prevailing winds. Windbreaks in this section of the country are not used for the same purpose that windbreaks are generally used in the northern climates where winter protection is the main use. Windbreaks throughout the Florida section are of greatest value against erosion of the lighter soils because of prevailing winds and injuries to the more tender plants. 


\section{PLANTS FOR FLORIDA}

Bambusa argentea

Silver Bamboo

Bambusa striata

Striped Bamboo

Callitris verrucosa

Cypress Pine

Casuarina equisetifolia

Australian Pine
Cinnamomum camphora

Camphor Tree

Grevillea robusta $(\mathrm{T})$ Silk Oak

Pithecolobium dulce

Manila Tamarind

Quercus nigra

Water Oak

\section{B. Trees for Street and Specimen Planting:}

a. Northern list: This group of trees covers material which can be used throughout northern Florida, southern Georgia, Alabama, and over the area which is known as the Coastal Plain. In general, this list does not extend into Florida farther than one hundred miles south of Jacksonville. Trees in this group which are marked thus $(+)$ are also adapted for street tree and specimen planting in the southern portion of Florida as shown on the accompanying list:

Acer rubrum
Red Maple
Albizzia julibrissin
Mimosa
Broussonetia papyrifera
Paper Mulberry
Cedrus deodara
Deodar
Cedrus libani
Cedar of Lebanon
Celtis occidentalis
Nettle Tree
+Cercis canadensis
Red-bud
+Cornus florida
Flowering Dogwood
Cunninghamia sinensis
Chinese Pine

\section{Ulmus americana}

Gordonia lasianthus Loblolly Bay

Ilex opaca American Holly

Liquidambar styracifua Sweet Gum

+Magnolia grandiflora Magnolia

Melia azedarach umbraculiformis Umbrella Tree

+Quercus laurifolia Laurel Oak

Quercus nigra Water Oak

Quercus phellos Willow Oak

Quercus virginiana Live Oak

American Elm

b. Southern list: This group of trees, together with those which are marked thus $(+)$ in the previous list, are adapted especially for street planting throughout the southern and middle section of Florida. Those marked $\left(^{*}\right)$ are the more commonly used and perhaps the better types for street tree planting.

Adenanthera pavonina

Circassian Bean

Albizzia lebbek (T)

Woman's Tongue Tree
Aleurites triloba

Candle-nut

Araucaria excelsa (T)

Norfolk Island Pine 


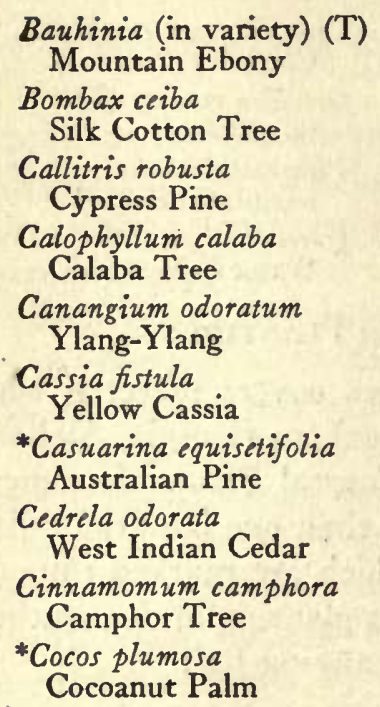

Cryptomeria japonica Japanese Cedar

Delonix regia $(\mathrm{T})$ Royal Poinciana

Ficus nitida Indian Laurel

Ficus species (T) Rubber and Fig Trees

Gordonia lasianthus Loblolly Bay

*Grevillea robusta (T) Silk Oak

Ilex specimens, especially Ilex opaca American Holly

Libocedrus decurrens Incense Cedar

Mangifera indica Mango

Sabal palmetto

Cabbage Palmetto

\section{*Washingtonia robusta} California Fan Palm

C. Vines. The first part of this group consists of those vines which are commonly known as scrambling vines and which must be provided with a definite support on which they can twine or to which tendrils can attach themselves in order to maintain their upright habit of growth. Most of the vines which are interesting in the north are of great value in Florida planting. There is also an extensive list of vines which will not grow in the northern climates, but which are valuable in Florida. Those which are marked thus $(t)$ are very interesting for Florida planting on account of their habit of producing flowers during the winter months. The second part of this group is composed of vines which can be used for covering bare wall surfaces and which will naturally attach themselves to walls of brick, stone, or concrete. These vines are of the evergreen type of foliage and are of value only for their foliage effect. ,

a. Lattices and wire fences:

Abrus precatorius Crab's Eye Vine

+ Allamanda hendersoni (T) Henderson's Allamanda

+ Allamanda williamsi (T)

Williams' Allamanda
Antigonon leptopus

Mountain Rose

Ampelopsis quinquefolia

Virginia Creeper

Aristolochia elegans

Dwarf Dutchman's Pipe 


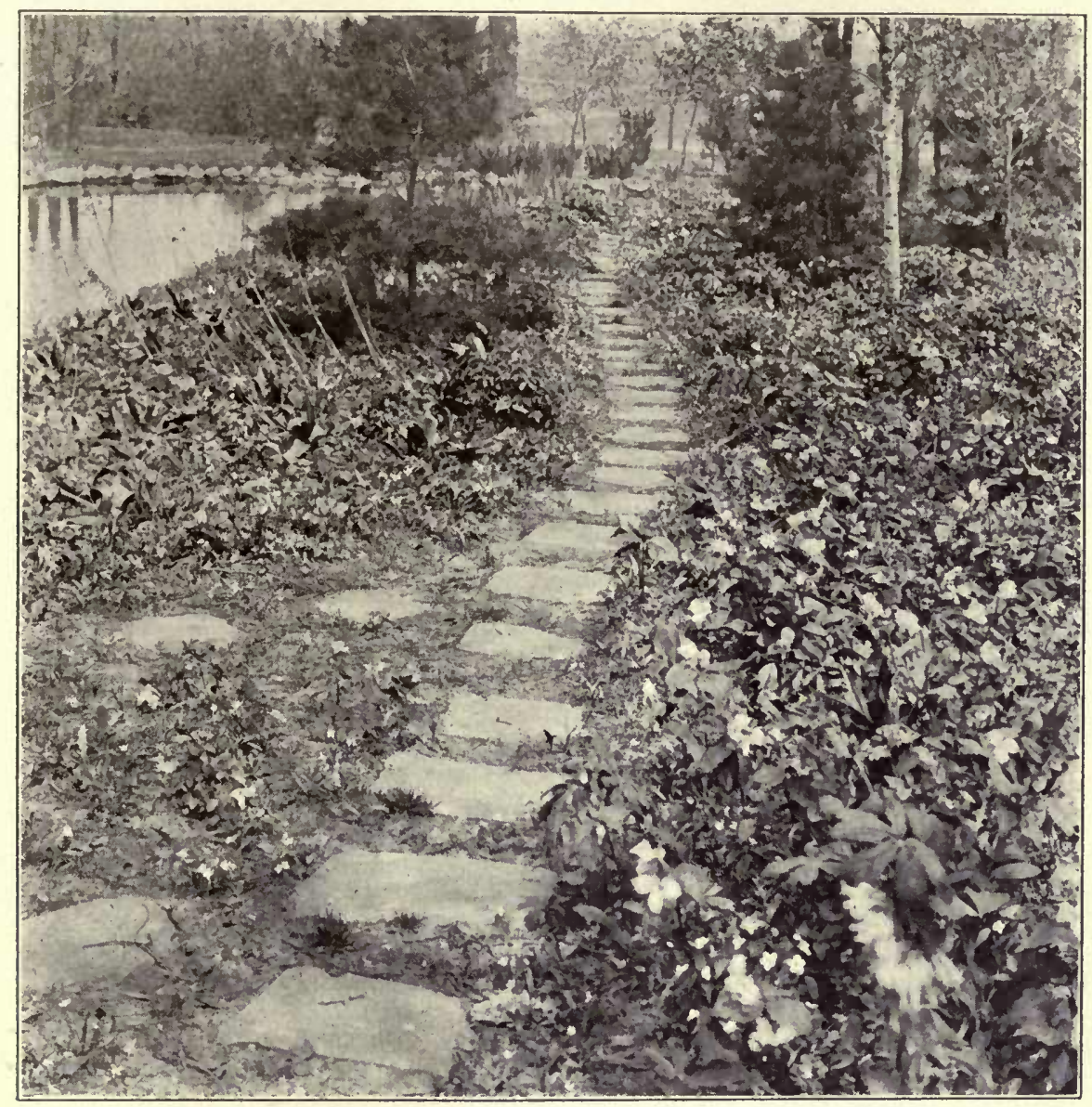

Plate XLVII. During the early spring no woodland wild garden is complete without its quota of trilliums, grape hyacinth, and hepatica which grow luxuriantly if happily surrounded by correct conditions of soil and shade. (See page 227 , group XXXI-C) 


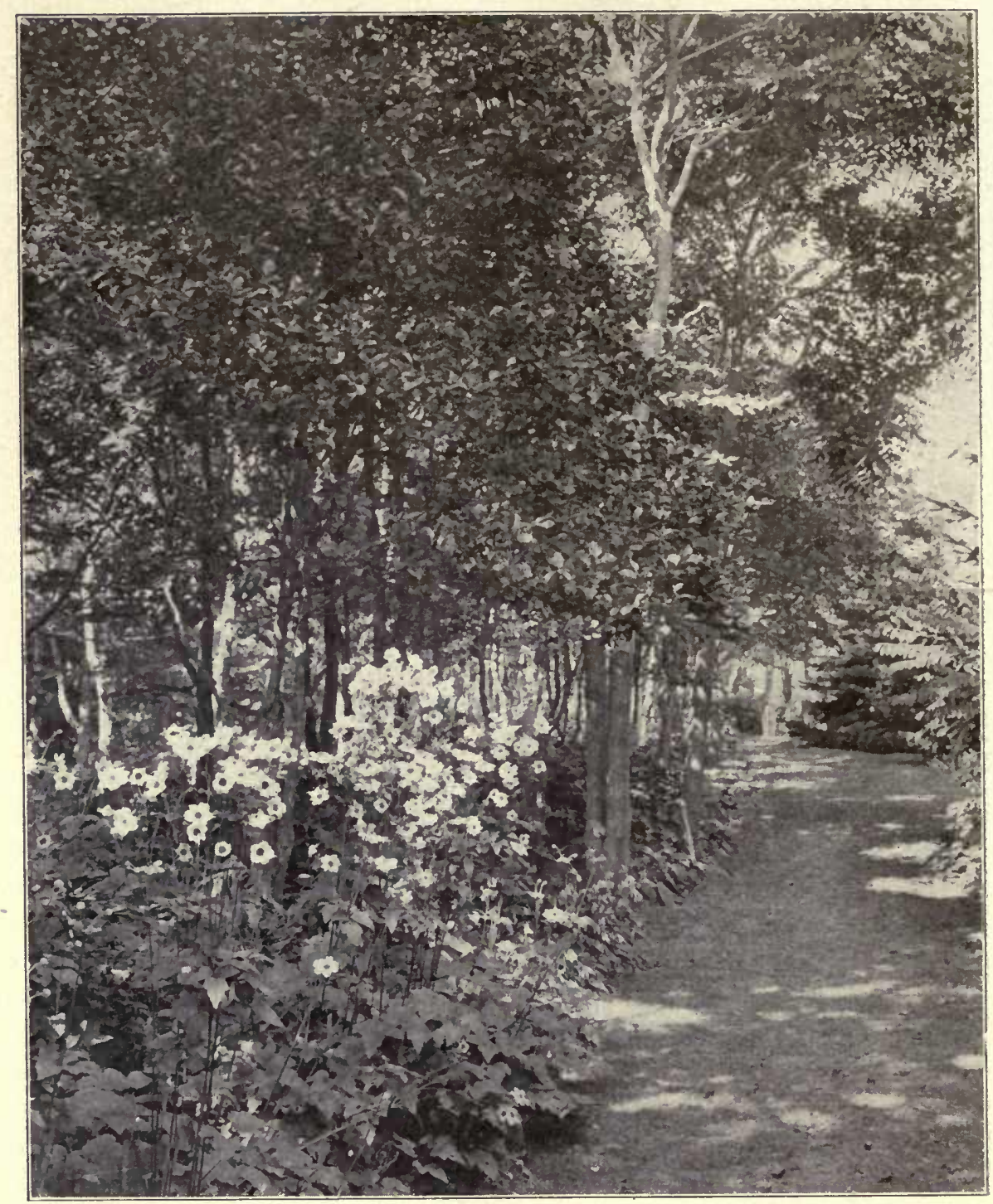

Plate XLVIII. Among those plants which become easily established in the wild garden, there is none the flower effect of which excels the Japanese windflower during the late summer. (See page 227, group XXXI-C) 
Beaumontia grandiflora

White-flowered Beaumontia

Bignonia chinensis

Chinese Trumpet Creeper

+Bougainvillea braziliensis

Paper Flower

+ Bougainvillea glabra sanderiana

Paper Flower

Cereus triangularis

Cereus Vine

Clematis paniculata Japanese Clematis

+Clerodendron thompsonae Scarlet Clerodendron

Cobaca scandens $(\mathrm{T})$

Cup and Saucer Vine

+Gelsemium sempervirens

Carolina Jasmine

Jasminum grandiflorum

Catalonian Jasmine

Lonicera japonica halliana (north) Japanese Honeysuckle

Lonicera sempervirens Coral Honeysuckle

$P$ assiflora incarnata

Purple Passion Flower
Petraea volubilis

Queen's Wreath

Pithecoctenium cynanchoides

Argentine Monkey's Comb

Porana paniculata

Snow Creeper

Pyrostegia venusta

Flame Flower

Rosa laevigata

Cherokee Rose

Rosa setigera (north only)

Prairie Rose

Rosa (climbing hybrids)

Rose

Smilax

Greenbrier

Solandra guttata

Chalice Vine

Solanum seaforthianum $(\mathrm{T})$

Tomatillo

Solanum wendlandi

Tomatillo

Thunbergia (in variety) (T)

Thunbergia

Trachelospermum jasminoides Confederate Jasmine

Vitis capensis

Evergreen Grape

b. Masonry walls:

Bignonia capreolata

Cross Flower

Bignonia radicans

Trumpet Vine

Bignonia speciosa South American Cross Vine

Evonymus radicans

Climbing Evonymus

Ficus repens

Creeping Fig

Ficus villosa

Large-leaved Creeping Fig

Hedera helix (north only)

English Ivy

Pyrostegia venusta

Flame Flower

D. Shrubs with Atrractive Fruit. The following is a group of shrubs which are of value in Florida plantations because of their fruiting characteristics, especially during the winter months. Quite different from similar shrubs in northern climates, these shrubs fruit much more abundantly and retain their fruit a greater length of time in this mild climate, than would be the case farther north. 
Ardisia revoluta

Turkey Fruit

Baccharis halimifolia

Groundsel Bush

Bixa orellana

Arnalto

Carissa acuminata (T)

Natal Plum

Chalcas paniculata

Orange Jasmine

Citrus deliciosa

Kid Glove Orange

Citrus grandis

Grape-fruit

Citrus japonica

Kumquat

Citrus sinensis

Orange

Clerodendron siphonanthus

Turk's Turban

Cotoneaster acuminata

Rose Box

Cotoneaster frigida

Rose Box

Cotoneaster pannosa

Silver-leaved Rose Box

Duranta repens

Golden Dewdrop
Eleagnus pungens

Silver Thorn

Eriobotrya japonica

Medlar

Eugenia jambos

Rose Apple

Eugenia uniflora

Surinam Cherry

Hamelia erecta

Scarlet Bush

Ilex cassine

Dahoon Holly

Ilex opaca

American Holly

Laurocerasus caroliniana Wild Orange

Malpighia coccigera

Dwarf Barbadoes Cherry

Mangifera indica

Mango

Musa

Banana

Punica granatum

Pomegranate

Rhodomyrtus tomentosus

Downy Myrtle

Tamarindus indica

Tamarind

Triphasia trifoliata

Bergamot Berry

E. Hedges. For hedge planting there is in Florida a wider range of material adapted to such use than is ordinarily found in northern types of material. The first group given includes those shrubs which make low, compact hedges together with those which develop into a larger and looser type of hedge. Those shrubs which are marked (+) are valuable for hedge planting because of their flowering and fruiting characteristics. The remainder are valuable mostly on account of the foliage effect. The second list of material, which is for northern Florida, could be greatly enlarged provided it should seem advisable to use material which is often used in hedges planted farther north and which shed their leaves during the winter months. The group includes plants which are practically evergreen or which have some value for their fruit or flowers. Practically all of these can be used with equal success in middle and southern Florida. 
a. Middle and southern Florida:

+Acalypha hispida (T)

Chenille Plant

Bambusa disticha

Bamboo

+Carissa bispinosa (T)

Natal Plum

Cinnamomum camphora

Camphor Tree

+Eugenia uniflora

Surinam Cherry

+ Gardenia florida

Cape Jasmine

Gordonia lasianthus

Loblolly Bay

+ Hibiscus rosa-sinensis

Chinese Hibiscus

Juniperus lucayana

Southern Red Cedar

Nerium oleander

Oleander

b. Northern Florida:

Abelia grandiflora

Hybrid Abelia

Berberis thunbergi

Thunberg's Japanese Barberry

Buxus sempervirens

Tree Box

Citrus trifoliata

Hardy Orange

Evonymus japonicus

Evergreen Evonymus

\author{
Phyllanthus nivosus \\ Snow Bush \\ Pittosporum tobira \\ Tobira Shrub \\ Pittosporum undulatum \\ Victorian Box \\ Prunus caroliniana \\ Carolina Laurel Cherry \\ Psidium cattleianum \\ Cattley Guava \\ Raphiolepis indica \\ Indian Hawthorn \\ Severinia buxifolia \\ Severino's Citrus \\ Tabernaemontana coronaria flore pleno \\ Rose Bay \\ Triphasia trifoliata \\ Bergamot Berry \\ Viburnum tinus \\ Laurestinus
}

Ligustrum amurense Amoor River Privet

Ligustrum nepalense variegata

Variegated Nepaul Privet

Nerium oleander

Oleander

Punica granatum

Pomegranate

Rosa rugosa

Japanese Rose

Thea sinensis

Tea Plant

F. Flowering Shrubs for Middle and Southern Florida. The following is a group of shrubs of more refined habit of growth which are adapted to middle and southern Florida. Those shrubs which are marked $(+)$ are in flower during the winter months and are especially valuable for the northern tourists who visit Florida then.

a. White flowers:

Abelia grandiflora

Hybrid Abelia

Aralia spinosa

Hercules Club
+Assonia natalensis

White Assonia

+ Aralea indica

Indian Azalea 
+ Bauhinia acuminata (T)

White Mountain Ebony

Chalcas paniculata (T)

Orange Jasmine

+Chionanthus virginica

White Fringe

Cotoneaster frigida

Rose Box

Cotoneaster pannosa

Silver-leaved Rose Box

Eleagnus pungens

Silver Thorn

Gardenia florida

Cape Jasmine

+ Hibiscus rosa-sinensis

Chinese Hibiscus

Hydrangea hortensis

Japanese Hydrangea

Ixora colei $(\mathrm{T})$

White Ixora

+Lagerstroemia indica

Crape Myrtle

+Laurocerasus caroliniana Wild Orange
Lawsonia inermis (T) Henna.

Ligustrum nepalense Nepaul Privet

+ Nerium oleander (single white) White Oleander

Osmanthus americanus

Florida Olive

Osmanthus fragrans

Sweet Olive

+ Pittosporum tobira

Tobira Shrub

+ Plumbago capensis alba

White Leadwort

+ Rosa (on multiflora stock)

Garden Roses

+ Tabernaemontana coronaria flore pleno

Rose Bay

Tetrapanax papyriferum

Rice Paper Plant

Thunbergia erecta alba

White Thunbergia

Viburnum odoratissimum

Fragrant Japanese Viburnum

\section{$+V i b u r n u m$ tinus}

Laurestinus

b. Pink flowers:

+Assonia punctata

Pink Assonia

+ Azalea indica

Indian Azalea

+ Bauhinia purpurea triandra

Pink-flowering Mountain Ebony

Camellia japonica

Japonica

+ Cestrum elegans

Red Coral Jasmine

Chaenomeles japonica

Japanese Quince

Cotoneaster acuminata

Rose Box

+ Hibiscus rosa-sinensis

Chinese Hibiscus

Hydrangea opuloides otaksa Hydrangea

Ixora rosea splendens ( $\mathrm{T}$ )

Rose-coloured Ixora

Lagerstroemia indica

Crape Myrtle

Nerium oleander Savort

Pink Oleander

Punicea granatum

Pomegranate

Rhodomyrtus tomentosus (T)

Downy Myrtle

+ Rosa (on multiflora stock)

Garden Roses

Tamarix caspica

Tamarisk

c. Yellow flowers:

Acacia farnesiana

Papinac

+ Allamanda nerifolia

Yellow Allamanda

\author{
Artobotrys odoratissimus \\ False Ylang-Ylang \\ + Bauhinia tomentosa (T) \\ Yellow Mountain Ebony
}




\section{PLANTS FOR FLORIDA}

+ Caesalpina pulcherrima flava

Barbadoes Flower Fence

+Cestrum aurantiacum (T)

Yellow Cestrum

Hamelia sphaerocarpa

Scarlet Bush

Ixora flore luteo (T)

Yellow Ixora

+ Jasminum nudiflorum

Naked-flowered Jasmine

+ Jasminum primulinum

New Chinese Jasmine
+Michelia fuscata Banana Shrub

Paritium tiliaceum

Yellow Ernajagua

Podachaenium eminens Mexican Shrub Daisy

+ Rosa (on multiflora stock) Garden Roses

+Stenolobium stans sambucifolia Yellow-flowering Elder

+ Tecoma stans

Yellow Elder

Thevetia nerlfolia

Trumpet Flower

\section{d. Red flowers:}

+Acalypha hispida (T)

Chenille Plant

+ Azalea indica

Indian Azalea

Caesalpina pulcherrima

Barbadoes Flower Fence

Callistemon lanceolatus

Bottle-brush

Calycanthus floridus

Strawberry Shrub

Euphorbia pulcherrima

Poinsettia

Hamelia erecta (T)

Scarlet Bush

e. Purple and blue flowers:

+ Allamanda purpurea

Purple Allamanda

Asystasia bella

Mackaya

+ Aralea indica

Indian Azalea

Bauhinia purpurea (T)

Purple Mountain Ebony

Callicarpa americana

Beauty Fruit
$+H i b i s c u s$ rosa-sinensis

Chinese Hibiscus

Ixora coccinea (T)

Scarlet Ixora

Lagerstroemia indica

Crape Myrtle

Lawsonia rubra

Red Flowering Henna

Malvaviscus arboreus Turk's Cap

Nerium oleander DeBrun

Double Crimson Oleander

+ Roses (on multiflora stock)

Garden Roses

+ Daedalacanthus nervosus (T)

Blue Justicia

Duranta repens

Golden Dewdrop

+Hibiscus rosa-sinensis

Chinese Hibiscus

Hydrangea opuloides otaksa

Hydrangea

Lagerestroemia indica

Crape Myrtle

Blue Leadwort

G. Ground-cover Plants. This list contains a group of vines which are interesting for ground cover in partially shaded situations. Most of these vines are evergreen in their habit of foliage and are of 
value for covering banks and other bare areas where it is desired to have another covering than grass.

Ferns (in moist shade) Ferns

Gelsemium sempervirens Carolina Jasmine

Hedera helix English Ivy

Lonicera japonica halliana Japanese Honeysuckle
Lonicera sempervirens Coral Honeysuckle

Zebrina pendula Wandering Jew

Zoysia matrella Manilla Grass

Zoysia tenuifolia Mascarene Grass

H. Shrubs for Shady Conditions. The following is a group of shrubs most of which are evergreen in their foliage characteristics, and all of which are adapted for plantations in partial shade, either under large trees or on the north side of buildings where full sunlight is not available.

Azalea indica

Indian Azalea

Camellia japonica

Japonica

Hamelia erecta

Scarlet Bush

Hamelia sphaerocarpa

Scarlet Bush
Ligustrum amurense Amoor River Privet

Ligustrum nepalense variegata Variegated Nepaul Privet

Osmanthus fragrans

Sweet Olive

Severinia buxifolia

Severino's Citrus

I. Herbaceous Plants. This group includes plants many of which are semi-woody in character and which fundamentally are known as herbaceous stock. There is still a great opportunity to introduce a number of the northern types of herbaceous stock into the garden plantations of Florida. This list is compiled as a partial list of those which to date have been found to be of real interest and value. Many other plants may be added to this list in safety, but because of the lack of record of experiments conducted with their growth in this climate they have not been included.

The climate of middle and southern Florida has been aptly described by one horticulturist as that of a great out-of-door greenhouse. The climate is such that many of the flowering annuals so familiar to the gardens of the north prove failures when grown in the Florida garden. Such plants as the annual larkspur, snapdragon, China aster, sweet William, and baby's breath, producing such an abundance of cut flowers when grown in the north, are grown with little success in Florida. 
Nasturtiums, annual phlox, gaillardia, zinnias, and marigolds produce quantities of flowers.

In the north such annuals are seeded in the latter part of April. Flowers are then produced early in July. In the Florida garden, if flowers are desired early in January, the nasturtium seeds are sown during the first week of September, alyssum seeds not later than November tenth, sweet peas in early September, and the other annuals, such as annual phlox, gaillardia, verbenas, annual carnation, and calendulas, are seeded not later than the first week in October. If flowers are wanted at an earlier date seeds should be sown proportionately earlier.

The winter months are better for the growth of flowers. Very few persons in Florida attempt to grow annuals during the hot and usually dry months of summer.

It seems at first, to the garden lover from the north, that any of the northern garden flowers should grow vigorously in the Florida climate. Many keen disappointments await these persons. Those who have tried growing many kinds in an effort to obtain garden flower effects and flowers for table use have finally accepted, as the reliable types, the few that are starred in the following group:

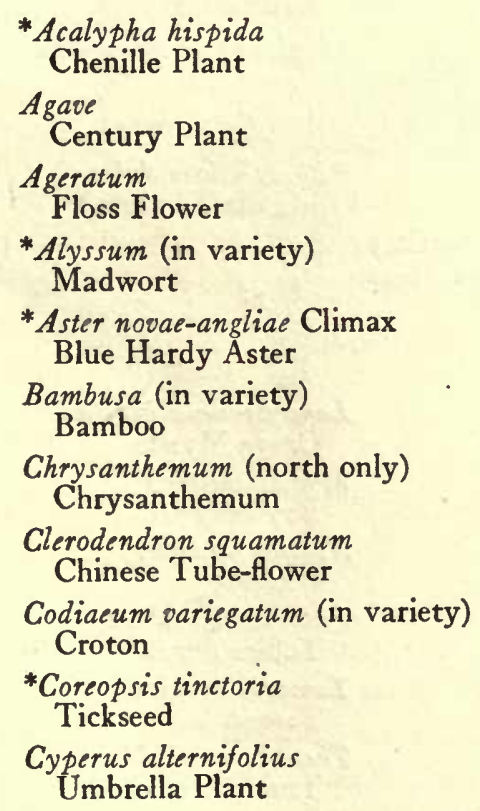

\author{
*Dianthus caryophyllus \\ Carnation \\ Funkia (north only) \\ Plantain Lily \\ * Gaillardia grandiflora \\ Blanket Flower \\ Gynerium (north only) \\ Pampas Grass \\ Gypsophila paniculata \\ Baby's Breath \\ Hemerocallis (north only) \\ Day Lily \\ Hippeastrum \\ Amaryllis \\ Iris hexagona \\ Florida Iris \\ Lantana (T) \\ Lantana \\ Lilium henryi \\ Yellow Lily \\ Limnocharis humboldti \\ Water Poppy
}


Nelumbo

American Lotus

Nuphar

Spatter-dock

Nymphaea

Water-lily

*Phlox drummondi

Drummond's Phlox

Russelia juncea

Fountain Plant
*Tropacolum majus

Nasturtium

*Verbena hybrida

Verbena

$V$ inca

Periwinkle

Viola

Violet

*Yucca filamentosa

Adam's Needle

*Zinnia elegans
Zinnia

J. Plants for Seashore Planting. Peculiar as it may seem, along the shores of the larger lakes, and along the seashore particularly, the group of plants which can be used is restricted to those plants which are particularly adapted to light, sandy soils and also to withstand the heavy storms, mostly in the nature of wind storms, to which such plants are often subjected.

a. Trees:

Casuarina equisetifolia Australian Pine

Coccoloba unifera Shore Grape

Eucalyptus citriodora Lemon Gum

Ficus aurea Wild Rubber

Gliricidia maculata Madre

\author{
Ilex opaca \\ American Holly \\ Juniperus barbadensis \\ Red Cedar \\ Liquidambar styraciflua \\ Sweet Gum \\ Palms (in variety) \\ Pithecolobium dulce \\ Manila Tamarind
}

b. Shrubs:

Acacia farnesiana Papinac

Caesalpina pulcherrima Barbadoes Flower Fence

Callistemon

Bottle-brush

Carissa acuminata

Natal Plum

Hibiscus rosa-sinensis Chinese Hibiscus

Ixora (in variety) Ixora
Lagerstroemia indica Crape Myrtle

Myrica cerifera Bayberry

Nerium oleander Oleander

Pittosporum tobira Tobira Shrub

Tamarix caspica Tamarisk

Theoetia nereifolia Trumpet Flower 


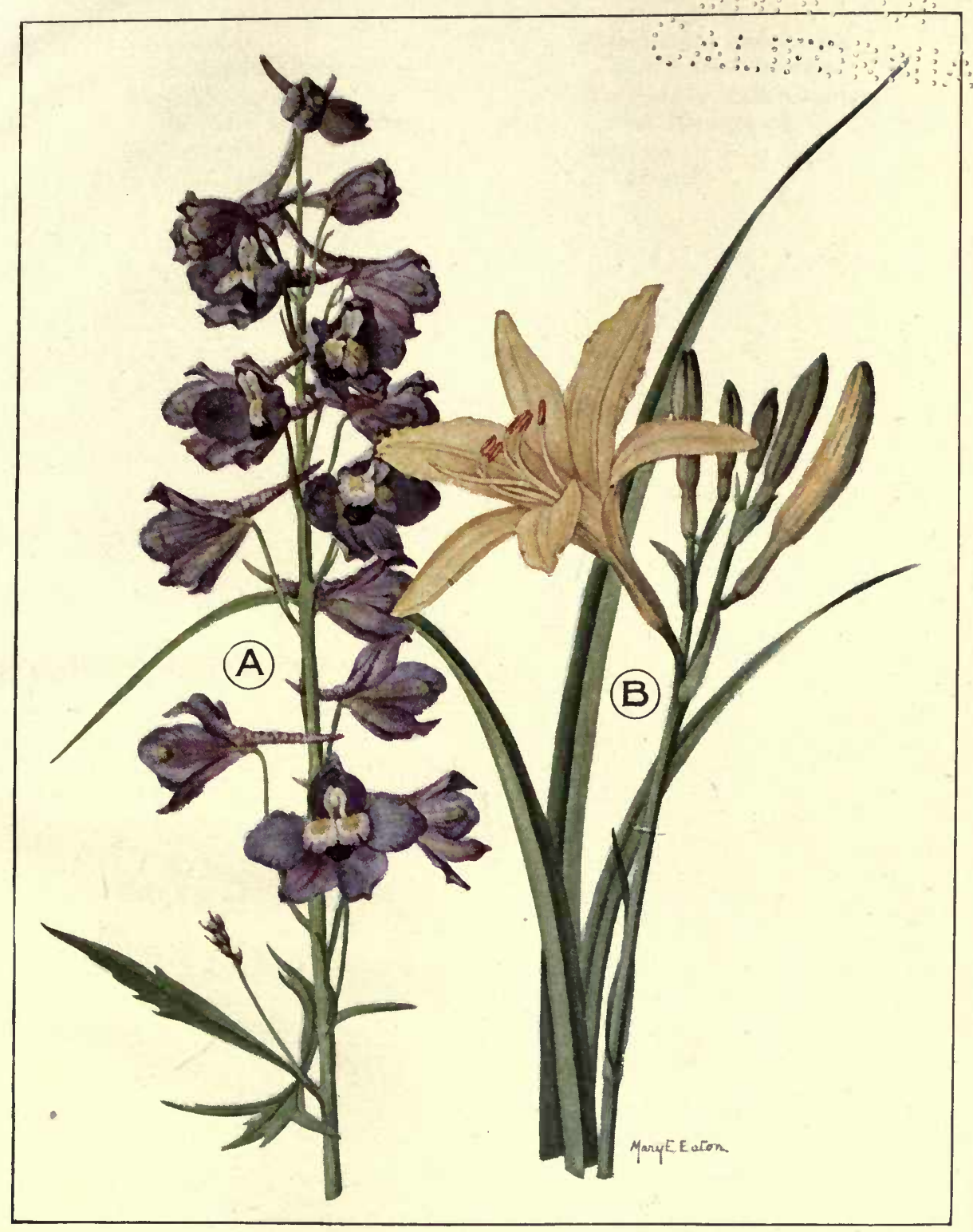

Plate XLIX. In the selection of perennials for the garden not only should the possibilities of interesting colour combinations in the flower effects be observed, but also the possibilities for interesting texture of foliage. (A) larkspur; (B) lemon lily (commonly called day lily). (See page 23I) 
यद्य

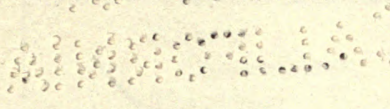




\section{PLANTS FOR FLORIDA}

c. Vines:

Allamanda

Allamanda Vine

Bignonia unguis-cati

Argentine Trumpet Vine

Bougainvillea

Paper Flower
Clerodendron thompsonae Scarlet Clerodendron

Cryptostegia madagascariensis

Pink Madagascar Cryptostegia

Solanum

* Tomatillo 


\section{CHAPTER XLIV \\ PLANTS FOR MINNESOTA}

THE lists given in this chapter cover the more common uses for which plants are selected. Perennial lists are not given because perennial plantings succeed according to the skill of the grower in adapting them to his location and giving them necessary winter protection. Constant care must be exercised to replace winter losses. The discussion in the main part of the foregoing text under the different lists and groups of plants applies equally well to most of the northern part of the United States, including Minnesota and adjoining territory.

Throughout this region spring planting is preferable to autumn, if it is done early enough, except of course for peonies and irises. In especially dry autumn weather autumn-planted stock is quite likely to prove a total loss. Ordinary shrubs and trees can be moved in the autumn under good conditions and this is also true of locally grown conifers moved in September; but other plants, and especially the perennials, should be moved only in the spring. Owing to the severity of the climate, especially in dry winters, sometimes without snow more than six inches deep, there is little tendency to encourage experimenting with half-hardy stock and most of the lists given are short.

These lists apply to an area within a two-hundred-mile radius of the Twin Cities in every direction. In eastern Wisconsin the Great Lakes would temper the climate, while northern Minnesota would be still more severe than at the Twin Cities, especially on sandy pine soils. Western Minnesota is quite similar, but a little more subject to drought and high winds. Central Iowa can grow a slightly larger list of plants because of a warmer climate and perhaps a little more rainfall.

In making a selection of plants from any of the other lists in this book for use in this region, first consult List XLIV-G to eliminate all types which have proved not hardy. The other lists may be consulted freely 
with this exception. All plants of questionable hardiness should be carefully protected.

\section{LIST OF PLANTS FOR MINNESOTA}

A. Hedges. Owing to the severe exposure to which a hedge may be subjected only small groups can be recommended as entirely "ironclad." No broad-leaved evergreens can be listed and only the most hardy sorts of conifers, among them being the Black Hills variety of the white spruce, given here as picea canadensis. Early spring-flowering shrubs like the golden bell and deutzia are not hardy and none of the beeches should be used for windbreaks or other types of hedges. Most of the other plants shown in Chapter XII can be planted safely.

\section{a. Barriers:}

Crataegus coccinea Scarlet-fruited Thorn

Hippophae rhamnoides Sea Buckthorn

Juniperus virginiana Red Cedar

Lonicera tatarica Tartarian Honeysuckle

Picea canadensis Black Hills Spruce

b. Windbreaks:

Acer tataricum Tartarian Maple

Picea canadensis Black Hills Spruce

$P$ inus nigra austriaca Austrian Pine
Picea excelsa

Norway Spruce

Rhamnus cathartica

Common Buckthorn

Ribes alpinum

Alpine Currant

Ribes oxycanthoides

Wild Gooseberry

Rosa rugosa

Japanese Rose

Pinus strobus

White Pine

Pinus sylvestris

Scotch Pine

Salix

Willow

B. Ground Cover. No evergreen ground-cover plants seem tó prove hardy in the region covered by this list, and so the plants given are confined to deciduous shrubs and vines. Perennials can be used in proportion to the winter protection provided for them.

a. Shrubs:

Artemisia sericea

Siberian Wormwood

Comptonia asplenifolia

Sweet Fern
Ribes aureum

Flowering Currant

Ribes oxycanthoides

Wild Gooseberry 


\title{
THE COMPLETE GARDEN
}

Rosa arkansana

Arkansas Rose

Rubus odoratus

Flowering Raspberry
Spiraea sorbifolia Sorb-leaved Spirea

Spiraea tomentosa Hardhack

Symphoricarpos oulgaris

Indian-currant

b. Vines:

Ampelopsis quinquefolia

Virginia Creeper

Celastrus scandens

American Bitter-sweet

\author{
Lycium halimifolium \\ Matrimony Vine \\ Menispermum canadense \\ Common Moonseed
}

C. Plants Valuable for Autumn Colouration of Leaves. Only plants which show good autumn colour, either at an early or medium season, prove valuable in this region since late colour is invariably destroyed by hard freezes.

a. Early:

Acer negundo

Box Elder

Acer rubrum

Red Maple

Acer saccharum

Sugar Maple

Betula lutea

Yellow Birch

b. Medium:

Ampelopsis quinquefolia

Virginia Creeper

Berberis thunbergi

Thunberg's Japanese Barberry

Fraxinus americana

White Ash

\author{
Celtis occidentalis \\ Nettle Tree \\ Populus eugenei \\ Carolina Poplar \\ Rhus typhina \\ Staghorn Sumac \\ Sassafras officinale \\ Common Sassafras
}

D. Heavy, Formal Effects. Either due to the prevalence of ice storms which break them down or to their inherent lack of hardiness, most of the plants which are elsewhere available for heavy, formal effects are not available in this region. This group is accordingly a small one.

Juniperus virginiana

Red Cedar

Juniperus virginiana glauca

Blue Virginia Cedar
Picea excelsa pyramidalis Pyramidal Norway Spruce

Populus alba pyramidalis Bolle's Poplar

Populus nigra italica

Lombardy Poplar 
E. Street Trees. The group of trees (a) given as entirely hardy is interesting for the following reasons: The American linden, here substituted for the European linden-which is of doubtful hardiness-is not ordinarily used elsewhere on account of dropping its leaves in late summer when used as a city street tree. The hackberry, while a native of the major part of the United States east of the Rocky Mountains, does not succeed well enough outside of the northwestern portion of its range to enable listing it elsewhere as a street tree. Its natural habitat is rich, moist soil. The white ash is a handsome ornamental tree native of the eastern United States and not nearly often enough used as a street tree.

a. Entirely hardy under all conditions:

Acer saccharum
Sugar Maple
Celtis occidentalis
Nettle Tree
Fraxinus americana
White Ash

\author{
Quercus coccinea \\ Scarlet Oak \\ Quercus rubra \\ Red Oak \\ Tilia americana \\ American Linden
}

Ulmus americana American Elm

b. Which should be selected with a thorough knowledge of the conditions under which they are to be used:
Acer saccharinum
Soft Maple
Acer platanoides
Norway Maple
Betula papyrifera
Paper Birch

\author{
Populus eugenei \\ Carolina Poplar \\ Pyrus ioensis \\ Western Crab \\ Sorbus americana \\ American Mountain Ash
}

F. Evergreens Most Used. The group of conifers most used in Minnesota is restricted to a few of the "ironclad" sorts. These are all native species and when used the following notes should be borne in mind. The hemlock is not naturally adapted to windswept places anywhere, and especially not in this region. Of the white fir only the Colorado form should be used, and while this plant will withstand considerable heat and drought it is intolerant of smoke and soot. The arborvitae suffers frequently from ice storms and should be protected from them. The Douglas spruce is one of the fastest if not the fastest 
growing conifer. It produces a soft foliage which requires that it be planted in groups for mutual protection against strong winds.

\author{
Abies concolor \\ White Fir \\ Juniperus (in variety) \\ Cedar \\ Picea alba \\ White Spruce \\ Picea canadensis \\ Black Hills Spruce \\ Picea excelsa \\ Norway Spruce \\ Picea pungens glauca \\ Koster's Blue Spruce
}

\author{
Pinus nigra austriaca \\ Austrian Pine \\ Pinus resinosa \\ Red Pine \\ Pinus strobus \\ White Pine \\ Pinus sylvestris \\ Scotch Pine \\ Pseudotsuga douglasi \\ Douglas Fir \\ Thuja occidentalis (in variety) \\ American Arborvitae
}

Tsuga canadensis

Canadian Hemlock

G. Not Hardy in Minnesota. The following group contains plants which are not hardy when used in the Minnesota section. These plants are generally in one of three groups: the early spring-flowering types, the broad-leaved and tender evergreens, and those which ripen their wood late in the fall. As a result of years of experience in landscape planting, these types have not proved hardy, although many of them are extremely hardy when used throughout the northwestern and central portions of the United States.

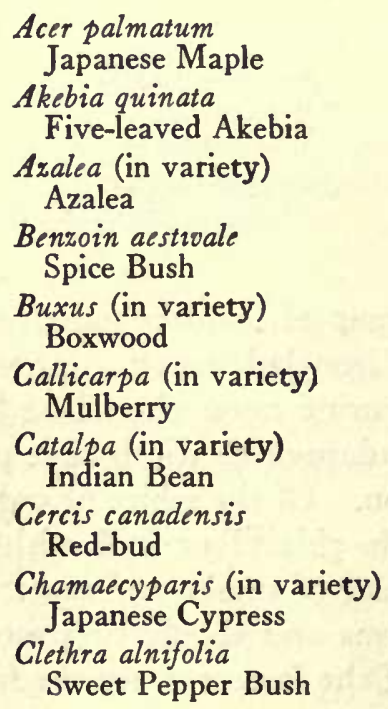

\section{Cornus florida} Flowering Dogwood

Cornus kousa Japanese Dogwood

Cornus mas Cornelian Cherry

Deutzia (in variety) Deutzia

Exochorda (in variety) Pearl Bush

Fagus sylvatica European Beech

Forsythia (in variety) Golden Bell

Halesia tetraptera Silver Bell Tree

Hibiscus (in variety) Rose of Sharon

Ilex (except verticillata) Holly 


\section{PLANTS FOR MINNESOTA}

Jasminum (in variety) Jasmine

Kalmia (in variety)

Laurel

Kerria (in variety)

Globe-flower

Ligustrum (most varieties) Privet

Lonicera japonica halliana Japanese Honeysuckle
Magnolia (in variety)

Magnolia

Mahonia (in variety)

Oregon Grape

Myrica (in variety)

$$
\text { Bayberry }
$$

Prunus (most varieties)

Flowering Almonds and Cherries

Rhododendron (in variety)

Rhododendron

Taxus (in variety)

Yew 


\section{CHAPTER XLV}

\section{PLANTS FOR SOUTH ATLANTIC STATES}

THE territory for which this list has been prepared comprises that lying between the Atlantic Ocean on the east and the Appalachian foothills or Piedmont on the west, and extending from Washington, D. C., to Savannah, Atlanta, and southern Alabama. This territory includes the eastern half of Virginia and of North Carolina, nearly all of South Carolina and of Georgia and all of Alabama lying south and east of Birmingham (See Plate No. II).

Owing to the influence of the mountains on the west and north, and of the Atlantic Ocean with its Gulf Stream on the east, this territory is especially favourable for the growing of plants which would not succeed at the same latitude farther inland. This territory has a high annual average humidity and a rainfall of 50 to 60 inches each year. It has a low narrow range in temperature-about 30 degreesand a long growing season, extending from one hundred and eighty days in the north to two hundred days in the south. All of these factors contribute to the successful growth of many somewhat tender plants and in some cases also force the growth of northern plants to a great size.

The most that can be done under present conditions with a list of this kind and until such time as further information is compiled, is to tabulate some of the more important types of plants which have been used throughout this southern territory. It must be remembered that with the much longer growing season and the higher average of rainfall plants will grow much more vigorously and much larger than the same plants will grow throughout the northern zones. Plants which may be adapted to a certain use in the zones farther north may be entirely inappropriate for a similar use in this southern territory. For this reason intimate knowledge should be obtained concerning the growing characteristics of any types that are to be introduced into the southern conditions.

Many of the plants adapted for use in the northern zones will readily produce an abnormal growth in these southern zones as represented by 

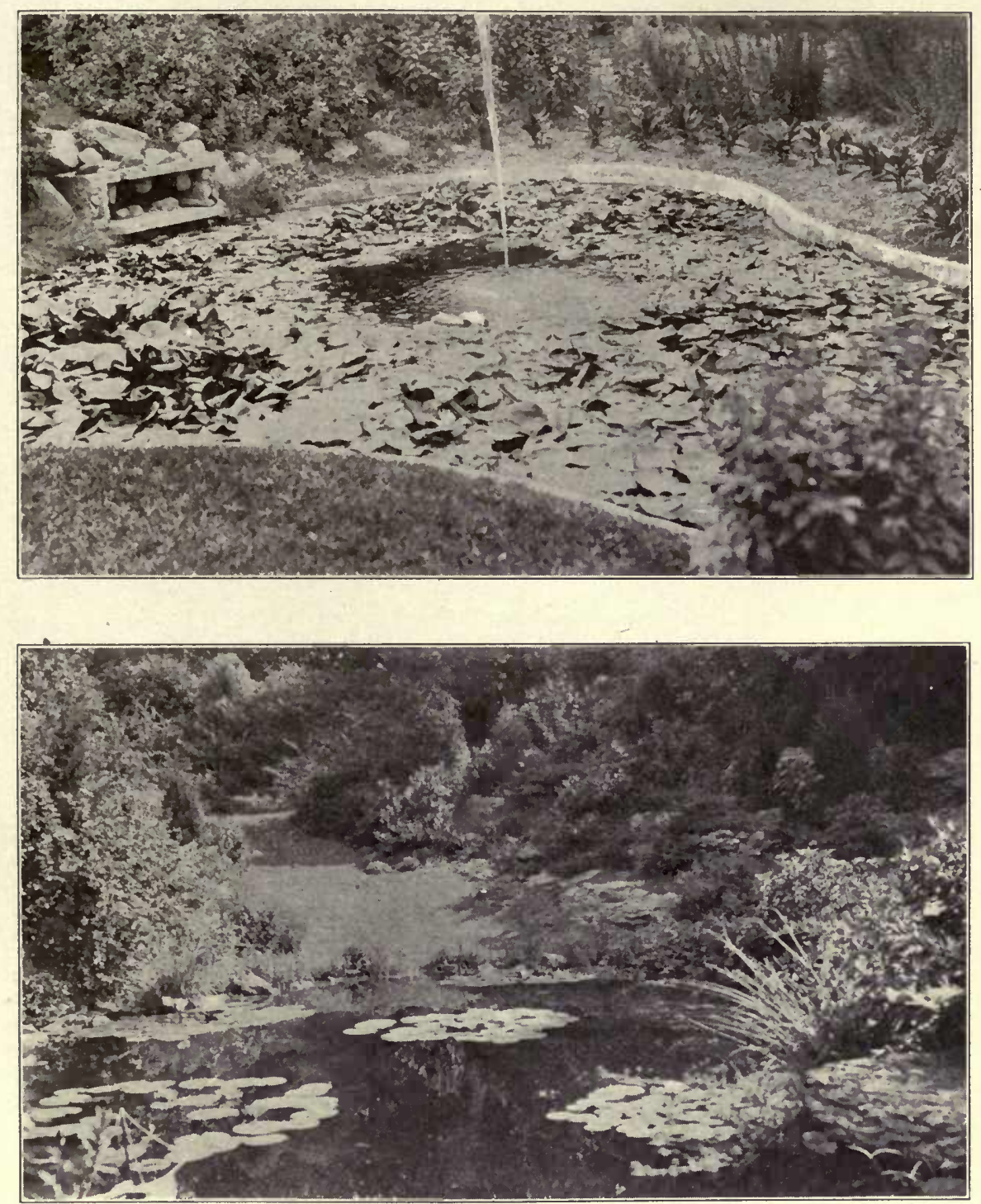

Plate L. A few water lilies may enhance a picture such as the above, but a proper restraint on their use and control is always desirable. (See page 234 , group XXXI-L-a) 


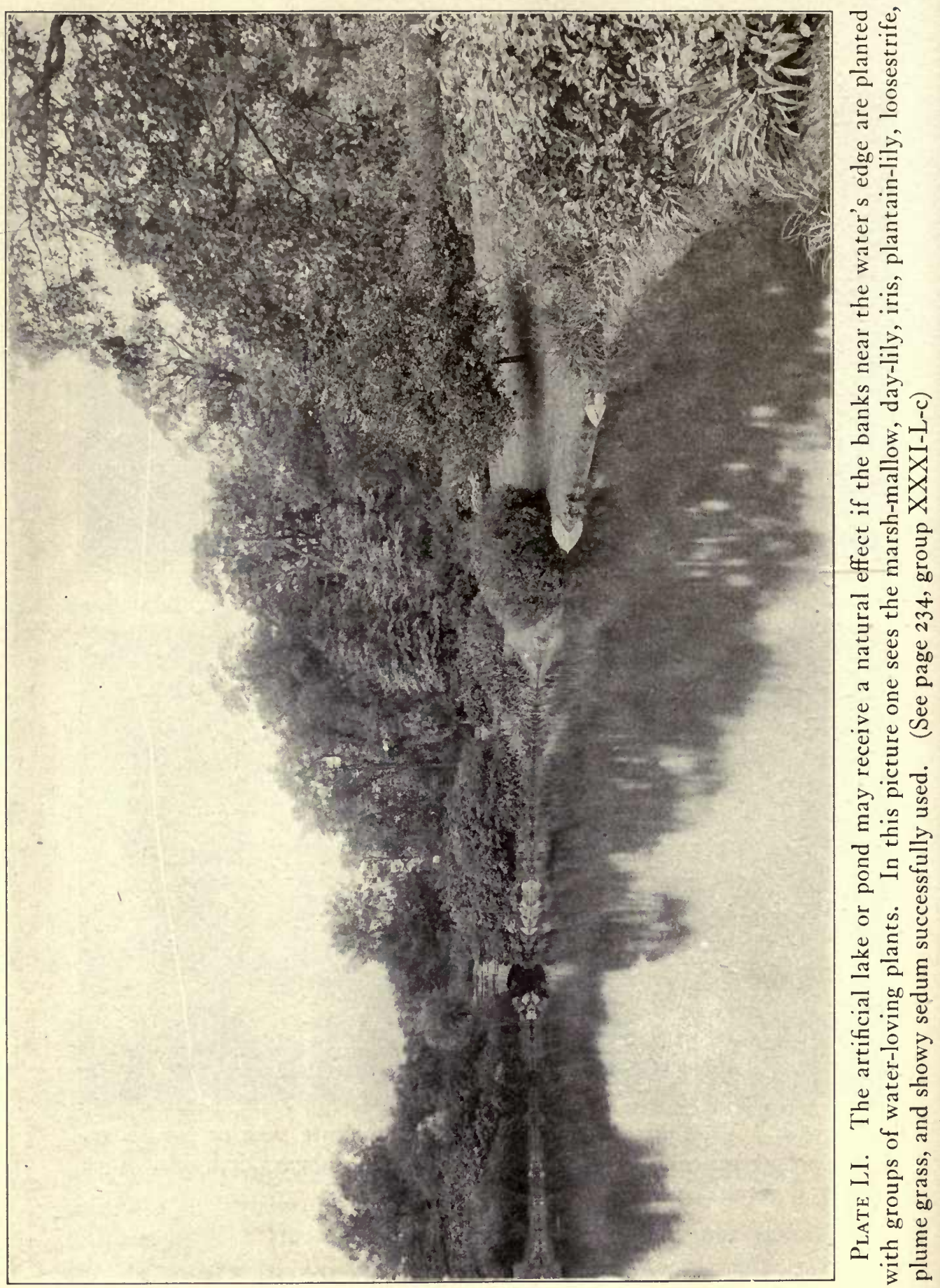


the south Atlantic states. On the other hand, very few of the plants which are indigenous to this south Atlantic area will prove hardy when used in the territory north of Washington. For instance, Hall's climbing honeysuckle is one of the plants common to both the northern zone and the southern zone, but in the southern territory this plant produces a much more interesting development of foliage and of flowers while in the northern zones the same plant suffers severely from winterkilling of the small and more tender portions of its growth. There are a few of our desirable northern types, such as lilacs, which adjust themselves with extreme difficulty to the changed climatic conditions. On the other hand, the hydrangea is grown with remarkable success in the south.

\section{LIST OF PLANTS FOR SOUTH ATLANTIC STATES}

A. Ground Cover. This group of plants for ground cover is more restricted than the group including plants available for use farther north. This is due to the fact that many herbaceous perennials do not succeed in the long, hot summers of the south.

a. Moist places:

Asarum arifolium Mottled Snakeroot

Asarum virginicum

Virginia Snakeroot

Dalibarda repens Barren Strawberry

Evonymus radicans

Climbing Evonymus

Hedera helix

English Ivy

Helonias bullata

Swamp Pink

b. Dry places:

\footnotetext{
Ampelopsis quinquefolia Virginia Creeper

Ampelopsis tricuspidata veitchi Boston Ivy

Ceratiola ericoides Southern Heather

Clematis paniculata. Japanese Clematis
}

\author{
Houstonia serpyllifolia \\ Creeping Bluet \\ Lysimachia nummularia \\ Moneywort \\ Phlox subulata \\ Moss Pink \\ Sedum nevi \\ Nevius' Stonecrop \\ $V$ inca minor \\ Periwinkle \\ Viola cornuta \\ Tufted Pansy
}

Coronilla cappadocica Mediterranean Crown Vetch

Coronilla emerus Scorpion Senna

Coronilla varia European Crown Vetch

Duchesnea indica Yellow Strawberry 
Iris cristata

Crested Iris

Lonicera browni

Brown's Honeysuckle

Lonicera heckrotti

Purple-flowering Honeysuckle

Lonicera japonica halliana

Japanese Honeysuckle

Opuntia oulgaris

Barberry Fig
Saxifraga oirginiensis

Early-blooming Saxifrage

Shortia galacifolia

Shortia

Vinca major

Trailing Vinca

Yucca filamentosa

Adam's Needle

Yucca flaccida

Drooping-leaved Adam's Needle

B. Hedges. The following groups include mostly plants which are distinctive in this region or are not available for use farther north. This is especially true of the evergreen list.

a. Holding leaves throughout winter:

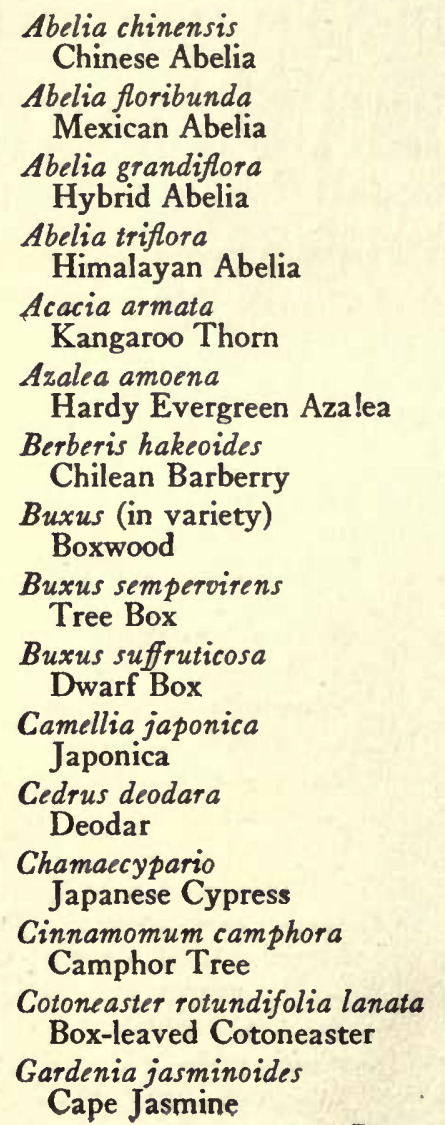

Ilex aquifolium English Holly

Ilex crenata Japanese Holly

Ilex opaca American Holly

Juniperus oirginiana Red Cedar

Libocedrus decurrens Incense Cedar

Ligustrum amurense Amoor River Privet

Ligustrum ibota Japanese Privet

Ligustrum japonicum Evergreen Privet

Ligustrum lucidum Shining-leaved Privet

Ligustrum nepalense Nepaul Privet

Ligustrum quihoui Late-blooming Privet

Ligustrum sinense Chinese Privet

Osmanthus aquifolium Fragrant Olive

Osmanthus fragrans Sweet Olive

Pittosporum tobira Tobira Shrub

Prunus caroliniana Carolina Laurel Cherry 


\section{PLANTS FOR SOUTH ATLANTIC STATES}

\section{Pyracantha coccinea lalandi}

Evergreen Thorn

Thea sinensis

Tea Plant
Thuja orientalis Oriental Arborvitae

Viburnum tinus Laurestinus

Yucca filamentosa

Adam's Needie

b. Not holding leaves throughout winter:

Deutzia purpurascens Purple-flowered Deutzia

Hibiscus syriacus Rose of Sharon

Ligustrum ovalifolium California Privet

Lonicera fragrantissima Early Fragrant Honeysuckle Prunus americana Wild Plum

C. Trees for Street Planting. This group comprises only those street trees which are most likely to produce the best results under normal conditions.

\author{
Aesculus indica \\ Himalayan Horse-chestnut \\ Acsculus octandra \\ Sweet Buckeye \\ Aesculus wilsoni \\ Wilson's Chinese Horse-chestnut \\ Ailanthus glandulosa \\ Tree of Heaven \\ Celtis mississippiensis \\ Southern Hackberry \\ Celtis occidentalis \\ Nettle Tree \\ Celtis sinensis \\ Chinese Nettle Tree \\ Fraxinus biltmoreana \\ Biltmore Ash \\ Fraxinus caroliniana \\ Water Ash \\ Ginkgo biloba \\ Maidenhair Tree \\ Gleditsia delavayi \\ Long-spined Honey Locust
}

Gleditsia ja'ponica

Japanese Honey Locust

Gleditsia sinensis Chinese Honey Locust

Liquidambar styraciflua Sweet Gum

Magnolia acuminata Cucumber Tree

Magnolia grandiflora Magnolia

Magnolia tripetala Umbrella Tree

Nyssa sylvatica Tupelo

Quercus coccinea Scarlet Oak

Quercus imbricaria Shingle Oak

Quercus laurifolia Laurel Oak

Ouercus nigra Water Oak 
Quercus palustris

Pin Oak

Quercus phellos

Willow Oak
Quercus rubra

Red Oak

Quercus virginiana

Live Oak

\section{Ulmus alata \\ Winged Elm}

D. Evergreens Most Used. The climate of the south Atlantic states (Virginia, North Carolina, South Carolina, Georgia, and Alabama) provides an opportunity to use the broad-leaved evergreens in great profusion as well as certain sorts of conifers which are not desirable farther north. All the broad-leaved evergreens mentioned elsewhere in this book are useful in this region, as well as the coniferous plants named below. All of these plants, however, with the exception of the junipers, require at least partial shade (See Chapter XXXIII). The firs, spruces, hemlocks, American arborvitae, and Douglas fir should never be used in this region at elevations below $I, 200$ feet above sea level.

Cedrus atlantica
Mt. Atlas Cedar
Cedrus atlantica glauca
Mt. Atlas Silver Cedar
Cedrus deodara
Deodar
Cedrus libani
Cedar of Lebanon
Cephalotaxus drupacea
Large-fruited Yew
Cephalotaxus fortunei
Fortune's Yew
Chamaecyparis ericoides
Compact White Cedar
Chamaecyparis lawsoniana
Lawson's Cypress
Chamaecyparis pisifera
Pea-fruited Cypress

Thuja orientalis

Chamacyparis pisifera filifera

Thread-branched Cypress

Chamacyparis pisifera plumosa

Plume-like Cypress

Cryptomeria japonica (in variety)

Japanese Cedar

Cupressus sempervirens fastigiata Italian Cypress

Juniperus virginiana glauca Blue Virginia Cedar

Libocedrus decurrens Incense Cedar

Pinus excelsa Bhotan Pine

Taxus baccata (in variety)

English Yew

Taxus cuspidata (in variety) Japanese Yew

Oriental Arborvitae

E. Formal Effects. The plants in this group are mostly trees of a compact, upright habit of growth, and are useful as "exclamation points" and for marking axes in formal gardens.

Catalpa bungei Round-leaved Catalpa

Cedrus deodara

Deodar
Cephalotaxus harringtoniana fastigiata Columnar Stem-fruited Yew

Gercidiphyllum japonicum Kadsura Tree 


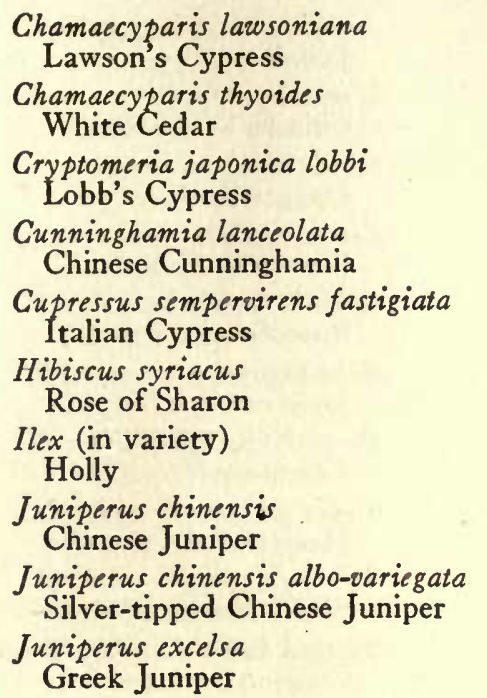

Juniperus virginiana glauca Blue Virginia Cedar

Juniperus virginiana schotti Schott's Red Cedar

Laurocerasus caroliniana Wild Orange

Libocedrus decurrens Incense Cedar

Ligustrum (in variety) Privet

Quercus robur pedunculata English Oak

Sciadopitys verticillata

Umbrella Pine

Taxodium distichum

Bald Cypress

Taxus (in variety) Yew

Thuja orientalis pyramidalis Pyramidal Oriental Arborvitae

F. Border Planting. As most plants, when used in the south Atlantic states, double their northern height, the problem is to find low-growers. The following groups have thus been confined to lowgrowing plants (below five feet) and medium-growing plants (from five to ten feet).

a. Low-growing deciduous shrubs:

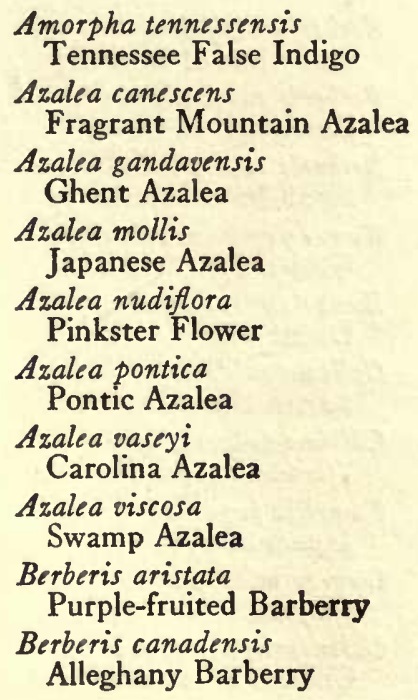

\section{Berberis heteropoda Fragrant Barberry \\ Berberis sieboldi Siebold's Barberry \\ Berberis wilsonae Wilson's Barberry \\ Callicarpa americana Beauty Fruit \\ Callicarpa purpurea Beauty Fruit \\ Caryopteris incana Blue Spirea \\ Ceanothus hybridus} Hybrid New Jersey Tea

Comptonia asplenifolia Sweet Fern

Coronilla emerus Scorpion Senna

Corylopsis pauciflora Japanese Flowering Hazel 
Daphne genkwa

Lilac-flowered Daphne

Daphne mezereum

Caucasian Daphne

Deutzia gracilis

Slender Deutzia

Elsholtzia cristata

Dwarf Elsholtzia

Fothergilla gardeni

Dwarf Alder

Fothergilla paroiflora

Southern Dwarf Alder

Hydrangea opuloides hortensia

Garden Hydrangea

Hypericum aureum

Large-flowered St. John's Wort

Hypericum calycinum

Aaron's Beard

Hypericum glomeratum

Mountain St. John's Wort

Hypericum moserianum

Gold-flower

Hypericum nudiflorum

Naked-flowered St. John's Wort

Hypericum prolificum

Shrubby St. John's Wort
Jasminum (in variety)

Jasmine

Meratia praecox

Chinese Sweet Shrub

Pieris mariana

Stagger Bush

Prunus triloba

Flowering Plum

Robinia hispida

Rose Acacia

Rosa rugosa

Japanese Rose

Rosmarinus officinalis

Rosemary

Salvia greggi

Mexican Salvia

Salvia greggi alba

White Mexican Salvia

Spiraea bumalda anthony waterer

Crimson Spirea

Stephanandra flexuosa

Stephanandra

Symphoricarpos racemosus Snowberry

Symphoricarpos oulgaris

Indian Currant

\section{Zenobia speciosa}

Zenobia

b. Low-growing evergreen shrubs:

Abelia floribunda

Mexican Abelia

Ardisia crenulata rubra

Ardisia

Aucuba japonica

Japanese Laurel

Aucuba japonica latimaculata

Spotted Japanese Laurel

Azalea amoena

Hardy Evergreen Azalea

Azalea indica

Indian Azalea

Azalea indica kaempferi

Orange-flowered Azalea

Azalea obtusa

Hardy Indian Azalea

Berberis buxifolia

Box-leaved Barberry

Berberis darwini

Darwin's Barberry
Berberis ilicifolia

Holly-leaved Barberry

Berberis sargentiana Evergreen Barberry

Berberis stenophylla Small-leaved Barberry

Buxus japonica aurea Golden Japanese Box

Buxus suffruticosa

Dwarf Box

Calluna vulgaris Scotch Heather

Calluna oulgaris alba White-flowered Heather

Camellia japonica Japonica

Cleyera ochnacea Cleyera

Cotoneaster dammeri Chinese Prostrate Cotoneaster 
Cotoneaster horizontalis

Prostrate Cotoneaster

Cotoneaster microphylla

Small-leaved Cotoneaster

Cotoneaster microphylla gracilis

Dwarf Cotoneaster

Cotoneaster rotundifolia

Round-leaved Cotoneaster

Cotoneaster rotundifolia lanata

Box-leaved Cotoneaster

Cotoneaster thymifolia

Thyme-leaved Cotoneaster

Daphne cneorum

Garland Flower

Elacagnus macrophylla

Broad-leaved Oleaster.

Gardenia florida

1 Cape Jasmine

Ilex glabra

Inkberry
Leiophyllum buxifolium Sand Myrtle

Leucothoë catesbaei Catesby's Andromeda

Mahonia aquifolium Oregon Grape

Mahonia repens Creeping Mahonia

Pieris floribunda Mt. Fetterbush

Pieris japonica Japanese Fetterbush

Rhododendron myrtifolium Myrtle-leaved Rhododendron

Rhododendron punctatum Early-flowering Rhododendron

Yucca filamentosa Adam's Needle

Yucca glauca Early-flowering Adam's Needle

Yucca gloriosa

Late-flowering Adam's Needle

c. Medium-growing deciduous shrubs:

Aronia melanocarpa

Black Chokeberry

Baccharis halimifolia

Groundsel Bush

Benroin aestivale

Spice Bush

Buddleia (in variety)

Summer Lilac

Calycanthus floridus

Strawberry Shrub

Calycanthus occidentalis

Western Sweet-scented Shrub

Cassia corymbosa Argentina Senna

Chaenomeles sinensis Chinese Flowering Quince

Cistus laurifolius Laurel-leaved Rock Rose

Clethra acuminata Mt. Pepper Bush

Clethra tomentosa Woolly-leaved White Alder

Cornus paucinervis Square-twigged Dogwood

Corylus maxima purpurea Purple-leaved Hazel
Cotoneaster acutifolia Pointed-leaved Cotoneaster

Cotoneaster multiflora Spanish Cotoneaster

Cotoneaster racemiflora Cotoneaster

Cytisus praecox

Hybrid Broom

Cytisus scoparius Scotch Broom

Deutzia lemoinei

Lemoine's Deutzia

Deutzia rosea

Dwarf Pink Deutzia

Deutzia scabra

Single White Deutzia

Dirca palustris

Leather-wood

Elaeagnus longipes

Japanese Oleaster

Elaeagnus parviflora

Small-leaved Silver Thorn

Elaeagnus umbellata

Japanese Oleaster

Forsythia suspensa

Drooping Golden Bell 


\section{THE COMPLETE GARDEN}

Genista tinctoria

Dyer's Greenweed

Halimodendron halodena'ron

Salt Tree

Hydrangea arborescens grandiflora

Large-flowered Wild Hydrangea

Hydrangea quercifolia

Oak-leaved Hydrangea

Itea virginica

Virginian Willow

Kerria japonica

Globe-flower

Lespedeza bicolor

Shrubby Bush Clover

Lespedeza sieboldi

Siebold's Desmodium

Lonicera standishi

- Standish's Bush Honeysuckle

Myrica carolinensis

Bayberry
Myrica cerifera

Bayberry

Myrica gale

Bayberry

Myricaria germanica

German Tamarisk

Neoiusia alabamensis Snow Wreath

Prunus triloba

Flowering Plum

Spiraea prunifolia

Bridal Wreath

Spiraea vanhouttei

Van Houtte's Bridal Wreath

Styrax americana

American Storax

Styrax japonica

Japanese Storax

Styrax obassia

Broad-leaved Storax

\section{d. Medium-growing evergreen shrubs:}

Abelia floribunda

Mexican Abelia

Abelia grandiflora

Hybrid Abelia

Berberis hakeoides

Chilean Barberry

Berberis neuberti latifolia

Holly-leaved Barberry

Buxus semperoirens handworthi

Handworth's Tree Box

Cotoneaster simonsi

Himalayan Rose Box

Elacagnus pungens

Silver Thorn

Elacagnus pungens variegata

Variegated Silver Thorn

Gardenia jasminoides

Cape Jasmine

Gardenia jasminoides fortuniana

Fortune's Cape Jasmine

Gardenia jasminoides veitchi

Veitch's Cape Jasmine

Laurus nobilis

Bay Tree

Ligustrum coriaceum Round-leaved Privet

Mahonia aquifolium

Oregon Grape
Mahonia fortunei

Chinese Mahonia

Mahonia japonica

Japanese Mahonia

Mahonia pinnata Southwestern Mahonia

Michelia fuscata

Banana Shrub

Myrtus communis

True Myrtle

Nandina domestica

Japanese Nandina

Pittosporum tobira

Tobira Shrub

Prunus laurocerasus schipkaensis

Hardy English Laurel

Raphiolepis indica

Indian Hawthorn

Rhododendron arbutifolium

Dwarf Rhododendron

Rhododendron catawbiense hybridum

Hybrid Rhododendron

Rhododendron ponticum

Dwarf Rhododendron

Skimmia japonica

Japanese Skimmia

Viburnum suspensum

Pink Snowball 
G. Fruit Valuable for Its Colour Effects. The following plants bear fruit which makes them useful for ornamental planting. The group comprises mainly those species which are better adapted to southern conditions.

Arbutus unedo
Strawberry Tree
Ardisia crenulata
Scallop-leaved Ardisia
Aucuba japonica
Japanese Laurel
Callicarpa americana
Beauty Fruit
Celastrus (in variety)
Bitter-sweet
Cleyera japonica
Himalayan Cleyera
Coriaria japonica
Japanese Coriaria
Cornus florida
Flowering Dogwood
Cotoneaster (in variety)
Rose Box
Cotoneaster francheti
Franchet's Rose Box
Cotoneaster frigida
Rose Box
Cotoneaster horizontalis
Prostrate Cotoneaster
Cotoneaster microphylla
Small-leaved Cotoneaster
Cotoneaster simonsi
Himalayan Rose Box
Crataegus collina
Round-fruited Thorn

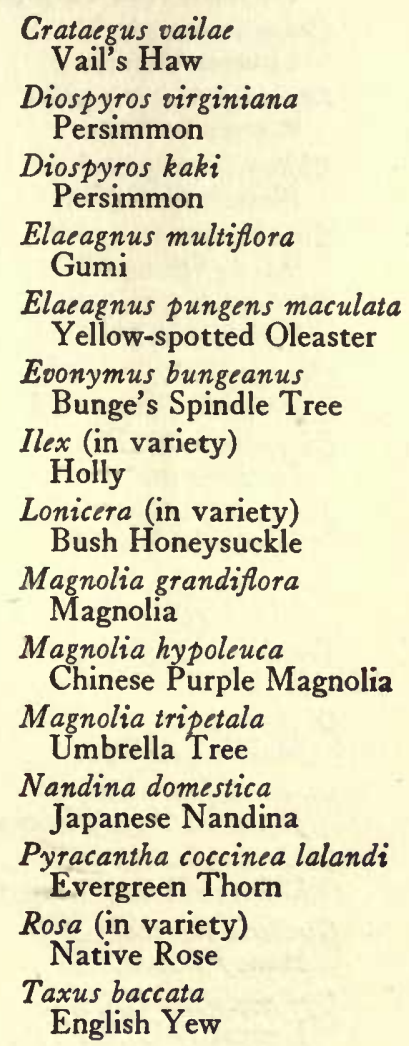

H. Specimen Trees and Shrubs. The following groups comprise only plants which are most successful when used singly or in small groups.

a. Trees

\author{
Albizzia julibrissin \\ Mimosa \\ Aleurites fordi \\ China Wood-oil Tree \\ Aphananthe aspera \\ Chinese Hackberry
}

\author{
Aralia spinosa \\ Hercules Club \\ Broussonetia papyrifera \\ Paper Mulberry \\ Carya aquatica \\ Water Pecan
}


Carya myristicaeformis Nutmeg Hickory

Carya pecan Pecan

Catalpa bungei Round-leaved Catalpa

Cedrela sinensis Chinese Cedrela

Cephalotaxus fortunei Fortune's Yew

Chilopsis saligna Flowering Willow

Citrus trifoliata Hardy Orange

Cladrastris lutea Yellow-wood

Cornus florida Flowering Dogwood

Diosporos virginiana Persimmon

Fagus americana American Beech

Fraxinus americana acuminata Silver-leaved White Ash

Fraxinus pennsylvanica Red Ash

Ginkgo biloba Maidenhair Tree

Gleditsia japonica Japanese Honey Locust

Gleditsia sinensis Chinese Honey Locust

Gleditsia triacanthos Honey Locust

Gymnocladus dioica Kentucky Coffee Tree

Halesia carolina Silver Bell

Hovenia dulcis Japanese Raisin Tree

Juglans cinerea Butternut

Juglans sieboldiana Japanese Walnut

Koelreuteria paniculata Varnish Tree

Liquidambar stryaciflua Sweet Gum

Magnolia (in variety) Magnolia
Magnolia acuminata Cucumber Tree

Magnolia denudata Yulan Magnolia

Magnolia grandiflora Magnolia

Magnolia macrophylla Great-leaved Magnolia

Magnolia soulangeana Soulange's Magnolia

Melia azedarach umbraculiformis Umbrella Tree

Nyssa aquatica Cotton Gum

Nyssa sylvatica Tupelo

Oxydendrun arboreum Sourwood

Parkinsonia aculeata Jerusalem Thorn

Paulownia tomentosa Empress Tree

Photinia arbutifolia Christmas Berry

Photinia serrulata Evergreen Photinia

Populus alba pyramidalis Bolle's Poplar

Populus deltoides Southern Cottonwood

Populus deltoides monilifera Northern Cottonwood

Prunus cerasifera pissardi Purple Plum

Pterocarya fraxinifolia False Walnut

Pyrus coronaria Wild Crab

Quercus acuta Korean Oak

Quercus falcata Spanish Oak

Quercus laurifolia

Laurel Oak

Quercus muhlenbergi Yellow Chestnut Oak

Quercus nigra

Water Oak

Quercus pagodaefolia Swamp Spanish Oak 


\section{PLANTS FOR SOUTH ATLANTIC STATES}

Sapium pebiferum Chinese Tallow Tree

Sophora japonica Japanese Pagoda Tree
Sterculia platanifolia Japanese Varnish Tree

Taxodiumy distichum Bald Copress

Ulmus montana pendula

Camperdown Weeping Elm

b. Shrubs:
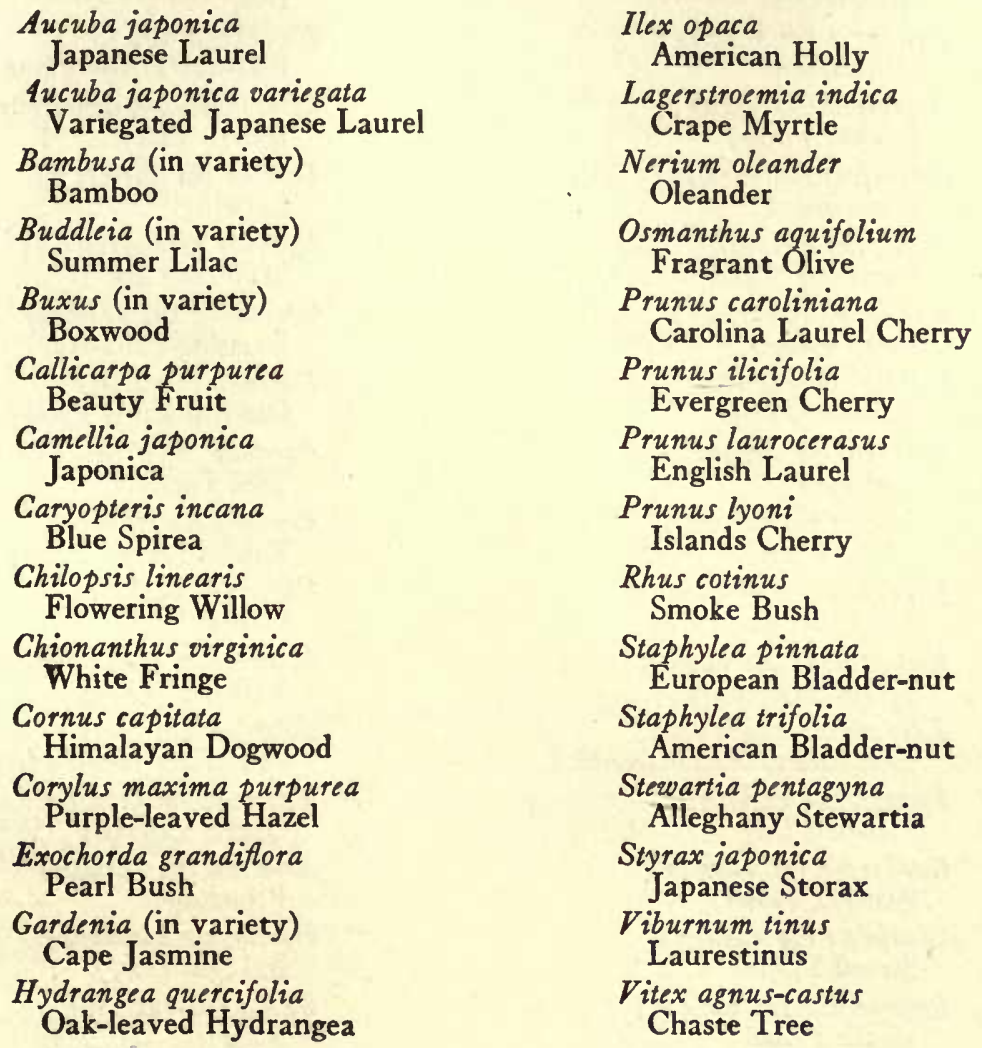

I. Perennials for Gardens and Cut Flowers. The following group of perennials includes several plants, such as the gladiolus, which are not hardy in the open ground in winter in the north. Most of the plants are the same sorts which are used elsewhere, but which have been selected after experience has shown their adaptability to the conditions of this territory.
Aconitum (in variety)
Monkshood
Adonis vernalis
Pheasant's Eye
Alstroemeria chilensis Chilean Lily
Alyssum (in variety)
Golden Tuft


Anchusa (in variety)

Alkanet

Anemone coronaria

Poppy-flowered Anemone

Anthemis tinctoria kelwayi

Hardy Marguerite

Antirrhinum majus

Snapdragon

Aquilegia (in variety)

Columbine

Argemone (in variety)

Prickly Poppy

Artemisia (in variety)

Wormwood

Asclepias tuberosa

Butterfly Weed

Baptisia (in variety)

False Indigo

Dahlia (in variety)

Garden Dahlia

Delphinium (in variety)

Larkspur

Echinops (in variety)

Globe Thistle

Eryngium amethystinum

Amethyst Sea Holly

Eupatorium (in variety)

White Snakeroot

Filipendula hexapetala

Herbaceous Meadow-sweet

Funkia (in variety)

Plantain Lily

Gaillardia (in variety)

Blanket Flower

Gladiolus (in variety)

Sword Flower

Gypsophila (in variety)

Chalk Plant

Helenium (in variety)

Sneezeweed

Helianthemum (in variety)

Rock Rose

Helianthus (in variety)

Hardy Perennial Sun-flower
Hesperis matronalis Sweet Rocket

Heuchera sanguinea Coral-bells

Incarvillea delevayi Hardy Gloxinea

Iris (in variety)

Iris

Kniphofia uvaria Red-hot Poker Plant

Lithospermum canescens Indian Paint

Lobelia (in variety) Lobelia

Lychnis coronaria Mullein Pink

Oenothera (in variety)

Evening Primrose

Paconia officinalis Old-fashioned Peony

Paeonia suffruticosa Tree Peony

Paeonia tenuifolia Fennel-leaved Peony

Phlox (in variety) Garden Phlox

Platycodon grandiflorum Balloon Flower

Polemonium caeruleum American Jacob's Ladder

Polemonium reptans

Greek Valerian

Primula (in variety)

Primrose

Pyrethrum coccineum Painted Daisy

Salvia (in variety) Sage

Thalictrum (in variety)

Meadow-rue

Veronica (in variety) Speedwell

$\boldsymbol{V}$ iola (in variety)

Violet

J. Perennials for Naturalizing in Wild Gardens. The plants in this group are common sorts which after trial have proven adaptable and useful for naturalizing in this territory. This group could be considerably enlarged; but the species named will fill most of the requirements of ordinary planting schemes. 


$\begin{array}{cc}\text { Actaea (in variety) } & \text { Fragaria (in variety) } \\ \text { Baneberry } & \text { Wild Strawberry } \\ \text { Adiantum pedatum } & \text { Frittilaria meleagris } \\ \text { Maidenhair Fern } & \text { Guinea-hen Flower } \\ \text { Allium moly } & \text { Galanthus nivalis } \\ \text { Lily Leek } & \text { Common Snowdrop } \\ \text { Althaea officinalis } & \text { Galax aphylla } \\ \text { Marsh Mallow } & \text { Galax } \\ \text { Amorpha (in variety) } & \text { Habenaria ciliaris } \\ \text { False Indigo } & \text { Yellow-fringed Orchis } \\ \text { Arabis (in variety) } & \text { Liatris pycnostachya } \\ \text { Rock Cress } & \text { Blazing Star } \\ \text { Armeria (in variety) } & \text { Lilium (in variety) } \\ \text { Sea Thrift } & \text { Lily } \\ \text { Belamcanda chinensis } & \text { Mertensia virginica } \\ \text { Blackberry Lily } & \text { Bluebell } \\ \text { Centranthus ruber } & \text { Monarda (in variety) } \\ \text { Red Valerian } & \text { Bergamot } \\ \text { Cimicifuga racemosa } & \text { Narcissus (in variety) } \\ \text { Snakeroot } & \text { Daffodil and Narcissus } \\ \text { Dalibarda repens } & \text { Saxifraga (in variety) } \\ \text { Barren Strawberry } & \text { Stone-breaker } \\ \text { Dentaria diphylla } & \text { Sedum (in variety) } \\ \text { Two-leaved Toothwort } & \text { Stonecrop } \\ \text { Erythronium americanum } & \text { Shortia galacifolia } \\ \text { Adder's tongue } & \text { Shortia } \\ & \end{array}$

K. Plants Which Are Commonly and Freely Used in the South but Are Not Hardy Farther North. This group comprises trees and shrubs which are valuable and may be used in the south with safety, but which are not hardy in the north.

a. Trees:

\author{
Albizzia julibrissin \\ Mimosa \\ Aleurites fordi \\ China Wood-oil Tree \\ Cedrus atlantica \\ Mt. Atlas Cedar \\ Cedrus deodara \\ Deodar \\ Cedrus libani \\ Cedar of Lebanon \\ Libocedrus decurrens \\ Incense Cedar \\ Magnolia grandiflora \\ Magnolia
}

Melia azedarach, umbraculiformis Umbrella Tree

Quercus acuta

$$
\text { Korean Oak }
$$

Quercus laurifolia

Laurel Oak

Quercus nigra

Water Oak

Quercus phellos

Willow Oak

Sophora japonica

Japanese Pagoda Tree

Sterculia platanifolia

Japanese Varnish Tree 
b. Shrubs:

Arbutus unedo
Strawberry Tree
Ardisia crenulata
Scallop-leaved Ardisia
Aucuba japonica
Japanese Laurel
Berberis hakeoides
Chilean Barberry
Cassia corymbosa
Argentine Senna
Chilopsis linearis
Flowering Willow
Cleyera japonica
Himalayan Cleyera
Gardenia florida
Cape Jasmine
Jasminum primulinum
Jasmine
Lagerstroemia indica
Crape Myrtle

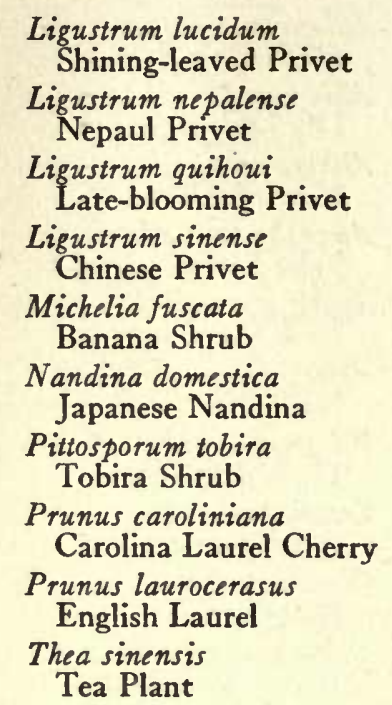

Viburnum tinus Laurestinus

L. Vines for the South. There is an extensive group of vines which can be used throughout the far south. Many of the vines so common to the north are extremely valuable because of their added growth during the longer growing season and their luxuriant foliage effects.

\author{
Actinidia chinensis \\ Chinese Silver Vine \\ Antigonon leptopus \\ Mountain Rose \\ Berchemia racemosa \\ Supple-Jack \\ Berchemia scandens \\ Supple-Jack \\ Bignonia capreolata \\ Cross Flower \\ Bignonia chinensis \\ Chinese Trumpet Creeper \\ Bignonia hybrida \\ Hybrid Trumpet Creeper \\ Bignonia radicans \\ Trumpet Vine \\ Celastrus angulatus \\ Chinese Bitter-sweet
}

Clematis apiifolia

Parsley-leaved Clematis

Clematis crispa

Purple Clematis

Clematis flammula

Sweet Clematis

Clematis texensis

Texas Clematis

Clematis viorna

Leather-flower

Clematis virginiana

Wild Clematis

Ficus pumila

Climbing Fig

Gelsemium sempervirens

Carolina Yellow Jasmine

Gelsemium sempervirens flore pleno Double Yellow Jasmine 


\section{PLANTS FOR SOUTH ATLANTIC STATES}

Hedera canariensis

Algerian Ivy

Hedera helix

English Ivy

Humulus lupulus

Hop Vine

Hydrangea petiolaris

Climbing Hydrangea

Jasminum officinale Jasmine

Jasminum primulinum Jasmine

Menispermum canadense Common Moonseed

Parthenocissus henryana Henry's Ivy
Passiflora caerulea Passion-flower

Periploca graeca Silk Vine

Polygonum baldschuanicum Knotweed

Pueraria hirsuta Kudzu Vine

Pyrostegia venusta Flame Flower

Smilax lanceolata Florida Smilax

Solanum jasminoides grandiflorum: Jerusalem Cherry Vine

Trachelospermum jasminoides Confederate Jasmine 


\section{CHAPTER XLVI}

\section{PLANTS FOR USE ON THE OREGON AND WASHING- TON COASTAL PLAIN}

THE planting districts in the northwest are very sharply defined. They include (I) the West Slope; that is, between the coast and the mountains, or west of the Cascade Range, and (2) eastern and central Oregon and eastern Washington; that is, all of the district sometimes spoken of as the Inland Empire where conditions show very marked changes. The following lists of plants apply only to ( $\mathrm{I}$ ), this being all of the territory west of the Cascade Range exclusive of the mountain slopes and known as the Oregon and Washington Coastal Plain. No effort has been made to compile lists for (2) known as the Inland Empire. There the rainfall is very much lighter, more snow falls in the winter, and much hotter days prevail in the summer, although the nights are always cool.

There is also another separate district spoken of as southern Oregon. The elevation here is from one thousand to eighteen hundred feet, with conditions much drier than through the Willamette Valley and all through western Washington. The factor in southern Oregon which appears to control plant growth is water, and if one has plenty of that coupled with a reasonable amount of good soil, normal growth can be developed.

Even in western Washington and Oregon the days are fairly warm and the nights in most cases are cool. This condition makes itself felt very much in the growth of annual vines, because they do not like the cool nights.

This entire western country appears to be the natural home for coniferous evergreens and for most of the broad-leaved evergreens. They do wonderfully well all through the northwest, west of the mountains. Portland has become known as the Rose City. It has found one particular thing, however, that is not proving a success. The camellia has been largely planted and is generally proving more or less disappointing. The mountain laurel should probably be placed in the 


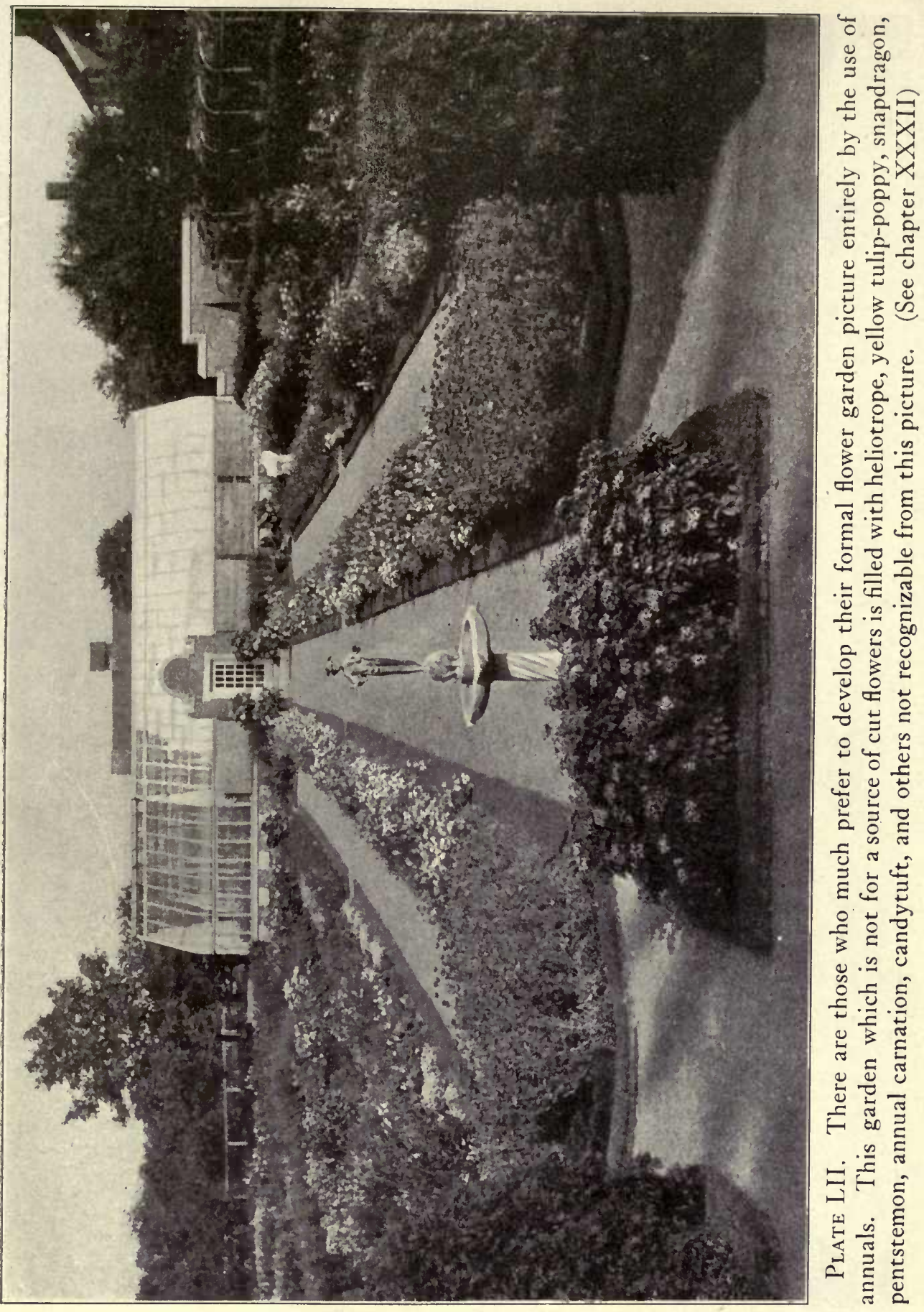




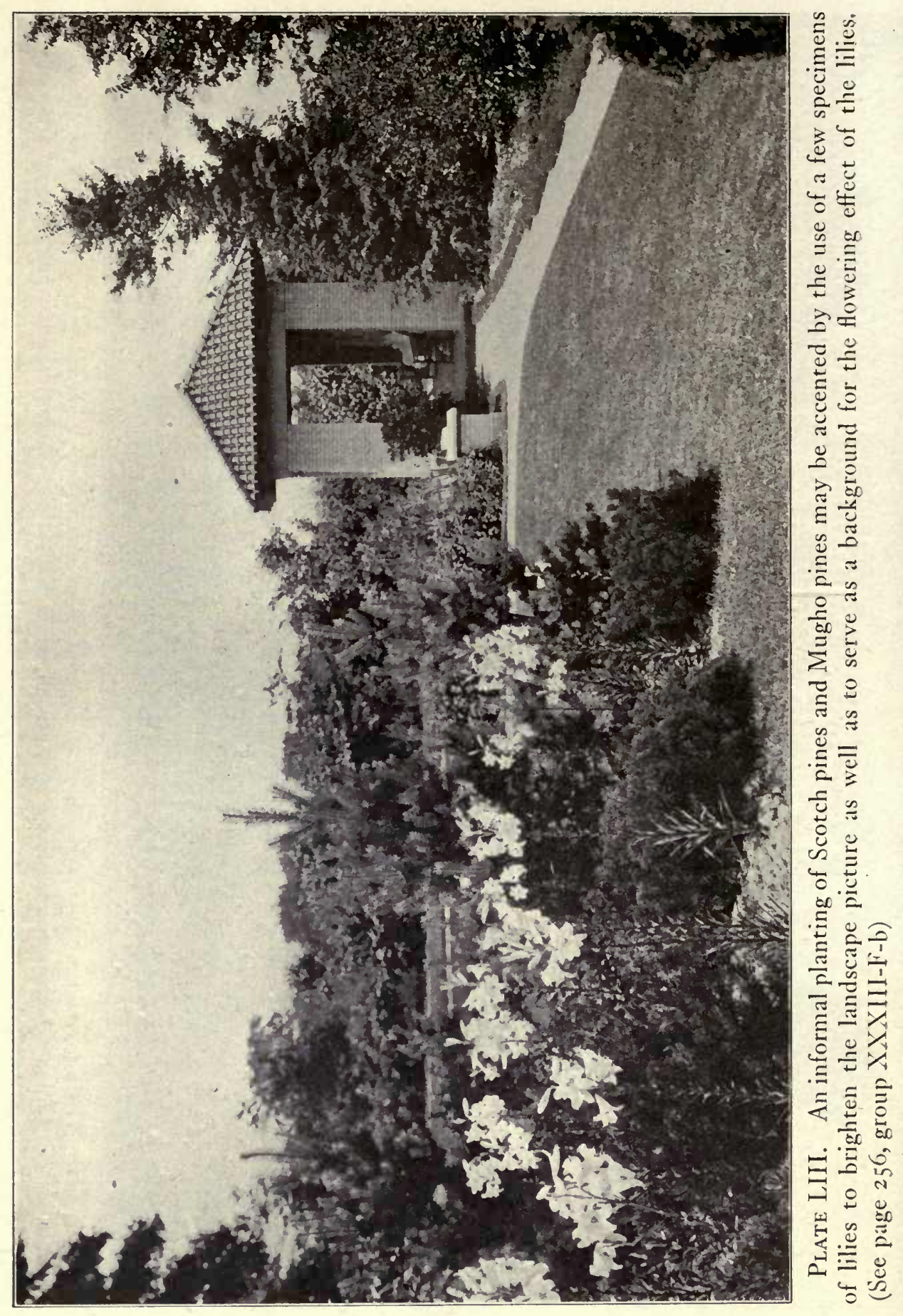




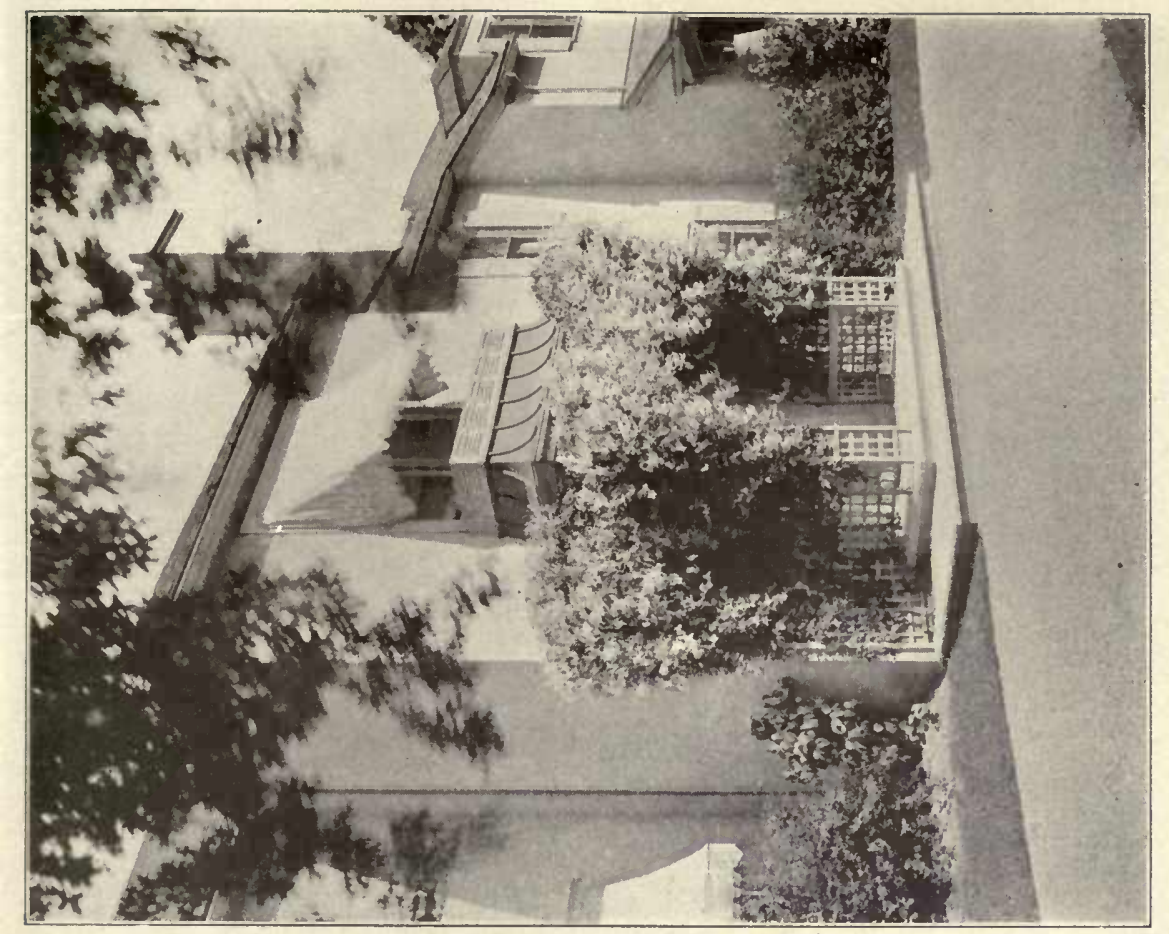

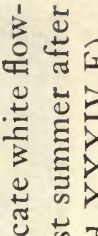

岂

$\div 1$

㟧

$\propto$ 层

ก 气

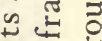

$\mp 80$

를

की

运突

$\stackrel{\infty}{=} 58$

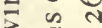

3.

की

$\frac{1}{1}$ 过

르응

䓠岕

แ ส

$\circ \Xi$

है

$\mp 0$

पै त

过

른

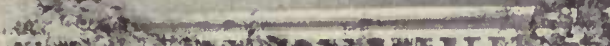

可

范

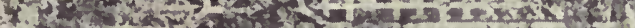

E

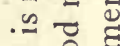

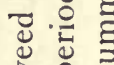

है क

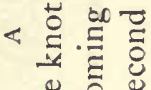

¿

$\rightarrow \frac{1}{10}$

$>$ ¿

늘 을

约

\&

a

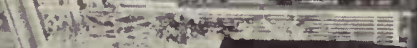
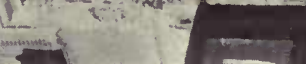


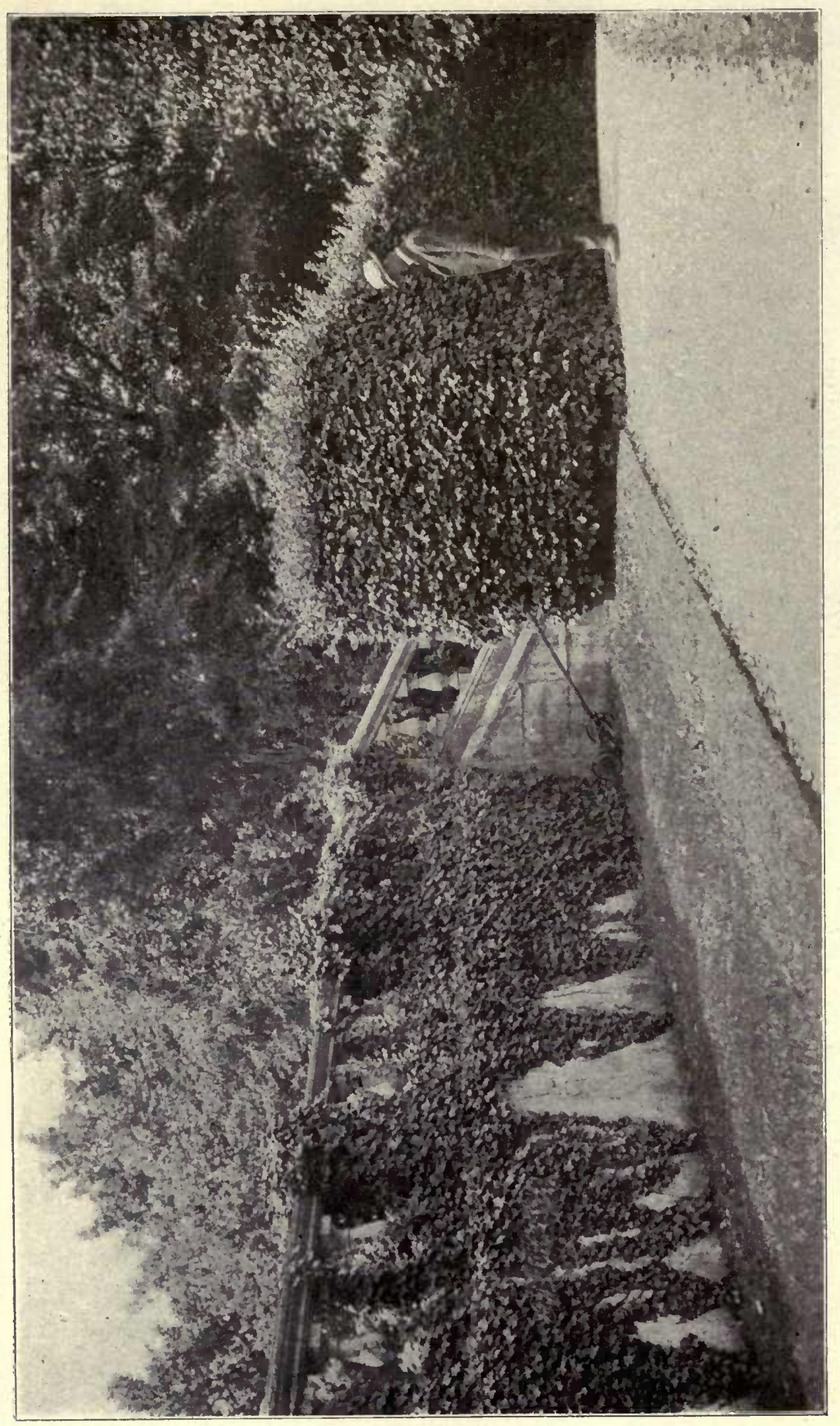

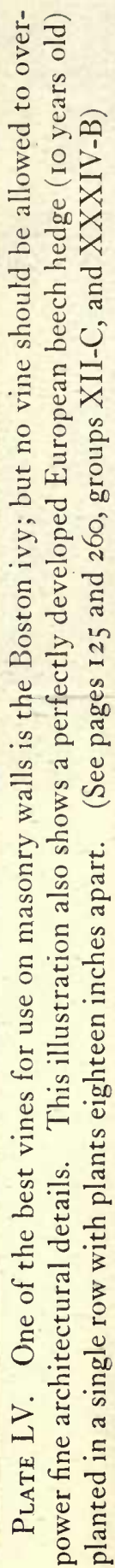


same class. It does not appear to do well and yet rhododendrons planted under exactly the same conditions thrive.

This section of the country is still on the uncharted list so far as complete information covering the lists of plants that are adapted to this territory is concerned. In addition to those plants which are tabulated in the following lists there is a wide range of plants which can be selected from the main text of this book, practically all of which plants are adapted for use in this territory.

\section{LIST OF PLANTS FOR USE ON THE OREGON AND WASH- INGTON COASTAL PLAIN}

A. Hedges. This group is divided into deciduous and evergreen plants. It is noteworthy by reason of the fact that there are more broad-leaved plants than deciduous ones. This is not the case in other portions of the country, except possibly in the far south.

\section{a. Deciduous:}

Berberis thunbergi

Thunberg's Japanese Barberry

Chaenomeles japonica

Japanese Quince

Crataegus oxycantha

May Thorn
Ligustrum ibota

Japanese Privet

Ligustrum ovalifolium

California Privet

Ligustrum vulgare European Privet

\section{Rosa rugosa}

Japanese Rose

b. Evergreen:

Aucuba japonica

Japanese Laurel

Chamaecyparis lawsoniana

Lawson's Cypress

Ilex aquifolium

English Holly

Ilex crenata

Japanese Holly

Mahonia aquifolium

Oregon Grape

Picea excelsa Norway Spruce

Prunus laurocerasus English Laurel

Prunus lusitanica Portugese Laurel

Pyracantha coccinea Evergreen Thorn

Ulex europaus Gorse

\section{Viburnum tinus}

Laurestinus

B. Plants for Ground Cover. Practically all of these groundcover plants are evergreen in character; both those adapted to the open 
sun and those given for use in the shade. No attempt has been made to name the herbaceous perennials suitable for this purpose.

a. Open sun:

Arctostaphylos uva-ursi Bearberry

Iberis semperoirens

Evergreen Candytuft
Pachysandra terminalis Japanese Spurge

Phlox subulata

Moss Pink

Saxifraga cordifolia

Saxifrage

b. Shade:

Evonymus radicans

Climbing Evonymus

Gaultheria shallon

Salal

Hedera helix

English Ivy

Lonicera japonica halliana

Japanese Honeysuckle

Pachysandra terminalis

Japanese Spurge

$V$ inca minor

Periwinkle

C. Plants for Border Planting. The shrubs and trees given in the group for refined lawn masses are confined largely to those sorts which are not generally available throughout the east for border planting by reason of their soil and moisture requirements. The native collected plants are very similar to the same sort of material found throughout the northern central states.

a. Refined lawn masses:

Abelia grandiflora

Hybrid Abelia

Acer palmatum

Japanese Maple

Aralea hinodigiri

Crimson Evergreen Azalea

Azalea indica

Indian Azalea

Berberis buxifolia

Box-leaved Barberry

Berberis darwini

Darwin's Barberry

Berberis ilicifolia

Holly-leaved Barberry

Calluna vulgaris

Scotch Heather

Cornus mas

Cornelian Cherry
Cornus paniculata

Grey.Dogwood

Cotoneaster francheti

Franchet's Rose Box

Cotoneaster simonsi

Himalayan Rose Box

Deutzia gracilis

Slender Deutzia

Diervilla hybrida

Hybrid Weigela

Enkianthus perulatus

Enkianthus

Erica mediterranea

Pink Heather

Forsythia suspensa fortunei

Fortune's Golden Bell

Lonicera maacki

Late-blooming Honeysuckle 
Philadelphus lemoinei

Lemoine's Mock Orange

Pieris floribunda

Mountain Fetterbush

Prunus triloba

Flowering Plum
Spiraea vanhouttei

Van Houtte's Bridal Wreath

Syringa oulgaris hybrida

Hybrid Lilac

Viburnum carlesi

Korean Viburnum

b. Native and collected plants:
Acer circinatum
Vine Maple
Calycanthus floridus
Strawberry Shrub
Clethra alnifolia
Sweet Pepper Bush
Cornus nuttalli
Oregon Dogwood
Cornus stolonifera
Red Osier Cornel
Elaeagnus angustifolia
Russian Olive
Holodiscus discolor ariaefolius
Ocean Spray

\author{
Philadelphus lewisi \\ Native Mock Orange \\ Rhus glabra \\ Smooth Sumac \\ Rosa blanda \\ Meadow Rose \\ Rosa lucida \\ Glossy Rose \\ Symphoricarpos racemosus \\ Snowberry \\ Symphoricarpos vulgaris \\ Indian Currant \\ Viburnum americanum \\ American High-bush Cranberry
}

D. Street and Avenue Planting. This group with the exception of the Oregon maple and the thornless locust is practically identical with a similar group for any portion of the northern and eastern states.
Acer macrophyllum
Oregon Maple
Acer platanoides
Norway Maple
Acer pseudoplatanus
Sycamore Maple
Aesculus hippocastanum rubicunda
Red Flowering Horse-chestnut
Fraxinus americana
White Ash

\author{
Platanus orientalis \\ Oriental Plane \\ Quercus coccinea \\ Scarlet Oak \\ Robinia pseudacacia bessoniana \\ Thornless Locust \\ Tilia euchlora \\ Crimean Linden \\ Ulmus americana \\ American Elm
}

E. Plants for Heavily Shaded Locations. This group contains only plants native to this portion of the country and some of the better known plants given in previous lists.

Abies balsamea

Balsam Fir

Calycanthus floridus

Strawberry Shrub
Chaenomeles japonica Japanese Quince

Gaultheria shallon Salal 


\title{
THE COMPLETE GARDEN
}

\section{Lonicera morrowi \\ Japanese Bush Honeysuckle \\ Mahonia nervosa \\ Dwarf Oregon Grape \\ Philadelphus gordonianus \\ Gordon's Mock Orange}

Philadelphus lewisi

Native Mock Orange

Pinus strobus

White Pine

Sambucus canadensis American Elder

\section{Tsuga canadensis}

Canadian Hemlock

\section{F. Plants Valuable for Autumn Colouration of Leaves.} The plants in this group are selected for their use to furnish colour in the landscape in autumn and special attention is called to the vine maple and Oregon dogwood which are not available in other sections of the country.

\author{
Acer circinatum \\ Vine Maple \\ Acer ginnala \\ Siberian Maple \\ Acer rubrum \\ Red Maple \\ Betula alba \\ European White Birch \\ Betula lenta \\ Black Birch \\ Berberis thunbergi \\ Japanese Barberry \\ Berberis wilsonae \\ Wilson's Barberry
}

\author{
Cornus nuttalli \\ Oregon Dogwood \\ Evonymus alatus \\ Cork-barked Burning Bush \\ Ligustrum amurense \\ Amoor River Privet \\ Quercus coccinea \\ Scarlet Oak \\ Rhus glabra \\ Smooth Sumac \\ Stephanandra flexuosa \\ Stephanandra \\ Tilia vulgaris. \\ Common Linden
}

G. Vines. This group of vines is very similar to the group previously given and shows the large number of species which are available in this territory.

Ampelopsis engelmanni

Englemann's Ampelopsis

Ampelopsis tricuspidata veitchi Boston Ivy

Bignonia radicans

Trumpet Vine

Celastrus orbiculatus

Japanese Bitter-sweet

Clematis montana White Clematis

Clematis montana rubra Red Clematis

Clematis paniculata Japanese Clematis
Eoonymus radicans .

Climbing Evonymus

Hedera helix English Ivy

Jasminum nudiflorum Naked-flowered Jasmine

Jasminum primulinum New Chinese Jasmine

Lonicera japonica halliana Japanese Honeysuckle

Lonicera periclymenum belgica

Dutch Honeysuckle

Polygonum baldschuanicum

Knotweed 
Pueraria thunbergiana

Kudzu Vine
Wisteria multijuga Japanese Wisteria

Wisteria sinensis

Chinese Wisteria

H. Evergreens Most Used. Among the plants grouped here will be found many coniferous and broad-leaved evergreens which it is not safe to use as far north as this in any other portion of the United States. Among these, in particular, are the cedar of Lebanon, Lawson's cypress, yellow cypress, hybrid abelia, and Portugese and English laurels.

a. Conifers:

Abies concolor

White Fir

Abies grandis

Silver Fir

Abies nobilis

Red Fir

Cedrus atlantica

Mt. Atlas Cedar

Cedrus deodora

Deodar

Cedrus libani

Cedar of Lebanon

Chamaecyparis lawsoniana

Lawson's Cypress

Chamaecyparis nootkatensis

Yellow Cedar

Picea engelmanni

Engelmann's Spruce

Picca sitchensis Sitka Spruce

$P$ inus attenuata

Knot-cone Pine

Pinus contorta

Oregon Pine

b. Broad-leaved:

Abelia grandiflora

Hybrid Abelia

Arbutus menziesi

Madrona

Aucuba japonica

Japanese Laurel
Pinus monticola

Mountain White Pine

Pinus nigra austriaca

Austrian Pine

Pinus ponderosa

Bull Pine

Pinus radiata

Monterey Pine

Pinus strobus

White Pine

Pinus sylvestris

Scotch Pine

Pseudotsuga douglasi

Douglas Fir

Chamaecyparis (all species) Japanese Cypress

Taxus baccata

English Yew

Taxus baccata fastigiata

Irish Yew

Taxus brevifolia

Western Yew

Tsuga heterophylla

Western Hemlock

Berberis buxifolia Box-leaved Barberry

Berberis ilicifolia

Holly-leaved Barberry

Berberis stenophylla Small-leaved Barberry 


\section{THE COMPLETE GARDEN}

Cotoneaster francheti Franchet's Rose Box

Cotoneaster horizontalis

Prostrate Cotoneaster

Cotoneaster microphylla

Small-leaved Cotoneaster

Ilex aquifolium

English Holly

Ilex crenata

Japanese Holly

Ligustrum japonicum

Evergreen Privet
Osmanthus aquifolium

Fragrant Olive

Photinia glabra Japanese Photinia

Pieris floribunda Mountain Fetterbush

Prunus laurocerasus

English Laurel

Prunus lusitanica

Portuguese Laurel

Rhododendron catawbiense hybridum Hybrid Rhododendron 


\section{BIBLIOGRAPHY}





\section{BIBLIOGRAPHY}

THE following is a compilation of the more important practical books on various subjects relating to landscape plantings and of interest to the gardener and to the owner of private estates. An effort has been made to include a reference list of some of the more important articles which have appeared from time to time in different magazines, as discussions on these subjects. An attempt has been made in compiling this list of references not to cover the entire field of literature written on these subjects, but to include only a sufficient number of books of real value from which information can be readily obtained.

The author does not wish to imply that there are not many other interesting publications pertaining to this subject matter. It is imperative, however, that this list should not become overburdened, and yet, if references have been omitted which should have been included, any suggestions or corrections will be welcome.

\section{Botany}

\section{BOOKS}

Manual of the Flora of the Northern States and Canada, by N. L. Britton.

Field, Forest and Garden Botany, by Asa Gray.

Official Catalog of Plant Names, by American Joint Committee on Horticultural Nomenclature.

Bulbs

Daffodils, by Joseph Jacob.

The Bulb Book, by John Weathers.

Bulb Culture, by Henderson.

Bulb Garden, by Grace Tabor.

The Book of Bulbs, by S. Arnott.

Bulbs and Tuberous-Rooted Plants, by C. L. Allen.

Daffodils, Narcissus, and How to Grow Them, by M. Kirby.

Tulips, by Joseph Jacob.

\section{Evergreens and Rhododendrons}

Evergreens and How to Grow Them, by C. L. Harrison.

The Rhododendron and American Plants, by E. S. Rand, Jr.

Handy Book of Ornamental Conifers and Rhododendrons, by $\mathrm{H}$. Fraser.

Hedges and Evergreens, by J. A. Warder.

Rhododendrons and Azaleas, by Wm. Watson. 
Flower Gardens (Perennials and Annuals)

The Book of Perennials, by H. H. Saylor.

The Book of Annuals, by H. H. Saylor.

Color Schemes in the Flower Garden, by Gertrude Jekyll.

The Flower Garden, by Ida Bennett.

The American Flower Garden, by Neltje Blanchan.

The English Flower Garden, by W. Robinson.

Flower Gardening, by H. S. Adams.

Familiar Flowers of Field and Garden, by F. S. Matthews.

Color in My Garden, by Louise B. Wilder.

Irises, by W. R. Dykes.

The Book of the Peony, by Mrs. Edward Harding.

Our Garden Flowers, by Harriet L. Keeler.

The Garden, Month by Month, by Mabel Sedgwick.

Flower Gardens-A Selected List of Books, The New York Public Library (January, I915).

The Garden Blue Book, by L. B. Holland.

Popular Garden Flowers, by Walter Page Wright.

Garden Flowers of Spring, Summer, Autumn, and Winter, by Ellen E. Shaw, edited by Leonard Barron.

\section{Forestry}

Forest Mensuration, by H. S. Graves.

Foresters' Manual, by E. T. Seton.

Principles of American Forestry, by S. B. Green.

Practical Forestry, by John Gifford.

Practical Forestry, by Andrew S. Fuller.

Principles of Handling Woodlands, by H. S. Graves.

A List of Books on Trees and Forestry, Boston Public Library, 1899.

\section{Garden Architecture}

The Practical Book of Garden Architecture, by Phoebe W. Humphrey. The Book of Garden Furniture, by Charles Thonger.

Garden Ornaments, by Gertrude Jekyll.

Italian Gardens, by Inigo Triggs.

\section{Herb Gardens}

The Herb Garden, by Frances A. Bardwell.

The Book of the Scented Garden, by F. W. Burbridge.

\section{Japanese Gardens}

The Art of Landscape Gardening in Japan, by Josiah Conder.

Landscape Gardening in Japan, by Josiah Conder.

The Flowers and Gardens of Japan, by Florence Du Cane.

Japanese Flower Arrangement Applied to Western Needs, by Mary Averill. 
Lawns

Lawns and How to Make Them, by Leonard Barron.

Making a Lawn, by Luke J. Doogue.

Turf for Golf Courses, by Piper and Oakley.

\section{Miscellaneous}

The New Gardening, by Walter P. Wright.

Catalog of the Codman Collection of Books on Landscape Gardening, Boston Public Library, 1899.

The Landscape Beautiful, by F. A. Waugh.

Practical Landscape Gardening, by Robert B. Cridland.

Gardening for Beginners, by E. T. Cook.

Farm and Garden Rule Book, by L. H. Bailey.

Manual of Gardening, by L. H. Bailey.

Standard Cyclopedia of Horticulture, by L. H. Bailey.

Gardeners' Dictionary, by G. W. Johnson.

The Book of Topiary, by C. H. Curtis and W. Gibson.

My Growing Garden, by J. Horace MacFarland.

Book of Garden Plans, by Stephen F. Hamblin.

Native Plants

Wild Flowers of New England, by Lincoln.

Ferns and How to Grow Them, by G. A. Woolson.

Ferns and Their Haunts, by W. N. Clute.

The Book of Choice Ferns, by G. Schneider.

An Illustrated Flora, by N. L. Britton and Addison Brown.

Our Northern Shrubs, by Harriet L. Keeler.

Silva of North America, by C. S. Sargent.

Field Book of American Trees and Shrubs, by F. S. Mathews.

Pennsylvania Trees, by J. S. Illick.

Plant Life of Alabama, by Charles Mohr.

Tree Book, by Julia E. Rogers.

Trees and Shrubs of Northeastern America, by C. S. Newhall.

Wild Flowers of the North American Mountains, by Julia W. Henshaw.

Key to Trees of Northeastern United States and Canada, by Collin and Preston.

A Guide to the Wild Flowers, by Alice Lounsberry.

\section{Ornamental Trees and Shrubs}

Aristocrats of the Garden, by E. H. Wilson.

Trees and Shrubs, by C. S. Sargent.

Ornamental Shrubs of the United States, by A. G. Apgar.

Garden Trees and Shrubs, by W. P. Wright.

Shade Trees in Towns and Cities, by William Solataroff.

Ornamental Shrubs for Garden, Lawn, and Park Planting, by L. D.

Davis. 


\section{Plant Diseases}

Fungus Diseases of Plants, by B. M. Duggar.

Injurious Insects of the Farm and Garden, by Mrs. Mary Treat.

Spraying of Plants, by E. G. Lodeman.

Insects and Insecticides, by C. M. Weed.

\section{Propagation of Plants}

Plant Propagation, by Alfred C. Hottes.

Plant Culture, by George W. Oliver.

Nursery Book, by L. H. Bailey.

Plant Breeding, by L. H. Bailey.

Plant Physiology, With Special Reference to Plant Production, by B. M. Duggar.

Plant Propagation, by M. G. Kains.

Art of Propagation, by J. Jenkins.

\section{Pruning}

Pruning Manual, by L. H. Bailey.

Principles and Practice of Pruning, by M. G. Kains.

\section{Rock Gardens}

Alpine Flowers and Rock Gardens, by Walter P. Wright.

Alpine Flowers for Gardens, Rock, Wall, Marsh Plants and Mountain Shrubs, by W. Robinson.

Making a Rock Garden, by H. L. Adams.

The Small Rock Garden, by F. H. Jenkins.

My Rock Garden, by R. J. Farrer.

\section{Roses}

Roses, by H. R. Darlington.

Roses, Their History, Development, and Cultivation, by J. H. Pemberton.

The Rose, by H. B. Ellwanger.

Parsons, On the Rose, by S. B. Parsons.

The Practical Book of Outdoor Rose Growing, by Geo. C. Thomas, Jr. A Book about Roses, by S. Reynolds Hole.

Roses and Rose Gardens, by W. P. Wright.

Everblooming Roses for the Outdoor Garden of the Amateur, by G. T. Drennan.

\section{Street Trees}

Field Book for Street Tree Mapping, by William Solataroff.

Trees in Lawn, Street, and Park, by B. E. Fernow. 
Trees and Shrubs (Winter Characters and Form)

New England Trees in Winter, by Blakeslee and Jarvis.

Handbook of Trees of the Northern States and Canada, by Romeym B. Hough.

Vines

Climbing Plants, by W. Watson.

Book of Climbing Plants, by S. Arnott.

Vines and How to Grow Them, by William McCollum.

A Concise Handbook of Climbers, Twiners, and Wall Shrubs, by H. P. Fitzgerald.

Vines of Northeastern America, by C. S. Newhall.

\section{Wall Gardens}

Wall and Water Gardens, by Gertrude Jekyll.

Water Gardens

The Book of Water Gardening, by Peter Bisset.

Rock and Water Gardens, by Charles Thonger.

Making a Water Garden, by William Tricker.

Water Lilies and Aquatics, by Peter Henderson.

Water Lilies and How to Grow Them, by Conrad and Hus.

Winter Protection

Hedges, Shelters, Windbreaks, and Stone Fences, by E. P. Powell.

\section{ARTICLES}

PRUNING (ORNAMENTAL FLOWERING TREES, SHRUBS, VINES, AND PERENNIALS)

\begin{tabular}{|c|c|c|c|}
\hline TITLE OF ARTICLE & AUTHOR & MAGAZINE REFERENCE & DATE \\
\hline $\begin{array}{l}\text { Winter Pruning and } \\
\text { Spraying }\end{array}$ & Rockwell & $\begin{array}{l}\text { American Homes and } \\
\text { Gardens }\end{array}$ & Jan., I9I3 \\
\hline $\begin{array}{l}\text { Street Trees, Their } \\
\text { Care and Preserva- } \\
\text { tion }\end{array}$ & A. D. Taylor & Cornell Exper. Station & Bull. 256 \\
\hline $\begin{array}{l}\text { Pruning: A Fitting } \\
\text { Winter Activity }\end{array}$ & Kains & Garden Magazine & Dec., I9I6 \\
\hline $\begin{array}{l}\text { Pruning Shrubs and } \\
\text { Roses }\end{array}$ & Barnes & Suburban Life & Apr., I9I I \\
\hline $\begin{array}{l}\text { Pruning Table } \\
\text { Suggestions for Shrub } \\
\text { Trimming in Win- } \\
\text { ter }\end{array}$ & Rose & $\begin{array}{l}\text { Suburban Life } \\
\text { Suburban Life }\end{array}$ & $\begin{array}{l}\text { Mar., 1914 } \\
\text { Dec., I912 }\end{array}$ \\
\hline
\end{tabular}


TTTLE OF ARTICLE

AUTHOR

Solataroff

Right Way to Trim a Tree

Pruning
MAGAZINE REFERENCE

Suburban Life

Missouri Botanical

Garden Bulletin

Vol. VI, No. 9
DATE

Apr., I909

Nov., 1918

TRANSPLANTING TREES, SHRUBS, VINES, AND PERENNIALS

How to Succeed with Lurie Fall Planting

Fall Planting for Pendleton Spring Flowers

Experiences in Midsummer Transplanting

Planting and Shaping Young Trees

Planting Trees by Machine

Planting the Perennial: Weed Border

Fall Heeling-in for Tuthill Spring Planting

Transplanting Big Trees

Transplanting Out of Meller

- Season

September Transplanting

Perennials for Fall Planting

How to Plant Trees Johnson and Shrubs

Making a Success of Platt Tree Planting

Transplanting Large McLaughlin Trees

Planting and Seeding Taylor Seasons
Garden Magazine Oct., 1918

Garden Magazine Oct., 1918

Garden Magazine July, I918

Garden Magazine Apr., 1915

Scientific American Nov., 1916

House Beautiful Aug., IgI6

Garden Magazine Oct., 1916

Garden Magazine Feb., 1917

Garden Magazine July, 1917

House Beautiful Sept., 1917

Countryside Maga- Dec., I9I4 zine

Suburban Life Mar., 1908

Suburban Life Sept., 1914

Countryside Maga - Nov., I9I 5 zine

Landscape Archi- Apr., 1919 tecture

Garden Magazine Mar., 1920

MAINTENANCE OF PLANTING AND LAWNS

Green Grass in Dry Rockwell Country Life

Aug., 1916

Weather 
TITLE OF ARTICLE

AUTHOR

MAGAZINE REFERENCE

DATE

Getting the Lawn Oldcastle into Shape and

Keeping it so

Summer Care of the Bourne Lawn

Suburban Life

Apr., I9I 2

Suburban Life

June, 1908

WINTER PROTECTION AND MULCHING

Putting on the Gar- Wm. C. McCollum House and Garden Dec., 1918 den's Winter Clothes

To Protect Flowers From Frost

Putting the Garden Farrington into Its Winter Quarters

Winter Protection Meller

Winter Protection in Barnes the Garden

Timely Fall Work in Rexford the Border

Don't Hurry Winter Protection of Roses

Draftsman

Dec., 1914

Countryside Maga- Oct., 1916 zine

Garden Magazine Nov., 1917

Suburban Life Nov., 1910

Suburban Life Nov., I9II

Garden Magazine Oct., 1918

BULBS

Fall Planting of Spring Bulbs

Planting Bulbs for Mrs. Strang Spring Bloom

Naturalizing Spring- Weed Flowering Bulbs

Planting Tables for Bulbs Indoors and Outdoors

All Summer Bulb Garden Farrington

Summer-blooming Bulbs Rockwell for Spring Planting

The Fall Budget and Mrs. Strang Its Springtime

Yield

Bulbs and Tuberous Plants

Craftsman

Garden Magazine Oct., 1915

House Beautiful Oct., I916

Countryside Maga- Sept., I9I6 zine

Countryside Maga- Apr., I9I6 zine

Countryside Maga- Apr., I9I5 zine

House and Garden Oct., 1918

Missouri Botanical

Garden Bulletin

Vol. IV. No. 9 


\section{ARTICLES-MISCELLANEOUS}

TITLE OF ARTICLE

AUTHOR

The Best Hardy Coni- Wilson fers

Evergreens for the Wild Home Grounds

Evergreens for the Allen Home Landscape

The Uses, Choice, and Planting of Evergreens

Native Plants Suitable for the Gardens of Missouri and $\mathrm{Ad}$. joining States

Making an Old-Fashioned Garden

The Perennial or Old- Wild Fashioned Garden

Planning Features for Garden Special Effects

The Garden of Wild Flowers

Gardens of Sweet Burke Odour

Hardy Perennials for Richie Landscape Use

One Hundred Native Perennials for the Wild Garden

Roses and How to Rockwell Grow Them

Have We Lost Some- Barron thing in Roses?

Hardy Shrubs That Gibson Can Be Forced

Finding the Shrub to Richie Fit the Place

Dual Purpose Shrubs Farrington and Trees

Shrubs with Brightly Miller Coloured Twigs
MAGAZINE REFERENCE

DATE

Garden Magazine

Dec., 1915

House and Garden Sept., I9I4

House and Garden Sept., 1915

House and Garden I9I8

Missouri Botanical Garden Bulletin

Vol. VIII

House and Garden

July, 1917

House and Garden Oct., 19I4

Garden Magazine Feb., 1915

House and Garden Sept., 1918

House and Garden Mar., 19I5

Garden Magazine Feb., I9I5

Garden Magazine May, I915

House and Garden April, 1913

Country Life June, 19I4

Gardener's Chron- Oct., I919 icle of America

Garden Magazine Apr., 1915

Country Life

Mar., 1920

Country Life

Dec., 1915 


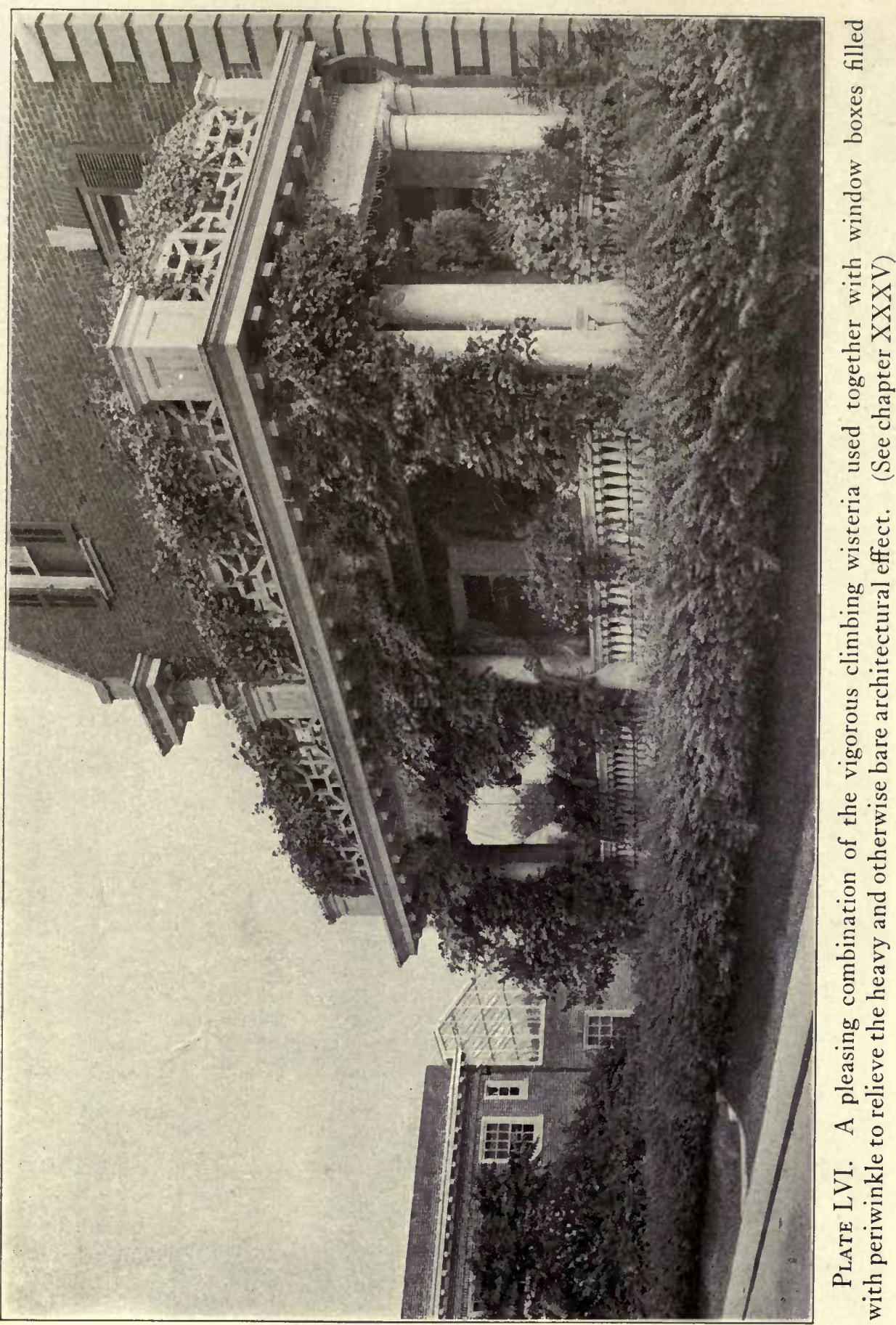




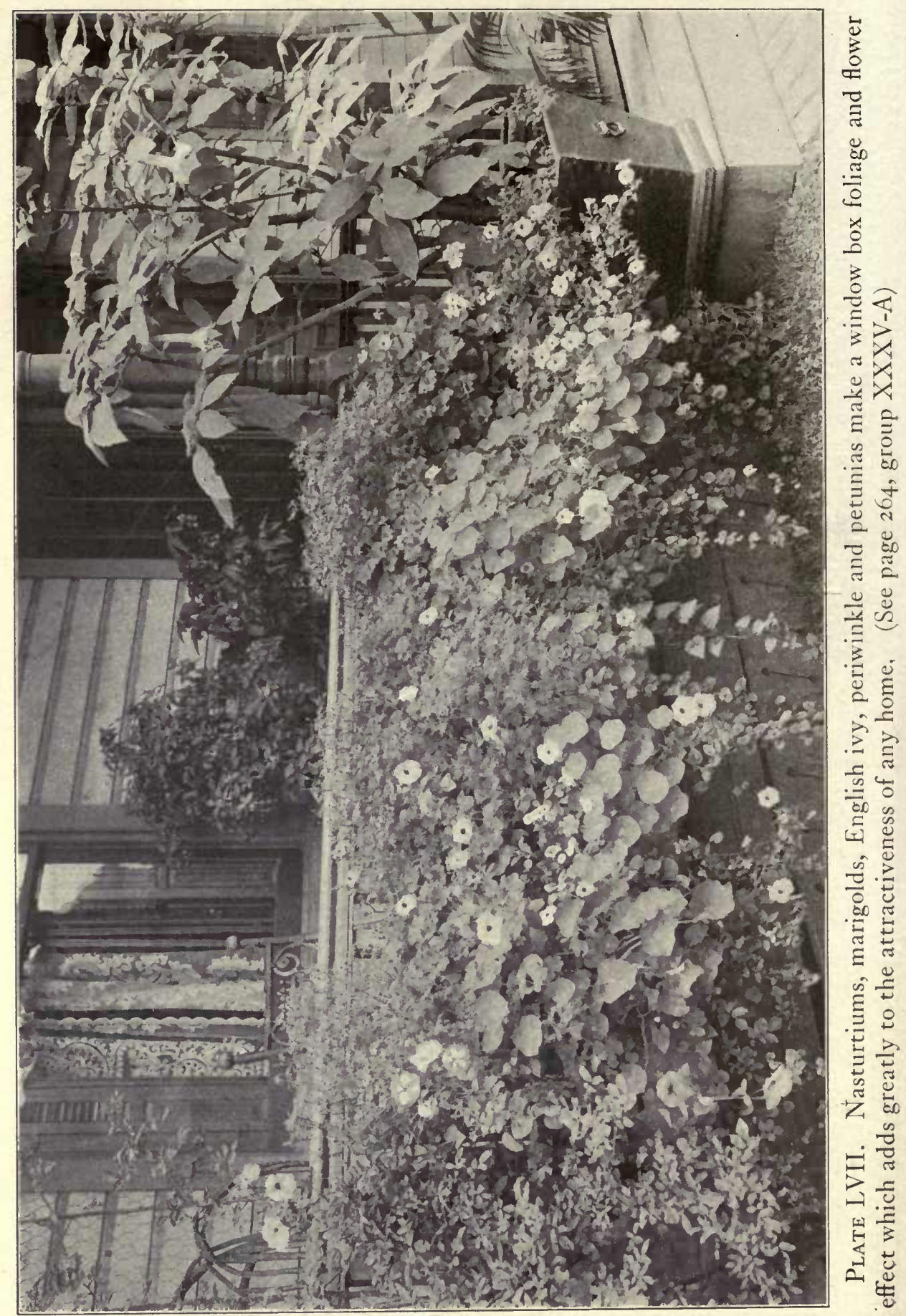




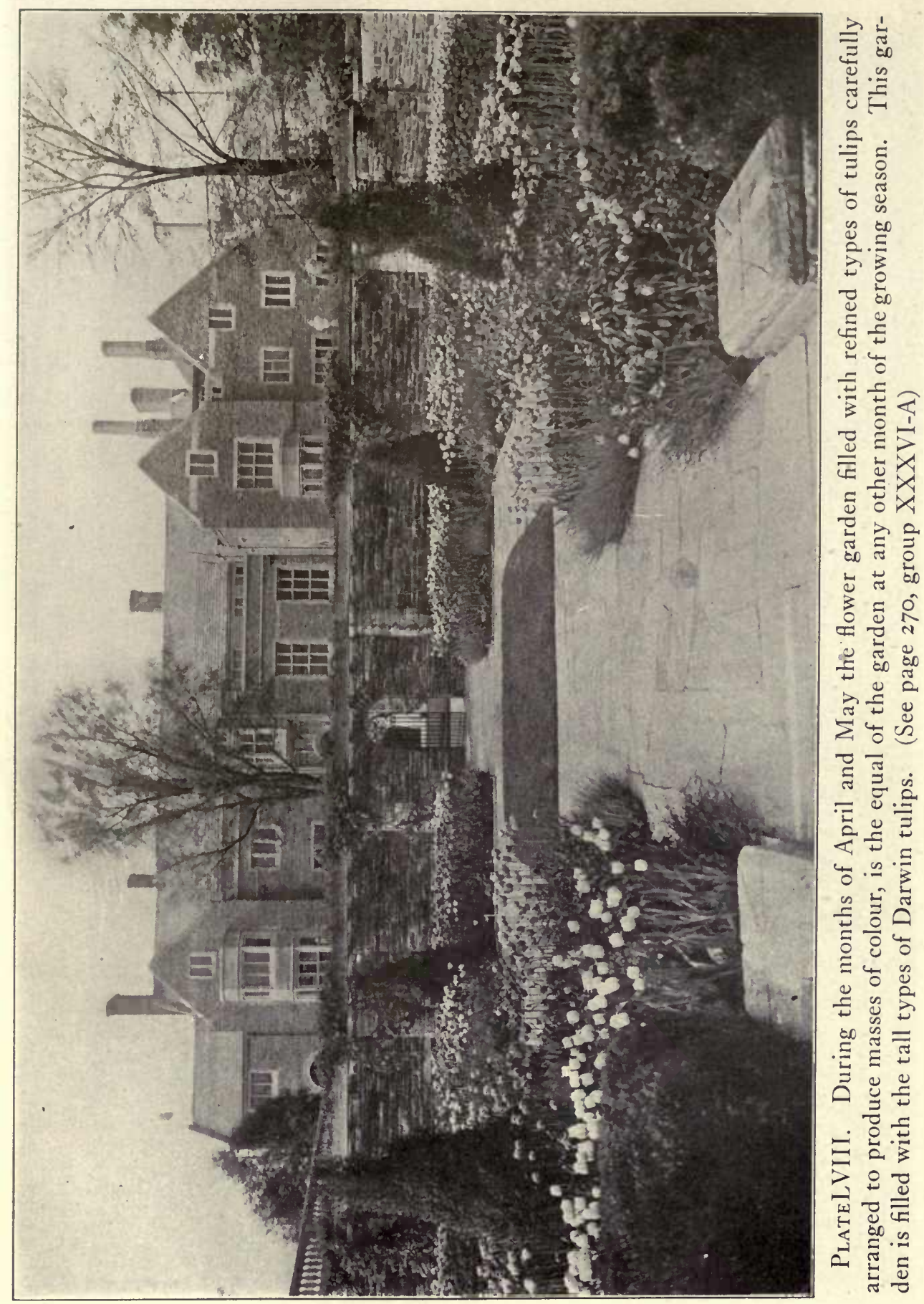




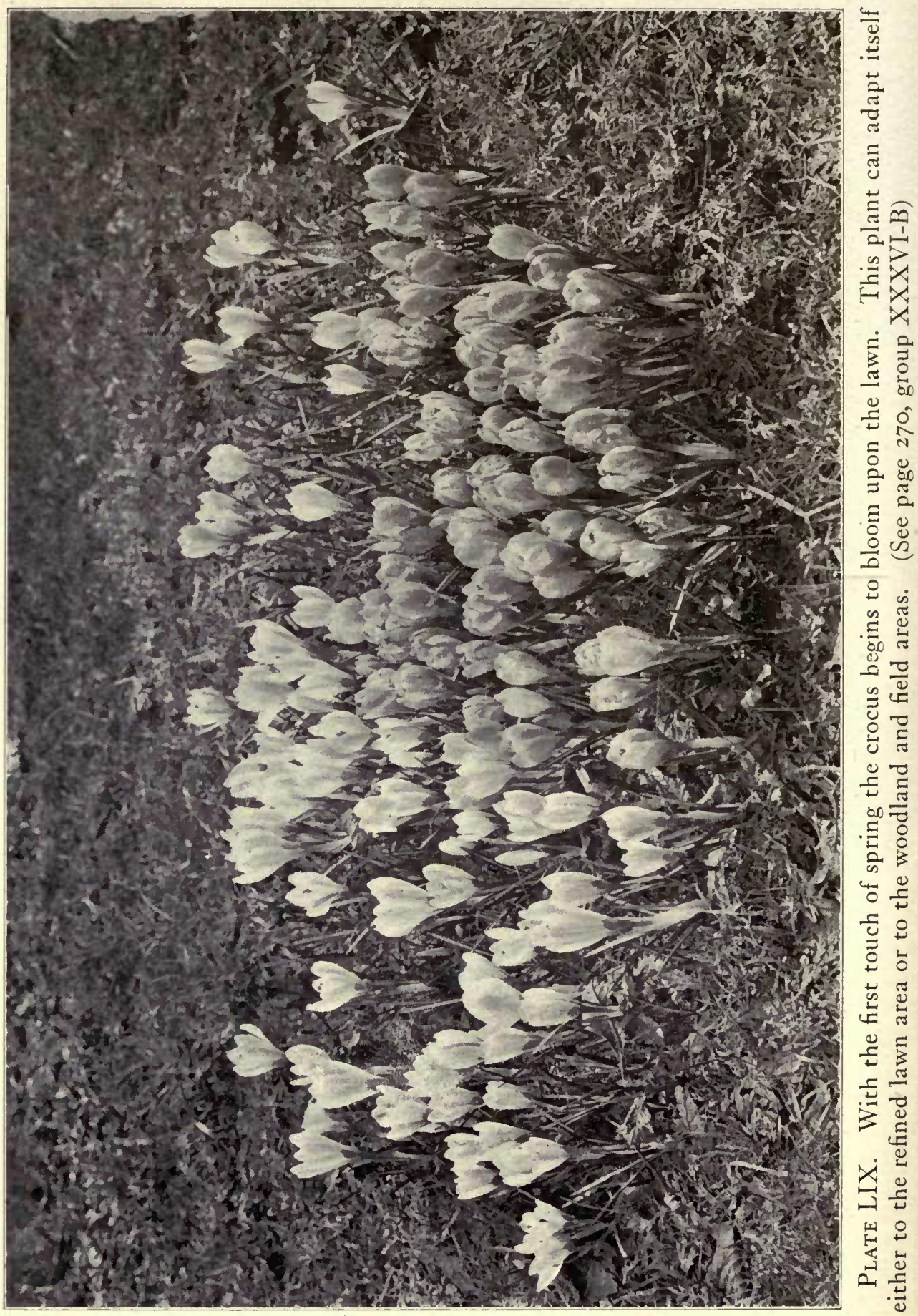


TITLE OF ARTICLE AUTHOR

Trees and Shrubs Worth Planting for Their Conspicuously Ornamental Fruits

Ornamental Flowering Trees

The Peril of Our Shade Trees

SomeTreesand Shrubs for Trying Sites

Wilson
MAGAZINE REFERENCE

DATE

Garden Magazine

Oct., 1915

Gardener's Chron- Apr., May, icle of America

June, July, I 920

Country Life Mar., I916

Garden Magazine Mar., 1914 

GLOSSARY 



\section{GLOSSARY}

THE author has attempted in this glossary to compile a set of terms or words commonly used in landscape literature pertaining to general planting design. Landscape architecture is one of the younger professions. It has no distinct vocabulary so recognized by the dictionary of to-day.

Such words as establish, naturalize, open allee, pleached allee, puddle, and leggy as applied to the language of this profession require a definition other than those commonly given to such words. The definitions here given are those which are generally accepted by practicing landscape architects.

No attempt has been made to define a large group of other words which are used in the general field of landscape construction work as differentiated from planting design and its execution.

\section{Accent Plant:}

A plant used to give prominence to its location either because of peculiarly interesting habit of growth, characteristics of fruit or of flowers or foliage.

Acclimatize:

v. To make accustomed to a climate to which a plant is not native.

\section{Acid Soil:}

A soil containing an excess of uncombined acids. Any acid soil is objectionable (even when only very slightly acid) to most plants, except ericaceous plants. Changes blue litmus paper to red.

\section{Agricultural Lime:}

An unstandardized product from the unburned cores of lime kilns, mixed with other better material but rarely having a better value than fine pulverized limestone.

\section{Air-slaked Lime:}

Is the compound formed by the action of carbon dioxide, from the air, on hydrated lime. Its formula is ( $\mathrm{Ca} \mathrm{CO})$, or the same as pure limestone.

\section{Alkaline Soil:}

A soil containing an excess of uncombined alkali, lime, magnesia, sodium carbonate, etc. A good soil should be very slightly alkaline. Changes red litmus paper to blue. 
Allee, open:

A way framed on either side by symmetrical rows of closely planted trees or tall shrubs (of a height not less than twice the width between rows), and so maintained that either side presents a continuous vertical wall of close-growing foliage.

Allee, pleached:

A way framed on either side by symmetrical rows of closely planted trees or shrubs, so maintained that the branches of the continuous walls of close-growing foliage arch and interweave across the top of the way, at a height of not less than seven or eight feet.

Annuals:

Plants which develop from seeds each year, mature, produce ripened seed, and die during the same growing season.

\section{Alpine Plants:}

Plants adapted to living in exposed situations but requiring a constant seepage of cool water through the soil surrounding their roots. Alpine plants are not drought-resisting.

Anthracnose:

A plant disease caused by a parasitic fungus of one definite class (melanconiae).

\section{Arborescent Shrubs:}

Those plants on the borderline between shrubs and trees.

Ball:

In transplanting work it is the mass of earth containing the roots of a plant, and it is transplanted with the plant to its new location.

\section{Ball-and-Burlap:}

The process of covering a ball of earth, containing the roots of a plant, with burlap or other bagging so that the plant may be safely transported a considerable distance without losing the earth from about its roots.

\section{Bedding Plants:}

Herbaceous plants selected for the purpose of producing a solid ground cover of flowers or foliage as a part of a definite design in a refined garden or lawn development.

\section{Bell-glass:}

A bell-shaped glass used to cover small plants growing in the open, as a protection from wind and rain and frequent temperature changes. 
Biennials:

Plants which require two years to produce ripened seed. They form buds at the crown of the root at the end of the first season. The next season they bear ripened seed, and the plants die.

Blight:

A diseased condition caused by a parasitic fungus.

Bog Garden:

A garden composed largely of bog-loving plants. A garden on a relatively low area consisting of a continuously wet, peaty soil, but not containing stagnant water.

\section{Budding:}

The insertion of a bud from one plant (together with some live surrounding tissue) beneath the bark'of another plant so that the cambium layers join and grow together.

Bulb:

A subterranean leaf-bud consisting usually of several fleshy scales.

Calcium Oxide:

A compound resulting from the burning of limestone containing, when pure, $4^{\circ}$ parts of calcium and 16 parts of oxygen by weight. It is also known as fresh burned or quicklime.

\section{Callus:}

The new tissue which forms over a wound as over the end of a cutting; a protective measure provided in nature; but not always an indication that the cutting will produce roots.

Cambium, or cambium layer:

The soft, very thin tissue lying between the bark and the woody tissue. This is the tissue from which new wood originates and is the only truly live portion of the stem of a plant. Plant food rises from roots to leaves through the cells on the inner half of the cambium layer and returns from the leaves downward as available plant food through cells on the outer half of the cambium layer.

Canker:

An area attacked by a parasitic fungus.

Carpet bedding:

A design of plants which form a close mat on the surface of the ground and respond to severe cutting back, as distinguished from groundcover plants which may stand several inches above the ground. 
Clay:

Earthy material (occurring in nature), whose chief property is plasticity when wet. The size of particles varies from $\mathrm{I}-5000$ to $\mathrm{I}-25000$ of an inch in diameter. Bakes and cracks freely when dried out.

\section{Clay Loam:}

A loam soil containing a predominance of clay.

\section{Clump:}

A cluster of roots or bulbs or tubers capable of being divided into separate plants or of producing one large mass of plants resembling a single plant.

\section{Collected Stock:}

Plants which have been taken from their native habitat and shipped direct from the collecting ground to the new location. These require more care and are subject to greater loss than nursery-grown stock.

\section{Cold Frame:}

An unheated, outdoor, covered plant house, generally covered with glazed sash; but sometimes prepared paper or cloth is used. No manure is used in the soil at bottom of a cold frame. Cold frames are most frequently used as a transition space in the hardening-off process.

\section{Compost:}

A soil made by mixing loam with decaying organic compounds and sometimes inorganic fertilizers, allowing nitrification and oxidation to proceed; but preventing plant growth until a very rich soil is produced.

\section{Congested:}

A term applied in planting to a situation having impure air or restricted feeding area for roots, or both.

\section{Conifer:}

A plant which bears its seeds in a cone. With the exception of the ginkgo, the larches, and the bald cypress practically all conifers are evergreen needle-bearing plants, as the pine, spruce, and fir. (See Evergreen.)

\section{Cover Crop:}

A herbaceous crop sown to cover the ground temporarily and thus protect it from atmospheric and water action; generally plowed under for its fertilizing value. 
Creeping Plants:

Those plants whose stems run along either on or under the ground and root at intervals.

\section{Crevice Plants:}

Those plants with tenacious root systems adapted for use in the narrow and congested soil areas between flagstones in a walk or between stones in a dry wall.

\section{Cross Fertilization:}

The conveyance of pollen from one flower to another.

Crown, of bulbs or other herbaceous plants:

The persistent portion of the stem which bears the buds which form the next stem.

\section{Cuttings:}

Detached leaf buds or portions of branches which are capable under favourable circumstances of forming new plants when placed in a moist, warm soil.

\section{Deciduous:}

Plants that drop their leaves each fall and produce a complete new set of leaves each spring.

\section{Dehorn:}

To remove a portion of the top of a plant, leaving only short portions of the main branches.

\section{Design Bedding:}

A design of herbaceous plants used for the purpose of producing a definite effect from their flowers and not their foliage, and allowed to continue their normal growth without being cut back.

\section{Dibble:}

A pointed implement of wood or metal used to make holes in the ground, especially for plants, seeds, or bulbs.

\section{Dividing:}

The propagation of plants by separating the roots; more especially the dividing of bulbous and tuberous plants into several plants.

\section{Dormant:}

A resting condition of plants when growth is not active and the flow of sap is stopped. 


\section{Double Flowers:}

Commonly the result of the substitution of brightly coloured petals for stamens or pistils. A perfect double flower has no stamens or pistils, hence is sterile and the plant must be propagated by cuttings.

\section{Drainage for plants:}

The carrying away of excess water from the soil in which plants are placed. This drainage promotes a deep root system, which aids the plant in surviving periods of drought; it also prevents a soil from becoming water-soaked and "drowning" the root system, especially of newly transplanted stock.

\section{Dry Wall:}

A wall constructed of individual stones with loam filling the crevices between them. Such a wall may be used either as a retaining wall to support an embankment of earth or against an earth slope to prevent unnecessary erosion.

\section{Ericaceous:}

A family of plants which require for their normal growth an acid soil (a soil free from lime or magnesium).

\section{Establish:}

The act of transplanting any plant to a new location and causing root growth which makes the plant as capable in its new location as in its old location, of continuing normal growth.

\section{Evergreen:}

Plants with persistent leaves. These plants drop but a small portion of the old leaves each year, and may be conifers, broad-leaved evergreens, or opposite-leaved evergreens.

\section{Excurrent:}

Having a main stem extending up through the top of the plant.

\section{Fertilizer:}

Plant food, either directly available, or which upon nitrification will be available for use by the plant. Many fertilizers (such as sheep manure and dried blood) contain plant food in an immediately soluble form for plant requirements or in a form (such as bone meal and lime rock) which does not become available until after a period of chemical reaction. 
Field-grown Stock:

Nursery-grown stock which is grown in the field, as distinguished from plants grown in pots, in cold frames, or under other especially favourable and artificial conditions, which tend to make better looking specimens, but usually less hardy plants. Thus, field-grown plants are often more desirable, even though not nearly as good looking specimens.

Fillers:

Short-lived or rapidly growing plants temporarily planted between permanent plants as in orchards or in mass plantings.

Fire blight:

A bacterial disease.

Flat:

A shallow box, averaging in depth from three to four inches, to receive soil in which to plant seeds, or to start cuttings.

Flowering on new wood:

A term used in referring to plants which bear flowers on wood grown that same season. Hence they are mostly late-summer and fallflowering plants and should be pruned in late winter or early spring before growth begins.

Flowering on old wood:

A term used in referring to plants which bear flowers on wood formed the previous year, hence mostly spring-flowering plants. They should always be pruned immediately after the period of bloom is completed. (Never prune in early spring.)

Force:

v. To stimulate growth by artificial means such as heat, light, and fertilizers. Usually adopted for the purpose of obtaining fruits or flowers of unusual size or quantity either in season or out of season.

Forcing:

The acceleration of growth by gradually increasing temperature, water supply, and quickly available plant food such as sodium nitrate.

\section{Frame:}

See Cold frame or Hot-bed.

Fresh-burned Lime:

See calcium oxide. 
Friable:

Easily crumbled, mellow, allowing free and unobstructed root development. A term used in describing a condition of soil.

\section{Frozen Ball:}

A solidly frozen ball of earth containing a major part of the root system of a plant (usually a tree) which is being transplanted. Ball of earth must be frozen sufficiently solid so that it will not split during normal transplanting operations.

\section{Fungus:}

A flowerless plant not containing chlorophyll and generally parasitic upon another living plant.

\section{Furrow:}

A shallow trench made by or as by a plow.

Gall:

An abnormal swelling or excrescence caused by gall flies.

Gas Lime:

Is a mixture of slaked lime or calcium hydrate, and carbonate of lime, together with sulphites and sulphides of lime. These last are injurious to young plant life until they have been exposed to the air for some time. Gas lime usually contains 40 per cent. of calcium oxide and sometimes a small percentage of nitrogen.

\section{Girdle:}

n. An incision or several incisions which sever the cambium layer of a woody plant to the woody tissue and for the whole circumference of the stem. It may be a circular cut, a spiral cut, or may consist of several cuts more or less widely separated, but whose horizontal projection would form a closed circle. v. To kill a tree by girdling it.

\section{Ground Cover:}

Small plants or vines, usually growing not more than a foot high, which will spread out and conceal the surface of the ground from view.

\section{Grubbing:}

Clipping and digging out roots, stumps, etc. Turning over and breaking up the sod with a grub hoe or mattock.

\section{Guying Trees:}

Placing wires or stays on trees or portions of trees to prevent them being blown over or broken by the wind; more especially the placing 
of three or more guys on trees recently transplanted to hold them firmly in place until an adequate root system has been established, and to prevent swaying of the trees and loosening of root system.

Hammock Land:

Land, mostly in the southern part of Florida, covered with luxuriant growth of trees (hardwoods, or cabbage palms and palmettos). The soil is rich in fertilizer value.

\section{Harden-off:}

To so care for plants previously grown in a greenhouse that they will be able to withstand normal outdoor exposures. It is customary to move such plants from the greenhouse to cold frames.

\section{Heave-out:}

The partial lifting of plants out of the soil by frost action. This is apt to occur when ground previously deeply frozen and thawed out on top is again frozen. The layer of frozen soil beneath, which has not yet thawed out, forms an unyielding barrier and the expansion of the soil in freezing is then wholly upward. The stresses thus caused are enormous and plants are lifted sometimes almost wholly out of the ground.

\section{Hedge:}

A row composed of living plants usually in a straight line and planted closely to each other (See Plate XV, Page 95).

\section{Hedgerow:}

A hedge or fence of bushes or shrubs either in the form of a definite hedge or of an irregular border-planting, of varying width and oftentimes varying types of plants.

\section{Heeling-in:}

Placing plants with roots covered with soil pressed down with the heel or toe to preserve them in a dormant condition for short periods until they can be permanently planted. Usually a deep furrow is dug, the roots placed close together in the furrow, with stems in a slanting position, and roots then covered with soil. The soil used in this covering is taken from the furrow of the next row (See Plate VI, Page 34).

Herb:

A plant with no persistent stem above ground.

\section{Horticultural Variety:}

Said of certain varieties of plants developed because of some desirable characteristic. They are not necessarily hybrids, but usually are arti- 
ficially hybridized, then propagated by grafts, buds, cuttings, etc., to preserve in the new plant the desirable characteristics of the parent, which might be lost if grown from seed.

\section{Host Plant:}

A living plant attacked by a parasitic fungus or supporting a parasitic plant.

\section{Hotbed:}

A bed of earth enclosed in a glass-covered frame and heated by means of fermenting manure placed well below the surface of the soil in the Humus: hotbed.

Vegetable mould or partly decayed organic matter in the soil.

Hybrid:

A cross between two species of the same genus or two varieties of the same species.

\section{Hybrid Tea:}

A section of the Hybrid Perpetual group crossed back upon the tea-scented China rose. They have a lighter green and less wrinkled foliage than the pure Hybrid Perpetual. They are generally less hardy but more continuous in bloom than Hybrid Perpetuals, sometimes blooming from June until frost.

\section{Hybrid Perpetual:}

Or Hybrid Remontant roses have a stiff upright growth, dull wrinkled foliage, and large flat flowers generally of dark colours. They embrace generally the characteristics of the Provence, Damask, French, and Chinese groups. They mostly have only one season of bloom, in June, but sometimes give scattered bloom later on in the season.

\section{Hybridization:}

Cross fertilization between plants of different varieties or species and sometimes of different genera.

\section{Hydrated Lime:}

The compound formed by the action of water or steam on fresh burned lime. Its good physical condition makes even distribution possible, and thus permits maximum effectiveness to be obtained.

\section{Indigenous:}

Native and original to the country in which the plant is growing. 
Land Plaster:

Is a sulphate of calcium compound and its tendency is to make a soil sour. It should not be considered as a means of correcting soil acidity.

\section{Larva:}

The immature wingless, worm-like form in which insects (which undergo metamorphosis) have their first stage or stages before acquiring wings.

\section{Leaching:}

In soils; the loss, through solution in drainage water, of lime or plant food.

\section{Leader:}

The terminal leaf bud which will often form the main stalk of the plant; not only this bud, but also the previous year's growth is included by the term.

\section{Leaf Curl:}

In peaches is a condition caused by too rapid cell multiplication in response to the stimulus caused by a parasitic fungus. In snowball bushes the stimulus is caused by aphids.

\section{Leaf Mould:}

Decayed leaves combined with other organic matter found on a forest floor.

\section{Leggy:}

A term used to describe a plant (usually a shrub) on which old growth has developed in such a manner that the mass of fine branches and foliage is on the top part of the plant, and the lower part shows a few bare stems. Usually the result of overcrowding plants or of incorrect pruning (See Plate V).

\section{Lime, or Limestone:}

A stone containing the element calcium which will unite with oxygen and carbon dioxide to form calcium carbonate or "lime,". as used on the land.

\section{Line-out:}

As applied to planting work usually means the operation of planting small nursery stock in definite rows where such stock can make a further normal growth and be easily maintained. 


\section{Litter:}

The soiled straw or leaves which have been used for bedding in stables, but which does not contain any considerable quantity of manure except that which it has absorbed in the form of fluids. Frequently used for mulching purposes.

\section{Loam:}

Earthy matter containing clay, silt, sand, and organic matter in such proportions as to make a soil adapted to supporting vegetable growth. Loam varies from a very sandy loam to a very clayey loam. Usually called topsoil. (See topsoil 6.)

Loam, sandy:

Loamy soil which contains a predominance of sand.

Lump Lime:

Burned limestone not evenly slaked so as to become finely divided.

Magnesian Lime:

A term describing a lime or limestone containing both magnesium carbonate and calcium carbonate.

\section{Magnesium:}

An element, usually occurring as magnesium carbonate, which is a compound useful in correcting soil acidity.

\section{Manure:}

Any material, either organic or inorganic, containing a superabundance of plant food or material which upon decomposition or nitrification becomes available plant food.

Marl:

An earthy, crumbly deposit consisting chiefly of clay and calcium carbonate much used as a substitute for land lime. "Green sand" marl may be acid, but good chalk marl is valuable for neutralizing acids.

\section{Miidew:}

A diseased condition caused by the downy mildew fungus.

\section{Muck:}

Black swamp earth which varies widely in available plant food, very similar to peat except that water is not constantly present during the process of decay; hence the nitrifying bacteria are present and the material is better suited for immediate use as plant food. It is in an intermediate stage between leaf mould and peat, 


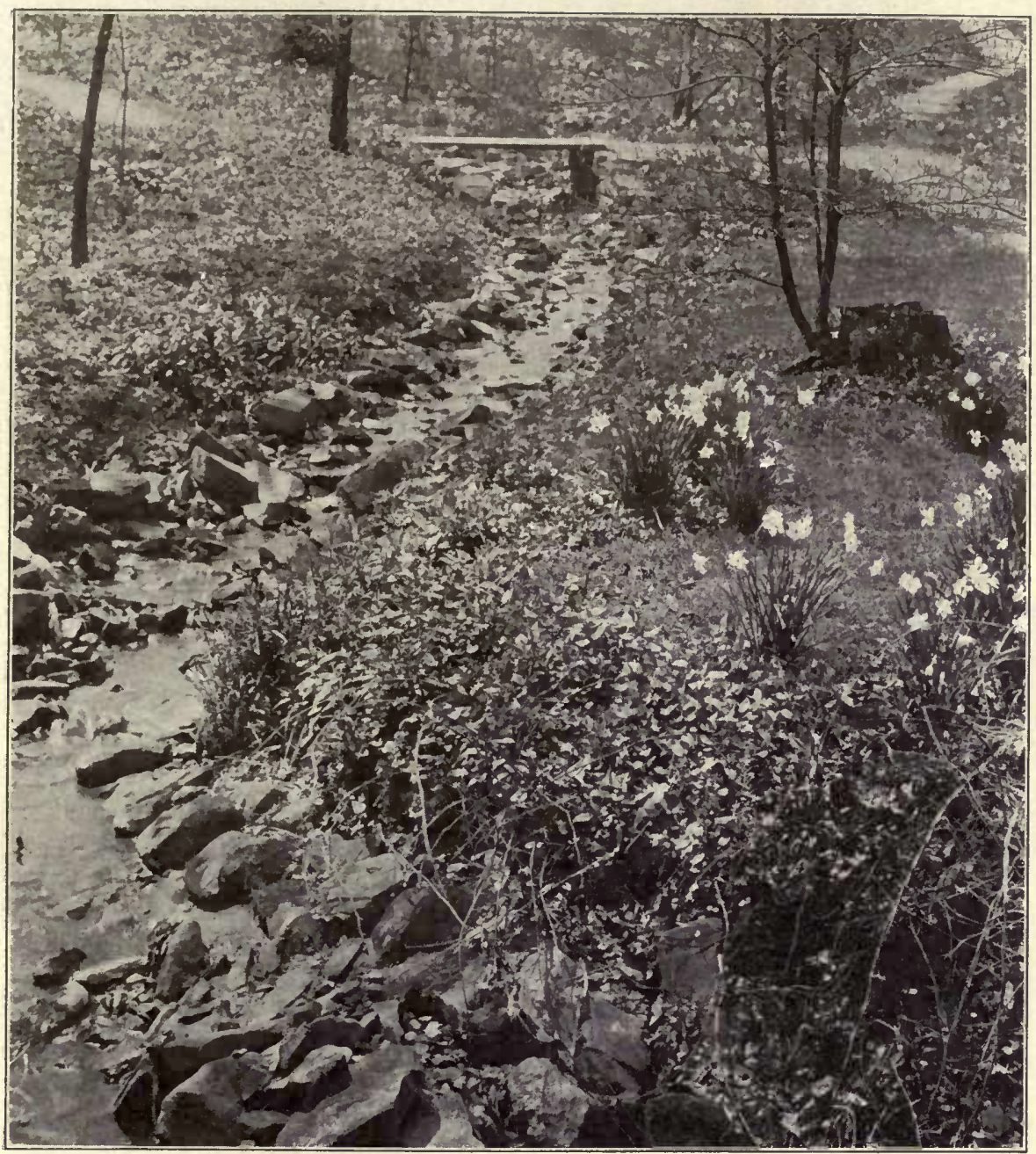

Plate LX. There is always an opportunity on every large estate for the naturalizing of bulbs. Poet's narcissus is quite happy in a wild garden or field environment. (See page 270 , group XXXVI-B) 

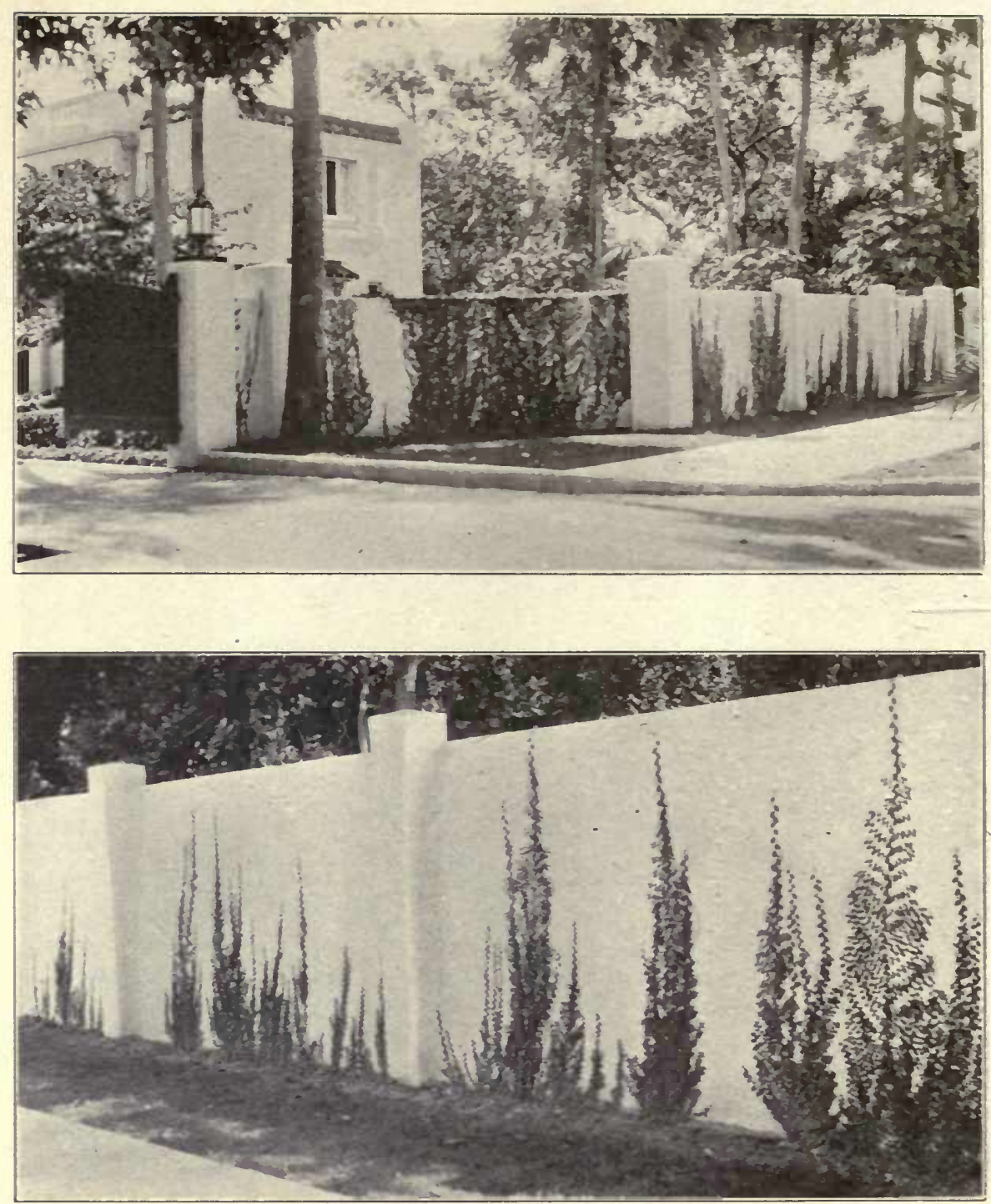

Plate LXI. Throughout the Southern States the creeping fig is one of the most desirable vines for growth on masonry walls. It develops interesting foliage of a fine texture and is a vigorous grower and compares favourably with the Lowe's Boston ivy, so successfully used in the Northern States. (See page 303, group XLIII-C-b) 
Mulch:

A surface covering about the base of plants to prevent or retard evaporation of moisture from the soil, and prevent sudden freezing and thawing in the soil. Dead leaves, straw, manure, etc., are commonly used.

Naturalize:

To adapt and to cause to grow, without artificial care, in a woodland or field environment. This does not imply reproduction of its kind in the new location.

\section{Nitrification:}

The process resulting in the formation of nitrates in the soil. Certain bacteria known as "nitrifying bacteria" are the cause of this change of nitrogen and nitrogen compounds into nitrates. It is thus the oxidation of nitrogen caused by bacteria in the soil. Nitrification cannot proceed except in a moist, warm soil which is well aerated. It is checked entirely when the soil temperature is lower than $40^{\circ} \mathrm{F}$. and also when the soil becomes water logged or saturated, and proceeds rapidly when the temperature reaches $75^{\circ} \mathrm{Fahr}$. and when only 40 to 50 per cent. of the water necessary to cause saturation is present.

Nursery:

A place for growing plants out-of-doors, usually under intensive cultivation.

Nursery-grown Stock:

Plants which have been grown at least one full year in a nursery, under the supervision of competent gardeners or nurserymen so as to produce a number of even-sized superior plants for transplanting.

\section{Open Allee:}

A way framed on either side by symmetrical rows of closely planted trees or tall shrubs (of a height not less than twice the width between rows), and so maintained that both sides present a continuous vertical wall of close-growing foliage.

\section{Opening-up:}

In discussions on pruning this term means the cutting out of sufficient growth to admit the sunshine to the centre of the plant or to the area about a group of plants.

\section{Organic Manure:}

Manure consisting largely of decaying matter of animal or plant origin as distinguished from mineral manures which are inorganic. 


\section{Parasitic Plants:}

Plants growing on or deriving nourishment from other plants; e. g., mistletoe.

\section{Paring and burning:}

This operation consists of paring off the sod containing foul or objectionable growth to a depth of about two inches and after allowing it to dry burning it and spreading the ash over the ground.

Peat:

Decayed organic matter of vegetable origin naturally deposited under still water, hence found in the form of bogs. As it has been deposited under water and is usually found still under water, nitrifying bacteria are not present and peat is unavailable as plant food until mixed with soil in which nitrifying bacteria are present. Peat varies in colour from a pale brown or yellowish brown to almost black and in texture varies from a fibrous substance, containing particles easily recognized as plant remains, to a compact mass of fine particles which when still wet resemble clay except in colour.

\section{Perennial:}

Plants growing year after year. Properly includes trees and shrubs; but in practice the term is limited to those plants which have no persistent stem above ground, but do nevertheless grow year after year, merely dying back to a crown bud each fall and sending out new stems each spring. Perennial herb is the proper term to express this meaning.

Piedmont:

A region lying at the base of a mountain range.

Pleached Allee:

A way framed on either side by symmetrical rows of closely planted trees or shrubs, so maintained that the branches of the continuous walls of close-growing foliage arch and interweave across the top of the way at a height of not less than seven or eight feet.

\section{Pocket-planting:}

The planting of trees and shrubs in a pocket of fertile soil formed by digging a large hole in a more or less unfertile soil and refilling with fertile soil; frequently adopted to save expense of preparing beds and also to save unnecessary washing of an area of loose soil on slopes.

\section{Pollard:}

v. To remove the crown of a tree, usually at a point below the lowest branches, for the purpose of promoting a dense head of foliage or for rejuvenating the tree. 
Preparation, of planting beds:

This process normally includes plowing, spading, or grubbing, pulverizing the soil, applying manure and mixing with soil, and getting the beds into first-class condition to receive the plants. In clay soils it also includes removing clay to proper depth, and replacing with fertile topsoil.

\section{Propagation:}

To cause to multiply either by reproduction from seed or from cuttings.

\section{Puddling:}

The dipping of the roots of plants into a mixture of clayey soil and water having the consistency of molasses, in order to get close contact between root hairs and the soil. This protects the root hairs from injury in transportation, retards drying out of the roots, and promotes the acquiring of a speedy contact between roots and the soil into which the roots are placed.

\section{Quicklime:}

Unslaked lime. In planting, any lime not wholly slaked is called quicklime. See calcium oxide.

Refined Lawns, Gardens, etc.

Said of a studied landscape arrangement which shows neatness and careful maintenance as contrasted to a naturalistic arrangement which permits each plant to grow in unrestrained competition with the surrounding plants.

\section{Renovate:}

To systematically prune old plants, either trees or shrubs, but more especially shrubs, so that at the end of two or three years the plant consists almost entirely of new wood grown within that period. This may also mean to give new life to old plants by cultivating and fertilizing the soil and by systematic pruning of the plant itself.

\section{Retardation:}

The artificial application of cold temperatures or other conditions whereby the resting period is prolonged.

\section{Reversion:}

A tendency to revert to parental or ancestral characteristics.

\section{Root-bound:}

A term used in speaking of any plant whose root system cannot develop further because confined to a limited area. Thus, when the 
root system of a potted plant has filled the pot the plant is root-bound, or when the root system of stock planted in pockets has filled the pocket and the surrounding soil is so compact that the roots cannot penetrate it, the plant becomes root-bound.

\section{Root Prune:}

To prune or cut the roots of a plant in order to check excessive growth of the woody tops; often done to secure a compact root system consisting of a mass of fine roots confined to a limited area in order to permit of the plant being transplanted with a greater degree of certainty that the plant will continue to live (See Plate VI, Page 34). Sometimes done merely to permit of the plant being more easily fed and decrease the probability of the plant food being lost in the greater area of soil, or taken up by plants for which it is not intended.

\section{Root Stock:}

The subterranean runner or partially subterranean runner which is a part of the root system (not a part of the stem) which roots at intervals and sends up stems similar to a stolon. It is a part of the true root system, while a stolon is part of the stem.

\section{Rotted Manure:}

Organic manure in which oxidation is so nearly completed that no appreciable amount of heat is given off and much of the material is available as plant food.

\section{Runner:}

A slender stolon. (See Root Stock).

Rust:

A diseased condition caused by a rust fungus.

\section{Sanctuary:}

A place of refuge in which birds or animals may continue their normal habits without fear of being molested.

\section{Scald:}

A diseased condition of the bark of a woody plant caused either by the action of frost in bursting the cells or by excessive drying due to sun or wind action.

\section{Scion:}

Any bud or shoot or other portion of the stem of a plant capable of propagation cut off and prepared for grafting. 
Scraping tree trunks:

The process of scraping off the loose bark from the trunk of a tree.

The chief reason is to remove the hiding places of injurious insects.

Seepage:

The process of percolation, as ground water through the soil.

\section{Shothole:}

A small local centre of attack caused by parasitic fungi.

Shrub:

A woody perennial as distinguished from a tree mainly by its low stature and having several primary stalks arising at or near the ground.

\section{Slaked Lime:}

Is fresh burnt lime reduced to a fine condition by the addition of water.

Smut:

A diseased condition caused by a smut fungus.

Sod:

That stratum of earth which is filled with the roots of grass, herbs, etc.

\section{Sour Soil:}

An acid soil; a term generally applied to a soil which is not only acic but deficient in soil aeration and in drainage.

\section{Specimen Plant:}

A plant specially grown by itself so as to display it to best advantage or to allow the plant to assume normal and unrestricted growth.

\section{Spore:}

A minute portion of a fungus capable of germinating and growing into a new fungus.

\section{Sport:}

An unusual variation from the normal type as commonly demonstrated in habits of growth and qualities of colour or size of flowers.

\section{Sprigging:}

Planting of grass by inserting roots or whole plants in the ground as

Bermuda grass is generally planted. 


\section{Stagger:}

To plant alternately at equal distances in a row on either side of 2 middle line (as in the planting of hedges) or to arrange over any area at equal distances without any reference to any definite line.

\section{Stag-head:}

Said of a tree the top of which is dead or nearly so, due to injury by accident or disease.

\section{Stem:}

One of the three divisions of all plants, which consist of roots, stem, and leaves. The stem is the ascending axis of the plant.

\section{Stolon:}

A branch from the stem, as distinguished from the root system. A stolon roots, or is disposed to root, at intervals, thus forming a new plant.

\section{Stratify:}

To store seeds between layers of earth, leaves, or other material, or to bury them so as to keep them fresh and moist, but not so warm as to germinate.

\section{Straw Manure:}

Manure which contains a portion of the straw which was used for bedding. Chiefly applied to the manure from stables in which straw was used as bedding, as distinguished from stables in which sand, sawdust, shavings, etc., are used as bedding.

\section{Subsoil:}

That soil lying directly beneath the topsoil; chemically similar but physically different. Without special treatment it will not sustain vegetation, but on aeration will sustain some hardy plants most of which are vigorous weeds.

\section{Suckers:}

Adventitious shoots appearing on the roots or stems of plants. When they come on grafted plants, arising below the graft, they are of the same variety as the root, not the variety of the top.

\section{Suffocating Root Systems:}

A cause of abnormal loss among newly transplanted stock, especially the shallow-rooted type of trees, such as beech, maple, elm, and birch. The smaller feeding roots are deprived of properly aerated soil because of excessive depth of fill over the roots or because of compact clay soil 
being filled around the base of the trees during the transplanting operation.

\section{Sun-scald:}

An injury to the cambium layer of a plant caused by the heat of the sun's rays; also a burning of the leaves of certain plants.

\section{Suppressed Growth:}

Growth in shaded areas that has been retarded because of a lack of sunlight.

\section{Tamping:}

The operation of making firm and solid all earth filled around roots of newly transplanted stock. It helps to eliminate unnecessary air spaces.

\section{Tap-root:}

A long central root running deep into the soil.

\section{Tip-burn:}

The condition of the edge of leaves of plants caused by too luxuriant growth followed by excessive heat and drought.

\section{Topiary Work:}

The cutting and trimming of shrubs and trees, especially evergreens, into odd or ornamental shapes, thus producing an effect entirely different from that produced by the natural growing habits of the plant. (Birds, vases, urns, etc.)

Top-dressing:

A thin layer of manure spread over the surface of the ground, no attempt being made to work it into the soil.

Top-pruning:

The pruning of the top of a plant, especially the removal of the leader, to cause the plant to spread over a wider area and attain less height. Sometimes called "topping."

\section{Topsoil:}

A term applied to that part of the earth's surface which is tilled and consists of a soil ranging from a sandy loam to a clayey loam, containing the chief elements necessary to support vegetation, in a condition readily made available as plant food, and containing sufficient moisture to support plant life. Usually consisting of the top layer of virgin soil (four inches to eighteen inches deep). 
Is the result of the action of heat, frost, air, cultivation, surface or rain water, soil bacteria, etc. It is of finer particles than the subsoil, darker in colour, and looser in texture, and is rich in organic matter. A good topsoil, thoroughly dried, should contain 30 to 40 per cent. voids, when well shaken down in a box; that is 30 to 40 per cent. of its own volume of water should fill it to saturation but not increase the volume of the soil. It should contain from 40 to 60 per cent. of this amount of water to properly support plant life.

Training:

A procedure consisting principally of judicious pruning to adapt plants to limited areas or to form particular shapes, also to encourage the formation of flowers and fruit.

\section{Transpiration:}

The giving off of water vapour through the leaf pores of the plant.

\section{Transplanting:}

To remove a plant from one location and plant it in another location.

Tree:

A woody perennial, having a single main trunk.

Tree Pit:

A pocket or pit excavated to permit the introduction of sufficient fertile soil to support a tree; a common practice in planting street trees in city streets. The surface of the soil in the pit should be sufficiently lower than the surrounding area so that much of the rain falling on the surrounding area will flow to the pit, and the bottom of the pit must be well drained to remove excess water.

\section{Trench:}

v. To spade ground so deeply that the digging of ditches is necessary; hence to spade ground to two or more times the depth of a spade. In landscape work trenching is usually done for the purpose of saving good topsoil that has been buried under useless subsoil and also for the purpose of mixing manure and fertilizers into soil to a depth of one or more feet, especially in the vicinity of large trees and garden areas.

Turf:

The upper stratum of earth which is filled with roots of grass; sod. 

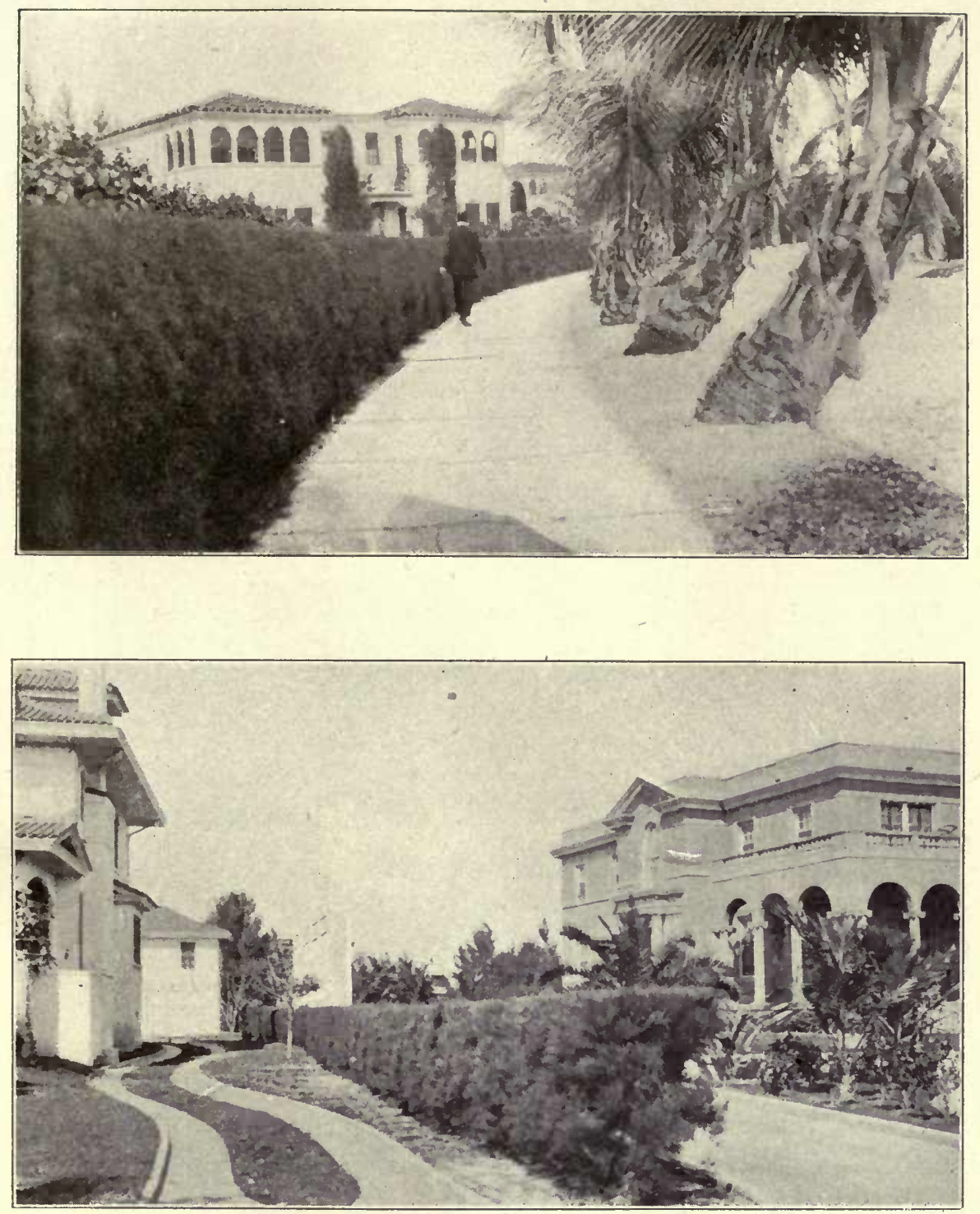

Plate LXII. Used as a tree for screen effects, specimen planting, or hedges, the Australian pine is throughout southern Florida one of the most freely used plants. (See page 3 Io, group XLIII-J) 


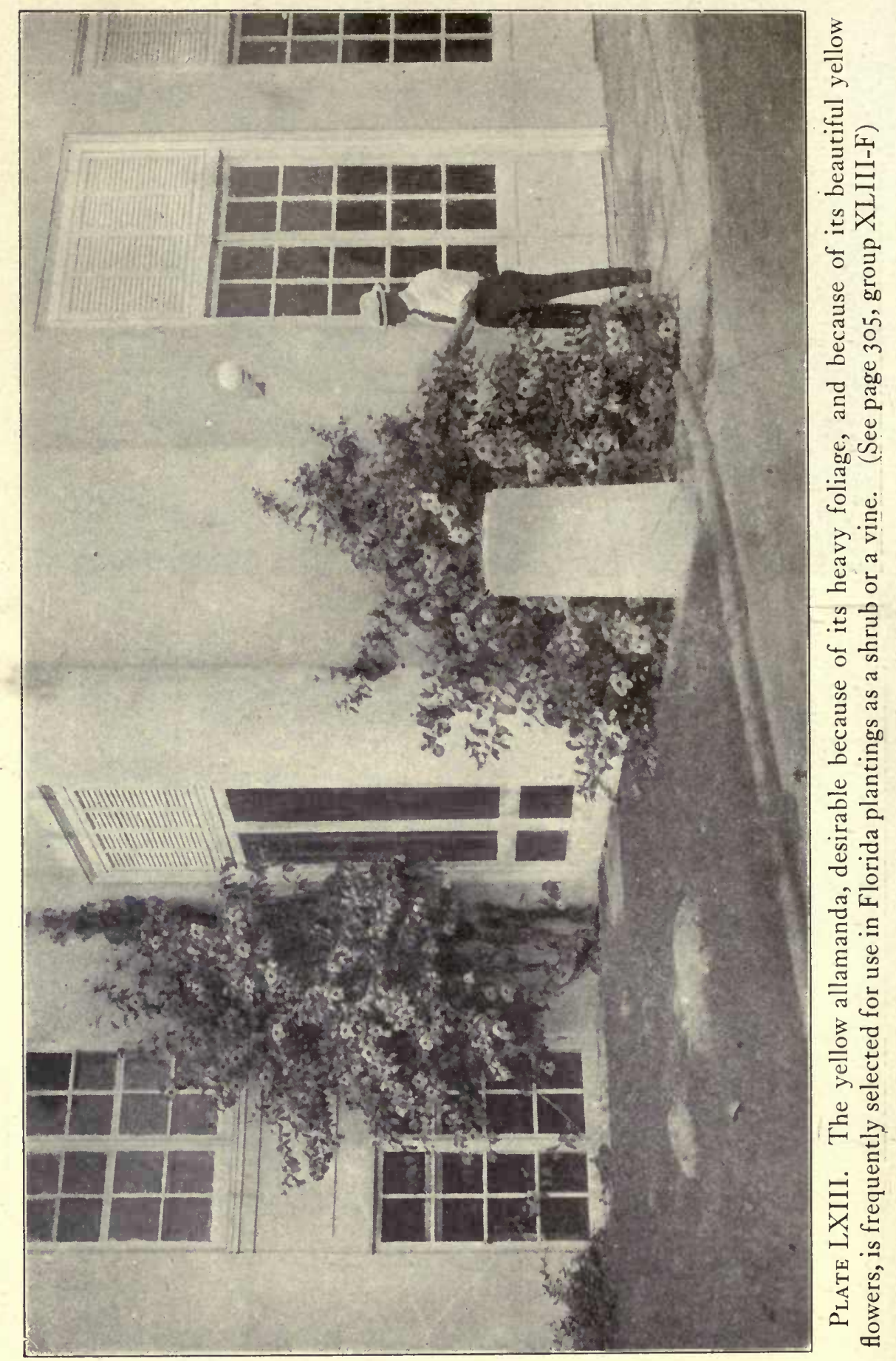


Vase Form:

In a plant, a manner of growth where the top springs from a single stem and spreads outward toward the top as the shape commonly taken by the American elm when growing in the open. For hedges see Plate V.

Vista:

A view or prospect; commonly through or along an avenue of trees.

Wall Garden:

A garden made by planting small plants in the crevices between the stones in a dry wall which is acting to support an earth embankment.

\section{Warm Soil:}

A soil in which temperature conditions are such that normal root growth is active, and the root fibres attach themselves to the minute particles of soil.

Water Garden:

A garden having a predominarice of water-loving plants, with pools to sustain them.

\section{Water-soaked Soil:}

A soil where excess moisture conditions cause the air voids to become clogged with water and air to be entirely excluded, thus causing a condition .termed "drowning-out" of root systems.

\section{Wild Garden:}

A garden on which little work has been done to disturb natural conditions, or a garden deliberately made to imitate natural conditions, the planting consisting chiefly of native plants, planted to get natural effects.

Wilt:

n. A parasitic disease generally caused by the anthracnose fungus.

Windbreak:

A planting composed of plants placed in such location as to shield certain areas from undesirable winds, usually the cold northwest winds of winter.

\section{Wind-burn:}

An injury caused by the drying effect of wind upon soft bark or leaves of a plant. 
Winter-killing:

The death of plants in winter due generally to sudden changes of temperature or to the ground becoming frozen too deeply.

Yellows:

A diseased leaf condition due to the breaking down or oxidizing of the plant leaf tissue caused by a ferment.

\section{Zone (Planting)}

An area characterized by a planting season of similar duration and dates for beginning and ending. 
INDEX

1 



\section{INDEX}

For the scientific names used in this book the author's authority is The Standard Cyclopedia of Horticulture and the Official Code of Standardized Plant Names, which latter has not been followed absolutely in every in. stance, though an earnest endeavor has been made to make the names conform to this nomenclature.

It has been necessary to invent a few common names as no book in common use furnished a satisfactory name for many of the less well known plants. Many of these common names were taken from Britton's Manual and from the excellent catalogues issued some years ago by the Biltmore Nursery. The botanicalor scientific names are indicated in italics. The group numbers refer to subdivisions of the table of contents.

\section{Aaron's Beard}

NAME

Aaron's Beard

Abelia chinensis
Chinese

Chinese

floribunda
grandiflora.

Himalayan

Hybrid

Mexican

trifiora

Abies (in variety)

balsamea

brachyphylla

concolor

concolor glabosa (spherical)

fraseri

grandis

nobilis

nordmanniana

veitchi

Abrus precatorius

Abyssinian Banana

Acacia armata

farnesiana.

Acalypha hispida

wilkesiana

Acanthus

Accent trees and shrubs

Acer (in variety)

campestre.

circinatum

ginnala.

macrophyllum .

palmatum and varieties

pennsylvanicum

platanoides

platanoides globosum

platanoides schwedleri.

pseudoplatanus

rubrum

rubrum drummandi

saccharinum

saccharinum pyramidale

saccharum.

saccharum monumentale

tataricum

Achillea boule de neige filipendula.

ptarmica flore pleno

tomentosa
Achyranthes, Narrow-leaved

Round-leaved

\section{Group}

28-B, 29-E-b, 29-H, 45-F-a

45-B-a

45-B-a

45-B-a, 45-F-b; 45-F-d

16-C, $22-\mathrm{C}-\mathrm{b}, 40-\mathrm{C}-\mathrm{b}, 43-\mathrm{E}-\mathrm{b}, 43-\mathrm{F}-\mathrm{a}$, 45-B-a, 45-F-d, 46-C-a, 46-H-b .

16-C, $22-\mathrm{C}-\mathrm{b}, 40-\mathrm{C}-\mathrm{b}, 43-\mathrm{E}-\mathrm{b}, 43-\mathrm{F}-\mathrm{a}$, 16-B-a, 45-F-d, 46-C-a, 46-H-b ? 45-B-a, 45-F-b, 45-F-d . . : : 45-B-a,

14-A-a, 42-D

9-C, 24-C-a, 28-A, 46-E

9-A, 9-B, 14-A-b, 16-D-b-2, 24-C-à

9-A, 9-B, 11-A, 14-A-b, 44-F, 46-H-a

9-E

46-H-a

$46-\mathrm{H}-\mathrm{a}$

9-C

9-A, 9-B, 24-C-a

43-C-a : * : : : : 302

${ }_{45-\mathrm{B}-\mathrm{C}}^{16} \cdot \dot{*}: \div \quad 146$

43-F-c, 43-J-b

43-E-a, 43-F-d, 43-I.

32-G-b-1

$31-\mathrm{M}-\mathrm{b}$

30-A, $3 \dot{0}-\mathrm{B}$

$12-\mathrm{A}-\mathrm{b}, 16-\mathrm{B}-\mathrm{b}, 16-\mathrm{b}-\mathrm{a}, 45-\dot{\mathrm{B}}-\mathrm{b} . \quad: \quad: \quad 124,145,146,321$

$46-\mathrm{C}-\mathrm{b}, 46-$

12-C, 22-A, 25-A, 26-B-a, 46-F 46-D

10-C, 12-C, 22-A, 23-A, 44-Cं-a.

14-A-a, 15-B, 22-B, 40-C-b, 44-G, 46-C-a

21,27

10-B, 22-C-a, 44-E-b, 46-D .

16-B-b

14-A-a.

46-D

19-A, 20-B, 22-A, 24-A-a, 24-C-á,

26-A-a, 38-C-b, 40-B, 43-B-a, 44-C-a, 46-F

10-C, $12-\mathrm{E}-\mathrm{e}, 23-\mathrm{A}, 40 \dot{-B}, 44-\mathrm{E}-\mathrm{b}$

12-C, 12-D, 14-A-b, 16-A, 16-D-b10-A, 22-A, 24-C-a, 28-A, 44-C-a, 44-E-a

14-A-b, 16-A, i6-D-b-i

12-C, 44-A-b

15-C, 31-B-f, 31-I.

31-D, 3i-E

29-A, 31-B-h

32-G-b-2, 35-B-c :

32-G-b-1 . :

$117,173,315,337$
Achyranthes

PAGE

$197,207,209,324$

320

$320,324,326$

$146,174,290,305,320$.

$326,336,339$

$146,174,290,305,320$

$326,336,339$

$320,324,326$

320

133,298

$113,182,196,337$

$111,112,134,147,182$

$111,112,119,134,316,339$

114

13

112,182

306,310

$305,307,309$

244

235

132

337,338

$125,173,186,191,338$

337

$117,125,173,177,314$

$133,139,173,290,316,336$

169,193

1175
133

133

$154,162,173,180,182,189$, $281,289,301,314,338$

281

$117,126,177,289,315$

$125,134,144,147$,

$116,173,182,196,314,315$

$134,144,147$

125,313

$139,224,232$

184

203,225

244,266

244 
NAME

Aconite, Winter

Aconitum (in variety) autumnale

nopellus

wilsoni

Acorus japonicus variegatus

Actaea (in variety)

alba.

Actinidia (in varjety) arguta.

Adam's Needie

Drooping-leaved
Early-flowering Late-flowering

Adaptation, Plants in general Evergreens

Adder's-tongue

Adenanthera pavonina

Adiantum pedalum

Adlumia cirrhosa

Adonis vernalis

Aegopodium podagraria.

Aesculus (in variety)

hippocastanum

hippocastanum rubicunda

octandra

parviflora

wilsoni

African Corn Lily

Agapanthus umbellatus

Ageratum (in variety)

houstonianum

Imperial Dwarf Blue

Imperial Dwarf White

Ailanthus altissim

Ajuga genevensis.

reptans
Akebia, Divided-leaved.

Five-leaved

lobata.

quinata.

Albizzia julibrissin

lebbek

Black

Dwarf

Smooth

Southern Dwar

Speckled

Woolly-leaved White.

Aleurites fordi

triloba

Alisma plantago

Alkaline soils, Trees and shrubs for.

Alkanet

Caucasian

Italian

Allamande (in variety)

hendersoni

Henderson's : :

nerifolis

Purple.

purpurea

Vine

williams

William's

Yellow

Allee, Ope

Alleghany Stewartia

Alleghany Vine

Allium moly.
GrouP

Page

36-B

31-B-i, $31-\dot{N}, 45-\mathrm{I}$

70

31-H

31-G, 38-A

31-E .

45-J

31- C-a

24-B-C, 24-C-c, 34-C, 34-D, 34-E

25-C, 34-A.

45-L

18-A, 24-E, 29-B, 29-G, 31-B-f, 33-E-g, 37-A-c, 42-B-b, 43-I, 45-A-b, 45-B-a, 45-F-b $45-\mathrm{B}-\mathrm{b}$

18-A, 45

$45-\mathrm{F}-\mathrm{b}$

29-H், 36-B, 45-J

28-B, 29-D-b, 45-J

32-F-a

31-B-d, 45-I

$29-\mathrm{C}$

14-A-a, 19-B, $42-\dot{C}$

10-C, 11-A, 20-F.

46-D

$45-\mathrm{C}$

$14-\mathrm{B}, 19-\mathrm{G}-\mathrm{b}$

$45-\mathrm{C}$

36-E-a

16-C

$43-1$

32-A, 32-Bं, 32- $\dot{\mathrm{E}}, \quad 32-\dot{\mathrm{G}}-\mathrm{b}-2, \quad 35-\dot{\mathrm{A}}-\dot{\mathrm{a}}$, 35-A-C

32-G-a-2

$24-D$

10-B, 1i-A, 20-F, 23-A, $45-\dot{C}$

31-B-a

28-B, 29-A, 29-C : : :

28-B, 29-A, 29-C

22-C-b-2,24-C-c, 34-D, 44-G

22-C-b-2

22-C-b-2,24-C-c, 34-D, 44-G

43-B-a, 45-H-a, 45-K-a .

43-B-b .

$30-\mathrm{A}, 39$

24-A-a, 25-A

45-F-a

24-A-a $26-\dot{A}-c$

45-F-a

24-A-a, 26-A-c

45-F-c

45-H-a, 45-K-a

43-B-b.

31-L-b

24-D

24-E, 45-I:

24-E

$16-\mathrm{C}^{-2}$

16-C, 43-J-C

43-C-a.

43-F-c :

43-F-e

43-Fe

16-C, $43-J-\dot{C}$

43-C-a.

43-Ca.

43-F-c

16-D-b

14-B, 19-D, 19-G-b, 45-H-b.

$32-\mathrm{F}-\mathrm{a}$

36-B, 45-J.

$175,183,261,316$
236,329

231

231,279

229

23

227

197

$182,183,260,261$

187,260

187

$151,184,205,209,225,253$, $277,297,310,321,320,325$

151,320

325

6

209. 271, 331

$197,206,331$

223,329

205

$133,155,298$

$117,119,167$

337

321

135,158

274

146

309

$240,241,242,244,264,265$

244

183

$117,119,167,177,321$

222

197, 203, 205

$175,183,261,316$

175

$301,327,331$

301

212,284

180,18

324

180,190

324,190

325

327,351

301

183

184,330

184

222, illus. 294

146,311

302

302

306

307

307

146,311

(1)

306 , illus. 375

147, illus. 190, 191

146

$135,156,159,329$

270,331 
NAME:

Almond, Flowering . Alnus (in variety) glutinosa ruposa serrulate

Alpine Plants

Alstroemeria chilensis

Alternanthera

Narrow-leaved

Round-leaved

Althaea officinalis

rosea

rosea alba

rosea-yellow.

Alyssum (in variety)

argenteum

Lilac Sweet

maritimum.

maritimum Lilac Q́ueè

maritimum Little Gem

maritimum variegatum

saxatile.

saxatile compactum

saxat

Sweet

Variegated-leaved Sweet

White Sweet

Amanita muscaria

phalloides

Amaranth, Giobe

Amaryllis.

Amelanchier (in variety)

canadensis

oblongifolio

rolundifolia

Amorpha (in variety)

canescens

ruticosa

Ampelopsis aconitifolia.

engelmanni.

Engelmann'

heterophylla

quinquefolia

triscuspidata lowi

triscuspidala veilch

Anagallis (in variety)

italic

.

mysotidifiora

Andromeda

Anemone coronaria

japonica

nemorosa

Dennsylvanica

Poppy-flowered

sylvestris

White Wood

Angelica Tree

Five-leaved

Annual Meadow Grass

Annuals

Carpet Bedding, annuals for

Cut flowers, valuable for

Design Bedding, annuals for

Difficult to transplant

Early blossoming

Ground cover, sown for .

Planted in several sowings to

insure succession of bloom.

Started indoors to produce good bloom before frost

Transplanting of

Vines

Delicate foliage.

Heavy foliage

Anthemis (in variety)

tinctoria kelwayi

Antigonon leplopus

\section{Grour}

13-A-b, 14-B, 19-E-a, 44-G

30-A

24-A-a, 25-A

24-A-a, 26-A-c

24-A-a, 26-A-c

15

32-G-a-

32-G-a-1

32-G-a-1

45-J

31-B-g, 31-E, 31-N

43-I, 45-I

$15-$

32-G-a-2

29-I, 32-A

32-B, 32-G-a-2

32-G-a-1

31-B-d .

15-C, 29-A.

29-I, 32-A 32-B

32-G-a-1

$32-\mathrm{G}-\mathrm{a}-2$

38-A

32-A

43-I

20-D-a, 22-B, 41

13-B-C

17, 19-A, 26-B-a, 27

13-A-b, 17

$45-J$

18-B

13-B-b, 19-H, 42-A-b

25-C, 29-E-c, 34-D, 34-E

34-B, 46-G

34-B, 46-G.

25-C, 29-E-C, 34-D, 34-E

29-E-c, 34-C, 34-D, 43-C-a, 26-A-c 44-C-b, 45-A-b 34-B

$34-B, 4 \dot{5}-\mathrm{A}-\mathrm{b}, \dot{4} 6-\dot{\mathrm{G}}$

$32-\mathrm{B}$

45-I : : :

24-E, 3i-B-a, $\dot{31-\dot{H}}$

24-E

26-A-c

18-A, 33-E-b

45-I

31-A, 3i-B-j, 31-B-k, 31-F, 31-í, 31-I,

$31-K-a, 40-B$ 40-C-a

15-C, 28-B, 31-B-b, 31-C-a, 40-A

$45-\mathrm{I}$

31-B-b .

24-C-b, 42-B-b

. . . . . 182, 297

129,17

38-C-a . . . . . . . . 281

32

$32-\dot{G}$

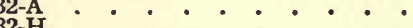

$32-\mathrm{C}: \div: \div: \div: 241$

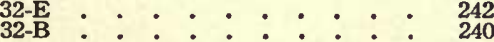

32-D . . . . . . . . 241

32-E • . . . . . • • . . 242

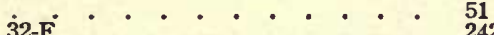

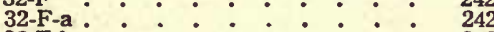

$32-\mathrm{F}-\mathrm{b} \cdot \div \cdot \div \cdot \circ 242$

$37-\mathrm{B}-\mathrm{b}, 3 \mathrm{i}-\mathrm{b}, \dot{3} 1-\dot{\mathrm{D}}, 31-\dot{\mathrm{H}}, 3 \dot{1}-\mathrm{K}-\mathrm{c}, 45-\dot{\mathrm{I}} 22$

43-C-a, 45-L 302, 332
PAGE

, 135, 157, 317

80,186

190

0,190

6

43

243

229, 236

5

09,329

10,240

241,244

39,203

$10,240,241$

244

279

240

$65,173,293$

$149,154,191,193$

129,149

331

$30,159,297$

$23,207,261$

60,338

$87,207,261$

$65,173,182,187,190,207$. $60,261,302,314,319$,

60

319,338

30

$84,222,231$

84

51,252

$21,226,230,231,232,233$

89 , illus. 303

$39,197,222,227,289$

1

illus. 287,334

1

0

2

2

$225,229,231,234,330$

02,332 
NAME

Antirthinum (in variety) majus

majus nanum

Aphananthe aspero

Apple

Aquatic Plants

Aquilegia (in variety) caerulea

caerulea hybrida

canadensis

chrysantha.

formosa hybrida

hybrida Rose Queen

hybrida.

nivea grandiflota

oulgaris.

Arabis (in variety)

albida.

alpina

Aralia (in variety).

pentaphylla

racemosa

spinosa.

Araucaria excelsa

Arborvitae

American

Columnar Oriental

Compact

Douglas'

Dwarf

Elwanger's

Fastigiate

George Peabody's Golden

Globe

Hovey's

Japanese

Little Gem.

Oriental

Pyramidal

Pyramidal Oriental

Rosenthal'

Tall Pointed

Tom Thumb

Vervaene's.

Western

Woodward's Dwaif

Arbutus, Trailing menziesi

$$
\text { unedo }
$$

Arctotis grandis

Arctostaphylos uva-ursi

Arctostap

crenulata

crenulata rubra

Scallop-leaved

\section{revaluia.}

Arenaria caespilosa

montane

Argemone (in variety)

Argentine Monkey's Comb

Arisaema iriphyllum.

Aristolochia elegans sipho

Armeria (in variety)

maritima

maritima alba.

maritima laucheana

Arnalto

Aronia (in variety)

arbutifolia

melanocarpa

Arrowhead,-Giant

Arrow-wood

Downy-leaved.

Artemisia (in variety)

abrotanum

dracunculus

frigida

lactiflore

sericea
Grour

PAGE

35-A-a, 35-A-b

31-J, 32-A, 32-E, 32-H-b; 45-I

32-H-a .

45-H-a

39

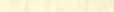

31-A 31-I, 31-K-a, 3i-N, 40-A, 45-I

31-H

31-B-a $3 i-B-\dot{c}, \dot{3} 1-\dot{C}-a$

31-B-d, 31-H .

31-B-c

$31-\mathrm{F}$

31-B-b .

31-C-a .

29-F, 3i-B-b, 37-A-c

24-E, 29-A, 29-F, 31-B-b

24-C-b, 42-B-b

13-A-b, 22-C-b-1

$28-$

11-B, 20ं-B, 43-F-a, 45்-H-a

43-B-b

12-A-a, 14-A-a, 30-A, 39, 42-E

9-B, 9-D, 24-A-a, 24-C-a, 44-F

14-A-b.

9-E

9. A

9-E

9-E, 12-B

9-A

9-A, 9-E், 12-B, 18-A

9-E

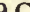

9-A, 9-E், 18-A

9-B, 16-D-b-2, 45-B-a, 45-D

9-A, 14-A-b, 16-A, 16-C

\section{5-E}

9-A $, 9-\dot{B}, 16-\dot{D}-\mathrm{b}-\dot{2}$

$9-A$

12-B

9-A

16-D-b-2

29-A, 30-A, 33-E-b, 37-A-c, 40-Cं-a 46-H-b

45-G, 45-K-b : : : : : : :

$32-A$

28-A, 29-B, 29-E-a, 33-E-b, 46-B-á.

45-F-b

45-G, 45-K-b

45- $\mathrm{F}-\mathrm{b}$

45-G, 45-K-b

43-D

29-B

15-C, 24-E.

45-1.

38-C-a

43-C-a

34-A, 34-C, 34-E

31-K-b, 45-J

29-A, 29-F, 29-G

31-B-b .

31-B-C

43-D

20-D-a

13-B-b, 24-A-a, 28-A, 29-H

13-B-b, 24-A-a, 28-A, 45-F-c

31-L-b

19. $22,0^{\circ} \mathrm{A}$

27

42-B-b, 45-i

24-E, 27-B-b

37-B-b

38-C-a

31-B-f, 31-B-j. 37-A-c
264

$233,240,242,246,330$

245

34 , illus. 318

$221,232,233,236,289,330$

231

$139,223,227$

223,231

223

223

230

227

331

208, 222, 276

$184,203,208,223$

139

182,297

129,17

197
120,

$120,162,305,327$

$124,134,212,284,298$

$113,180,182,316$

135

114

112

114,125

135

112

$112,114,125,151$

114

$112,114,151$

$113,147,321,322$

$112,135,145,146$

323

$112,113,147$

112

125

112

147

$204,212,253,277,290$

339

327,332

$196,204,206,252,336$

32

327. 332

324

327,332

304

139,184

139,
330
303

279

302

260,261

$204,208,209$

223

304

165

$130,180,196,209$

$130,180,196,325$

234

$156,173,190,193$

193

297, 330

184,277

277

$224,226,276$ 


\section{NAME}

Artemisia stelleriana. Artobotrys odoratissimus Aruncus sylvester

Arundo donax

Asarum arifolium canadense virginicum

Asclepias incarnata

$$
\text { ubra }
$$$$
\text { tuberosa }
$$

Ash American Mountain Biltmore

European Mountain

Mountain

Pyramidal Mountain. Oak-leaved Mountain Red

Silver-leaved White

Water

White

Ash Trees

Asiatic Creeper

Asimina triloba

Asparagus Fern .

Asparagus sprenger:

Aspen, Trembling

Asperula hexaphylla. odorata

Aspidistra lurida Tall Evergreen

Aspidium acrostichoides. cristatum goldieanum. marginale

Aspienium ebeneum flix-foemina trichomanes

Assonia natalensis Pink

punctata

White

Asier (in variety)

acuminatus

Bog

Bog

corymbosus.

ericoides

Hardy

Hardy Garden

nemoralis.

novae-angliae

novae-angliae Climax.

novi-belgi

patens

Sharp-leaved

Spreading .

Starwort

Stokes

White Heath

Wild

Woody

Astilbe biternata

davidi

grandis

Japanese

japonica

Large-flowered

\section{Asystasia bella}

Atropa belladonno

Aubrietia deltoidea

deltoidea graeco

Aucuba japonica.

japonica latimaculata . japonica variegata.

Australian Pine
GrouP

24-E

43-F-C

31-B-f, 31-Cं-a, 31-L-c • • • 306

31-E 229

45-A-a . . . . . . . 319

209

45-A-a . •,$\quad . \quad 319$

31-L-c • • • • • • • • • • 234

31-C-a, 45-i : $: \cdot: \quad: \quad 227,330$

25-A, 44-E-b . . . . . . . . 186, 315

45-C

10-C, 20-B. * • • •

20-D-b, 42-C . . : :

14-A-b". 135

14-A-a, 16-D-b-1 . . . . . 134, 147

45-H-a . . . • . . . . 328

45-H-a 328

45-C

22-B, 24-A-a, $25-\dot{A}^{\circ}, \quad 44-\mathrm{C}-\dot{b}, 44-\dot{\mathrm{E}}-\mathrm{a}^{\circ} \quad$ 173, 180, 186, 314, 315, 337 46-D

10-B, 11-A, 39

25-

20-A . . . . . 162

35-A-c, 35-B-a . . . . . . . 265,

35-A-c, 35-B-a 265 ,

21 • • • • • • • • • • 170

31-C-b . . . 228

29-A, 29-F, 37-A-C, 37-B-b : : : : 204, 208, 276, 277

35-B-C

28-B, 29-D-a, 29-D-b, 33-E-b : $\quad$ - $\quad 197,206,252$

29-D-b

$\cdot \cdot 206$

28-B, 29-D-a, 29-D-b, 3i-C-b : $\quad \cdot \quad \cdot \quad 197,206,228$,

29-D-a . • . . . • . 206

$29-\mathrm{D}-\mathrm{b} \cdot \dot{*} \quad \cdot \quad \cdot \quad \cdot \quad \cdot \quad \cdot \quad \cdot \quad \cdot \quad 206$

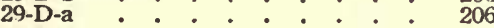

43-F-a • . . . . . . . . . 305

43-F-b • • • • • • • • • 306

43-F-a 305

30-A, 31-A, 31-B-i, 3i-B-j, 31-B-k, 212, 221, 226, 229, 230, 234, 31-E, 31-F, 31-L-c, 31-M-b, 39 . . 235, 284 28-B

31-I, 43-I :

197

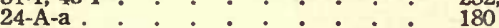

28-B, 3i-C-a $: \div \quad 197,227$

28-B, 31-C-a : : : : : : 197, 227

29-B, 31-C-a, 38-C-a $\quad$ - $\quad 204,227,280$

30-A, 31-B-j, 31-E, 31-F, 31-L-c : .

31-K-c, 38-C-a

24-A-a .

31-K-c, 38-C-a 234,280

31-H, 31-I, 43-I : • . . . 232, 309

$31-\mathrm{K}-\mathrm{c} . \quad . \quad . \quad . \quad . \quad . \quad . \quad . \quad 234$

28-B • • • • • • • • • • 197

$28-\mathrm{B} \cdot \cdot \cdot \cdot \cdot \cdot \cdot \cdot \cdot \cdot 197$

28-B, 3i-C-a

• • • • • • 197,

30-A 212

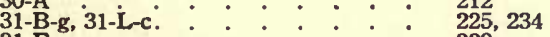

31-E

12-B, 19-C, 31-B-f, 3i-I . . . .

12-B, 19-C, 31-B-f, 31-I : :

31-E . . . . . . . . . . 229

43-F-e $\quad 207$

38-A . . . 279

29-F, 33-E-b $\quad \cdot \quad \cdot \quad \cdot \quad \cdot \quad \cdot \quad+\quad 208,252$

31-B-a . . . 222

16-C, 45-F-b, 45-G, 45-H-b, 45-K-b, 146, 324, 327, 329, 332, 335, 46-A-b, 46-H-b

45-F-b

$45-\mathrm{H}-\mathrm{b}$

43-A, 43-B-b, 43-j-a . . . . $301,302,310$, illus. 374 
Autumn Colouration

\section{NAME}

Autumn Colouration of Leaves Early :
Late
Coloured foliage
Green foliage
Shrubs
Vines :

Autumn flowering

Perennials.

Shrubs

Orang

Orange (Trees for)

Azalea (in variety) See rhododendron

amoena.

arborescens

canescens

Carolina

Crimson Evergree

Flame-coloured

Fragrant Mountain

gandavensis

Hardy Ėvergreen.

Hardy Indian

hinodigizi $i$.

Indian

indica

indica kaempferi

Japanese

japonice

lutea

Native

nudifiora

obtusa

Orange-flowered

Pontic

pontica

Smooth

Swamp

vaseyi.

viscosa.

Baby's Breath

Pink

Baby's Slippers

Baccharis halimifolic

Bald Cypress

Balm of Gilead

Ball of Snow

Balloon Flower

Balloon Vine.

Balsam, Garden

Bamboo Silver

Striped.

Bambusa (in variety)

argentea

disticha.

striata

Banana Shrub

Baneberry

White

Baptisia (in variety)

australis

tinctoria

Barbadoes Cherry, Ḋwarf

Barbadoes Flower Fence

Barberry (in variety)

Alleghany

Box-leaved.

Chilean,

Darwin's

Evergreen.
GROUP

PAge

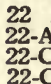

71 , illus. 247

173

173

173

174

174

175

$22-\mathrm{C}-\mathrm{b}-2$

226

31-B-k .

19-D 31-B-c, 31-D : : : : : : $\quad 156$

31-B-d : : * : : : : : 223

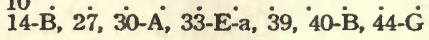

$135,193,212,252,284$.

$124,320,324$

$13-\mathrm{B}-\mathrm{b}, 37-\mathrm{A}-\mathrm{a}, \mathrm{*} \cdot \mathrm{:}: \quad: \quad 130,275$

$37-A-a, 45-F-a$

13-B-a, 19-A, 19-E-a, 45-F-a $130,154,157,323$, illus. 214

46-C-a

13-B-a, 19-A, 19-F-b $: \vdots \vdots \quad 130,154,158$

$37-\mathrm{A}-\mathrm{a}, 45-\mathrm{F}-\mathrm{a}$

45-F-a

45-F-a

12-B, $4 \dot{5}-\mathrm{B}-\mathrm{a}, 4 \dot{4}-\dot{\mathrm{F}}-\mathrm{b}$

45-F-b

275,323

323

$124,320,324$

324

$305,306,307,308,324,336$

43-F-a, 43-F-b, 43-F-d, 43-F-e, 43-F, 45-F-b, 46-C-a

43-F-a, 43-F-b, 43-F-d, 43-F-e, 43-H, 45-F-b, 46-C-a . 45-F-b

15-B, 19-B, 45-F-a

15-B, 19-B

13-B-a, 19-A, 19-F-b

45-F-a

27

13-B-a, 15-B, 19-A, 19-E-a, 24-B-b, 45-F-a

45-F-b

45-F-a .

45-F-a

13-B-b, 37-A-a

19-G-a, 37-A-a, 45-F-

13-B-a, 19-A, 19-E-a, 45-F-a

19-G-a, 37-A-a, 45-F-a

31-B-f, 31-I, 32-A, 32-C, 32-D, 43-I .

29-F

19-D, 26-A-c, 43-D, 45-F-c

14-A-a, 16-D-b-1, 24-A-a, 45-E, 45-H-a 14-A-b.

37-B-b

15-C, 3i-B-f, 31-I.

24-E, 31-B-e, 45-I

$32-\mathrm{F}-\mathrm{a}$

$32-\mathrm{A}$

43-E-a, 43-ì, 45-H-b

43-A

43-A, 45-H-b

43-A

43-E-a :

43-A

43-F-c, 45- $\dot{\mathrm{F}}-\mathrm{d}, 45-\mathrm{K}-\mathrm{b}$

45-J

31-C-a

31-M-b, 45-I

31-B-e, 31-H

31-B-d .

43-D

43-F-c, 43-F- $-\dot{d}, 43-J-b$

19-F-a, 20-B, 20-C, 20-D-a, 39

45-F-a - b, 46-C -a, 46-H-b

45-B-a, 45-F-d, 45-K-b

45-F-b, 46-C-a

$33-\mathrm{E}-\mathrm{b}, 45-\mathrm{F}-\mathrm{b}$
$305,306,307,308,324,336$

324

$139,155,323$

139. 155

$130,154,158$

323

$130,139,154,157,181,323$

324

324

323

130,275

$158,276,323$

$130,154,157,323$

158, 276, 323

$225,232,240,241,309$

241

$156,190,304,325$

$134,147,180,323,329$

135

$139,224,232$

$184,224,330$

242

$305,309,329$

30

301

309,329

301

305

301

$307,326,332$

331

235,330

224,231

223

307,310

$157,162,163,165,284$

323

$324,336,339$

$320,326,332$

324,336

252. 324 
Barberry, Fragrant Holly-leaved Purple-fruited.

Siebold's

Small-leaved

Thunberg's Japanese

Wilson's

Barren Strawberry

Barrenwort, American Japanese

Barriers, Plants for

Bauhinia (in variety) acuminata.

purpurea

purpurea triandra.

comentasa

Bayberry.

Bay Tree.

Beaked-rush, White"

Bean, Scarlet Runne

Bearberry

Bear's Breech

Beaumontia grandifiora White-flowered

Beauty Fruit.

Bedding Plants for design bed-

ding , Northern: : :

Beech (in variety)

American

European

Fern-leaved European

Beechdrop

Beechnut.

Begonia, Beddin

Cherry-red Bedding

rex.

semperfiorens, 'Triomphe de

Iorraine.

semperflorens, Vernon

(tuberous-rooted)

Tuberous

Belamcanda chinensis

Bellis perennis

Bending-road Planting

Benzoin aestivale.

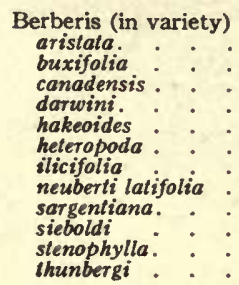

\section{wilsonae}

Berchemia scandens.

racemosa

Bergamot

Wild

Bergamot Berry

Bermuda grass planting

Berries, See Fruiting Plants

Betula (in variety)

albe
45-F-a

45-F-b, 45-F-d, 46-C-a, 46- $\dot{H}-\mathrm{b}$

45-F-a.

45-F-a

45-F-b, 46- $\mathrm{H}-\mathrm{b}$

$11-\mathrm{B}, 12-\mathrm{A}-\mathrm{b}, 12-\mathrm{B}, 12-\mathrm{E}-\mathrm{b}, 12-\mathrm{E}-\mathrm{c}$

12-E-d, 13-A-a, 16-B-b, 22-B, 24-C-b 26-A-c, 42-A-a, 43-E-b, 44-C-b,

46-A-a, 46-F
$22-\mathrm{C}-\mathrm{b}-1,45-\mathrm{F}-\mathrm{a}, 46-\mathrm{F}:$

15-C, 45-A-a, 45-J

$15-\mathrm{C}$

12-A

43-B-b

43-F-a

$43-\mathrm{F}-\mathrm{b}$

$43-\mathrm{F}-\mathrm{b}$.

13-A-a, 13-B-a, $18-B^{\circ}, 20-B^{\circ}, 20-C^{\circ}$ 20-D-b, 22-C-a, 24-B-b, 25-B, 26-A-c, 28-A, 29-E-a, 39, 40-C-a, 43-J-b, 44-G, 45-F-c

16-C, $45-\mathrm{F}-\mathrm{d}$

16-C. $45-1$

28-A, 29-B, 29-E-a, 33-E-b, 46-B-a.

31-M-b.

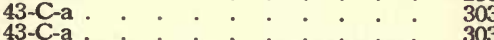

13-A-a, 13-B-a, 20-B, -43-F-e, 45-F-a, 126, 130, 162, 307, 323, 327, 45-G, 45-H-b .

32-H

. $\quad 245$

14-A-a, 24-C-a, 30-A, 39 .

12-A-b, 12-C, 21, 22-C-a, 40-C -a, 45-H-à $124,125,170,174,290,328$

$12-\mathrm{A}-\mathrm{a}, 12-\mathrm{C}, 12-\mathrm{D}, 16-\mathrm{D}-\mathrm{a}, 40-\mathrm{B}, \quad 123,125,146,289,291,316$ $40-C^{-b}, 44-G$

14-A-a

30-B

212

2-G-b-2 . 244

244

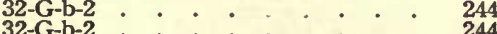

32-G-b-2 • . • . . . . 244

32-G-b-2 $: 244$

$35-\mathrm{A}-\mathrm{b}, 35-\mathrm{B}-\mathrm{b}: \div \quad 264,266$

35-A-b, 35-B-b . . 264, 266

$30-B, 45-J .212,331$

29-A, 29-F, 31-B-c, 3i-J,31-K-c : : 204, 208, 223, 233, 234

$18 . \dot{0} \cdot \dot{0} \cdot 150$

19-A, 19-F-a, 20-立-a, 27, 28-A, 30-A,

37-B-a, 40-B, 42-A-a, 44-G, 45-F-c .

19-F-a, 20-B, 20-C, 20-D-a . . .

45-F-a

$154,157,165,193,196,212$. $277,289,296,316,325$

$157,162,163,165$

323

$324,336,339$

324,336

$320,326,332$

323

$324,336,339$

326

252,324

323

$120,339,126,128,145,173$,

$182,124,126,128,145,173$,
$300,296,305,314,335$, 338

$174,323,338$

332

$225,233,277,331$

304,305

62 , illus. 41

$117,133,212,289,290$

10-C, 14-A-a, 30-A, 40-B, 40-C-a 25-A, 46-F 
NAme

Betula alba fastigiato lenta nigra papyrifera. populifolia.

Bibliography.

$B$ idens fro

Biennials

Bignonia capreolata chinensis

hybrida

radicans

speciosa

unguis-cat

$\mathrm{Birch}$ (in variety)

American White

Black

European White

Paper

Pyramidal White

Red

Yello

Birds

Attracted by fruits

Cover plants for

Fruits for

American

\section{Chinese}

Japanese

Bixa orellana

Blackberry Lily

Black Haw

Bladder-nut

American

Bladder Senna

Blanket Flower

Blazing Star . Bleeding Heart
Wild

Bloodroot

Bluebell

Blueberry

High-bush

Blue Flowers. Perennials Shrubs

Blue Lily-of-the-Nile Bluet

\section{Creeping}

Bocconia cordata

Boggy soils, Plants for

Boltonia, Aster-like asteroides Broad-scaled latisquama

Bombax ceiba.

Books, Bibliography of .

Border Planting.

Collected native shrub Low-growing shrubs Medium-growing shrubs Tall-growing shrubs Refined lawn areas Low-growing shrubs
Medium-growing shrubs Tall-growing shrubs

Botany, Books on

Bottle-Brush

Baugainvillea (in variety) braziliensis.
glabra sanderiana

\section{GrouP}

14-A-b, 16-A, 16-D-b-1

46-

22-A, 44-C-a

$21,22-A, 24-A-a$

$21,26-\mathrm{A}-\mathrm{a}, 44-\mathrm{E}-\mathrm{b}$
$21,25-\mathrm{A}, 26-\mathrm{A}-\mathrm{a}$.

30-B

31-J

43-C-b, 45-i

43-C-a, 45-L

45-L

29-E-c, 34-A, 34-B, 34-C, 34-E, 43-C-b, 43-C-b.

43-J-c

10-C, 14-A-a, 30-A, 39, 40-B, $40-\mathbf{C}-\dot{a}$, $21,25-\mathbf{A}, 2 \dot{6}-\dot{A}-\mathbf{a}$ 46-F

25-A, 46-F

21, 26-A-a, 44-E-b

$14-A-b, 16-A, 16-D-b-1$

21, 22-A, 24-A-a .

22-A, 44-C-a

$20-\mathrm{D}-\mathrm{C}$

30

20-D-a, 20-D-b

20-D-b, 24-B-c, 39, 45-G

20-B, 20-C, 25-C, 29-E-C, 34-C, 34-D, 44-B-b . . . . . . . 18-B, 29-E-c, 34-D், $46-\mathrm{G}$ 43-D

30-B, 45-J

16-B-b, 19-B, 27

42-B-a

13-B-c, 20-A, $20-\dot{B}, 2 \dot{8}-\mathbf{A}, 45-H-\dot{b}$

20-A, 45-H-b

19-F-b, 20-A, 20-B, 40-B, 41

29-G, 31-B-h, 31-D, 31-F, 31-I, 32-A 32-H-a, 43-I, 45-I

24-E, 31-C-a, 31-E, 31-G, 45-J.

31-B-c, 31-F, 40-A

15-C, 31-B-g

28-B, 29-C, 31-B-b, 31-C-b, $40-\dot{A}$

29-H, 31-B-a, 45-J

20-B, 20-D-a, 24-A-a, 30-A, 33-E-b 22-B, 24-B-b, 44-C-b

40-C-a .

31-B-a, 31-B-e, 31-B-i

19-H, 43-F-e

$16-\mathrm{C}$

29-H

45-A-a

15-C, 31-B-e, 31

31-B-f, 31-E, 31-K-c, 31-M-

24-A-a .

31-B-j, 31-E, 31-F, 3i-I

31-B-k,

31-B-k .

43-B-b

is

$13-\mathrm{B}$

13-B-a

13-B-b

13-A

13-A-a

$13-\mathrm{A}-\mathrm{b}$

3-A-C

43-F-d, 43-J-b

16-C, 43-J-C

43-C-a .
Page

$135,144,147$

(3)

173,314

$169,173,180$

$169,189,315$

$169,186,189$

343

212

233

303,332

303,332

33

$207,260,261,303,332,338$

303

117, 133, 212, 284, 289, 290,

illus. 190

$169,186,189$

338

186,338

$169,189,315$

$135,144,147$

$169,173,180$

173,314

166

166

165,166

$166,182,284,327$

$162,163,187,207,261,314$

332

$151,207,261,338$

145, 155,193

297

$131,162,163,197,329$

162,329

$158,162,289,293$

$209,226,229,230,232,240$, $246,309,330$

$184,227,230,231,331$

223, 230, 289

140,225

$198,205,223,228,289$

$209,222,331$

$163,166,180,212,253$

$173,182,314$

290

222, 224, 226

159,307

146

209

$139,224,232$

224, 229, 234, 235

180

$226,229,230,232$

226, 229, 230, 232

226

302

343

127

130

130

130

128

128

129

129

343

307,310

146,311

303

303 
NAME

Box, Dwarf

Golden Japanese . Handworth's Tree Tree

Victorian

Boxwood.

Brachycome iberidifolia Brambles.

Brickwork, Vines for

Bridal Wreath

Van Houtte's :

Brier, Lord Penzance Hybrid.

Broad-leaved Evergreens :

Broussonetia papyrifera.

Buckeye

Sweet

Alder

Carolina

Common

Sea

Buddleia (in variety)

${ }_{\text {davidi }}^{\text {Sweet-scented }}{ }^{\circ}$

veitchiana

Buffalo Berry

Canadian

Bugle$$
\text { Erect }
$$

Bulbs, Articles on Books on

Bulb Culture.

Characteristics of bulbs Depth for planting bulbs Fertilizers for bulbs

Forcing bulbs

Mulching bulbs

Reproduction of bulbs Soil and drainage requirements

Time for planting bulbs

Treatment after flowering

Bulbs, Discussion of uses for Best varieties for forcing

For forcing in soil

For forcing in soil

Narcissi for different location

Naturalizing in woodland and wild gardens

Refined lawn and garden areas

Tulip combinations

Cottage

Darwins.

Single

Bull Brier

Bulrush
Great

Great .

Burnet

Burning Bush

Cork-barked

Butomus umbellatus .

Buttercup

Butterfy Flower

Butterfly Weed

Butternut

Button Bush.

Buxus (in variety)

japoniea aurea.

sempervirens

sempervirens handworihi
suffruticosa
Grour

PAGE

12-B, 15-A, 45-B-a, 45-F-b

45-F- $\mathrm{b}$.

40-C-b, 43-E-b, 45ं-B-a

43-E-a.

16-B-a, 16-C, 37-B-a, 44-G, 45-B-a, 32-A, 32-E, 32-G-a-2

20-D-a, 30-A

13-A-b, 19-A, i9-Gं-b, 42-A-a, 45-F-c 12-D, 12-E-c, 12-E-e, 13-A-b, 17, 19-B, 19-G-a, 19-1, 24-B-b, 38-C-a, 42-A-a, 37-B-a

20-B, 20-D-b, 37-Bं-a

33-E-b

43-B-a, 45- $\mathrm{H}-\mathrm{a}^{\circ}$

43.

39 -

11-B, 20-D-b,

12-A-b

$12-\mathrm{C}, 2 \dot{7}, 2 \dot{8}-\mathrm{A}$

12-A-b, 12-D, 12-E-b, 12-E-d, 16-D-a

24-B-b, 25-B, 40-C-b, 42-A-a, 44-A-a

12-A-b. 12-E-d, 17, 20-B, 24-B-b,

26-A-c, 33-E-b, 42-A-a, 44-A-a . $31-\mathrm{H}, 45-\mathrm{F}-\mathrm{c}, 45-\mathrm{H}-\mathrm{b}$.

42-A-b .

19-D, 19-4, 37-A-a, 40-B

12-E-b, 12-E-d, 25-B, 26-A-c, 29-E-a : 28-B, 29-A, 29-C

28-B, $29-4$

$\div: \div: \vdots: \vdots:$

$\vdots: \vdots: \vdots: \vdots: \vdots:$

$\therefore: \vdots: \quad: \quad \cdot \quad \cdot \cdot$

$: \vdots: \vdots \vdots: \vdots: \vdots \vdots: \vdots 0$

. . . . . . . . . 6

. . . . . . . . . 66

$\cdot \cdot \cdot \cdot \cdot \cdot 68$

36-E $\cdot \bullet \cdot \cdot \cdot$

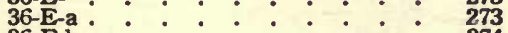

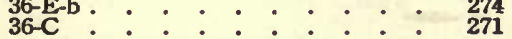

$36-\mathrm{B}$

36-A

36-D

$36-\mathrm{D}-\mathrm{d}$

$36-\mathrm{D}-\mathrm{b}$

$36-\mathrm{D}-\mathrm{a}$

25-C

31-L-b

15-A, 28-B, 29-C

37-B-b

13-B-c, 20-A, 20-B, 20-D-b, 22-C-a, 13-A-b, $14-\mathrm{B}, 1 \dot{0}-\mathrm{B}-\mathrm{b}, 20-\mathrm{B}, 22-\mathrm{C}-\mathrm{a}$ 13-A-b, 31-L-F

30-A

32-A, $32-\mathrm{E}$

31-C-a, 45-i

13-B-b, 20-A, 24-A-a 42-A-a 131, 162, 180, 296

13-B-b, 20-A, 24-A-a, 42-A-a
$16-\mathrm{B}-\mathrm{a}, 16-\mathrm{C}, 37-\mathrm{B}-\mathrm{a}, 44-\mathrm{G}, 45-\mathrm{B}-\mathrm{a}, \quad 131,162,180,296$ 45-F-b

40-C-b, 43-E-b, 45-B-a

45-F-d

12-B, 15-A, 45-B-a, 45-F-b

$197,203,205$
$124,138,320,324$

326

$290,305,320$

$145,146,277,316,320,329$

$240,242,244$

166,212

$129,154,159,297,326$

$25,126,129,149,155,158$,

277

$163,166,277$

301,327

284

120,166

$125,193,197$

$124,125,126,147,181,187$.

$124,126,149,163,181,190$, $253,296,313$ $232,325,329$

297, illus. 226

$156,159,276,289$

$126,187,190,207$

343

7, illus. 46

8

270 , illus. 351,366

270, illus. 350

272

272

272

187

234

$138,197,205$

131, 162, 163, 166, 174, 296

$129,135,145,162,173,338$

234

212

240, 242

324

$290,305,320$

$124,138,320,324$ 
NAME

Cabbage Palmetto

Caesalpina pulcherrima pulcherrima flava

Calaba Tree

Caladium.

Calandrinia umbellata

Calcareous soils, Lilies for

Calendula officinalis.

Calla palustris

Callicarpa (in variety) americana purpurea

Callistemon (in variety) lanceolatus

Callistephus chinensis

$$
\text { hortensis }
$$

Callitris robusta

verrucosa.

Calluna vulgar

vulgaris alba

Calonyction aculeatum

Calophyllum calaba

Caltha palustris

palustris flore pleno

Calycanthus floridus.

occidentalis

Camassia esculento

Camellia japonico

Campanula carpatica

carpatica alba

medium

medium calycanthema albo medium, pink

persicifolia.

persicifolia alba

persicifolia caerulea

pyramidalis

pyramidalis alba

Camperdown Weeping Elm

Camphor Tree

Campion, Autumn

Seaside.

Red

Camplosorus rhizophyllus

Canangium odoratum

Canary Bird Vine

Canby's Mountain Lover

Candile-nut

Candytuft

Evergreen

Rocket.

Canterbury Bell

Cape Jasmine

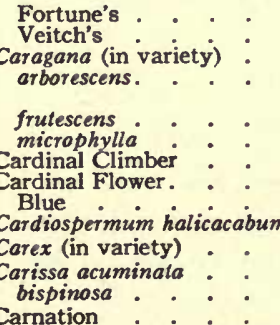

Carnation

Carpet bedding, Annuals for

Car pinus betulus betulus fastigiala betulus globosa. caroliniana.

Carya (in variety)

alba

equatica

myristicaeformis

myistic

pecan

\section{Grour}

PAGE

43-B-b $43-\mathrm{J}-\mathrm{b}$

43-F-c

$35-\mathrm{A}-\mathrm{b}, 35-\mathrm{B}-\mathrm{c}$

24-E

32-A, 32- $\dot{3}-\mathrm{a}$

$31-\mathrm{L}-\mathrm{b}$

44-G

43-F-e, 45-F-a, 45-G

13-A-a, 13-B-a, 20-B, 45-F-a, 45-H-b $43-J-b$

$32-\mathrm{H}-\mathrm{a}, 32-\mathrm{H}-\mathrm{b}$

32-A, 32-E.

43-B-b

43-A

26-B-c, $40-\dot{C}-b, 45-F-b, 46-\dot{C}-a$

$45-\mathrm{F}-\mathrm{b}$

32-F-b

$31-\mathrm{L}-\mathrm{b}$

$31-\mathrm{L}-\mathrm{C}$

13-B-b, 24-C-b, 27, 28-A, 37-A-a, 40-B, 43-F-d, 45-F-c, 46-C-b, 46-E 45-F-c

43- $\mathrm{F}-\mathrm{b}, 43-\dot{\mathrm{H}}, \dot{4} 5-\dot{\mathrm{B}}-\mathrm{a}, 45-\mathrm{F}-\dot{\mathrm{b}}, 4 \dot{5}-\dot{\mathrm{H}}-\mathrm{b}$ 15-C, 29-A, 31-B-e, 31-D

31-B-f

31-B-e, 31-J

31-B-f

31-B-g .

31-B-e .

31-B-1

31-B-e, $31-j$

31-B-f

14-A

43-A, 43-B-b, $43-\dot{E}-a, 45-B-a$

$15-\mathrm{C}$

$15-\mathrm{C}$

29-D-a, 29-F

43-B-b

32-F-a

$15-\mathrm{A}, 2 \mathrm{~A}-\mathrm{A}$

32-A, 32-B, 32-D, 32-G-a-2

15-C, 29-A, 29-F, 31-B-b, 31-M-a 33-E-b-2,

31-B-e, 31-B-f, 31-B-g, 3i-J

43-E-a, 43-F-a, 45-B-a, 45-F-b, 45-F-d, $45-\mathrm{H}-\mathrm{b}, 45-\mathrm{K}-\mathrm{b}$ 45-F-d

45-F-d

42-B-a .

12-E-b, 14-B, 19-B, 19-F-b, 24-B-b, 41.-A

$32-\mathrm{F}-\mathrm{b}$

31-B-g, 31-C-a, 31-L-c : . : . 225

31-B-e

30-b, 3i-L-B

43-D, 43-J-b

34-E-a

43-I

32-G

12-A-b, 16-A, 16-B-b, 16-D-a, 40-C-b

14-A-b

$16-\mathrm{B}-\mathrm{b}$

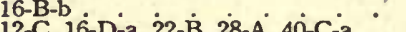

12-C, 16-D-a, 22-B, 28-A, 40-C-a .

40-C-a

$45-\mathrm{H}-\mathrm{a}$

$45-\mathrm{H}-\mathrm{a}$

38-C-a
302

307,310

307

265,266

184

257

240,245

234

16. illus. 230

$307,323,327$

$128,130,162,323,329$

310

245,246

240,242

302

$191,291,324,336$

324

242

302

234

$131,182,193,196,276,289$, $307,325,337$ 325

$306,308,320,324,329$

$139,204,224,229$

224

224,233

224

224

224

224,233

224

$301,302,305,320$

140

140

233

206,208

302

$138,181,197$

301

$240,241,244$

$140,204,208,223,235,253$, 140,
244

$224,225,233$

$305,306,320,325,326,329$, 336

326

297

$126,135,155,158,181,186$

293

227,235

42

212,234

304,310

305

309

243

$124,144,145,146,291$

135

$125,146,173,196,290$

290

173

327

328

280
328 
Caryopteris

NAME

Caryopter is incana

incana candida
Cassia corymbosa
fistula :
Yellow
Castanea (in variety)
Casuarina equisetifalia
Catalpa (in variety)
bignoniaides
bignoniaides nana.
bungei
Round-ieaved :
speciasa :
Western :
Catchfly :
Alpine :
Catesby's Andromeda
Catmint
Cattley Guava
Ceanothus americanus
hybridus :
Cedar
Blue Virginia:
Columnar Tufted:
Compact White

Compact White

Globe Red

Incense, - See Incense Cedar

Lebanon, - see 'Cedar of Lebanon.

Mt. Atlas

Mt. Atlas Silver

Pyramidal Red

Red

Rocky Mountain Silver

Schott's Red

Southern Red

Spreading Red

West Indian

White

Yellow

Cedar of Lebanon

Cedrela, Chinese.

odorata.

sinensis

Cedranello

Cedrus atlantica

atlantica glauca

deodara.

libani

Celastrus (in variety)

angulatus

orbiculatus

scandens

Celosia argentea.

Plumed
Celtis mississippiensis accidentalis.

\section{sinensis}

Centaurea americano

cineraria

cyanus.

imperialis

gymnocarpa

macrocep

Centranthus ruber

Century Plant

Cephalanthus occidentalis

Cephalaria tatarica

Cephalotexus (in variety)

drupacea

fortunei.

harringtoniana fastigiata Cerastium tomentosum

Ceratiola ericaides
Ceratiola

Group

PAGE

13-A-a, 16-C, 19-H, 31-B-i, 45-F-a, 31-B-j

45-F-c, 45-K-b

43-B-b

$43-\mathrm{B}-\mathrm{b}$.

30-B

43-A, 43-B-b, 4.3-j-a

$10-C, 19-\mathrm{C}, 20-\mathrm{F}, 39,42-\mathrm{C}, 44-\dot{G}$ 24-C-a

14-A-a, 16-A, 45-E, 45-H-a

14-A-a, 16-A, 45-E, 45-H-a

20-A, 23-A, 37-A-b

20-A, 23-A, 37-A-b

31-C-a.

29-F

28-A, 29-H; 33-E-b, 45-F-b

43-E-a

13-B-a, 18-B, 27, 28-A, 42-A-b

45-F-a

16-A, 44-D, 45-D, 45-E :

9-A, 16-A

45-D

9-E

43-B-b, 45-D

45-D, 45-K-a, 46-H-a

45-D

9-A, 9-D, 11-A, 12-C, 14-A-a, 16-A 20-D-b, 24-B-a, 25-A, 26-A-b, 29-E-a, 38-C-a, 43-J-a, 44-A-a, 44-D, 45-B-a 9-A

9-A, 14-A-b, 16-A, 16-D-b-2, 45-E

43-E-a

18-A-B-b

24-A-a, 45-E

16-B-a, 46-H-a

43-B-a, 45-D, 45-K-a, 46-H-a $\quad \vdots \quad \vdots \quad 301,322,331,339$

45- $\mathrm{H}-\mathrm{a}$

43-B-b

$45-\mathrm{H}-\mathrm{a}$

45-D, 45-K-a, 46-H-a $\quad: \quad \vdots \quad: \quad 322,331,339$

43-B-a, 45-B-a, 45-D, 45-E, 45-K-a, 46- $\mathrm{H}-\mathrm{a}$

46-H-a $\dot{-1}-\dot{\mathrm{K}} \cdot 46-\mathrm{H} \cdot \cdot \cdot$ 20-D-b, 24-B-c, 45-G.

45-L

18-B, 28-E-c, $34-\dot{D}, 46-G$

20-B, 20-C, 25-C, 29-E-c, 34-C, 34-D, 44-B-b

32-H-b

10-B, 11-A, $20-\mathrm{D}^{\circ} \mathrm{a}, 20-\mathrm{F}^{\circ} 2 \dot{6}-\mathrm{B}^{\circ} \mathrm{a}$,

$43-\mathrm{B}-\mathrm{a}, 44-\mathrm{C}-\mathrm{a}, 44-\mathrm{E}-\mathrm{a}, 45-\mathrm{C}^{2}$. $45-C$

32-G-b-i

2-G-b-1

32-A, 32-C, 32-D, 32-H-a, 38-C-a :

$32-\mathrm{A}$

$32-\mathrm{G}-\mathrm{b}-\mathrm{i}$

31-B-h

15-C, 3i-B-e, 31-1

45-

13-B-b, 20-A, 24-Aं-a, 42-A-a $\quad: \quad: \quad 131,162,180,296$

31-B-h, $20-\mathrm{A}, 24-\mathrm{A}-\mathrm{a}, 42-\mathrm{A}-\mathrm{a}: \vdots: \vdots 225$

9-C $: \cdot \div: \vdots: \vdots: 113$

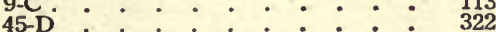

45-D, 45-H-a $\vdots \vdots \vdots \vdots \vdots \vdots \vdots 322,328$

15-C, $24-\mathrm{E}, 29-\mathrm{B}, 29-\mathrm{F}, 29-\mathrm{G}, \dot{31}-\dot{\mathrm{B}}-\mathrm{b}$;

31-H, 31-M-a , 29 , $29-\mathrm{C}, 31-\mathrm{B}-\mathrm{b}$

45-A-b.
$128,146,159,226,323,329$

325,332

$301,302,310$

182

$33,144,322,328$

(4), 322, 328

$62,177,276$

62, 177,276

$96,209,253,325$

40,184

$130,151,193,196,297$

, illus. 78

$144,314,322,323$

111,144

114

302,322

$22,331,339$

35

$11,113,119,125,133,144$, $310,313,314,320$

111 ,

$1135,145,147,323$

151

180,323

02

$301,320,322,331,339$

166 ,

151, 207, 261, 338

$162,163,187,207,261,314$

246

246

$117,119,165,167,191,301$, 321

$240,241,245,280$

240

244

$39,224,232$

322

$139,184,204,208,209,223$, 319
$301,322,331,339$ 


\section{NAME}

Ceratostigma plumbaginoides Cercidiphyllum japonicum . Cercis canadensis

\section{Cereus triangularis \\ Cereus Vine \\ Cestrum aurantiacum elegans \\ Chaenomeles japonica \\ sinensis \\ Chalcas paniculata \\ Chalice Vine \\ Chalk Plant \\ Chamaecyparis (in variety). eticoides \\ lawsoniana. \\ nootkatensis \\ obtusa \\ obtusa nana \\ obtusa nana aurea. \\ pisifera. \\ pisifera filifera. \\ pisifera plumosa \\ pisifera squartosa \\ thyoides \\ Chamaedaphne calyculata \\ Chamomile \\ Chaste Tree \\ Cheiranthus allioni cheiri \\ Chenille Plant \\ Cherokee Rose \\ Cherry \\ Carolina Laure. \\ Cornelian}

European Double-flowering

Evergreen

Hybrid European Bird

Hybrid

Japanese Flowering

Japanese Pink-flowering

Japanese Weeping Roseflowering

Rose-pink Flowering

Sand

Weeping

Western Sand.

Wild

Wild Black

Chestnut

Chinese Flowering

Chickweed

Chilopsis linearis saligna

Chimaphila maculato umbellata

Chimney Bell-flower

China Aster

Chrysanthemum-fiowered

Early Half-dwarf Late-flowering Quilled

China Wood-oil Tree

Chinese Pine

Chinese Sweet Shrub

Chiogenes hispidula

Chionanthus retusa

virginica

Chionodoxa (in variety). luciliae

Chokeberry

Black

Red

Christmas Berry

Christmas Rose
Group

Page

15-C, 29-F, 31-B-i, 31-M-a

14-A-a, 16-A, 22-A, 45-E

11-A, 13-A-c, 14-A-a, 19-A, 19-E-a, 22-A, 40-C-a, 41, 42-A-a, 43-B-a, 44-G

43-C-a

43-F-c

$43-F-b$.

- 307

12-A-b, 14-B, 19-A. 19-I, 22-C-b-1, $41^{\circ}$,

$43-\mathrm{F}-\mathrm{b}$ 45-F-c

43-D $43-\mathrm{F}_{-\mathrm{a}} \cdot \mathrm{C}^{\circ} \cdot \mathrm{C}^{\circ} \cdot$

43-D, 43-F-a

43-C-a

14-A-a, 42-E, $\dot{\text { A4-G, }}$ 45-B-a, $46-\dot{\mathrm{H}}-\mathrm{a}$

$45-n$

9-C, 14-A-b, 45-D, 45-E, 46-A-b, 46-H-a 16-B-a, 46-H-a

9-A, ${ }^{15-\mathrm{B}}, \mathbf{1 6}-\dot{\mathrm{B}}-\mathbf{a}$.

9-E, 15-A. 16-B-a.

9-E, 15-A

9-B, 45-D

9-C, 12-A-a, $4 \dot{5}-\mathrm{D}$

9-B

24-A-a, 45-E

18-A, 26-A-c, 29-H, 33-Eं-b

37-B-b

16-C, $19-\mathrm{D}, 19-\mathrm{H}, 40-\mathrm{B}, 45-\dot{\mathrm{H}} \mathrm{b}$

24-5

32-E, 37-A-C

43-E-a, 43-F-d, 43-I

43-C-a .

20-D-a, 39

43-E-a, 45-B-a, 45-H-b, 4 45-ं்-b 12-D, 19-F-a, 24-B-b, 27, 41, 44-G,

17 -

$41,42-\mathrm{B}-\mathrm{a}, 44-\mathrm{G}$

$14-\mathrm{A}-\mathrm{a}, 24-\mathrm{B}-\mathrm{a}$

14-A-a,

19-A, 19-E-a, 33-க்

33-C

33-C

26-B-a

14-A-a.

19-E-a

$30-A$

26-A-a, 38-A

30-B, 39

$19-\mathrm{C}, 42-\mathrm{B}-\mathrm{a}$

30-A, 30-B.

45- $\mathrm{H}-\mathrm{b}, 45-\mathrm{K}-\mathrm{b}$

45- $\mathrm{H}-\mathrm{a}$

28-B, 33-E-b

33-E-b

31-B-e, 31-B-f, 31-J

32-A, 32-E.

32-H-b

42-H-a

32- $\mathrm{H}-\mathrm{b}$

32-H-a

45-H-a, 45-K-a

43-B-a.

45-F-a

33-E-b . . . . . . . . . 252

14-B. 135

$3-B-c, 14-B, 17,19-B, 19-G-a, 20-B$

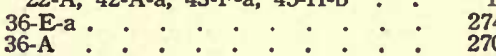

20-D-a.

13-B-b, 24-A-a, 28-A, 45-F-c

3-B-b, 24-A-a, 28-A, 29-H

29-A, 31-B-b, 31-F, 33-E-b, 38-A
$140,208,226,235$

$144,173,322$

$19,129,133,154,157,173$ 303 303

307

306

$124,135,154,159,174,293$, 325

304,306

303

330
133,

$133,298,316,320,339$

$113,135,322,323,335,339$

145,339

$111,112,145$

114,138

113,322

112,322

$113,123,322$

112

180,323

$151,190,209,252$

277

$146,156,159,290,329$

242, 276

$305,307,309$

303

165, 284

$305,320,329,332$

$125,157,181,193,293,316$ 336

329

$293,297,317$

133,181

154, 157,250

250 , illus. 223

250

191

133

12

189,279

212,284

212,213

329,332

328

197,252

224, 233

240,242

246

16

245

327,331

135

$131,135,149,155,158,162$,

174

270
165

130, 180, 196, 325

$130,180,196,209$

328

$204,223,230,253,279$ 


\section{NAME}

Chrysanthemum (in variety)

coronarium

coronarium flore pleno

Double Summer

Glory of Seven Oaks

Hardy

indicum

leucanthemum

maximum

maximum Kंing Edward

parthenium aureum

parthenium glaucum

Pompon

shasia daisy

Summer

Cicuta maculato

Cigar Plant

Cimicifuga racemosa

Cineraria maritima

Cinnamomum camphora.

Cinquefoil, Evergreen

$$
\text { Shrubby }
$$

Circassian Bean

Cistus laurifolius

Citrus deliciosa

grand is

japonica,

sinensis

irifoliato

City conditions and effect on plants

Cladrastis (in variety)

$$
\text { lutea }
$$

Clarkia, Broad-leaved Clustered-flowered elegans

pulchello

Clay soils

Claytonia virginico

Clematis

apiifolio

crispa

davidiana

Herbaceous

Japanese

montana

montana rubra.

paniculata

Parsley-leaved

Purple

recto

Red

Texas

texensis

viorna

virginiana

White

Clerodendron siphononthus squamatum.

Scarlet .

thompsonae.

Clethra acuminat alnifolia

\section{tomentosa}

Cleyera

Himalayan japonica

Climbing Roses, Best types of.

Climbing Vines

Closed Gentian
Group

PAGE

31-A, 31-B-j, 31-B-k, 31-B-1, 31-F, 31-1, 221, 226, 227, 230, 232, 233, $31-\mathrm{K}-\mathrm{a}, 39,40-\mathrm{B}, 43-1$. $\quad 284,289,309$

32-A 32-G-b-2

$32-\mathrm{G}-\mathrm{b}-2$

31-H

31-B-j, 31-B-k, 3i-B-i, 3i-F; 31-K-a

$31-\mathrm{K}-\mathrm{c}$.

31-K-c

3I-D

32-G-b-i

32-G-b-1

$31-K-c$

31-B-f, 31-í, 3i- $\dot{\mathrm{H}}, 3 \dot{1}-\mathrm{I}$

32-A

38-A

32-G-a-2, 32-G-b-2, 35-B-b

28-B, 31-C-a, 45-J

35-B-c

43-A, 43-B-b, $43-\dot{E}-\mathrm{a}, 45-\dot{B}-\mathrm{a}$

33-E-b

19-D, 19-F-b, 29-A. . . . . . . 156, 158, 204

43-B-b.

43-D

43-D

43-D

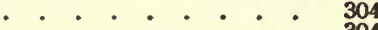

43-E-a, 43-H : : : : $\quad$ : 305,308

12-A-b, 43-E-b, 45-B-b, 45-H-a $\quad$ : : $124,305,321,328$

11

$124,305,321,328$

118

42-B-b 297

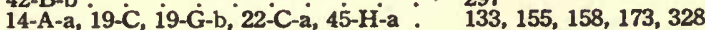

32-H-b

32- $\mathrm{H}-\mathrm{a}$

32-H-b.

24-C

- C 182

31-C-b . . . . . . . . . . 228

34-A • • • • • • • • . • 260

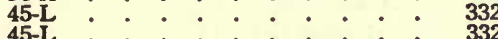

31-B-e, 37-A-c : $: \dot{*}: \dot{*}^{\circ} \quad 224,276$

31-B-e, 37-A-c. $: \bullet^{\circ} \cdot \bullet^{\circ} \quad 224,276$

45-L 332

31-B-f, 37-A-c $: \cdot \dot{*}: \dot{*}: \quad 332,276$

22-C-b-2, 34-C, 34-D, 34-E, 43-C-a, 175, 261, 303, 319, 338 46-A-b, 46-G : : : : : : 338

$46-\mathrm{G} \cdot \cdot \cdot \cdot \cdot \cdot \cdot \cdot \cdot \cdot \cdot 338$

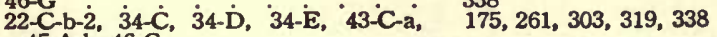

45-A-b, 46-G : : : : : : : 332

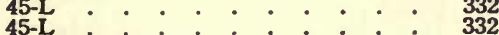

31-B-f, $31-\dot{H}, 37-\dot{A}-c^{4} \quad: \quad \cdot \quad \cdot \quad: \quad 225,231,276$

46-G . . . . . . . . . 338

45-L • • • • • • • • • • 332

45-L $: \div: \div \cdot: \cdot 332$

45-L : : : : : 332

34-C, 34-D, 45-L $\quad \div \quad 261,332$

34-G, 34-D, 45-L: : : : : : : 261,332

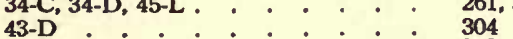

43-I : : $: 309$

43-C-a, 43-J-c. : : : : : : : 303, 311

13-F-c, 19-D, 19-G-b, 24-A-a, 26-B-c, $131,156,158,180,191,193$.

$27,28-A, 37-A-a, 42-A-b, 44-G, 46-C-b$

45-F-c.

45-F-b $\cdot{ }^{\circ} \cdot \bullet^{*} \cdot 32$

45-G, 45-K-b : : : : : $\quad: \quad 327,332$

45-G, 45-K-b : $: \quad: \quad \vdots \quad: \quad: \quad 327,332$

45-F-b . . : 324

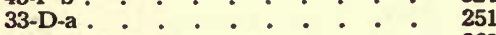

$34-\mathrm{C} \cdot \cdot \cdot \cdot \cdot \cdot \cdot \cdot \cdot \cdot \quad \cdot 260$

31-Lc . 235 
NAME

Clover

Shrubby Bush.

White

Cobaea scandens

Coccoloba uvifera.

Cocoanut Palm

Cocos plumos

variegatum

Cohosh

Coleus

blumei verschaf́felt

Branched

Collected Stock.

Transplanting and Establishing of

Colours, Bark

Combinations of flowers for.

Flowers selected for

Fruits selected for

Leaves selected for autumn

Tulips selected for combinations of

Twigs selected for

Colt's

Columbine (in variety).

American
California Hybrid.
European :
Gold-spurred :
Hybrid Pink :
Rocky Mountain :
White
Colulea arborescens :
Combinations of colours
Comptonia asplenifolia.

\section{Cone-flower}

$$
\text { Purple }
$$

Congested City Conditions

Conium maculatum

Convallaria majalis

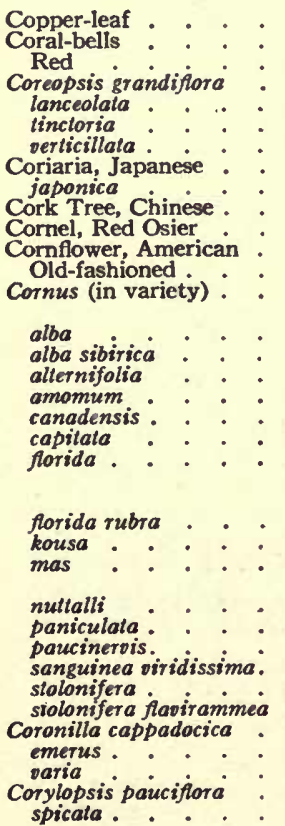

\section{GrouP}

30-A

45-F-c

32-F-a, 35-B-a, 43-C-a

43-J-a

43-B-b

43-B-b

35-A-a

43-I

35-B-c

$35-\mathrm{B}-\mathrm{c}$
$31-\mathrm{G}-\mathrm{b}-1,3 \dot{5}-\mathrm{B}-\mathrm{c}$

. . . . . . . . . . 33

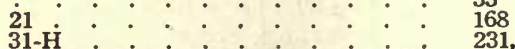

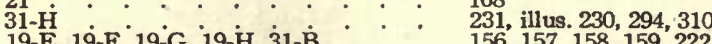

19-E, 19-F, 19-G, 19-H, 31-B . . 156, 157, 158, 159, 222

$22-B$

36-D

$21 . \mathrm{C}$

31-A, 3i-F, 31-i, 3i-K-a, $31-\dot{N}, 39,4 \dot{0}-\dot{A}^{\circ}$

15- 31-F, 31-1, 31-K-a, 31-N, 39, 40-A

15-C, $31-\mathrm{B}-\mathrm{c}, 31-\dot{\mathrm{C}}-\mathrm{a}$.

31-B-C.

31-Ca.

31-B-c

31-B-a

31-B-b

19-F-b, 20-A, $20-\dot{B}, 40-B, 41$

31-H

13-B-a, 24-B-b, 26-A-c, 29-E-a, 37-B-a 40-C-a, 44-B-a, 45-F-a.

31-B-h, 31-E, 31-F, 31-I, 31-K-a ·

31-C-a.

11

38-A

28-B, 29-C 31-B-b, 31-C-b, 31-i, 36-B, 36-E-a, 37-A-C

32-G-b-1

15-C, 30-A, 31-B-c, 3i-C-b, 31-i, $4 \dot{5}-\mathrm{I}$

15-C, 3

31-B-h

31-B-h, 31-D, 31-H, 31-I

32-A, 32-D, 43-I

$15-C$

45-G

$10-\mathrm{B}, 2 \dot{3}-\mathrm{A}$

19-B, 20-B, 23-B, 46-C-b

32-A

32-A, 32-C, 32-D, 32-H-a, 38-C-a

11-B, 13-A-b, 17, 19-G-a, 20-D-a 24-C-b, 42-A-a

21

19-C, $20-\mathrm{B}, 21^{\circ}, 23-\mathrm{B}, 25-\mathrm{B}$

19-B, 20-B, 27, 28-A

26-B-c

15-A, 28-B, 29-C

15-H-b 14-A-a, 19-A $20-\dot{B}, 22-\dot{C}-\dot{a}$

13-B-c, 14-A-a, 19-A, 20-B, $22-\mathrm{C}-\mathrm{a}$,
24-B-a, 27, 28-A, 40-B, 40-C-b, 43-B-a, 44-G, 45-G, 45-H-a

19-E-a.

14-A-a, 44-G

12-D, 19-F-a, 24-B-b, 27, 41, 44-G, 46-C-a

46-C-b, 46-F

16-

16-B-b, 19-C, 20-B, 21, 46-C-a 21

19-B, 20-B, 23-B, 46-C-b

14-B, 21

45-A-b

45-A-b, 45-F-a

$15-\mathrm{C}, 45-\mathrm{A}-\mathrm{b}$

19-F-a, 45-F-a

37-A-a.

$138,197,205$
PAGe

212

326

$42,265,303$,

310

302

309

197

244,266

244

162, illus. 230

271

169

$221,230,232,233,236,284$,

$139,223,227$

223

223

223

222

$158,162,289,293$

231 130, 181, 190, 206, 277, 290, $226,230,232,233$

227

118 , illus. 94

$197,205,223,228,232,270$, 274,276

244

$140,212,223,228,232,330$

140,229

225

$225,229,231,232$

$240,241,309$

140

327

327

117,177

$155,162,177,337$

240

$240,241,245,280$

$120,129,149,158,165,182$, 296

169

$153,162,169,177,187$

$155,162,193,196$

191

329

$131,133,154,162,173,181$, $193,196,289,291,301,316$, 157

133,316

$125,157,181,193,293,316$, 336

337,338

$145,155,162,170,336$

325

$170,162,177,337$

135, 170

319

319,323

140,319

157. 323 
NAME

Corylus (in variety) americana. avellana maxima maxima purpurea.

Cosmos

bipinnatus.

Cotoneaster (in variety) acuminata acutifolia

Box-leaved.

Chinese

Chinese Prostrate.

Creeping

dammeri

dielsiana

Dwarf

fiancheti

frigida

horizontalis

horizontalis perpusillo

hupehensis

Hybrid.

Hybrid Prostrate

lucida

microphylla

microphylla gracilis

multiflora

multiflora calocarpo

Pointed-leaved

pannosa

Prostrate

racemiflora.

rotundifolia

rotundifolia lanata

Round-leaved

salicifolia floccosa

simonsi.

Small-leaved :

Spanish

Thyme-leaved.

thymifolia

Cotton Gum

Cotton Tree, Silk

Cottonwood, Northern

Southern

Cow-parsnip, Giant.

Cowbane

Cowslip, English

Crab

Arnold's Large Rंose-flower-

ing

Bechtel's

Chinese Flowering, River's Semi-double.

Deep Pink-flowering:

Flowering

Low-growing Japanese

Narrow-leaved

Parkman's

Sargent's White-fiowerin

Scheidecker's Semi-double Rose-flowering .

Siberian Flowering

Siebold's Blush-flowering

Western

Wild

Crab's Eye Vine

Cranberry, American High Bush Dwarf Bush

High Bush.

Japanese Bush

Crane's Bill

Crape Myrtle

\section{Group}

30-A, 30-B

$13-\mathrm{B}-\mathrm{C}, 41$

24-C-b

16-D-a

14-B, $45-\mathrm{F}-\mathrm{c}, 45-\mathrm{H}-\mathrm{b}$

$32-\mathrm{A}, 32-\mathrm{E}$

$32-\mathrm{A}, 32-\mathrm{E}$.

20-B, 22-B, 42-A-a, 45-F-c, 45-G . 162, 173, 296, 325, 327,

43-D, 43-F-b

15-B, 22-C-b-1, 33-E-b

45-B-a, 45-F-b

13-A-b, 20-B

$45-\mathrm{F}-\mathrm{b}$

15-B, 22-C-b-1, 33-E-b

(5-b

$13-\mathrm{A}-\mathrm{b}, 20-\mathrm{B}$

20-B

$45-\mathrm{F}-\mathrm{b}$

45-G, 46-C-a, $46-\dot{H}-b$

43-D, 43-F-a, 45-G

15-B, 22-C-b-l, 29-E-a, 29-H, 33-E-b, $20-8$ $20-B$

13-A-b

20-B

$13-\mathrm{A}-\mathrm{b}$

33-E-b, 45-F-b, 45-G, 46-H-b

45-F-b

20-B

45-F-C

43-D, 43-F-a

15-B, 22-C-b-i, 29-E-a, 29-H, 33-E-b, 40-B, 45-F-b, 45-G, 46-H-b 20-B, 45-F-c

$45-\mathrm{F}-\mathrm{b}$

45-B-a, 45-F-b

$45-\mathrm{F}-\mathrm{b}$

45-F-d, 45-G, 46-C-

$33-E-b, 45-F \cdot b, 45-G, 46-H-b$

45-F-c

$45-\mathrm{F}-\mathrm{b}$

$45-\mathrm{F}-\mathrm{b}$.

45-H-a

43-B-b

26-A-a, 45-H-a . . . . . . . 189, 328

$38-\mathrm{C}-\mathrm{a}, 45-\mathrm{H}-\mathrm{a} \quad \cdot \quad \cdot \quad \cdot \quad \cdot \quad \cdot \quad 281,328$

24-D * . . . • . . . 183

$31-\mathrm{L}-\mathrm{C} \cdot \cdot 235$

38-A . . . . 279

15-C, 29-F, 31-B-d : $: \vdots: \quad 140,208,224$

13-B-c, 14-A-a, 19-B, 30-A, 40-C-b. : 131, 134, 155, 212, 291

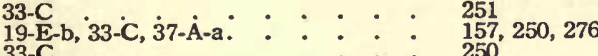

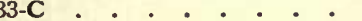

33-C, 37-A-a • • • • • • • . 251,276

19-E-

33-C

$19-\mathrm{E}-\mathrm{a}, 37-\mathrm{A}-\mathrm{a}$

19-E-a, 33-C, 41

33-C

20-A, 24-B-a, 25-A, 33-C; 37-A-a $33-\mathrm{C}$.

44-E-b

19-E-a, 37-A-a, 45-H-a

43-C-a

19-I, 20-C, 46-C-

12-B, 15-B, 16-B-b, 18-B, 22-C-b-1 13-A-C, 17, 19-C, 20-C, 25-B-, 27 13-A-b, 20-C

$15-\mathrm{C}, 28-\mathrm{B}, 31-\mathrm{B}-\mathrm{C}$

16-C, 43-F-a, 43-F-b, 43-F-d, 43-F-e 43-J-b, 45-H-b, 45-K-b
PAge

31,293

25,329

04, 306

$39,174,253$

29,162

174,253

29,162

336,340

39, 174, 207, 209, 253, 289, 62

162

29

$325,327,340$

306

, 174, 207, 209, 253, 289, 62,325

320,325

62

$6,327,336$

$325,327,339$

157,276

$157,250,293$

25

251, illus. 222

$162,181,186,250,276$

251

$157,276,328$

302

$159,164,337$

$125,139,145,151,175$

$130,149,156,164,187,193$

129,164 , illus. 231

$140,197,223$

$146,306,307,310,329,332$ 
NAME

Cralaegus (in variety)

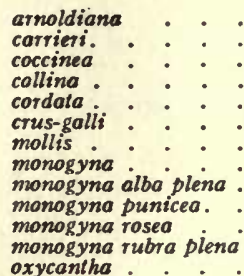

oxycanthe

oxycantha pauli punctato

Crevices, Plants for

Paved areas

Walks

Walls

Crimson Gilory Vine

Crocus

Mammoth Yellow

Cross Flower.

Cross Vine, South American

Croton

Crowberry, Black-fruited

Pink-fruited

Red-fruited

Crown Vetch

European

Mediterranean

Cryptomeria japonica

japonica lobbi

Cryplostegia madagascariensis Pink Madagascar.

Cucumber Tree.

Cucumber, Wild

Cunninghamia, Chinese lanceolata

sinensis

Cuphea ignea.

llavea

Cupressus sempervirens fastigiata

Cup and Saucer Vine

Currant, Alpine

American Black

Flowering

Indian, (See Indian-currant).

Curving roadway plantings

Cut flower garden os. flower garden

Cut flowers

Annuals for

Cyperess

alternifolius sirigosus

Cypress (in variety)

Dwarf Golden Japanese .

Dwarf Japanese

Italian.

Japanese

Lawson's

Lobb's

Pea-fruited

Thread-branched

Veitch's Silver

Cypress Pine.

Cypress Vine

Cypripedium (in variety)

candidum . . .

Cytisus praecox . . . .
Group

11-A, 12-E-d, 13-B-c, 14-A-a, 19-B, 19-G-a, 20-B, 20-C, 22-B, 40-B, 40-C-b, 33-C

12-A-b, 20-D-b, 25ं-A, 26-B-a, 44-A-a

$45-\mathrm{G}$

45-G

12-A-b, 20-D-b, 26-B-a, 33-C
12-A-b, 16-B-b, 20-D-b, 26-R-a

33-C

12-E-e

$33-\mathrm{C}$

$33-\mathrm{C}$

12-A-b, $16-B-b, \quad 16-D-a, ~ 16-D-b-i$ $20-\mathrm{D}-\mathrm{b}, 25-\mathrm{A}, 26-\mathrm{B}-\mathrm{a}, 46-\mathrm{A}-\mathrm{a}$

33-C

43-C

29-F

15

29-E-c

36-A, 36-E-b

36-E-b

43-C-b, $45-\mathrm{L}$

43-C-b

35-A-a, 43-I

33-E-b

33-E-b

15-C

45-A-b

43-B-b, $45-\mathrm{D}$

45-E

43-J-c

$20-\mathrm{J}-\mathrm{c}, 45-\mathrm{C}, 45-\mathrm{H}-\mathrm{a}: \vdots \vdots \vdots \vdots \vdots \quad 31$

$32-\mathrm{F}$

45-E

45-E

32-G-a-2

$32-G-b-2,35-B-b ： \vdots \quad \vdots \quad \vdots \quad 244,266$

45-D, 45-E 322, 323

32-F-a, 35-B-a, 43-C-a . . . . 242, 265, 303

44-A-a . . 313

13-A-b, $17,19-\mathrm{B}, 19-\dot{\mathrm{F}}-\mathrm{a}, 22-\mathrm{B}, 37-\dot{\mathrm{A}}-\mathrm{a}$, 41, 44-B-a

18

. . . . . . . . . 237

32-A

3I-1. $:$

$31-\mathrm{L}-\mathrm{b} . \quad \cdot \quad \cdot \quad \cdot \quad \cdot \quad 234$

$\begin{aligned} & 35-\mathrm{B}-\mathrm{c}, 43-\mathrm{I} ： \vdots \\ & 31-\mathrm{L}-\mathrm{b}, \vdots\end{aligned} \quad \vdots \quad \vdots \quad 266,309$

14-A-a, 45-D

234,298

9-E, 15-A

9-E, 15-A, 16-B-z: $\quad \vdots \quad \vdots \quad \vdots \quad \vdots \quad 114,138,145$

45-D 45-E

9-A, 9-B, 44-G, 45-B-a, $46-\dot{\mathrm{H}}-\mathrm{a}: \vdots \quad 111,112,316,320,339$

9-C, 14-A-b, 45-D, 45-E, 46-A-b, 46-H-a 113, 135, 322, 323, 335, 339

45- $\mathrm{E}$

9-C, 45-D

9 C, 12-A-a, 45-D. . . . . . . $113,123,322$

9-B,

• • • • • • • 112

301, 302

$32-\mathrm{F}-\mathrm{b}, 34-\mathrm{A}: \div \div \div \div \quad \div \quad 242,260$

$28-\mathrm{B} \cdot \cdot \cdot \cdot \cdot \cdot \cdot \cdot \cdot \cdot 197$

19-F-a, 24-B-b, 26-B-C, 45-F-c : : : $325,181,191,325$
PAGB

$126,131,133,155,158,162$ 3, 289, 291

$66,186,191,313$

$24,145,166,191$

$145,146,147,166,186$

$149,155,158,173,276$
93,313

2, 322

12 


\section{NAME}

Daedalacanthus neroosus Daffodil (in variety) Long Trumpet

Medium Trumpet

Short-cupped White . Trumpe

Dahlia (in variety)$$
\text { Garden }
$$

Daisy, African Mexican Shrub Orange

Ox-eye

Painted

Swan River

Dalibarda repens.

Dandelion

Daphne (in variety)

blagayana. .

Caucasian

cneorum

Deciduous

genkwa

Lilac-flowered.

mezereum

Darnel ...

Datura stramonium

Dead Nettle.

Death Camas

Delonix regia .

Delphinium (in variety)

ajacis

belladonina

formosum

grandifiorum album

Dennstaedtia punctilobula

Dentaria diphylla

Deodar

Depth for transplanting

Depth of planting bulbs

Design Bedding, Annuals for

Desmodium, Siebold's

White-flowering

\section{Deutzia}

crenata, Pride of Rochester

Dwarf Pink

gracilis

kalmiaeflora

Large-flowered

lemoinei

Lemoine's

longifolia

Long-leaved

Pink-flowered Hybrid

purpurascens

Purple-flowered

rosea

scabra

Single White

Slender.

White-flowered Hybrid

Dewberry, European

Dianthus (in variety) barbatus

caryophyllus chinensis

heddewigi

latifolius atrococcineus

Napoleon III

plumarius

Dicentra eximia

spectabilis.

\section{GroUr}

Page

43-F-

$36-\mathrm{A}, 36-\mathrm{B}, \quad: \quad: \quad \div \quad \vdots \quad 270,271$

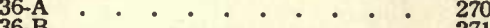

36-B

36-A

45-I

45-1.

$\cdot \cdot \cdot \cdot$

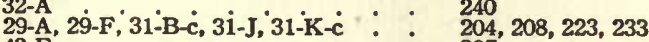

43-F-C

: $: 246$

$31-\mathrm{B}-\mathrm{h}, 38-\mathrm{C}-\mathrm{a}: \vdots \vdots \vdots \quad \vdots \quad 226,280$

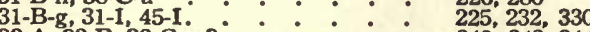

32-A, 32-E, 32-G-a-2. • • . . . 240, 242, 244

$15-\mathrm{C}, 45-\mathrm{A}-\mathrm{a}, 45-\mathrm{J}$. . . . . $140,319,331$

30-A

39, 42-B-a : : : $\quad 284,297$

33-E-b

45-F-a 324

15-A, 19-A, 29-A, 33-E- $\mathrm{b}, 37-\mathrm{A}-\mathrm{a}$, $42-\mathrm{B}-\mathrm{a}$.

$45-\mathrm{F}-\mathrm{a}$.

45-F-a.

$: \cdot \circ \cdot \cdot 324$

$38-A$.

28-B, 3i-C-b： : : : : : : ${ }^{279} 228$

38-A $\cdot$ • • • • • • • • 279

31-B-b, 31-B-e, 31-D, 31-H, 31-i, 31-N, $221,224,229,231,232,236$, $32-\mathrm{A}, 32-\mathrm{c}, 32-\mathrm{H}-\mathrm{b} . \cdots \quad \therefore \quad 240,241,246$

31-F, 31-H. • • • • • • • • 230, 231

$31-\mathrm{H} \cdot \bullet^{\circ} \cdot 0^{\circ} \cdot \bullet^{\circ} \cdot \bullet^{\circ} 231$

38-A $\cdot: \cdot: \cdot \cdot \cdot \cdot \cdot \cdot 279$

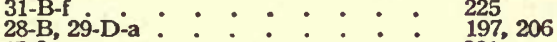

45-J

43-B-a, 45-B-a, 45-D, $\dot{4} 5-\dot{\mathrm{E}}, \dot{4}$ 45- $\dot{\mathrm{K}}-\mathrm{a}, \quad 301,320,322,331,339$

46-H-a $\therefore \therefore \therefore \therefore \div 34$

67. Plate IX

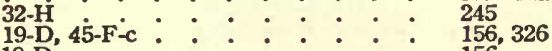

19-D 1956

17. 19-B, 19-G-b, $42-\dot{A}-a, 44-G$. : : $149,155,158,296,316$, illus. 110

$23-\mathrm{B}$

18-B, 19-E-b, 45-F-c

12-B, 13-A-a, 15-B, 18-B, 41, 45-F-a, 124, 128, 139, 151, 293, 324,

46-C-a $\cdot \cdot \cdot \cdot \cdot \cdot \cdot \cdot 336$ 45-B-b.

321

23.

$13-\mathrm{A}-\mathrm{a}, 18-\mathrm{B}, \dot{4} 5-\dot{\mathrm{F}}-\mathrm{c}$

13-A-a, 18-B, 45-F-C

45-B-b.

45-B-b

45-B-b :

45-B-b :

18-B, $19-\mathrm{E}-\mathrm{b}, \dot{4} 5-\dot{\mathrm{F}}-\mathrm{c}$

14-B, 45-F-C

12-B, $13-\mathrm{F}-\mathrm{A}-\mathrm{a}, 15-\mathrm{B}, 18-\mathrm{B}, \dot{4} 1,45-\mathrm{F}-\mathrm{a}$, $46-\mathrm{C}-\mathrm{a}$

45-B-b .

29-E-a

31-B-f, 31-B-g, 31-H, 31-I, 31-J, 3i-N, $32-\mathrm{H}-\mathrm{a}$

43-1.

32-A, 38-C-a 29-B, 29-F, 29-G, 31-B-C $31-\mathrm{D}$. 29-I, 32-A

31-

15-C, 29-B, 31-B-b, 31-B-c, 37-Aं-c.

15-C, 31-B-

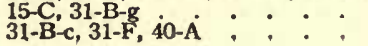

177

$128,151,325$

$128,151,325$

321

321

321

$151,157,325$

135,325

$124,128,139,151,293,324$, 336

207

$225,231,232,233,236,246$

309

240,280

$140,184,204,208,209,223$, 229

231

$140,204,223,276$

223, 230, 289 
Name

Dictamnus fraxinella

fraxinella alba

Diervilla (in variety)

foribunde

florida.

hybrida lutea-marginato

Eva Rathke

trifido

Digitalis (in variety)

gloxiniaeflora.

grandiflora.

purpurea

Dimorphotheca aurantiaco

Diospyros kaki

virginiana

Dirca palustris

Diseases of Plants
Dividing Perennials.

Dividing Perennial

Dogwood (in variety)

Alternate-leaved

Flowering

Green-stemmed

Himalayan

Japanese

Red-flowerin

Red-twigged

Siberian

Silky

Square-twigged

Dolichos lablab

Doronicum

excelsum

plantagineum

plantagineum excelsum

Draba azoides

Dracaena indivisa

Dracena (in variety)

Dragon Head

Drainage

For lawns

Tree pits

Dropwort

Drought resisting plants

Duchesnea indice

Duranta repens

Dusty Feverfew

Dusty Miller.

Plumose-leaved

Dutchman's Pipe

Dwarf

Dyer's Greenweed

Ebony, Mountain

Pink-flowering Mountain

Purple Mountain

White Mountain

Yellow Mountain.

Echeveria atropurpurea

fulgens.

glauca.

Glaucous

Purple-leaved

Red-margined.

secunda

Smooth-stemmed

Echinacea purpurea

Echinocystis lobata

Echinops (in variety)

ritro

Edgings for walks
GROUP

31-B-g, 37-A-c, 37-B-b

31-B-f

$13-\dot{A-C}$

13-A-c, 19-E-b, 23-B

$13-A-b, 19-\mathrm{C}, 19-\mathrm{I}, 42-\mathrm{A}-\mathrm{a}, 46-\dot{\mathrm{C}}-\mathrm{a}$

14-B, 27

$13-\mathrm{A}-\mathrm{b}$

13-B-a, 18-B, 24-Cं-b, 27

$31-I$

$31-\mathrm{N}$

31-B-h

$31-\mathrm{C}-\mathrm{a}, 31-\mathrm{J}$

31-B-g .

45-G

$20-A, 45-G ; 45-H-a$

(3)

39

$31-\mathrm{K}$

11-C, i3- $\dot{A}-b$; $17, \quad 19-G-\dot{a}, \quad 20-\dot{D}-a$ 24-C-b, 39, 42-A-a

19-B, 20-B, 27, 28-A $\quad \dot{A}$ :

13-B-c, 14-A-a, 19-a, 20-B, 22-C-a, 44-G, 45-G, 45-H-a $40-\mathrm{C}$-b, 43-B-a, 21

16-B-b, 19-C, $20-\dot{B}, 2 \dot{1}, 46-\dot{\mathrm{C}}-\mathrm{a}$

45-H-b

14-A-a, 44-G

19-E-a.

19-C, 20 -B, 21, 23-B, $25-\mathrm{B}$

26-B-c

45-F-c :

31-M-b.

31-B-d .

31-A

15-C, $2 \dot{4}-\mathrm{E}$

15-C, 24-E- $-\mathrm{A}-\mathrm{b}, 3 \dot{\mathrm{B}}-\mathrm{B}-\mathrm{c}$

35-A-a, 35-A-b, 35-B-c

. . . . . . . . 54

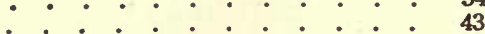

31-B-f : $: \div: \div \quad: \quad 225$

24-E • . • • • • . 183

45-A-b . . . . . . . . . 319

43-D, 43-F-e . . . . . . 304, 307

$32-\mathrm{G}-\mathrm{b}-1$

32-G-b-1, 35-B-c . • • • • • • 244, 266

32-G-b-1 • . . • • • • 244

34-A, 34-C, 34-E . . . . . . - 260, 261

19-F-b, 26-B-c, 29-E-a, 45-F-c . . . 158, 191, 207, 326

43-B-b

43-F-b.

43-F-a

$43-F-c$

$32-\mathrm{G}-\mathrm{a}-\mathrm{i}$

$32-G-a-1$

$32-G-a-1$

32-G-a-1

32-G-a-1

32-G-a-1

32-G-a-1

32-G-a-1

31-C-a .

32-F-b

45-I

24-E, 3i-B-e

12-B
PAge

25,277

9, 157, 177

9. 155, 159, 296, 336

193

$151,182,193$

233

6

$62,327,328$

$31,191,296,325$

$88,219,233$

120,129 , 284,296

162, 193, 196

$133,154,162,173,181$

193, 196, 289, 291, 301, 316 70

$45,155,162,170,336$

33,316

337,338

$55,162,169,177,187$

325

235

221

140,184

64,266

$25,230,231,232$

9

302

306

307

306

243

43

243

243

243

243

243

243

227

242

330

184, 224

124 
Elaeagnus

NAME

Elaeagnus (in variety) angustifolia

\section{argentea}

macrophylla

multiflora

multiflora rolundifolia.

parvifolia

pungens maculat

tungens variegata.

umbellato

Elder (in variety)

American

Box .

Dwar

Golden

Marsh

Red-berried

Southern Dwarf

Yellow

Yellow-flowering

Elephant's Ear

Elm (in variety)

American

Camperdown Weeping

Columnar

English.

Fastigiate

Scotch

Wheatley's Cornish

Winged

Elsholtzia (in variety)

cristate

stauntoni

Emilia flammea

Empetrum atropurpureum eamesi

nigrum

Empress Tree

Enkianthus perulatus

Entrances, Plantings for Epigaea repens

Epimedium macranthum

Equisctum hyemalis

Eranthis hyemalis

Erice

mediterranea

vagans

Ericaceous plants

Erigeron speciosus

Eriobotrya jgponica

Ernajagua, Yellow

Eryngium amethystinum

Erysimum pulchellum

Erythronium (in variety) americanum

Eschscholtzia californica.

Eucalyptus cilriodora

ucharidium grandiflorum

Large-flowered

Eugenia jambos.

uniflora

Eupatorium (in variety)

ageratoides

coelestinum.

purpureum.

verbenaefolium.

Euphorbia corollata

pulcherrima epilhymoides

Evergreens

Adapted to shade in wooded areas

Atmospheric conditions :

Books on

Broad-leaved
PAGE

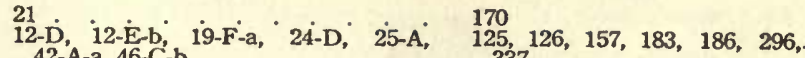
42-A-a, 46-C-b. - . : $\quad 337$

19-F-a, 20-B, 45-F-c

45-F-b

$45-\mathrm{G}$

22-C.-b-1

45-F-c

16-C, $43-D, 43-F-a, 45-F_{-}^{\circ}$,

45-F-d

20-D-a, $30-A$

13-B-c, 17, 19-C, 19-G-b, 20-B, 23-B, 26-A-c, 42-A-a, 46-E

10-C, 12-C, 22-A, 23-A, 39, 44-C-a : $45-\mathrm{F}-\mathrm{a}$

14-B

38-C-a

13-B-c, 19-B, 19-G-b, 20-B

45-F-a

43-F-c

35- $35-\mathrm{C}, 35-\mathrm{B}-\mathrm{c}$

24-D, 39

10-A, 22-A, 24-A-a, 25-A, 40-B, 43-B-a, 44-E-a, 46-D

14-A-a, 45-H-

16-D-b-1

10-B, 11-A, 16-D-a

14-A-b

14-A-a, 14-A-b, 16-D-b-1.

$45-C$

19-D, 19-H

45-F-a

45-F-a

32-A, 32-C.

33-E-b .

33-E-b

33-E-b

19-H, 37-A-b, 42-Cं, 45-H-a

$157,162,325$

325 ;

174

$146,304,306,326$

327

325

166,212

$131,149,156,159,163,177$. $190,297,338$

$117,125,173,177,284,314$

324

281

$131,155,159,163$

324

307

265, 266

265,266

$117,173,180,186,290,301$. 315,337

134,329

147

$117,119,147$

135

$134,135,147$

156,159

324

324

156, 159

240,241

253

252

$159,276,298,328$

$46-\mathrm{C}-\mathrm{a}$

18

29-A, 30-A, 33-E-b, 37-A-c, $40-\dot{C}-a$

$15-\mathrm{C}$

$30-\mathrm{A}$

36-B

46-C-a

15-A

40-B

24-E

43-F-c

43-F-c .

24-E, 3i-B-e, 45-I $\quad \vdots \quad \vdots \quad \vdots \quad \vdots \quad 184,224,330$

$15-\mathrm{C}$

36-B, 45-

32-A, 32-C, 32-H-a

$43-\mathrm{J}-\mathrm{a}$

32-A

43-D

43-D, 43-E-a

31-E, 45-I

31-B-j, 31- $\dot{\mathrm{H}}, 31-\mathbf{L}_{-\mathrm{c}}$

31-B-i, 31-I, 31-L-c

$31-C-a$

38-C-a.

$15-\mathrm{C}$

43-F-d

24-E

列

150

$204,212,253,277,290$

140

212

(2)

204

336

138

289

(184

140

271, 331

$240,241,246$

310

(1)

304

304,305

226, 232, 235

$226,232,235$

227

180

140

140

307
109

9-D : $: \div \div \div \div \div \div 113$

9-D : : : : : : : $: 113$

33-E : : : : : : : : 343 
Evergreens, Climate

Lists of. Cing Low-growing, formal types Mass planting

Most hardy for general use Not generally used in mid. west .

Planting seasons

Protection

Site

Used most in mid-west

Evonymus (in variety)

alatus

americanus.

alvopurpureus

bungeanus

bungeanus semipersistens.

Climbing

\section{europaeus}

japonicus

obovalus

radicans

radicans acutus

radicans carrieri

radicans minima

radicans vegetus

yedoensis

Exochorda (in variety)

Exposed sites, Plants for

Fagus

americañ

syloatica

sylvatica heterophylla.

Fast-growing types for producing screen effects

$$
\text { Shrubs }
$$

Feather Fleece, Mountain

Ferns (For ground cover)

Dry, shady places

Moist, shady places

Ferns (in variety)

\section{Boston}

Broad Beech

Christmas .

Cinnamon

Dwarf

Dwarf 's wood

Goldie's Wood

Lad

Maidenhair

Margined

Native

Neat

Ostrich.

Royal.

Sensitive

Sweet

Virginia Chais

Walking

Fertilizers

Annuals

Aquatic plants

Bulbs

Forcing flowering plants

Lawns-new

Lawns-topdreasing

Newly transplanted stock

Perennials.

Preparation of planting areas

Rhododendrons

Rose garden beds.
9

9.A

9-C

-

9-B

20-D-b, 39, 42-A-a

13-A-b, 14-B, 16-B-b, 20-B, 22-C-a, 46-F 11-B, 13-B-b, 14-B, 20-B

13-B-C, 20-A, 20-B, 22-C-a .

13-A-c, 45-G

28-B, 29-A, 33-E-b, 34-B, 34-C, 43-C-b, 45-A-a, 46-B-b, 46-G

13-A-C, 14-B, 20-B, 22-C-a

16-C. 43-E-b

16-C, 43-E-b

15-B, 18-B, 28-B, 29-C

28-B, 29-A, 33-E-b, 34-B 34-C, 43-C-b. 45-A-a, 46-B-b, 46-G
$28-\mathrm{B}, 29-\mathrm{A}, 29-\mathrm{C}, 29-\mathrm{E}-\mathrm{c}$,

18-A

29-F

18-A, 29-A

13-A-b

44-G $-\mathrm{A}-\mathrm{c}, 14-\dot{\mathrm{B}}, 19-\dot{\mathrm{B}}, 4 \dot{5}-\mathrm{H}-\mathrm{b}$

25-B, 25-C

14-A-a, 24-C-a, 30-A

$12-A-b, 12-C, 21,22-\dot{C}-a, 30-B, 40-C-a$

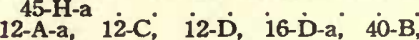
$40-{ }^{-}-b, 44-C$

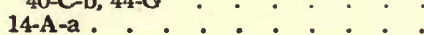

23

23-B

31-E

i9-Di-a

29-H, 31-C-a, 31-M-b, 35-A-b, 35-A-c 29-H, 31-C-a, 31-M-b, 35-A-b, 35-A-c, $35-\mathrm{A}-\mathrm{C}$

29-D-b

B, 29-D-a, 29-B-b, 33-E-

8-A-a, 29-D-b

29-D-b

29-D-b

28-B, 29-D-a

29-D-b

28-B, 29-D-b, 45-j

28-B, 29-D-a, 29-D-b, 31-C-

31-M-b

29-D-a

28-B, 29-D-b

24-A-a, 29-D-b

13-B-a, 24-B-b, 26-A-c, $29-\dot{E}-\mathrm{a}, 37-\dot{\mathrm{B}}-\mathrm{a}$, $40-\mathrm{C}-\mathrm{a}, 44-\mathrm{B}-\mathrm{a}, 45-\mathrm{F}-\mathrm{a}$. 29-D-b

29-D-a, 29-F
109

111

illus. 63,78

111

113

illus, 14

110, jllus. 62

110

110

$112,284,296$

$129,135,145,162,173,338$

$120,131,135,163$

$131,162,163,174$

129,327

174

97, 204, 253, 260, 261, 303, $319,336,338$

$129,135,163,174$

146,305

139, 151, 197, 205

$197,204,253,260,261,303$, $319,336,338$

$197,204,205,207$

197,
151
208

151,204

129

$129,135,155,329$

186,187

$133,182,212$

$124,125,170,174,212,290$, $123,125,146,289,291,316$, illus. 335 133

176

176

230

205

209 , 227, 235, 264, 265, 266, 308

266

197, 206, 252

180,206

197,206

206

197, 206

206

$197,206,331$

235

.

197, 206

180,206

$130,181,190,206,277,290$ 313,323

206,208

91
220
66
91
53
84
40
91
36
83
98 


\section{Fertilizers}

\section{Name}

Fertilizers, Shrub

Trees-established plants Trees-newly planted Vines

Wild garden plants

Fescue Grass, Blue .

Festuca glauca

Fetterbush

Mountain

Ficus aurea

nitida

pumila.

repens.

villosa.

Fig, Barberry

Creeping

Large-leaved Creeping

Fig Tree

Filbert

Filipendula camtschatica hexapetula

hexapetala flore pleno

purpurea

rubra

Fir (in variety)

Balsam.

Douglas

Fraser's Balsam

Globe White

Nikko

Nordman's.

Red

Silver.

Veitch's Silver

White

Flag, Blue Dwarf Dwarf

Yellow Water

Flame Flower

Flax, Pcrennial

Fleabane, Oregon

Flora's Paint-brush

Florida

Flowering shrubs for middle and southern Florida

Blue and purple

Pink

Red

White

Fruiting effect, valuable characteristics

Ground cover plants:

Hedges. and southern Florida Florida

Herbaceous plants

Lawns for

Seashore planting

Shrubs

Trees

Shrubs for shade conditions

Street and specimen planting

Northern list

Southern list

Vines

Lattice and wire fences Walls

Windbreaks

Floss Flower

Dwarf Blue

Dwarf White

Flpwer Gardens .

\section{Flower Gardens}

Group

Pagr

29-A, 29-B.

29-A, 29-B.

29- $\mathrm{H}, 40-\mathrm{B}$

15-A, $18-\mathrm{A} 22-\mathrm{C}, 24-\mathrm{A}-\mathrm{b}, 33-\mathrm{E}-\mathrm{b}$, 45-F-b, 46-C-a, 46-H-b

43-J-a

45- $\mathrm{L}$ -

43-C-b :

43-B-b .

43-C-b.

45-A-b

43-- $\mathrm{C}-\mathrm{b}$

43-C-b

43-B-b :

16-D-a, 24-C-b

31-E

31-C-a, 45-I

13-B-a, 31-L-c.

31-C-a

14-A-a, 39, 42-D

9-C, 24-C-a, 28-A, 46-

9-A, 9-B, 9-D, 44-F, 46-H-a.

9-C

9-A, 9-B, 14-A-b, i6-D-b-2, 24-Cं-a.

46-H-a

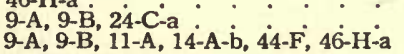
31-B-a, 31-C-a 29-F

31-B-d, 31-C-a, 31-L-

43-C-a, 43-C-b, 45-

15-C, 31-B-a

24-E

32-A, 32-C.

43

82
74
45
84
217
204
204
209

209,289

$138,151,174,181,253,325$, 337,340

310

302

303

302

303

320

332

303 , illus. 367

302

146, 182

230

227,330

130,235 ,

227

133, 284, 298

$113,182,196,337$

$112,113,316,339$

113

$111,112,134,147,182$

113

339

111, 112, 182

$111,112,119,134,316,339$

222,227

208

224, 227, 234,

303,333

140,222

184

240, 241

299

43-F

43-F-b.

43-F-d :

. . . . . . 307

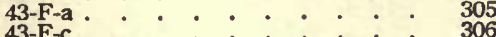

43-D . . . . . . . . . 303

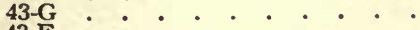

43-E $\vdots \vdots \div \quad: \quad \cdot \quad 304$, illus. 374

43-E-a . . . . . . . . 305

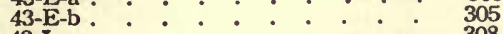

43-I. : * : * : : : : $\quad 308$, illus, 41

$43-j \div \vdots \vdots \vdots \vdots \div \div \quad 310$

43-J-b • • • • • • • • $\quad 310$

43-J-a $\cdot \cdot \cdot \cdot \cdot \cdot \cdot \cdot \cdot 310$

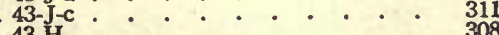

43-B $\div: \div \quad: \quad \div \quad 301$

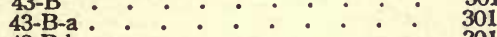

43-B-b $\vdots \vdots \vdots \vdots \vdots \vdots \vdots \vdots \vdots 301$

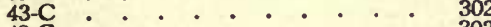

43-C-a * : : : : : : : 302, jllus. 367

43-A 300

32-A, 32-B, 32-E, 32-G்-b-2, 35-A-a, $35-A-c, 43-1$

$32-\mathrm{G}-\mathrm{a}-2$

$240,241,242,244,264,265$,

244

244

214,237 , illus. 286 
NAME

Flowering Effects-Trees and Shrubs

Blue flowers $\cdot \cdot \cdot$

Continuous bloom from twelve shrubs

Red and pink flowers.

Early fowering.

Late spring and summer flowering.

Spring, after leaves appear

Spring, before leaves appear.

Summer, Early

Summer, Late, and early autumn

Early flowering.

Late spring and summer ate spring

Yellow flowers

Farly flowering. Late spring and summer
flowering

Flowering plants, Fertilizers for Foam-flower

Fontanesia fortunei

Fortune's

Forcing, Bulbs for

Shrubs for

Twigs for

Forestry, Books on

Forget-me-not

Formal effects with plants

Allees, Trees and Shrubs for. Not pleached Deciduous Evergree

Pleached .

Topiary work and shearing

Deciduous

Evergreen

Formal gardens, Perennials to be avoided

Forsythia (in variety)

intermedia

intermedia spectabilis

suspensa

suspensa fortunei

oiridissime

Fothergille gardeni

parvifiora

Fountain Plant

Foxglove (in variety)

$$
\text { Pink }
$$

Yellow

Fragaria

Fragrant plants

Fragrant flowers.

Perennials

Shrubs

Fragrant leaves

Phrubs and trees

Frangipani Tree.

Fraxinus (in variety)

americana

americana acuminata

biltmoreana

caroliniana.

pennsylvanico

Freesia

refracta alba

Fringe Tree, Chinese

Fritillaria meleagris

Frost-weed

Fruit Trees

Fruit, Vines valuable for
Grour

\section{Pagr}

19

154, illus. 206, 214, 222, 223

19-

19-I

159

19-E-a : : : : : : : : : 157

19-E-b

19-B

19-A

157

154 , illus. 214

154, illus. 214

19-D

156

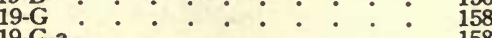

-a $\cdot 0$

19-G-b . . . . . . . . . . 158

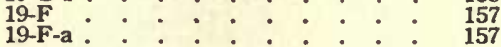

19-F-b . 158

29-F • • • • • • • • • 91

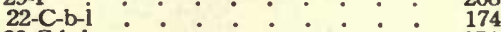

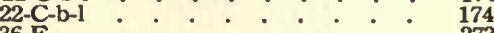

36-E • • • • • • • • • • 273

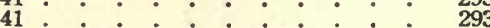

29-A, 31-B-a, 31-C-b, 31-D, 31-i-ci, $204,222,228,229,235,241$ 32-B, 32-D .

16- $\dot{D}$

16-D-b

16-D-b-1

16-D-a

16-A

16-B

$16-\mathrm{B}-\mathrm{b}: \div \quad \div \quad 145$

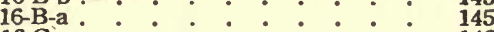

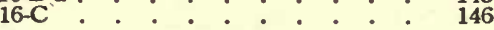

31-E 229

11-B, 19-A, 19-F-a, 4i, 42-A-a $44-\dot{G} \quad: \quad 120,154,157,293,296,316$

12-D, 13-A-c . • • • • . • • 125, 130

$13-\mathrm{A}-\mathrm{b}$

$17,19-i, 45-\mathrm{F}-\mathrm{c}$

$13-\mathrm{A}-\mathrm{c}, 46-\mathrm{C}-\mathrm{a}$

12-D, 13-A-c, 21, 22-ं-a, 22-C-b-1

45-F-a

45-F-a

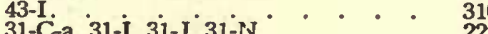

31-B-g. • • • • : : : : 22

31-B-h . . . . . . . . . 225

45-J • • • . • .

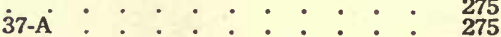

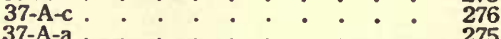

37-A-b • • • • • • • ・ 275

37-B

$37-\mathrm{B}-\mathrm{b}$

37-B-a

43-J-a

22-B, 24-A-a, 25-A, 44-C-b, 44-E-a, $46-\mathrm{D}$. 45- $\mathrm{H}-\mathrm{a}$

45-C

36-E-a

36-E-a

14-B

$36-\mathrm{B}, 45-\mathrm{J}$. . . . . . 271, 331

24-E, 30-b . . . . . . . . 184, 212

20-A . . . . . . . . 162

34-D . . . . . . . . 261
1. illus. 159, 174

46

47

6 , illus. 158,175

49159,325

$25,130,170,174$

$232,233,236$

5
5
6
5
7

277

310

$173,180,186,314,315,33$

328

(2)

328

74

274

62 


\section{Fruiting Plants}

\section{NAME}

Fruiting Plants

Attractive to birds

In summer

In winter

List of birds

Fruit which attracts birds from other fruits

Form or size Winter months

Fruits Trained

Fuchsio (in variety).

procumbens

Trailing

Funkio (in variety)

caerulea

fortunei.

lancifolia

sieboldiane

subcordata grandifioro

Gaillardia (in variety) aristata

pulchella picto

Galanthus (in variety) elevesi

nivalis

Galax (in variety)

aphyllo

Galium boreale

Game cover plants

Foliage, buds and blossoms (spring cover)

Nuts or seeds (autumn cover)

Garden architecture, Books on

Garden architecture, Books on

Gardens, Books on

forida

josminoides

jasminoides fortuniana

jasminoides veitchi

Garland Flower.

White

Gas Plant

Gaultheria procumbens

shallon.

Gelsemium sempervirens.

sempervirens flore pleno

Genista tinctoria.

Gentiane andrewsi

Geranium (in variety)

Bronze-leaved

Cardinal

Ivy-leaved

maculatum

Madame Salleroi

Salmon Double

sanguineum

Scarlet.

Geum

coccineum

heldreichi

Ginger, Wild

Gladiolus (in variety)

Glaucium flavum.

luteum

Gleditsia delavayi

japonica

sinensis

triacanthos

Gliricidia meculata

Globe-flower

Globe Thistle

Glory-of-the-Snow
401

Glory-of-the-Snow

Group

Page

20

20-D

20-D-b

20-B-c

20-E

20-A

$16-\mathrm{C}$

$35-\mathrm{A}-\mathrm{c}, 35-\mathrm{B}-\mathrm{b}$

$35-\mathrm{A}-\mathrm{c}, 35-\mathrm{B}-\mathrm{a}$

29-A, 31-M-a, 37-A-c, 43-I, 45-I

31-B-e

31-B-e

31-B-e

31-b-f

45-I . . 330

29-G, 3i-B-h, 31-D, 31-F, 31-1： $\quad \vdots \quad \vdots \quad 209,226,229,230,232$

43-1. * : 309

32-A, 32-H-a . . . . 240, 246

36-E-a • . . . . . . . . . 274

36-A

$45-\mathrm{J}$

29-H, 33-E-b, 45-J * . . 209, 253, 331

29-H, 33-E-b, 45-J

$28-\mathrm{B} \cdot \dot{0} \cdot \cdot \cdot \cdot \cdot 197$

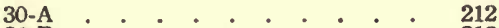

$30-\mathrm{B} \vdots \vdots \vdots \vdots \vdots \vdots \vdots \vdots \quad 2^{212}$

•. . . . . . . . . . 344

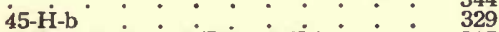

43-E-a, 43-F-a, 45-F-b, 45-K-b $: \quad \vdots \quad 305,306,325,332$

45-B-a, 45-F-d $\bullet$ • • . . . 320, 326

45-F-d . . . . . . . . 326

15-A, i9-A, 29-A, 33-E-b, 37-A-a,

35-F-b : : : : $: \vdots: 253$

31-B-f, 31-B-g, 37-A-c, 37-B-b $\vdots \vdots \vdots \quad 225,277$

15-A, 20-D-a, 24-A-a, 29-B, 29-C, 138, 165, 180, 204, 205, 253

46-B-b, 46-E : $: \div 336,337$

43-C-a, 43-G, 45-L : : : $\quad \vdots \quad \vdots \quad 303,308,332$

45-L 332

19-F-b, 26-B-c, 29-E-a, 45-F-c : : 158, 191, 207, 326

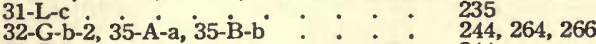

32-G-b-1 * . * . * : 244

$35-\mathrm{A}-\mathrm{a}$

35-A-a, 35-A-b

28-B

264

264,265

197

243

$32-G-a-1$

15-C, $31-B-c$

$35-\mathrm{A}-\mathrm{a}$.

35-B-a .

$35-\mathrm{B}-$

31-B-c, 31-D

31-B-d

10-B, 1i-A, 22-C-a, 45-c, 45-H-a

31-G, 36-E-a, 45-I

24-E

$31-\mathbf{J}$

4.

45-C, $45-\mathrm{H}-\mathrm{a}$

10-C, $12-\mathrm{A}-\mathrm{b}, 20-\dot{\mathrm{A}} 2 \dot{0}-\mathrm{F}, 24-\mathrm{D}, 26-\mathrm{B}-\dot{\mathrm{a}}$, 37-A-b, 45-H-a

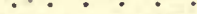

13-A-a, 19-F-b, 2i, 3i-B-d, 40-A, 40-B,

$41,42-A-\mathrm{a}, 44-\mathrm{G}, 45-\mathrm{F}-\mathrm{c}$. .

24-E, 31-B-e, 45-I

64

140,223

264

(1)

223,229

(2.3.

209

$117,119,174,321,328$

$231,274,330$

184

321,328

$117,124,162,167,183,191$, 117, 124,1 310

$128,158,170,224,289,293$, 296, 317, 326

184,224,
270,274 
NAME

GROUP

PAGE

Gloxinea, Hardy .

Goat's Beard (in variety) : False

Siberian

Gold-flower (in variety)

Dark Green

Drooping

Hybrid

Golden Chain

Golden Dewdrop

Golden Feather

Golden Glow.

Goldenrod (in variety)
Blue-stemmed.

Sharp-leaved

Showy.

Swamp.

Golden Seal

Golden Tuft

Goodyera pubescens

Gooseberry, Wild

Gordonia lasianthus

Gorse

Grape (in variety)

Evergreen .

Grapefruit

Grape Hyacinth

Grass seed mixtures.

Grasses

Greenbrier

$$
\text { Prickly }
$$

Grevillea robusta

Ground cover

Annuals used for:

Crevices between stepping stones, etc.

Dry locations • • • •

Embankments and rocky slopes

Perennials : : : :

Shrubs

Vines

Dry, shady places

Moist, shady places

Moist locations

Open, sunny exposures

Rhododendrons and Azaleas.

Roses

Roses jocations

Ground Ivy

Groundse

Groundsel Bush :

Guinea-hen Flower

Gumi

Round-ieaved

Gymnocladus dioica

Gynerium.

Gypsophila (in variety)

elegans.

muralis.

paniculata

31-I - - , $31-\dot{C}-\mathrm{a}, 31-\dot{\mathrm{L}}-\mathrm{c}$

30-A

31-E

13-A-a, 15-B, 29-H, 31-B-h, 45-F-a

11-B, 19-A, 19-F-a, 41, 42-A-a, 44-G 12-D, 13-A-c, 21, 22-C-a, 22-C-b-1 . $17,19-1,45-\mathrm{F}-\mathrm{C}$

13-A-c, 46-C-a

12-D, 13-A-b, 13-A-c

$17,19-\mathrm{F}-\mathrm{b}, 42-\mathrm{B}-\mathrm{a}$

43-D, 43-F-e

32-G-b-1

31-E-1, 31-C-a, 31-E, 38-C-a, 45ं-J

28-B

28-B

24-A-a:

28-B $15-\mathrm{O}$

15-C, 29-A, 31-B-d, 45-I $:$ : : : 139

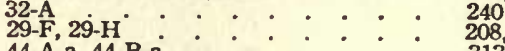

44-A-a, 44-B-a . . . . 313

43-B-a, 43-B-b, 43-E-a . . . . 301, 302, 305

46-A-b . . . . . . . . 335

205

20-D-a, 24-B-c, 25ं-C

43-C-a.

43-D

32-A

$30-\mathrm{A}, 43-\mathrm{C}-$

43-A, 43-B-b

32-B

227,234

230

$209,226,32$

$120,154,157,293,296,316$

$149,130,170,174$

130,336

$125,129,130$

$149,158,297$

304,307

244

$227,228,230,281$

29-F • • • • • • • • • • 208

$6,182,187$

303

304

270

55

212,303

175

301,302

199 , illus. 270

$29-\mathbf{E} \cdot$ • • • • • • . • 206

29-E-b . • . . . . . • . . 207

29-E-a • • • • • • • • • 206

29-E-c • • • • • • • 207

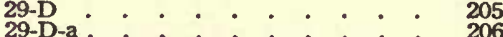

29-D-b 206

29-A . . . . . . . . . . 203

29-G • • • • • • . 208

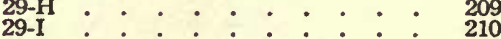

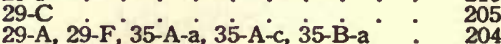

29-A, 29-F, 35-A-a, 35-A-c, 35-B-a $\quad$ 204, 208, 264, 265

19-a, $31-L-c$ i $\dot{D}, \dot{F}-{ }^{\circ}$

45-G

22-C-b-i

$20-\mathrm{A}, 45-\mathrm{H}-\mathrm{a}: \therefore: \quad: \quad: \quad: \quad 162,328$

43-I

45-I.

$32-\mathrm{A}, 32-\mathrm{C}, 32-\mathrm{D}$. . . . . . . 240, 241

31-B-f, 31-i, 43-1 : : : : : : : $225,232,309$

Habenaria ciliaris

Hackberry

Chinese

Halesia (in variety)

carolina

Halimodendron halodendron

Hamelia erecta

sphaerocarpa

Hamamelis japonica.

virginiana

Hanging Baskets

Hardhack (in variety)

45-J

45-1ं-a:

45-C

14-B, 19-B, 19-G-a, 24-C-b, $45-\dot{H}-\mathrm{a}$

44-G

44-G • • • • •

43-D, 43-F-d, 43-H

43-F-c, 43-H

13-B-c, 19-D, 22-C-a, 24-B-b, 24-C-b, 27, 28-A, 30-B, 42-Á-a

35-B

19-E-b, 25-B, 29-E-a, 42-A-a, 44-B-a
331

284

321

297

$135,155,158,182,328$

(1)

183,326

$304,307,308$

307,308

154,158

$131,156,174,181,182,193$, $196,212,296$

$157,187,207,297,314$ 
NAME

Harebell, Carpathian Peach-leaved

Haw, Vail's

Double White-flowering:

English.

English.

Pink-flowering

Single Pink

Hazel

Flowering

Japanese Flowering

Purple-leaved

Hazelnut (in variety)

Heath (in variety)

Cornish

Meather, Pink

Scotch

Southern

White-flowered

Heavy Effects

Hedera canariensis

helix

helix conglomerata.

helix lobata.

Hedges

Barriers, Hedges, for

Holding leaves during win-

ter.

Not holding leaves during

Bleak exposures
Close shearing

Fruiting hedges

Late foliage.

Shady places

Unsheared hedges

Edgings for walks and garden borders

Privacy : :

Windbreaks and for solid
screens

Hedysarum coronarium

Heeling-in plants

Helenium (in variety)

autumnale

autumnale superbuin

Riverton Beauty

Helianthemum (in variety)

canadense

chamaecistus

Helianthus (in variety)

\section{engustifalius}

annuus.

Helichrysum bracteatum.

Heliopsis.

Heliotrope

Blue Garden

Garden.

Heliatropium peruvianum

Queen of Violets

regale

Hellebore, Green

Helleborus niger

Helonias bullata.

Hemerocallis (in variety) aurantiaca.

flave

fwlve

thunbergi

Hemlock, Canadian.

Carolina

Dwarf .
Group

Page

15-C, 29-A, 31-B-e, 31-B-f, 31-D

45-G-e, 31-B-f. : : : : : : 327

4, 229

33-C * . • . . . . . . 250

12-E-e : : : : : : : : ${ }_{126}^{250}$

43-E-a,45-F-d $\vdots \vdots \vdots \vdots \vdots \vdots 305,326$

33-C $\cdot \cdot \cdot \cdot$

$33-\mathrm{C} \cdot \cdot \cdot \cdot \cdot \cdot \cdot \cdot \cdot 250$

39.

19-F-a, 45- $\mathrm{F}-\mathrm{a}$

: * $135,325,329$

0-A, 30-B, 41

29-A

$131,212,293$

204

138

${ }_{46-\mathrm{C}-\mathrm{a}}^{29-\mathrm{H}} \cdot \cdot \cdot \cdot \cdot{ }_{336}$

26-B-c, 40-C-b, 45-F-b, 46-Cं-a $: \quad: \quad{ }_{191}, 291,324,336$

45-A-b. : : : : 319

45-F-b . . . . . . . . . 324

$16 \cdot \cdot \cdot \cdot \cdot \cdot \cdot \cdot \cdot \cdot 141$

28-B, 34-B, 35-A-A, 35-B-a, 40-B, $197,260,264,265,289,303$ 43-C-b, 43-G, 45-A-a, 45-L, 46-B-b, 15-C

$12 \div \cdot \bullet \cdot \bullet \cdot \bullet 205$

$12-\AA$

12-A-a

123, illus. 345

12-A-b

$12-\mathrm{E}$

12-E-b .

$12-E_{-a}$ :

12-E-e

12-E-c :

12-B

$260,264,265,289,303$

40

124

126

126

126

126

12-D

124, illus. 95, 110, 159

12-C

31-Kं-c, 45-i

31-B-1

31-E, 3i-L

31-B-1, 31-H

24-E, 45-I

30-B

28-B, 33-E-

15-C, 29-B, 31-B-d, 3i-k-a $\quad$ 140, 204, 223, 233

31-B-h, 31-C-a, 31-E- 31-I, 31-K-a, 226, 227, 230, 232, 233, 235

$31-M-b, 45-I, 31-E-31-1,31-K-a$, $38-\mathrm{C}-\mathrm{a}$.

32-A

$32-\mathrm{A}$

31-B-h

$32-A, 32-E, 35-A-a, 35-A-b$ : $\quad: \quad 240,242,264,265$

32-G-b-2

$32-\mathrm{H}-\mathrm{b}$

$32-A, 32-E, 35-A-a, 35-A-b$

32-G-b-2

(3)

31-B-h, 31-C-a, 31-F, 31-M-b, 43-I.

37-A-c

$31-\mathrm{H}, 31-\mathrm{L}-\mathrm{C}, 37-\dot{\mathrm{A}}-\mathrm{C}$

$31-\mathrm{H}$

$37-\mathrm{A}-\mathrm{C}$.

9-A, 9-B, 9-D, $12-\mathrm{A}-\mathrm{a}, 12-\mathrm{C}, 14-\mathrm{A}-\mathrm{a}$ 16-B-a, 20-D-b, 24-C-a, 27, 28-A, 30-B, 40-C-a, 44-F, 46-E

9-A, 9-B, 12-C
125

34,36 , illus. 34

233, 330

230,235

184,330

280

240

246

$240,242,264,265$

244

279

$204,223,230,253,279$

$180,209,235,319$

$226,227,230,235,309$

277

231, 235, 277

231
277

$112,113,124,125,134,145$ $166,182,193,197,213,290$,

316,338

$112,113,125$ 
NAmE

Hemlock, Globe Sargent's Weeping Western

Hemp-tree, Cut-leaved

Henna

Red-flowering

Hepatica (in variety)

triloba.

Heracleum mantegazzianum.

Herb gardens, Books on

Hercules Club

Herniaria glabra

Herniary .

Hesperis matranalis

Heuchera (in variety) brizoides

sanguinea

Hibiscus (in variety)

Chinese

\section{moscheutos}

moscheutos hybrido

syriacus

syriacus ardens

rosa-sinensis

Hickory

Nutmeg

Hills of Snow

Hippeastrum

Hippophae thamnoides.

Hobble-bush

Holly (in variety)

American

\section{Dahoon \\ English \\ Japanese \\ Small-leaved}

Hollyhock

Holodiscus discolor ariaefolius.

Honesty

Honeysuckle

Brown's

Bush

Doral

Early Fragrant

Fly Bush

French

Heliotrope

Japanese

Japanese Bush

Large-fruited

Prostrate

Prostrate -fowerin

Standish's Bush

Tartarian .

White Tartarian

Yellow

Zabel's

Hop Tree.

Cut-leaved

Hop, Japanese

Hornbeam

American

European

Globe

Pyramidal
GROUP

9-E

14-A-b, 46- $\mathrm{H}-\mathrm{a}$

42-A-b .

43-F-a

28-B, 29-C, 31-C-b, 40-A

28-B, 29-C, 31-C-b, 40-A

31-L-C

i1-B, 20-B, 43-F-a, 45-H-a

29-A

29-A

$31-\mathrm{C}-\mathrm{a}, 37-\mathrm{A}-\mathrm{c}, 45-\mathrm{I}$

30-A

15-C, 3i-D

15-C, 31-B-c, 31-C-b, 31-H, 31-I, 45-I.

16-C, 43-E-a, 43-F-a, 43-F-b, 43-F-d, 43-F-e, 43-J-b

31-B-j, 31-B-k, 31-E, 31- L-c . .

31-M-b.

$11-\mathrm{B}, 12-\mathrm{D}, 14-\mathrm{B}, 16-\mathrm{A}, 19-\mathrm{D}$

19-I, 26-B-C, 40-B, 40-C-b, 42-A-b, 45-B-b, 45-E • . . . . . 19-H, 43-E-a, 43-F-a, 43-F-b, 43-F-d, 43-F-e, 43-J-b

22-B, 38-C-a, 39, 40-Cं - .

..

5-H-a $\bullet \cdot \cdot \cdot \cdot \cdot \cdot \cdot 328$

19-C • • • • . . . . 155

43-I. * 309

12-A-b, 12-E-d, 17, 20-B, 24-B-b 26-A-c, 33-E-b, 42-A-a, 44-A-a . 27 44-G, 45-E, 45-G

$20-B, 20-C_{1}, 20-D-b, 40-\bar{C}-\dot{b}, \quad \dot{3}-\dot{B}-a$, 43-B-b, 43-D, 43-J-a, 45-B-a, 45-H-b 43-D

45-B-a, $46-\dot{A}-\dot{b}, 46-\dot{-}-\dot{b}$

16-B-a, 20-B, 45-B-a, 46-A ·b, 46- - $-\mathrm{-b}$ 26-A-c

31-B-f, 31-B-g, 31-B-h, 31-E, 31-N,'39. 46-C-b

$31-J$

20-D-a, 20-D-b, 34-A, 34-C, 42-A-a

45-A-b

13-B-a, 18-B, 23-B, 24-C-b, 27, 45-G 22-C

12-A-b, 17, 18-B, 19-A, 19-F-a. $2 \dot{2}-\mathrm{C}-\mathrm{b}-1$, $37-\mathrm{A}-\mathrm{a}, 41,45-\mathrm{B}-\mathrm{b}$.

12-E-e, 37-A-a

$31-\mathrm{J}$

18-B, 22-C-b-2, 24-B-c, 24-C-c, 25-c. 29-E-c, 34-E, 43-C-a. 43-G, 44-G, 45-A-b, 46-B-b, 46-G

13-A-c, 19-B, 19-G-a, 20-B, 46-E

15-B, 18-B, 29-E-a, 37-A-a .

12-D, 13-A-c, 46-C-a

29-E-a

(9)

19-A, 22-C-b-1, 45-F-c 19-B, 19-i, 20-B 26-A-c, 27, 42-B-a, 44-A-a

19-G-a

12-D, 13-A-c, i9-B

17, 25-A, 26-B-a .

32-F-b, 45-L

32-F-b

$34-\mathrm{E}$

39

$12-\dot{C}, 1 \dot{6}-\mathrm{D}-\mathrm{a}, 22-\dot{\mathrm{B}}, 2 \dot{8}-\dot{\mathrm{A}}, 4 \dot{0}-\mathrm{C}-\mathrm{a}$

12-A-b, 16-A, 16-B-b, 16-D-a, 40-C-b 16-B-b

22-C-a, 30-A, 30-B, 40-C-a
Page

114

135,339

297

306

$197,205,228,289$

$197,205,228,289$

235

344

$120,162,305,327$

204

$227,277,330$

(12

140,229

$140,223,228,231,232,330$

316

$146,305,306,307,310$

$226,230,235$

$120,125,135,144,156,159$, $191,289,291,297,321,323$

159

$146,305,306,307,310$

$173,280,284,290$

55

$124,126,149,163,181,190$, 193 316,327

$163,166,291,301,302,304$, $310,320,329$

304

$320,335,340$

$145,163,320,335,340$

190

124

$224,225,229,236,284$

(3)

$165,166,260,261,296$

320

$130,151,177,182,193,327$

$175,303,308$

338

$124,149,151,154,158,175$, 126,276

233

$151,175,182,183,187,207$, $261,303,308,317,320,336$, 338

$130,155,158,163,338$

139, 151, 207, 276

$125,130,336$

207

$154,175,326$

$125,130,145,155,159,163$,

158

$125,130,155$

$149,186,191$

242,333

242

261

$125,146,173,196,290$

$124,144,145,146,291$

145

$174,212,213,290$

135 
Horse-chestnut

NAME

Horse-chestnut Common

Himalayan

Red-flowering

Wilson's Chinese

Wilson's Chinese

Horticultural Varieties

Houseleek

Alpine.

Spiderweb :

serpyllifolia

Hovenia dulcis

Hunnemannia fumariaefolia

Humulus japonicus lupulus.

lupulus japonicus

Hyacinth (in variety)
Summer

Hyacinth Bean

Hyacinthus

candicans

Hybrid Broom

Hydrangea (in variety)

arborescens

arborescens graindifiora

arborescens sterilis.

Climbing

Garden

hortensis

Japanese

Large-flowered

Large-flowered Wild

Oak-leaved

opuloides hortensia

opuloides otaksa

Panicled

lato

paniculata grandifiore

petiolaris

quercifolia

Wild

Hydrastis canadensis

Hydrophyllum appendiculatum virgenscum

Hypericum (in variety) aureum

buckleyi

calycinum

densiflorum

glomeratum

kalmianum.

moserianum

patulum henr

prolificum

Iberis amara coronaria . sempervirens

umbellata

Ilex (in variety)

aquifolium

cassine

crenata.

glabra

microphylla

opaca

specimens

verticillata

Illustrations, List of

Impatiens balsamine biflora.

pallida.

sultana

Incarvillea delevayi

Incense Cedar

\section{Incense Cedar}

GROUP

PAGE

14-A-a, 19-B, 39, 42-C

10-C, 11-A, 20-F

14-B, 19-G-b, 42-B-b.

45-C

46-D

$45-C$

$30-A$

33

$24-\mathrm{E}^{-}, 29-\mathrm{G}, 32-\mathrm{G}-\dot{a}-1$

32-G-a-1

29-F, 32-G-a-1

29-H

45-A-a

45- $\mathrm{H}-\mathrm{a}$

$32-\mathrm{A}, 32-\mathrm{H}-\mathrm{a}$

34-E

32-F-b, 45-L

32-F-b

36-A, 36-E-a, 36- $\dot{\mathrm{E}}-\mathrm{b}$

31-G

32-F-b :

36-A

45-F-c

14-B, 16-C, 19-G-b, 26-B-c, 39, 42-A-b, 43-F-b, 43-F-e

13-B-b, 19-D, $27,28-\dot{A}, 42-\dot{A}-a^{\circ} \cdot$ 26-A-c, 45-F-c.

19-C

34-B, 45-L

45-F-a

43-F-a

19-D, 19-I, 24-B-

22-A-C, $45-\mathrm{F}-\mathrm{c}$.

45-F-a

16-C, $4 \dot{3}-\mathrm{F}-\mathrm{b}, 43-\dot{\mathrm{F}}-\mathrm{e}$

19-D

19-D

19-D, 19-I, 24-B-b

45-

22-B, 27, 45-F-c, $45-\dot{\mathrm{H}}-\mathrm{b}$

13-B-b, 19-D, 27, 28-A, 42-A-a

28-B

29-C

19-D, 19-F-b

13-B-a, 33-E-b, 45-F-a

22-C-B, 29-E-b, 29-H, $45-\mathrm{F}-\mathrm{a}$

24-A-a

45-F-a

26-B-c, 28-B

13-A-a, 15-B, 29-H, 31-B-h, 45-F-a 45-F-a

13-A-a, 22-C-b-1

$45-\mathrm{F}-\mathrm{a}$

32-G-a-2

15-C, 29-A, 29- $\dot{\mathrm{F}}, 31-\mathrm{B}-\mathrm{b}, \quad 31-\dot{\mathrm{M}}-\mathrm{a}$, 32-A, 32-B, 32-D, 32-G-a-2 :

44-G, 45-E, 45-G

45-B-2, 46-A-b, 46-H-b

16-D-a, 20-B, $45-\dot{B}-\mathrm{a}, 46-\mathrm{A}-\dot{\mathrm{b}}, 4 \dot{6}-\mathrm{H}-\mathrm{b}$

12-B, 13-B-b, 16-B-b, 29-H, 40-C-b 45-F-b

12-B

$20-\mathrm{B}, 20-\dot{\mathrm{C}}, 20-\dot{\mathrm{D}}-\mathrm{b}, 40-\mathrm{C}-\mathrm{b}, 43-\dot{\mathrm{B}}-\mathrm{a}$ 43-B-b, 43-D, 43-J-a, 45-B-a, 45-H-b 43-B-b

13-B-c, 20-B, 20-C, 20-D-b, 24-A-a,

32-A

$31-\mathrm{N}$

30-B

43-- $\mathrm{B}-\mathrm{b}$
$133,155,284,298$

$117,119,167$

321

337

321

212

$184,209,243$

243

208,243

209

319

240,246

261,333

242,333

270,274

231

242

270

325

$35,146,158,191,284,297$. 306,307

$131,156,193,196,296$

190,326

260,333

324

324

306

$156,159,181$

190,326

$173,193,326,329$

324

$146,306,307$

156

$156,159,181$

$173,193,326,329$

$131,156,193,196,296$

197

205

156,158

$130,253,324$

175

$197,207,209,324$

180

324,197

128, 139, 209, 226, 324

324

128,175

324

244 336

$240,241,244$

$316,323,327$

$320,335,340$

304

$145,163,320,335,340$

$124,131,145,209,291,325$

124 $63,166,291,301,302,304$,
$310,320,329$

$131,163,166,180,190,196$

$\mathrm{XXV}$

240

236

213

330

$302,320,322,323,331$
$135,158,297$

$140,204,208,223,235,253$, 
Indian Bean

NAME

Indian Bean Dwarf

Indian-currant

Indian Paint.

Indigo, Blue

False

Tennessee False

Yellow False

Informal Effects

Inkberry

Insecticides

Insects, Plants subject to

Introduction

Arrangement of the material

Evergreens and their adaptation.

Grouping of plants, method and reason

Illustrations, The purpose of the

Index and method of using :

Method of treatment

Method of using the book

Range of material Range of plant adaptation in

Ipomoea (in variety)

hederacea

purpurea

Iresine herbst

lindeni.

Iris

American D $\dot{\mathrm{D}}$ arf

Celeste

Crested

cristata

Dalmatian

Diseases of

Furopean D

forentina

Florida.

German (in variety)

germanica

germanica fiavescens

germanica hybrids.

germanica Kharput

germanica-Queen of May

hexagona

Japanese

kaempferi

Lriental

orientalis

pallida dalmatica

Pink German .

Planting

pseudacorus

pumila

pumila azurea

pumila hybrida

Rotting

Siberian

sibirica

Transplanting of

verna

versicolor

Ironweed

Itea virginica

Iva ciliate

Ivy, Algerian

Boston

Carrier's Japanese Evergreen

English.

Henry's
Hybrid Japanese Evergreen.
GROUP

Page

10-C, 19-C, 20-F, 24-C-a, 42-C, 44-G

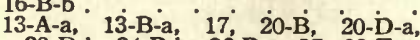
20-D-b, 24-B-b, 26-B-e, 27, 29-E-a, 44-B-a, 45-F-a, 46-C-b. . . 45-I

31-B-e.

13-B-b, 19-H, 31-M-b, $42-A-b^{\circ}, 45-I^{\circ}$ 45-J

45-F-a

17

12-B, $13-B-b, 16-B-\dot{b}, 29-\dot{H}, 40-\dot{C}-b$,

39

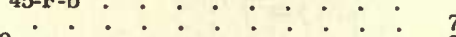

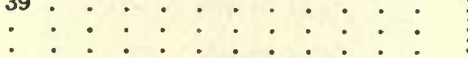

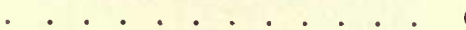

. . . . . . . . 6

: $:$ : $:$ : $:$ : $:$ : $: 4$

$\div: \div: \div: \div: 54$

35-A-c, $35-\dot{B}-a^{\circ} \cdot \cdot \cdot \cdot \cdot 6$

32-F-a

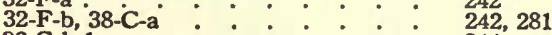

$32-\mathrm{G}-\mathrm{b}-1$ - : : $\quad 2^{-}$

32-G-b-1, 35-B-c : 244, 266

31-A, 31-K-b, 39, 40-A, 45-1

29-F

15-C, 29-F, 31-B-a, 3i-Cंb, 45-A-b.

15-C, 29-F, 31-B-a, 31-C-b, 45-A-b.

31-

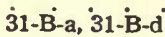

29-A

43-I.

31-B-a, 31-B-d, 3i-F, 31-I, 37-Á-c

31-F, 31-I, 37-A-c

31-B-d .

31-B-a :

31-B-c

43-I.

31-B-e, 31-B-f, 31-F, 31-i, 3i-L-C

31-B-e, 31-B-f, 31-F, 31-H, 31-I, 31-L-c

31-Li-c

31-B-e, 31-H

31-B-c.

31-Bं-d, 31-C-a, 3i-L-b 29-F

31-B-a

31-B-d .

31-B-e, 31-B-f, 31-C-á

31-B-e, 31-B-f, 31-C-a

29-F

31-B-a, 31-C-a

38-C-a

13-B-a, $18-B, 24-A-a, 26-B-c, 37-A-a$, 45-F-c

35-C-a

34-B, 39, 45-A-b, 46- $\dot{\mathrm{G}}$

28-B, 29-C, 34-B, 35-A-a, 35-Bं-a, 39. $40-\mathrm{B}, 43-\mathrm{C}-\mathrm{b}, 43-\mathrm{G}, 45-\mathrm{A}-\mathrm{a}, 45-\mathrm{L}$

$45-\mathrm{L}$

28-B, 29-A, 29-C, 29-E-C

224, 225, 227
$117,155,167,182,298,316$

145

$9,130,149,163,166,182$ 30

$30,159,235,297,330,331$

323

$24,131,145,209,291,325$

6

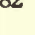

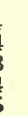

$222,233,284,289,330$

231

$140,208,222,228,320$

$140,208,222,228,320$

140,
224

284

222,224

204

309

$222,223,230,232,277$

$230,232,277$

223

222

231

223

$224,225,230,232,235$

$224,225,230,231,232,235$

91

235

224,231

223

39

224, 227, 234

208

222

224

$224,225,227$

90

222,227

281

$130,151,180,191,276,326$

281

333

$260,284,319,338$, illus. 335

$197,205,260,264,265,284$,

$289,303,308,319,333,336$, 338

197, 204, 205, 207 


\section{Page}

Ivy, Kenilworth Large-flowered Kenilworth : Scarlet-fruited Japanese Ėver-

green ${ }^{2}$ all-leaved English:

Small-leaved Japanese Evergreen

Ixia

Ixora

coccinea

colei

flore luteo

rosea splenden

Rose-coloured.

Wharlet

Yellow

15-C, 35-A-b, 35-B-a

34-B

140,265

140

18-A, 29-A.

151,204

29-F

140

35-F-a :

36-E-a .

43-F-d.

43-F-a.

43-F-b

$43-\mathrm{F}-\mathrm{b}$

43-F-d .

43-F-a

208

265
274

310

307

306

307

306

307

306

38-A

279

Jack-in-the-pulpit

Jacob's Ladder, Ámérican :

Jamestown Weed

36-E-b .

$31-\mathrm{C}-\mathrm{a}, 45-\mathrm{I}$

38-A

227,330

15

Books on

Japanese Raisin Tree

Japonica

Cape, See Cape Jasmine:

Carolina

Carolina Yellow

Catalonian.

Confederate

Crape

Double Yellow

Naked-flowered

New Chinese

Orange.

Red Coral

Jasminum (in variety)

grandiflorum

nudiflorum

officinale

primulinum

Jerusalem Cherry Vine

Jewel-weed

Joe-Pye Weed

Juglans cinerea

nigra

sieboldiana

June Berry

Chinese

Common

Dwarf

Golden

Greek

Irish

45- $\dot{\mathrm{H}}-\mathrm{a}$

43-F-b, 43-نे, $45-\dot{B}-\mathrm{a}, 45-\mathrm{F}-\dot{\mathrm{b}}, 4 \dot{5}-\mathrm{H}-\mathrm{b}$

44-G, 45-F-a, 45-K-b, 45-L .

136

344

328

$306,308,320,324,329$

$317,324,332,333$

Savin $\dot{\text { Silver-tipped Chinese }}$

Slender Greek

Swedish

Trailing

Juniperus (in variety)

barbadensis
chinensis

chinensis albo-variegata

chinensis pfitzeriana

communis

communis aurea

communis depress

communis hibernica

communis suecica.

excelsa

excelsa stricto

horizontalis

horizontalis douglasi

lucayana

prostrata
43-C-a, 43-G

45-L

43-C-a .

43-C-a, 45-i

16-C

19-F-a, 43-F-c, 46-G

43-F-c, 46-G

43-D, 43-F-a

43-F-b

44-G, 45-F-a

43-C-a

19-F-a, 43-F-c, 46-G

43-F-c, 45-K-b, 45-L, 46-G

35-A-b, 35-B-a, 45-L

30-B, 31-N

31-C-a

40-C-a, 45-H-a

38-C-a, 40-C-a

45- $\mathrm{H}-\mathrm{a}$

13-A-b, 17

45-E

9-A, 15-A, 24-B-b, 25-A

18-A $15-A, 24-B-b, 25-A$

18-

9-A 45-E

9-A, 15-A, 26-B-b, 40-C-

45-E

303,308

332

303,333

146

332

58, 307, 338

307,338

304,306

306

317,324

303

$158,307,338$

333

$307,332,333,338$

265,333

213,236

227

290, 328

281,290

129, 149

112, 284, 298

323

$111,138,181,186$

151

111,323

144

111

$111,138,191,290$

111,147

135,144

111,151

14-A-b, 16-A

9-A, 18-A

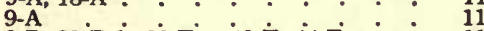

9-B, 20-D-b, 29-E-a, 42-E, $44-F$

43-J-a .

45- E

9-A

9-A, 15-A, 24-B-b, 25-A:

9-A

18-A

$14-A-b$

9-C, $45-\mathrm{E}$

$9-\mathrm{A}, 16-\mathrm{D}-\mathrm{b}-2$

9-A, 18-A

$9-\mathrm{A}$

43-E-a
111

$112,166,207,298,316$

310

323

111

$111,138,181,186$

111

135,144

113,323

111,147

111,151

111

190 


\section{NAME}

Juniperus sabina sabina tamariscifolio scopulorum. virginiana.

\section{virginiana cannarti virginiana glauca virginiana globosa virginiana pyramidalis virginiana schotti virginiana tripartit Justicia, Blue}

\section{Kadsura Tree}

Kalmia (in variety) angustifolia

carolina latifolia.

\section{polifolia}

Kentucky Coffee Tree

Kerria (in variety)

japonica

White

\section{Knapweed \\ Kniphofia pfizeri uvaria \\ Koelreuteria (in variety) paniculate.}

Kudzu Vine

Kumquat.

\section{Labrador Tea}

Narrow-leaved

Laburnum vulgare

Ladies' Eardrop

Lady's Slipper

Small White

Lagerstroemia indica

Lake front and river conditions

Shrubs :

Lamium maculatum

Lantana

camara

Lantana

Larch

European

Japanese

Larix (in variety)

europaea

laricina.

Larkspur

\section{Annual \\ Chinese \\ Everblooming}

Lathyrus latifolius odoratus

Laurel (in variety)

Carolina

Hardy English

Indian

Japanese

Mountain

Portuguese

Sheep.
9-A, 15-A, 26-B-b, 40-C-a

15-A, 18-A.

9-A 9-11-A $12-C^{\circ}$ 24-B-a, 25-A, 25-A-b, 38-C-a, 44-A-a, 44-D, 45-B-a

9-A, 16-A

$16-\mathrm{A}, 44-\mathrm{D}, 45-\mathrm{D}, 45-\mathrm{E}$

9-E

14-A-b.

9-A, 14-A-b, 16-A; 16-D-b-2, 45-E

18-A $-\mathrm{e}$

14-A-a, 16-A, 22-A, 45-E

13-B-b, 30-A, 40-B, 44-C

18-A, 19-E-a, 24-A-b, 29-E-a, 33-E-b, 38-A

19-C, 19-E-b, 24-A-b, 27, 33-E-b, 38 A, $40-\mathrm{C}$

33-E-b

$20-\mathrm{A}, 45-\mathrm{H}-\mathrm{a}$

44-G

13-A-a, 19-F-b, 2i, 40-B, $41,42-\dot{A}-a$, 45-F-c ${ }^{\circ}{ }^{\circ} \cdot 0^{\circ}$ 3-A-b, 19-B, 19-G-b, 20-B, 20-C, 26-B-c,

31-B-1, 31-G

31-B-k, 31-D, 31-i, 45ं-I

31-E, 34-A, 45-L, 46-G

14-A-a, 19-C; 19-F-b, 22-A, 24-D, $29-\mathrm{E}-\mathrm{H}-\mathrm{a}, 34-\dot{\mathrm{C}}, 34-\dot{\mathrm{E}}, 4 \dot{5}-\mathrm{L}, 46-\dot{G}^{\circ}$ : : : 29-E-c, 34-C, 34-E, 45-L, 46-G : :

24-A-b, 29-H, 33-E-b

$33-\mathrm{E}-\mathrm{b}$

17, 19-F-b, 42-B-a

35-B-b

28-B

24-A-a

16-C, 43-F-a, 43-F-b, 43-F-d, 43-F-e, 43-J-b, 45-H-b, 45-K-b

25

25-A

25-C

28-B, 31-C-b

35-B-a, 35-B-b, 43-I .

32-G-b-2

32-G-b-2, 35-B-a, 35-B-b, 43-I

14-A-a, 39

12-C, 23-A, 24-C

12-C, 16-D-b-1, 24-C-a

12-C, $23-A, 24-\mathrm{C}-\mathrm{a}$

24-A-a, 24-C-a, 26-A-b, 40-C-a

12-C, 16-D-b-1, 24-C-a 31-A, 31-B-e, 31-D, 31-i, 31-N, 38-A,

$32-\mathrm{A}, 32-\mathrm{C}, 32-\mathrm{H}-\mathrm{b}$

31-B-f

$31-\mathrm{F}$

$31-\mathrm{F}, 3 \dot{4}-\mathrm{A}$

$32-\mathrm{A}, 32-\mathrm{C}$

13-B-b, 30-A, 40-B. 44-G

33-E-b

45-B-a, 45-H-b, 45-K-b, $\dot{4} 6-\dot{A}-b, 46-H-\dot{b}$ 45-F-d .

16-C, $45-\mathrm{F}-\mathrm{b}, 45-\mathrm{G}, 45^{\circ}-\mathrm{H}-\mathrm{b}, 45-\mathrm{K}-\mathrm{b}$, 46-A-b, 46-H-b 19-C, 19-E-b, 24-A-b, 27, 33-E-b, 38-Aं, $40-\mathrm{C}-\mathrm{b}$

46-A-b, 46- $\mathrm{H}-\mathrm{b} \div \quad: \quad: \quad:$ 18-A, 19-E-a, 24-A-b, 29-E-a, 33-E-b,
$111,138,191,290$

138,151

$111,113,119,125,133,144$, $181,186,190,281,313,314$,

111,144

$144,314,322,323$

114

$111,135,145,147,323$

151

307

$133,144,173,322$

$131,212,289,317$

$151,157,181,207,253,279$

$155,157,181,193,253,279$, 291

253,328

317

$128,158,170,289,293,296$ $129,155,159,163,191,193$, 296

225

227,231

$226,229,232,330$

2.30. 260, 333, 338, illus. 334

$133,155,158,173,183,328$

207, 261, 333, 339

$181,209,253$

253

$149,158,297$

266

197

180

$146,306,307,310,329$

185

187

186

197, 228 , 266,309

244

$244,265,266,309$

133,284

$125,177,182$

$125,147,182$

13

$125,177,182$

$180,182,190,290$

$221,224,229,232,236,279$, 330 , jllus. 310

$240,241,246$

225

229,260

240,241

$131,212,289,317$

253

$321,329,332,335,340$

326

$146,324,327,329,332,335$, 339

$155,157,181,193,253,279$, 291

335,340
$151,157,181,207,253,279$ 
NAME

Laurel, Spotted Japanese Swamp

Variegated Japanese :

Laurestinus . . .

\section{Laurocerasus caroliniana \\ Laurus nobilis \\ Laurus nobilis \\ Lavandula vera $\rightarrow$ is \\ Lavender \\ Lavender Cotton $\quad: \quad: \quad$ : \\ Lawns- . \\ Books on \\ Keeping free from weeds \\ Drainage of lawn areas ertilizer for lawn prepara-} tion

Preparation of lawn areas. Seeding of lawns Sodding

Old lawns, Renovating of Plantings for

Seasons for seeding

Southern lawns

Planting and seeding

Soil and climatic conditions as affecting

Types of grasses for Types of soils

Lawsonia inermis

Lead Plan

eadwor

Blue

Leather-flower

Leather-leaf

Leather-wood

Leaves, Autumn colouration of.

Leaves, Selected for fragrance.

Ledum groenlandicum palustre

Leiophyllum

buxifolium

Lemon Balm

Leopard's Bane

Leplamnium virginianum

Lespedeza bicolor . japonicum

Leucanthemum

lacustre

Group

Page

45-F-b

33-E-b

43-E-a, 43- $\dot{\mathrm{F}}-\mathrm{a}, 45-\mathrm{B}-\mathrm{a}, 4 \dot{5}-\mathrm{F}-\mathrm{d}, 45-\dot{\mathrm{H}}-\mathrm{b}$, 43- $\mathrm{C}-\mathrm{b}, 46-\mathrm{A}-\mathrm{b}$

43-D, 43-F-a,

37-A-c, 37-B-b

$32-\mathrm{C}$

37-A-c, 37-B-b

24-E, 29-B, 32-G-b-1, 37-B-b$$
\text { : }
$$

i3-A

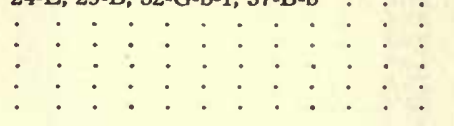$$
\cdot
$$ 
NAME

Lilac, Persian

Tree

Lilacs, Hybrid

Blue to bluish lavender Double

Deep purple red to reddish Double

Single

Pink to rosy
Double

Single

Select list of

White

Double

Lilies, for:

Accent plants

Calcareous soil

Clay (if well drained)

ture in garden soil

Moist and boggy situations .

Open sun

Sandy or dry soils

Shady places

Undergrowth and shrubbery borders

Lilium (in variety)

auralum

canadense

candidum

carolinianum

croceum

elegans.

hansoni.

henryi

japonicum

martagon

monadelphum

parryi

philadelphicum

regale

speciosum

superbum

tenuifolium

testaceum

tigrinum

wallacei

washingtonianum

Lily (in variety)

Alpine

American Turk's Cap

Blue Plantain

Boland's

Caucasian .

Chilean

Coral

European Turk's Cap

Fortune's Plantain

Fragrant Orange.

Gold-banded

Golden Turk's Cap

Japanese

Large-flowered Plantain

Lemon

Leopard

Madonn

Nankeen

Panther

Parry's.

Plantain

Royal

Santa Cru

Showy Siberian coral

Siebold's Plantain
Grour

PAGE

13-A-b . . $: 129$

19--I, 33-A, 46-C-a

19-I, 33-A, 46-C-a : : : : : : 249

33-A : $: 0249$

33-A • • • • • • • • . 249

33-A $*$ : : : 249

33-A . . . . . . . . . 249

$33-\mathbf{A} \div \div \div \div \div$

33-A $\cdot \cdot \cdot \cdot \cdot \cdot \cdot \cdot \cdot \cdot 249$

33-A $\bullet \cdot \cdot \cdot \cdot \cdot \cdot \cdot \cdot 249$

33-A * . . . . . . . . 249

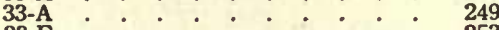

33-F $\cdot \cdot \cdot \cdot \cdot \cdot \cdot \cdot \quad 253$

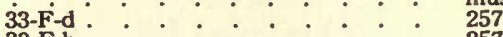

33-F-h • • • • • • • • ・ 257

33-F-c $: \cdot \cdot \cdot \cdot \cdot \cdot 256$

33-F-e : : . : * : . 257

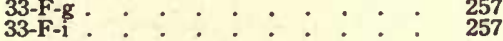

33-F-f 257

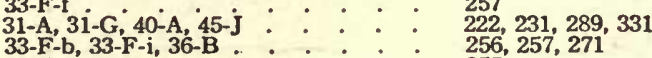

33-F-g

31-H, 33-F-b, 33-F-d, 33-F-e, 33-F-h, 36-B .

33-F-g

33-F-b, 33-F-e, 33-F-h

33-F-e, 33-F-h

33-F-d, 33-F-h, 33-Fi

33-F-i, 43-I

$33-\mathrm{F}-\mathrm{i}$

33-F-d, 33-F-e.

33-F-d, 33-F-e, 33-F-h

33-F-c, 33-F-i

33-F-C

33-F-b, 33-F-e, 33-F-g, 33-F-h, 36-B

33-F-b

29-F-c 3i-H, 33-F-ib, 33-F-f, 36-B

29-H, 33-F-c

33-F-d

33-F-d $: \vdots: \quad: \quad 256$

33-F-b, 33-F-e, 33-F-h, 36-B $\quad: \quad$ : 256

33-F-b * * * * : : : : 256

31-A, 3i-G, 40-A, $45^{\circ}-$

33-F-a, 33-F-e, 33-F-h

33-F-c .

31-B-e .

33-F-g

$45-I$

31-F-b, 31-C-a, 3i-F, 31-M-b, 43-I.

33-F-d, 33-F-e.

, 257,271

$209,256,271$

$231,256,257,271$

257

256 ,

257,309

(5)

257

256, 257

$256,257,271$

256

$209,231,256,257,271$

209,256

09,256

257,271

$222,231,289,331$

256,257

257

329

$226,227,230,235,309$,

257

31-B-e

33-F-b, 33-F-i, 36-B

33-F-d, 33-F-h, 33-F-i

29-H, 33-F-i, 36-B

31-B-f

31-L-c, $37-\dot{A}-c$.

33-F-c

33-F-a, 33-F-d, 33-Fe, 33-F-h, 36-B

29-H

33-F-c, 33-F-i

29-A, 31-M-a, 37-Aं-c, 43-I, 45-I

33-F-b

33-F-C

33-F-b, 33-F-f, 36-B

29-H
224

$256,257,271$

$256,257,271$

209,257

235,277 , illus. 310

253

$256,257,271$

257

256, 257

$204,235,277,309,330$

256

$256,257,271$

209 
Name

GrouP

33-F-C

33-F-g

33-F-e, 33-F-h

33-F-b, 33-F-e, 33-F-h, 36-B

29-H

$35-\mathrm{F}-\mathrm{b}$

33-F-b, 33-F-e, 33-F-g, 33-F-h, 36-B

29-H, 33-F-c, 36-B - g, 33-F-h, 36-B

43.

33-F-i

45-J

Yellow Showy

Yellow

Lily-of-the-valley

Limnocharis humboldli

Linaria cynbalaria cymbalaria maxima

Linden

American

Common

Crimean

Surope

Linnaea borealis

Linum perenne

Liquidambar styracifitua.

Liriodendron tulipifera

tulipifera pyramidalis

Lists for reference

Lithospermum canescens

Lobelia

Lobelia (in variety)

Annual

Blue Compact.

cardinalis.

Double

erinus alba

erinus compacta Crystal Palace

erinus flore pleno

erinus tricolor

speciosa

Spotted

syphilitica

Loblolly Bay

Loco-weed, Slender

Black

\section{Chinese Honey}

Honey .

Long-spined Honey Japanese Honey

Pyramidal Black

Thornless

Lolium temulentiom

Lonicera (in variety)

\section{belle}

brown

fragrantissima

heckratti

japonica halliana

maacki

morrowi

periclymenum belgica

prostrata

sempervirens

spinosa alberts

standishi
28-B, 29-C, 31-B-b, 3i-C-b, 31-i, 36-B

36-E-a, 37-A-c

15-I. 35-A-c, 35-B-a :

$15-$

24-E, 3i-D

37-A-b, 39

24-A-a, 44-E-a

10-A, 46-F

10-A, 46-D

11-A

10-A, 11-A; 14-A-a

15-A, 29-F

15-C, 31-B-a, 31-H

10-B, 14-A-a, 20-A, 22-A, 40-B, 40-C-a 43-B-a, 43-J-a, 45-C, 45-H-a. 42-C

$10-\mathrm{B}, 2 \dot{0}-\mathrm{A}, 22 \dot{-A}, 40-\dot{\mathrm{B}}, 40-\dot{\mathrm{C}} \mathrm{b}$

14-A-b .

45-1

32-E, 35-B-a, 45-1

35-A-a, 45-I

35-A-a.

32-G-a-2

31-B-g, 31-C-a, 31-L

32-G-a-2

32-E

32-G-a-2

32-G-a-2

32-G-a-2

32-G-a-2

35-B-a

32-G-a-2

31-B-e

32-G-a-2

43-B-a, 43-B-b, 43-D-a

38-A

10- $\mathrm{C}, 11-\mathrm{A}, \quad \dot{\mathrm{C}}, 19-\dot{\mathrm{C}}, 19-\dot{\mathrm{C}}-\mathrm{b}, 23-\mathrm{A}$

24-B-a, 24-D, 25-A, 26-B-a, 37-A-b,

$$
\text { 42-B-b }
$$

45-C, 45-H-a : $:$ : $:$ : :

10-C, 12-A-b, 20-A, 20-F, 24-D, 26-B-a 37-A-b, 45-H-a .

45-C, $4 \dot{-}-\mathrm{H}-\mathrm{a}$.

$14-\mathrm{A}-\mathrm{b}$.

46-D

38-A •

20-D-a, 20-D-b, 23-B, 34-A, 34-C, 42-A-a, 45-G

12-D, 13-A-c, 19-B

45- $\mathrm{A}-\mathrm{b}$.

12-A-b, 17, 18-B, 19-A, 19-F-a, 22-Cं-b-i, 45-A-b

18-B, 22-C-b-2, 24-B-c, $24-\dot{C}$ -

29-E-c, 34-E, 43-C-a, 43-G, 44-G, 45-A-b, 46-B-b, 46-G

12-D, 13-A-c, 46-C-a

13-A-c, 19-B, 19-G-a, 20-B, 46-E

$46-G$

22-C-a-i, $3-\dot{C}-\dot{a}, \dot{4} 3-\dot{G}$

15-B, 18-B, 29-E-a, 37-A-a

19-A, 22-C-b-1, 45-F-c . 37-A-a, 41, 45-B-b
PAGE

256

257

257

$256,257,271$

209

256

$256,257,271$

$209,256,271$

309

257

331

$197,205,223,228,232,270$,

274

140, 265

140

184, 229

276,284

180,315

117,338

117,337

119

$117,119,134$

138,208

$140,222,231$

$117,133,162,173,289,291$, $301,310,320,328$

117, 162, 173, 289, 291

135

107

330

$242,265,330$

264,330

264

$225,227,235$

244

244

244

244

244

265

244

244

$301,302,305$

279,298

$117,119,149,155,159,177$,

$181,183,186,191,276,297$

321,328

$117,124,162,167,183,191$. 321 321,328

321
337

$165,166,177,260,261,296$. 327

$125,130,155$

320

$124,149,151,154,158,175$, $276,293,321$ 320

$151,175,182,183,187,207$, $261,303,308,317,320,336$,

$125,130,336$

$130,155,158,163,338$

338
207

$175,303,308$

$139,151,207,276$

$154,175,326$ 
NAME

Lonicera syringantha tatarica

tatarica alba

xylosteum

Loose-strife, Common Ýellow Japanese

Lotus (in variety)

American

corniculatus

Love-in-a-mist

Low-growing plants along the inner side of curving roadways and at entrances.

Deciduous

Evergreen

Lunaria annuo

Lupine

False

Lupinus hirsutus

polyphyllus

Lychnis

chalcedonica

coronaria

dioica

viscaria splendens

Lycium barbarum

chinense

halimifolium

Lyonia ligustrino

Lysimachia clethroides nummularia

vulgaris.

Lythrum salicaria roseum

salicaria roseum superbum

Mackaya

Maclura pomifera

Madre

Madrona

Madwort

Silvery

Magnolia (in variety)

acuminata

Chinese Purple

Chinese White

conspicua

denudata

grandiflore

Great-leaved

hypoleuca

mactophylla

soulangeana

Soulange's

Starry

Swam

tripetala

tripetal

Mahonia (in variety) aquifolium

Chinese

Creeping

fortunei.

Japanese

japonica

nervosa.

pinnala.

binnata wagner

Pinnate-leaved

repens :

Maidenhair Tree.
Group

29-E-a

2-D, 13-A-c, 16-A, i9-B, i9-I, 20-B 26-A-c, 27, 42-B-a, 44-A-a. 19-G-a

12-E-e, 37-A-a

31-L-c .

31-C-a .

31-B-g, 31-E, 31-L-c

43-I.

29-F

32-A, 32-C, 32-D

18

18-A

31-J

$32-C$

24-E, 3i-B-

32-C

24-E, 3i-B-e

$31-\mathrm{C}-\mathrm{a}, 31-\mathrm{N}$

$31-J$

31-B-g :

31-B-g, 31-i , 31-J, 3i-K-a, 45-i

31-J

15-C, 3i-B-g

26-A-c

24-B-C, 25-C, 29-E-c, 34-D, 44-B-b

26-A-C

31-C-a

28-B, 29-A, 29-C, 35-B-a, 45-A-a

31-E, 31-L-C

43-F-e

12-A-b, $20-A_{1}, 23-A$

43-J-a

46-H-b.$\quad 339$

43-I. $\div \quad \div \quad \div \quad \div \quad \div$

15-C 139

14-A-a, 19-A, 39, 40-B, 42-B-a, 43-B-a, 133, 154, 284, 289, 297, 301, 44-G, 45-C, 45-G, 45-H-a, 45-K-a . $20-\mathrm{A}, 45-\mathrm{C}, 45-\mathrm{H}-\mathrm{a}$ 45-G

37-A-a

37-A-a .

45-H-a

19-B, 37-A-a $45-\mathrm{C}, 45-\mathrm{G}, 45-\mathrm{H}-\mathrm{a}, 45-\mathrm{K}-\mathrm{a}$

45-H-a .

45-G

45- $\mathrm{H}-\mathrm{a}$

19-E-a, 45-H-a

19-E-a, 45-H-a

13-A-b, 19-G-a

13-A-b, 19-G-a

19-B, 37-A-a

45-C, 45-G.

$45-\mathrm{H}-\mathrm{a}$

42-B-a, 44-G

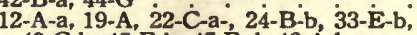
40-C-b, 45-F-b, 45-F-d, 46-Á-b 45-F-d

15-A, 18-A, 28-B, 29-C, 33-E-b, 45-F-b $45-\mathrm{F}-\mathrm{d}$

45-F-d.

$46-\mathrm{E}$

45-F-d

33-E-b

15-A, 18-A, 28-B, 29-C, 33-E-b, 45-F-b $45-\mathrm{F}$

10-B, 11-A, 22-C-a, 45-C, 45-H-a
Page

207

$25,130,145,155,159,163$. 58

126, 276

235

$225,230,235$

234

208

240; 241

150

151

241

226

184,224

184,224

227, 236

233

$225,229,233,330$

140,225

190

$182,187,207,261,314$

190

197, 204, 205, 265, 319

(35

230,235

307

$4,162,177$

$317,321,327,328,331$

$162,321,328$

327

276

328

155, 276

$301,321,327,328,331$

328

327

157,328

157,328

129,158

129,158

155,276

321,327

328

297,317

$24,154,174,181,253,291$, $325,326,335$

326

$138,151,197,205,253,325$

326

326

326

338

326

(5)

$138,151,197,205,253,325$

$117,119,174,321,328$ 
Maintenance.

Chemicals used in spraying

Different types of gardens,

$$
\text { Maintenance of }
$$

Annual flower gardens

Cutting gardens, Mainte-

nance of flower gardens,

Maintenance of.

Refined flower gardens, Maintenance of

Rock gardens, Mainte-

Rose gardens, Maintenance of gall gardens, Maintenance

Water gardens, Maintenance of .

Wild gardens, Maintenance of

Evergreens, Maintenance of .

Fertilizing annuals

Forms of sprays.

Formulas for sprays .

Lawns, Maintenance of

Fertilizing lawns

Mowing lawns

Rolling and weeding

Watering lawns

Putfits for spraying .

Diseases of perennials and control

GROUP

Dividing perennials and renovating beds

Fertilizing perennials :

Mulching perennials for winter protection

Removing seed pods and

general care
Watering perennials

Requirements

Rhododendrons and other broad-leaved evergreens. Fertilizing rhododendrons.

Season for spraying.

Shrubs, Maintenance of

Spraying don'ts

Spraying trees and shrubs

Symptoms and treatments.

Trees, Maintenance of

Fertilizing trees

Tree surgery

Watering trees

Vines, Maintenance of

Mallow

Marsh

Musk

Mallow Marvels

Malpighia coccigera .

Maltese Cross

Malva moschato

Malvaviscus arboreus

Mandrake

Mangifera indica

Mango

Manilla Grass

Manure, How to use for

Bulbs

Irises

Peonies.

Maple (in variety)

Columnar Suga

Drummond's

European Cork

Japanese

Norway

Oregon

$32-c$

45-

31-B-j, 31-B-k, 31-E, 31-L-c

31-M-b

31-B-

37-A-c

$43-\mathrm{F}-\mathrm{d}$

28-B

43-B-b, 43-D

43-B-b, 43-D

43-G

$\therefore: \vdots: \vdots: \vdots: \vdots 66$

$30-A, 30-B, 39 \div \quad \vdots \quad \vdots \quad \vdots \quad 212,284$

16-A, 16-D-b-1 • . • * • • • 144, 147

38-C-b

13-A-b, 16-B-b, 16-D-a, 45-B-b. : . 124, 145, 146, 321, illus. 158 14-B-b-a, $15-\mathrm{B}, \quad \dot{2}-\dot{B}, \quad \dot{4}-\dot{\mathrm{C}}-\mathrm{b}, \dot{4} \dot{4}-\mathrm{G}^{\circ}$ 46-C-a

10-B, 22-C-a, 44-E-b, 46-D :
145

$133,139,173,290,316,336$

$117,173,315,337$ 
NAME

Maple, Pyramidal Silver Pyramidal Sugar

Schwedler's Purple
Siberian :
Silver $:$
Soft. :
Striped :
Sugar.

Sugar.

Sycamore

Tartaria

Marguerite, Hardy

Marigold, African varieties

French

Marsh .

Pot

Tall Double African

Mascarene Grass

Mass plantings, Shrubs for

Matrimony Vine

African.

Matthiola

incana

incona annua

Maurandia (in variety)

Maurandy Vine (in variety)

Meadow Beauty

Meadow-rue

Meadow-sweet

Herbaceous

Japanese

Medlar

Melia azedarach umbraculifor-

Mis
Melissa officinalis

Menispermum canadense

Meratia praecox

Mertia praecox

Mice, Protection against

Michelia fuscala.

Mignonette

Milfoil, Yellow

Milkweed, Red

Swamp

Milkwort

Box-leaved

Mimosa

Minnesota, Plants for

Autumn colouration of leaves Early

Medium

Evergreens

Ground cover

Shrubs

Vines

Hedges

Windbreaks

Heavy, formal effects

Plants not hardy in Minne-

$$
\text { sota }
$$

treet trees

Adapted to special conditions

$$
\text { Entirely hardy }
$$

Miscanthus (in variety)

Miscellaneous book references

Mist Flower

Mitchella repens

Mixtures of grass seed .

Mock Orange

Common

Falconer's

Golden Dwarf.
GROUP

12-C, 12-D, 14-A-b, 16-A, 16-D-b-1

14-A-b

19-A, 20-B, 22-A, 24-A-a, 24-C-a, 26-A-a, 38-C-b, 40-B, 43-B-a, 44-C-a,

14-A-a $22-A, 25-A, 26-B_{-2}, 46-F^{\circ}$ :

12-E-e, 23-A, 40-B

$10-\mathrm{C}, 44-\mathrm{E}-\mathrm{b}$

10-A, 22- $\dot{\mathrm{A}}, 24-\dot{\mathrm{C}}-\dot{\mathrm{a}}, 28-\dot{\mathrm{A}}, \quad 44-\mathrm{C}-\mathrm{a}$, $44-$

46-D

12-C, 44-A-b

31-A, 31-B-h, 31-D, 31-K-c, 45-

32-H-a

31-L-b, 31-L-c.

32-A, 32-H-a

32-H-b

13-G

24-B-c, 25-C $29-\dot{\mathrm{E}}-\mathrm{c}, 34-\mathrm{D}, \dot{4} 4-\dot{\mathrm{B}}-\mathrm{b}$

26-A-c

26-B-c

32-A, 32-E, 32-H-a

$32-\mathrm{H}-\mathrm{a}$

35-A-a, 35-B-a

35-A-a, 35-B-a

24-A-a

15-C, 30-A, 31-B-b, 3i-C-a, 31-L-c, 45-i

19-C., 26-A-C, 29-E-a

31-C-a, 45-I

31-C-a .

$43-\mathrm{D}$

30-B

43-B-a, 45-H-a, 45-K-a

$31-\mathrm{N}$

44-B-b, 45-i

$45-F-a$

29-H, 3i-B-a, 45-j

43-F-c, $45-\dot{\mathrm{F}}-\mathrm{d}, 45-\mathrm{K}$

29-I, 32-A, 32-B, 32-D

29-A, 31-B-h .

24-A-a.

$31-\mathrm{L}-\mathrm{c}$

33-E-b

43-B-a, 45-H-a, 45-K-a

44

44-C

44-C-a

44-F

44-B

44-B-a

44-B-

44-A

44-A-a

44-D

44-G

44-E

44-E-b .

44-E-a

31-E, 3i-L-c

$38-C_{-2} \cdot \therefore \quad: \quad: \quad \cdot \quad: \quad 345$

15-C, 24-A-a, 28-B, 29-B, 29-C, 29-H, 30-A, 31-C-B

i9-C, 19-G-b, $27,41,42-\dot{A}-\mathrm{a}$

12-E-e, 13-A-c, 19-1, 25-B, 37-A-a

12-B, 15-B.

13-A-C

$12-B$
PAGE

125, 134, 144, 147

$154,162,173,180,182,189$

$281,289,301,314,338$

133

$125,173,186,191,338$

$126,177,289$

117,315

$116,173,182,196,314,315$

337

125, 313

$221,225,229,233,330$, illus. 294

240,246

246

234,235

240,245

246

308

$182,187,207,261,314$

190

246

$240,242,246$

246

264,265

264,265

180

$140,212,223,228,235,330$

$156,190,207$

227, 330

227

213

$301,328,331$

236

314,333

324

209, 222, 331

116

$307,326,332$

$210,240,241$

203,225

180

205

253

$301,327,331$

312

314

314

315

313

314

313

313

314

316

315

315

230,235

226, 232, 235

$140,180,197,204,205,209$, 212,228

55

$155,158,193,293,296$

$126,130,159,187,276$

124,139

130
124 
NAME

Mock Orange, Gordon's. Hybrid.

Large-flowered

Lemoine's .

Native

Moentless
Moist soils, Ground cover for Monarda

fistulosa

Moneywort

Monkshood

Wilson's

Moonseed, Common

Moon Vine

Morning Glory Common

Japanese

orus rubra.

alba tatarica

Moss, Flowering.

Rose

Mother of Thyme

Mountain Rose.

Mourning Bride

Mulberry

Pape

Red $\dot{\text { Tep }}$

Mulching

Fertilizers for (See Fertilizers)

For the winter
Mullein, Clasping-leaved

Greek

Nettle-leaved :

Purple

Musa (in variety)

ensete biscari botryoides

Muscari botr

Mustard, Rock-loving Hedge

Myosotis alpestris

palustris

palustris semperflorens

Myrica (in variety).

carolinensis

cerifera

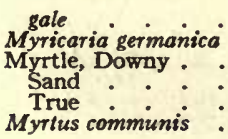

Nandina domestica Japanese

Narcissus (in variety)

$$
\text { barri }
$$

horsfieldi

incomparabilis

leedsi

leedsi amabilis

Paper White

poeticus

Poet's

polyanthus

Trumpet

Trumpet Majo

Yellow Paper White

Nasturtium

ative collected shrubs.

Native plants, Books on

Natural informal effects

Naturalizing, Bulbs for .

In wild garden.

Perennials

Shrubs.
Group

Page

36-

37-A-a

$17,23-\mathrm{B} \cdot 0_{1} \cdot 0_{149,177}$

46-C-a

46-C-b, 46-E • • . . . . . . 337, 338

28-A

29-A $37-\mathrm{A}-\mathrm{i}$ - $\mathrm{J}$

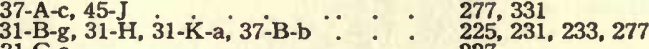

31-C-a : : 227

28-B, 29-A, 29-C, 35-B-a, 45-A-a : : 197, 204, 205, 265, 319

31-B-i, 31-G, 31-N, 38-A, 45-1.

31-E

226, 231, 236, 279, 319

44-B-b, 45-L . . . . . . . 314, 333

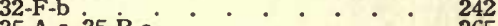

$35-A-c, 35-B-a$

32-F-b, 38-C-a

32-F-b

20-D-a, 40-B .

23.A

15-A, 29-F, 29-H, 33-E-b : : : : 139, 208, 209, 253

29-I, 32-B, 32-G-a-2

32-G-a-1

43-C-a, 45-i

31-B-e, 31-I, 32-A

23-A, 39, 44-G

43-B-a, 45-H-a

20-D-a, 40-B

14-A-a.

242,281

165,289

$210,241,244$

243

302,332

$224,232,240$

$177,284,316$

301,327

165,289

133

24-

24-E

24-E

43-D

16-C

36-A

38-A

15-C

29-A, 31-C-b, 31-L-c, 32-D

B-a, 31-D

44-C

40-C-a, 45- $\dot{F}-\mathrm{c}$

$13-\mathrm{A}-\mathrm{a}, 13-\mathrm{B}-\mathrm{a}, \quad 18-\mathrm{B}, 20-\mathrm{B}, 2 \dot{0}-\mathrm{C}$, 20-D-b, 22-C-a, 24-B-b, 25-B, 26-A-c, 28-A, 45-F-c

45-F-

43-D, 43-F-b

29-B, 33-E-b, 45-F-b

45-F-d .

100

184

184

184

304

146

270

140

$204,228,235,241$

222, 229

317

290,326

$29,130,151,163,166,174$

$181,187,190,207,310,326$

197,326

304,306

$204,253,325$

326

45-F-d, 45-G, 45-K-b

45-F-d, 45-G, 45-K-b

36-A, 39, 45-J

36-A

36-E-b

36-A

36-B

36-E-b

36-A, 36-B.

36-A, 36-B.

36-E-b .

$36-\mathrm{A}, 36-\mathrm{B}$

36-E-b .

32-A, 32-C, 35-A-b, 35-B-a, $43-\dot{\mathrm{I}}$

i7

$326,327,332$

$326,327,332$

$270,285,331$

270

274

270

270

271

270,271, illus. 366

270,271 , illus. 366

274

270,271

274

$240,241,265,310$

244

148

270

270

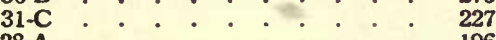

28-A 196 
31-L-a, 43-I

26-A-c

29-A, $2 \dot{9}-\mathrm{F}, 35-\mathrm{A}-\mathrm{a}, 3 \dot{5}-\mathrm{A}-\mathrm{c}, 3 \mathbf{3}-\dot{\mathrm{B}}-\mathrm{a}$

15-C, 24-E.

$16-C$

mussini

Nerium (in variety) oleander oleander DeBrun

oleander Savort

Nettle Tree.

Chinese

Neviusia alabamensis New Jersey Tea

Hybrid

Nicotiana

Nietembergia gracilis

Nigello damascena

Nightshade, Deadly. Woody

Ninebark

Norfolk Island Pine.

Nuphar

Nut Trees

Nymphaea

alba.

marliaceo

odorata

odorata sulphurea.

Nyssa aquatica

syloatica

Oak

Black

California White

English.

Korean.

Laurel

Live

Mossy Cup

Pin

Pyramidal English

Red.

Scarlet

Shingle

Swamp Spanish

Swamp White.

Water

\section{White \\ Willow \\ Yellow Chestnut}

Ocean Spray

Oenothera (in variety)

biennis.

fruticose

fruticosa youngi

'missouriensis

speciosa

Oleander

Double Crimson

Pink

White

Oleaster, Broad-leaved

Bronze

Japanese

Yellow-spotted

Olive, American

Florida

Fragrant

Russian

Sweet

Onoclea sensibilis

struthiopteris

opuntia vulgaris
43-E-a, 43-E-b, 43-F-a, 43-J-b, 45-H-b. 43-F-d 10-B, i1-A, 20-D-a, $20-\dot{\mathrm{F}}, 26-\mathrm{B}-\mathrm{a}_{\mathrm{a}}$ 45-C

45-F-c

13-B-a, 18-B, $27,28-\dot{A}, 42-\dot{A}-b$

45-F-a

35-B-b

$32-\mathrm{A}, 32-\mathrm{C}, 32-\mathrm{D}$

2.-A,

34-A

11-B, 17, $19-\mathrm{G}-\mathrm{b}, 20-\mathrm{B}, \quad 23-\dot{\mathrm{B}}, 28-\dot{\mathrm{A}}$ $43-\mathrm{B}-\mathrm{b}$.

43-I

$20-\mathrm{F}$

43-I

31-L-a

31-La .

31-L-a

31-L- -

14-A-a, 20-D-a, 22-B, $24-\dot{A}-\mathrm{a}, 40-{ }^{-}-a^{\circ}$

14-A-a, 30-B, 39

$10-\mathrm{A}, 22-\mathrm{B}$

24-D

16-A, $16-\mathrm{D}-\mathrm{b}-1,45-\mathrm{E}$

16-D-a, 45-K-a $45-\mathrm{C}$ - $45-\mathrm{H}-\mathrm{a}, 45-\dot{K}_{-} \mathrm{a}$ : 43-B-a, $45-\mathrm{C}$

43-B-

10-B, 1i-A; 24-A-a, 45-C

14-A-b

10-A $22-\dot{B}, 24-\dot{B}-\mathrm{a}, 2 \dot{6}-\mathrm{A}-\mathrm{a}, 40-\dot{\mathrm{C}}-\mathrm{b}$, $44-\mathrm{C}-\mathrm{b}, 44-\mathrm{E}-\mathrm{a}, 45-\mathrm{C}$

$10-A, 22-C-a, 44-E-a, 45-C, 46-\mathrm{D}, 46-\dot{\mathrm{F}}$ $45-\mathrm{C}$

45- H-a

24- $\mathrm{H}-\mathrm{a}$

38-C-a, 43-A, 43-B-a, 45-C, 45-H-a, $45-\mathrm{K}-\mathrm{a}$

10-A, 22-C-a, 24-A-a

43-B-a, 45-C, 45-K-a

45- $\mathrm{H}-\mathrm{a}$.

46-C-b .

$37-A-c, 45-i$

$31-\mathrm{C}-\mathrm{b}$

24-E

$31-\mathrm{D}$

31-B-h, 31-H

24-E

16-C, 43-E-a, 43-E-b, 43-J-b, 45-H-b

43-F-b .

43-F-a .

45-F-a

19-F-a, 20-B, $45-\dot{F}-\mathrm{c}$

45-C

43-F-a

37-A-a, 45-B-a, 45-H-b, $46-\dot{\mathrm{H}}-\mathrm{b}^{\circ}$

12-D, 12-E-b, 19-F-a, 24-D, 25-A 42-A-a, 46-C-b

43-F-a, 43-H, 45-B-a.

28-B, 29-D-b .

45-A-b.
43-F-d
234, 310

190

$204,208,264,265$

140,184

146

$305,306,310,329$

307

117, 119, 165, 167, 191, 301, $314,315,321$ 321

$130,151,193,196,297$

323

242

240,241

279

$120,149,158,163,177,197$. 301

310

167

310

234

234

234

328

$133,165,173,180,290,321$,

$134,213,285$

117, 173

183

$145,147,323$

328,331

$147,301,321,328,331$

301,322

186

$117,119,180,322$

$116,173,181,189,291,314$, 315,322

$116,174,315,321,337,338$

321

328

328
180

$281,301,321,328,331$

$116,174,180$

$301,322,331$

328

337

277,330

228

184

226, 232

184

$146,305,310,329$

307

306

306

325

157, 162, 325

327

170

276, 320,329, 340

125, $126,157,183,186,196$, 337

$306,308,320$

197, 206

197. 206

320 
NAME

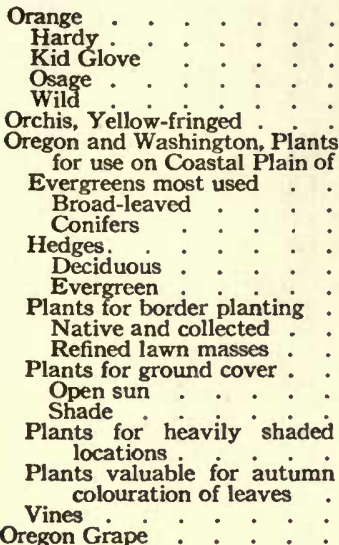

Dwarf.
Ornamental plants subject to disease and insect pests.

Ornamental trees and shrubs, Books on

Ornithogalum umbellatum

Orris Root

Osier, Golden-twigged

Osmanthus americanus aquifolium

Osmunda cinnamomea claytoniana

regalis

Ostrya virginiana

Oxalis

Oxalis

corniculato

Creeping

floribunda

Oxytropus lambertini

Pachistima canbyi

Pachysandra caroliniana terminalis

Paeonia (in variety) albiflora sinensis festiva maxima officinalis officinalis alba suffruticosa tenuifolia.

Pagoda Tree

Japanese

Painted Tongue

Palm

California Fan

Pampas Grass

Pansy

Tufted

Papaver (in variety) nudicaule

orientale

Paper Flow

Paritium tiliaceum

Parkinsonia aculeato

Parthenocissus henryane

Partridge Berry

Passiflora ceerulea incarnata
GrouP

12-A-b, 43-E-b, 45-B-b, 45-H்

$12-\mathrm{A}-\mathrm{b}, 20-\dot{A}, 23-\dot{\mathrm{A}}, 3 \dot{9}$

43-D, 43-F-a, 45-E

$45-$

46

46-H $\dot{H}-\mathrm{b}$

46-H-a

46-A

46-A-a

46-A-b.

46-C

46-C-b

46-C-a

46-B-a

46-B-b

Page

46-E

46-F

12-A-a, 19-A, 22-C-a, 24-B-b, 33-E-b, 338

40-C-b, 42-B-a, 44-G, 45-F-b, 45-F-d, 46-

39

36-B

29-A 2 i

43-F-a

37-A-a, $45-\dot{B} \cdot \mathrm{a}, 45-\mathrm{H}-\mathrm{b}, 46-\dot{\mathrm{H}}-\mathrm{b}$.

43-F-a, 43-H, 45-B-a

24-A-a, 29-D-b

28-B, 28-D-a

$22-\mathrm{C}-\mathrm{a}, 30-\mathrm{A}, 30-\dot{\mathrm{B}}, 40-\mathrm{C}-\mathrm{a}$

35-B-a

30-A

32-G-a-1

32-G-a-1

35-B-a

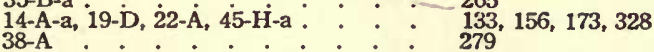

15-A, 24-A-b, 28-B

15-A, 15-C, 29-B, 29-C, 29-E-b, 29-H

33-E-b, 46-B-a, 46-B-b

31-A, 31-H, 31-I, 31-K-a, 40-A

31-B-f, 31-B-g, 31-F, 37-A-c.

31-H

31-B-c, 45-i

31-B-b

31-B-b, 31-B-c, 45-I

31-B-c, 45-I

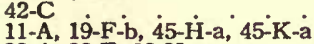

32-A, 32-E, 32-H-a

35-B-c, 43-J-a

43-B-b.

23-I. 29-I, 31-I, 32-A, 32-E

29-A, 29-I, 31-B-a, 31-D, 31-J 45-A-a 32-A, 32-C, 32-D

24-E, 3i-B-f, 31-B-g

16-C, 43-C-a. 43-J-c

43-F-c, 43-J-b

$43-\mathrm{F}-\mathrm{c}$.

45-H-a

15-C, 24-A-a, 28-B, 29-B், 29-Cं, 2y-H, 30-A, 31-C35-B-a, 45-L 38-B-a, 43-C-a
304

$124,305,321,328$

304

$124,162,177,285$

$304,306,323$

331

334

339

(3)

335

335

335

336
337

337

335

336

337 , 154, 174, 181, 253, 291, 338

282

345
271

204

135,170

$276,320,329,340$

$306,308,320$

180,206

197,206

$174,212,213,290$

265

43

138, 181, 197

205

138. 140, 204, 205, 207, 209,

253,335 , illus. 270

$222,231,232,233,289$

$225,230,277$

231

223,330

223,330

223,330

298

$119,158,329,331$

$240,242,246$

266,310

302

309

$204,210,233,240,242$

$204,210,222,229,233,319$

240,241

229

184,225

$146,303,311$

306,310

307

333

140, 180, 197, 204, 205, 209,

212, 228

265, 333 
Passion Flower

NAME

Passion Flower Purple.

Paulownia (in variety)

tomentose

Paved areas, Plants for.

Pavio

Paw-Paw

each

Common

David's Flowering

Double Rose-flowering

Double White-flowering

Flowering

Pearl Bush

Pea Shrub

Dahurian

Siberian

Peaty Soils

$$
\text { Water }
$$

Pelarganium

hortorum

hortorum Madame Salleroi Deltatum

Pentstemon bäbatus

Bearded

Peony.

Best varieties

Chinese

Deep Pink.

Diseases of

Fennel-leaved

Fertilizing.

Old-fashioned

Old-fashioned Red

Pale Pink

Planting of .

Transplanting of .

Tree

White

Yellor

Mountain
Perennials for different purposes - gardens, Perennials for.

Bog gardens, Pere

Autumn-pink to crimison.

Autumn-purple, lavender. or blue

Autumn-white

Autumn-yellow to orange Spring-pink to crimson Spring-purple, lavender, or blue

Spring-white

Spring-yellow to orange

Summer-pink to crimson.

Summer-pink to crimson. Summer-

or blue

Summer-yellow to orange

Cut flowers

Dividing of

Edge of shrub borders

Low-growing

Tall-growing

Fertilizers for

For shade,

For water's edge

Fragrant flowers

Good blooming combination

Hardy for general use
Humming birds, Perennials for attracting

List of

Long flowering period

Mulching of
Perennials

Group

PAGE

35-B-a, 38-A, 45-L

43-C-a

$19-\mathrm{H}, 3 \dot{7}-\mathrm{A}-\mathrm{b}, 4 \dot{4}-\dot{\mathrm{H}}-\mathrm{a}$

29-F

42-B-b

$20-\mathrm{A}$

39

19-E-a

24-D

33-C

14-A-a

13-A-c, 14-B, i9-B, 44-G, 45-H-b

42-B-a

12-E-b, 14-B, 19-B, 19-F-b, 24-B-b, 25-A, 41.

$24-\mathrm{A}-\mathrm{b}$

45- $\mathrm{H}-\mathrm{a}$

32-G-b-2

$32-\mathrm{G}-\mathrm{b}-1$

32-G-a-1

35-A-a, 35-A-b

31-B-g .

31-B-g

31-A, 3i-I, 31-K-b, 33-B, 39, 40-A

33-B

31-B-f, 31-B-g, 31-F, 37-A-c

$\dot{3} 1-\dot{K}-\mathbf{a}$

31-B-c, 45-i

33-Bं

31-B-b, 45-I

31-B-c

33-B

31-B-b, 31-B-c, 45-I

33-B

13-B-b, 19-D, 19-G-b, 24-A-a, 26-B-c 27, 28-A, 37-A-a, 42-A-b, 44-G, 46-C-b.

31

24-A-a

31-B-k

31-B-i

31-B-j

31-B-c

31-B-a

31-B-b

31-B-g

31-B-e

31-B-f

31-B

31-K

31-M

31-M-b.

28-B

$31-\mathrm{L}-\mathrm{c}$

37-A-C .

31-H

$31-N$

31 .

31-D
$265,279,333$

303

$159,276,328$

208

297

162

285
157

183

250

250

$129,135,155,316,329$

297

$126,135,155,158,181,186$, 293

181

328

327

244

243

264,265

225

$222,232,233,250,285,289$

250

$225,230,277$

250

90,233

223,330

91

233,330

223

250

286

250

223,330

250

131. $156,158,180,191,193$, $196,276,297,316,337$ 325

214

180

226

226

226

223

222

223

224

225

88,233

235

235

91
197

237

276

231

236

221

102 


\section{Perennials}

\section{NAME}

Perennials

Naturalizing in wild gardens Low types

Tall types desirable in small, refined, formal gardens

Peonies, Interplanting with. Protection of

Season for transplanting.

Shade enduring, Ground cover Dry locations

Moist locations.

In woods

Shady locations

Supplying perpetual bloom

To be transplanted frequently

Divided each year

Divided every three years.

Divided every two years.

Treated as biennials

Transplanting of

Water planting, Perennials for Deep water

Land at water side.

Shallow water

Periploca graeca.

Periwinkle

White

Perpetual bloom, Plants for
Persimmon

Petraea volubilis

Petunia (in variety)

\section{hybrida}

Phalaris arundinacea

Phaseolus multifiorus

Pheasant's Eye

Phegopteris hexaganoptera

Phellodendron amurense.

Philadelphus (in variety)

coronarius

coronarius nanus:

coronarius nanus aureus

falconeri

gordonianus

grandiflorus

inodorus

lewisi

zeyheri .

Phlox (in variety)

Annual

Creeping

drummondi

Drummond's

Early-flowering

Early Garden

Garden

glaberrima suffruticosa

Miss Lingard

Mountain

ovate

paniculata

stolonifera

subulata

subulata alba

suffruticasa
Photinia arbutifolia

Evergreen

glabra

serrulata

Phragmites communis

Phyllanthus nivosus.
Phyllanthus

Group

Page

$31-C$

$31-\mathrm{C}-\mathrm{b}: \vdots: 2_{228}$

$31-\mathrm{C}-\mathrm{a}: \vdots: \vdots: \vdots \vdots: 2_{227}$

31-E

229

102

$\cdot \cdot \cdot{ }^{\circ} \cdot \bullet^{\circ} \cdot \cdot{ }^{\circ} \cdot 286$

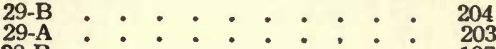

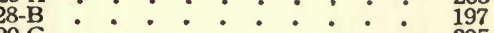

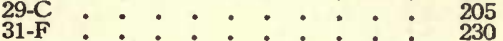

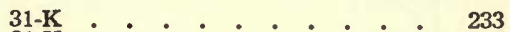

$31-\mathrm{K}-\mathrm{c}: \quad: \quad: \quad: \quad \vdots \quad \div 233$

$31-\mathrm{K}-\mathrm{b} \cdot \cdot \cdot \cdot \cdot \cdot \cdot \cdot 233$

${ }_{31-\mathrm{J}}^{31-\mathrm{K}}: \vdots: \vdots \vdots \vdots \vdots \vdots 233$

उ1-L : : • • • • : : $\begin{array}{r}47 \\ \hline\end{array}$

31-L-a $\vdots \vdots \vdots \vdots \vdots \vdots \vdots \vdots 234$

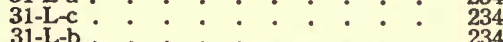

25-C, 29-E-C, 34-C, 34-E, 45-L： $\quad$ : $\quad 187,207,261,333$

15-C, 28-B, 29-A, 29-B, 29-C, 29-E-b, 140, 198, 204, 205, 207, 208 29-F, 29-H, 31-B-a, 33-E-b, 43-I, 210, 222, 253, 310, 319, 336

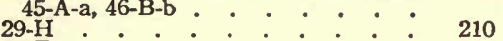

$31-\mathrm{F}$

$20-\mathrm{A}, 4 \dot{5}-\mathrm{G}, 45-\mathrm{H}-\mathrm{a} \quad \vdots \quad \vdots \quad \therefore \quad 162,327,328$

43-C-a

$29-\mathrm{I}, 32-\mathrm{E}^{*}, \quad \dot{2}-\dot{\mathrm{G}}-\mathrm{b}-\dot{2}, \quad 32-\dot{\mathrm{H}}-\mathrm{a}, 3 \dot{2}-\mathrm{E}, \quad 210,242,244,246,265,266$

35-A-b, 35-A-c, 35-B-a, 35-B-b 9-I, 32-E, 32-G-b-2, 32-H-a, 35-A-b, 35-A-c, 35-B-a, 35-B-b

31-L-C,

$32-\mathrm{F}-\mathrm{b} .<235,244$

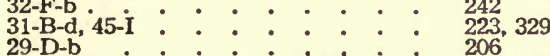

10-B, 23-A: : . : 117, 177

19-C, 19-G-b, $\dot{4} 1, \dot{4} 2-\dot{A}-a^{\circ} \quad: \quad \vdots \quad 155,158,293,296$

12-E-e, 13-A-c, 19-I, 25-B, 27, 37-A-a $\quad$ 126, 130, 159, 187, 193, 276

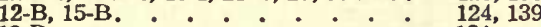

$12-\mathrm{B}:$ : : : : : : 124

$13-\mathrm{A}-\mathrm{c}$ : : : : : : : 130

46-E

$17,23-\dot{B}$

28-A

46-C-a .

46-C-b, 46-E . . . . . . . 337, 338

$37-A-a+0^{\circ} \cdot 0^{\circ} \cdot{ }^{\circ} 276$

$31-\mathrm{A}, 39,45-\mathrm{I} \quad \cdot \quad \cdot \quad \cdot \quad \cdot \quad \cdot \quad \cdot 222,285,330$

29-1. 2 - $-\mathrm{A}, 29-\mathrm{F}, 31-\dot{\mathrm{B}}-\mathrm{c}, 31-\mathrm{C}-\dot{\mathrm{b}}: \quad: \quad 210$

15-C, 29-A, 29-F, 31-B-c, 31-C-b •.

28-B, 31-C-a, 31-C-b, 40-A .

29-1, 32-D, 32-G-a-2, 32-H-a, 35-A-a, 32-D, 32-G-a-2, 32ं-H-a, 3ं5-Aं-a, 43-I 31-B-f

$210,241,244,246,264,310$

$241,244,246,264,310$

31-D 0.229

31-B-e, 31-B-f, 31-B-g, 3i-F, 31-i, 31-K-a, 31-K-b, 37-A-c, 45-I . . . 31-D

31-H

31-G-b

31-B-e, 31-B-f, 31-B-g, 31-F, 31-ं,$\dot{3} 1-\dot{1}$, 31-K-a, 31-K-b, 37-A-c . . 15-C, 29-A, 29-F, 31-B-c, 31-C-b $\vdots$ 15-C, 29-A, 29-B, 29-E-b, 29-F, 29-G, 31-B-c, 31-C-b, 45-A-a, 46-B-a : 31-B-b

45-H-a

45-H-a

$46-\mathrm{H}-\mathrm{b}$

$45-\mathrm{H}-\mathrm{a}$

$46-\mathrm{H}-\mathrm{b}$

31-L-b-a

$24,225,230,232,233,277$, 229

229

231

$224,225230,231,232,233$,

$140,204,208,223,228$

$140,204,205,207,208,209$, $223,228,319,336$

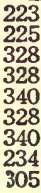


NAME

Physocarpus opulifolius

Physostegia virginiana

Picea (in variety)

alba.

\section{alcockiana. \\ canadensis}

engelmanni.

excelsa.

excelsa clanbrasitiano

excelsa columnaris.

excelsa compacta.

excelsa gregoriana

excelsa nana

excelsa pygmaea

excelsa pyramidalis

excelsa tabulaeformis

mariana

omorika

orientalis

orientalis nano

pungens

pungens compacta

pungens glauca

rubra

sitchensis

Pieris (in variety)

floribunde

japonica

mariana

Pimpernel

Pine (in variety)

Austrian

Bhotan.

Bull

Bush White

Corean

Dwarf Japanese Red

Dwarf Mountain

Dwarf Swiss Stone

Dwarf White.

Globe Scotch .

Jack

Japanese Red:

Jeffrey's

Knot-cone

Long-leaved

Monterey

Mountain White

Oregon

Pitch

Red

Swiss Mountain

Swiss Stone

Umbrella

White

Pink

Chinese

Japanese

Moss

Mullein

Scotch

White

White Ground

Wild

Pink Flowers.

Perennials

Shrubs

Pinkster Flower

Hybrid

\section{Group}

11-B, 17, 19-G-b, 20-B, 23-B, 28-A, $42-\mathrm{A}-\mathrm{a}$

31-B-g, 31-E, 31- $\dot{\mathrm{G}}, 31-1$

12-C, 14-A-a, 30-A, 32-D

9-A, 9-B, 24-A-a, 25-A, 26-A-b, $27^{\circ}$, 9-A 9 - - $\dot{B}$

4-A, $9-\mathrm{B}, 44-\mathrm{A}-\mathrm{b}, 44-\mathrm{F}$

9-A, 9-B, 46-H-a

9-A, 9-B, 12-A-a, 16-B-a, 23-A, 24-C-a, a. $\mathrm{E}$

14-A-b, 16-D-bi-2

14-A

9-E, 16-A, i8-A

9-E, 18-A

9-E

14-A-b, 16-A, i6-D-b-2, 44-D

9-E

9-A, 9-B, $\dot{16}-\dot{\mathrm{D}-b-2}$

16-B-a.

9-A, 11-A

9-B, 26-A-b, 44-F:

26-A-b.

46- $\mathrm{H}-\mathrm{a}$.

29- $\mathrm{H}, 40$-B

15-A, 18-A, 22- $\dot{C}_{-a}, 24-\mathrm{A}-\mathrm{b}, \quad 33-\mathrm{E}-\mathrm{b}$, $45-\mathrm{F}-\mathrm{b}, 46-\mathrm{C}-\mathrm{a}, 46-\mathrm{H}-\mathrm{b}$

$12-\mathrm{B}, 45-\mathrm{F}-\mathrm{b}$

45-F-a.

32-B

14-A-a, 39, 42-D

9-A, 9-B, 25-A, 26-B-b, 44-A-b, 44-F, 46-H-2.

45-D

9-C, $46-\mathrm{H}-\mathrm{a}$

9-E

9-A $9-\dot{\mathrm{E}} 1 \dot{6}-\dot{\mathrm{B}}$

9-A, 9-B, 9-E, 11-A, 15-A, 16-B-a, 25-A 9-E

9-E

9-E, 9- $\dot{\mathrm{D}}, 24-\dot{\mathrm{B}}-\mathrm{a}, 25-\dot{\mathrm{A}}, 26-\dot{\mathrm{A}}-\mathrm{b}$

26.B-b.

46- H-a

46-H-a

46- $\mathrm{H}-\mathrm{a}$.

46- H-a .

9-A, 9-B, 12-C, 26-A-b, 44-F

9-A, 9-B, 11-A, 23-A, 24-B-a, 25-A,

26-B-b, 44-A-b, 44-F, 46-H-a

16-B-a, 26-A-b, 28-A

9-A, 9-B, 16-B-a

9-A, 9-B, 14-A-a i6 $\dot{A} \cdot \dot{0} \cdot$ 9-A, 9-B, 9-D, 12-C, 24-B-a, 24-C-a, 44-A-b, 44-F, 46-E, 46-H-a

31-A

32-A, 38-C-a

29-I, 32-A. ${ }^{\circ}$. 15-C, 24-E, 29-B, 29-F, 29-G, 31-B-C, 15-C, 29-A, 29-B, 29-E-b, 29-F, 29-G, 31-B-c, 31-C-b, 45-A-a, 46-B-a 31-B-g, 31-D, 31-J, 31-K-a, 31-N, 45-I. 15-C, 29-B, 31-B-b, 31-B-c, 37-A-c. 31-J 31-B-b

31-B

19-E, 43-F-b : $: \quad \therefore \quad:$ 13-B-a, 15-B, 19-A, 19-E-a, 24-B-b, 37-A-a.
PAGE

$120,149,158,163,177,197$, 296

$225,230,231,232$

$125,133,212,298$

$111,112,180,186,190,193$. 316

111,112

$111,112,339$

$112,124,145,177,182,186$,

114,147

114

$114,138,151$

114,151

114

$135,145,147,314$

114

112,147

145

114

112,119

114

$112,190,316$

190

209,289

$138,151,174,181,253,325$, 337,34
124,325

324

241

$133,285,298$

$112,186,191,313,316,339$

322

113,339

114

$112,114,145$

$112,114,119,139,145,186$

114

114

$113,181,186,190$

191

113

1139

113

339
339

339

$181,186,190,213$

$112,113,125,190,316$

$112,113,119,177,181,186$. $191,313,316,339$

$145,190,197$

112,145

$112,113,133,145,323$

$112,113,125,181,182,313$, 221

240,280

$140,184,204,208,209,223$, 140,184

$140,204,205,207,208,209$,

$225,229,233,236,330$

$140,204,223,276$

233

140

222

156,306

$130,139,154,157,181,323$

276 
NAME

Pinus (in variety) attenuata banksiana cembra

cembra compacta contorta.

densiflora.

densiflora umbraculifera (tanyosho).

excelsa.

jeffreyi

montana

montana mughus

monticala

nigra austriace

palustris

ponderosa

radiata

resinosa

rigida

strobus

strobus brevifolia

strabus umbraculifera

sylvestris

sylvestris pumila

Pipsissewa

Piqueria trinerva.

Pitcher Plant

Pithecoctenium cynarchoides

Pithecolobium dulce.

Pittosporum tobira.

undulatum

Plane, America Oriental

Plant diseases

Books on

Plantain, Rattle-snake

Planting (See Transplanting)

Planting and seeding seasons

Deciduous trees, shrubs, and
Denting and seding seans vines

Evergreens, Planting seasons for.

General considerations

Graphic chart showing plant ing and seeding dates

Lawns Perennials, Planting seasons

Tabulation of planting and seeding dates.

Deciduous plants

Evergreens$$
\text { Luwns }
$$

Planting, chart of seasons

Beds, General preparation of Spacing of plants

Plantings,

Plants for use in congested city Shrubs districts

Trees

Pleached Allees

Platanus occidentalis

orientalis.

Plalycodon grandiflorum

Plum

Beach

Flowering

Japanese

Natal

Purple

Purple-leaved

Wila

Plumeria:

\section{Group}

14-A-a, 42-D

46- $\mathrm{H}-\mathrm{a}$

9-A, 9-B, 16-B-a

9-E

$46-\mathrm{H}-\mathrm{a}$
$26-\mathrm{B}-\mathrm{b}$

PAGE

9-A, 9-E, 16-B-a

9-C

16-B-a, 26-A-b, 28-A

9-A, 9-B, 9-E, 11-A, 15-A, 16-B-a, 25-A

46-H-a

9-A, 9-B, 25-A, 26-B-b, 44-A-b, 44-F,

9-C $\mathrm{C}, 46-\mathrm{H}-\mathrm{a}$

46- $\mathrm{H}-\mathrm{a}$

9-A, 9-B, $12-C^{\circ}, 26-A-b, 44-F$

24-B-a, 25-A, 26-A-b, 30-B

9-A, 19-B, 9-D, 12-C, 24-B-a, 24-C-a, 44-A-b, 44-F, 46-E, 46-H-a . . . 9-E

9-A, 9-B, 11- $\dot{A}, 23-\dot{A}, 24-\dot{B}-a, 25-\dot{A}^{\circ}$ 9-E

28-B, 33-E-b

32-G-b-1

24-A-a, 31-L-c.

43-C-a

43-A, 43-J-a

43-E-a, 43-F-a, 43-J-b, 45-B-a, 45-F-d

\section{5-K-b} 43-E-a

10-C, 26-B-a

10-B, 11-A, 20-A, 21, 22-A, 23-A, 24-D, $46-\mathrm{D}$. 39

29-F, 29-H

133,298

112,145

114

339

$112,114,145$

322

113

$1145,190,197$

113

113,139

$181,186,190,213$

114

114

197,252

244

180,235

303

301,310

305

117,191

282

208,209
9-C, 9-D, 24-B-a, 25-A, 26- $\dot{A}-\mathrm{b}$

$113,181,186,190$

$112,114,119,139,145,186$

$112,186,191,313,316,339$

$112,113,125,190,316$

$112,113,125,181,182,313$

$112,113,119,177,181,186$, $191,313,316,339$

$305,306,310,320,326,332$

$117,119,162,170,173,177$

29

9 , illus. 14

12, illus. 14

14

13

12

15

15

16

14

30

$23 \div \vdots \vdots \vdots \vdots \vdots \vdots \vdots \vdots 176$

11

118

$11-\mathrm{A}$

16-D-a

$10-\mathrm{C}, 26-\mathrm{B}-\mathrm{a}$

10-B, 11-A, 20-A, 21, 22-A, 23-A, 24-D;

46-D 3 i-B-e, 45-I

19-G-a, 20-D-a

24-B-b, 25-B, 26-A-c

13-A-b, 14-B, 19-A, 33-C, 41, 45-F-a, 45-F-c, 46-C-a

19-E-a

43-D, 43-E-a, 43-J-b

45- $\mathrm{H}-\mathrm{a}$

$14-A-a$

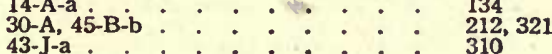

119 , illus. 158, 175

$117,191,162,170,173,177$, 183,337

$184,224,230$

158,165

$181,187,190$, illus. 254

$129,135,154,250,293,324$

157

$304,305,310$

(2) 
Name

Plumbago capensis capensis alba

Plume Gras

Pocket Planting

Podachaenium eminen

Podophyllum peltatum

Poinsettia

Poison Hemlock

Poison Ivy

Poison Sumac

Poisonous plants.

Hay fever

Internally poisonous

Skin irritants

Polemonium coeruleum reptans

Polygala chamaebuxics paucifolia

Polygonum baldschuanicum persicaria

sachalinense

Polygonatum multifiorum

Polypodium vulgare

Polypody

Pomegranate.

Poplar

Balsam.

Bolle's .

Carolina

Lombardy

White

Poppy

Californi

Iceland.

Mexican

Oriental

Plume.

Shirley

Yellow Horned

Populus (in variety)

alba.

alba pyramidalis

\section{balsamifera}

delloides

delloides monilifera

eugenie

fremonti

nigra italica

tremuloides.

Porana paniculat

Porcupine Grass

Portulaca grandiflora oleracea.

Polentilla fruticosa tridentata.

Prickly-ash

Primrose .

Himalayan

Japanese

Missouri Evening.

Young's Evening

Primula (in variety) denticulata

Hairy.

japonica

veris

Privet

Amoor River

California .
Grour

43-Fe

31-F-a 3i-L-c, 38-C-a

38-C-a

43-F-c

28-B

$43-\mathrm{F}-\mathrm{d}$

38-A

38-B

38-B

38

38-C

$38-\mathrm{B}$

31-C-a, 45-i

29-F, 31-B-a, 31-c-b, 45-I

33-E-b .

34-A, 45ं-L, 46-G :

30-B

29-C, 3i-C-b

28-B, 29-D-a

28-B, 29-D-a

43-D, 43-E-b, 43-F-b

31-L-a

23- $\mathrm{A}, 30-\mathrm{A}, 39,40-\mathrm{B}$

14-A-a, 14-A-b, i6-A, 26-B-a, 44-D, 45- $-a^{2}$

10-C, 25-A, 44-C-a, 44-E-b :

14-A-a, 14-A-b, 16-A, 16-D-b-1, 26-A-a, 26-A-a

32-C, 32-D

32-A

32-A, 32-C, 32-H-a

31-D

32-A, 32-H-a

24-E, 31-B-f, 31-B-g

31-B-f, 31-E, 31-K-C, 31-M-b

45-I.

$12-\mathrm{C}, 23-\mathrm{A}, 30^{\circ}-\mathrm{A}, 40-\mathrm{B}$

26-A-a

4-A-a, 14-A-b, 16-A, 26-B-a, 44-D, 25-A, $26-\mathrm{a}-\mathrm{A}-\mathrm{a}$

$38-\mathrm{C}-\mathrm{a}, 45-\mathrm{H}-\mathrm{a}$

26-A-a, 45-H-a

10-C, 25-A, 44-C-a, 44-E-b

14-A-a, 14-A-b, 16-A, 16-D-b-1, 26-A-a, 214

$43-\mathrm{C}$

38-B

29-I, 32-B, 32-G-a-2 .

19-D, $1 \dot{9}-\mathrm{F}-\mathrm{b}, \dot{29-\dot{A}}$

$27,28-\dot{A}, 2 \dot{9}-E_{-a}$

31-C-b, 31-I, 40-A, 45-I

31-C-b, 37-A-c, 45-I

31-B-a

31-B-c, $31-\dot{L}-\mathrm{c}$

31-B-h

24-E

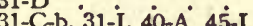

31-C-b, 31-I, 40-A, 45-I

31-B-a

38-B

$31-B-c, 31-\dot{L}-\mathrm{c}$

38-B

15-C, 29-F, 31-B-d

11-B, 12-D, 19-G-b, 20-B, 27, 39, 42-A-a, 44-G, 45-E. $45-\mathrm{B}-\mathrm{a}, 46-\mathrm{F}$.

22-C-B-a, 46-F- 4 -B, 46-Aं-a $: \quad: \quad:$
PAge

307

306

$230,235,280$

281

307

198

198
307

279

280

280

280

280

279

279

227,330

$208,222,228,330$

253

205

$260,333,338$

213

205,228

198,206

198, 206

$304,305,306$

234

$125,177,212,285,289$

186, 189

$133,135,145,191,314,328$

$117,186,314,315$

$133,135,145,147,189,314$

189

240

$240,241,246$

229

240,246

184,225

$224,229,233,235$

240

233

$125,177,212,289$

$133,135,145,191,314,328$

186,189

281,328

$117,186,314,315$

$133,135,145,147,189,314$

170

280

$210,241,244$

212

$156,158,204$

$193,197,207$

$228,232,289,330$

222

223,235

226

184

$228,232,289,330$

280

223,235

280

$140,208,224$

$120,125,158,263,193,285$

$296,317,323$, illus. 20 , 159

$129,175,177,305,308,320$, 338

$175,321,335$ 
NAME

Privet, Chinese

European

Evergreen -

Japanese

Late-blooming

Nepaul

Regel's

Round-leaved

Variegated Nepaul

Propagation of plants, Books on

Pruning, Articles on

Books on

Pruning of Ornamental Plants.

Evergreens, Pruning of

Hedges, Pruning of

Precautions to observe

Reasons for pruning

Results from pruning

Rhododendrons, Pruning of :

Roses, Pruning of .

Shrubs, Pruning of

Tools and wound dressings

Topiary effects, Pruning for:

Trees, Pruning of

$$
\text { Toot pruning }
$$

Vines, pruning

Pruning, pruning of

uning, Lists for . . Evergreens that can be

Evergreens that must be pruned in May or June

Shrubs needing complete

pruning
Late summer and fall flowering.

fpring and early summer flowering .

Shrubs needing removal of old wood only

Summer pruning

Winter pruning.

Trees which require little or

no pruning
Prunus(in variety) : : : :

avium plena

besseyi.

caraliniana

cerasifera pissardi

cerasus.

davidiana

fruticosa pendula

ilicifolia

japonica

laurocerasus

laurocerasus schipkaensis.

lusitanica

lyoni

maritima

padus commutata

persica.

persica alba plena.

persica rosea plena

persica vulgaris

pissardi

pumila.

serotina.

serrulata

sieboldi

spinosa
subhirtelle (in variety)

subhirtella pendula

tomentosa

triloba.

Pseudotsuga douglasi

douglasi globosa

Psidium cattleianum

Ptelea trifoliata

Plerocarya fraxinifolia
Group

45-B-a, 45-K-b

16-B-b, 20-C 26-A-c, 46-A-a

22-C-b-1, 45-B-a, 46-H-b

16-B-b, 19-C, $20-\dot{\mathrm{C}}, 4 \dot{5}-\mathrm{B}-\mathrm{a}, \dot{4} 6-\dot{\mathrm{A}}-\mathrm{a}$

16-B-b, 19-C, 2

45-B-a, 45-K-b

$12-\mathrm{B}, 13-\mathrm{A}-\mathrm{b}, 26-\mathrm{A}-\mathrm{c}$

45-F-d

$45-\mathrm{B}-\mathrm{a}, 45-\mathrm{K}-\mathrm{b}$

43-E-b, 43-H .

. $.5:$

43-F-a, 45-B-a, 45-K-b

PAGE

320,332

$145,163,190,335$

$175,320,340$

$145,155,163,320,335$

320,332

$306,320,332$

$124,129,190$

326

320,332

305,308

346

347

346
18
26

22 , illus. 20,24

18

18

19

27 , illus. 24

23 , illus. 24

19

23

21

19, illus. 24

27
296

298

42-E

298

42-A . . . . . . . 296

42-A-b . . . . . . . . . 297

42-A-a . . . . . . . . . 296

42-B . . . . 297

${ }_{42-\mathrm{B}-\mathrm{a}}^{42}: \vdots: \vdots: \vdots: \vdots{ }_{297}^{297}$

42-C 298

19-A, 19-G-a, 20-D-a, 30-A, 44-G : : $\quad 154,158,165,212,317$,

45-B-b .

17

19-E-a :

43-E-a, 45-B-a, 45-H-b, 45-Kं-b

45-H-a

$33-\mathrm{C}, 41,42-\mathrm{B}-\mathrm{a}$

24-D

14-A- $\mathrm{H}-\mathrm{b}$

$13-A-b$ (

45-B-a, 45-H-b, 45-K-b, 46-A-b, $46-\dot{H}-\mathrm{b}$, 45-F-d

$46-\mathrm{A}-\mathrm{b}, 46-\mathrm{H}-\mathrm{b}$

$45-\mathrm{H}-\mathrm{b}$

24-B-b, 25-B, 26-A-c . . . . . 181, 187, 190

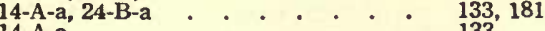

14-A-a.

33-C

19-E-

14-A-a :

26-B-a

26-A-a, 38- $\dot{A}$

321
149

149

$305,320,329,332$

328

293,297

183

29

$29,135,157$

$321,329,332,335,340$

326

340

133

250

250

134

191

189,279

$33-\mathrm{C} \cdot . \cdot 250$

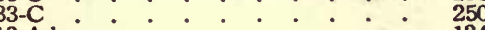

12-A-b : $: \cdot \cdot: \cdot:$ : 124

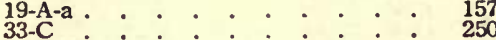

19-E-a:

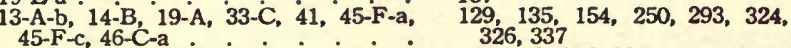

9-A, 9-B, 9-D, 44-F, 46-نे-a.

9-A

9-E-E-a $: \vdots \vdots: \vdots: \vdots \vdots \vdots \frac{114}{305}$

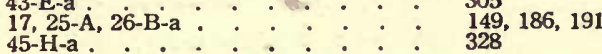


NAME

Pueraria hirsula thunbergiana

Punica granatum

Purslane

Pyracantha

coccinea

coccinea lalandi

coccinea pauciflora

Pyrethrum coccineum

roseum.

Pyrostegia venusta

Pyrus (in variety)

angustifolio

afrosanguinea

baccata

coronaria

floribunda

halliana parkmani

ioensis

coensis bechteli

malus niedzwetzkyan

pulcherrima arnoldian

pulcherrime scheideckeri

sargenti.

sieboldi

spectabilis riversi

sumi

Pyxidanthere barbulate
Group

45-L

29-E-c, 34-C, 34-E, 46-G

43-D, 43-E-b, 43-F-b.

30-A

42-B-a ${ }^{\circ} 3^{\circ}-{ }^{\circ}$

$12-\mathrm{A}-\mathrm{a}, 12-\mathrm{B}, 16-\mathrm{C}, 45-\mathrm{B}-\mathrm{a}, 45-\mathrm{G}$

33-E-b .

45- 1

31-B-g, 31-i

43-C-a, 43-C-b, 45-

13-B-c, 14-A-a, 19-B, 30-A, 40-C-b

19-E-a, 37-A-a

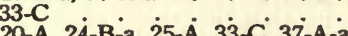

19-E-a, 37-A-a, 45-H-a.

19-E-a, 37-A-a

19-E-a, 33-C, 41

44-E-b

19-E-b, 33-C, 37-A-a

33-C

$33-\mathrm{C}$

33-C

$33-\mathrm{C}$

15-A, 29-F, 29-H, 33-E-b

32-F-b

242,260

43-C-a

14-A-a, 30-B

5-H-a, 45-K-a

-A, 22-C-a, 24-A-a

10-A, 22-C-a, 44-E-a, 45-C, 46-D , 46-F 45-H-a

$45-$

16-D-a, 43-B-a, 45-C, 45-H-a, 45-K-a . 24-D

25-A

$38-\mathrm{C}-\mathrm{a}, 43-\dot{\mathrm{A}}, 43-\dot{\mathrm{B}}-\mathrm{a}, 45-\mathrm{C}, 45-\dot{\mathrm{H}}-\mathrm{a}$

45-H-a

10-B, 11-A, 24-A-a, 45-C

43-B-a, 45-C, 45-K-a.

16-A, 16-D-b-1

45-E

10-A, $22-\dot{B}, 24-\dot{B}-a, 2 \dot{6}-A-a, 40-\dot{C}-\dot{b}$, 44-C-b,

43-B-a, 45-C

39

45-F-c

12-A-b, 14-B, 19-A, i9-i, 22-C-b-i, 4 i, 43-F-b 46-A-a, 46-E

15-C, 31-B-g

30-A

43-E-a, 45-D-

23-A, $23-B$

26-B-c, 28-A, 29-E-a, 37-A-ć, 44-B-a

19-C. 29-E-a, 37-A-a

29-E-a.

31-L-b

31-E

11-A, 13-A-c, 14-A-a, 19-A, 19-E-a, 22-A, 39, 40-C-b, 41, 42-A-a, 43-B-a,

\section{4}

31-B

19-E, 43-F-d $31-\mathrm{B}-\mathrm{k}, 31-\mathrm{B}-1,31-\mathrm{C}, 31-\mathrm{I}, 45-\mathrm{I}$

31-B-k, 31-B-1, 31-D, 31-G, 31-I, 45-I
13-A
29-I, 32-A, 32-B, 32-D $: \vdots: \vdots$

PAGE

332

$207,261,339$

112

$163,253,335$

$124,146,321,327$

253

225,232

303,332

$131,134,155,212,291$

157,276

250

$162,181,186,250,276$

$157,276,328$

$157,250,293$

315

$157,250,276$

251

251

251

251,276

$139,208,209,253$

180

$116,174,315,321,337,338$

328

$147,301,321,328,331$

183 '

183

328

$281,301,321,328,331$

328

$117,119,180,322$

$301,322,331$

145,147

323

$135,173,181,189,291,314$. 315,322

116,173

285

$124,135,154,159,174,293$, $306,335,337$

140,225

212

140

305, 326

176, 177

191, 197, 207, 276, 314

$156,207,276$

207

234

$119,129,133,154,157,173$

285, 291, 293, 296, 301, 316,

222

$226,227,229,231,232,330$

128

$210,240,241$

Refinet lawn plantings

Reseda odorata

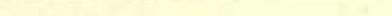


Nave

Rhommus (in variety) caroliniane. cathartica.

frangula (variety latifolia)

Rheum officinale
Rhexia orginica

Rhododendron (in variety)

\section{arborescens}

arbutifolium

azaleoides

calendulaccum

campanulatum.

canadense

carolinisurim

calawbiense

catawbiense album

catawbiense hybridum.

Dwarf

Early-fiowering

ferrugineum

hirsulum

japonicum

japonicum

kaempfers

maximum

motieri

myrtifolium

Myrtle-leaved

nudifior um

obtusum amoenum.

ponticum

punctatum

Rusty-leaved

smirnovi

vaseyi .

viscosum

Rhododendrons, Books on

Directions for planting of

Ground cover for

Hybrids and Species Maintenance of

Rhodora

canadensis

Rhodomyrtus tomentosus

Rhodotypos kerrioides

Rhubarb, Medicinal

Rhus (in variety)

canadensis.

copallina

cotinus

glabra.

radicans

toxicodendron

typhina.

vernix.

Ribbon-grass.

Ribes (in variety)

alpinum

americanum

aureum

gordonianum

oxycanthoides

Rice Paper Plant

River Bank Plantings

Robinia (in variety).

hispida

pseudacacia bessaniana

pseudacacia pyramidalis
Group

PAGE

11-B, 20-D-b

12-A-b, 12-D, 12-E-b, 12-E-d, 16-D்-a

24-B-b, 25-B, 40-C-b, 42-A-a, 44-A-a $12-\mathrm{A}-\mathrm{b}$

31-L-c.

$\cdot \cdot \cdot \cdot 235$

13-B-b, 17, 19-G-b, 24-A-b, 27, 28-A,

33-E-a, 39

33-E-a

33-E-a, 45-F-d

33-E-a, 37-A-a

33-E-a

33-E-a.

33-E-a

33-E-a

15-A, 33-E-a

33-E-a

33-E-a

19-C, 45-F-d, 46-H-b

15- $\mathrm{A}$,

15-A, 33-E-a

33-E-a

19-C, 45-F-d, 46-Hं-b

33-E-a

33-E-a :

33-E-a.

33-E-a

33-E-a

33-E-a, 45-F-b

45-F-b

33-E-a .

33-E-a

45-F-d

15-A

15-A $-\mathrm{E}-\mathrm{a}$

33-E-a

33-E-a

. . 343

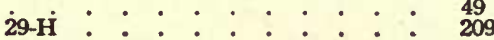

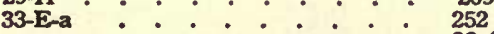

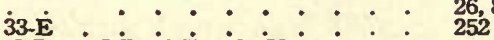

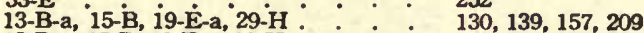

13-B-a, 15-B, 19-E-a, 29-H 130, 139, 157, 209

43-D, 43-F-b . . . 304, 306

13-A-b, 19-B, 19-G-b, 20-B, 20-C, 129, 155, 159, 163, 191, 193,

26-B-c, 27, 42-A-a. . * . . 235

31-L-c

149,166

$129,131,173,181,187,207$ 277,290

129, 191, 207

$135,155,329$

$163,187,190,207,337,338$

13-A-b, 26-B-c, 29-E-a

4-B, 19-C, 45-H-b

20-B, 20-C, 25-B, 26-A-c, 29-E-a, 46

38-B

20-B, 20-C, 22-A, 25-B, 26-A-c, 29-E-a 38-B

280

$163,173,187,190,207,281$,

$31-\mathrm{L}-\mathrm{c}, 32-\mathrm{G}-\mathrm{b}-1$

17 . . . . . . . . . . 149

44-A-a - • • • • • - • • - 313

13-A-b, 19-B, 19- $\dot{\mathrm{F}}-\mathrm{a}, 22-\mathrm{B}, 37-\mathrm{A}-\mathrm{a}, 41$, 44-B-a

37-A-a

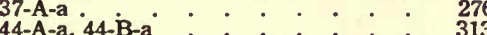

43-F-a. $\quad . \quad+\quad . \quad . \quad . \quad \div \quad 306$

$25 .+. . . .186$

42-C . . 298

14-B, 26-B-c, 42-A-a, 45-F-a 135, 191, 296, 324

10-C, 11-A, 17, 19-C, 19-G-b, 23-A, 24-B-a, 24-D, 25-A, 2G-B-a, 37-A-b, 46-D

$117,119,149,155,159,177$

$181,183,186,191,276,297$

337

135 
Rock Cress

\section{NAME}

Rock Cress

Alpine

Dwarf Alpine

Grecian Purple

Purple

Rock gardens, Japanese gargardens, Japanese gar
dens, and wall gardens dens,

Deciduous trees and shrubs. Evercreens

Perennials for

Rock Purslane

Rock Rose

Laurel-leaved Root pruning as aid to trans-

Rosa (in variety)

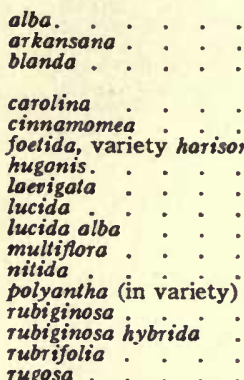

rubrifolio

\section{setigera}

spinosissimo

spinosissima altaica

wichuraiane

Rosmarinus officinalis

Rosemary

Wild

Best hybrid tea roses.

Books on

Climbing roses, Lists of best .

Ground covers for

Hardiest as tested in Central Ontario and Maine

Crimson and red

Moss.

Pink

White

Rose (in variety)

Rose Acacia

Rose Apple

Rose Bay

Rose Box

Franchet's

Himalayan

Silver-leaved

Rose, Arkansas

Carolina

Cherokee

Climbing

Cinnamon .

Fairy

Glossy :

Harison's Yellow

Japanese .

Japanese Climbing Meadow

Memorial
Grour

24-E, 29-F, 31-B-b, 27-A-c, 45-J 29-A, 29-F, 31-B-b

15-C

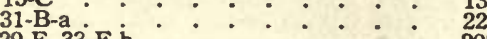

29-F, 33-E-b : 208, 252

15

15-B

15-A

24-E

15-C, 28-B, 29-B, 31-B-d, 31- $\mathrm{K}-\dot{\mathrm{a}}$ 45-F-c

i2-E-d, 34-A, 34-D, 37-A-a, $43-\mathrm{C}_{-}^{\circ}$ 45-G.

19-G-b .

$12-B, 20-B, 20-C, 20-D-b, 21,26-B-c$,

18-B, 20-D-b, 26-B-c : : : :

19-B

19-F-b, 31- $\mathrm{H}$

19-F-b

43-C-a

20-D-b, 21, 26-A-c, 46-C-b

19-G-b, 21 , $\dot{19-G}$

13-B-a, 20-D-b, 26-B-c .

12-B

20-B, 20-D-b, $37-\dot{\mathrm{B}}-\mathrm{a}$.

37-B-a

20-B, 20-D-b

12-A-b, 12-E-d, 17, 20-B, 20-C, 20 -D -b,

24-B-b, 25-B, 26-A-c, 40-B, 43-E-b,

$44-\mathrm{A}-\mathrm{a}, 45-\mathrm{B}-\mathrm{b}, 45-\mathrm{F}-\mathrm{a}, 46-\mathrm{A}-\mathrm{a}$

18-B, 20-D-b, 26-A-c, 29-E-a, 43-C-a :

13-A-a, 19-G-b, 20-D-b, 26-B-c

18-B, 29-E-a

18-B, 20-D-b, 29-E-c

37-B-b, 45-F-a

37-B-b, 45-F-a

18-A, 33-E-b

33-D

33-рं-a

29-I.

33-D-b

33-D-b-1

33-D-b-5

33-D-b-3

33-D-b-4

13-B-b, 19-C, 19-E்-b, 34-D, 37-A-a, $39^{\circ}$ 43-C-a, 43-F-a, 43-F-b, 43-F-c, 43-F-d. 14-B, 26-B-c, 42-A-a, 45-F-a

43-D

43-E-a, 43-F-a

43-D, 43-F-a, 43-F-b, 45-G

45-G, 46-C-a, 46-H-b.

45-F-d, 45-G, 46-C-a

43-D, 43-F-a

44-B-a

18-B, 20-D-b, 26-B-c

34-A, 34-D

19-B

19-F-b :

20-D-b, 21, 26-A-c, 46-C-b

19-F-b, 31-H

12-A-b, 12-E-d, 17, 20-B, 20-C, 20-D-b,

$24-\mathrm{B}-\mathrm{b}, 25-\mathrm{B}, 26-\mathrm{A}-\mathrm{c}, 40-\mathrm{B}, 43-\mathrm{E}-\mathrm{b}$,

44-A-a, 45-B-b, 45-F-a, 46-A-a

19-G-b, 20-B, 20-C, 20-D-b, 26-B-c

$12-\mathrm{B}, 20-\mathrm{B}, 20-\mathrm{C}, 20-\mathrm{D}-\mathrm{b}, 21,26-\mathrm{B}-\mathrm{C}$, 46-C-b

18-B, 20-D-b, 29-E-C : : :
PAGE

$184,208,222,276,331$

$203,208,223$

136 , illus. $126,127,142,143$

344

139

139

184

$140,197,204,223,233,253$, 325

41 , illus. 34

$126,260,261,276,303,327$

159

$124,163,164,166,170,191$, $337,166,191$

155

158,231

158

$166,170,190,337$

159, 170

159. 163, 164, 166, 191

$130,166,191$

124

$163,166,277$

277

163,166

$124,126,149,163,164,166$ $181,187,190,290,305,313$ $321,324,335$

151, $166,190,207,303$

$129,159,166,191$

151,207

$151,166,207$

277, 324

277,324

151,252

251

251

346

251

251

251

251

251

251

$131,156,157,261,276,285$, $303,306,307$

$135,191,296,324$

305,307

$304,306,327$.

$327,336,340$

$326,327,336$

304,306

314

$151,166,191$

303

260,261

155

158

$124,170,190,337$

158,231

$124,126,149,163,164,166$ $181,187,190,290,305,313$. $321,324,335$

$159,163,164,166,191$

$124,163,164,166,170,191$. 337

$151,166,207$ 


\section{NAME}

Rose, Native

Prairie

Protection of roses

Pruning of roses

Red-leaved

Scotch

Shining-leaved

Tausendschoen

White-flowered

White-flowered Glossy

Rose gardens, Fertilizer for

Rose of Sharon

Blue

Royal Poinciana.

Rubber Tree

Rubber, Wild

Rubus (in variety) crataegifolius deliciosus

dumetarum odoratus

Rudbeckia (in variety) laciniata

$$
\text { maxima }
$$

Rumex acetosilla

Rush, Flowering

Russelia juncea

Rynchaspora alba

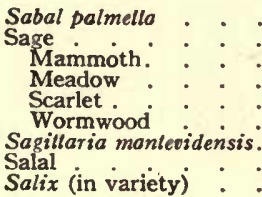

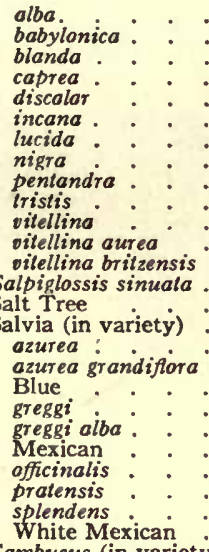

Sambucus (in variety) canadensis

canadensis aurea

racemos

Sandwort

Tufted

Sandy soils, Plants for

Sanguinaria canadensis

Sanguisorba minor

Santolina chamaecyparissus

Sapium sebiferum

Saponaria ocymoides

\section{Group}

18-E-d, 20-D-b, 26-A-c, 29-E-a, 43-C-a

20-B, 20 -D-b

13-A-a, 18-B, 19-G-b, 20-D-b, 26-B-c, 13-B-a, 20-D-b, 26-B-c

33-D-a

(9-G-b

19-G-b, 21

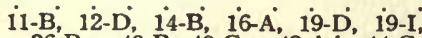
26-B-c, 40-B, 40-C-a, 42-A-b, 44-G, 19- $\mathrm{H}$

43-B-b.

43-J-a

20-D-a, 30-A

29-E-a

19-C, 29-E-a, 37- $\dot{A}-\mathbf{a}$

29-E-a

26-B-c, 28-A, 29-E்-a, 37-A-a, 44-B-a

31-B-h,

31-E, 3i-F

31-L-b

24-A-a

43-B-

37-B-b

24-E

32-E, 32-G-b-2, 35ं-B-b

$38-\mathrm{C}-\mathrm{a}$

31-L-b $-\mathrm{B}-\mathrm{b}, 46-\mathrm{E}$

10-C, 11-A, 12-C, 23-A, 24-A-a, 30-A.$$
\text { 1, 26-A-a }
$$

17

17 -A -a

19-A, 19-F-a, 41

19-F-a

25-B

26-A-a .

16-D-a, 26-B-a

24-B-b

25-A

21, 26-B-a

14-A-a, 21 ; $32-\mathrm{H}$ -

32-A, 32-E, 32-H-

$24-\mathrm{D}, 45-\mathrm{F}-\mathrm{c}$

15-I

24-E.

24-E, 3i-B-i

45-F-a.

45-F-a

45-F-a

37-B-b

24-E

45-F-a

13-B-c, $17,19-\mathrm{C}, 19-\mathrm{G}-\mathrm{b}, 2 \dot{0}-\mathrm{B}, 2 \dot{3}-\mathrm{B}$,

\section{6-A-c, 42-A-a, 46-E}

14-B - c, 19-B, i9-Gं-b, 20-B

15-C, 24-E.

29-B

24-B

28-B, 29-C, 31-B-b, 31-C-b, $40-\dot{A}$

37-B-b

24-E, 29-B, 32-G-b-1, 37-B-b

45-H-a

15-C, 29-A, 3i-B-c, 3i-C-b
PAGE

126,327

$151,166,190,207,303$

104

163, 166

129, 151, 159, 166, 191, 207

$130,166,191$

251

159,170

98

$120,125,135,144,156,159$ $191,289,291,297,316,321$

159

302

310

166,212

156, 207, 276

207

$191,197,207,276,314$

$226,232,233$

230

230

213

310

180

302

330

277

$242,244,266$

280

234

336,337

$117,119,125,177,180,212$, 313

170,189

149

$154,158,293$

158

187

189

281

147,191

181

170,191

134,170

$240,242,246$

183,326

330

184

184,226

324

324

324

184

$242,244,266$

324

166,212

$131,149,156,159,163,177$.

$190,297,338$

135

$131,155,159,163$

139,184

204

$198,205,223,228,289$

277

$184,205,244,277$

329

$140,204,223,228$ 
NAME

Sarracenia drummondi purpurea

Sassafras, Common .

officinale

Savin, Dwarf

Tamarisk-leaved

Saxifraga (in variety)

cordifolia

sarmentosa

virginiensis

Saxifrage

Early-blooming

Scabiosa atropurpureo

caucasica

Giant

graminifolio

Grass-leaved

sylvatica

Scarlet Bush

Scented Flowers

Schizanthus pinnatus

Schizophragma hydrangeoides

Sciadopitys verticillata

Scilla campanulata sibirica

Scirpus lacusitis

tabernaemontanus zebrinus

Scotch Broom

Screen plantings, Lists for

Sea Holly, Amethyst

Sea Lavender, Broad-leaved

Sea Poppy

Seaside planting, Trees and shrubs for.

Hardy in less severe seaside exposures

Conifers

Deciduous trees

Shrubs under exposure of North Atlantic Coast Conifers

Deciduous trees

Shrubs

Sedge

Variegated Sweet

Sedum (in variety)

acre

album

nevi

sexangulare

spectabile

purium

stoloniferum

Seeding annuals

Seeding seasons (for lawns)

Select list of horticultura varieties

Evergreens, Broad-leaved

Other broad-leaved ever-

$$
\text { greens. }
$$

Rhododendrons and azaleas

Lilacs

Calcareous soil

Clay soil

Easy culture in garden soi

Moist and boggy locations

Open sun

Sandy or dry soils

Shady locations

Undergrowth

Lily table

Peonies.

Roses

Trees, Smail Flowering

Sempervioum (in variety)

arachnoideum

calcareum

lectorum
Grour

31-L-c

24-A-a

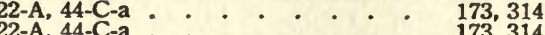

26-A-b

15-A, 18-A.

30-A, 31-M-a, 45-

$15-\mathrm{C}, 31-\mathrm{B}-\mathrm{a}, 46-\mathrm{B}-\mathrm{a}$

35-B-a

15-C, 3i-B-a, 31-i-a, 46-B-a

$45-\mathrm{A}-\mathrm{b}$

31-B-e, 31-i

31-

31-B-

31-D

31-D

31-D

43-D, 43-F-c, $43-\dot{F}-d, 43-H$.

32-A, 32-E

9-A, 9-B, 14-A-a, i6-A, 45-E 36-B

36-A

$31-\mathrm{L}-\mathrm{b}$

19-F-a, 24-B-b, 26-B-c, 45-F-e

$12-\mathrm{C}, 23$

24-E, 31-B-e, 45-I

31-B-e, 31-B-i

24-E

26

26-B

26-B-b 191

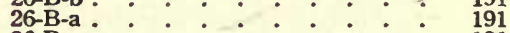

26-B-c . . . . . . . . . 191

26-A

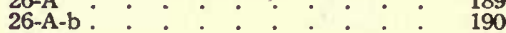

26-A-a . • . . • • • • . . 189

(

30-B, 31-L-b . . . . . . . . 212, 234

31-L-b

24-E, 31-B-j, 31-B-k, 31-M-a, 45-J - 184, 226, 235, 331

15-C, 29-F, 29-G

15-C, $29-$

45-A-a

$15-\mathrm{C}, 29-\mathrm{G}$

$15-\mathrm{C}$

29-B, $29-\mathrm{C}$

$33-\mathrm{E}$

33-E-b

33-E-a

33-A

33-F-d

33-F-h

33-F-b

33-F-c

33-F-e

33-F-1

33-F-f

33-F-a

33-B

33-D

24-E, 29-G

29-F, 32-G-a-1

32-G-a-1

32-G-a-1
$140,208,209$

140,205

319

140. 209

140

205

384

13,16 , illus. 14

249
252

Page

151

2, 235, 331

65

$222,235,336$

232

$113,134,145,323$

7 181, 191, 325

25, 176

, illus. 254

252

252

249

253

257
257

256

256

257

257

257

250

250

184,209

208,243

243 
NAME

Senecio clivorum cineraria

scandens

Senna, Argentine

Scorpion

Shad-bush

Shade-loving plants

Shade of woodland, Plants for.

Shaded locations, Plants for

Shasta Daisy.

Large

Shepherdia argentea.

canadensis.

Shooting Star

Shore Grape .

Shore Planting (See Lake,

Shortiver, or Seaside) alacifolia:

Shrubs for accent and specimens forcing in water in early spring

Fast-growing

Sidalcea (in variety) candida.

Silene alpestri:

maritima

pennsylvanica.

schafta

Silk Oak

Silk Vine

Silver Bell

Silver Bell Tree

Silver Berry .

Silver Vine

Chinese

Skimmia japonica

Japanese garden areas, Plants for

Smilacina racemosa

Smilax

Florida.

hispida

anceolata.

Smoke Bush.

Snakeroot

Large Button:

Mottled

Virginia

Snapdragon

Half-dwarf.

Sneezeweed

Tall

Yellow

Snowbal!

Chinese

Japanese

Pink

Single Japanese

Snowberry

Evergreen

Snow Bush

Snow Creener

Snowdrop

Common

Giant

Snowflake

Summer

Snow Garland, Hybrid

Snow-in-summer

Snow Wreath

\section{Group}

31-C-a, 31-L-c.

32-G-b-

35-B-a

45-F-c, 45-K-b

43-E-a, 43-H

13-B-C, 17, 19-A, 20-D-a, 22-B, 26-B-a, $27^{27}$

27

31-B-f, $31-\dot{\mathrm{F}}, 31-\mathrm{I}, 31-\mathrm{K}-\dot{\mathrm{C}}$

31-D

13-A-c, 19-C, 26-B-c, 27

12-E-b, 12-E-d 25-B, 26-A-c, 29-E-a 15-C

43-J-a

15-A, 29-H, 33-E-b, 45-A-b, 45-J

15-A, 29-H, 33-E-g, 45-A-b, 45-J

14-B

23-B

31-B-f, $31-\dot{C}-\mathrm{a}$.

31-B-f, 31-C-a.

31-B-f, 31-C-a.

29-F

15-C

15-C

43-A, 43-B-b

25-C, 29-E-C, 34-C, 34-E, 45-L

14-B, 19-B, 19-G-a 24-C-b, 42-B-a, 45- $\mathrm{H}-\mathrm{a}$ 44-G

24-B-c, 24-C-a, 25-C, 34-C, 34-D், 34-E

25-C, 34-A.

45-F-d.

45-F-d :

31-E-a:

30-A, 43-C-a

45-L

22-C-b-2

45-I

25-C

$14-\mathrm{B}, 19-\mathrm{C}, 45-\mathrm{H}-\mathrm{b}$

28-B, 31-C-a, 45-J

24-E-

$45-\mathrm{A}-\mathrm{a}$

31-B-j, 31-E, 31-L-c, 45-i

31-J, 32-A, 32-E, 32-H-b, 35-A-a $35-\mathrm{A}-\mathrm{b}, 39,45-\mathrm{I}$. $32-\mathrm{H}-\mathrm{a}$

$31-\mathrm{K}-\mathrm{c} .45-\mathrm{I}$

31-E, 31-L-C

31-B-1

39

22-Cं-b-i

40-B, 40-C-b

45-F-d

13-A-b, 19-B

11-B, 12-E-d, 12-E-e, 13-A-a, 13-B-a,

17, 20-B, 20-D-a, 20-D-b, 27, 42-A-b, 45-F-a, 46-C-b. 33-E-b

33-E-b

43-E-a.

36-E-a

$45-\mathrm{J}$

36-A

36-B

31-L-c

13-A-a, 19-A, i9-B, 19-G-a, $41,42-\dot{A}-a$

15-C, 24-E, 29-B, 29-F, 29-G, 31-B-b,

31-M-a. $45-\mathrm{F}-\mathrm{c}$.
Page

227,235

244

325,332

319,323

305,308

$131,149,154,165,173,191$, $193,285,293$

192

192

$225,230,232,234$

$130,156,191,193$

(126,

$126,187,190,207$

140

$139,209,253,320,331$

$139,209,253,320,331$

135

292

225,228

, 228

140

140

140

301,302

$187,207,261,333$

$135,155,158,182,297,328$

316

$182,183,187,260,261$

332

187,260

326

326

(2)

212,303

333

175

333

187

$135,155,329$

$197,227,331$

184

$226,230,235,330$

$233,240,242,246,264,285$, 330

246

234,330

230,235

227

175

290 , 291, illus. 206

326

129,155

$120,126,129,130,149,163$.

$166,192,297,324,337$, illus. 238

252

05

303

274

331

270

271

$129,154,155,158,293,297$

$139,184,204,208,209,223$ 326 
Soapwort, Rock Soil conditions, Various types of of .

Boggy and peaty soils Boggy situations Peaty situations

Clay soils

Shrubs for

Trees for

Vines for

Drought-resisting plants

Light and sandy soils Shrubs for Trees for

Solandra guttato

Solanum (in variety)

dulcamara.

jasminoides grandiflorum. seaforthianum.

Solidago (in variety)

arguta

caesia

canadensis.

neglecta.

speciosa

Solomon's Seal

Sophora

Sophora (in variety)

$$
\text { japonica }
$$

Sorbaria arborea.

arborea glabrate

$$
\text { sorbifolia }
$$

Sorbus (in variety)

americana.

aucuparia

hybrida fastigiata

quercifolia

Sorrel, Sheep.

Wood

Sourwood

South Atlantic States, Plants for.

Border planting : : :

Shrubs, Low-growing deciduous

Shrubs, Low-growing evergreen - Medium-growing deciduous Shrubs, Medium-growing evergreen

Evergreens

Formal effects, for colou effects.

Ground cover

Dry places

Moist places

Hedges

Holding leaves in winter

Not holding leaves in winter

Not used in North

Shrubs

Trees ${ }^{\circ} \cdot{ }^{\circ} \cdot$

Perennials for gardens and

Perennials for naturalizing in wild gardens

Specimens

Shrubs

treet planting

Vines

Southernwood

Spacing of plant

Spatter-dock

Specimen trees and shrubs
15-C, 29-A, 31-B-c, 31-C-b

$140,204,223,228$

24

$24-1$

24-A-b .

24-C

24-C- b.

24-C-a.

24-C-c

24-B

24-B-b

24-B-a :

24-B-C :

43-C-a.

$34-\mathrm{D}$

$35-\mathrm{A}-\mathrm{b}, 35-\mathrm{B}-\mathrm{a}$

$45-1$

43-C-a .

31-B-1, 31-E, 45-J

28-B

31-C-a, 38-Cं-a

24-A-a

29-C, 3i-C-b, 39

42-C

13-A-b, 24-B-b

11-A, 19-F-b, 45-H-a, 45-K-a

$13-\mathrm{A}-\mathrm{b}, 24-\mathrm{B}-\mathrm{b}$

$42-\mathrm{A}-\mathrm{b}$

19-D, 19-I

25-B, 29-E-a

20-D-b, 42-C

25-A, 44-E-b

14-A-b

14-A-a, 16-D-b-1

30-B

30-A

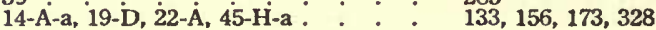

${ }_{45-F}^{45}: \quad: \quad: \quad: \quad: \quad \vdots \quad \vdots 332$

45-F-a . . . . . . . 323

45-F-b . . . . . . . . 324

45-F-c . . . . . . . . 325

45-F-d . . . . . . . . . . 326

${ }_{45-\mathrm{E}}^{45}: \quad \vdots \quad: \quad \vdots \quad \vdots \quad \vdots \quad \vdots \quad 322$

45-G . . . . . . • . . . 327

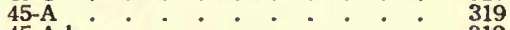

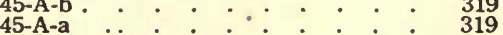

${ }_{45-\mathrm{B}}^{45-\mathrm{a}} \cdot: \vdots: \vdots \vdots \vdots \vdots 320$

45-B-a $\cdot \cdot \cdot \cdot \cdot \cdot \cdot, 320$

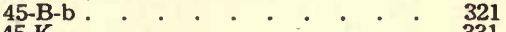

45-K • • • • • • • • • • 331

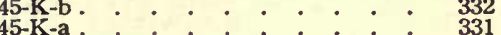

45-I. . . . . . . . . 329

45-J • • • . • • . . 330

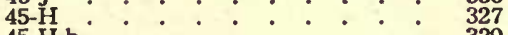

45-H-b. . . . . . . $\cdot 329$

$45-\mathrm{C}: \circ . \quad \cdot \quad \cdot \quad \cdot \quad 321$

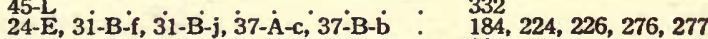

24-E, 31-B-f, 31-B-j, 37-A-c, 37-B-b : 29

43-1: $: \div: \div: \div: \vdots 310$

$14-1: \vdots \vdots: \vdots \vdots \vdots: \vdots \quad 310$, illus. 110,111

229,528

281

228,285

$182,329,331$

9, 182

66, 159

(

, 298

, 315

7,163

4,147

3

2

7

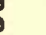

31

9


Speedwell

NAME

Speedwell. Creeping

Hoary

Rock

Rock

Spice Bush

Spiderwort

pikenard, America

False

Spindle Tree

Bunge's

European

Japanese

Spiraea (in variety)

argula.

bumalda anthony waterer

callosa albo

douglasi

japonica alba

prunifolia

prunifolia fiore pleno

salicifolia

tomentosa

oanhoutlet

veilchi

Spirea

Billard'

Blue

Chinese Mountain Ash

Crimson

David's

Douglas

Fortune's White

Mountain Ash-leaved

Sorb-leaved

Veitch's

Spleenwort, Ebony

Maidenhair

Spraying .

Sprekelia formosissima

Spring Beauty

Spring-flowering plants.

Spruce

Alcock

Black

Black Hills

Colorado

Columnar Norway

Compact Norway

Cone-shaped Norway

Dwarf Blue

Dwarf Norway

Dwarf Oriental

Dwarf Pyramidal Norway

Engelmann's

Globe Douglas

Gregory's Dwarf Norway

Koster's Blue

Norway

Oriental

Pyramidal Norway

Red

Servian.

Sitka

Tablet-shaped

White

Spurge, Carolina

Flowering
GROUP

29-F, 30-A, 31-I, 45-I

15-C, 29-A, 29-G .

15-C, 31-B-a

31-B-e

29-F

19-A, 19-F-a, 20-D-a, 27, 28-A, 30-A

$37-\mathrm{B}-\mathrm{a}, 39,40-\mathrm{B}, 42-\mathrm{A}-\mathrm{a}, 44-\mathrm{G}, 45-\mathrm{F}-\mathrm{C}$ 31-B-a, 31-C-a

31-D

31-C-a .

20-D-b

13-A-c, 45-G

13-A-c, 14-B, 20-Bं, 22-C-a

22-C-b-1

$13-\mathrm{A}-\mathrm{b}$

$11-\mathrm{B}$

13-A-a, 19-A, $19-\dot{B}, 19-\mathrm{G}_{-} \mathrm{a}, 411, \dot{4} 2-\dot{\mathrm{A}}-\mathrm{a}$. 19-D, 42-A-a

12-B, 13-A-a, 19-D, 19-E-b, 19-I, 45-F-a 12-B, 19-D

$42-\mathrm{A}-\mathrm{b}$

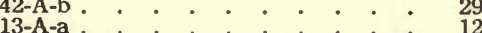

13-A-b, 19-G-b, 42-A-a, 45-F-c : : : $129,159,297,326$

19-A

19-C, 26-A-c, 29-E-a

44-B-a .

19-E-b, 25-B, 29-E-a, 42-A-a, 4ं-B-a

12-D, 12-E-c, 12-E-e, 13-A-b, 17, 19-B

19-G-a, 19-I, 24-B-b, 38-C-a, 42A-a, 45-F-c, 46-C-a ? 13-A-b

$11-\mathrm{B} \cdot \mathrm{*} \cdot \mathrm{*} \cdot 129$

19-D, 42-A-a : $: \cdot \cdot \cdot 120,297$

13-A-a, 16-C, 19-H, 3i-B-i, 31-B-j, 128, 146, 159, 226, 233, 329 45-F-a, 45-H-b. 19-D, 19-I, 42-A-b 12-B, 13-A-a, 19-D, 19-E-b, 19-I, 45-F-a $31-\mathrm{B}-\mathrm{g}, 31-\mathrm{L}-\mathrm{c}$ $42-\mathrm{A}-\mathrm{b}$

13-A-a

12-B, $19-\mathrm{D}$.

25-B, 29-E-a

44-B-a.

(29-D

29-D-a

36-E-b

PAGE

$208,212,232,330$

$140,204,209$

140,222

224

224

$154,157,165,193,196,212$, $277,285,289,296,316,325$

222,228

197

228

66

129,327

$129,135,163,174$

129

120

$129,154,155,158,293,297$

124, $129,156,157,159,324$

124,156

(9)

154

$156,190,207$

$157,187,207,297,314$

$125,126,129,149,155,158$ $159,182,281,297,326,337$

129

$156,159,297$

$124,129,156,157,159,324$

225,234

297

124,156

187,207

314

129

206

274

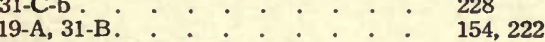

12-C, 14-A-a, 30-A, 39, 42-D . . . $125,133,212,285,298$, illus. 111

9-A, 9-B • • • • • • • • • 111, 112

9-C $\cdot 0^{\circ} \cdot 0^{\circ} \cdot 113$

$44-A-a, 44-\dot{A}-b_{0}, 44-F^{\circ} \quad \vdots \quad \vdots \quad: \quad 313,316$

9-A, 11-A . . . 112, 119

$14-A-b, 16-D-b-2 ： \vdots \vdots \quad: \quad 135,147$

9-E . • . . . . . . . 114

9-E $\cdot \cdot \cdot \cdot \cdot \cdot \cdot \cdot \cdot \cdot \cdot \cdot \cdot 114$

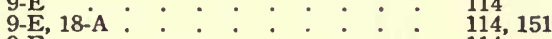

$9-\mathrm{E}: \div:$ : : : : : 114

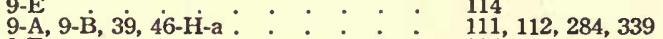

9-A, 9-B, 39, 46-H-a : $: \cdot: \cdot 111$,

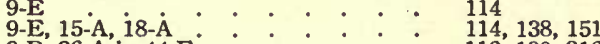

9-B, 26-A-b, 44-F $112,190,316$ 9-A, 9-B, 12-A-a, 16-B-a, 23-A, 24-C-a, $112,124,145,177,182,186$,
25-A, 44-A-a, 44-F, 46-A-b $\quad \cdot \quad 313,316,335$

16-B-a 16 , 16-A, i6-D-b-2, $44-\dot{D}$

145

$135,145,147,314$

26-A-b

9-E $\div \vdots \vdots \vdots \vdots \vdots \vdots \vdots \vdots 114$

9-A, 9-B, 24-A-a, 25-A, 26-A-b, 27, $44-\dot{\mathrm{F}}$

29-C

114 .

$1,112,180,186,190,193$,

205

15-C $, 15 \dot{5}-\mathrm{C}, 29-\mathrm{B}, 29-\mathrm{C}, 29-\mathrm{E}-\mathrm{b}, 29-\mathrm{H}, \quad 140,140,204,205,207,209$, 253,336 , illus. 270 
NAME

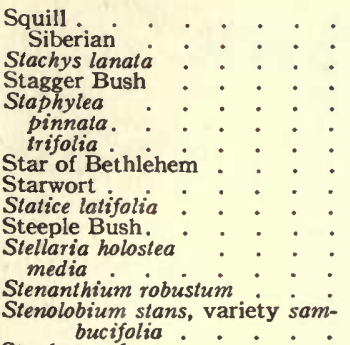

Stephanandra

fiexuosa

Sterculia platanifolio

Stevia

Dwarf .

serrata nana

Stewartia pentagyna

Sticktight

Stipa spartea

Stock, Ten Weeks Brompton

Stokesia cyanea

St. John's Wort Buckley's

Bushy

Hybrid

Kalm's.

Large-flowered

Mountain .

Naked-flowered

Shrubby

Stone, Vines to grow on

Stone-breaker

Stonecrop (in variety)

Brilliant

Dark Green

Mossy.

Nevius

Spreading

White

Storax, American Broad-leaved Japanese

Strawberry Bush

Strawberry Shrub

Strawberry Tree.

Strawberry, Wild Yellow.

Straw Flower

Street and avenue planting. Trees for

Hardy under all conditions :

Special conditions

Styrax americana

japonica

Subass

Fragrant

Shining.

Smooth

Staghorn

Summer-flowering Plants

Summer Lilac

Sundrops

Sunflower, Hardy

Single Annual

Sunny exposures, Perennials for
GROUP

36-B

36-A

$45-\mathrm{F}-\mathrm{a}$

42-B-a

20-A, 45-H-b

13-B-c, 20-A, 20-B, 28-A, 45-H16-B

15-C, 29-A; 31-B-b, 3i-M-b.

31-B-e, 31-B-i

13-B-a, 31-L-c.

15-C, 29-A, 31-B-b

30-A, 30-B

31-E

43-F-c

13-A-a, $40-\dot{B}, 42-\dot{A}-\mathrm{a}, 45-\mathrm{F}-\mathrm{a}, 4 \dot{6}-\mathrm{F}$

13-A-a, 40-B, 42-A-a, 45-F-a, 46-F

$45-\mathrm{H}-\mathrm{a}, 45-\mathrm{K}-\mathrm{a}$

35-B-b

$35-\mathrm{B}$

14-B, 19-D, 19-G-b, 45-H்-b

30-B

38-B

32-H-a

32-H-b $32-\mathrm{E}^{\circ} 32-\mathrm{H}$

15-C, 31-B-e, 31-I

19-D, 10-F-b

22-C-b-1

24-A-a

13-A-a, 22-C-b-1

26-B-c, 28-B

13-B-a, 33-E-b, 45-F-

$45-\mathrm{F}-\mathrm{a}$.

$45-\mathrm{F}-\mathrm{a}$.

$45-\mathrm{F}-\mathrm{a}$.

$34-\mathrm{B}$

$30-A, 4 \dot{5}-\mathrm{J}$

24-E, 31-B-j, 31-B-k, 31-M-a, 45-J.

$15-\mathrm{C}$

$15-\mathrm{C}, 29-\mathrm{G}$

15-C, 29-F, 29-G .

45-A-a

29-B, $29-\mathrm{C}$

15-C, 29-B

$45-\mathrm{F}-\mathrm{C}$

$45-\mathrm{F}-\mathrm{C}, 45-\mathrm{H}-\mathrm{b}$

$11-\mathrm{B}, 13-\mathrm{B}-\mathrm{b}, 14-\mathrm{B}, 20-\mathrm{B}$

15-B, 18-B, 28-B, 29-C

13-B-b, 24-C-b, 27, 28-A, 37-A-a, 40-B,

43-F-d, 45-F-c, 46-C-b, 46-E 45-G, 45-K-b

$45-$

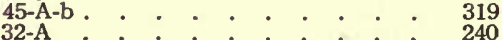

10 .

$10-\AA$

$10-\mathrm{B}$

10-C $\mathrm{F}-\mathrm{c}$

$45-\mathrm{F}-\mathrm{c}, \dot{4} 5-\dot{\mathrm{H}}-\mathrm{b}$

$45-\mathrm{F}-\mathrm{C}$

17, 20-D-b, $39^{\circ}$

13-A-b, 13-B-b, 22-B, 24-B-b, 25-B,

29-E-a, 37-B-a, 40-B 13-A-b, 26-B-c, 29-E-a 26-A-c, 29-E-a, $20-\mathrm{B}, 20-\mathrm{C}_{,} 25-\mathrm{B}, 26-\mathrm{A}-\mathrm{c}, 29-\mathrm{E}-\mathrm{a}$, $26-\mathrm{B}, 20-\mathrm{C}, 46-\mathrm{F}, 22-\mathrm{A}, 25-\dot{\mathrm{B}}, 26-\dot{\mathrm{A}}-\mathrm{c}, 29-\dot{\mathrm{E}}-\mathrm{a}$ 38-C-b, 44-C-a 19-C, 31-B. $19-\mathrm{H}, 37-\mathrm{A}-\mathrm{a}, 40-\mathrm{B}^{\circ} \quad 45-\mathrm{F}-\dot{\mathrm{C}}$ 45-H-b. . . . . . . $4-\mathrm{E}-\mathrm{H}-\mathrm{b}: \vdots \vdots \vdots \vdots \vdots \vdots \cdot$ 31-B-h, 31-C-a, 31-E, 31-i, 31-K-a, 31-M-b, 38-C-a, 45-1 32-A

\section{PAGE}

271

18

324

162,329

$131,162,163,197,329$

271

$140,204,223,235$

224,226

$140,204,223$

212,213

230 ,

307

$129,290,297,324,338$

$129,290,297,324,338$

329,331

244

266

$135,156,159,329$

212

280

246

$240,242,246$

$140,224,232$

156,158 , illus. 226

175

180,175

191,197

$130,253,324$

324

324

324

212,331

$184,226,235,331$, illus. 126

140

140,209

$140,208,209$

319

205

140,205

326

326

326,329

$120,131,135,163$

$139,151,197,205$

$130,182,193,196,276,289$ $307,325,337$

327,332

115

116

117

117

326,329

326

$149,166,285$

$129,131,173,181,187,207,277$

$129,191,207$

$163,187,190,207,337,338$

$163,173,187,190,207,281$. 314

155,224

$156,159,276,289,325$

$226,227,230,232,233,235$, 280,330

240
208 
NAME

Group

45-L

43-D, 43-E-a Page

Supple-jack

Surinam Cherry

Swainsona

Swainsona galegifolia

Swamp-pink

Sweet Gum .

Sweet Leaf, Japanese

Sweet Pea

Hardy

Sweet Rocket

Sweet-scented Flowers

Sweet Sultan.

Sweet William

Wild

Sword Flower (See also Gladiolus)

Sycamore.

Symphoricarpos (in variety) occidentalis. racemosus.

oulgaris.

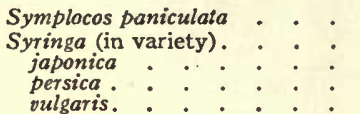

vulgaris hybrida

vulgaris President Grevy.

Tabernaemontana coronaria flore pleno

Table of Contents

Tagetes erecta.

patula

Tallow Tree, Chinese

Tamarack

Tamarindus indica

Tamarind

Manila

Tamarisk

French

German

Tamarix (in variety)

caspica

gallica

odessane

Tanacel

Double

Taraxacum officinale.

Tarragon

Taxadium distichum.

distichum pyramidatum

Taxus (in variety)

baccata

baccata fastigiata

baccata repandens

brevifolia

canadensis .

cuspidata

cuspidata brevifolic

cuspidata capitata.

cuspidata dense

cuspidata nana

Tea Plant

Tecoma stans

Telanthera amoena

bettzickiana

versicolor

Tetrapanax papyriferum

Thalia

dealbata
35-A-a.

35-A-a 264

24-A-a, 29-H, 31-L-c, 45-A-a $: \vdots 180,209,235,319$

$10-\mathrm{B}, 14-\mathrm{A}-\mathrm{a}, 20-\mathrm{A}, 22-\mathrm{A}, 39,40-\mathrm{B}, 117,133,162,173,285,289$, $40-\mathrm{C}-\mathrm{b}, 43-\mathrm{B}-\mathrm{a}, 43-\mathrm{J}-\mathrm{a}, 45-\mathrm{C}, 45-\mathrm{H}-\mathrm{a}$. 20-B

32-A, 32-C. . . . . . . . . 240, 241

31-D, 34-A . . . . . . 229, 260

31-C-a, 37-A-c, 45-I . . . . . . 227, 277, 330

32-A . . . . 240

31-B-f, 31-B-g, 31-I, 31-J, 31-N, 32-H-a $\quad 225,232,233,236,246$

28-B, 31-C-a, 31-C-b, 40-A . . . . 198, 227, 228, 289

31-G, 36-E-a, 45-I

$33 . \div 285$

11-B, 12-E-d, 20-D-a, 20-D-b . . . 120, 126, 166

12-E-e, 13-A-a, 13-B-a, 17, 20-B, 27, $126,129,130,149,163,193$, $42-A-b, 45-F-a, 46-C-b$ 13-A-a, $13-\mathrm{B}-\mathrm{a}, 17,20-\mathrm{B}, \quad 24-\mathrm{B}-\mathrm{b}$, 20-B $297,324,337,163,182,191$ $129,130,149,163,182,191$,
$207,314,324,337$

. 163

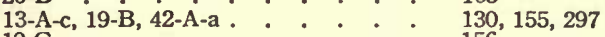

$19-\mathrm{C} \cdot$ • • • • • • . . 156

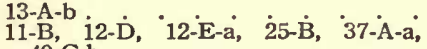
$40-\mathrm{C}-\mathrm{b}$

$19-\mathrm{I}, 46-\mathrm{C}-\mathrm{a}$

$120,125,126,187,276,291$

159,337

159

16-C

43-A-a, $43-\mathrm{F}-\mathrm{a} \quad: \quad \vdots \quad \vdots \quad \vdots \quad \vdots \quad 305,306$

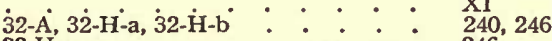

32-H-a .

24-A-a, 24-C-a, 26-A-b, 40-C-a $\vdots \quad \vdots \quad$ 180, 182, 190, 290

43-D • • • • • • • : 304

43-A, 43-J-a

19-D, 24-B-b, 43-F-b, 43-J-b $\quad . \quad 156,182,306,310$

$14-\mathrm{B}$

$17,40-\dot{B}$

45-F-c * * * * * • 326

$19-\mathrm{D}, 24-\mathrm{B}-\mathrm{b} \cdot . \quad \cdot 0^{\circ} \cdot 0^{\circ} \cdot 156,182$

43-F-b, 43-J-b. . . . . . . 306,310

$17,40-\mathrm{B}$

$14-\mathrm{B}$

37-B-b .

37-B-b

$30-A$

$37-\mathrm{B}-\mathrm{b}$ :

14-A-a, 16-D-b-1, 24-A-a, 45--E, 45-H-a

14-A-b, 42-E, 44-G, 45-E : : $: \quad \cdot \quad$ :

45-D, 45-G, 46-H-a

9-A, 9-B, 9-E, 15-A, i8-A

46- $\mathrm{H}-\mathrm{a}$.

9-A, 9-D, 15-A, 24-A-b, 27, 29-C, 29-H,

9-A, 16-B-a, 45-D

9-A, 16-B-a,
$9-\mathrm{A}, 9-\mathrm{B}, \mathrm{D}$
9.

9-B

9-E

15-A, 16-B-a

43-E-b, 45-B-a, 45-K-b

$43-\mathrm{F}-\mathrm{C}$

32-G-a-1

32-G-a-1

$32-G-a-1$

31-L-b .
135

277

277

229

212
277

$134,147,180,323,329$

135

$290,298,317,323$

147,339

$112,113,114,139,151$

$112,113,139,181,193,205$ 209, 290

$112,145,32$

$112,113,151$

113

114

139,145

$305,321,332$

307

243

(1)

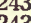

243

306

234
$322,327,339$ 46-C-b $27,29-\mathrm{E}-\mathrm{a}, 44-\mathrm{B}-\mathrm{a}, 45-\mathrm{F}-\mathrm{a}$,

$45-\mathrm{H}-\mathrm{a} \cdot \cdot \cdot \cdot \cdot \cdot 246$

43-F-a . 
NAME

Thaliclrum (in variety) adiantifolium aquilegifolium dipleracarpum Maidenhair

Thea sinensis

Thermopsis caroliniane

Thevetia nereifolia

Thorn.

Black

Cockspur

Carrier's Red-flowering

Evergreen

Jerusalem

Large-flowering

Large-fruited

Low-growing Fiery

Paul's Double

Scarletflowering

Red-flowering

Round-fruited.

Scarlet-fruited.

Silver

Variegated Silver

Washington

Thoroughwort, Rough

Thrift, Lauch's Sea.

Sea.

White Sea

Thuja (in variety)

accidentalis.

accidentalis aurea

occidentalis compacto.

occidentalis douglosi

occidentalis dumosa

accidentalis ellwangeriana

occidentalis fastigiate

accidentalis globoso

accidentalis hovevi

occidentalis, Little Gem

occidentalis lutea

accidentalis nana

occidentalis plicata

occidentalis pumila

occidentalis pyramidali

occidentalis reidi

occidentalis rasenthal

occidentalis Tom Thumb or variety umbraculifera

occidentalis vervaeneana

occidentalis wagnerian

occidentalis wareana

occidentalis woodwardi

orientalis

orientalis pyramidalis.

plicata.

Thujopsis dolobrala

Thujopsis

alata

erecta alba

Thunbergia

White

Thyme, Downy

Thymus serpyllum

serpyllum lanuginosus

riarella cordifolia

Tiarella cord

ickseed

Lance-leaved

Tick Trefoil

Tilia (in variety)

americana

euchlora

eutopaea

tomentaso

vulgaris
GROUP

Page

30-A, 45-I

31-B-h

15-C, 3i-B-b, 31-Cं-a

31-H, 31-L-c

31-B-h

31-B-h, 31-H .

43-F-c, 43-J-b

19-G-a, 20-B, 20-C, 22-B, 39, 40-B, 40-C-b

12-A-b, 16-B-b, 20-D-b, 26-B-a

12-A-a, 12-B, i6-Cं, 20-B, 20-C, 33-E-b, 42-B-a, 45-B-a, 45-G, 46-A-b

45-H-a

45-B-a

33-C

33-E-b

12-A-b, 16-B-b, 16-D-a, $1 \dot{0}-\mathrm{D}-\mathrm{b}-1$, 20-D-b, 25-A, 26-B-a, 46-A-a.

33-C

33-C

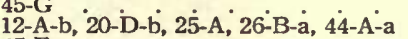

$45-\mathrm{F}-\mathrm{c}$

43-D, $4 \dot{3}-\mathrm{F}-\mathrm{a}, \dot{4} 5-\mathrm{F}-\mathrm{d}$

45-F-d

12-A-b, 20-D-b, 26-B-b, 33-Cं

24-A-a

29-A, 29-F, 29-G, 31-K-b, 45்-J .

31-B-b

12-A-a, 14-A-a, 30-A, 42-E

9-B, 9-D, 24-A-a, 24-C-a, 44-F .

9-A

9-E

9-A

9-E, 12-B

14-A-b

9-A, 9-E, 12-B, 18-A

9-E

9-A, 9-E, 18-A

16-D-b-2

9-E

9-A, 14-A-b

9-A, 16-A, 16-C

9-E

9-A

12-B

9-A

9-A, 9-B, 16-D-b- $\dot{2}$

9-B, 16-D-b-2, 45-B-a, 45-D

14-A-b, 45-E

$16-\mathrm{D}-\mathrm{b}-2$

9-C $-\mathrm{C}$.

35-B-a

43-F-a

35-B-a, 43-C-a

43-F-a

15-C, 29-A, 29-F, 31-K-b, 33-E-b

32-G-a-1

15-C, 29-A, 29-F, 31-K-b, 33-E-b 29-F

31-B-h, 31-D, 32-A, 32-D, 43-I

15-C

31-B-h, 31-i

30-B

37-A-b .

24-A-a, 44-E-a

$10-A, 46-D$

11-A $\mathrm{A}, 11-\mathrm{A}, 14-\mathrm{A}-\mathrm{a}$

10-A, 46-F
212,330

$140,223,228$

231,235

226

$305,321,332$

226,231

307,310

$119,126,131,133,155,158$ $162,163,173,285,289,290$

124

$124,145,166,191$

250

$124,146,163,253,297,321$. 327,335

328

320

250

250

253

$24,145,146,147,166,186$.

191,335

250

250

$124,166,186,191,313$

325

$304,306,326$

$124,166,191,250$

180

$204,208,209,233,331$

223

$124,134,212,298$

$113,180,182,316$

112

114

112

114,125

135

$112,114,125,151$

114

$112,114,151$

147

114,135

114

$112,145,146$

114

125

112

$112,113,147$

114

$113,147,321,322$

135,323

147

303

303

265

265, 303

306

$140,204,208,233,253$

243

$140,204,208,233,253$

$225,229,240,241,309$

225, 232

213

276

180,315

117,337

119

$117,119,134$ 


\section{NAME}

Toad-flax, Dalmatian

Tobacco Plant

Tobira Shrub

Tomatillo.

Tooth-wort, Two-leaved

Topiary Work, Plants for Pruning for

Torenia flava

Yellow

Touch-me-not

Trachelospermum jasminoides Tradescantia

virginica

Transplanting, Articles on

Transplanting ${ }^{\text {Annuals difficult to trans- }}$ plant

Annuals, Transplanting of Balled-and-burlapped root

Collected stock, Transplant-

Conditions for transplanting

Depth for transplanting

Drainage for transplanted stock

Evergreens, Transplanting of

Fertilizing transplanted stock Heeling-in stock to be transplanted

Irises, Transplanting of

Nursery-grown trees Transplanting of

Nursery stock, Transplanting Peonies, Transplanting of

Perennials Requiring transplanting

Perennials, Transplanting of Planting beds, Preparation of Plants difficult to transplant

Rarely transplanted

Recovering slowly
Pruning transplanted stock

Reasons for transplanting

Rhododendrons, Transplanting of.

Root protection and puddling for transplanting

Season for transplanting.

See also graphic chart

Shrubs, Transplanting efficiently

Spacing of plants

Specific seasons for transplanting

Autumn, List for

Spring, List for

Tamping and watering

Tramping and watering sed lings

Trees, transplanting of Drainage of holes or pits Fertilizing transplanted trees

Method of procedure in transplanting large trees Protection after transplanting

Pruning trees after trans-

planting Season to transplant and preparation of holes.

Vines, Transplanting of .

Winter protection after trans planting

Trees

Accent and specimens

Books on

Columnar or pyramida

Congested city district

Exposed water-front condi-

tions
GROUP

Page

24-E, 31-D

43-E-a, 43-F-a, 43-J-b, 45-B-a, 45-F-d

$45-\mathrm{K}-\mathrm{b}$

43-C-a, 43-J-c

3ं2-Gं-a-2

32-G-a-2

35-B-b

43-C-a, 45-L

31-B-a, 31-C-a

31-D

$\therefore: \vdots: \vdots: \vdots: \vdots 29$

$32-\mathrm{C}$

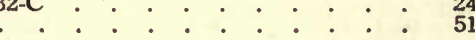

$31-\mathrm{K} \cdot .233$

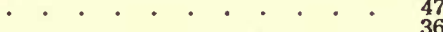

$40-\dot{c}: \vdots \vdots \vdots \div \quad \vdots \quad 290$

40-C-a. . . . . . . . . . 290

0-C-b.

$\therefore: \vdots: \vdots: \vdots \quad 2^{41}$

Plate III : $: \vdots: \vdots: \vdots: 14$

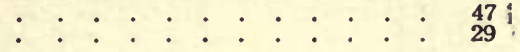

40

42
47

14-A-a

i4-A-b $: \vdots \vdots \vdots \vdots \vdots \vdots \vdots 134$

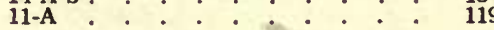

25-A. .0186
38

33

39

48

40

36

90

46

33

90

49

37

35,286

289

40

42

43

45

43

44 , illus. 40

45

41

133.

\section{, 229}

$306,310,320,326,332$

3, 311

45

44

\section{, 333}

228

41

0

(1)

86

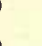

5

2

346,347

186 


\section{NAME}

Trees. Fast-growing

Fe tilizers for

Established specimens.

Newly transplanted specimens

Flowering effects

Fruiting effects

Lists of trees for

Street and avenue (See

Street and avenue planting)

Pruning of
Soils, Types for different

Specimen planting

Transplantizig of .

Tree of Heaven.

Tree surgery

Trifolium

repens

Trillium

erectum

erectum album

grandiflorum

Tribhasia trifoliata

Trollius europaeus

Tropaeolum canariense

majus

minus

Trumpet Creeper, Chinese

Trumpet Flower.

Trumpet Vine

Argentine

Tsuga canadensis

canadensis globosa.

canadensis nana

canodensis pendula (sargenti).

caroliniana.

heterophylla

Tub plants

Tube-flower, Chinese

Tufted Pansy-See Pansy,

Tulips Tufted

Combinations of :
Cottage Tulips
Darwin Tulips .
Double Tulips :
Single Tulips :
Early fóring Red
Early-flower : :
Lady :
Tulipa :
clusiana :
greigi :
kaufmanniana

Tulip Treenian

Pyramidal

Tunica saxifraga.

Saxifrage-like

Tupelo

Turkey Fruit

Turk's Cap

Turk's Turban

Tussilago farfara

Twigs, Coloured

Twin-flower

Ulex europoeus

Ulmus (in variety)

americana.

campestris

\section{GROUP}

Page

33-A

74

i9 $: \vdots: \vdots: \vdots \vdots \vdots \vdots: \vdots{ }_{160}^{45}$

115 , illus. 79

$24 \div \div \div \div \div \div \div$

14-A-a: : : $: \div: \div 3$

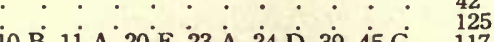

$117,119,166,177,183,285,321$

73

212

$198,209,289$, illus. 302

271

$223,228,271$

304,305

224,289

242

$240,241,265,310$

244

303,332

332

$207,260,261,303,332,338$

43-F-c, 43-j-b

29-E-c, 34-A, 34-B, 34-C, 34-E, 43-C-b

45-L, 46-G

43-J-c

9-A, 9-B, $9-\mathrm{D}, 12-\mathrm{A}-\mathrm{a}, 12-\mathrm{C}, 14-\mathrm{A}-\mathrm{a}$,
$16-\mathrm{B}-\mathrm{a} 20-\mathrm{D}-\mathrm{b}, 24-\mathrm{C}-\mathrm{a}, 27,28-\mathrm{A}, 30-\mathrm{B}$ 40-C-a, 44-F, 46-E 9-E

9-E

E $\dot{0} \cdot \dot{C}^{\circ} 114$

$112,113,125$

14-A-b, 46-H-a . . 135, 139

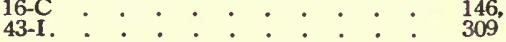

311

$12,113,124,125,134.145$. $166,182,193,197,213,290$, 316,338

113,125

, illus. 174

illus. 350

36- $\dot{\mathrm{D}}$

$36-\mathrm{D}-\mathrm{c}$

36-D-d

36-D-b

36-D-a .

$36-\mathrm{B}$

$36-\mathrm{B}$

36-A

36-B

36-B

10-B, 20-A, 22-A, 39, 40-B, $40-\mathrm{C}-\mathrm{a}$, $42-\mathrm{C}$

14-A-b $24-\mathrm{E}, 29-\mathrm{B}, 29-\mathrm{F}, 31-\dot{\mathrm{C}}-\mathrm{b}$

14-A-a, 20-D-a, 22-B, 24-A-a, 40-C-a

45-C, 45-H-a

43-D

43-F-d :

43-D

29-C

21 - $29-\mathrm{F}$

46-A-b

24-D

10-A, 22ं-A, 24-A-a, 25-A, 40-B, 43-B-a,

$10-\mathrm{B}, 11-\mathrm{A}, 16-\mathrm{D}-\mathrm{a} \cdot{ }^{\circ} \cdot{ }^{\circ}$
271

272

272

272

271

271

270

270

271 298

135

$140,184,205,208,228$

140, 184, 205, 208, 228

$133,165,173,180,290,321$, 328

304

307

304

205

168, illus. 246

138,208

335

183 $117,119,147$
117, 162, 173, 285, 289, 291,

117, 173, 180, 186, 290, 301, 
NAME

Ulmus foliacea whealley. faliacea dampieri .

glabra camperdowni glabra fastigiata montana pendula

Umbrella Plant

Umbrella Tree

Undergrowth planting wooded areas

Ground-cover plants for

Shrubs and small trees for

Upland Grass

Vaccinium (in variety) . corymbosum

vacillans

Valerian .

Greek

Red

Valeriana.

Vancouveria hexandra

Varnish Tree

Japanese

Veratrum viride

Verbascum

olympicum

phoeniceum

phlamoides

Verbena.

hybrida.

Vernonia noveboracencis.

Veronica (in variety)

incana

longifolia subsessilis

repens

rupestris

spicata.

teucrium, variety prostrato

Vetch

Viburnum (in variety) :

Viburnum (in variety)

acerifolium.

alnifolium

americanum

carlesi

cassinoides

dentatum

dilatatum

Evergreen:

Fragrant Japanese

Korean.

lantana

lentago

Maple-leaved

macrocephalum

nudum

odoratissimum

opulus

opulus nanum

plicatum

prunifolium

pubescens

rhytidophyllum

sieboldi

Siebold's

suspensum

tinus

\section{tomentosum}

Vicia

Vinca (in variety)

major

minor

minor alba
Group

PAGE

14-A-a, 14-A-b, 16-D-b-

14-A-b

10-A

16-D-b-1

45- $\mathrm{H}-\mathrm{a}$.

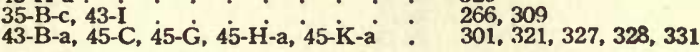

28

28-A

38-C-a.

194, illus. 255

197

280

20-B, 20-D-a, 24-A-a, 30-A, 33-E-b 22-B, 24

40-C-a

29-F, 31-B-a, 31-C $-\mathrm{b}, 45-\mathrm{r}$

45-J

$14-A-a, 19-C, 19-F-b, 22-A, 2 \dot{4}-D^{\circ}$, 42-B-a, 45-H-a .

45-H-a, 45-K-a

38-A

31-D

24-E

24-E : : : : : : : : : : 184

29-I, $3 \dot{2}-\dot{A}, 3 \dot{2}-\dot{E}, \quad \dot{3}-\dot{G}-b-2, \quad 32-\dot{H}-a$, 35-B-a, 39, 43-I $32-\dot{\mathrm{I}}-\mathrm{b}-2,32-\dot{\mathrm{H}}-\mathrm{a}$, 29-I, 32-A, 32-E, 32-G-b-2, 32-H-a, 31-B-i, 38-C-a

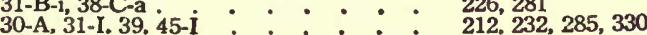

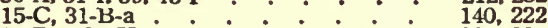

15-C, 31-B-a

15-C, 29-A, 29-G

31-B-e, 31-H :

31-B-e, 31-H : * * * * 208

29-F • • • • • • • • • • 208

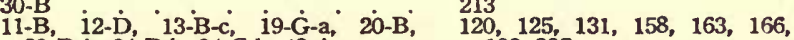

20-D-b, 24-B-b, 24-C-b, 42-A-a

$11-\mathrm{B}, 12-\mathrm{D}, 13-\mathrm{B}-\mathrm{c}, 19-\mathrm{G}-\mathrm{a}, 20-\mathrm{B}$

20-D-b, 24-B-b, 24-C-b, 42-A-a .

13-B-b, 22-B, 27, 28-A, 44-C-b.

27. 190 , 20 , $46-\mathrm{C}-\mathrm{b}^{\circ}$

$13-\mathrm{A}-\mathrm{b}, 19-\mathrm{C}, 37-\mathrm{A}-\mathrm{a}, 46-\mathrm{C}-\dot{\mathrm{a}}$

13-A-b, 19-C, 26-A-c

19-C, 22-B, 26-A-c, 27

13-A-b, $20-C$

22-C-b-1, 33-E-b

$43-\mathrm{F}-\mathrm{a}$

13-A-b, 19-C, 37- $\dot{A}-a, 46 \dot{C}-a$

13-A-c, 19-C, 26-Bं-c, $27^{\circ}$

13-B-b, 22-B, 27, 28-A, 44-Cं-b

22-C-b-1

24-A-b .

13-A-c, 17, 19-C, 20-Cे, 25-B, 2

13-A-C, 17, 19-C, 20-C, 25-B, 27

40-B, 40-C-

16-B-b, 19-B, 27 :

27

22-C-b-i, 33-E-b .

19-C, 22-C-b-1

19-C, 22

43-E-a, 43-F-a, 45-B-a, $4 \dot{5}-F^{\circ}-d, \dot{4}-\dot{H}-\dot{b}$, 45-K-b, 46-A-b

13-A-b, 19-B

30-B

43-I.

35-A-b, 35-A-c, 35-B-a, $45-\dot{A}-\mathbf{b}$

15-C, 29-B, 29-A, 29-B, 29-C, 29-E-b, 29-F, 29-H, 31-B-a, 33-E-b, 45-A-a, 29-H
$163,166,180,212,253$

$173,182,314$

$222,228,330$

140

$133,155,158,173,183,297$, 3. 331

279

$210,240,242,244,246,265$. 285,310

$210,240,242,244,246,265$.

10, 204, 209

140.2

24,232 $182,297,131,158,163,166$, 182,297 .

131.

$159,164,337$

$129,156,190$

$156,173,190,193$

129,164

175,25

$129,156,276,337$

130

$130,156,191,193$

$131,173,193,197,314$

175

181

$130,149,156,164,187,193$

$125,139,145,151,175$

290, 291

$145,155,193$

193

175,253

156,175

156,175

$305,306,321,326,329,332$, 335
29,155

213

310

265,320

$140,198,204,205,207,208$

$210,222,253,319,336$

210
$129,156,276,337$ 


\section{NAME}

Vinca, Trailing

Anes .

Books on

Fast-growing

Flowering

Foliage

Fruiting

Holding leaves in late autumn

Protection of

Walls, For brick and masonry

Viola (in variety)

canadensis

canina

cornuta alb

cornuta hybrida

cornuta lutea

cucullata

odorata semperflorens

pedata

pedata

Violet

\section{Bird's Foot}

Canadian

Common

Horned.

Scented

Yellow Horned

Virginia Creeper.

Vitex agnus-castus

$$
\text { incisa }
$$

Vitis (in variety)

capensis

coignetiae

Cut-leaved.

Wake Robin

Large-flowered

White

Wallflowe
Hybrid

Wall Gardens

Books on

Walnut

Black

False .

Wandering Jew

Washington (see Oregon)

Washingtonia robusta

Water Arum

Water Gardens, Books on

Water Leaf

Appendaged

Water-lily

Hybrid

White

Water-plantain

Water Poppy

Water-side planting

Perennials for

Shrubs for

Wayfaring Tree.

Weedy Plants

Weigela

Hybrid

Pink

Rose-coloured

Variegated.

Western Sweet-scented Shrub

White Cup
Group

PAGE

35-A-b, 35-A-c, 35-B-a, 45-A-b .

32-F

34-E்

34-A

$34-\mathrm{C}$

22-C-b-2

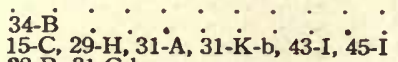
28-B, 31-C

29-A, 29-I, 31-B-a, 31-D, 31-J, 45-A-a.

31-B-b

31-F

31-B-d :

28-B

31-B-a

37-A-C

29-A, 29-I, 31-J, 32-A, 32-E

15-C, 29-H, 31-A, 31-K-b, 37-A-c, 39 43-I, 45-I

29-F

28-B, 3i-C-b

28-B

31-B-b, 31-F

31-B-a.

31-B-d

20-D-a, 22-B, 24-B-c, 25-C, 26-A-c, 29-E-c, 34-C, 34-D, 39, 43-C-a, 44-B-b, 16-C, 19-D, 19-H, 40-B, 45- H-b 42-A-b

• • • • •

43-C-a. : : : : : : 303

25-C, 29-E-c, 34-D், 34-E

28-B, 29-H, 36-B, 40-A

31-B-b, 31-C-b, 36-B

29-C

32-E, 37-A-C

24-E

39

8- $-\mathrm{C}, \mathrm{C}-\mathrm{a}$

45-

$43-\mathrm{G}$

43-B-b

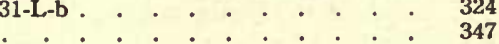

29-C

43-I.

31-L-a

31-L-a

31-L-b .

43-I

31-D

31-E

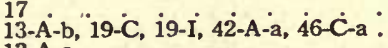
13-A-c

13-A-C, 19-E-b, 23-B

14-B, 27

45-F-a

35-B-b
265,320

258 , illus. 350

242

261 , illus. 334

260

261

175

260 , illus. $335,345,367$

$140,210,222,233,310,330$

198,228

228

$204,210,222,229,233,319$

230

224

222

277

$204,210,233,240,242$

$140,210,222,233,277,285$, 208

298,228

198

223,230

222

$165,173,182,187,190,207$, $260,261,285,302,314,319$

$146,156,159,290,329$

$166,182,187$

303
207

$187,207,261$

$198,209,271,289$

205

242,276

184

136 , illus. 143

347

281,290

328

328

302

347
205

205

310, illus. 318

234

234

234

309

illus. 318,319

234
187

130

369

149

$129,155,159,296,336$

$129,157,177$

135,193

66 
White Flowers

\section{NAME}

White Flowers

Perennials with

Shrubs with

White Fringe

Whitlow Grass, Aizoon-like

Wild Gardens

Maintenance of

Perennials for

Undergrowth plantings for

Wild Hyacinth plantings for

Willow

\section{Black}

Dwarf Gray

Flowering

Goat

Hybrid Yellow

Laurel-leaved

Pussy

Rosemary

Shining

Virginian

Weeping

White

Wisconsin Weeping

Windbreaks

List of plants for

Wind flower, Canadian

Japanese

Snowdrop

Window boxes and hanging baskets

Hanging baskets ${ }^{\circ} \cdot$ Upright habit and good flowers

Upright habit and good foliage

Vine-like habit

Window boxes

East exposure

North exposure.

Winter

South or west exposure

Colour of twigs in.

Fruits persistent in

Winter Protection and Mulching

Articles on

Bulbs, Winter protection of

General considerations

Lawns, Mulching of

Perennials, Winter protection of (see also "Maintenance")

Reasons for winter protection

Rhododendrons, Winter protection of

Roses, Winter protection of

Sources of winter injury and remedy

Trees and shrubs, Winter protection of.

Vines, Winter protection of Winterberry

Wintergreen

Winter killing

Wisconsin, Plants, for

Wisteria

Chinese

multijugo

sinensis

Witch Haze

Japanese
31-B

19-G, 43-F-a $14-\mathrm{B}, 19$ 19-B, 19-G-a, 20-B, 22-A, 42-A-a, 43-F-a, 45-H-b 15-C, 24-E

36-B

$31-\mathrm{C}$

28-B

36-B $A^{\circ}$

39, 44-A-b 12-C, 23-A, 24-A-a, 30-A, 38-C-b

24-B-b

$45-\mathrm{H}-\mathrm{a}, 45-\mathrm{H}-\mathrm{b}, 4 \dot{5}-\mathrm{K}^{\circ}-\mathrm{b}$

19-A, 19-F-a, 41

$21,26-\mathrm{B}-\mathrm{a}$

14-A-a, 21

16-D-a, 26-B-a

19-F-a

5-B

13-B-a, 18-B, 24-A-a, 26-B-c, 37- $\dot{A}-\mathrm{a}$, 45-F-c

17

$21,26-\dot{A}-\mathrm{a}$

14-A-a

25-A

12 -C

15-C, 28-B, 31-B-b, 31-Cं-a, $40-\dot{A}$

31-A, 31-B-j, 31-B-k, 31-F, 31-I, 31-K-a $40-\mathrm{B}$

$31-\mathrm{B}-\mathrm{b}$

$35-\mathrm{B}$

35-B-b

35-B-c

35-B-a

35-A

35-A-C

35-A-a

$\stackrel{21}{20-C}$

$20-\dot{C}$

:

•. • . . . . . . . .

$\therefore: \vdots: \vdots: \vdots: \vdots 100$

13-B-c, 20-B, 20-C, 20-D-b, 24-A-a, 26-A-c, 28-A 33-E-b $20-\mathrm{D}-\mathrm{a}, 24-\mathrm{A}-\mathrm{a}, 29-\mathrm{B}, 29-\mathrm{C}$

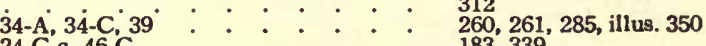

$24-C-C, 46-G$

46-G

13-B-c, 46-G $19-\mathrm{D}, 22-\mathrm{C}-\mathrm{a}, 2 \dot{4}-\mathrm{B}-\mathrm{b}, 24-\mathrm{C}-\mathrm{b}$,

27, 28-A, 30-B, 39, 42-A-a $24-\mathrm{C}-\mathrm{b}$ 19-A, 19-F-a.
106

102

104

104

101

105. illus. 62

$131,163,166,180,190,196$

$138,165,180,204,205,253$ 101

158,305

$131,135,149,155,158,162$. $173,296,306,329$

140,184

ilus. 302,303

270

227

970

$17,119,125,177,180,212$ 285,313 , illus. 94

81

$328,329,332$

170,191

34,17

147,

187
189

$130,151,180,191,296,326$

170,189

134

22 , illus. 110

139, 197, 222, 227, 289

$221,226,230,232,233,289$, illus.

222

62 , illus. 350

266

266

(64)

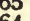

168 , illus. 246

(1)

66

183,339

339

183,339

$131,156,174,181,182,193$, $196,212,285,296$
154,158 
13-A-b, 19-C, 26-A-c

$24-\mathrm{A}-\mathrm{b}$

24-B

43-B-b

$31-\mathrm{C}-\mathrm{b}$

29-A, 29-F, 37-A-c, 37-B-b 28

29-D-a

$42-\mathrm{B}-\mathrm{b}, 45-1$

24-B

44-B-a

24-E

\section{2-B-a}

19-C $: 0.297$

13-A-a, 18-B, 24-A-b, 29-E-a, 29-H

24-E

31-B

$19-\mathrm{F}, 43-\mathrm{F}-\mathrm{C}$

13-A-a, 18-B, 24-A-b, 29-E-a, $29-\mathrm{H}$

14-A-a, 19-C, 19-G-b, 22-C-a, 42-B-b, 45- $\mathrm{H}-\mathrm{a}$

$40-\mathrm{B}, 42 \cdot \mathrm{E}, 44-\mathrm{G}, 45-\mathrm{E}$.

45-E

Columnar Stem-fruited

Clustered Japanese

Dwarf Japanese

English.

False

Fround

Irish

Japanese

Large-fruited

Short-leaved Japanese Spreading English

Western

Ylang-Ylang
False

Yucce (in variety)

filamentosa.

\section{flaccide}

glauca

gloriosa.

Zanthoxylum americanum

Zebrina pendula.

Zenobia

pulverulenta

speciosa

Zinnia.

elegans.

elegans robusta.

Tall

Zones for Planting and Seeding

Zoysia matrelca

Zygadenus iniermedius
9-B

45-D, 45-G, 46-H-a

$9-\mathrm{C}$

9-A, 9-D, 15-A, 24-A-b, 27, 29-C, 29$40-\mathrm{C}-\mathrm{a}$

16-D-b-1, 46-Hं-a

9-A, 15-A, 16-B-a, 45-D

45-D

9-A, 9-B, 18-A

9.A, $9-B$,

43-B-b.

43-F-C

24-E, 39, 42-B-b

18-A, 29-B, 29-G, 3i-B-f, 33-E-b, 37-A-c, 43-I, 45-A-b, 45-B-a, 45-F-b 45-F-b.

45-F-b

27, 28-A, 29-E-a

43-G

33-E-b.

33-E-b.

45-F-a

32-A, 32-H-a, 43-I

32-H-b

32-H-b

Plate II

43-G

38-A 18-A, 45-A-b . . . . . .

32-A, 32- H-a, $43-$
$129,156,190$

181

184

301

228

$204,208,276,277$

194

206

297,330

184

313

184

297

$129,151,181,207,210$

279

184

222 , illus. 292,310

157,306

$129,151,181,207,210$

$133,155,158,173,297,328$

$290,298,317,323$, illus. 78

322

114

$322,327,339$

113

322,328

$112,113,139,180,193,205$, 147,339

$112,139,145,322$

322

$112,113,151$

$112,113,114,139,151$

339

302

$184,285,297$

$151,205,209,225,253,277$, $310,320,321,325$

151,320

325

$193,197,207$

308

253

324

324

$240,246,310$

$240,246,310$

246

246

6
308

308

279 





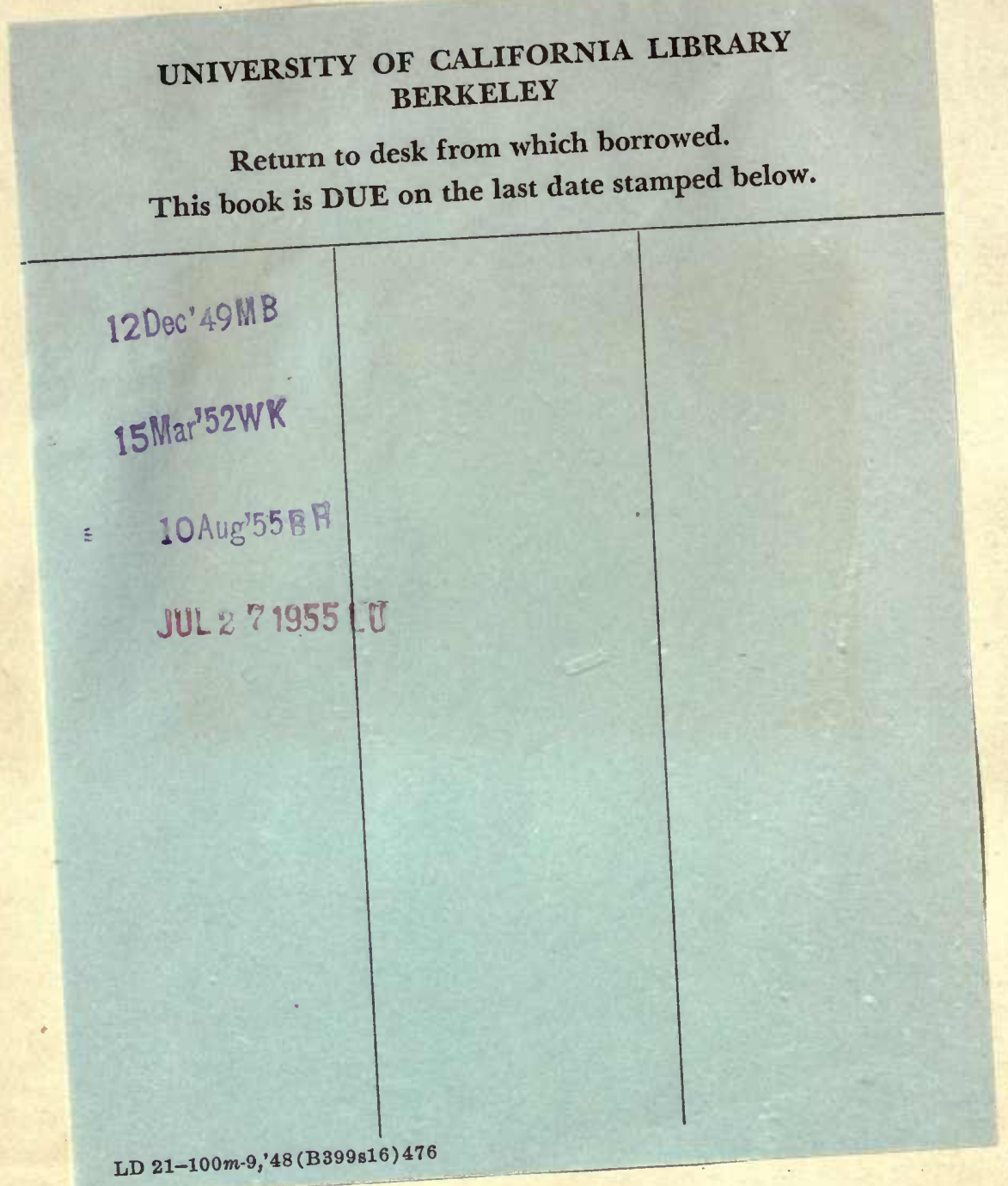




\section{YD 02417}

$$
\begin{aligned}
& 469660 \\
& 5 \beta 476 \\
& T_{3} \\
& 1921
\end{aligned}
$$

UNIVERSITY OF CALIFORNIA LIBRARY 
